$$
\begin{aligned}
& \text { 震 }
\end{aligned}
$$

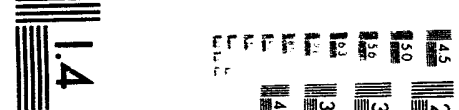

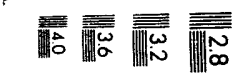

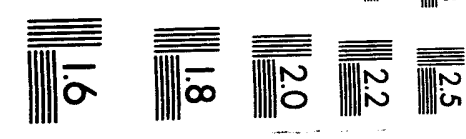



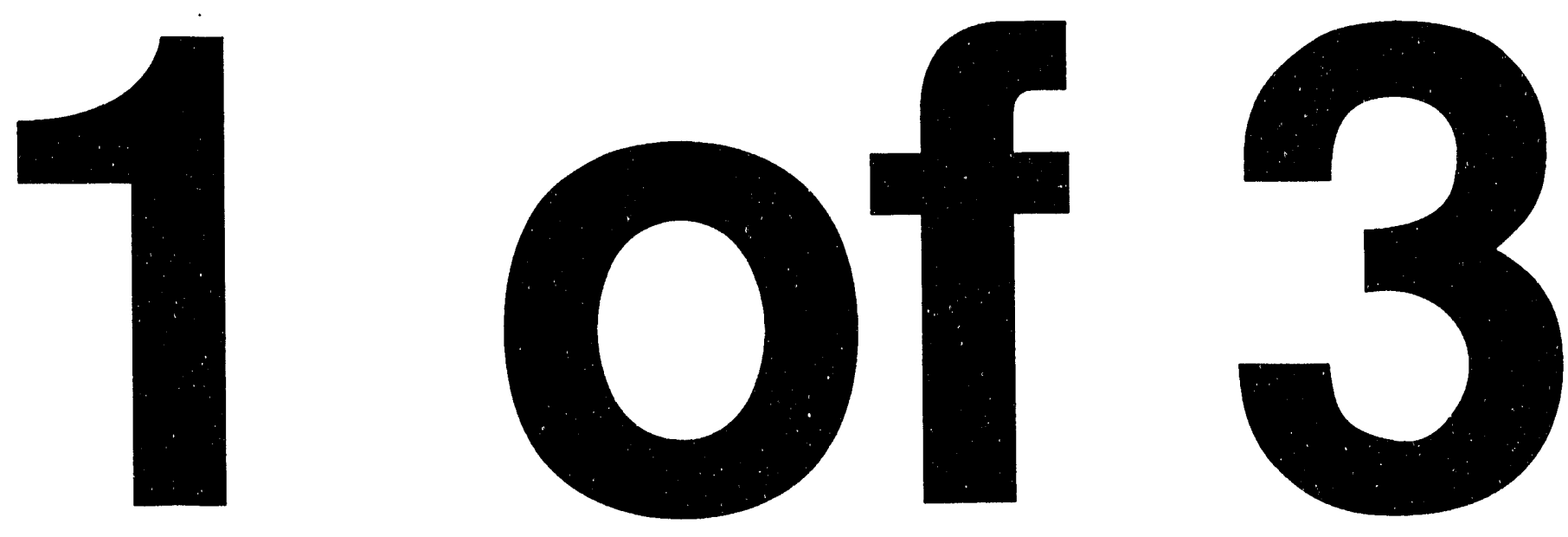
DISRTIBUTION:

M. J. Hitchler, 992-1W

D. R. Cox, 241-154H

M. L. Cowen, 992-1W

J. D. Menna, 992-1W

T. E. Britt, 992-1W

M. K. Gupta, 992-1W

B. J. Shapiro, 992-1W

D. S. Cramer, $992-1 \mathrm{~W}$

H. A. Ford, 992-1W

R. E. Vail, 992-1W

T. Temple, 703-H

G. A. Antaki, 707-35B

B. G. Croley, 241-121H

B. E. Long, 703-7C

J. P. Morin, 719-4A

R. M. Satterfield, 719-4A

D. C. Wood, 704-8C

W. B. Van Pelt, 241-154H

T. L. Ortner, 241-154H

WEST/PRA File, 992-1W

SRTC Records (4) 


\section{FREQUENCY OF DEFLAGRATION IN THE IN-TANK PRECIPITATION PROCESS TANKS DUE TO LOSS OF NITROGEN PURGE SYSTEM (U)}

Preparation:

J. M. Jansen (SAIC)

C. L. Mason (SAIC)

Human Reliability Analysis Support:

L. M. Olsen

B. J. Shapiro

Technical Support:

M. K. Gupta

T. E. Britt

Technical Review:

D. S. Cramer

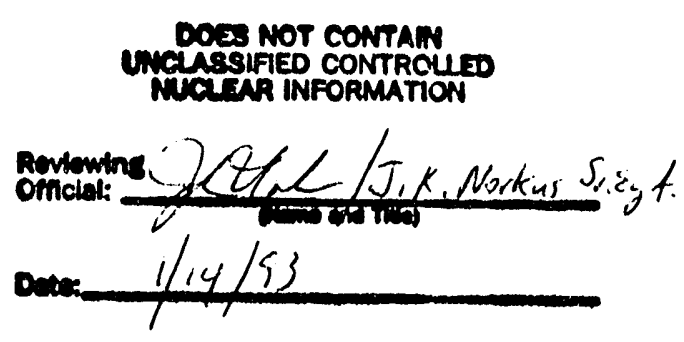

Westinghouse Savannah River Company

Savannah River Site

Alken, SC 29808

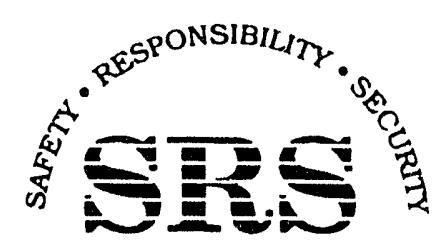

SAVANNAH RIVER SITE

PREPARED FOR THE U.S. DEPARTMENT OF ENERGY UNDER CONTRACT NO. DE-AC09-89SR18035 


\section{DISCLAIMER}

This report was prepared by Westinghouse Savannah
River Company (WSRC) for the United States Deportment of
Energy under Contract No. DE-AC09-89SR 18035 and is an
account of work performed under that contract. Neither
the United States Department of Energy, nor WSRC, nor any
of their employees makes any warranty, expressed or
implied, or assumes any legal liability or responsibility for
the accuracy, completeness, or usefulness, of any
information, apparatus, or product or process disclosed
herein or represents that its use will not infringe
privately owned rights. Reference herein to any specific
commercial product, process, or service by trademark,
name, manufacturer or otherwise does not necessarily
constitute or imply endorsement, recommendation, or
favoring of same by WSRC or by the United States
Government or any agency thereof. The views and
opinions of the authors expressed herein do not
necessarily state or reflect those of the United States
Government or any agency thereof.


Project:

Document:

Title:
In-Tank Precipitation

WSRC-TR-93-169/Rev. 2

Frequency "of Deflagration in the

In-Tank Precipitation Process Tanks

Due to Loss of Nitrogen Purge System (U)

\section{Approvals:}

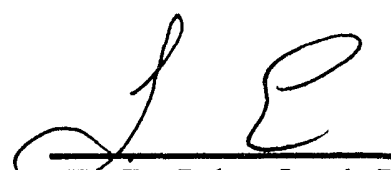

T. E. Britt, Lead Engineer, In-Tank Precipitation Projects, Author

M. K. Mutpos

Author

ifm.

L. M. Olsen, Senior Engineer Human Factors, Human Factors

Engineering, Author

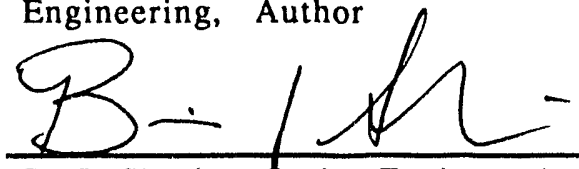

B. J. Shapiro, \$enior Engineer A, High Level Waste Analysis,

Author

SPench

D. S. Cramer, Fellow Scientist, Risk \& Consequence Analysis, Reviewer

S. (Q) Menna, Manager, Liquid

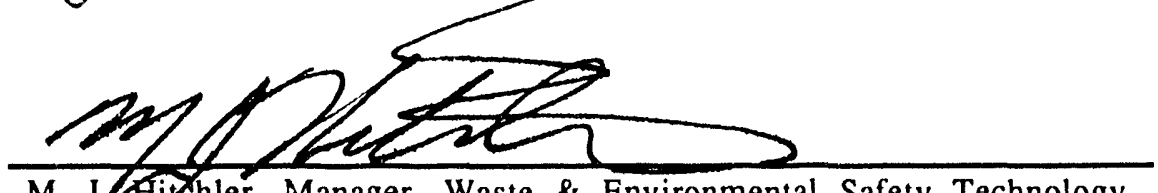

M. J Fip Chler, Manager, Waste \& Environmental Safety Technology Section $\frac{1 / 14 / \Omega H}{\text { Date: }}$

$\frac{1 / 14194}{\text { Date: }}$

$\frac{1114194}{\text { Date: }}$

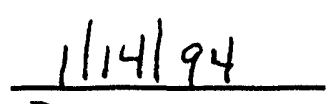

Date:

$\frac{1 / 14 / 94}{\text { Date: }}$
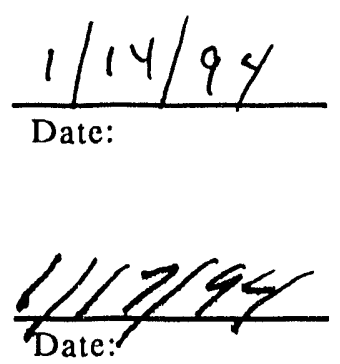


$\begin{array}{ll}\text { Key Words: } & \text { In-Tank Precipitation } \\ & \text { Deflagration } \\ & \text { Nitrogen } \\ \text { Purge } \\ \text { Fire } \\ \text { Frequency } \\ \text { Ignition }\end{array}$

\section{FREQUENCY OF DEFLAGRATION IN THE IN-TANK PRECIPITATION PROCESS TANKS DUE TO LOSS OF NITROGEN PURGE SYSTEM (U)}

Preparation:

J. M. Jansen (SAIC)

C. L. Mason (SAIC)

Human Reliability Analysis Support:

L. M. Olsen

B. J. Shapiro

Technical Support:

M. K. Gupta

T. E. Britt

Technical Review:

D. S. Cramer

Issued: January 1994

Westinghouse Savannah River Company

Savannah River Site

Alken, SC 29808

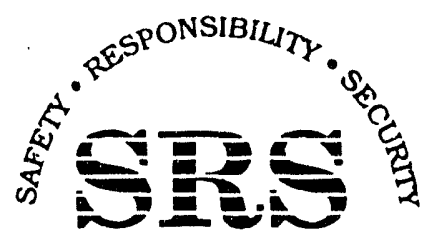

SAVANNAH RIVER SITE

PREPARED FOR THE U.S. DEPARTMENT OF ENERGY UNDER CONTRACT NO. DE-AC09-89SR18035 


\section{AC.KNOWLEDGMENT}

This report is the result of an effort to estimate the frequency of deflagration in the In-Tank Precipitation process tanks due to loss of the nitrogen purge system in Waste Tanks 48 and 49 coupled with a source of ignition. A note of appreciation is expressed for contributions made by staff members from several groups within the Savannah River Technology Center, personnel in the waste tank farms at SRS, for our sub-contractor Science Applications International Corporation who performed a major portion of this work, and for the many hours of careful review and insightful comments provided by the Technical Review Group (TRG). 


\section{CONTENTS}

LIST OF FIGURES.

LIST OF TABLES vii

1.0 INTRODUCTION AND SUMMARY

1

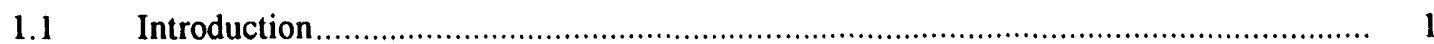

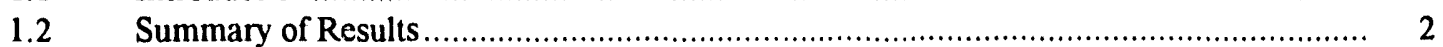

1.3 Limiting Conditions for Operation ................................................................................

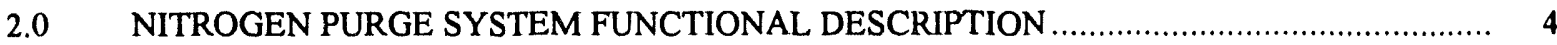

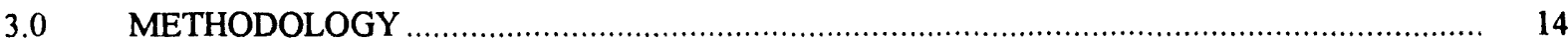

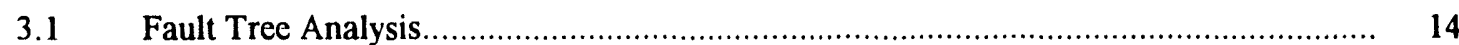

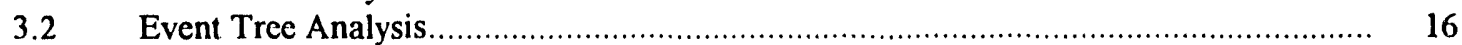

3.3 Human Reliability Analysis ........................................................................... 16

4.0 INTERNAL AND EXTERNAL EVENTS ANALYSIS _................................................. 18

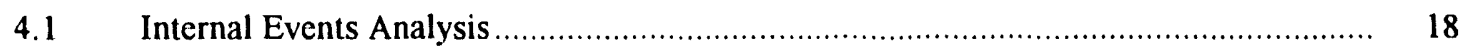

4.1.1 Fault Tree Construction …….............................................. 18

4.1.2 Fault Tree Evaluation ........................................................ 21

4.1.3 Fault Tree Results ................................................................... 33

4.2 External Events Analysis .............................................................................. 35

4.2.1 Severe Winter Storm .......................................................................... 37

4.2.2 Seismic and High Wind Events ......................................................... 38

4.2.3 Other External Events.................................................................. 39

4.2.4 Event Tree Results .............................................................. 44

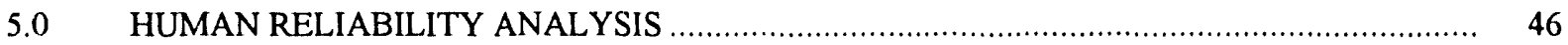

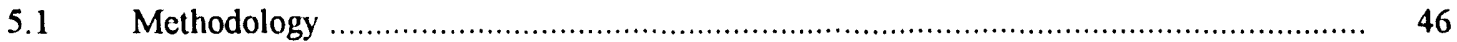

5.1.1 Normal Proceduralized Operating Actions/Recovery Methodology ...................... 48

5.1.2 Repair Methodology ................................................................................... 48

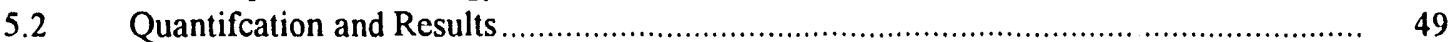

5.2.1 Normal Proceduralized Operating Actions/Recovery Actions ............................. 59

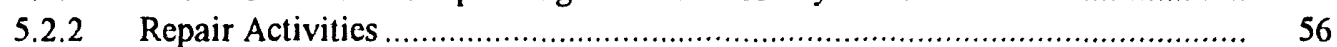

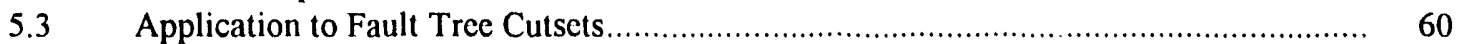

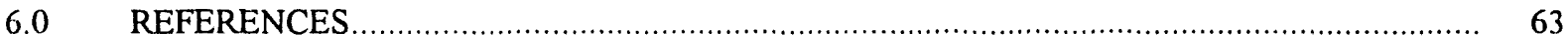

APPENDIX A - FAULT TREE FOR NITROGEN PURGE SYSTEM FOR TANKS 48 AND 49

APPENDIX B.1 - CUTSETS FOR APPENDIX A FAULT TREE WITHOUT RECOVERY ACTIONS OR REPAIR ACTIVITIES

APPENDIX B.2 - CUTSETS FOR APPENDIX A FAULT TREE $W I T H$ RECOVERY ACTIONS OR REPAIR ACTIVITIES INCLUDED

APPENDIX C - FAULT TREES AND CUTSETS FOR EXTERNAL AND RECOVERY EVENTS 


\section{LIST OF FIGURES}

$2-1$.

$2-2$.

$2-3$.

4-1.

4-2.

4-3.

$4-4$.

$5-1$.
Common Nitrogen Supply System 6 Tank 48 Nitrogen Supply and Exhaust Systems ...................... 7 Tank 49 Nitrogen Supply and Exhaust Systems $\ldots \ldots \ldots \ldots \ldots \ldots \ldots \ldots \ldots . \ldots \ldots$ Event Tree for Severe Winter Storm ................................. 40 Event Tree for Seismic Event ........................................ 41 Event Tree for Tornado Wind Events ............................... 42 Event tree for Other External Events ................................. 43 Fault Tree for Restart of Nitrogen Purge System

\section{LIST OF TABLES}

2-1. Procedures and Drawings Used To Determine Nitrogen Purge

\section{$2-2$.}

$2-3$. System Configuration 9 Electrical Load List ......................................................... 10

$4-1$. Valve Positions for Normal Operations and Loss of Nitrogen ............. 11

$4-2$.

$4-3$.

$4-4$.

$4-5$.

$5-1$.

$5-2$.

$5-3$.

$5-4$.

$5-5$.

$5-6$.

List of Data Sources ....

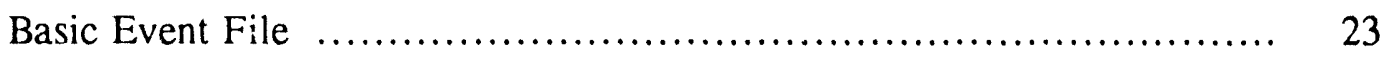

Type Code File .......................................................... 27

Exposure Times ................................................. $\quad 30$

Contributions to Seismic/High Wind Sequence Frequency................. 45

Procedure and Drawings Used in Human Reliability Analysis ............ 51

Time Estimates for Recovery Actions .................................. 52

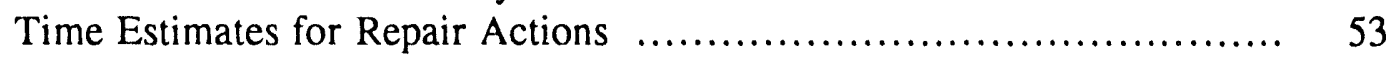

Post-Diagnosis Human Error Probabilities ............................... 54

Cutsets for Restart of Nitrogen Purge System............................... 59

Summary of Repair/Recovery Action Probabilities 


\subsection{INTRODUCTION AND SUMMARY}

\subsection{Introduction}

High-level liquid wastes (HLLW) from the processing of nuclear material at the Savannah River Site (SRS) are stored in large tanks in the F- and H-Area tank farms. In the tanks the wastes separate into sludge and salt solution. The salt solution is concentrated by evaporation and the salt and sludge are held for further processing. A detailed analysis of the tank farms and HLLW processing is provided in Reference 1. The In-Tank Precipitation (ITP) process is one step in the processing and disposal of HLLW. This process is described and analyzed in detail in Reference 2.

The ITP process decontaminates the salt solution so that it can be transferred to other facilities for further processing. The processing facility includes four large tanks, a filter building, an organic stripper building, filtrate hold tanks, and a cold chemical storage area.

The process hazards review for the ITP identified the need to implement provisions that minimize deflagration/explosion hazards associated with the process. The nitrogen purge system constitutes one of these provisions. One function of this system is to provide a continuous nitrogen sweep of the vapor space in Tanks 48 and 49 to maintain the oxygen concentration at a level that ensures that fires do not occur. Another function of this system is to maintain the concentration of flammable constituents below the composite lower flammability limit (LFL) to ensure that deflagrations do not occur.

The major considerations in this analysis are:

1. The response times available for repair or restoration of an inoperative nitrogen purge system before conditions for deflagrations can develop within a waste tank are dependent upon the system configuration at the time a failure occurs. Estimates of these times are (3):

Tank 48: 3 days, if Tank 48 is in the wash cycle when the nitrogen purge system becomes inoperable.

3 to 6 days, if Tank 48 is transferring its salt solution when the nitrogen purge system becomes inoperable.

6 days, if Tank 48 is in its normal processing cycle when the nitrogen purge system becomes inoperable.

Tank 49: Operations in Tank 49 are limited so that the time to reach the LFL is at least 3 days (4). 
2. Maintenance activities on active components of the nitrogen purge system serving Tanks 48 and 49 are assumed to occur as specified in the Operational Safety Requirements (OSRs) (4) and/or as specified explicitly in operating procedures.

3. Conditions favorable to a deflagration within a waste tank can develop in a specified time period after a loss of the nitrogen purge system. If an ignition source is present when the system becomes vulnerable to a deflagration, a deflagration is assumed to occur. An analysis to determine the probability of having an ignition source present during the window of vulnerability was performed (5). The ignition source probability is estimated to be $9.0 \mathrm{E}-2$ for non-seismic initiators and 0.13 for seismic initiators (5). (The difference between these probabilities is based on the assumption that because an earthquake could cause Sitewide damage, no credit was given for repairs to potentially damaged equipment. For the other events analyzed, the damage is iocallized and limited so little credit was given for repairs.)

4. Human action considerations were conservatively restricted to a single recovery activity and a single repair activity per cutset.

The objective of this analysis is to determine the frequency of a deflagration in Tank 48 and/or 49 due to nitrogen purge system failures (including external events) and coincident ignition source.

\subsection{Summary of Results}

A fault tree of the nitrogen purge system coupled with ignition source probability is used to identify dominant system failures that contribute to the frequency of deflagration. These system failures are then used in the recovery analysis.

Several human actions, recovery actions, and repair activities are identified that reduce total frequency. The actions are analyzed and quantified as part of a Human Reliability Analysis (HRA). The probabilities of failure of these actions are applied to the fault tree cutsets and the event trees.

The total frequency for a loss of nitrogen purge due to in:ernal and external events with the presence of an ignition source is $\sim 2.9 \mathrm{E}-07 / \mathrm{yr}$.

The total estimated frequency for a loss of the nitrogen purge system in Tanks 48 and 49 due to internal initiating events for sufficient time to reach the LFL with the presence of an ignition source is $7.2 \mathrm{E}-8 / \mathrm{yr}$. This frequency includes the probability of operators failing to align the emergency purge ventilation equipment (EPVE), the probability of failure of the EPVE to start and run, and the probability of maintenance failing to repair the failed equipment and return the system to normal operation. Approximately $25 \%$ of this total is due to failures of the digital 
control system (DCS), which fails the nitrogen purge to both tanks, combined with the above mentioned operator actions. Failures of the $\mathrm{O}_{2}$ analyzers combined with the same operator actions account for approximately $22 \%$ of the total failure frequency. Approximately $20 \%$ of the total failure frequency is due to failures of the exhaust fan trains combined with the operator actions. Approximately $16 \%$ of the total frequency is due to a loss of steam that results in a plugged HEPA filter combined with the operator actions. The remaining contributors are miscellaneous system failures.

The total frequency for a loss of nitrogen purge due to external events with the presence of an ignition source is $2.16 \mathrm{E}-7 / \mathrm{yr}$. The dominant sequence, which accounts for approximately $90 \%$ of the total external event sequence frequency, is a seismic or high-wind event that fails the entire nitrogen purge system coupled with failure to establish air-based ventilation with the EPVE. This frequency is dominated by a $0.02 \mathrm{~g}$ earthquake as the initiator, subsection 4.2 .4 discusses the context of this magnitude event in relation to the full spectrum of external events and its contribution to the overall external event sequence frequency.

\subsection{Limiting Conditions for Operation}

Credit has been taken in this analysis for several factors concerning system configuration, operating procedures, and administrative controls. These factors are limiting because the results of this analysis are valid only if the facility operation, system configuration, and administrative controls are maintained. The factors that have quantitative impact on the results of this analysis are summarized below:

o OSR limits on the time to reach LFL on Tanks 48 and 49 must be maintained.

o Two sets of EPVE are provided as backup to each tank (4 sets total). These units are self-powered. All EPVE sets will be protected to survive a Design Basis Earthquake (DBE) of $0.2 \mathrm{~g}$ and a high wind of $137 \mathrm{mph}$ (and any missiles generated) and can be physically relocated to Tanks 48 and 49 and made operable within the time limits specified in the OSRs (4).

o At least one compelling signal is generated immediately for each failure scenario for which a recovery/repair action is required as described in Section 5.0 .

- Adequate procedures exist for each scenario that would lead the operator(s) to the actions considered in Section 5.0. These procedures are written such that each involves step-by-step actions and requires independent check-off provisions, performed after critical steps in the procedure, to assure that the procedure is performed correctly. Operators are adequately trained on all procedures. 


\subsection{NITROGEN PURGE SYSTEM FUNCTIONAL DESCRIPTION}

The nitrogen purge system provides a continuous sweep of nitrogen gas through the vapor space of Tanks 48 and 49. This continuous sweep is required to remove benzene and hydrogen vapors formed by the ITP process occurring within these tanks. Nitrogen is used as the sweeping gas to limit the concentration of flammable constituents that accumulate in the tanks so that deflagrations do not occur. Figures 2-1, 2-2, and 2-3 provide simplified schematics of the common nitrogen supply for Tanks 48 and 49, the nitrogen purge system for Tank 48, and the nitrogen purge system for Tank 49, respectively. Table 2-1 lists the drawings and miscellaneous procedures used to determine the configuration of the system.

The nitrogen supply consists of a main 28,000-gal storage tank and four 13,000-gal backup tanks, each filled with liquid nitrogen. Each tank is self-pressurized by an ancillary vaporizer and pressure regulator. All tanks are interconnected to allow filling via either of two truck fill connectors. The tank outlets are connected to provide a continuous supply to the operating vaporizer train. The main tank, which is normally used, delivers liquid nitrogen at 145 psig to the operating vaporizer. The first backup supply (two 13,000-gal tanks) automatically delivers liquid nitrogen at 140 psig to the operating vaporizer. The second backup supply (two 13,000-gal tanks) delivers liquid nitrogen at $125 \mathrm{psig}$ to the operating vaporizer. The vaporizers are ambient vaporizers and do not rely on any external power source.

Gaseous nitrogen from the vaporizer discharge is routed through a valve and pressure regulator network and then through a permanently installed transfer line to Tanks 48 and 49 . A normally closed manual valve isolates the nitrogen system from a header designed to accommodate connection of a flexible transfer line to each tank. Normal operation of the nitrogen storage and vaporization function requires no operator involvement or intervention.

Gaseous nitrogen is supplied to each tank inlet through two normally open valves, one common valve located near the vaporizer valve and regulator network and the other located at each waste tank. The nitrogen from the second valve is routed through two identical paths to a common nozzle entering the tank. Each of the two active paths consists of a normally open manual valve, flow meter, flow control valve, flow switch, pressure regulator, and a second normally open manual valve. The flow meter and flow switch provide information and interlock signals to the DCS. The flow control valve receives control signals from the DCS.

Each tank exhaust system consists of a demister, condenser, heater, parallel HEPA filter trains, parallel flow control valves, an operating exhaust fan, and an installed spare exhaust fan. The demister is installed at the tank vapor outlet and functions to separate the suspended liquids from the exiting gas. An exhaust gas sample from the demister is drawn into the oxygen, LFL, and benzene analyzers.

Exhaust flow from the demister is routed to the condenser that is maintained cooler than the exhaust gas by a constant flow of cooling water from the chromated cooling water system. This temperature difference serves to condense moisture vapors from the exhaust stream. The cooled 
gas then passes through the heater that is maintained warmer than the gas by a constant flow of steam. This temperature difference serves to reduce the relative humidity of the stream. The combination of demister, condenser, and heater functions to dry the tank vapor so that moisture does not build up on the HEPA filters and cause excessive pressure drop or HEPA element failure.

The HEPA filters serve to remove particulates from the exhaust gas. The filters are valved into the exhaust piping so that one filter is functioning while the other is isolated as a backup. Filter selection valves are manually operated.

There are two functionally-identical, AC-powered, exhaust fans; one is normally operating. The second fan, in parallel, is on passive standby and must be manually started locally. Exit flow from the active exhaust fan is routed to a stack for final discharge.

Two sets of EPVE are provided as backup to each tank (four sets total) should both the primary and standby exhaust fans fail. These units consist of a motor, coupling, blower, appropriate valving, HEPA filter, and necessary connecting hose for mating with the tanks primary exhaust system. They also each contain their own power supply.

If the nitrogen purge is interrupted and cannot be re-established, air-based ventilation using either the normal exhaust fans or the EPVE is sufficient to prevent the tank atmosphere from reaching the lower flammability limit (6).

Both purge systems are controlled by one common DCS with appropriate software and programming to receive required information from the operating nitrogen purge system and to provide necessary operational control. The DCS is located in the control room of Building 241$82 \mathrm{H}$.

Exhaust flow from the HEPA filter passes through a flow control valve that is controlled by the DCS, based on a signal provided from the tank vacuum sensor. The DCS modulates the flow control valve to maintain a slight negative pressure within the waste tank.

As indicated in Figures 2-2 and 2-3, the DCS receives information from tank inlet flow meters and flow switches, as well as tank outlet oxygen analyzers and vacuum sensors. Control is provided by the DCS to the nitrogen inlet flow valves and the exhaust flow control valves.

Table 2-2 provides an electrical load list for the MCCs that feed the nitrogen purge system components.

Table 2-3 indicates valve positions during normal operations, and positions they take for the analysis following loss of the nitrogen purge system. The worst case position is "closed" for all the valves. The drawings referenced in Table $2-3$ in conjunction with interviews with operating personnel indicate that not all valves will go to the worst case position. Table 2-3 notes the impact on the results if all these valves were to go to the worst case position. 
WSRC-TR-93-169/Rev. 2

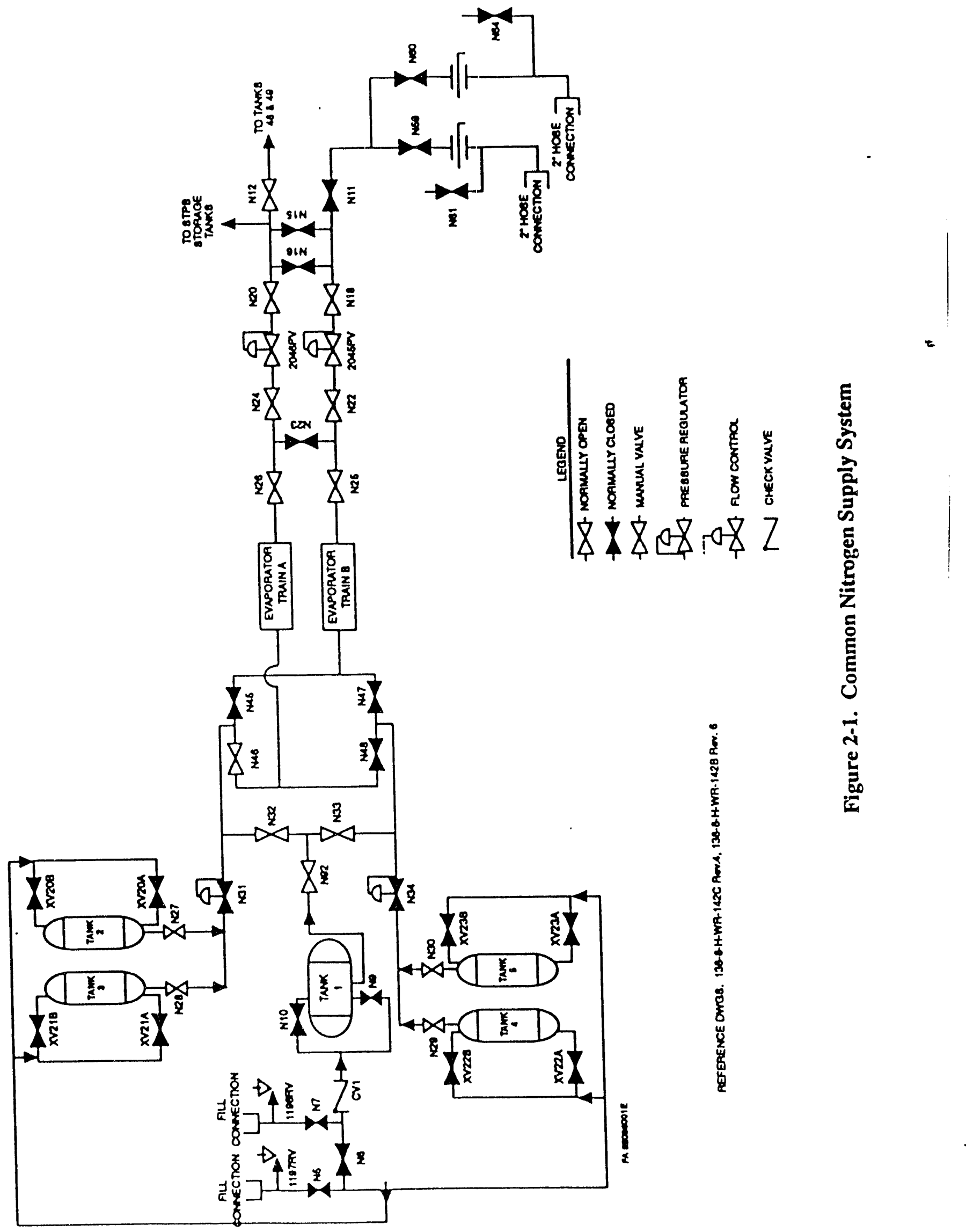




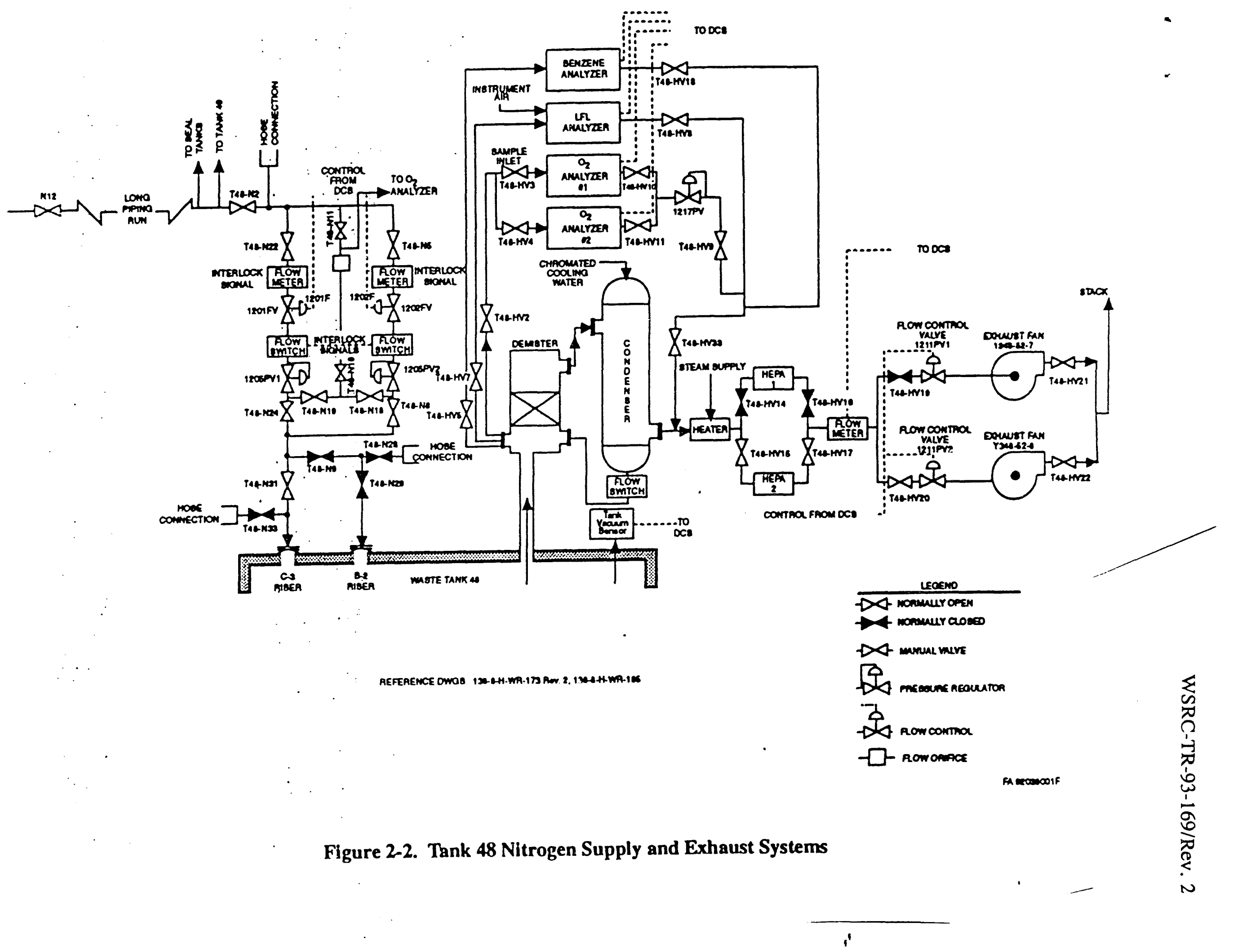


WSRC-TR-93-169/Rev. 2

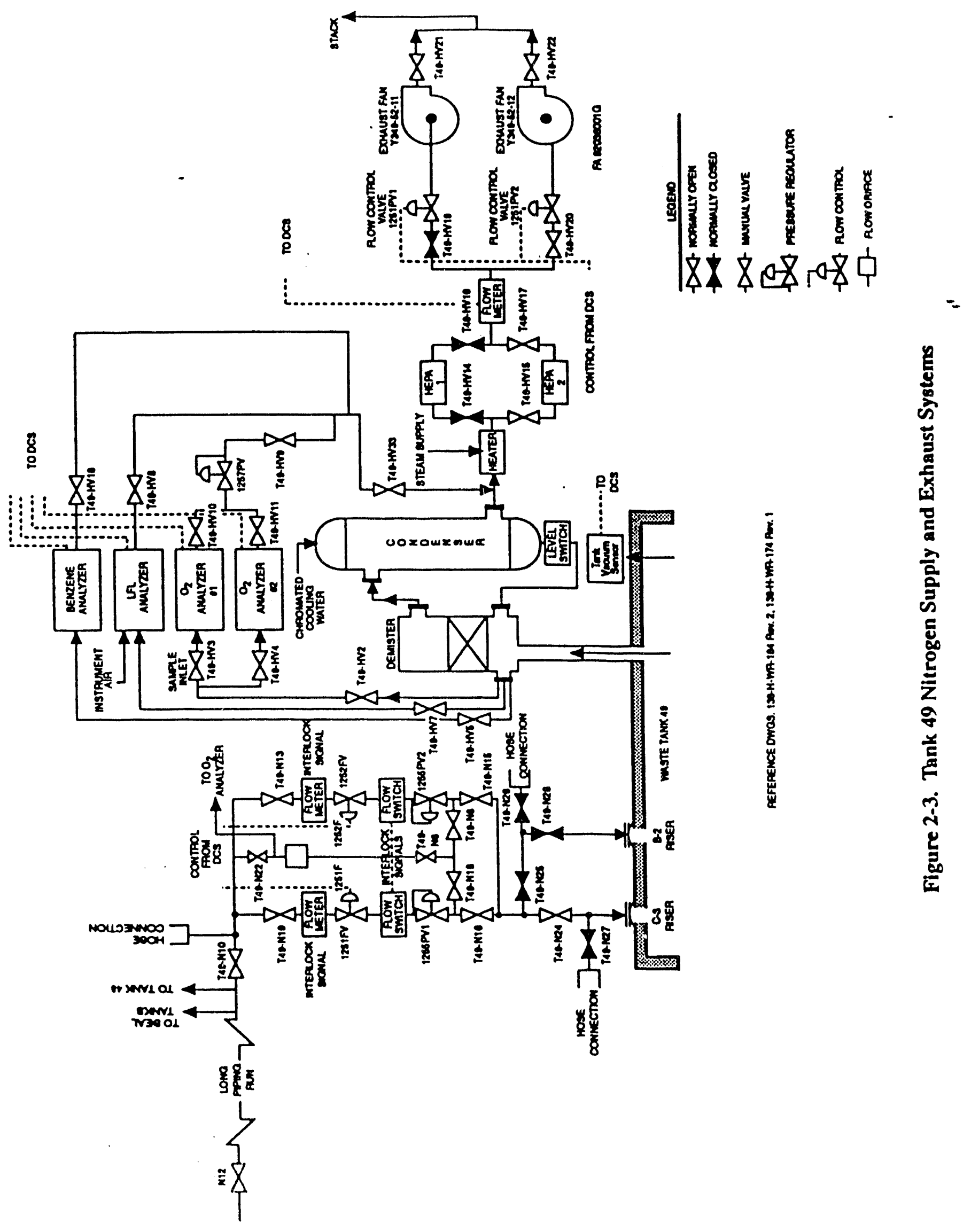


Table 2-1. Procedures and Drawings Used To Determine Nitrogen Purge System Configuration

\section{PROCEDURES}

241-H-1746SQ R2

241-H-1887SQ R2

241-H-1971 R1

241-H-1747SQ R2

241-H-1872 R0

241-H-1877Q/S R1

138-9-H-WR-168QS R2

241-H-1733Q R4

241-FH-1305T R4

241-H-1757SQ R2

241-H-1736Q R4

138-9-H-WR-210 R2

241-H-1731SQ R6

\section{DRAWINGS}

138-8-H-WR-187 R2

138-8-H-WR-186 R2

138-8-H-WR-142C R4

138-8-H-WR-142B R6

138-8-H-WR-173 R2

138-8-H-WR-185 R2

138-8-H-WR-184 R2

138-8-H-WR-174 RI
Tank 49 Ventilation System

Tank 49 Air Based Ventilation System Operation

Tank 48 Air Based Ventilation System Operation

Tank 48 Ventilation System

Tanks 48 and $49 \mathrm{~N}_{2}$ Supply Using Emergency Manifold

Waste Tanks 48 or 49 Nitrogen Purge Ventilation System Failure

Inspection of Nitrogen $\left(\mathrm{N}_{2}\right)$ Storage and Distribution System

Unloading $\mathrm{N}_{2}$ from Tanker to $\mathrm{N}_{2}$ Storage Tank

Operation of Installed Hydrogen Monitors

Action To Be Taken on L.FL Greater than Round Sheet Limits in Waste Tanks 48 or 49

Charging of Nitrogen Headers for ITP

Functional Check of Cold Feed Nitrogen Header Pressure Regulators

Loss of $\mathrm{N}_{2}$ to STPB, Tanks 48 and 49, Filtrate Hold Tanks and Benzene Stripper Columns

Tank 49 H\&V Steam

Tank 48 H\&V Steam

$\mathrm{N}_{2}$ Storage Area Pipe Routing

$\mathrm{N}_{2}$ Storage Arca Pipe Routing

Tank 48 Nitrogen Lines

Tank 48 Nitrogen Purge Exhaust System

Tank 49 Nitrogen Purge Exhaust System

Tank 49 Nitrogen Lines 
WSRC-TR-93-169/Rev. 2 ‘

Table 2-2. Electrical Load List

\begin{tabular}{|c|c|c|}
\hline $\mathrm{MCC}$ & Diesel & Loads \\
\hline $\mathrm{MCC} \mathrm{S}$ & EN136-50-1.60 & $\begin{array}{l}\text { Oxygen Analyzers } 1 \text { and } 2 \text {, Tank } 48 \\
\text { Oxygen Analyzers } 1 \text { and } 2 \text {, Tank } 49 \\
\text { Flow Control Valves } 1201 \mathrm{FV} \text { and } 1202 \mathrm{FV} \\
\text { Flow Control Valves } 1251 \mathrm{FV} \text { and } 1252 \mathrm{FV} \\
\text { Flow Control Valves } 1211 \mathrm{PV} 1 \text { and } 1211 \mathrm{PV} 2 \\
\text { Flow Control Valves } 1251 \mathrm{PV} 1 \text { and } 1251 \mathrm{PV} 2\end{array}$ \\
\hline MCC SFA & Y954-51-1 & $\begin{array}{l}\text { Exhaust Fan Y348-52-7 } \\
\text { Exhaust Fan Y348-52-8 } \\
\text { Exhaust Fan Y349-52-11 } \\
\text { Exhaust Fan Y349-52-12 } \\
\text { Digital Control System }\end{array}$ \\
\hline
\end{tabular}


WSRC-TR-93-169/Rev. 2

Table 2-3. Valve Positions for Normal Operation and Loss of Nitrogen

Component* Normal Position

Position on Loss of Nitrogen**

$\begin{array}{lll}2046 \mathrm{PV} & \text { Open } & \text { Open } \\ 1251 \mathrm{FV} & \text { Open } & \text { Open } \\ 1252 \mathrm{FV} & \text { Open } & \text { Open } \\ 1255 \mathrm{PV} 1 & \text { Open } & \text { Closed } \\ 1255 \mathrm{PV} 2 & \text { Open } & \text { Closed } \\ 1257 \mathrm{PV} & \text { Open } & \text { Open } \\ 1251 \mathrm{PV} 1 & \text { Open } & \text { Closed } \\ 1251 \mathrm{PV} 2 & \text { Open } & \text { Closed } \\ 1201 \mathrm{FV} & \text { Open } & \text { Open } \\ 1202 \mathrm{FV} & \text { Open } & \text { Open } \\ 1205 \mathrm{PV} 1 & \text { Open } & \text { Closed } \\ 1205 \mathrm{PV} 2 & \text { Open } & \text { Closed } \\ 1217 \mathrm{PV} & \text { Open } & \text { Open } \\ 1211 \mathrm{PV} 1 & \text { Open } & \text { Closed } \\ 1211 \mathrm{PV} 2 & \text { Open } & \text { Closed }\end{array}$

* All other valves are assumed to fail "as is."

** Table 2-3 indicates valve positions during normal operations, and positions they take following loss of the nitrogen purge system. These changes occur because of the action of the DCS or because of hardwired system interlocks. The worst case position is "closed" for each of these valves. Based on the drawings listed below and discussions with operating personnel, not all the valves go to their worst case position. If all these valves were to go to the worst case position, i.e., "closed", then the total frequency of $2.9 \mathrm{E}-07 / \mathrm{yr}$ for a loss of nitrogen purge due to int Inal and external events coupled with the presence of an ignition source would increase by no more than $20 \%$ (conservative estimate).

The valve positions noted above were determined by using the following drawings and updating their information based on discussions with operating personnel:

\begin{tabular}{|c|c|c|}
\hline W822682 & $\begin{array}{l}\text { Rev. } 7 \\
8 / 6 / 91\end{array}$ & $\begin{array}{l}\text { Savannah River Site Building } 241 \mathrm{H} \text { - Interim Waste } \\
\text { Management In-Tank Precipitation Tank } 48 \text { Nitrogen } \\
\text { Purge System Process and Instruments }\end{array}$ \\
\hline W822683 & $\begin{array}{l}\text { Rev. } 50 \\
11 / 21 / 90\end{array}$ & $\begin{array}{l}\text { Savannah River Site Building } 241 \mathrm{H} \text { - Interim Waste } \\
\text { Management In-Tank Precipitation Nitrogen Distribution } \\
\text { System Process and Instruments }\end{array}$ \\
\hline W822689 & $\begin{array}{l}\text { Rev. } 73 \\
8 / 6 / 91\end{array}$ & $\begin{array}{l}\text { Savannah River Site Building } 241 \mathrm{H} \text { - Interim Waste } \\
\text { Management In-Tank Precipitation Tank } 49 \text { Nitrogen } \\
\text { Purge System Process and Instruments }\end{array}$ \\
\hline
\end{tabular}




\section{Nitrogen Purge Exhaust Control Features}

The exhaust flow and nitrogen feed flow are controlled by the DCS. The exhaust flow is controlled by the DCS based on a tank vacuum input signal. The nitrogen flow control valves are also controlled by the DCS based on the oxygen analyzer input signal. The DCS balances the nitrogen feed flow and exhaust flow to maintain oxygen concentrations at $5 \%$ by volume. The initial alarms on high oxygen concentration are set at $6.3 \%$ with the hi-hi alarm set at $9.5 \%$. Nitrogen flow is expected to be approximately $300 \mathrm{scfm}$ with a low alarm at $150 \mathrm{scfm}$ and the low-low alarm at $100 \mathrm{scfm}$.

Hardwired interlocks independent of the DCS are also present. The exhaust fans shut down on low-low exhaust flow ( $<100 \mathrm{scfm})$, low-low nitrogen flow ( $<100 \mathrm{scfm})$, or hi-hi HEPA filter pressure drop. The flow control valves close on loss of an exhaust fan, low tank vacuum, or lowlow nitrogen flow.

Two oxygen analyzers operate in parallel to provide exhaust gas analysis information to the DCS. This information is used to control (modulate) the nitrogen inlet flow to the tank. A high oxygen concentration in the exhaust gas results in increased nitrogen inlet flow by opening the inlet flow control valve to provide more nitrogen. A slight increase in tank pressure results in the DCS increasing the exhaust flow by opening the exhaust flow control valve. Thus, the normal operation of the system is controlled and regulated for each tank by the DCS around two information sources: $\mathrm{O}_{2}$ concentration in the exhaust gas and tank pressure.

The following functional interlocks are provided for each tank:

1. Shutoff of exhaust fans on:
a. low tank exhaust flow (one-minute time delay) (hardwired)
b. high pressure differential across HEPA filters (hardwired)
c. low nitrogen flow (one-minute time delay) (hardwired and software)
d. high tank vacuum

2. Nitrogen supply control valves close on:
a. loss of an exhaust fan (hardwired and software)
b. low tank vacuum (hardwired)
c. low nitrogen flow (one-minute time delay) (hardwired and software) 


\section{Response to Alarms}

Operators verify all alarm conditions prior to taking action. This verification is defined in the Alarm Response Procedure for each alarm as required by 241-FEH-213, "Instructions for Preparation and Review of Alarm Response Procedures."

A keylock switch is used to bypass all the interlocks, except for $1 \mathrm{~b}$, in order to place the nitrogen purge system in manual (field) operation. 


\subsection{METHODOLOGY}

The methodology used to analyze the ITP nitrogen purge system consists of four steps:

- Establish the nitrogen purge system configuration based on system drawings and other information provided by Westinghouse Savannah River Company (WSRC). The system configuration is documented in Section 2.0.

- Perform a fault tree analysis (FTA) of the nitrogen purge system based on the configuration described in Section 2.0 and including the ignition source probability.

o Perform an event tree analysis (ETA) for external events, including the ignition source probability.

- Perform a HRA on the failures or combinations of failures identified in the fault tree and event tree analyses as contributing significantly to overall system failure probability.

\subsection{Fault Tree Analysis}

Frequencies of rare and hypothetical process accidents are usually evaluated by the FTA method. This method is a formalized procedure that is used to analyze potential accidents and/or evaluate high risk areas in process systems. It is a deductive process in which an undesirable state of a system is defined followed by systematic analysis of the system to determine fault events (initiators) and component failures (enablers) that produce the defined state. One of the advantages of FTA is that it locates those system elements that contribute significantly to the occurrence of the undesired event. These elements are then further analyzed in the recovery analysis.

In developing fault trees, consideration is given to independent component failures, common cause failures, human errors, and maintenance outages. Frequencies or probabilities are assigned to the lowest order event in a fault tree and the top event frequency is calculated using a computer program to perform the Boolean algebraic reductions.

For this analysis, a "frequency space" fault tree is developed. A frequency space fault tree is one in which the undesirable state is evaluated to determine its frequency of occurrence rather than its probability of occurrence. In quantifying the fault tree, frequency values can be greater than $1.0 / y r$, whereas, probability values can not.

To develop a frequency space fault tree, special modeling rules must be followed to ensure that all combinations of initiators/enablers are captured, and to ensure that frequencies are not combined in an "AND" gate (i.e., two frequencies "ANDed" together produce a (frequency) ${ }^{2}$ number). The 
possibility of frequencies being "ANDed" together occurs when redundant trains of equipment are modeled with an "AND"gate (i.e., two trains available (Train A and Train B), and only one is required for success). When there are two trains normally in operation, one train is chosen as the "primary" train (i.e., Train A), and all failures associated with this train are modeled using frequencies. The backup train (i.e., Train B) is modeled üsing probabilities. The probability is based on the chance that the backup Train B fails while Train A is being repaired following a failure. Therefore, the probabilities of basic event failures in Train B are quantified based on the mean time to repair (MTTR) Train A. This process only captures one half of the frequency of losing the system of redundant trains, since the model only considers the frequency of losing Train $A$, and the probability of losing Train $B$ while Train $A$ is being repaired. In order to capture the possibility that Train B is the initiator and Train A could fail while Train B is being repaired, the mission times for the "primary" train are doubled ( 2 per mission time).

Unavailabilities due to testing or maintenance are enablers and are therefore only modeled for the backup trains. Modeling testing/maintenance unavailabilites in both trains results in invalid cutsets, i.e., Trains A and B cannot be unavailable due to testing or maintenance at the same time. This process only captures one half of the probability of one train being unavailable due to testing or maintenance, since the model only considers the frequency of losing Train A and the probability of Train B being unavailable. In order to capture the possibility that Train B is the initiator and Train A could be unavailable due to testing or maintenance, the unavailabilities due to testing or maintenance for the backup trains are doubled.

A modeling convention often used to help the fault tree analyst differentiate between frequency events and probability events is the practice of placing a "*" at the end of every basic event name or gate name in which a frequency is being modeled. This aids in the cutset review process to assure that only one frequency event appears in each cutset.

The fault tree is developed and evaluated with the computer program CAFTA+ (Computer Aided Fault Tree Analysis (7)). CAFTA+ is a computer software tool used to build, modify, and evaluate fault tree models. It includes a fault tree editor, a basic event database, a component database, formatting routines, fault tree analysis routines, and a cutset editor. These processors are integrated into a single microcomputer-based analysis tool.

The principal interface between the fault tree analyst and CAFTA+ is the fault tree editor that is used to build and modify fault trees. Syntax and logic checks are performed on the models.

The fault tree editor also links the basic event reliability data from the database files to the fault tree. The basic event database includes the basic event name, mission time, description of the event, failure probability (either input for a specific event or calculated from the mission time and the component failure rate from the component type code file), and the source of the data. The component database includes failure rates for generic component types and failure modes and also includes the source of the data.

CAFTA+ analyzes fault tree models through a sophisticated fault tree and cutset processor. The fault tree processor generates and quantifies cutsets from fault tree models built by the analyst. A 
fault tree may be quantified in terms of the top fault condition and subtier fault conditions. Resulting cutsets are edited and analyzed in the recovery analysis.

A wide range of data sources are used to quantify the fault trees:

- Component and support system failure rate data from the Tank Farm Safety Analysis Report (SAR) (1),

o Other SRS data and analyses (8-13), and

o Other published literature sources (14-16).

The failure probability of a basic event is included in the basic event database that is developed as part of the fault tree.

\subsection{Event 'Tree Analysis}

Accident sequences that are initiated by external events are comprised of successive successfailure events that can generate several of outcomes (or end states). The sequences leading to each end state are identified and sequence frequencies are determined through the use of a logic diagram to identify possible outcomes of an undesired event (called the initiating event). This type of diagram is called an event tree.

Unwanted consequences are usually the result of an initiating event combined with failure of facility equipment and/or failure of human actions designed to mitigate consequences or reduce their magnitude. An event tree generates event sequences by taking into account both the success and failure of each mitigating feature or action that is relevant to the initiating event. Each event sequence is a unique combination of mitigator successes and failures and has a defined consequence as its end state.

Event trees are developed and evaluated with the computer program ETA-II (Event Tree Analysis-II) (17). ETA-II is a computer software tool used to build, modify, and evaluate event tree models. ETA-II provides an interactive environment in which to build and refine accident sequence models from beginning to end. Branches and events may be added, copied, or removed with no additional time spent in recalculating modified sequence probabilities. While developing a model the displayed tree reflects the latest changes. In addition, probabilities can be inserted one branch at a time or simultaneously for all branches of a given event. Sequences may be grouped to determine the significance of a particular end state. ETA-II sums the probabilities of these sequences automatically.

\subsection{Human Reliability Analysis (HRA)}

To incorporate operator actions into the fault tree and event tree analyses, a HRA is performed. Each of the dominant cutsets from the fault tree analysis is analyzed to identify operator corrective actions that can return the system to normal operation. The event tree analysis also 
identifies human actions that are required to prevent or mitigate undesirable consequences. The HRA is performed to quantify each human action based on the time available for the operator to perform the action. Results of the HRA are Human Error Probabilities (HEPs) that are assigned to each action. The HRA is performed according to the procedure outlined in Reference 18 unless otherwise noted. 


\subsection{INTERNAL AND EXTERNAL EVENT ANALYSIS}

The frequency of a deflagration in Tankd 48 and/or 49 is determined by a FTA of nitrogen purge system random failures and an ETA of external events that result in system failure. The development and results of these analyses are described in this section.

\subsection{Internal Event Analysis}

The FTA is performed on the nitrogen purge system for Tanks 48 and 49 based on the configuration and operation described in Section 2.0 and includes the ignition source probability.

\subsubsection{Fault Tree Construction}

The fault tree is presented in Appendix A. All components are modeled to include loss of recessary support systems (such as electric power and cooling water), hardware faults, unavailability due to maintenance, and common cause failures as appropriate.

The fault tree consists of five major branches "ANDed" with the ignition source probability:

1. Equipment failures common to both Tank 48 and Tank 49 (gate ITP03). This branch of the tree includes the DCS and the common nitrogen supply lines. All events in this branch of the tree result in a loss of the nitrogen purge to both Tank 48 and Tank 49.

2. Nitrogen purge for Tank 48 fails to operate during washing - three days (Mode X) (gate ITP01). This branch includes the probability that Tank 48 is in its wash cycle (probability of $0.2,20 \%$ of the time) (3). The probability is combined with various combinations of system failures leading to a loss of the nitrogen purge system to yield a total branch failure frequency.

3. Nitrogen purge for Tank 48 fails to operate during transfer - three to six days (Mode Y) (gate ITP110). This branch is identical to the branch described above (gate ITP01), except that it includes the probability that Tank 48 is in its salt solution transfer cycle (probability of $0.2,20 \%$ of the time) (3).

4. Nitrogen purge for Tank 48 fails to operate during normal processing - six days (Mode Z) (gate ITP02). This branch is identical to the branch described above (gate ITP110), except that it includes the probability that Tank 48 is in its normal processing cycle (probability of $0.6,60 \%$ of the time) (3). 
5. Nitrogen purge for Tank 49 fails to operate for three days (gate ITP04) (3). This branch of the fault tree includes the various combinations of system failures leading to a loss of the nitrogen purge system to yield a total branch failure frequency.

\section{Assumptions}

Assumptions and characteristics of system components and operation used in the FTA include:

1. Both oxygen analyzers are normally operating and failure of a single oxygen analyzer does not cause a loss of the nitrogen purge system.

2. Some valves fail in the least desirable position. Table $2-3$ indicates the failed position for key valves.

3. All EPVE sets can be interchanged between Tanks 48 and 49.

4. Compelling signals exist for all failure scenarios considered.

5. The DCS fails if air conditioning (HVAC) is lost in the control room. This can occur only if the outside temperature is greater than $80^{\circ} \mathrm{F}$.

\section{Common Cause Failures}

Common cause failures are considered for separate operating conditions. All common cause contributors for a single component type are collected under the dominant common cause failure.

\section{Normal Operation}

Common cause failures are quantified and modeled for the following components:

- $\mathrm{O}_{2}$ analyzers: Common cause miscalibration.

o Fan operation sensors: Common cause miscalibration.

o Flow sensors: Common cause miscalibration.

Common cause failures were not modeled for the following components. Justifications are provided for exclusion of common cause events.

o HEPA filters: Only one train is aligned for operation at a time and no credit is taken for the installed spare; therefore, no common cause failure of the HEPA filters is modeled. 
- Exhaust fans: Only one train is aligned for operation at a time and no credit is taken for the installed spare; therefore, no common cause failure of the exhaust fans is modeled.

- Vaporizers: Only one train is aligned for operation at a time and no credit is taken for the installed spare; therefore, no common cause failure of the vaporizers is modeled.

o Flow control valves $1211 \mathrm{PV} 1 / 2(1251 \mathrm{PV} 1 / 2)$ : Only one train is aligned for operation at a time and no credit is taken for the installed spare; therefore, no common cause failure of these flow control valves is modeled.

- Flow control valves $1201 \mathrm{FV} / 1202 \mathrm{FV}$ (1251FV/1252FV): The main concern associated with these valves is their failure to maintain flow. This can be caused by DCS failure (modeled), flow sensor failure (modeled), independent valve failures (modeled), or common cause mechanical failures (not modeled). The common cause mechanical failure is a "passive" failure and is not modeled due to low probability.

o Pressure regulators 1205PVI/1205PV2, 1255PV1/1255PV2, 2045PV/2046PV: The main concern associated with the pressure regulators is their failure to pass flow (transfer closed or plugged). Both of these failure modes are "passive." Common cause failures of passive failure modes are not modeled due to low probability.

\section{EPVE Operation}

When the EPVE sets are in use, no other nitrogen purge system components are necessary; therefore, only the EPVE sets are modeled. Common cause failures are modeled for the following components:

- EPVE fans: Between the two sets associated with Tank 48.

o EPVE fans: Between the two sets associated with Tank 49.

o EPVE fans: Between more than two sets out of the total of four associated with Tanks 48 and 49.

\section{Restart of Nitrogen Purge System}

When the nitrogen purge system is restarted, either train is available, in which one exhaust fan is required to start, an exhaust line flow control valve must open, and a supply line pressure regulating valve must open. Common cause failures are modeled for the following components: 
o Exhaust fan: Common cause failure to start.

- Flow control valve: Common cause failure to open.

o Pressure regulating valve: Common cause failure to open.

- Oxygen analyzer: Common caose failure to operate

\subsubsection{Fault Tree Evaluation}

All basic events from the fault tree are quantified using site-specific data (if available) or generic data and are included in the database files in CAFTA+. Data sources are listed in Table 4-1, and the basic events are shown in Table 4-2.

The nomenclature used to label the basic events enables quantification using the component database file option in CAFTA+. The first character of each basic event name identifies the system containing the component. These characters are "8" (Tank 48), "9" (Tank 49), or "N" (common to both tanks and the nitrogen supply system). The second and third characters of the basic event name identify the component type, such as flow control valve (FC) or manual valve (XV). The fourth, fith, and sixth characters identify the component by name or number. The seventh and eighth characters identify the failure mode such as hardware fault (HW) or fails to start (ST).

The component database file is based on component type (second and third characters) and failure mode (seventh and eighth characters). All components of the same type with the same failure mode are assumed to have the same failure rate or demand failure probability and are included in the component type code file, as shown in Table 4-3. From this file, the failure rate is automatically associated with the basic events in the basic event database file.

The basic events shown in Table 4-2 represent the probability of failure (or unavailability) of a piece of equipment in the system, the probability of an operations or maintenance error, or the frequency of an initiating event (actual initiator bringing about the system state being modeled). These failure probabilities and frequencies are functions of both the failure rate for the basic event and an exposure time. Table 4-4 describes the various exposure times and how they are used in the fault tree analysis.

CAFTA+ utilizes the information contained in the " $\mathrm{C}$ ", "factor", and "U" columns of Table 4-2 in conjunction with the "Rate" and "U" columns of Table 4-3 to determine the failure probability of each basic event modeled in the fault tree. The "Rate" column is the generic failure rate of a specific type of component, while the " $U$ " column of each table specifies whether the failure rate is per demand $(\mathrm{N})$ or per unit time. If the " $U$ " column is not compatible between the two tables, CAFTA+ generates an error message to warn the analyst of compatibility problems. The "Factor" column determines the mission time for each basic event that has a per unit time failure rate. If 
Table 4-1. List of Data Sources

1. Dexter, A. H. and Perkins, W. C. Component Failure Rate Data with Potential Applicability to a Nuclear Fuel Processing Plant (U). DP-1633. E. I. du Pont de Nemours \& Co., Savannah River Laboratory, Aiken, SC, July 1982.

2. IEEE Standard 500-1984. IEEE Guide to the Collection and Presentation of Electrical, Electronic, Sensing Component, and Mechanical Equipment Reliability Data for NuclearPower Generating Stations. Institute of Electrical and Electronics Engineers, New York, NY, (1983).

3. Some Published and Estimated Failure Rates To Use in Fault Tree Analysis (U). E. I. du Pont de Nemours \& Co., Wilmington, DE, January 9, 1981.

4. Generic Component Database for Severe Service Chemical Process Plants. SAIC 90/1026, Science Applications International Corporation, Richland, WA, January 1990.

5. Offshore Reliability Data Handbook. First Edition, (1984).

6. Legler, B. M., et al. Safety Analysis - 200 Area Savannah River Plant Separations Area Operations Liquid Radioactive Waste Handling Facilities $(U)$. Internal Report DPSTSA200-10. E. I. du Pont de Nemours \& Co., Savannah River Laboratory, Aiken, SC, August 1988 .

7. Durant, W. D. and Perkins, W. C. Safety Analysis - 200-S Area Savannah River Site Defense Waste Processing Facility Operations (U). Internal Report DPSTSA-200-10, SUP 20, Rev. 6/93 (Draft), Westinghouse Savannah River Company, Savannah River Site, Aiken, SC, June 1993.

8. Memo, J. E. Held to R. E. Vail and D. A. Sharp. Human Reliability Analysis of DWPF Calibration Activities (U). SRT-HFE-930011. Westinghouse Savannah River Company, Aiken, SC, May 7, 1993.

9. Memo, D. S. Cramer to T. E. Britt. Failure Probability To Start a System of Fans Driven By Gasoline Engines for the In Tank Precipitation Program. SRT-RST-930225. Westinghouse Savannah River Company, Aiken, SC, May 27, 1993.

10. Cramer, D. S. SRP Generic Database (SAIC/NY 85-8-14). Internal Report DPST-86-401, E. I. du Pont de Nemours \& Co., Savannah River Laboratory, Aiken, SC, April 1986. 
Table 4-2. Basic Event File

$18 \mathrm{AZO} 21 \mathrm{HW}+1$

2 8A2O22HWA

3 BAZO22TM

4 BAZO2SOM*

5 BCNCONHW

6 BDMDEMHW

8 8EC111TM

9 8FC112HW*

$108 \mathrm{FC} 121 \mathrm{HW}^{*}$

11 8FC122HW

12 8FC122TM

13 BFLHP2HW"

148 EN527HW

15 8FN527ST

16 8EN527TM

19 BESHEPHW *

22 BESNESCM.

23 BHOUSEO1

24 BHOUSEO2

25 8HOUSE03

26 8HOUSE04

27 BHTHTRHW* 1

29 BOPC-HS

29 BOPC-HS

31 BOPC-MS

31 OOPTRNBE

32 8PRPVIHW*

33 BPRPV $2 H W$

34 BPRPV2TM

35 BPRREGHW*

36 8SFFANCM*

37 8SFFANHW*

38 8VSVACHW -

39 8XVEN2PG*

40 8XV8N5PG

41 BXV8N8PG

42 8XVHV2PG*

43 BXVHV3PG

44 BXVHV4PGA

45 8XVHV9PG*

$468 \times V N 22 P G^{*}$

47 8XV24PG*
$2 Y$ TANK 48 O2 ANALYZER 1 HARDWARE FAULTS

$5.26 E+00$

3. $60 \mathrm{E}-03$

$3.60 \mathrm{E}-03$

2 TANK 48 O2 ANAIYZER 2 UNAVAILABLE DUE TO MAINTENANCE

Y

$Y$ LOCAL EAULTS OF TANK 48 CONDENSER

$Y$ LOCAL FAULTS OF TANK 48 DEMISTER

3 M FLOW CONTROL VALVE 1211PVI MECHANICAL EAULT (MODE C)

$2 \mathrm{~N}$ ELOW CONTROL VALVE 1211PVI MAINTENANCE

1 Y FLOW CONTROL VALVE 1211PV2 MECHANICAL FAULT

2 Y MECHANICAL FAULT OF TANK 48 FLOW CONTROL VALVE $1201 \mathrm{FV}$

D MECHANICAL EAULT OF TANK 48 FLON CONTROL VALVE $1202 \mathrm{FV}$

2 N TANK 48 FLOW CONTROL VALVE $1202 \mathrm{FV}$ UNAVAILABLE DUE TO MAINTENANCE

1 Y LOCAL EAULT OF HEPA FILTER 2

7 TANK 48 EXHAUST EAN Y 348-52-7 FAILS TO RUN FOR 6 DAYS

1 T TANK 48 EXHAUST FAN Y348-52-7 FAILS TO START DUE TO MECHANICAI FAULTS

$2 N$ TANK 48 EXHAUST EAN Y348-52-7 UNAVATLABLE DUE TO MAINTENANCE

TANK 48 EXHAUST FAN Y348-52-8 FAIS TO RUN DUE TO MECHANICAL EAULTS

1 Y TANK 40 EXTTROGEN OLOW SENSOR FOR EXHAUST ITNE EATLS

I TANK 48 NIT ACROSS HEPA EILTER FAILS DUE TO MECHANICAL EAULT

1 Y FLOW SENSOR ACROSS HEPA FILTER FAILS DUE TO MECHUN TO LOULT

2 T TANK 48 NITROGEN ELOW SENSOR FOR LINE A FAILS DUE TO LOCAL EAULTS (MODE CI

$1 Y$ BOTH NITROGEN FLOW SENSORS FAIL DUE TO COMMON MODE MISCALIBRATION

CONDITIONAL PROBABILITY OF
NO ACTION TAKEN FOR 48 HOURS

OCITON TAKEN FOR 4B HOURS

60 CONDITIONAL PROBABILITY OE BEING IN NORMAL PROCESSING MODE (10 C TEMP)

$Y$ LOCAL MECHANICAL FAULTS OE TANK 48 HEATER

I INTERLOCK EAILURE (FAN EXHAUST FLOW METER) CLOSES FLOW CONTROL VALVE

OPERATOR FAILS TO ENTER FIELD CONTROL MODE (HIGH STRESS LEVELS)

OPERATOR FAILS TO ENTER FIELD CONTROL MODE (MODERATE STRESS LEVELS)

OPERATOR FAILS TO ALIGN AND START TRAIN B FOR OPERATION - EXHAUST SIDE

2 Y MECHANICAL EAULTS OF TANK 48 PRESSURE REGULATING VALVE 1205PV1

D MECHANICAL ERULTS OF TANK 48 PRESSURE REGULATING VALVE 1205PV2

D TANK 48 PRESSURE REGULATING VALVE 1205 PV2 UNAVAILABLE DUE TO MAINTENANCE

Y TANK 48 FAILURE OF PRESSURE REGULATING VALVE 1217 PV

I $Y$ TANK 40 FAI MISCAIIBRATION FAILURE OF SENSORS DETECTING FAN OPERATION

1 Y SENSOR DETECTING FAN OPERATION FOR NORMALLY RUNNING FAN FAILS

Y SENSOR DETECTING TAN OPERTT ION BOR NORMALLY RUNNING EAN EATLS

1 Y TANK 48 VACUUM SENSR EATL THE NITROGEN SUPPLY FAILS TO REMAIN OPEN (PLUG)

1 Y TANK 48 VALVE T48-N5 FAILS TO REMAIN OPEN (PLUG)

7 D MANUAL VALVE T48-N5 FAILS TO REMAIN OPEN (PLUG)

7 D MANUAL VALVE T48-N8 FAILS TO REMAIN OPEN (PLUG)

1 Y MANUAL VALVE T48-HV2 EAILS TO REMAIN OPEN (PLUG)

2 Y MANUAL VALVE T48-HV3 FAILS TO REMAIN OPEN (PLUG)

7 D MANUAL VALVE T48-HV4 FAILS TO REMAIN OPEN (PLUG)

$Y$ TANK 48 O2 ANALYZER DISCHARGE VALVE T48-HV9 FAILS TO REMAIN OPEN (PLUG)
2

2 Y TANK 48 PATH A DISCHARGE VALVE T48-N24 FAILS TO REMAIN OPEN (PLUG)
$2.63 E-02$

$3.15 E-02$

$9.18 \mathrm{E}-03$

$7.20 \mathrm{E}-03$

$7.45 E-02$
$1.49 E-01$

$1.49 E-01$
$1.43 E-03$

$7.20 E-03$

$8.76 \mathrm{E}-03$

$1.34 E-03$

$4.80 \varepsilon-04$

3. $60 \mathrm{E}-03$

$7.01 E-02$

$1.05 E+00$

$1.05 E+00$

$2.10 E+00$

$2.00 E-02$

$2.00 E-02$

$4.40 E-01$

$2.00 E-01$

$1.00 E+00$

2. $00 E-01$

$6.00 E-01$

$1.75 E-04$

$4.03 E-01$

$1.00 E+00$

$1.00 E+00$

$1.00 E+00$

3. $85 \mathrm{E}-02$

3. $70 \mathrm{E}-04$

7. $20 \mathrm{E}-03$

1. $93 \mathrm{E}-02$

4. $40 E-01$

$1.84 E-01$

3. $07 \mathrm{E}-02$

1. $23 E-04$

2.35E-06

2. $35 E-06$

2. $35 E-06$

1. $23 \mathrm{E}-04$

2. 15E-04

$2.35 E-06$

1.23E-04

$2.45 E-04$
$2.45 E-04$ 
Table 4-2. Basic Event File (Continued)

I TANK 48 TANK INLET VALVE T48-N31 FAILS TO REMAIN OPEN (PLUG) $Y$ MANUAL VALVE T48-HVIO FAILS TO REMAIN OPEN (PLUG) D MANUAL VALVE T48-HV11 FAILS TO REMAIN OPEN (PLUG) 7 D MANUAL VALVE T48-HV11 FAILS TO REMAIN OPEN (PLUG) 1 Y MANUAL VALVE T48-HV15 FAILS TO REMAAN OPEN (PLUG)

1 Y MANUAL VALVE T48-HV17 FAILS TO REMATN ON DEMAND

I $Y$ MANUAL VALVE T48-HV19 FAILS TO OREN ON DEMAND

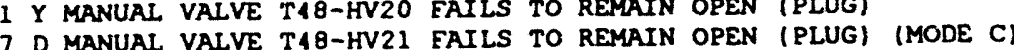

7 D MANUAL VALVE T48-HV21 FAILS TO REMAIN OPEN (PLUG)

1 Y MANUAI VALVE T48-HV22 EAILS TO REMAIN OPEN (PLUG) Y MANUAL VALVE T18-HV33 EAILS TO REMATN 2 TANK 19 O2 ANALYZER 1 HARDMARE FAULTS

D TANK 19 O2 ANALYZER 2 UARDVALABLE DUE TO MAINTENANCE

$Y$ COMON MODE SENSOR MISCALIBRATION FAILURE FOR O2 ANALYZERS

1 Y LOCAL FAULTS OF TANK 49 CONDENSER

$1 Y$ LOCAL FAULTS OF TANK 49 DEMISTER

2 Y MECHANICAI FAULT OF TANK 19 FLOH CONTROL VALVE 1251 FV

7 MECHANICAI FAULT OF TANK 49 FLOH CONTROL VALVE $1252 \mathrm{FV}$

TANK 9 FON CONTROL VALVE $1252 \mathrm{FV}$ UNAVAILABLE DUE TO MAINTENANCE

M TLO CONTROL VALVE 1251 PVI MECHANICAL FAULT

I TLON CONTOL VATVE 1251 PVI MATNTENANCE

2 N FLOW CONTROL VALVE 1251PV1 MATNTENANCE

1 Y LOCAI FAULT OF TANK 49 HEPA FILTER 2

1 Y LOCAL FAULT OE TANK 9 HEPA FILTER 2 TO RUN DUE TO MECHANICAL EAULTS

D TANK 19 EXHAUST EAN Y349-52 11 FAILS TO RUN DUE TO MECHANTCAL EAULTS

1 N TANK 9 EXHAUST EAN Y349-52-11 UNAVATLABLE DUE TO MAINTENANCE

$2 \mathrm{~N}$ TANK 19 EXHAUST FAN Y349-52-11 UNAVA TO RUN DUE TO MECHANICAL FAULTS

1 Y TANK 19 EXHAUST FAN Y349-52-12 FAILS TO RUN DUE TO MEC

1 Y TANK 19 NITROGEN FLOW SENSOR FOR EXHAUST LINE EATHS

1 Y FLOW SENSOR ACROSS HEPA FILTER FAILS DUE TO MECHAN TCAL FAULT

2 Y TANK 49 NITROGEN FLON SENSOR FOR LINE A FAILS DUE TO LOCAL FAULTS

7 D TANK 49 NITROGEN FLOW SENSOR FOR LINE B FAILS DUE TO LOCAL FAULTS

$1 Y$ BOTH NITROGEN FLOW SENSORS

NO ACTION TAKEN FOR 18 HRS

$1 Y$ LOCAL MECHANICAL FAULTS OF TANK 49 HEATER

1 Y INTERLOCK FAILURE (FAN EXHAUST FLOW METER) CLOSES FLOW CONTROL VALVE

OPERATOR FAILS TO ENTER MODE C - FIELD CONTROL (HIGH STRESS LEVELS I

OPERATOR EAILS TO ENTER MODE C - FIELD CONTROL (MODERATE STRESS LEVELS)

OPERATOR FAILS TO ALIGN AND START TRAIN B FOR OPERATION - EXHAUST SIDE

2 Y MECHANICAL FAULTS OF TANK 49 PRESSURE REGULATING VALVE 1255PVI

D MECHANTCAL EAULTS OF TANK 49 PRESSURE REGULATING VALVE 1255 PV

D TANK 9 PRESSURE REGULATING VALVE 1255PV2 UNAVAILABLE DUE TO MAINTENANCE

2 TANK 49 FAILURE OE PRESSURE REGULATING VALVE 1257 PV

Y COMMON MODE MISCALIBRATION FAILURE OF SENSORS DETECTING EAN OPERATION

$Y$ SENSOR DETECTING FAN OPERATION FOR NORMALLY RUNNING FAN FAILS

$Y$ TENK 49 VACUUM SENSOR FAILS AND CLOSES FAN FLOW CONTROL VALVES

1 Y MANUAL VALVE T49-HV2 EAILS TO REMAIN OPEN (PLUG)

2 Y MANUAL VALVE T49-HV3 FAILS TO REMAIN OPEN (PLUG)
$1.23 E-04$

$2.45 E-04$

$2.35 E-06$

$1.23 E-04$

$1.23 E-04$

$1.60 \mathrm{E}-04$

$1.23 E-04$

2. $35 \mathrm{E}-06$

$1.23 \mathrm{E}-04$

$1.23 E-04$

$5.26 \varepsilon+00$

4. $92 \mathrm{E}-02$

3. $60 \mathrm{E}-03$

2. 38E-01

2. $63 \mathrm{E}-02$

$3.15 \varepsilon-02$

$1.49 E-01$

$1.43 E-03$

$7.20 E-03$

9.18E-03

$7.20 E-03$

$7.45 E-02$

8. $76 \mathrm{E}-03$

1. 34E-03

$4.80 E-04$

3. $60 \mathrm{E}-03$

7. $01 E-03$

$7.01 E-02$

$1.05 E+00$

$1.05 E+00$

$2.10 E+00$

$2.00 E-02$

$4.40 E-01$

$1.00 E+00$

$1.75 E-04$

4. $03 E-01$

$1.00 E+00$

$1.00 E+00$

$1.00 E+00$

3. $85 \mathrm{E}-02$

3. $70 \mathrm{E}-04$

7. $20 \mathrm{E}-03$

$1.93 \mathrm{E}-02$

4. $40 E-01$

$1.84 E-01$

$3.07 E-02$

$1.23 E-04$

2. 45E-04 
Table 4-2. Basic Event File (Continued)

95 9XVHVAPG 96 9XVHV9PG* 97 9XVNIOPG: 98 9XVN13PG 99 9XVN15PG 100 9XVN16PG* 101 9XVN19PG* 102 9XVN24PG* 103 9XVV10PG* 104 9XVV11PG 105 9XVV15PG* 106 9XVV17PG* 107 9XV1 $19 H W$ 108 9XVV20PG* 109 9XVV21PG 110 9XVV22PG" 111 9XVV33PG* 112 EPVNTINT 113 HEPA

114 IGNITION

115 NCPDCSHY 116 NCPDCSHW 117 NELGRDHW* 118 NFCFCACM 119 NFCECANN 120 NFCFCBNN 121 NEN FNACM 122 NENENAST 123 NENENBST 124 NHOUSEO 1 125 NHVCOMHW* 1 126 NOPC-HS 127 NOPTRNBS 128 NPPDIVBK * 129 NPPNONBK* 130 NPR245HW 130 NPR245TM 131 NPR245TM 132 NPR246HW 133 NPRPRACM 134 NPRPANH 135 NPRPRBNN 136 NSSSTMHW 139 NVPVPBHW
D MANUAL VALVE T49-HV4 FAILS TO REMAIN OPEN (PLUG) Y TANK 49 O2 ANALYZER DISCHARGE VALVE T49-HV9 FAIL 1 Y MANUAL VALVE T49-N10 FAILS TO REMAIN OPEN (PLUG)

7 MANUAI VALVE T49-N13 FAILS TO REMAIN OPEN (PLUG)

7 D TANK 49 PATH B DISCHARGE VALVE T49-N15 EAILS TO REMAIN OPEN (PLUG:

2 Y TANK 49 PATH A DISCHARGE VALVE T49-N16 EAILS TO REMAIN OPEN (PLUG)

2 TANK 49 PATH A INLET VALVE T49-N19 EAILS TO REMAIN OPEN (PLUG)

(PLUG)

2 Y MANUAL VALVE T49-HVIO EATLS TO REMAIN OPEN (PLUG)

7 D MANUA VALVE T49-HVI1 EAILS TO REMAIN OPEN (PLUG)

Y MANUAL VALVE T49-HVI5 FAILS TO REMAIN OPEN (PLUG)

1 Y MANUAL VALVE T49-HVI7 FATLS TO REMAIN OPEN (PLUG)

1 MANUAL VALVE T49-HV19 FAILS TO OREN ON DEMAND

1 Y MANUAL VALVE T49-HVI

1 Y MANUAL VALVE T49-HV20 FAILS TO REMAIN OPEN (PLUG)

7 D MANUAL VALVE T49-HV21 FAILS TO REMAIN OPEN (PLUG)

1 Y MANUAL VALVE T49-HV22 FAILS TO REMAIN OPEN (PLUG)

2.35 -5 OPERATOR FAILS TO ALIGN OR START EMERGENCY PURGE VENT EQUIP OR HARDWARE FAULTS 1.03E-3 PROBABILITY OF NOT REPLACING/REPAIRING HEPA FILTER IS NEGLIGIBLE

09 CONDITIONAL PROBABILITY OF HAVING AN IGNITION SOURCE PRESENT

Y LOCAL MECHANICAL EAULTS OF DCS COMPUTER

Y MECHANICAL EAULTS IN CHROMATED COOLING WATER SYSTEM

$Y$ LOSS OF II-AREA POWER

Y LOSS OR :T-ARE POWER OF HON CONTROL VALVES TO OPEN

I $N$ FLOW CONTROL VALVE TRAIN A FAILS TO OPEN

I FLON CONTROL VALVE TRAIN A FAILS TO OPEN

1 N COMMON CAUSE EAILURE OF EXHAUST FANS TO START

1 N EXHAUST FAN TRAIN A FAILS TO START

I $N$ EXIAUUST FAN TRAIN B EAILS TO START

0.125 CONDITIONAL PROBABILITY OE OUTSIDE TEMPERATURE BEING $>80 \mathrm{~F}$

Y LOSS OF HVAC TO ROOM CONTAINING DCS COMPUTER

OPERATOR FAILS TO ENTER EIELD CONTROL MODE (HIGH STRESS LEVELS)

OPERATOR FAILS TO ALIGN TRAIN B FOR OPERATION - SUPPLY SIDE

$Y$ ISOLABLE GUILLOTINE PIPE BREAK

$1 Y$ NON-ISOLABLE GUILLOTINE PIPE BREAK

3 M PRESSURE REGULATING VALVE 2045PV FAILS

$2 N$ PRESSURE REGULATING VALVE 2045PV MAINTENANCE

1 Y PRESSURE REGULATING VALVE 2046PV FAILS

I N COMMON CAUSE FAILURE OF PRESSURE REGULATING VALVES TO OPEN

I N PRESSURE REGULATING VALVE TRAIN A FAILS TO OPEN

I PRESSURE REGULATING VALVE TRAIN B EAIIS TO OPEN

Y Y POSS OE STEAM SUPPLY TO HEATER

1 Y LOSS OE STEAM SUPRLY TO HEATER

I $Y$ EAILURE OF VAPORIZER A DUE TO HARDWARE EAULTS

$1 Y$ EAILURE OF VAPORILER A DUE TO HARDWARE EAULTS

7 D EAILURE OE VAPORIZER B DUE TO HARDWARE FAULTS

1 Y VALVE N12 FROM THE NITROGEN SUPPLY FAILS TO REMAIN OPEN (PLUG)
2. 35E-06

1.23E-04

$1.23 E-04$

$2.35 E-06$

$2.35 \mathrm{E}-06$

$2.45 E-04$

$2.45 E-04$

$1.23 E-04$

$2.45 E-04$

2. 35E-06

$1.23 \mathrm{E}-04$

$1.23 E-04$

$1.60 E-04$

$1.23 E-04$

2. 35E-06

$1.23 E-04$

1. $23 E-04$

$2.35 E-05$
$1.03 E-03$

$9.00 \mathrm{E}-02$

$7.88 \mathrm{E}-01$

$2.19 \mathrm{E}-01$

3. $00 E-01$

$1.00 \mathrm{E}-04$

1. $00 \mathrm{E}-03$

$1.00 \mathrm{E}-03$

1. 80E-05

4. $80 \mathrm{E}-04$

4.80E-04

$1.80 \mathrm{E}-04$
$1.25 \mathrm{E}-01$

$1.25 E-01$

$1.40 E-01$

$1.00 E+00$

$1.00 E \div 00$

8.76E-06

8.76E-06

2. 38E-03

$7.20 \mathrm{E}-03$

1. $93 \varepsilon-02$

8.10E-04

8.10E-03

8. $10 \varepsilon-03$

$2.63 E+00$

2.01E-05

3. $59 E-03$

6. 89E-05

$1.23 E-04$

1. $23 E-04$ 
Table 4-2. Basic Event File (Continued)

\begin{tabular}{lll}
\multicolumn{1}{c}{ NAME } & $C$ \\
\hdashline$-\cdots$ & \\
42 NXVN15HW & 1 \\
43 NXVN16HW & 1 \\
44 NXVN18PG & 3 \\
45 NXVN2OPG* & 1 \\
46 NXVN22PG & 3 \\
47 NXVN24PG* & 1 \\
48 NXVN25PG & 3 \\
49 NXVN26PG* & 1 \\
50 NXVN33PG & 3 \\
51 & NXVN46PG* & 1 \\
52 & NXVN47HW & 1 \\
53 & NXVN92PG* & 1 \\
54 & RECPWR & \\
55 & REPAIRM & \\
56 & REPAIRN &
\end{tabular}

$1.23 E-04$

1 Y MANUAL VALVE N92 FAILS TO REMAIN OPEN (PLUG),

$1.23 E-04$
$1.60 E-04$

1.8E-3 PROBABILITY OF NOT RECOVERING OFFSITE POWER

$1.23 E-04$

156 REPAIRN

.011 PROBABILITY OF NOT PERFORMING A MODERATE REPAIR PROCEDURE

PROBABIIITY OF NOT PERFORMING A SIMPLE REPAIR PROCEDURE

$1.80 \mathrm{E}-03$

$1.10 \mathrm{E}-02$ 
Table 4-3. Type Code File

. DATAIITP.TC RATE U

DESC

SOURCE COMAON

1 AZ CM 2.38E-1 Y O2 AHALYZER COMMON MODE MISCALIBRATION

2 AZ HW 3.0E-4 H O2 ANALYZER le MECHANICAL PAULT

3 AZ TM 1.0E-3 N O2 ANAIYZZR fe MAINTENANCR

3.08-6 H CONDEHSER CPE MECHANICAL FAULT

S $\mathrm{CP}$ int

5 CP $\mathrm{CH}$

7 on in

8 EL $\mathrm{WW}$

, PC CH

11 FC NA

12 FC TH

13 PL $\mathrm{rW}$

$11 \mathrm{IL} \mathrm{TM}$

$15 \mathrm{PH} \mathrm{CH}$

$16 \mathrm{FN} \mathrm{KN}$

$18 \mathrm{PN} S \mathrm{RC}$

$19 \mathrm{FH}$ SB

20 FI ST

21 in $\mathrm{Fm}$

23 is $\mathrm{kW}$

24 HT MN

25 HV HW

26 IL $\mathrm{HW}$

27 PP BK

28 PR CM

29 PR HW

3O PR NH

32 SP CM

33 SP $\mathrm{HA}$

34 sa $\mathrm{mm}$

$35 \mathrm{TK} \mathrm{HM}$

36 VP $\mathrm{HI}$

37 V8

39 XV PG

9.0E-5 H DIGITAI CONTROL BYSTEM Cle MEC

2.5E-5 H COOLIMG WATER MECHAHICAL PAULT

3.6E-6 H DEMISTER ClE PAILS D

3.13E-5 H LOSS OP H-AREA POWLR

1.OE-4 M COMON CAUSE PAILURE OF FLON CONTROL VALVES TO OPEN

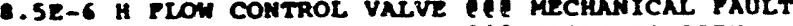

1.0E-3 M TLON CONTROL VALVE efe PAILS TO OPEM

3.6E-3 N PLOA COATROL VALVE Cle MAINTEMANCE

1.0E-6 H HEPA PILTER lle meCHANICAL TAUL

1.8E-3 N HEPA PILTZR C Cl MAINTENANCE

1.82-S COMHON CAUSE PAILURE OF PANS TO START

.0z-6 H EXHAUST FAH lef PAILS TO RUM

RE VENTILATION SYSTEM lle FAILS TO RUM

2.26E-S N COAON MODE PAILURE OF EMERGEHCY PURGE VENTILATION SYSTEM

PAILS TO START

. BE-4 EXHAUST PAH lle PAILS TO START

$1.82-3$ n EXHAUST PAN Cel maINTENANCE

1.4E-1 Y FLON SEMSOR MISCALIBRATION PAULT

1.02-1 H HEATER Cll MECHANICAL PAULT

2.0E- G HEATER PCE MECHANTCAT

1.62-5 H TMTERIOCX MECHANICAL PAUL.

1. OR-9 H GUTLLOTINE PIPE BREAK

1.OE-9 H GUTLCOT

2.2E-G H PRESSURE REGUIATING VALVE

2.2E-6 M PRESSURE REG UATTIMG VAIVE

3.

C.

2.1E-5 H PAM SEMSOR CE MECHANICAI FAULT

3. OE-4 H STEMH SUPPLX MECHANICAL PAULT

2.3E-9 H NITROGEA STORAGE TANR PLE LEAXS

1.1E-7 h VAPORIIER ele PAILS DUE to PLUCGING

3.5E-6 H VACUUN BENSOR MECHANICAL PAULT

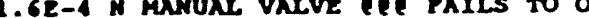

1.1E- h manual valve ele pails to REMAIM OPEM (PLUG)

Table 1-1, 8

Table 4-1, 1, Pg 10

Calculation

Tablo $4-1,13$

Table $4-1$, is

rable 1-1, 6

Table 1-1, 10

Tablo 1-1. to

Soction 1.1 .2

Table $1-1,11$. Pg 35

Table -1, 2. Pg 38

Calculation

Table 4-1, 11, Pg 16

cactoris

Table 1-1, 11, P9 16

Table $1-1$, is

Table 4-1.

Table 1-1, 9

Calculation

Table 4-1, 11, Pq 16

Table $-1,3$

Table $4-1,4, C D 85$

Table 4-1, 3

Table 1-1, 1, Pg 21

section 4.1 .2

Table 1-1, 1, P9 22

Table 1-1, 10

Calculation

Table 1-1, 11. Pg 25

Table $4-1,16$

Table $-1,3$

rable -1.02

rable -1, 1, Pg 25

rable $1-1$.

Table 1-1, 1, CP 57 
the failure rate is a per-demand failure rate, the "Factor" column determines the number of demands. Finally, the " $C$ " column tells CAFTA+ which failure probability formula is applicable to each basic event. The formulas CAFTA+ use in this analysis are:

(0) User-defined failure probability.

(1) $\lambda \mathrm{t}$ : Used for the initiators in the fault tree (components on the primary train).

(2) $\lambda t / 2$ : Used for the components on the backup trains that are maintained on a regular basis.

(3) $1-e^{-} \lambda t$ : Used for the enablers in the fault tree (the components not on the backup trains).

where:

$\lambda=$ operating failure rate

$\mathrm{t}=$ mission time (no repair)

The following paragraphs discuss quantification of specific types of basic events or components.

\section{Common Cause Miscalibration Failures}

An HRA has been performed to quantify the probability of miscalibrating groups of equipment. The analysis method used was Technique for Human Error Rate Prediction (THERP) from NUREG/CR-1278 (19). The results of this analysis are documented in Reference 11. The mean values for failure on demand (5.95E-2 for analyzers and 1.05E-1 for level sensors or flow sensors) were converted for this analysis to a frequency by multiplying by four (quarterly calibrations) to obtain a yearly frequency $(2.38 \mathrm{E}-1$ and $4.20 \mathrm{E}-1)$ at which miscalibrations occur.

\section{Common Cause Failure of the EPVE}

The EPVE consists of four portable fans each powered by a separate gasoline engine. These four sets can be used in various combinations to mitigate loss of the nitrogen purge. Only one fan is required per tank for successful operation. A probability is calculated for the common cause failure probabilities to start and run for two sets and for three or more sets. Credit is taken for the fact that in most cases a failure can be repaired and the sets restored to service within a few hours. No data are available specifically for the EPVE sets; however, several sources of generic data can be used to bound the calculation:

o Reference 14 recommends $1.0 \mathrm{E}-2$ /demand as the mean failure probability for a "Diesel Engine". This is a conservative value since the failure probability for a diesel to start is expected to bound the failure probability of a gasoline engine. 
- The failure rate for a gasoline driven fan to run is taken to be $8.0 \mathrm{E}-6 / \mathrm{hr}$ which is also consistent with Reference 14 and bounds engine failure rates based on manufacturer's test data (20). The failure probability for a single fan to operate for 7 days is, therefore, $1.34 \mathrm{E}-3=(8.0 \mathrm{E}-6 / \mathrm{hr}) \times(7$ days $) \times(24 \mathrm{hrs} /$ day $)$.

- The combined failure probability for a single gasoline driven fan to start and run 7 days is $1.13 \mathrm{E}-2 /$ demand $=(1.0 \mathrm{E}-2)+(1.34 \mathrm{E}-3)$ based on the above values. At this point in the calculation, no credit has been taken for repair.

o Without identifying the specific root causes, it is possible to estimate the common cause failure probabilities that may occur between gasoline powered fan sets. Based on previous work with common cause failure probabilities with a broad spectrum of equipment at SRS (21), it has been found that upper bounds can be established for these probabilities. For example, given that the failure probability for one set is $1.13 \mathrm{E}-2$, the failure probability that two fail is bounded by $1.13 \mathrm{E}-3$. This can be expressed, alternatively, as a conditional probability, i.e., given that the first set has failed, the conditional probability that the second set also fails is 0.1 . Continuing, it is also conservative to assume that given that the first and second sets have failed, the third fails with a probability of 0.5 . For four sets, given that the first, second, and third sets fail, it is conservative to assume that the fourth set fails with certainty, i.e., probability equal to 1.0

o Before these probabilities are applied, it is necessary to consider repair of common cause failures. Based on manufacturer's data (20), it takes less than 3 hours to repair a gasoline fueled combustion engine (several horsepower), including complete disassembly if needed. This time is consistent with Reference 14, which indicates an average time of $1.18 \mathrm{hrs}$ to repair a "Gasoline Engine Driven Generator". Therefore, for common cause failures, it is reasonable to give credit for repair. A failure probability of 0.02 is used for failure to diagnose, repair, and/or correct the common cause. This value is conservative since the action takes place many hours after the initiating event has occurred when the stress has decreased significantly. Another conservative assumption is made that if the operators are not able to repair one set, they cannot repair any sets affected by the common cause. No credit is taken for repair of the failure of a single set in order to avoid cutsets containing two different repair actions.

o The common cause failure probabilities are calculated as:

$$
\begin{aligned}
2.26 \mathrm{E}-5 / \text { demand }= & \{1.13 \mathrm{E}-2 \text { first set/(start and run } 7 \text { days })\} \times \\
& \{0.1 \text { second set fails }\} \times \\
& \{0.02 \text { failure to repair the common cause }\}
\end{aligned}
$$


Table 4-4. Exposure Times

1 year

Primary operating train components not in a redundant system when both trains are normally operating.

7 days

Equipment on Backup Trains. If primary train fails, OSRs require repair/restoration within 7 days; therefore, backup train must be available for 7 days.

$2 \mathrm{~N}$

To correctly account for testing/maintenance unavailability in a frequency space fault tree, the probability of having the backup train in maintenance is doubled, and no test maintenance fault is modeled for the primary train (see Section 3.1).

2 years

To correctly account for backup trains in fault trees with frequency events, primary train components in a redundant system where both trains are normally operating are modeled with their frequency doubled (see Section 3.1).

3 months

Components with quarterly maintenance (flow control valves, pressure regulation valves). 
This value is used for a common cause failure that may occur between two sets ( 1 and 2) for Tank 48 (or sets 3 and 4 for Tank 49).
1.13E-5/demand $=\{1.13 \mathrm{E}-2$ first set/(start and run 7 days $)\} \times$ \{0.1 second set fails $\} \times$ $\{0.5$ third set fails $\mathrm{x}$ $\{0.02$ failure to repair the common cause $\}$

This value is used for a common cause failure that may occur between two sets used with Tank 48 (or 49) and a third set from the other tank.

\section{Common Cause Failure to Restart Equipment}

Common cause failure probabilities for the normal exhaust fans failing to restart, the flow control valves failing to open, and the pressure regulating valves failing to open are calculated using the same methodology as discussed above. The common cause failure probabilities are calculated as follows:

- Fan fails to restart:

4.8E-5/demand $=\{4.8 \mathrm{E}-4 /$ demand first fan fails to start $\} \mathrm{x}$ \{0.1 second fan fails to start

This value is used for a common cause failure that may occur between two fans.

- Flow control valve fails to reopen:

\section{$1.0 \mathrm{E}-4 /$ demand $=\{1.0 \mathrm{E}-3 /$ demand first flow control valve fails $\} \mathrm{x}$} \{0.1 second flow control valve fails $\}$

This value is used for a common cause failure that may occur between two flow control valves.

- Pressure regulating valves fail to reopen:

$$
\begin{aligned}
8.1 \mathrm{E}-4 / \text { demand }= & \{8.1 \mathrm{E}-3 / \text { demand first pressure regulating valve fails }\} \times \\
& \{0.1 \text { second pressure regulating valve fails }\}
\end{aligned}
$$

This value is used for a common cause failure that may occur between two pressure regulating valves. 
o It is assumed that these nominal values encompass all unlisted contributors.

\section{Preventive Maintenance Unavailabilities}

In the following, nominal times for preventive maintenance are estimated based on the repair times given in Table 5-3

o Oxygen analyzer maintenance:

- time to maintain analyzer $=\sim 4 \mathrm{hrs}$

- maintenance performed four times per year

(4 times $/ \mathrm{yr}) \times(1 \mathrm{yr} / 8760 \mathrm{hr}) \times(4 \mathrm{hr} / \mathrm{time})=1.8 \mathrm{E}-3 / \mathrm{demand}$

- Exhaust fan maintenance:

- time to maintain and test fan $=\sim 16 \mathrm{hr}$

- maintenance performed one time per year

(1 time/yr $) \times(1 \mathrm{yr} / 8760 \mathrm{hr}) \times(16 \mathrm{hr} / \mathrm{time})=1.8 \mathrm{E}-3 /$ demand

o HEPA filter maintenance:

- time to replace HEPA filter $=-16 \mathrm{hr}$

- maintenance performed one time per year

(1 time/yr $) \times(1 \mathrm{yr} / 8760 \mathrm{hr}) \times(16 \mathrm{hr} /$ time $)=1.8 \mathrm{E}-3 /$ demand

- Flow control valves, pressure regulator valves:

- $\quad$ time to repair/replace valve $=-8 \mathrm{hr}$ (similar to manual valve)

- maintenance performed four times per year

(4 times $/ \mathrm{yr}) \times(1 \mathrm{yr} / 8760 \mathrm{hr}) \times(8 \mathrm{hr} / \mathrm{time})=3.6 \mathrm{E}-3 / \mathrm{demand}$

Unavailabilities due to corrective maintenance are accounted for by using the seven-day mission time for backup trains. This implies that the primary train fails and is unavailable (due to maintenance) for the following seven days. 


\section{Component Failure Data}

A wide range of data sources are used to arrive at component failure data. The specific failure data and sources are discussed below.

For demisters, a value of $3.06 \mathrm{E}-6 / \mathrm{hr}$ was taken from Reference 13 for filters. This choice was made since the internal construction of the demisters is similar to typical filter designs and principles of operation. Additionally, SRS experience with demisters that are integral to the filter compartments used for the reactor buildings indicates that the value of $3.06 \mathrm{E}-6 / \mathrm{hr}$ is conservative since no catastrophic failures have occurred in over a million demister hours of service over the last 18 years in South Carolina's humid climate.

For vaporizers, steam generator tubes in Reference 9 have a failure rate of 3.0E-7/hr and evaporators in Reference 14 for an electrical humidifier has a failure rate of $4.1 \mathrm{E}-7 / \mathrm{hr}$. Since both of these components are more complicated in design and function than the vaporizers that are powered by the ambient influx of heat energy, their failure rates are expected to bound the vaporizer failure rate. The value of $4.1 \mathrm{E}-7 / \mathrm{hr}$ is used.

For the Digital Control System (DCS) a failure rate of $9.0 \mathrm{E}-5 / \mathrm{hr}$ is used. A comparison of this failure rate with those discussed in "Operational Failure Experience of Fault-Tolerant Digital Control Systems" (23) showed this rate to account for hardware and software failures. Since initial testing of the DCS has not been completed, this generic value is used.

For oxygen analyzer mechanical fault, generic failure rates ranged from $1.1 \mathrm{E}-4 / \mathrm{hr}$ to $8.0 \mathrm{E}-4 / \mathrm{hr}$. The mean of the rates was taken to determine a failure rate of $3.0 \mathrm{E}-4 / \mathrm{hr}$ for this analysis.

For flow control valve mechanical fault, the failure rates listed in the data sources range from a low value of $1.68 \mathrm{E}-6 / \mathrm{hr}$ to a high value of $2.1 \mathrm{E}-5 / \mathrm{hr}$. The "average" failure rates ranged from $2.2 \mathrm{E}-6 / \mathrm{hr}$ to $8.5 \mathrm{E}-6 / \mathrm{hr}$. For this analysis, the highest "average" failure rate was used.

For exhaust fan (permanent) fails to run, the failure rates listed in the data sources range from $1.1 \mathrm{E}-7 / \mathrm{hr}$ to $9.0 \mathrm{E}-5 / \mathrm{hr}$. For this analysis, a mean value of $8.0 \mathrm{E}-6 / \mathrm{hr}$ was used.

\subsubsection{Fault Tree Results}

The quantified basic events are used to derive quantified cutsets using CAFTA+. The initial quantification of the nitrogen purge system fault tree provides cutsets that reflect the major failure paths for the system excluding recovery and repair considerations. The types of failures that

contribute significantly are:

o Loss of steam supply to the heater.

o Failure of flow sensor across HEPA filters. 
o Failure of nitrogen exhaust line flow sensor.

o Interlock failures.

The quantification of the nitrogen purge system fault tree including recovery and repair considerations identified the following failures as those that contribute significantly:

- DCS failure coupled with

- Failure to repair and restore the DCS to operation (includes restoring the nitrogen purge system) coupled with

- Failure of the EPVE (includes operator failure to align and start ihe EPVE sets plus single and common cause hardware faults among the sets) coupled with

- Probability that a source is present that causes ignition.

- Oxygen analyzer failure (includes hardware faults plus common cause miscalibrations) coupled with

- Failure to repair and restore the analyzers to operation (includes restoring the nitrogen purge system) coupled with

- Failure of the EPVE (includes operator failure to align and start the EPVE sets plus single and common cause hardware faults among the sets) coupled with

- Probability that a source is present that causes ignition.

o Loss of steam to the heater resulting in the HEPA filter plugging coupled with

- Failure to replace the filter and restore the filter line to operation (includes restoring the nitrogen purge system) coupled with

- Failure of the EPVE (includes operator failure to align and start the EPVE sets plus single and common cause hardware faults among the sets) coupled with

- Probability that a source is present that causes ignition. 
o Hardware failure of the exhaust train flow sensor coupled with

- Failure to repair the flow sensor to operation (includes restoring the nitrogen purge system to operation) coupled with

- Failure of the EPVE (includes operator failure to align and start the EPVE set plus single and common cause hardware faults among the sets) coupled with

- Probability that a source is present that causes ignition.

Dominant cutsets (with and without recovery actions applied) for the fault tree are shown in Appendix B.

\subsection{External Events Analysis}

The external event analysis for the nitrogen purge system considers seven initiating events in which no credit is given for component repair or restoration of power, except where noted.

o Severe winter storm that delays nitrogen delivery for more than four days. Frequency is $1 \mathrm{E}-2 / \mathrm{yr}$ for a storm that results in significant accumulation of snow and/or ice on the roads (24). It is assumed that this storm is severe enough to precl. 'e nitrogen deliveries for four days.

o Seismic event resulting in structural failure of the liquid nitrogen storage and vaporization systems and the normal exhaust systems. This event is defined as having a peak horizontal ground acceleration of $0.02 \mathrm{~g}$ and an occurrence frequency of 5E-2/yr for general-use structures for the SRS (25).

o High wind event that fails both the nitrogen supply and exhaust systems. Frequency is $2 \mathrm{E}-2 / \mathrm{yr}$ for a $78-\mathrm{mph}$ straight wind for SRS general-use structures (26).

o Tornado missile that damages the nitrogen supply system. This event is assumed to affect only the supply system, because there is more equipment surface area (tanks and overhead piping) available for impact. The frequency of this event is $2 \mathrm{E}-5 / \mathrm{yr}(26)$.

o Vehicle accident that damages the nitrogen supply system. Vehicle crashes are assumed to impact only the nitrogen supply system, because there are no roads or vehicle access to the area around the exhaust fans. The frequency of this event is based on the following estimates from SRS experience: failure 
rate of 1.9E-8 accidents per vehicle mile (27) for 0.2 miles of road being traveled by 100 vehicles per day, or

$(1.9 \mathrm{E}-8$ accidents $/ \mathrm{mile}) \times(0.2$ mile $) \times(100$ vehicles $/$ day $) \times(365$ days $/ \mathrm{yr})=$ $1.4 \mathrm{E}-4 / \mathrm{yr}$

- Helicopter crash that damages the nitrogen supply system. The frequency of this event is $3.5 \mathrm{E}-5 / \mathrm{yr}-\mathrm{km}^{2}(10)$. The area of the nitrogen supply system is approximately $100 \mathrm{ft} \times 100 \mathrm{ft}$. Therefore, the frequency of helicopter crash is:

$$
\left(3.5 \mathrm{E}-5 / \mathrm{yr}-\mathrm{km}^{2}\right) \times\left(1 \mathrm{E} 4 \mathrm{ft}^{2}\right) \times\left(1 \mathrm{~km}^{2} / 9.29 \mathrm{E} 6 \mathrm{ft}^{2}\right)=3.8 \mathrm{E}-8 / \mathrm{yr}
$$

Therefore, this event is not credible and is not considered further. The frequency and consequences of a helicopter crash at Tanks 48 and 49 are evaluated as part of the overall ITP accident analysis $(1,2)$ and are not part of this analysis, which is limited to the nitrogen purge system.

- Aircraft crash that damages the nitrogen supply system. The frequency of this event is $1 \mathrm{E}-8 /$ flight- $\mathrm{mi}^{2}(10)$. The area of the nitrogen supply system is approximately $100 \mathrm{ft} \times 100 \mathrm{ft}$ and the total number of flights is estimated to be $12 /$ day (10). Therefore, the frequency of aircraft crash is:

$\left(1 \mathrm{E}-8 / \mathrm{flight}-\mathrm{mi}^{2}\right) \times\left(1 \mathrm{E} 4 \mathrm{ft}^{2}\right) \times\left(1 \mathrm{mi}^{2} / 2.79 \mathrm{E} 7 \mathrm{ft}^{2}\right) \times(12 \mathrm{flights} /$ day $) \times$ $(365$ days $/ y r)=1.6 \mathrm{E}-8 / \mathrm{yr}$

Therefore this event is not credible and is not considered further. The frequency and consequences of an aircraft crash at Tanks 48 and 49 are evaluated as part of the overall ITP accident analysis $(1,2)$ and are not part of this analysis, which is limited to the nitrogen purge system.

Three event trees have been developed that show event sequences for all of the credible initiating events:

STORM: Includes sequences for initiating events that fail supply of nitrogen to the site (severe winter storm). Total initiating event frequency is $1.0 \mathrm{E}-2 / \mathrm{yr}$.

SEISMIC: Includes sequences for initiating events that fail both the nitrogen supply and exhaust systems (seismic, high wind). Total initiating event frequency is $7.0 \mathrm{E}-2 / \mathrm{yr}$.

OTHERS: Includes sequences for initiating events that fail the nitrogen supply system only (tornado missile, vehicle crash). Total initiating event frequency is $1.6 \mathrm{E}-4 / \mathrm{yr}$. 
Events that reflect operating conditions associated with external events are developed. Three scenarios are considered:

- Failure of normal exhaust fans to continue to run for seven days.

- Failure of continuing nitrogen supply to Tanks 48 and 49 for seven days. This scenario includes the main nitrogen supply tank and all piping and valving to Tanks 48 and 49.

o Failure of three of four EPVE sets to start and run for seven days. If EPVE sets are required during external events, it is assumed that they are required for both Tanks 48 and 49 at the same time, and that there are two sets available for each tank. Since only one set is required for each tank, three of the four available sets must fail before this condition is not satisfied.

The seven-day mission time is based on the assumption that the OSR requirement for repair/restoration of primary system components within seven days also applies to external events. This assumption is considered valid based on the normal repair times discussed in Section 5.0 and practice in the nuclear industry.

Hardware failures and normal proceduralized operator actions (described in Subsection 5.2.1) are included in these fault trees. The fault trees and cutsets developed specifically for the external events analysis are included in Appendix C.

\subsubsection{Severe Winter Storm}

A severe winter storm challenges the site's ability to maintain nitrogen supply due to impassible roads. Although a minimum nitrogen supply of $26,000 \mathrm{gal}$ (4) would be on hand as prescribed by the OSR, as a conservative analysis, no credit is taken for this supply. Times required to reach the LFL after nitrogen flow stops are based on an analysis provided in Reference 3.

The key operating parameters applied in this analysis are described below.

1. The onsite nitrogen supply is $26,000 \mathrm{gal}$ at the time the event occurs. This is the OSR minimum.

2. Tank 48 is in the washing cycle and the LFL is reached in three days.

3. Procedures and administrative controls are in place to establish air-based ventilation in the tanks if nitrogen supply cannot be restored within one shift after the storm abates. 
The event tree showing the severe winter storm scenario is shown in Figure 4-1. The recovery action of establishing air-based ventilation for the sequences in which nitrogen flow cannot be restored or the exhaust system fails is included. This action requires moving the EPVE into position and aligning, connecting, and starting one set of EPVE for each tank. Estimates of the probabilities of the events shown in Figure 4-1 are discussed below:

Event $\mathrm{I}$ : Initiating event frequency is $1.0 \mathrm{E}-2 / \mathrm{yr}$.

Event A: Probability that the nitrogen supply is inadequate. Since no credit is given for the supply to last through the severe storm, the failure probability is set to 1.0 .

Event B: Probability of failing to align, connect, and start the EPVE is estimated to be 5.3E-6 (see Subsection 5.2.1).

Event C: Probability that the EPVE fails to start and run for seven days is estimated to be $1.8 \mathrm{E}-5$, based on fault tree quantification (see Appendix C) (Repair included).

Event D: Probability that ignition source is present is $0.09(5)$.

\subsubsection{Seismic and High Wind Events}

The seismic and high wind events are assumed to fail the entire nitrogen supply and exhaust systems. The times required to reach the LFL after nitrogen flow stops are assumed to be three days for both tanks (Tank 48 is assumed to be in the wash cycle). Two sets of EPVE with power supplies are available for each tank (four sets total) and survive the event. The recovery action of establishing air-based ventilation requires moving the EPVE into position and aligning, connecting, and starting a unit for each tank.

The event tree showing the seismic and high wind event scenarios with a single recovery action is shown in Figures 4-2 and 4-3. Estimates of the probabilities of the events shown in the figures are as follows:

Event I: The initiating event frequency for the seismic event tree is $2.0 \mathrm{E}-2 / \mathrm{yr}$ and $5.0 \mathrm{E}-2$ for the high wind.

Event A: Probability of failing to align, connect, and start the EPVE is estimated to be 5.3E-6 (see Subsection 5.2.1).

Event B: Probability that the EPVE fails to start and run for seven days is estimated to be 1.8E-5, based on fault tree quantification (see Appendix C) (Repair included). 
Event C: Probability that ignition source is present is 0.13 for the seismic event and 0.09 for the high wind (5).

\subsubsection{Other External Events}

The event tree for the other external events is similar to that for the seismic and high wind events except that only the nitrogen supply system is affected. The times required to reach the LFL after nitrogen flow stops are assumed to be three days for both tanks (Tank 48 is assumed to be in the wash cycle). Two sets of EPVE with power supplies are available for each tank (four sets total) and that air-based ventilation is required using the EPVE (normal exhaust system does not restart). This action requires moving the EPVE into position and aligning, connecting, and starting a unit for each tank.

The event tree showing the other external event scenario with a single recovery action is shown in Figure 4-4. Estimates of the probabilities of the events shown in Figure 4-4 are as follows:

Event I: The combined initiating event frequency for other external events is $1.6 \mathrm{E}-4 / \mathrm{yr}$.

Event A: Probability of failing to align, connect, and start the EPVE is estimated to be 5.3E-6 (see Subsection 5.2.1).

Event B: Probability that the EPVE fails to start and run for seven days is estimated to be $1.8 \mathrm{E}-5$, based on fault tree quantification (see Appendix C) (Repair included).

Event C: Probability that ignition source is present is $0.09(5)$. 


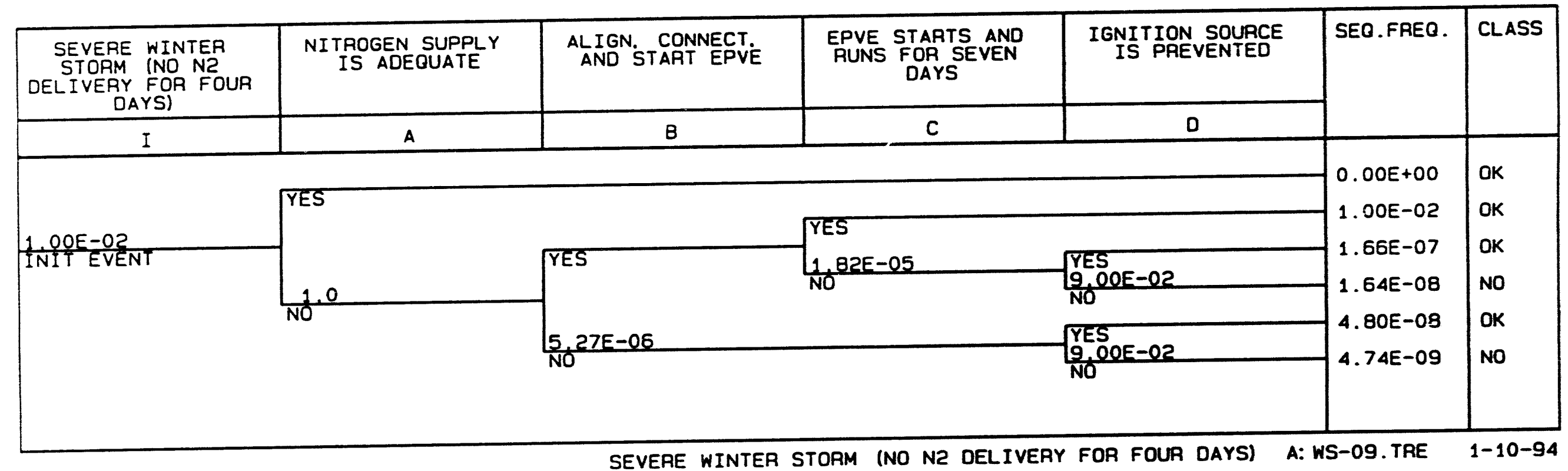




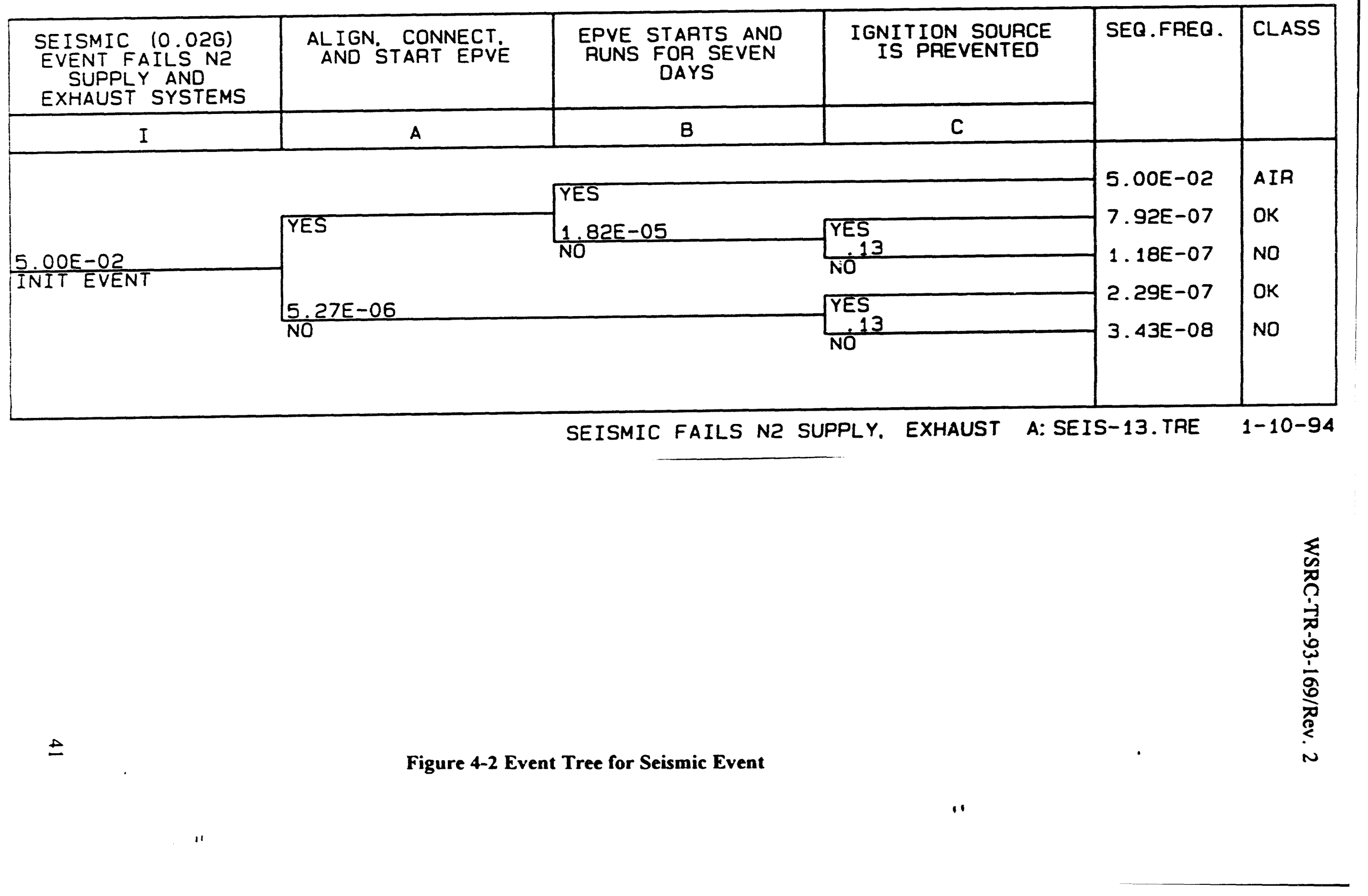




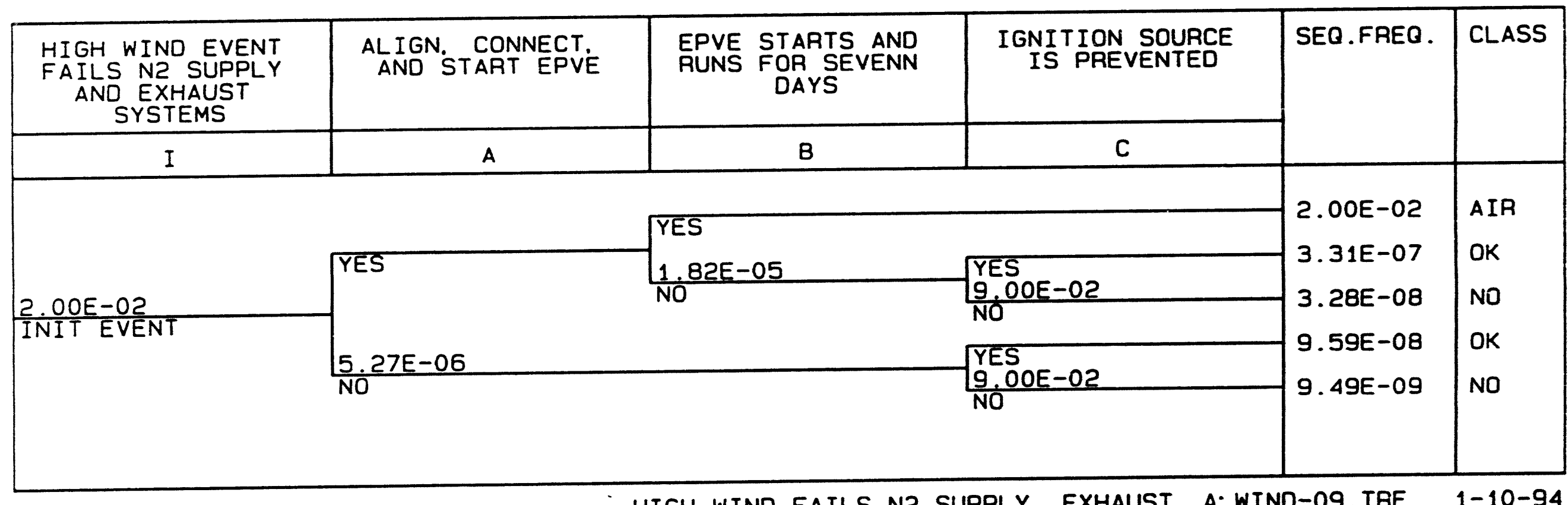




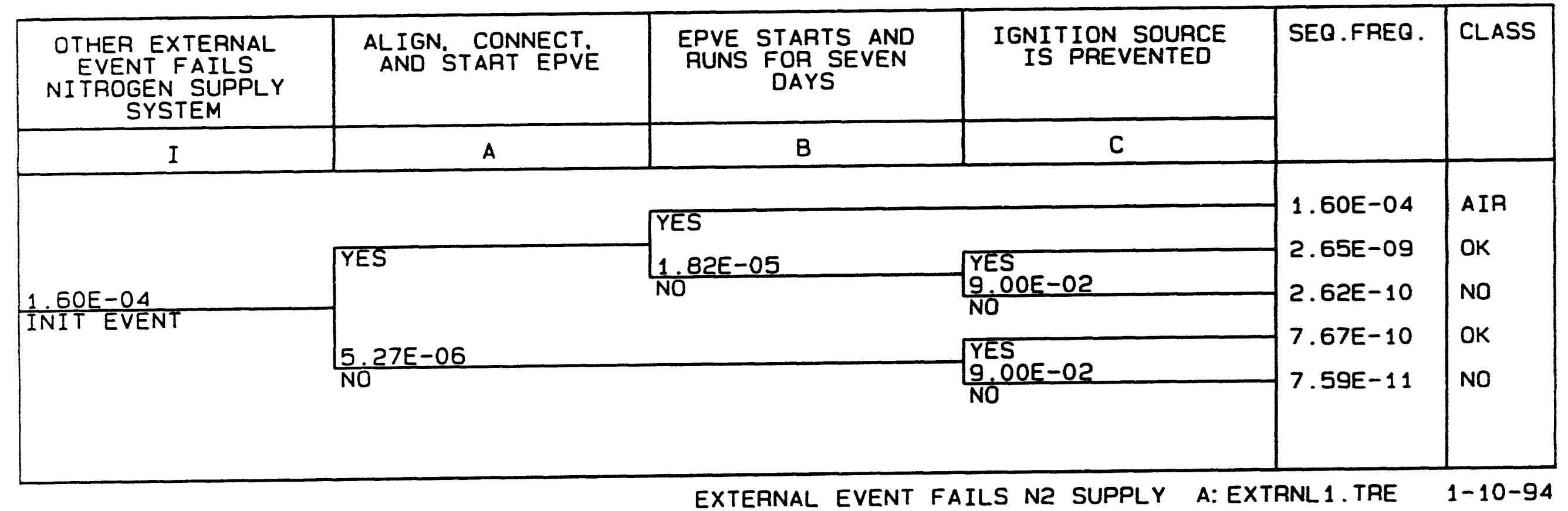




\subsubsection{Event Tree Results}

Total sequence frequencies for unacceptable end states for all credible external initiating events are:

\section{Event Tree}

STORM

SEISMIC

HIGH WIND

OTHERS
Total Frequency for

Unacceptable End States

2.1E-8/yr

$1.52 \mathrm{E}-7 / \mathrm{yr}$

$4.23 \mathrm{E}-8 / \mathrm{yr}$

$3.38 \mathrm{E}-10 / \mathrm{yr}$

Total

$2.16 \mathrm{E}-7 / \mathrm{yr}$

The dominate sequence for the external events is a seismic initiated accident. Seismic events account for more than $70 \%$ of the external event frequency.

Although all magnitude earthquakes are represented in this report with a single sequence frequency of $2.0 \mathrm{E}-2 / \mathrm{yr}$., it should be noted that an earthquake large enough to cause such extensive damage represents a small contribution to this overall initiating event frequency. This analysis is based on an initiating frequency of $.02 / \mathrm{yr}$. which corresponds to a much smaller earthquake of about a $0.02 \mathrm{~g}$ magnitude. The basis for this initiator is the limited scope seismic analyses that exist for the ITP facility and its surrounding support facilities. This earthquake is assumed to fail equipment, but not challenge the structural integrity of the buildings or roadways. Earthquakes of this magnitude have already occurred at the SRS with no reported damage. However, with limited technical bases, no credit is taken for continued operation or restoration of facilities that could reasonably be expected following a high frequency, low intensity seismic event. Therefore credit is taken only for the EPVE.

The most likely seismic event that could significantly challenge buildings and roadways would be on the order of $0.1 \mathrm{~g}$ or greater (29). At this range, challenges to equipment and supporting facilities is credible, and real challenges to operator performance are genuine. Events of such magnitude, however, are small contributors to the overall sequence frequency due to their lower initiating event frequencies. These relative contributions are summarized in Table 4-5 which includes the contributions of various seismic and wind events.

The challenges for which immediate operator action would not be credited are limited to less than $3 \%$ of the total event sequence frequencies (such as seismic events of $0.1 \mathrm{~g}$ or greater). Of this, the event that might cause some level of sitewide damage, $0.1 \mathrm{~g}$ earthquake or greater, contributes approximately $1.5 \%$ to the total. It is for a seismic event of $0.2 \mathrm{~g}$ that the HRA and ignition source probability analyses are predicated and for which the results are applicable. Applied to events of magnitude of less than $0.2 \mathrm{~g}$, the results of the analyses are applicable and conservative. 
Table 4-5. Contributions to Seismic/High Wind Event Sequence Frequency

\begin{tabular}{lccc|}
\hline Initiating Event & $\begin{array}{c}\text { Exceedance } \\
\text { Frequency, /yr }\end{array}$ & $\begin{array}{c}\text { Sequence } \\
\text { Frequency, /yr }\end{array}$ & $\begin{array}{c}\% \text { Contribution } \\
\text { to Total }\end{array}$ \\
\hline $0.02 \mathrm{~g}$ Seismic & $5 \mathrm{E}-2$ & $1.52 \mathrm{E}-8$ & $76 \%$ \\
$78 \mathrm{mph}$ Straight Wind & $2 \mathrm{E}-2$ & $4.23 \mathrm{E}-8$ & $21 \%$ \\
$0.1 \mathrm{~g}$ Seismic & $1 \mathrm{E}-3$ & $3.1 \mathrm{E}-9$ & $1.5 \%$ \\
$109 \mathrm{mph}$ Straight Wind & $1 \mathrm{E}-3$ & $2.11 \mathrm{E}-9$ & $1.1 \%$ \\
DBE (0.2g Seismic) & $2 \mathrm{E}-4$ & $6.1 \mathrm{E}-10$ & $0.3 \%$ \\
DBT (137 mph Tornado) & $2 \mathrm{E}-5$ & $4.23 \mathrm{E}-11$ & $0.02 \%$ \\
\hline
\end{tabular}




\subsection{HUMAN RELIABILITY ANALYSIS}

The FTA/ETA of the nitrogen purge system for Tanks 48 and 49 identified various human actions that could be taken to mitigate the accident being considered. These actions fall into two groups: normal proceduralized operating actions/recovery actions and repair activities.

This section discusses the methodology used in quantifying these actions, and the results of the quantification. The numbers generated from this analysis are used in the fault/event tree quantification discussed previously in this report.

\subsection{Methodology}

The goal of the HRA is to provide estimates of HEPs. These estimates are then used to quantify the fault trees and event trees that depict the accident scenarios.

A detailed HRA study was not performed for all actions. Where a simplified approach was taken, methodology provides results that are sufficiently accurate for use in the fault/event trees. It should be noted that by using a simplified approach, conservative results are obtained. If a detailed HRA analysis were to be performed, the anticipated results would yield lower failure probabilities. The methods used for quantifying the recovery and repair actions are described below in their respective sections. Because there are separate operating and maintenance crews, independence between repair and recovery actions is assumed.

The HRA is predicated on the fact that compelling signals are generated to notify the operators of a ventilation upset. The alarms were not modeled individually, however; the ITP facility contains multiple alarms that will indicate a ventilation upset. No common mode failure mechanisms were identified which would fail all the alarms with the possible exception of loss of electrical power. The interruption of power to the control panels is in itself a compelling signal, since, the operator would detect this failure simply through visual inspection of the "powerless" panel immediately or, at the latest, when taking the required control room readings or shiftly field verification (4). In either case, the detection would lead to further investigation and detection of the loss of ventilation.

There are multiple alarms available to aid the operator in assessing the status of the normal ITP tank ventilation. Independent signals are available from the DCS (Distributed Control System) and from the 7400B panel "hard-wired" alarms which effectively duplicate the DCS signals (32 and 33). The signals include the LFL alarm, the two $\mathrm{O}_{2}$ alarms, the benzene alarm, nitrogen flow alarm, exhaust air flow alarm, HEPA $\triangle \mathrm{P}$ alarm and tank vacuum alarm. Failure of any single device will not prevent the operator from getting other compelling signals from one or more alarms. Based on typical failure rates for alarms, $\sim 5 \times 10^{-5} / \mathrm{hr}$., ( 9 and 34$)$, the probability that multiple failures would occur and prevent the operations from receiving a compelling signal is estimated to be on the order of $10^{-7} / \mathrm{yr}$. This is based on a failure of each instrument on the $7400 \mathrm{~B}$ panel, failure of the DCS, and failure to conduct the required visual inspection of the 
ventilation equipment. Thus, the contribution of multiple alarm failures to the deflagration frequency is very small. If an extremely conservative assumption is made that all the instruments which would indicate an interruption of tank ventilation have failed in such a manner that the alarms and signal readouts fail to indicate such, an OSR requirement for a shiftily field verification of the status of the tank ventilation system would detect the loss of ventilation. For the tank to reach a deflagrable mixture of benzene and hydrogen, the ventilation system must fail and not be detected by multiple shifts over a three day period. The likelihood of multiple shifts failing to identify the loss of ventilation combined with the loss of all alarms and control room indications is considered to be incredible.

It should be noted that this system is fully automated and does not require operator intervention during normal operations. However, it is possible for an operator to misinterpret the information received from the DCS. To minimize the potential for erronous responses, immediate action based on data received which is outside procedural requirements - but does not constitute an alarm condition - is not permitted in existing procedures. Under alarm conditions, the initial response includes acknowledgement and confirmation (31) of the alarm condition.

Operator errors during normal operation in which tank ventilation could be interrupted, thought to be unlikely, are recoverable. In order to stop the ventilation system, an operator must sequence through several computer screens (on the DCS) before reaching the menu screen that contains a stop command option. Nevertheless, whether the fans were interrupted by computer signal or manual action, there are many alarms and indicators which would signal the operator of the loss of ventilation [such as the LFL monitors, nitrogen flow indications, tank $\triangle \mathrm{P}$ gauge, oxygen monitors, etc] and allow for rapid recovery. Since there are three days available to respond, immediate recovery upon discovery is not critical. There is ample time to respond and correct the situation. Therefore, obvious errors of commission are considered small contributors to the event frequency and are not included in the analysis.

The ITP process is a new facility and, as such, procedure development and training are on-going. Because final procedures to cover all the human actions quantified are not available, several general assumptions had to be made. These assumptions have been reviewed and accepted by the facility. The results of this analysis rely heavily on these assumptions which are listed below

o Compelling signals are generated immediately for each scenario considered.

- Adequate procedures exist for each scenario that would lead the operator to the actions considered.

o Procedures will be written such that each involves step-by-step actions, when appropriate.

o Operators are adequately trained on all procedures. 
o Procedures require independent check-off provisions, where appropriate, to assure that the procedure was performed correctly. These are performed after critical steps in the procedure.

\subsubsection{Normal Proceduralized Operation, Actions/Recovery Methodology}

The first step in evaluating the recovery actions was to review the existing procedures and drawings available that deal with the operation of the nitrogen purge system. This review provided the background information for the analysis and established current operations practices. A list of the procedures and drawings examined is shown in Table 5-1.

There are three normal proceduralized operating modes for the nitrogen purge system: 1) DCS control; 2) DCS/field control, and 3) field control. Since a failure of the DCS is assumed to be catastrophic, no credit is taken for the DCS/field control.

The "Post-Accident Nominal" model from Section 8 of Reference 18, "Accident Sequence Evaluation Program Human Reliability Analysis Procedure", known as the ASEP method, is the method used to quantify human actions (18), unless noted otherwise. This method is a widely accepted HRA tool that can be applied with considerably less background information and judgement than is required for a more detailed HRA methods such as the Technique for Human Error Rate Prediction (THERP) (19). It has been shown that the ASEP method yields estimates that are typically more conservative than those generated by more detailed methods.

Interviews with operations personnel are used to establish the times required to adequately perform the recovery actions. The ASEP procedure requires that time estimates gathered directly from operating personnel instead of through simulated measurements be doubled. The doubling is done to compensate for inherent under-estimation of task completion times by personnel. The results of these interviews and the corresponding times which have been adjusted (doubled) are shown in Table 5-2. The adjusted times are used in the analysis. See Section 5.2.2 for a discussion of the times associated with installation and starting of the Emergency Purge Ventilation Equipment.

\subsubsection{Repair Methodology}

The first step is to establish the expected repair times for vital equipment. Interviews with ITP personnel were held with representatives from Waste Management Operations, Maintenance, and Computer Services. As with the recovery estimates, all time estimates derived from the interviews are doubled to compensate for inherent underestimation of task completion times by personnel. The results of these interviews and the repair time estimates are shown in Table 5-3.

The times reflected in the doubled column are examined to determine how likely repair would be in the time allotted by the accident scenario being considered. Repairs are categorized as either simple or moderate (see Section 5.2.3). 


\subsection{Quantification and Results}

The following section describes the quantification of the operator actions and repair activities analysed.

\subsubsection{Normal Proceduralized Operating Actions/Recovery Actions}

This section includes quantification for each human action considered explicitly in the fault tree analysis. These results are valid when considering one operator action only, excluding repair activities. When more than one human action is applicable to a specific cutset, for example, an operator action considered explicitly in the fault tree and an additional recovery action, a screening value of 1.0 is applied to the action with the higher failure probability to account for any dependencies between those actions.

As documented earlier in this report, all accident scenarios allow for at least a three-day (72hr) recovery time. It is assumed that a compelling signal is generated. A comparison of the times required to perform the recovery actions, shown in Table 5-2, and the total time available (three days) shows that at least $24 \mathrm{hrs}$ are available for diagnosis following a compelling signal. Based on calculations using NUREG/CR-4772 (18), the failure to diagnose properly over a 24-hr period can be assumed to be negligible compared to the failure contribution from post-diagnosis errors. Post diagnosis values are taken from NUREG/CR-4772 and are shown in Table 5-4.

A value of 0.1 is used in quantifying the recovery actions to give credit for performance of recovery actions by additional shifts beyond the first shift. The value of 0.1 is based on Section 3 of Reference 18, which indicates that this value should be used for human redundancy.

\section{Operator Fails To Align and Start Train B - Exhaust Side}

Upon loss of the normally operating exhaust fan, the operator is required to manually realign to the backup exhaust fan train, and manually start the backup exhaust fan.

- Time available to identify and accomplish action: $72 \mathrm{hr}$

- Time allowed for diagnosis: $24 \mathrm{hr}$

- Probability of failing to properly diagnose in $24 \mathrm{hr}$ : negligible

o Time remaining for action: $48 \mathrm{hr}$

- Task is a critical action as part of a step-by-step procedure done under moderately high stress

- Four shifts are available to perform this action 
- HEP for initial action: 0.02

- Verification of action: 0.2

- Credit for additional shifts: 0.1

o Total Failure Probability: $(0.02)(0.2)(0.1)=4 E-4$

\section{Operator Fails To Enter Field Control Mode (Moderate Stress Levels)}

If a failure occurs while operating the nitrogen purge system in automatic mode, the operator can take manual control of the system. Procedures instruct the operator on how to override the automatic controls and interlocks, and manually control nitrogen flow and the exhaust fan.

- Time available to identify and accomplish action: $72 \mathrm{hr}$

o Time allowed for diagnosis: $24 \mathrm{hr}$

- Probability of failing to properly diagnose in $24 \mathrm{hr}$ : negligible

o Time remaining for action: $48 \mathrm{hr}$

- Task is a critical action as part of a step-by-step procedure done under moderately high stress

- Four shifts are available to perform this action

- HEP for initial action: 0.02

- Verification of action: 0.2

- $\quad$ Credit for additional shifts: 0.1

o Total Failure Probability: $(0.02)(0.2)(0.1)=4 \mathrm{E}-4$

\section{Operator Fails To Enter Field Control Mode (High Stress Levels)}

This recovery action is identical to the manual mode-moderate stress action described above; however, this task is performed under extremely high stress. A loss of the DCS as well as common cause sensor failures are assumed to create extremely high stress situations.

- Time available to identify and accomplish action: $72 \mathrm{hr}$ 
Table 5-1. Procedures and Drawings Used in Human Reliability Analysis

\section{PROCEDURES}

241-H-1731

241-H-1746SQ

241-H-1747SQ

241-H-1757SQ

241-H-1779Q

241-H-1877SQ

241-H-1897S

\section{SKETCHES}

138-8-H-WR-173 Tank 48 Nitrogen Lines

138-8-H-WR-174 Tank 49 Nitrogen Lines

138-8-H-WR-177 Tanks 48 and 49 Emergency N2 Supply

138-8-H-WR-204 Tanks 48 and 49 Emergency Exhaust Skid Stripper Columns

Tank 49 Ventilation System

Tank 48 Ventilation System Tanks 48 or 49

Conserving Nitrogen Inventory

Loss of $\mathrm{N}_{2}$ to STPB, Tank 48 and 49, Filtrate Hold Tanks and Benzene

Action To Be Taken on LFL Greater than Round Sheet Limits in Waste

Set-up and Operation of Portable Purge Exhaust Unit for Tanks 48 and 49

Waste Tanks 48 or 49 Nitrogen Purge Ventilation System Failure 
WSRC-TR-93-169/Rev. $2^{\prime}$

Table 5-2. Time Estimates for Recovery Actions

Equipment

Action

Time Estimate

Adjusted Time

Standby Exhaust

Perform procedure to start standby $\sim 30 \mathrm{~min}$.

$60 \mathrm{~min}$.

Fan exhaust fan

Nitrogen Valves

Establish manual control of $\sim 30 \mathrm{~min}$.

$60 \mathrm{~min}$. valves

40-60 $\mathrm{min}$

Miscellaneous

Transfer operation of system from

20-30 $\mathrm{min}$. automatic to manual mode

Transfer operation of system from $\quad \sim 20-30 \mathrm{~min}$. 40-60 min. manual mode to air-based ventilation

For a discussion of the Time Estimate and Adjusted Time for the Emergency Purge Ventilation Equipment (EPVP), see Section 5.2.1. 
Table 5-3. Time Estimates for Repair Actions

\begin{tabular}{|c|c|c|c|}
\hline Equipment & Action & Time Estimate & Adjusted Time \\
\hline DCS & Repair DCS & $\sim 2 \mathrm{hr}$ & $4 \mathrm{hr}$ \\
\hline \multirow[t]{3}{*}{$\mathrm{O}_{2}$ Analyzer } & $\begin{array}{l}\text { Diagnose/troubleshoot problem } \\
\text { with analyzer }\end{array}$ & $\sim 1-1.5 \mathrm{hr}$ & $2-3 \mathrm{hr}$ \\
\hline & Replace one analyzer & $\sim 30-45 \mathrm{~min}$ & $1-1.5 \mathrm{hr}$ \\
\hline & Check out/test new analyzer & $\sim 1-1.5 \mathrm{hr}$ & $2-3 \mathrm{hr}$ \\
\hline \multirow[t]{4}{*}{ Exhaust Fan } & Diagnose loss of fan & $\sim 4-6 \mathrm{hr}$ & $8-12 \mathrm{hr}$ \\
\hline & Troubleshoot problem with fan & $\sim 2-3 \mathrm{hr}$ & $4-6 \mathrm{hr}$ \\
\hline & $\begin{array}{l}\text { Repair/replace exhaust fan } \\
\text { component }\end{array}$ & $\sim 4-6 \mathrm{hr}$ & $8-12 \mathrm{hr}$ \\
\hline & Check out/test fan & $\sim 1-1.5 \mathrm{hr}$ & $2-3 \mathrm{hr}$ \\
\hline \multirow[t]{3}{*}{ Vacuum Sensor } & Diagnose failure of vacuum sensor & $\sim 2 \mathrm{hr}$ & $4 \mathrm{hr}$ \\
\hline & Install spare sensor & $\sim \mathrm{hr}$ & $2 \mathrm{hr}$ \\
\hline & Check out/test sensor & $\sim 1 \mathrm{hr}$ & $2 \mathrm{hr}$ \\
\hline HEPA Filter & Replace one filter & $\sim 4-8 \mathrm{hr}$ & $8-16 \mathrm{hr}$ \\
\hline Manual Valve & Repair/replace one valve & $\sim 4 \mathrm{hr}$ & $8 \mathrm{hr}$ \\
\hline
\end{tabular}


Table 5-4. Post-Diagnosis Human Error Probabilities

Perform a critical action as part of a step-by-step task done under moderately high stress

Perform a critical action as part of a dynamic task done under moderately high stress or a step-by-step task done under extremely high stress

Perform a critical action as part of a dynamic task done under extremely high stress

Verify the correctness of a critical action as part of a step-by-step task under moderately high stress

0.5

Verify the correctness of a critical action as part of a dynamic task done under moderately high stress or a step-by-step task done under extremely high stress

Verify the correctness of a critical action as part of a dynamic task done under extremely high stress 
- Time allowed for diagnosis: $24 \mathrm{hr}$

- Probability of failing to properly diagnose in $24 \mathrm{hr}$ : negligible

- Time remaining for action: $48 \mathrm{hr}$

- Task is a critical action as part of a step-by-step procedure done under extremely high stress

- Four shifts are available to perform this action

- HEP for initial action: 0.05

- Verification of action: 0.5

- Credit for additional shifts: 0.1

o Total Failure Probability: $(0.05)(0.5)(0.1)=2.5 \mathrm{E}-3$

\section{Operator Fails to Align and Start EPVE}

The major recovery action for failure of the ITP process nitrogen purge system is establishing airbased ventilation using EPVE. Reference 22 documents the methodology used for calculating the HEP for setup and use of EPVE on ITP process Tanks 48 and 49 after a failure of the nitrogen purge system following a seismic event. The analyses were performed according to THERP as described in NUREG/CR-1278 (19)

The analysis assumes a seismic event initiator which presents the greatest challenge for operator response. Onsite and offsite power is assumed to be unavailable, and all operator control actions are to be performed locally on the tank top. A task analysis was performed based on Off Normal Procedure (ONP), "Loss of Ventilation," and the Standard Operating Procedure (SOP), "Tank 48 System." Due to the current startup mode of ITP process operations, several assumptions had to be made in order to perform the analysis. Assumptions regarding procedures, staffing, equipment locations, equipment tagging, equipment availability, and training were made and documented in Reference 22. This analysis bounds all the accident scenarios analyzed.

The HEP to align, connect and startup the EPVE following an external event or random system failure is reported in Reference 22 as a median value of 4.2E-6. For use in the fault tree quantification, this number was converted to a point value of 5.3E-6 which approximates a mean value assuming a lognomral distribution with an error factor of 3 . An error factor of 3 was assigned since the largest contributors to the event tree (22) have an error factor of 3 . It is important to note that this result is predicated on maintaining all of the assumptions listed in the "Assumptions" section of Reference 22 and does not include hardware faults associated with the EPVE. 
The failure probability for align, connect, startup and run the EPVE, following a random system failure or external event is $2.3 \mathrm{E}-5$. This failure probability is a summation of the failure probability of the hardware faults associated with the EPVE to start and nu (1.8E-5; see Appendix C) combined with the HEP discussed above (5.3E-6).

\subsubsection{Repair Activities}

Repairs are divided into two groups of difficulty where each group has associated with it a different failure probability. Generally, components that require power operation are considered to be the most difficult to repair and have the largest failure probability to repair. Conversely, components which do not require power are considered simple to repair and have a smaller failure probability to repair. Exceptions are the vacuum sensor, hardwired interlocks, and common cause miscalibrations which require power but for which repair is considered simple because of their inherently simple design. The ability to obtain replacement parts in three days is considered very likely. Extra parts can be taken from the backup train of the unaffected tank in most cases. For the case of external events, no credit is given for repair.

\section{Simple Repairs}

The failure probability is the summation of the HEP for failing to perform the repair and the failure probability of the hardware faults associated with restarting the system following the repair.

The failure to perform simple repairs in less than 3 days is determined to be negligible, therefore, the failure probability is set to $1 \mathrm{E}-6$. Components with simple repairs are:

\section{- Sensor repair and/or replacement \\ - Interlock repair \\ - Manual valve replacement/repair}

Added to the failure to repair is the failure probability of the hardware faults associated with restarting the system. The failure probability to restart the system is evaluated using FTA as shown in Figure 5-1. Quantification of the fault tree results in a failure probability of 1.0E-3 as shown in Table 5-5. Therefore the total failure probability for simple repairs followed by restoration of the system is $1.0 \mathrm{E}-3(1.0 \mathrm{E}-6+1.0 \mathrm{E}-3)$.

\section{Moderate Repairs}

Similarly, the failure probability for failed components which are more complex to repair is the sum of HEP for failing to perform the repair of moderate complexity and the failure probability of the hardware faults associated with restarting the system following repair. 
Repairs that are more difficult than those listed above are given a moderate chance of repair (failure probability estimated to be 0.01 ). Based on the times shown in Table 5-3, 0.01 is a conservative estimate. Moderate repairs are:
- Flow control valve replacement/repair
- Regulating valve replacement/repair
- Exhaust fan repair
- Piping repair
- Analyzer calibrations/repair/replacement
- DCS

The failure probability of the hardware faults associated with restarting the system is evaluated using FTA as shown in Figure 5-1. Quantification of the fault tree results in a failure probability of $1.0 \mathrm{E}-3$ as shown in Table 5-5. Therefore the total failure probability for moderate repairs followed by restoration of the system is $1.1 \mathrm{E}-2(1.0 \mathrm{E}-2+1.0 \mathrm{E}-3)$.

\section{HEPA Filter Repair/Replacement}

The failure probability to repair/replace a HEPA filter is a summation of the HEP for failing to repair or replace the HEPA filter and the failure probability of the hardware faults associated with restarting the system following the filter replacement.

Failures that cause the HEPA filters to plug, i.e., loss of steam, loss of condenser, etc., are detectable via pressure drop indication and constant air monitors and do not cause an immediate loss of the filter. An additional three days are available to either repair the failed component or replace the HEPA filter. Therefore, failure to repair from this type of failure is considered to be negligible and the repair probability is set to $1 \mathrm{E}-6$.

The failure probability of the hardware faults associated with restarting the system is evaluated using FTA as shown in Figure 5-1. Quantification of the fault tree results in a failure probability of $1.0 \mathrm{E}-3$ as shown in Table 5-5. Therefore the total failure probability for repairing/replacing a HEP filter followed by restoration of the system is $1.0 \mathrm{E}-3(1.0 \mathrm{E}-6+1.0 \mathrm{E}-3)$. 


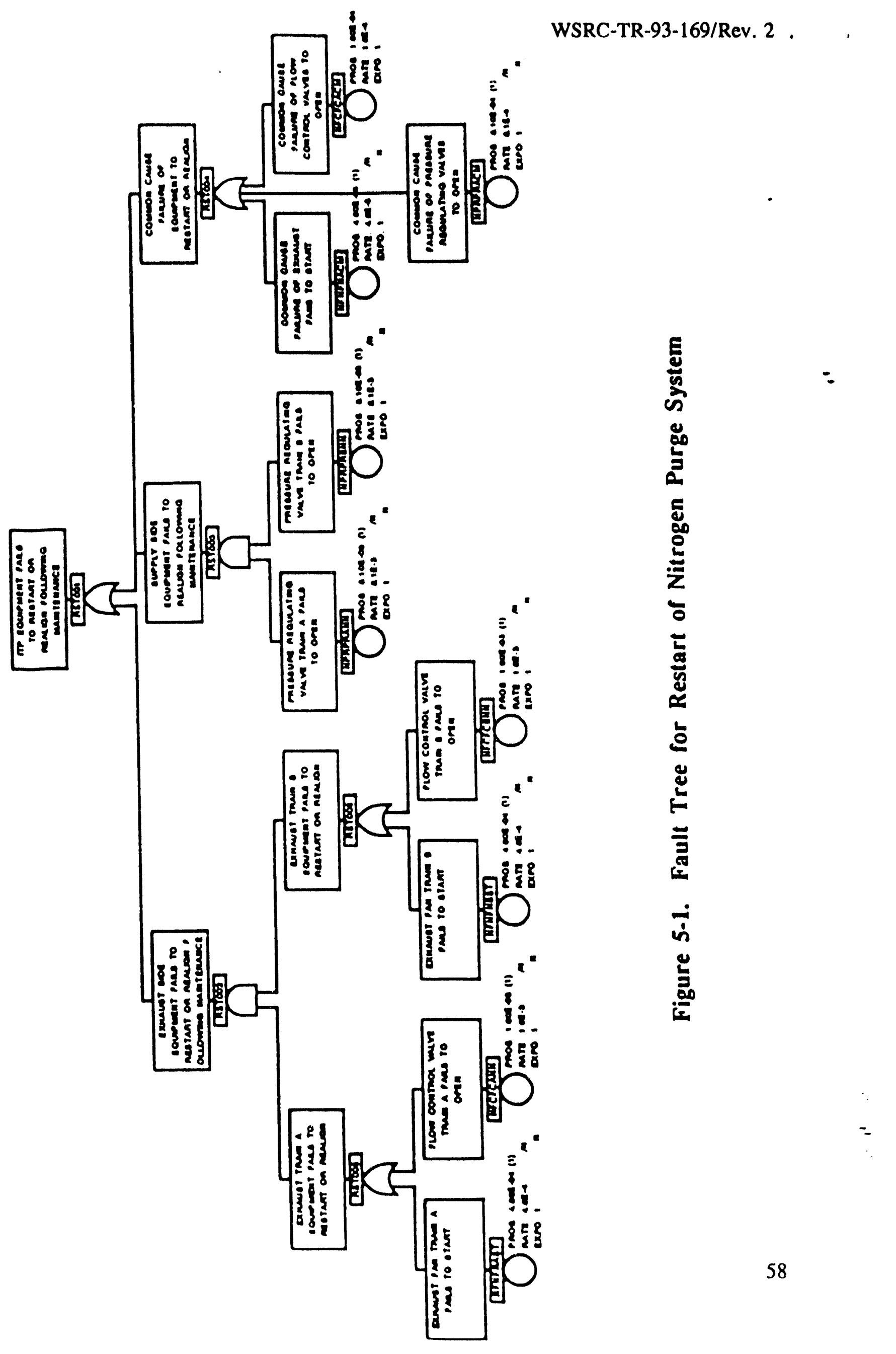


Table 5.5. Cutsets for Restart of Nitrogen Purge System

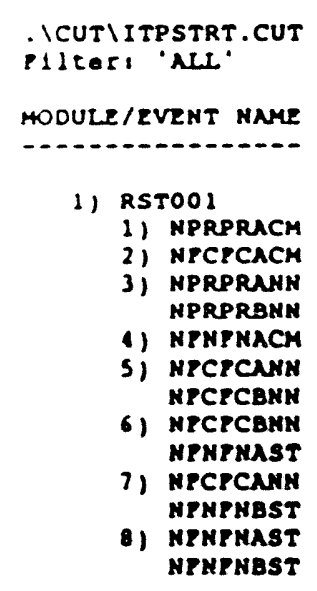

Truncation Linlt: $1.008-08$

DESCRIPTION

COMHON CAUSZ PAILURE OP PRESSURE REGULATING VALVES TO OPEN COMONON CAUSE PAILURE OP PLOW CONTROL VALVES TO OPEN

PRESSURE REGULATIMG VALVE TRAIN A PAILS TO OPEM PRESSURE REGULATING VALVE TRAIM B PAILS TO OPEM COMAO CAUSE PAILURE OF EXHAUST PANS TO BTART

PLOA CONTROL VALVE TRAIM A PAILB TO OPEN

PLOA COUTROL VALVE TRAIH B PAILS TO OPEM

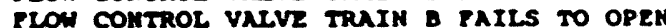

EXHUUBT PNI TRUIM A PAILS TO BTART

PLON CONTROL VALVE TRAIN A EAILB TO OPEN

EXHAUST PAN TRAIN B PAILS TO START

EXHAUST PAN TRAIM A PATLS TO START

EXHAUST PAN TRAIN B PAILS TO BTART

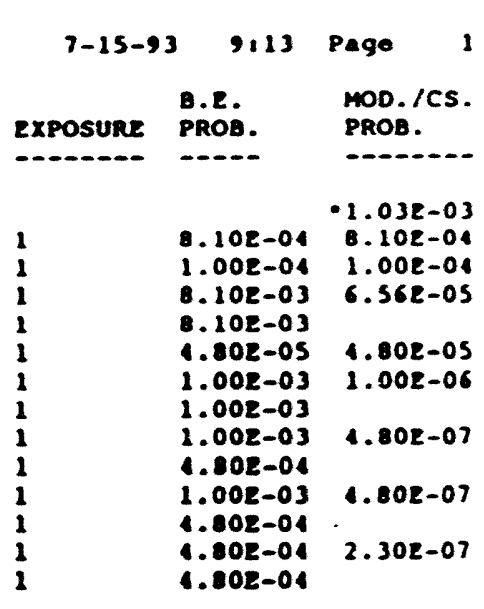




\section{Recovery of Offsite Power}

Based on Reference 30 and the time available to restore power ( -3 days), the probability of failing to recover from a loss of offsite power is $1.8 \mathrm{E}-3$. No credit is taken for recovery of offsite power after an external event.

\subsection{Application to Fault Tree Cutsets}

The probabilities of the repair/recovery actions are summarized in Table 5-6. Basic guidelines are followed when determining which actions are applicable for each cutset. The following rules are followed:

Apply REPAIRN to:

1. Cutsets associated with Tank 48 in the normal processing mode (cutset contains event 8HOUSE04)

2. Cutsets containing manual valve failures

3. Cutsets containing sensor failures

4. Cutsets containing interlock failures

Apply HEPA to:

1. Cutsets containing HEPA filter failures

2. Cutsets containing heater failures

3. Cutsets containing condenser failures

4. Cutsets containing demister failures

5. Cutsets containing steam failures

6. Cutsets containing chromated water failures

7. Cutsets containing vaporizer failures

Apply RECPWR to:

1. Cutsets containing electric power failures 
Apply REPAIRM to:

1. Cutsets containing any hardware failures not already mentioned

2. Cutsets containing instrument air failures

3. Cutsets containing DCS hardware failures

Apply EPVNTINT to:

1. Cutsets containing any hardware failures

It should be noted, as discussed in Subsections 5.2.1 and 5.2.2, that a screening value of 1.0 is applied to the higher of any two operating or recovery actions that is applicable to a single cutset. Thus, a single cutset contains at most one operating or recovery action, and one repair activity. 
Table 5-6. Summary of Repair/Recovery Action Probabilities

\begin{tabular}{lll}
\hline & Basic Event Name & Failure Probability \\
\hline Action & 8OPTRNBE & 4E-4 (screening value = 1.0) \\
$\begin{array}{l}\text { Align and Start } \\
\text { Train B - Exhaust Side }\end{array}$ & 9OPTRNBE & \\
$\begin{array}{l}\text { Enter Field Control } \\
\text { Mode (Moderate Stress) }\end{array}$ & 8OPC-MS & $4 \mathrm{E}-4$ (screening value = 1.0) \\
$\begin{array}{l}\text { Enter Field Control } \\
\text { Mode (High Stress) }\end{array}$ & $\begin{array}{l}\text { 8OPC-HS } \\
\text { 9OPC-HS }\end{array}$ & $2.5 \mathrm{E}-3$ (screening value = 1.0) \\
NOPC-HS & \\
$\begin{array}{l}\text { Align and Start EPVE } \\
\text { combined with start and run EPVE EPVNTINT }\end{array}$ & \\
$\begin{array}{l}\text { Recovery of Normal } \\
\text { Power Supply }\end{array}$ & RECPWR & $2.3 \mathrm{E}-6$ \\
HEPA Filter & & $1.8 \mathrm{E}-3$ \\
Repair/Replacement & HEPA & \\
Simple Repairs & & $1.0 \mathrm{E}-3$ \\
Moderate Repairs & REPAIRN & $1.0 \mathrm{E}-3$ \\
\hline
\end{tabular}




\subsection{REFERENCES}

1. Legler, B. M., et al. Safety Analysis - 200 Area Savannah River Plant Separations Arèa Operations Liquid Radioactive Waste Handling Facilities (U). Internal Report DPSTSA200-10, E. I. du Pont de Nemours \& Co., Savannah River Laboratory, Aiken, SC, August 1988.

2. Safety Analysis Report Savannah River Site Liquid Radioactive Waste Handling Facility, Addendum I Additional Analysis for DWPF Feed Preparation by In-Tank Processing (U). Internal Report DPSTSA-200-10, SUP-18, DOE Approval Draft, November 1992.

3. Memo, D. D. Walker to E. J. Majzlik. "Accumulations of Combustible Gases in the InTank Precipitation Processing Tanks (U)." WSRC-RP-93-537, Westinghouse Savannah River Company, Aiken, SC, April 14, 1993.

4. Operational Safety Requirements In-Tank Precipitation Process Savannah River Site (U). WSRC-RP-90-1124, Rev. 1, Westinghouse Savannah River Company, Savannah River Technology Center, Aiken, SC, June 1993.

5. Cramer, D. S. and Ford, H. A. Probability of Ignition Sources in Waste Tank 48 or 49 (U). WSRC-RP-93-770, Rev 1, Westinghouse Savannah River Company, Aiken, SC, January 1994.

6. Norkus, J. K. Benzene Layer Thickness in Tank 48 Following Loss of Nitrogen Purge (U). SRT-WAG-930104, Westinghouse Savannah River Company, Aiken, SC, June 1993.

7. CAFTA Manual for Version 2.2. Science Applications International Corporation, Los Altos, CA, May 1992.

8. Some Published and Estimated Failure Rates for Use on Fault Tree Analysis (U). E. I. du Pont de Nemours \& Co., Wilmington, DE, January 9, 1981.

9. Dexter, A. H. and Perkins, W. C. Component Failure Rate Data with Potential Applicability to a Nuclear Fuel Reprocessing Plant (U). DP-1633, E. I. du Pont de Nemours \& Co., Savannah River Laboratory, Aiken, SC, July 1982.

10. Durant, W. D. and Perkins, W. C. Safety Analysis - 200-S Area Savannah River Site Defense Waste Processing Facility Operations $(U)$. Internal Report DPSTSA-200-10, Rev. 6/93 (Draft), SUP-20, Westinghouse Savannah River Company, Savannah River Site, Aiken, SC, June 1993.

11. Memo, J. E. Held to R. E. Vail and D. A. Sharp. "Human Reliability Analysis of DWPF Calibration Activities (U)." SRT-HFE-930011. Westinghouse Savannah River Company, Aiken, SC, May 7, 1993. 
12. Memo, D. S. Cramer to T. E. Britt. Failure Probability To Start a System of Fans Driven by Gasoline Engines for the In-Tank Precipitation Program. SRT-RST-930225. Westinghouse Savannah River Company, Aiken, SC, May 27, 1993.

13. Cramer, D. S. SRP Generic Database (SAIC/NY 85-8-14). Internal Report DPST-86-401, E. I. du Pont de Nemours \& Co., Savannah River Laboratory, Aiken, SC, April 1986.

14. IEEE Standard 500-1984. IEEE Guide to the Collection and Presentation of Electrical, Electronic Sensing Component, and Mechanical Equipment Reliability Data for Nuclear Power Generating Stations. Institute of Electrical and Electronic Engineers, New York, NY, (1983).

15. Generic Component Database for Severe Service Chemical Process Plants. SAIC 90/1026, Science Applications International Corporation, Richland, WA, January 1990.

16. Offshore Reliability Data Handbook. First Edition, (1984).

17. ETA-II User's Manual, Version 2.1. Science Applications International Corporation, Los Altos, CA, August 1992.

18. Swain, A. D. Accident Sequence Evaluation Program Human Reliability Analysis Procedure. NUREG/CR-4772, Sandia National Laboratories, Albuquerque, NM, February 1987.

19. Swain, A. D., and Guttmann, H. E. Handbook of Human Reliability Analysis with Emphasis on Nuclear Power Plant Applications - Final Report. NUREG/CR-1278, Sandia National Laboratories, Albuquerque, NM, August 1983.

20. Personal Communication, D. S. Cramer (WSRC) and B. Radcliff (Briggs \& Steaton), July 13, 1993.

21. Ford, H. A. Common Cause Failure Rates for Selected Components in the SRS K-Reactor Rev. I, Level I PRA Derived with MGL Methodology (U). WSRC-RP-92-1193, Westinghouse Savannah River Company, Aiken, SC, October 1992.

22. Olsen, L. M. Human Reliability Analysis for In-Tank Precipitation Alignment and Startup of Emergency Purge Ventilation Equipment (U). WSRC-TR-93-301, Rev. 2. Westinghouse Savannah River Company, Aiken, SC, January 1994.

23. Paula, H. M., Roberts, M. W., and Battle, R. E. "Operational Failure Experience of FaultTolerant Digital Controls Systems." Reliability Engineering and System Safety, submitted for publication July 1991. 
24. Memo, C. H. Hunter to M. K. Gupta. "Occurrence of Heavy Ice and Snow at SRS." SRTETS-930539, Westinghouse Savannah River Company, Aiken, SC, May 1993.

25. Memo, B. D. Thomas to T. E. Britt. "Low Level Earthquake (U)." EPD-SE-93-0197:68. Westinghouse Savannah River Company, Aiken, SC, May 28, 1993.

26. Kennedy, R. P., et al. Design and Evaluation Guidelines for Department of Energy Facilities Subjected to Natural Phenomena Hazards. UCRL-15910, U.S. Department of Energy, Washington, D.C., June 1990.

27. Evaluation of Accident Risks in the Transportation of Hazardous Materials by Truck and Rail at the Savannah River Site (U). Internal Report WSRC-RP-89-715, Revision 1, Westinghouse Savannah River Company, Aiken, SC, September 1992.

28. Memo, G. A. Taylor to M. J. Augeri. "Nitrogen Usage." WER-ITP-930286. Westinghouse Savannah River Company, Aiken, SC, March 26, 1993.

29. McCann, M. W., Jr., et al. Lower Bound Earthquake Magnitude for Probabilistic Seismic Hazard Evaluation. Nuclear Engineering and Design 123, (1990).

30. Smith, J. A., Electric Power System Model, Internal Report DPST-88-253, Westinghouse Savannah River Company, Savannah River Site, Aiken, SC, January 25, 1988.

31. SW-12-HLW-16.01, Conduct of Operations Manual.

32. WSRC-SW-1.27 241-82H 7400B Panel Alarm Response Manual, Rev 1.

33. J-DCP-H-92001, Rev 1, Design Change Package, Replace CSI Computer System 3781 with a Texas Instrument D/S System Including 3782, 1588, and 2081.

34. IEEE Guide to the Collection and Presentation of electrical, Electronic and Sensing Component Reliability Data for Nuclear Generating Stations, IEEE Std 500-1977. 


\section{APPENDIX A}

\section{FAULT TREE FOR NITROGEN PURGE SYSTEM FOR TANKS 48 AND 49}

This fault tree models the different component and support system failure paths that lead to a loss of the nitrogen purge system to either one or both tanks and includes the coincident ignition source probability. The following conventions are applied in developing this fault tree:

1. As discussed in Section 3.1 a frequency-based fault tree is developed rather than a probability-based fault tree.

2. Point estimates for failure rates, initiators (per year) and failure probabilities are expressed where possible as means. Therefore, data values which were clearly expressed as medians in the data sources were converted to means to input to the fault tree quantification. For example, the human error probability (HEP) to align, connect and startup the EPVE following an external event or random system failure is reported (22) as a median value of $4.2 \mathrm{E}-6$. For use in the fault tree quantification, this number was converted to a point value of 5.3E-6 which approximates the mean value assuming a Lognormal distribution with an error factor of 3. An error factor of 3 was assigned since the dominant terms in the event tree (22) have an error factor of 3.

3. Unavailabilities due to testing and maintenance are not modeled for components that do not have backups, e.g., condenser or vaporizer. Unavailabilities are modeled for equipment in standby trains, such as the permanent exhaust fans; however, the final analysis is conservative in that it does not take any credit for the operator switching to these trains. The unavailabilities are doubled as discussed in Section 3.1.

4. The final analysis is conservative in that it does not take any credit for the manual bypass line or its cross-connect for nitrogen feed into the tank.

5. HEPA filters eventually plug after a loss of the demister, condenser, or heater.

6. Plugging is the only valid HEP $\AA$ filter failure mode considered. A rupture of the filter may result in a release, but does not fail the function modeled by this fault tree.

7. For each tank, only one HEPA filter train is online during operation. The fault tree assumes HEPA filter Train B is online and HEPA Train A is on standby. The final analysis is conservative in that no credit is taken for the HEPA filter on standby. 
8. One exhaust fan for each tank is normally operating. The other fan (one for each tank) is in standby.

9. Both hardware and software failures are considered for the DCS. Since only limited site-specific data are available, a generic estimate is taken from industrial experience for software and hardware failure rates (23).

10. Since the OSRs require a minimum of 26,000 gallons of liquid nitrogen onsite at all times, the fault tree conservatively models the complete volume of available liquid nitrogen in Tank 1 and no credit is taken for automatic switch over to Tanks $2,3,4$ or 5 .

11. The fault trees do not model components whose function is to provide information only, e. $g$., benzene analyzer and LFL analyzer. 


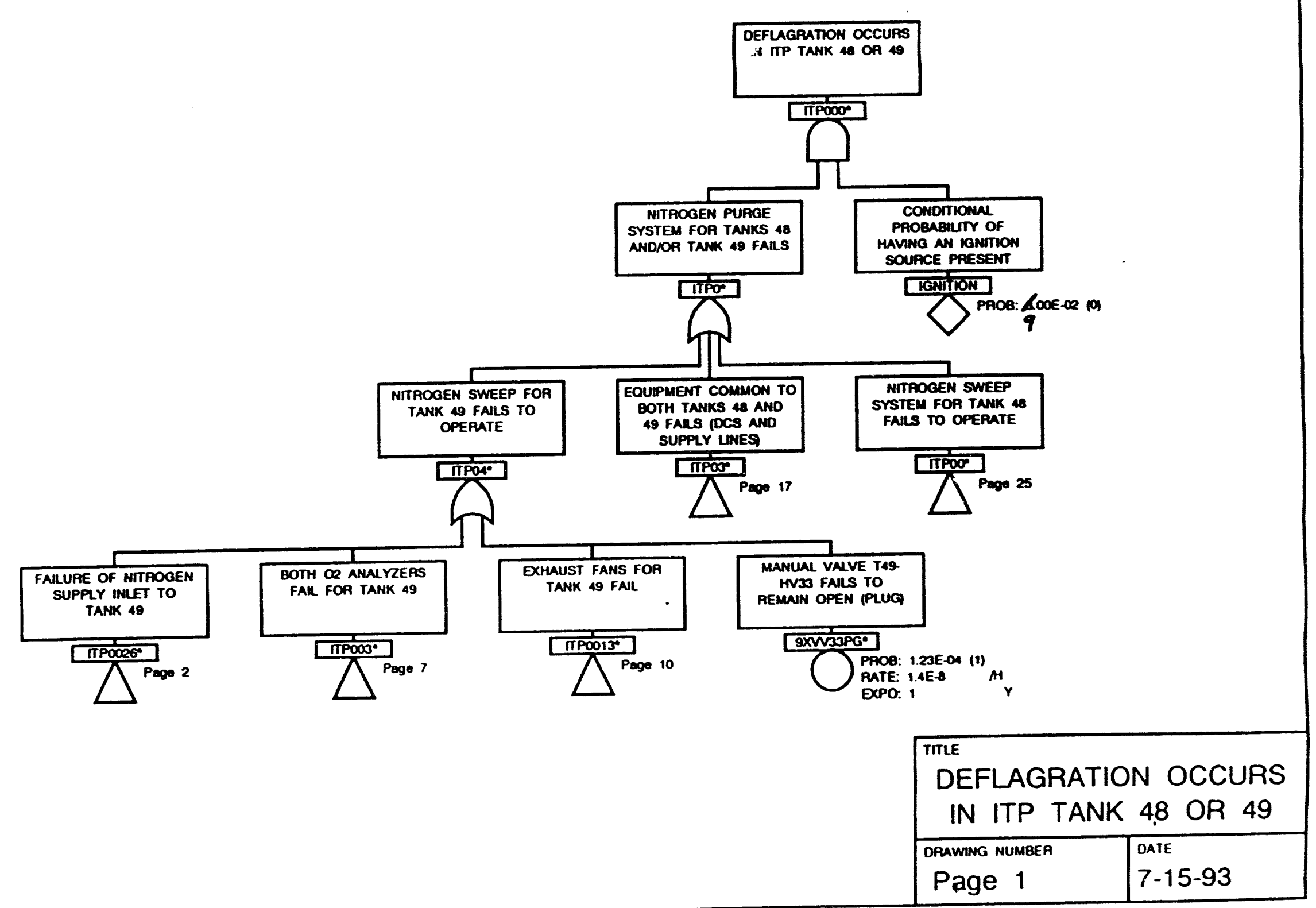




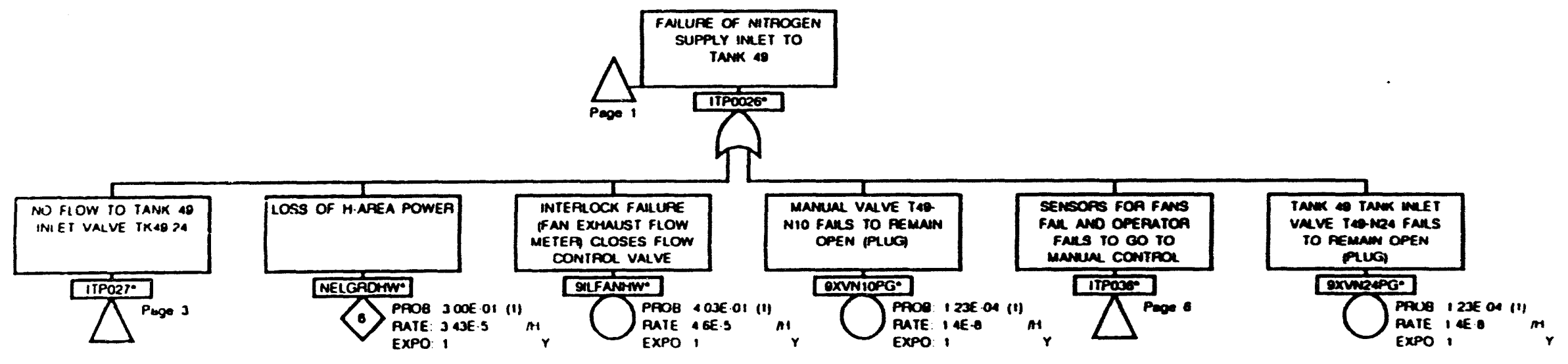

\begin{tabular}{|c|c|}
\hline \multicolumn{2}{|c|}{$\begin{array}{l}\text { DEFLAGRATION OCCURS } \\
\text { IN ITP TANK } 48 \text { OR } 49\end{array}$} \\
\hline & \\
\hline Page & $7-15-93$ \\
\hline
\end{tabular}




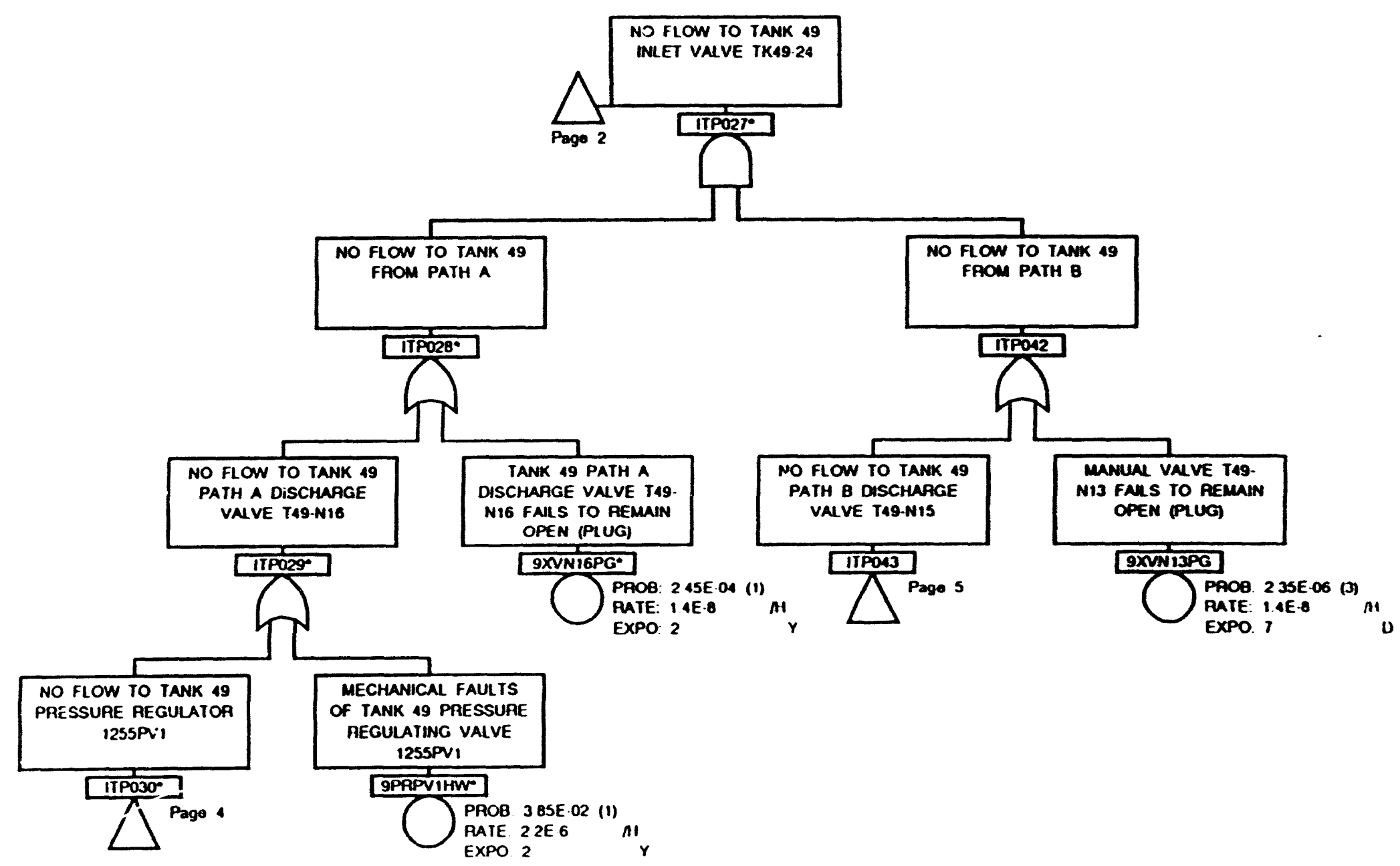

\begin{tabular}{|l|l|}
\hline IIILE \\
DEFLAGRATION OCCURS \\
IN ITP TANK 48 OR 49 \\
\hline $\begin{array}{l}\text { DPAWMG MUMBER } \\
\text { Page } 3\end{array}$ & DAIE \\
\hline
\end{tabular}




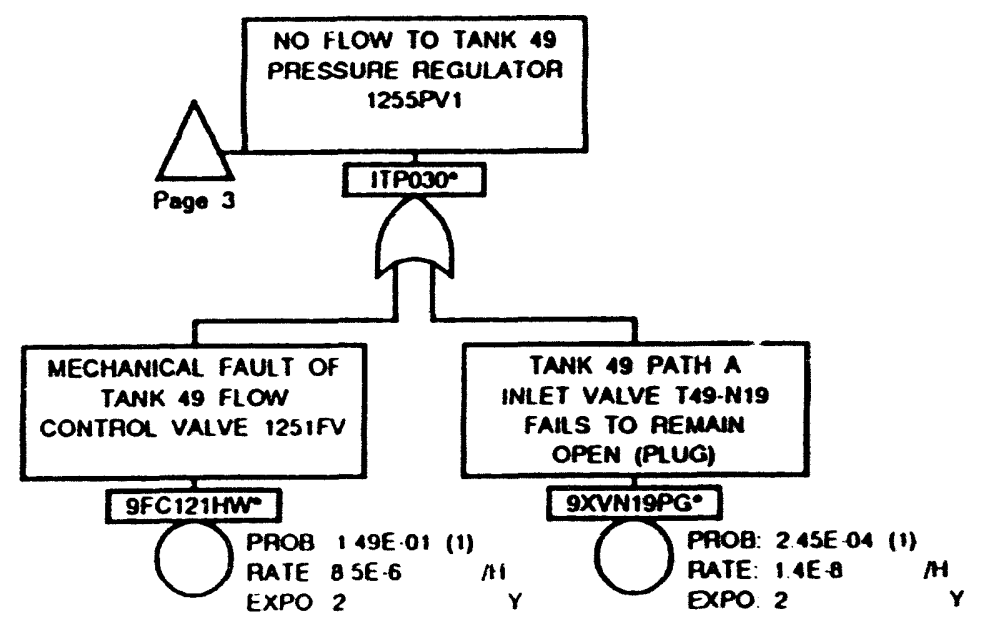

\begin{tabular}{|c|c|}
\hline \multicolumn{2}{|c|}{ 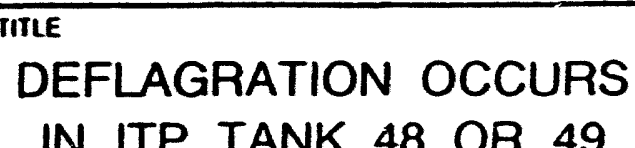 } \\
\hline DFAMMNG NUMBER & \\
\hline Page 4 & $7-15-93$ \\
\hline
\end{tabular}




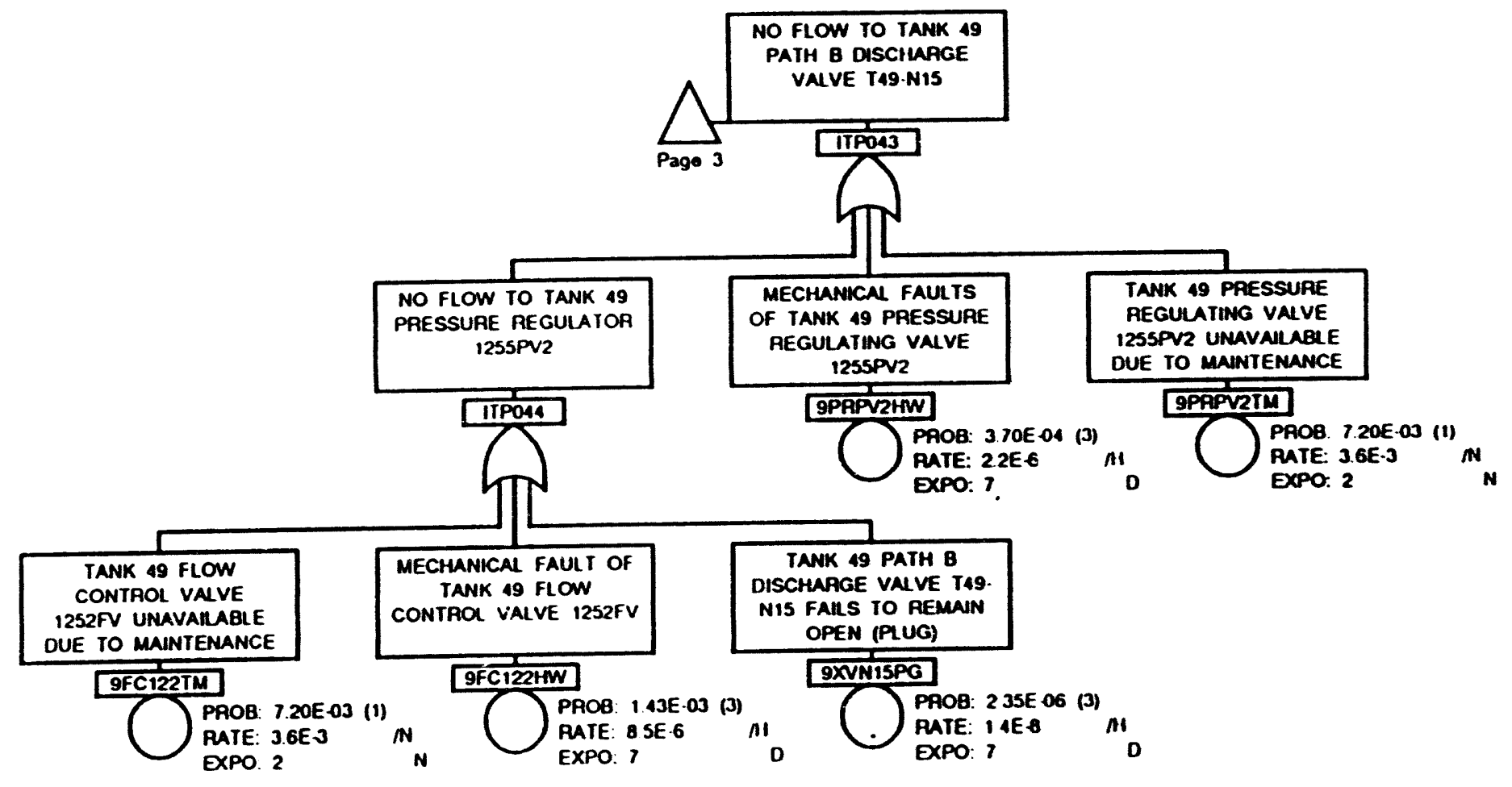

\begin{tabular}{|c|c|}
\hline \multicolumn{2}{|c|}{$\begin{array}{l}\text { TIILE } \\
\text { DEFLAGRATION OCCURS } \\
\text { IN ITP TANK } 48 \text { OR } 49\end{array}$} \\
\hline $\begin{array}{l}\text { Draming NumBte } \\
\text { Page } 5\end{array}$ & $\begin{array}{l}\text { DATE } \\
7-15-93\end{array}$ \\
\hline
\end{tabular}




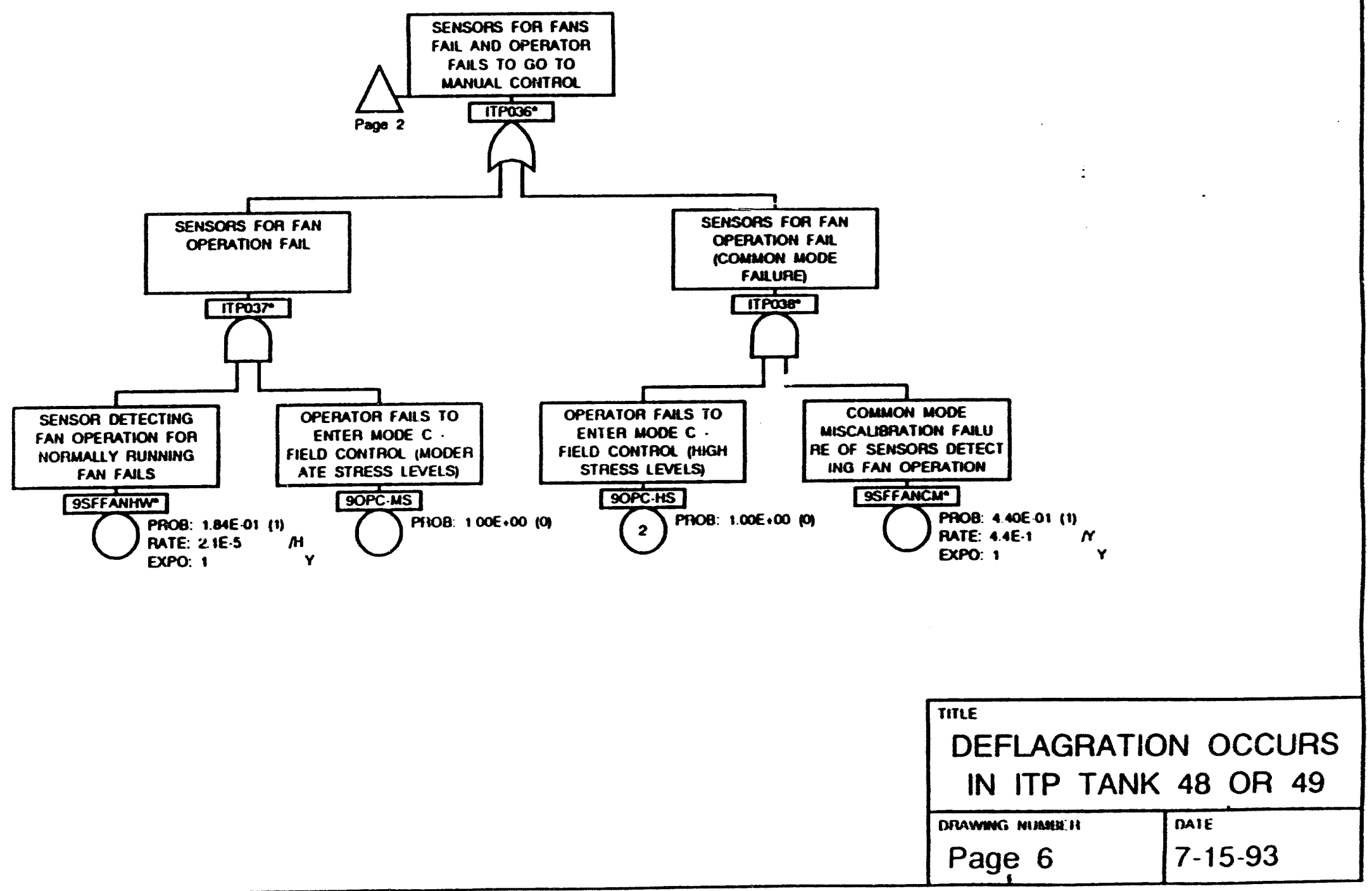




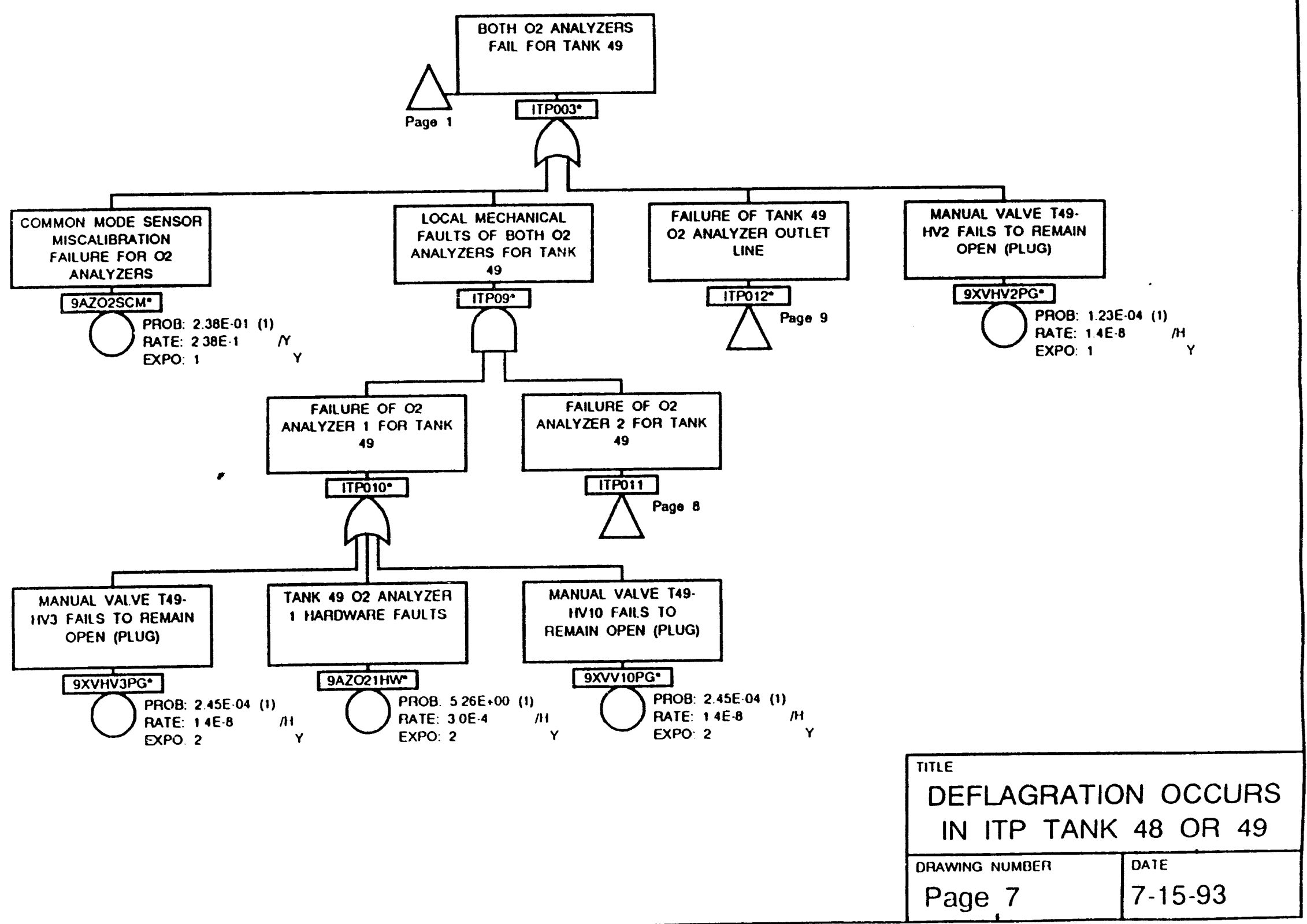




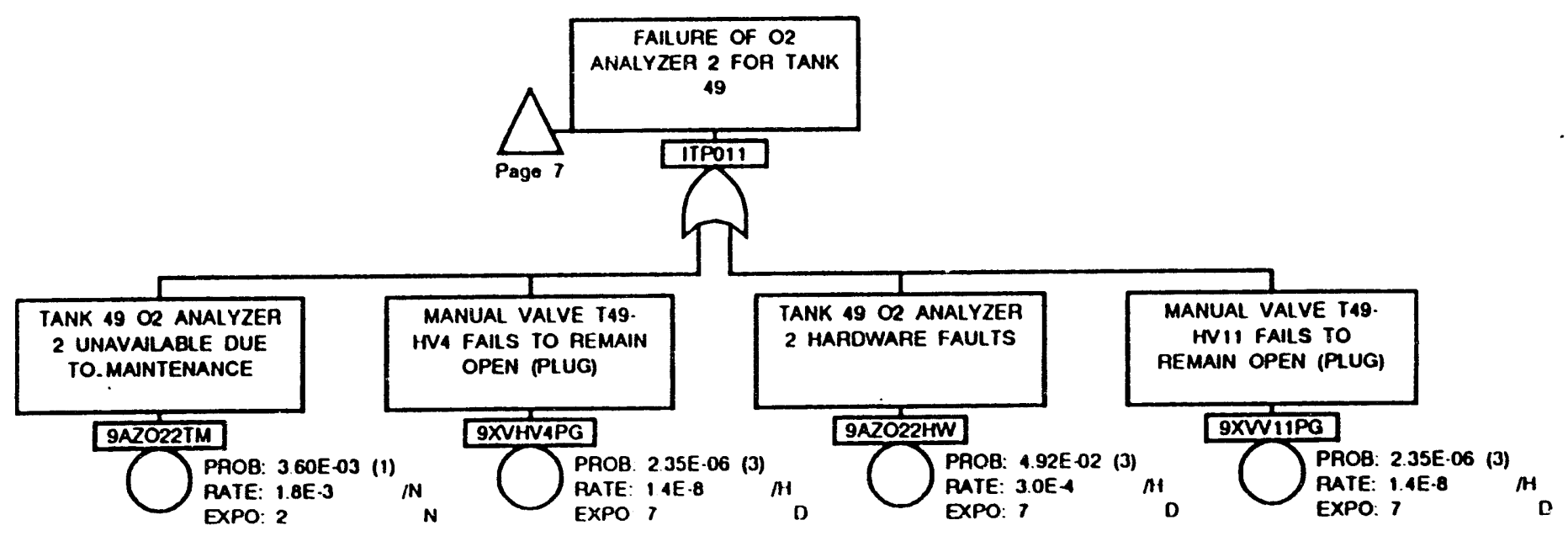

\begin{tabular}{|l|l|}
\hline IIILE \\
DEFLAGRATION OCCURS \\
IN ITP TANK 48 OQR 49 \\
\hline DRAWING NUMGEA & DATE \\
Page, 8 & $7-15-93$ \\
\hline
\end{tabular}




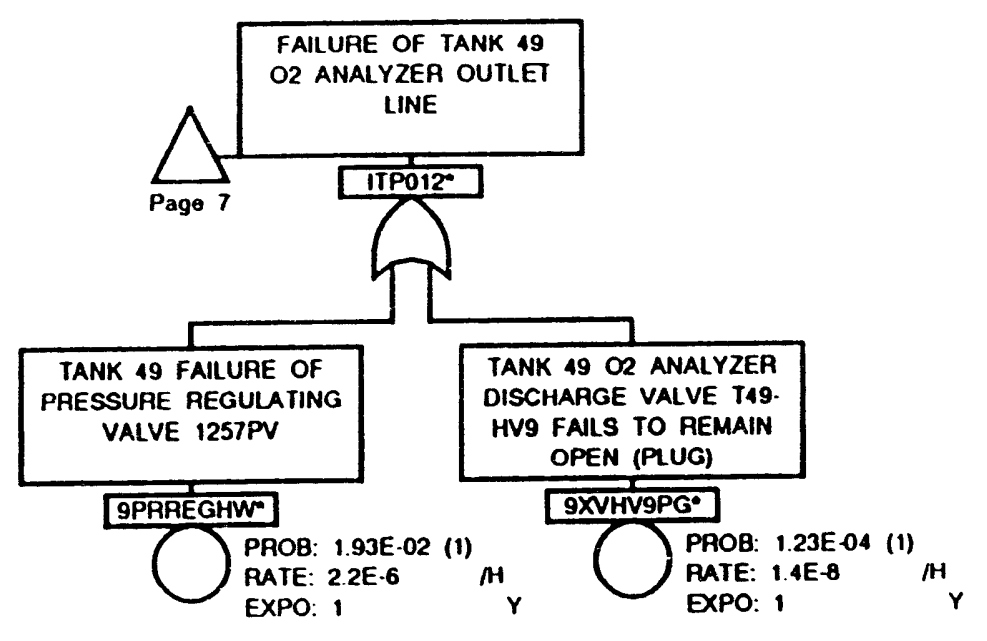

\begin{tabular}{|c|c|}
\hline \multicolumn{2}{|c|}{ DEFLAGRATION OCCURS } \\
\hline DRAWING NUME & \\
\hline Page 9 & $7-15-93$ \\
\hline
\end{tabular}




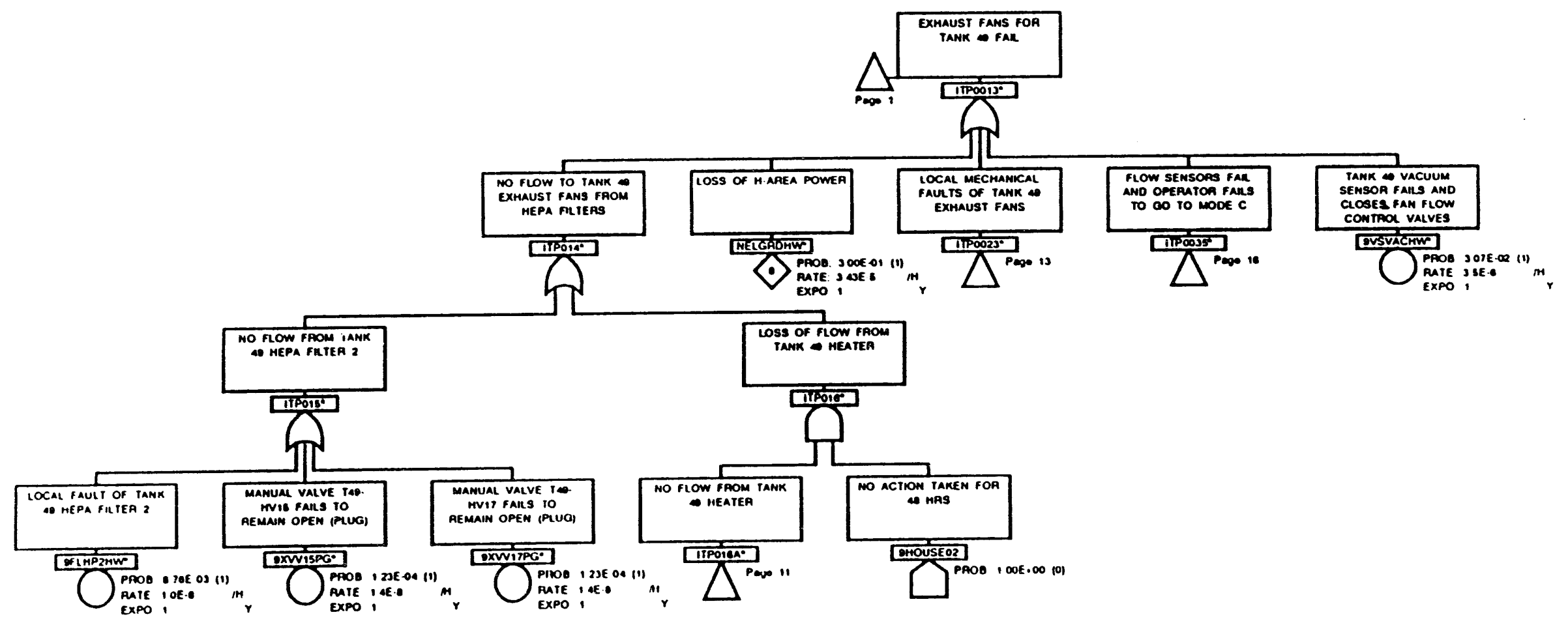

\begin{tabular}{|c|c|}
\hline \multicolumn{2}{|c|}{$\begin{array}{l}\text { DITLE } \\
\text { DEFLAGRATION OCCURS } \\
\text { IN ITP TANK } 48 \text { OR } 49\end{array}$} \\
\hline DHAWING NUMBSE & \\
\hline Page 10 & $7-15-93$ \\
\hline
\end{tabular}




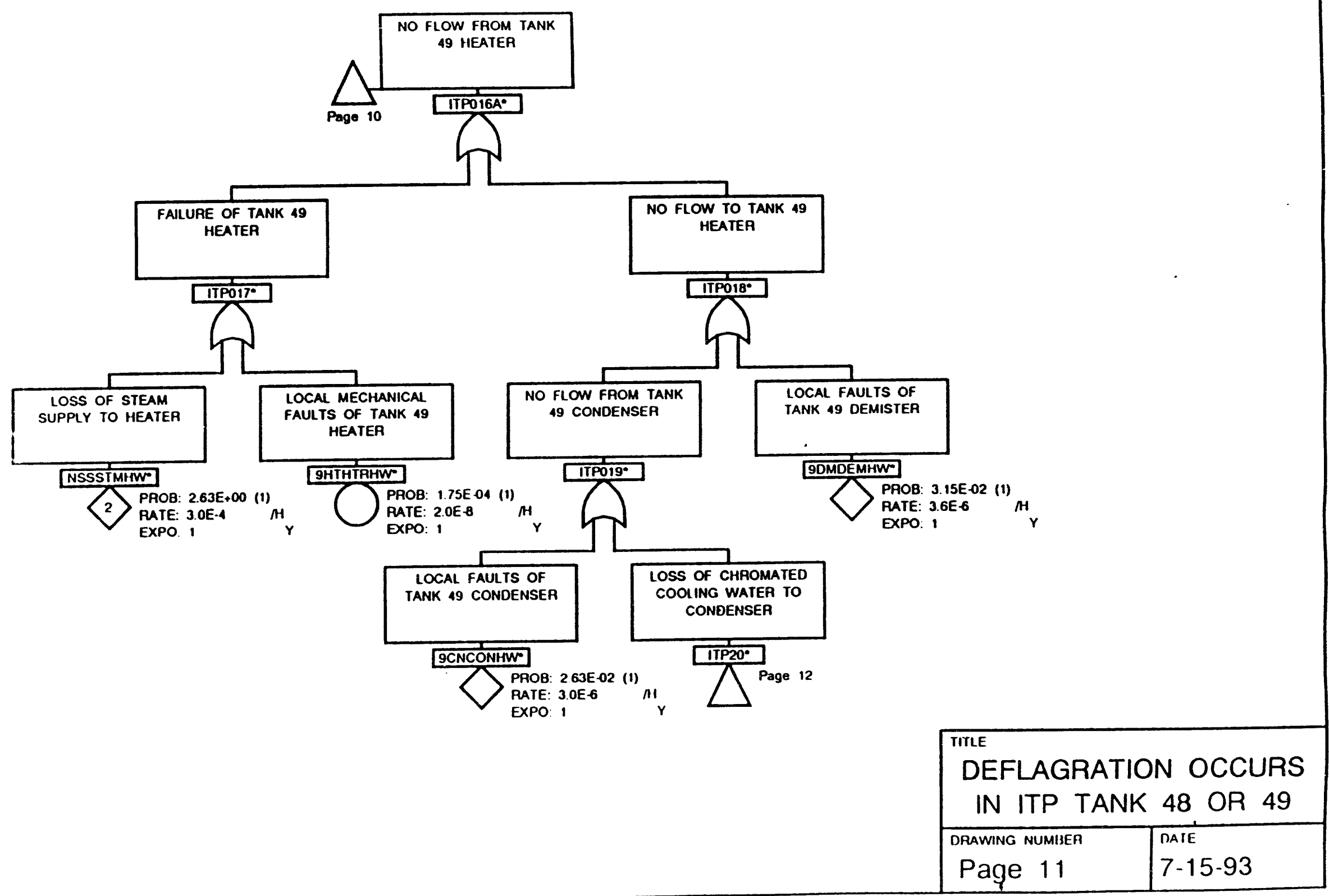




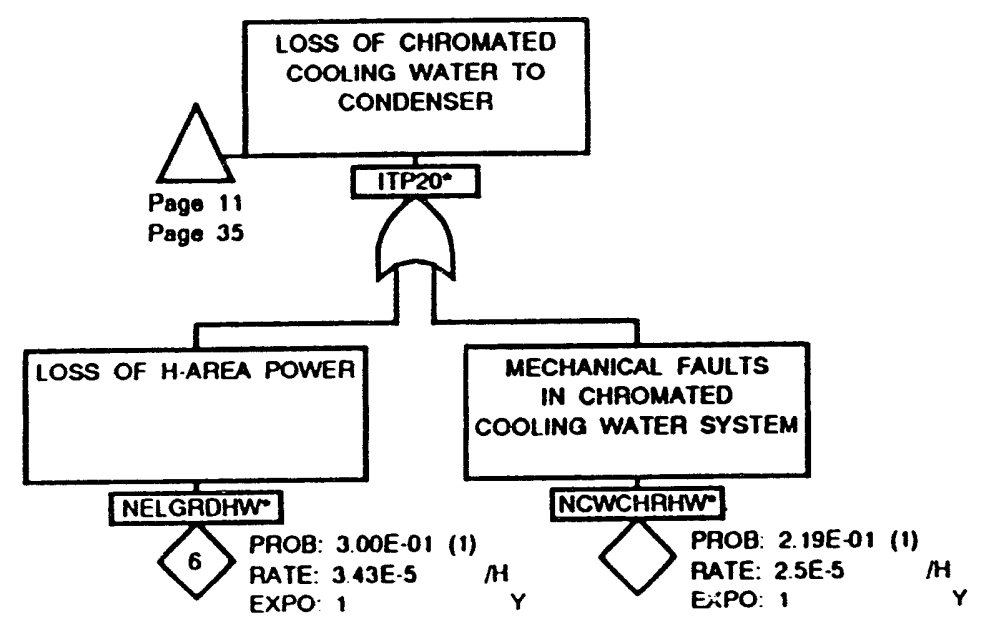

\begin{tabular}{|c|c|}
\hline \multirow{2}{*}{\multicolumn{2}{|c|}{ DEFLAGRATION OCCURS }} \\
\hline IN ITP T & \\
\hline DPAWING NU & DATE \\
\hline
\end{tabular}




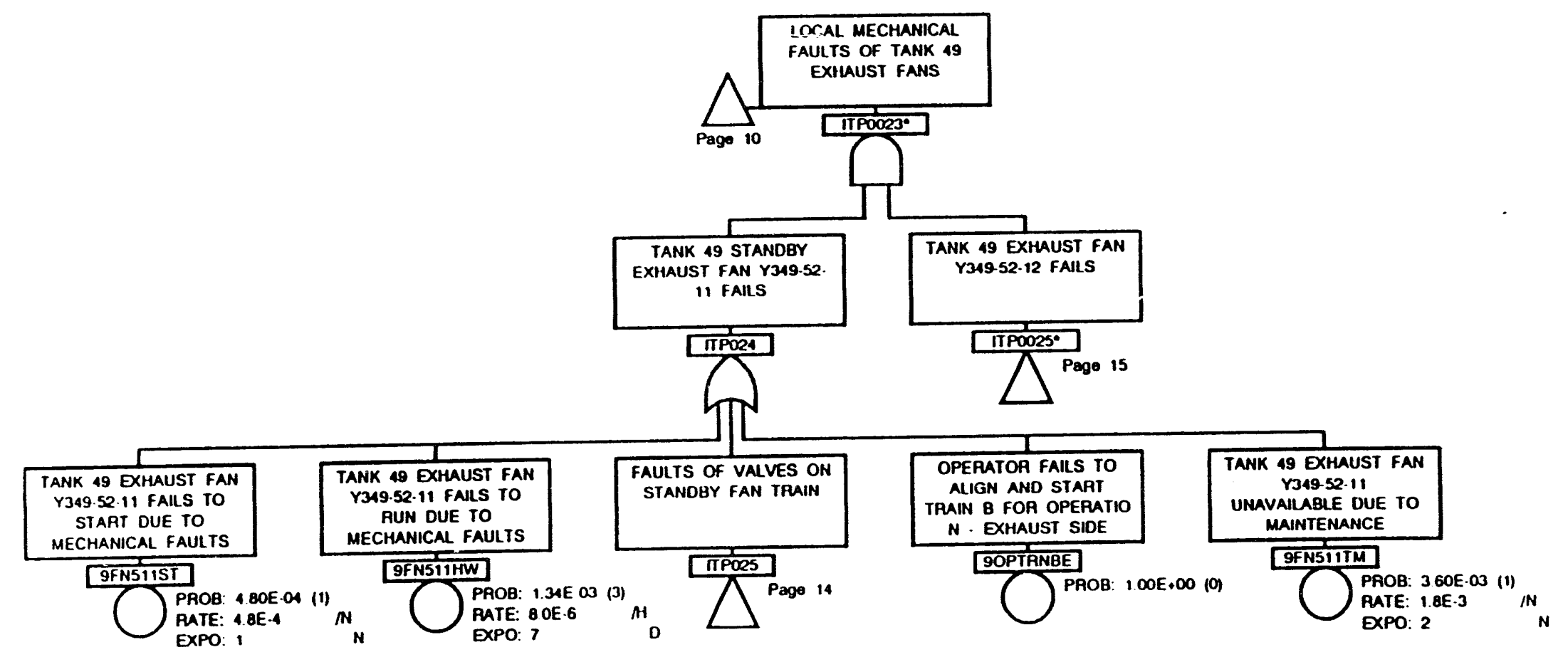

\begin{tabular}{|l|l|}
\hline TITLE \\
DEFLAGRATION OCCURS \\
IN ITP TANK 48 OR 49 \\
\hline IRAWING NUMBER & DATE \\
Page 13 & $7-15-93$ \\
\hline
\end{tabular}




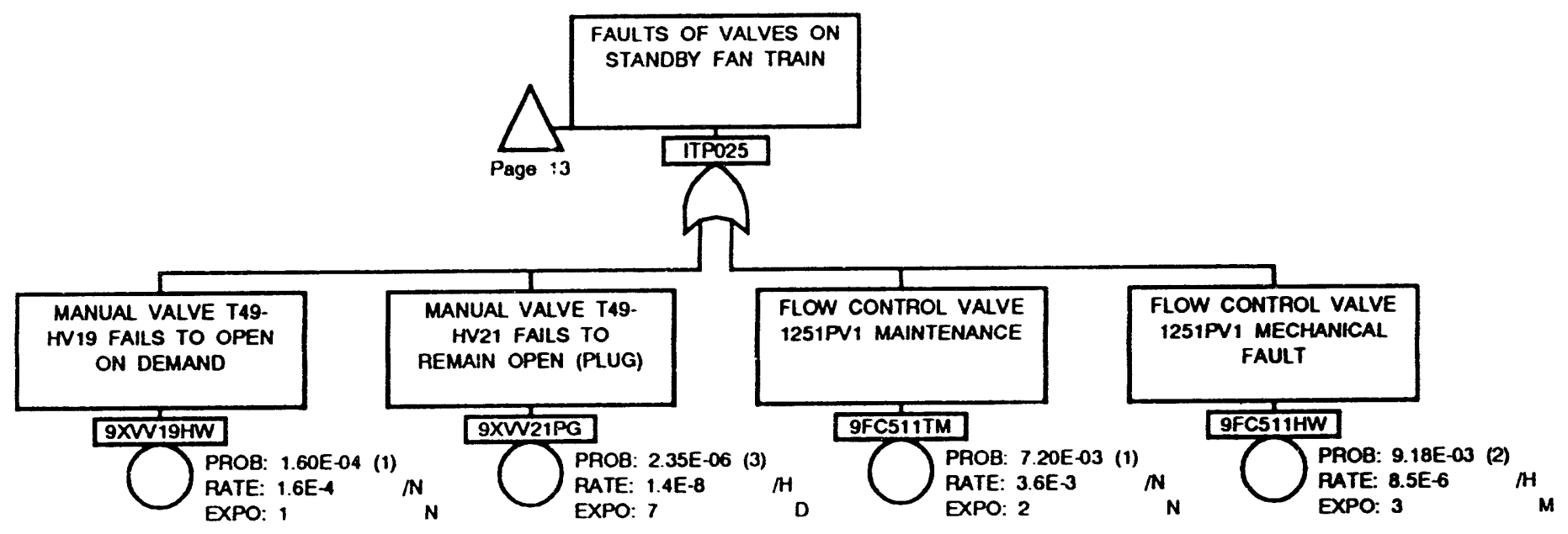

\begin{tabular}{|c|c|}
\hline \multicolumn{2}{|c|}{$\begin{array}{l}\text { TITE } \\
\text { DEFLAGRATION OCCURS } \\
\text { IN ITP TANK } 48 \text { OR } 49\end{array}$} \\
\hline $\begin{array}{l}\text { DRAWING NUMBER } \\
\text { Paǵ } 14\end{array}$ & $\begin{array}{l}\text { DATE } \\
7-15-93\end{array}$ \\
\hline
\end{tabular}




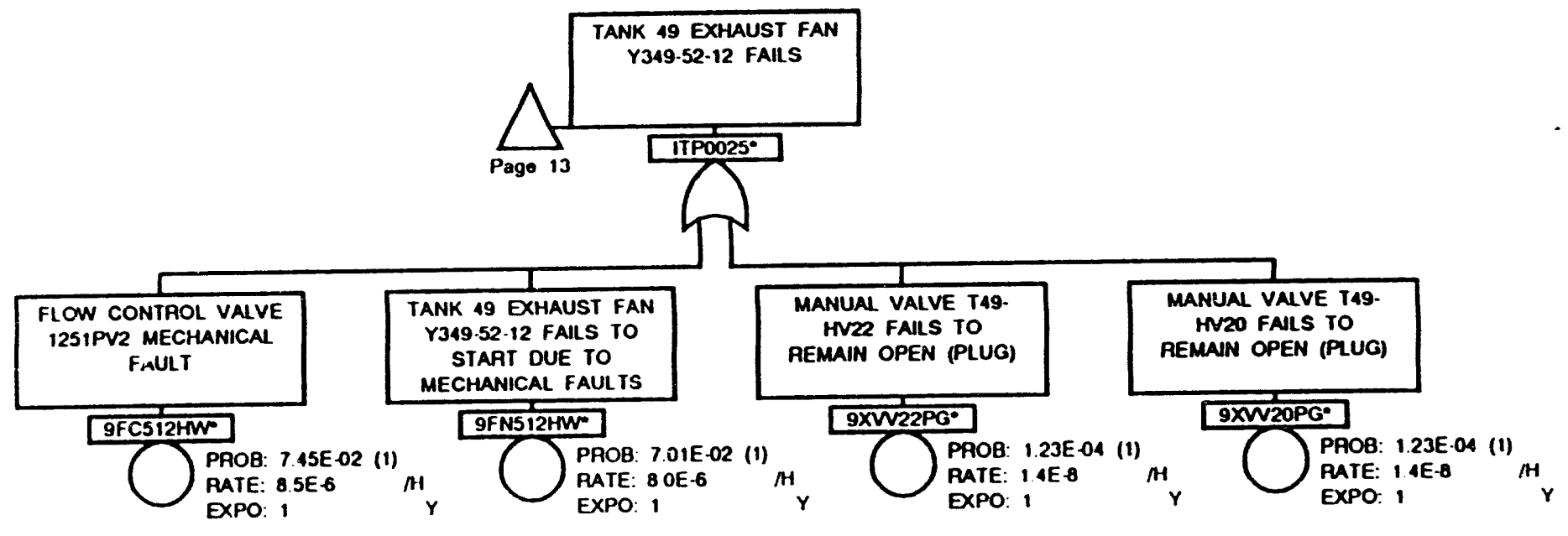

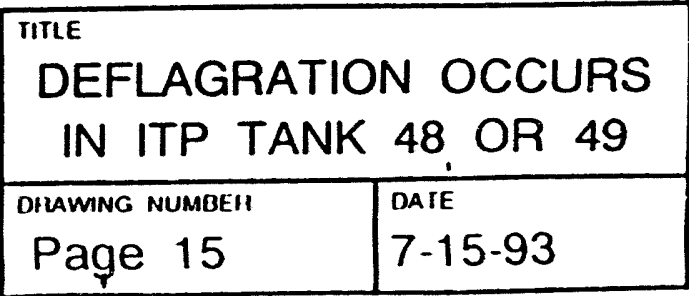




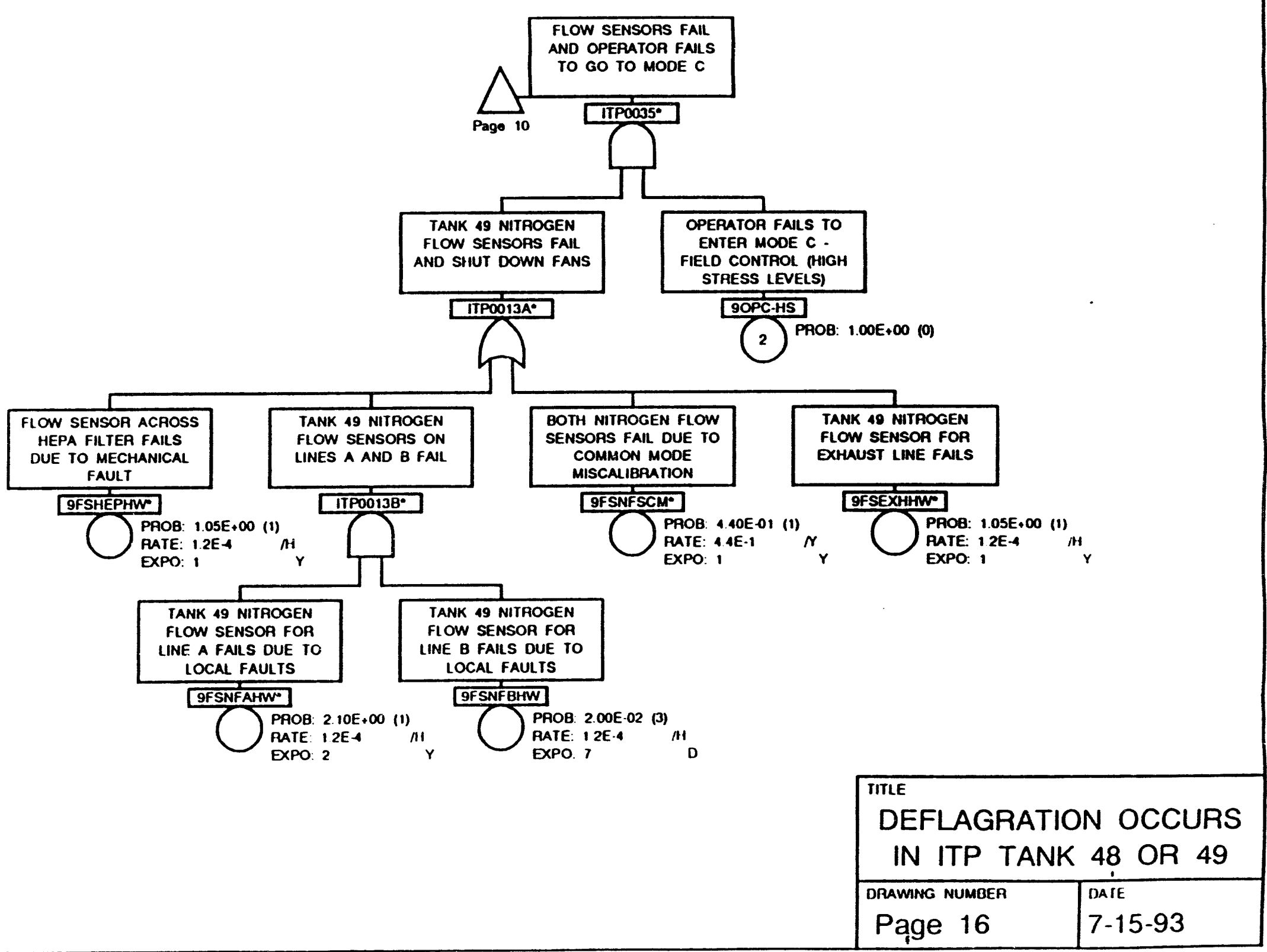




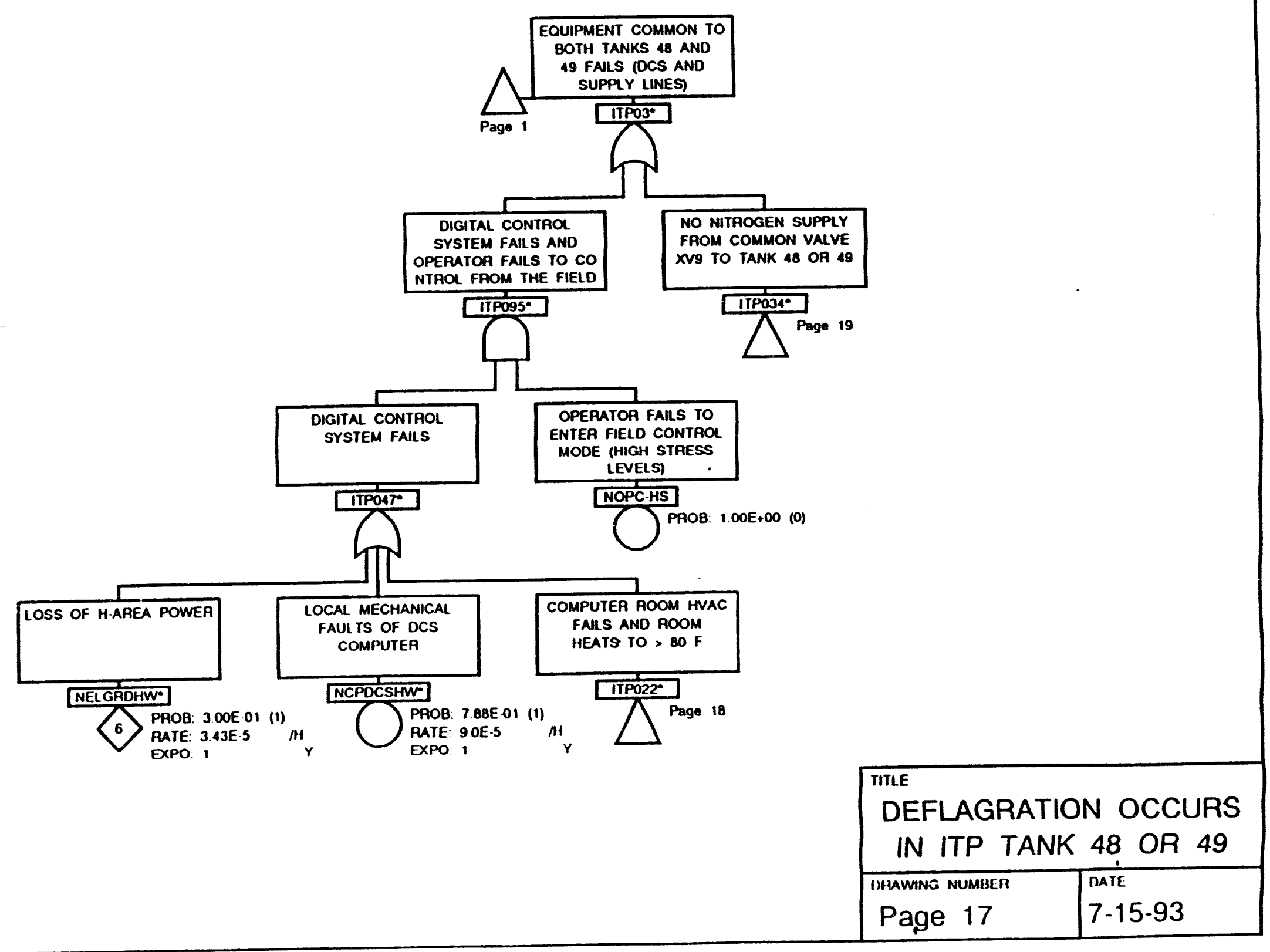




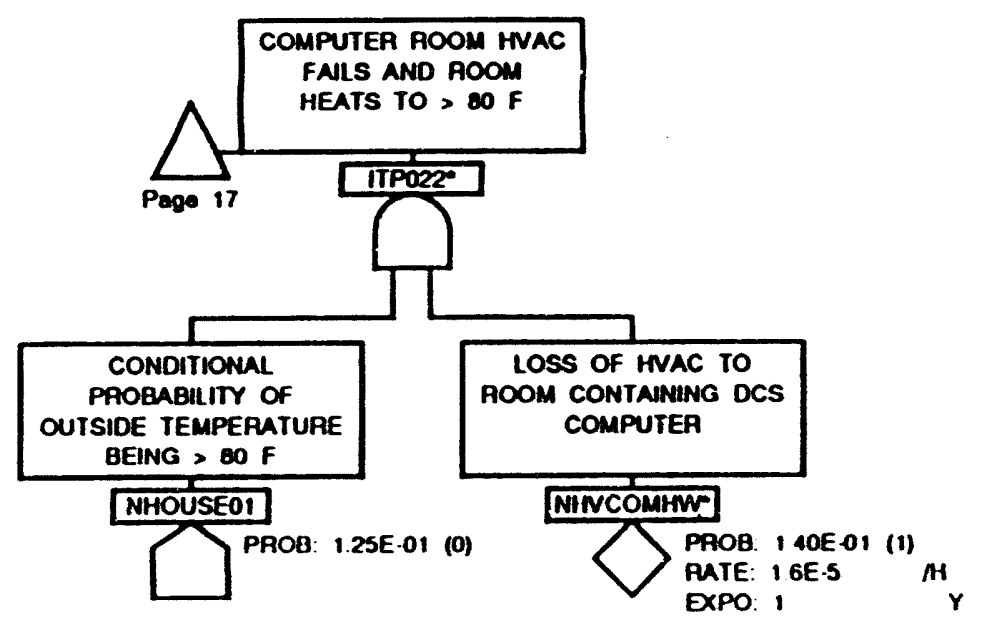

\begin{tabular}{|c|c|}
\hline \multicolumn{2}{|c|}{$\begin{array}{l}\text { DITLE } \\
\text { DEFLAGRATION OCCURS } \\
\text { IN ITP TANK } 48 \text { OR } 49\end{array}$} \\
\hline DRAMMNG NUMBEI" & \\
\hline Page 18 & $7-15-93$ \\
\hline
\end{tabular}




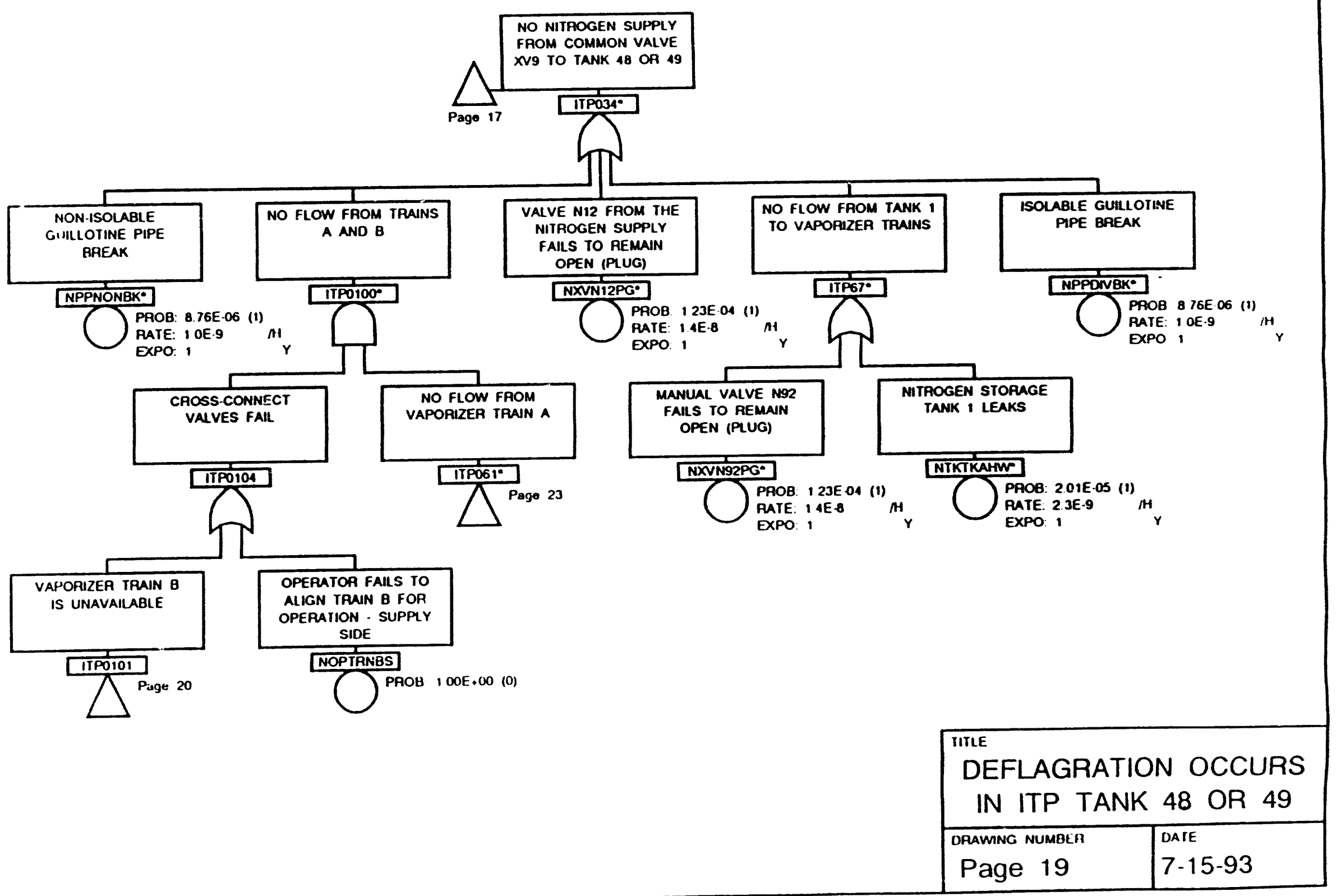




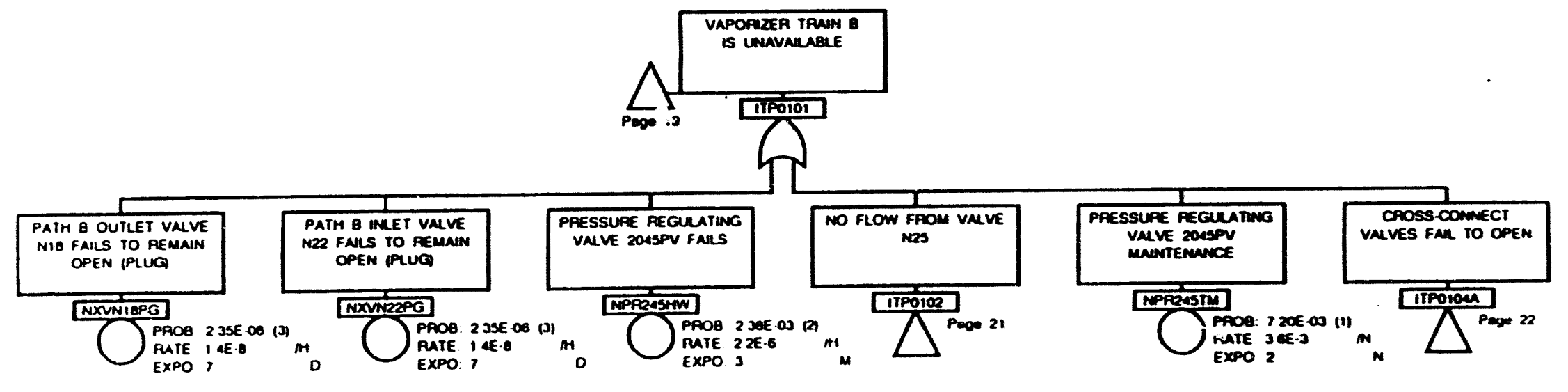

\begin{tabular}{|l|l|}
\hline TITIE \\
DEFLAGRATION OCCURS \\
IN ITP TANK 48 OR 49 \\
\hline DRAMUNG NUMBER & DAIE \\
Page 20 & $7-15-93$ \\
\hline
\end{tabular}




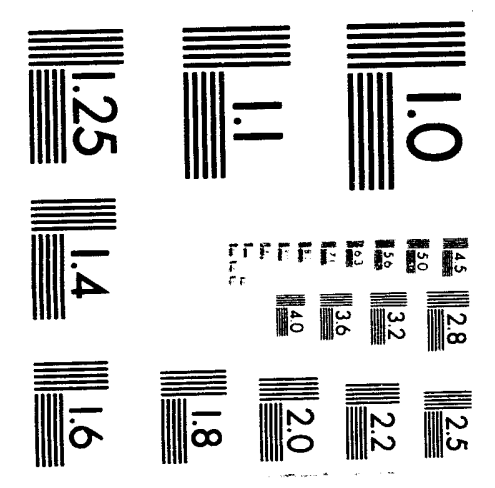



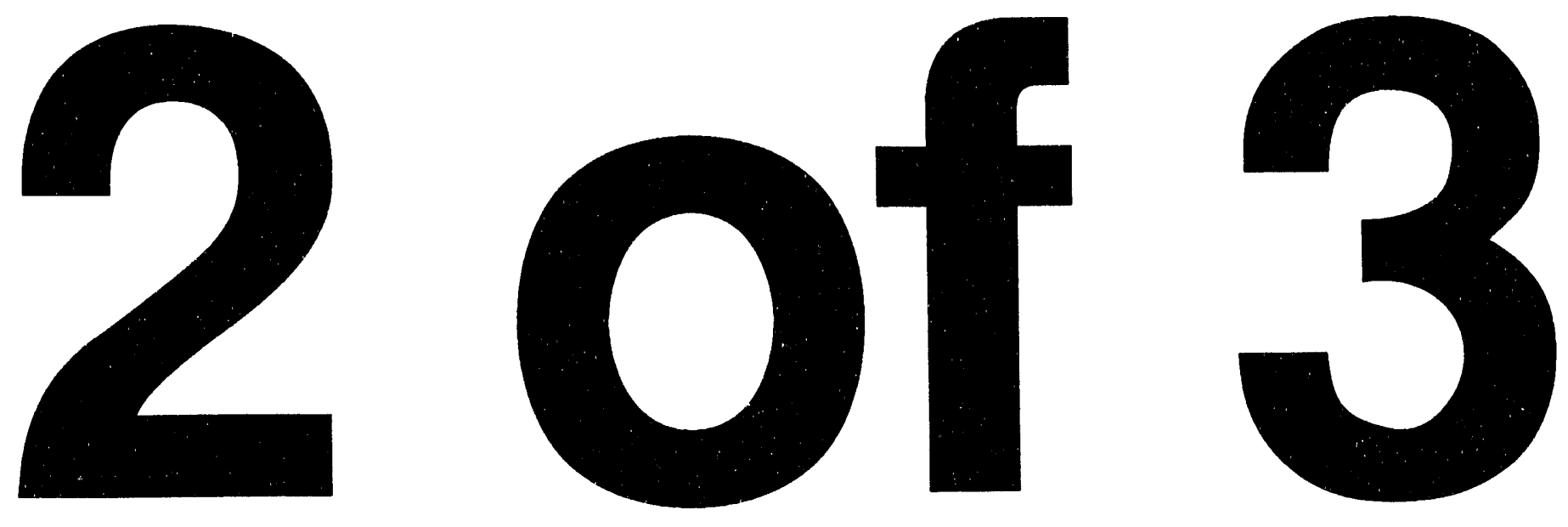


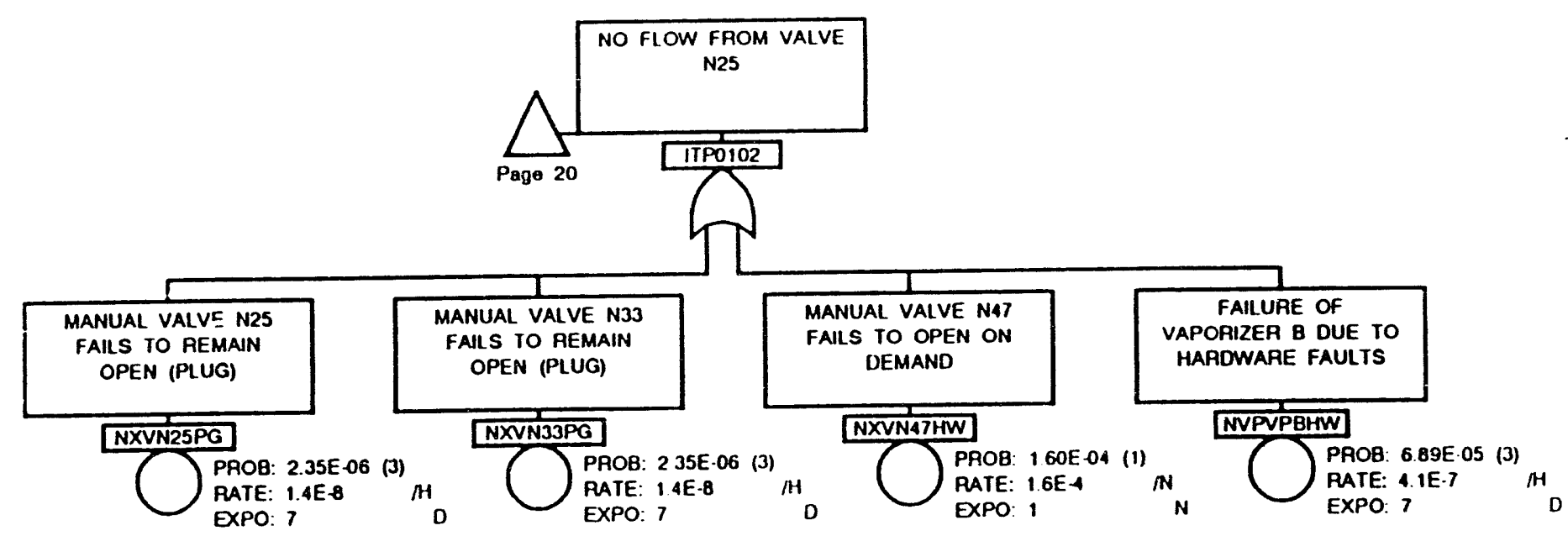

\begin{tabular}{|c|c|}
\hline \multirow{2}{*}{\multicolumn{2}{|c|}{$\begin{array}{l}\text { DEFLAGRATION OCCURS } \\
\text { IN ITP TANK } 48 \text { OR } 49\end{array}$}} \\
\hline & \\
\hline DRAWING & \\
\hline Page & $7-15-93$ \\
\hline
\end{tabular}




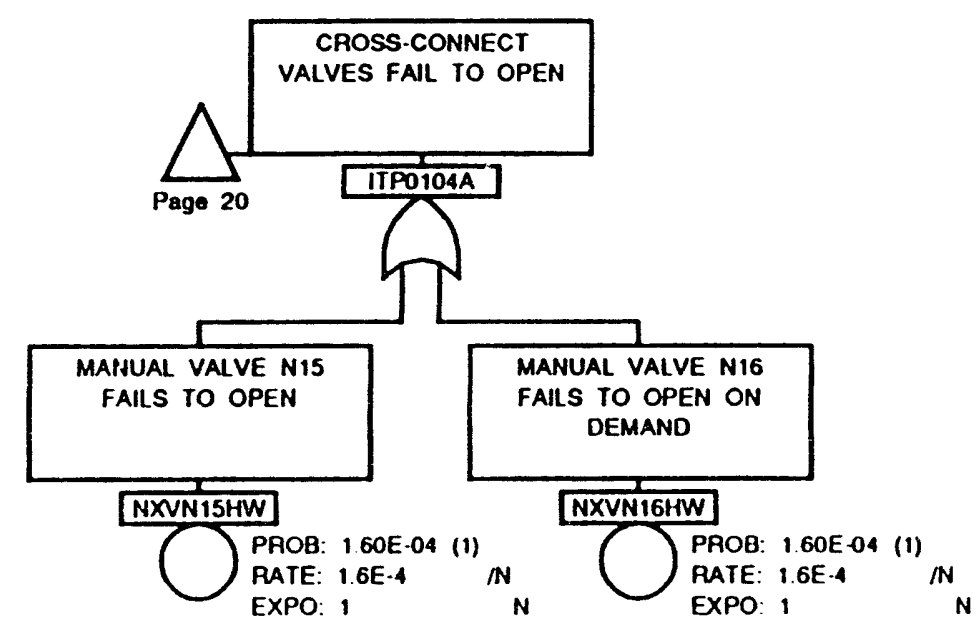

\begin{tabular}{|c|c|}
\hline \multicolumn{2}{|c|}{ DEFLAGRATION OCCURS } \\
\hline DFRAWING NUMBSEn & DAIE: \\
\hline Page 22 & $7-15-93$ \\
\hline
\end{tabular}




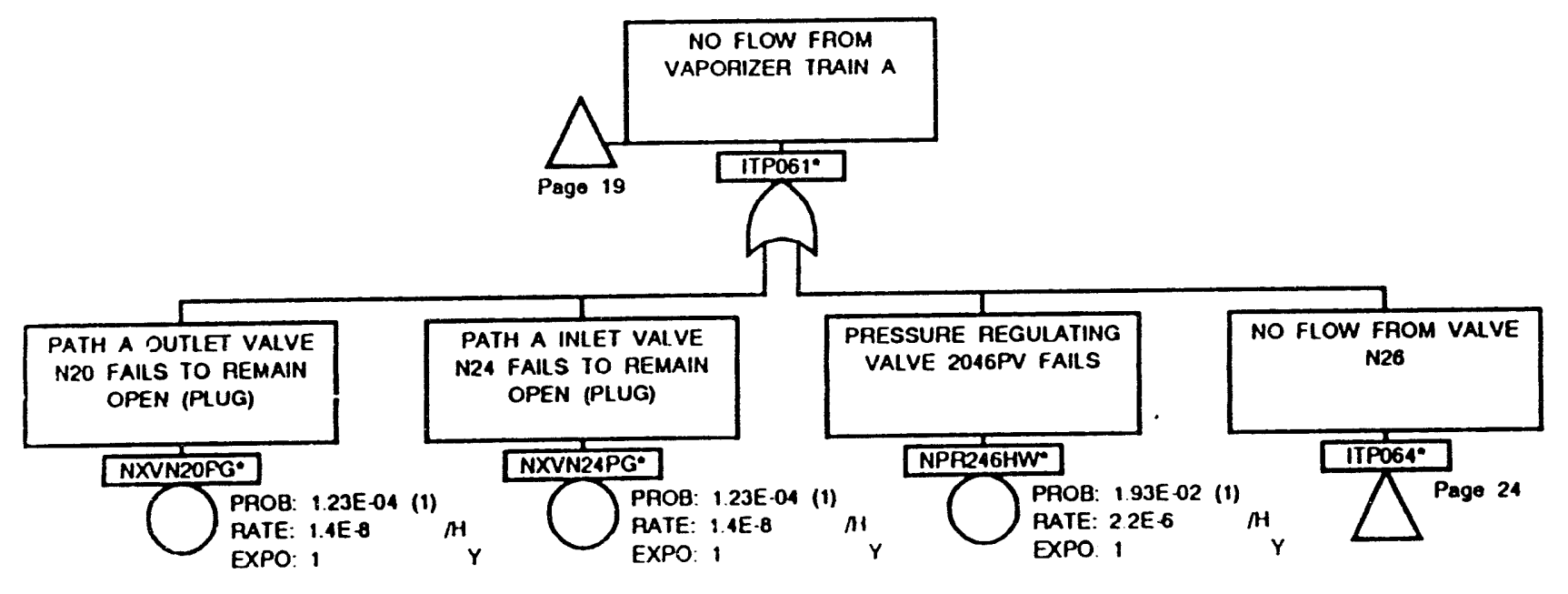

\begin{tabular}{|c|c|}
\hline \multicolumn{2}{|c|}{$\begin{array}{l}\text { IITLE } \\
\text { DEFLAGRATION OCCURS } \\
\text { IN ITP TANK } 48 \text { OR } 49\end{array}$} \\
\hline DHAWING NUMBEER & \\
\hline Page,23 & $7-15-93$ \\
\hline
\end{tabular}




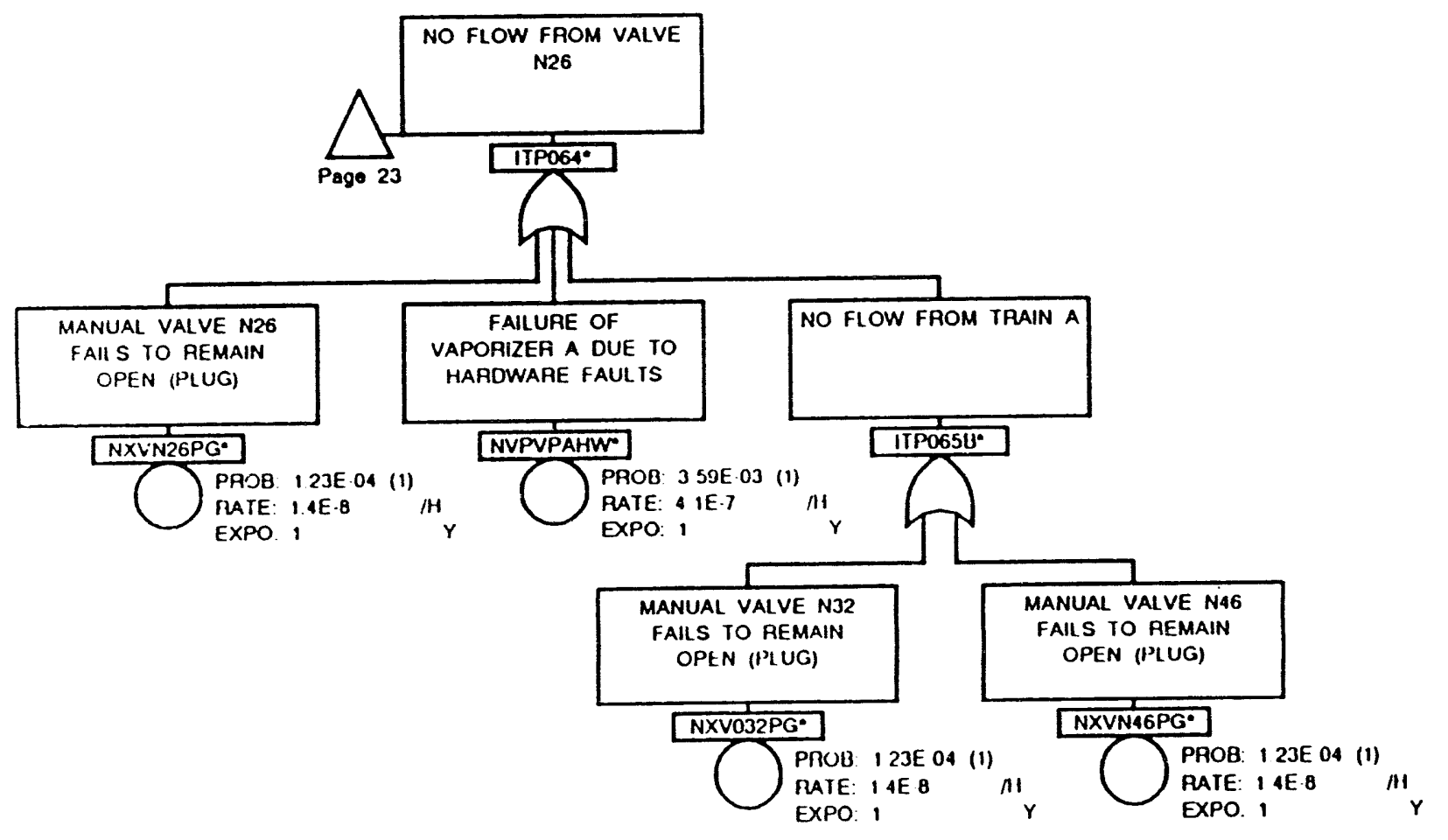

\begin{tabular}{|l|l|}
\hline TITLE \\
DEFLAGRATION OCCURS \\
IN ITP TANK 48 OR 49 \\
\hline $\begin{array}{l}\text { DRAWING NUMBER } \\
\text { Page } 24\end{array}$ \\
\hline
\end{tabular}




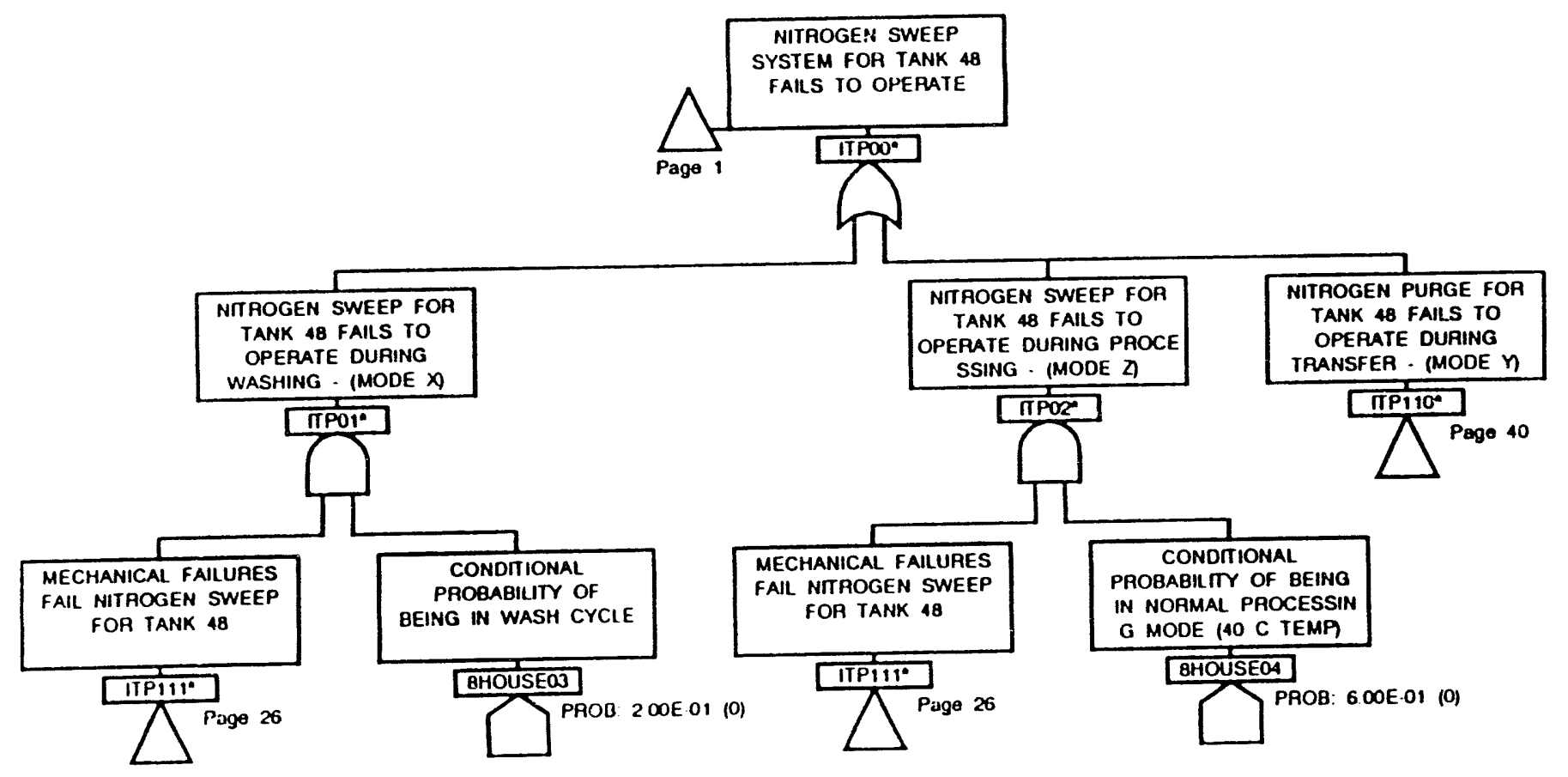

\begin{tabular}{|l|l|}
\hline TimLE \\
DEFLAGRATION OCCURS \\
IN ITP TANK 48 OR 49 \\
\hline Drawing NuMBER & DATE \\
Page 25 & $7-15-93$ \\
\hline
\end{tabular}




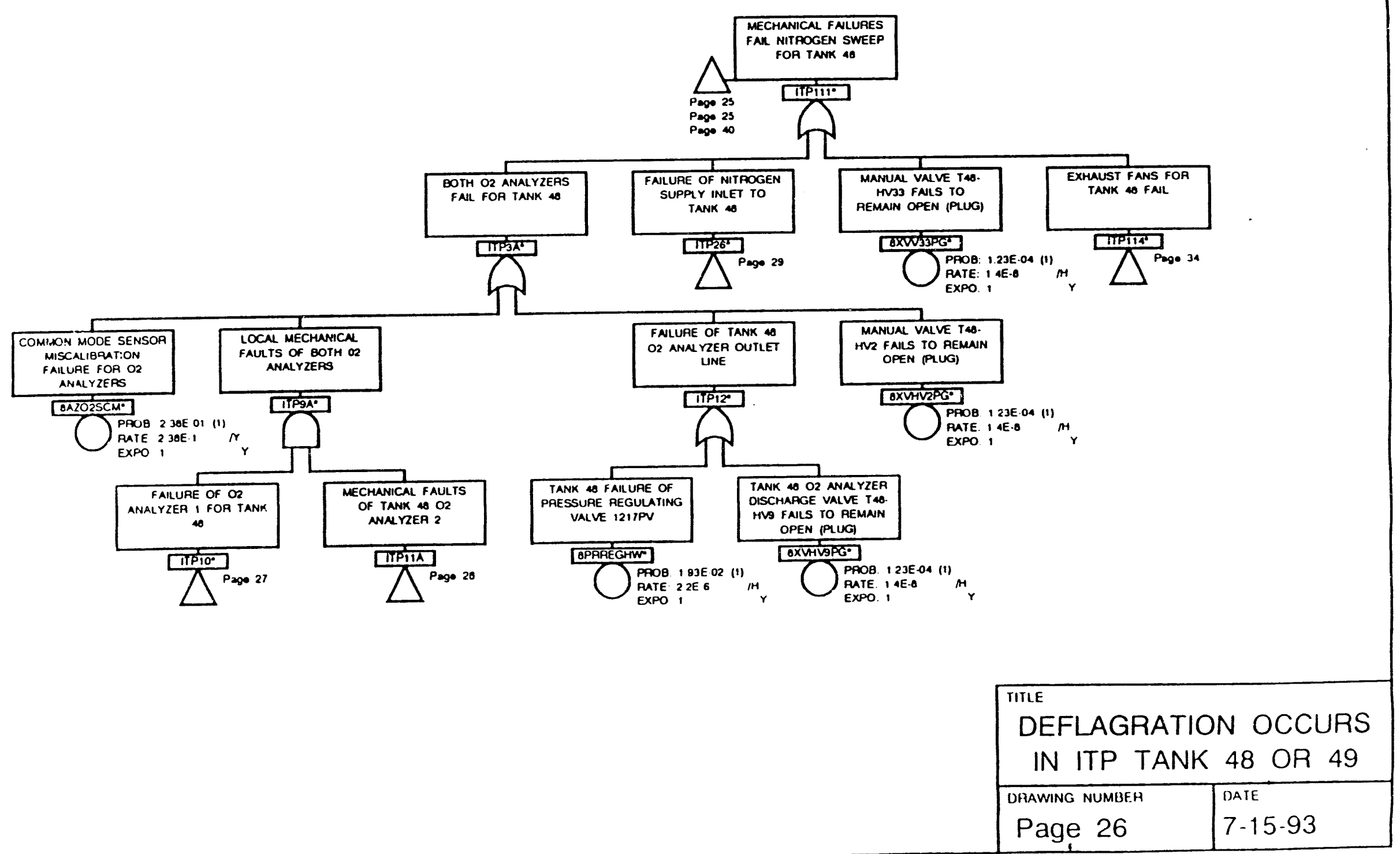




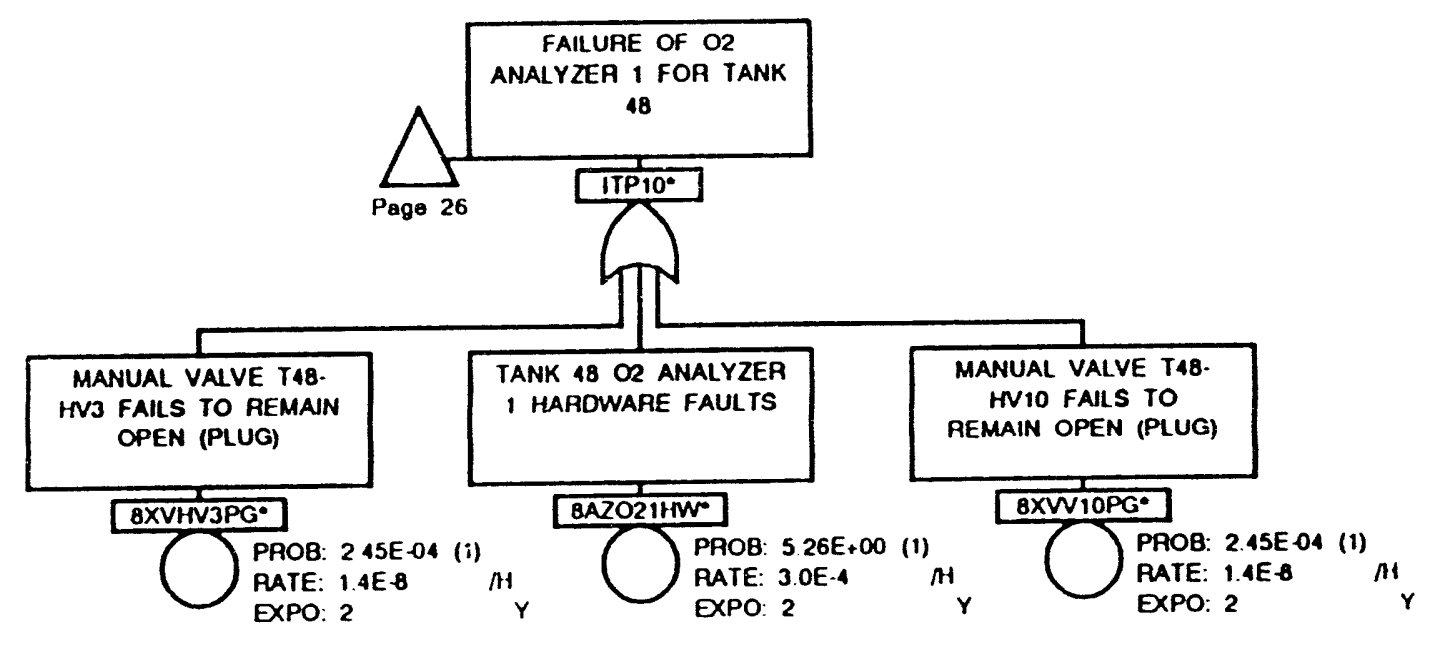

\begin{tabular}{|l|l|}
\hline IIILE \\
DEFLAGRATION OCCURS \\
IN ITP TANK 48, OR 49 \\
\hline Drawing NUMBLE & DAIE \\
Page 27 & $7-15-93$ \\
\hline
\end{tabular}




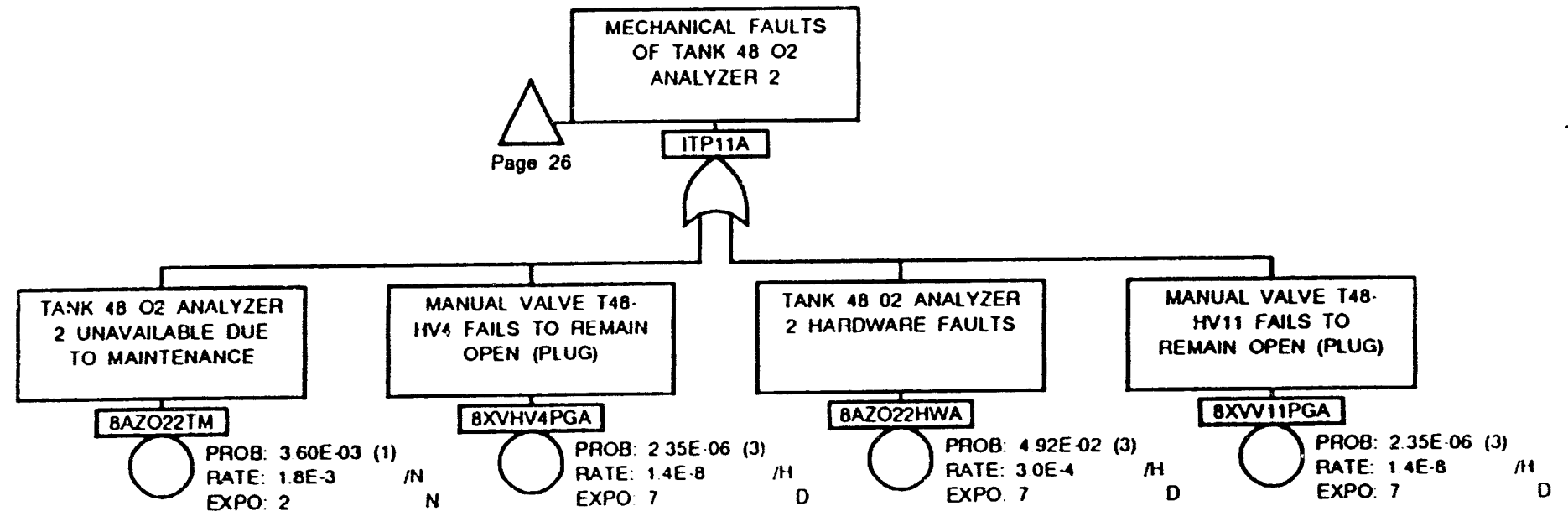

\begin{tabular}{|l|l|}
\hline TITLE \\
DEFLAGRATION OCCURS \\
IN ITP TANK 48 OR 49 \\
\hline DRAWING HUMBER & DATE \\
Page 28 & $7-15-93$ \\
\hline
\end{tabular}




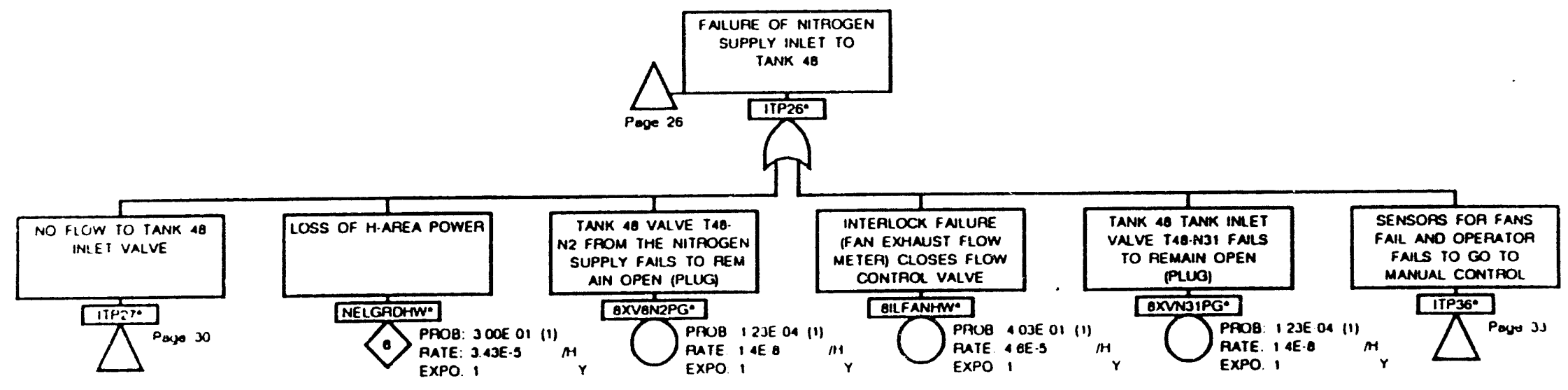

\begin{tabular}{|c|c|}
\hline $\begin{array}{l}\text { TiILE } \\
\text { DEFLAGR } \\
\text { IN ITP T }\end{array}$ & $\begin{array}{c}\text { N OCCURS } \\
48 \text { OR } 49\end{array}$ \\
\hline $\begin{array}{l}\text { DHRAWING NUMBIE" } \\
\text { Page } 29\end{array}$ & $\begin{array}{l}\text { DAIE } \\
7-15-93\end{array}$ \\
\hline
\end{tabular}




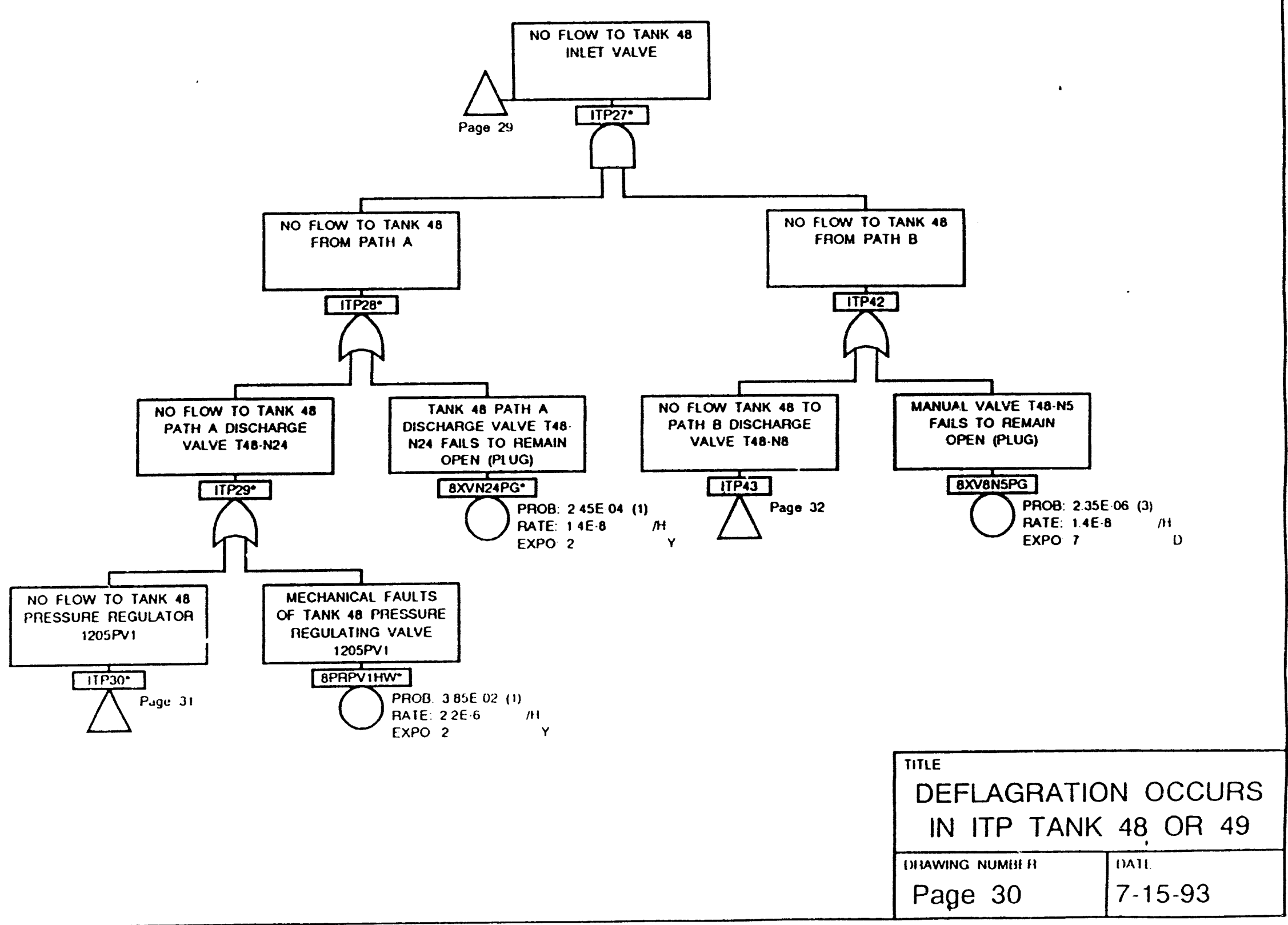




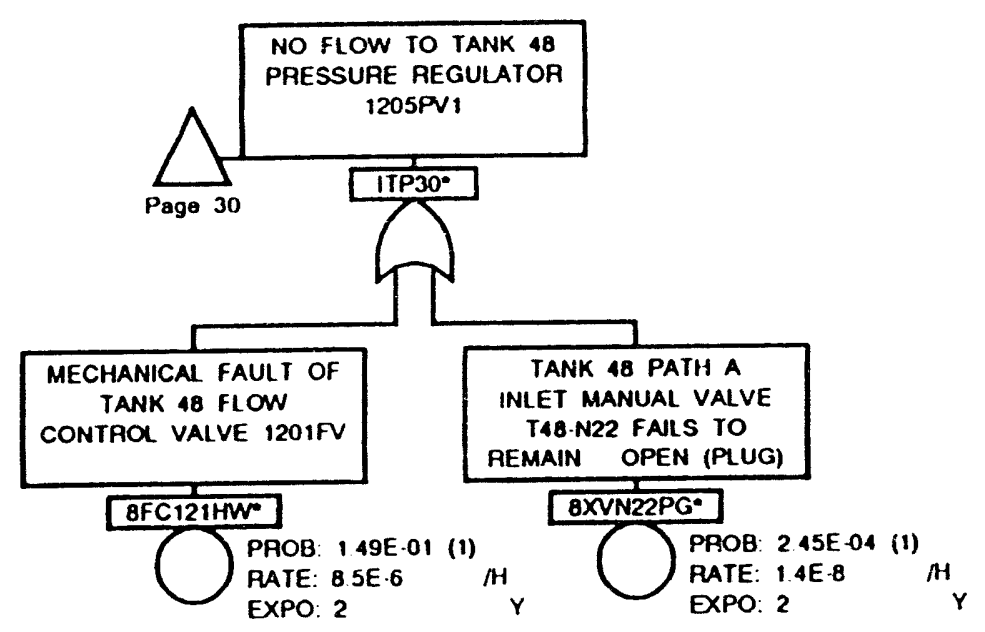

\begin{tabular}{|l|l|}
\hline TITLE \\
DEFLAGRATION OCCURS \\
IN ITP TANK 48 OR 49 \\
\hline DPAWING NUMBER & DATE \\
Page 31 & $7-15-93$ \\
\hline
\end{tabular}






\begin{tabular}{|l|l|}
\hline TirLE \\
DEFLAGRATION OCCURS \\
IN ITP TANK 48 OR 49 \\
\hline DHAWNG NUMBLA & DATL \\
Page 32 & $7-15-93$ \\
\hline
\end{tabular}




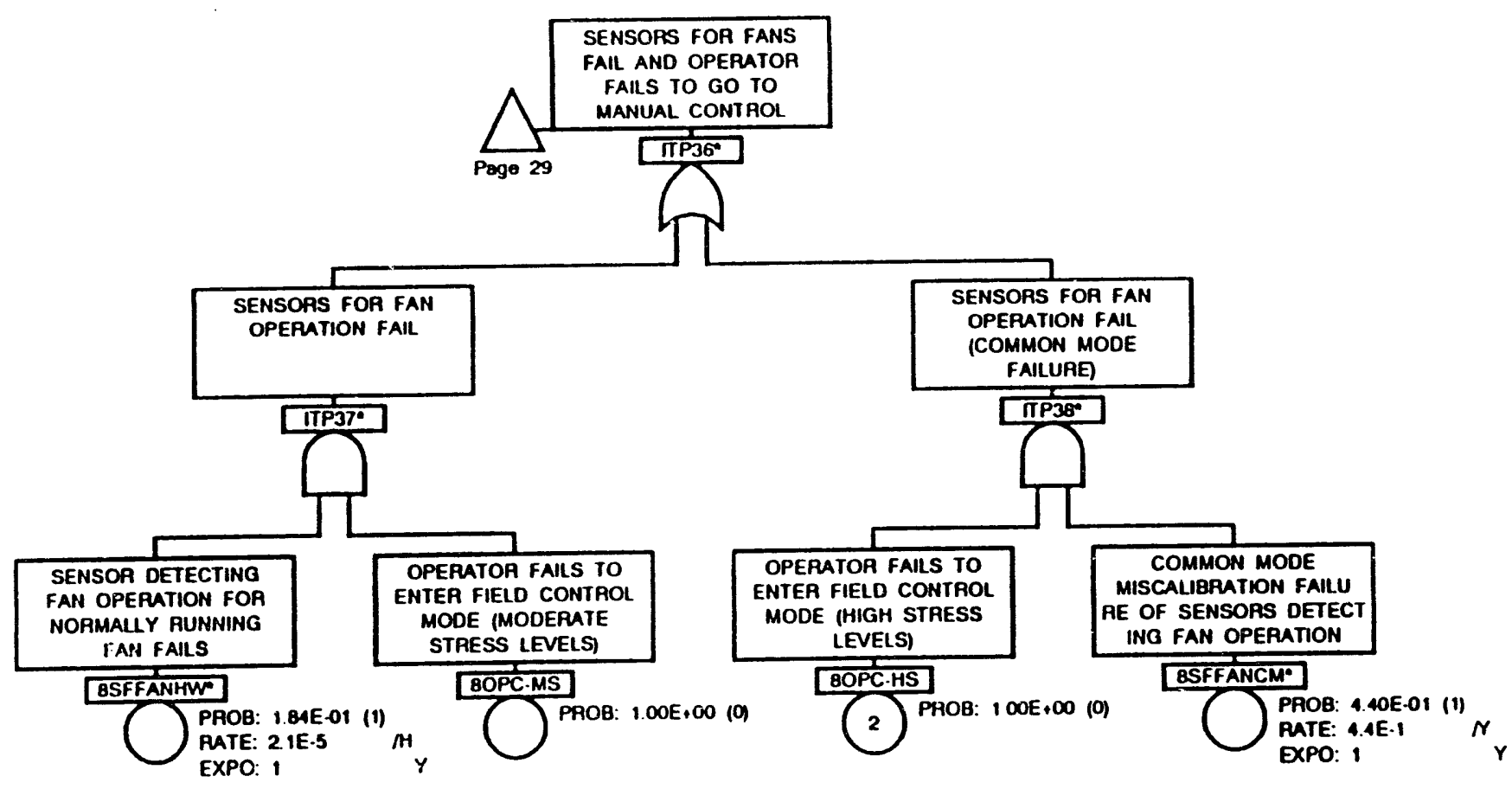

\begin{tabular}{|l|l|}
\hline TiTLE \\
DEFLAGRATION OCCURS \\
IN ITP TANK 48 OR 49 \\
\hline orawing NUMBER & DATE \\
Page 33 & $7-15-93$ \\
\hline
\end{tabular}




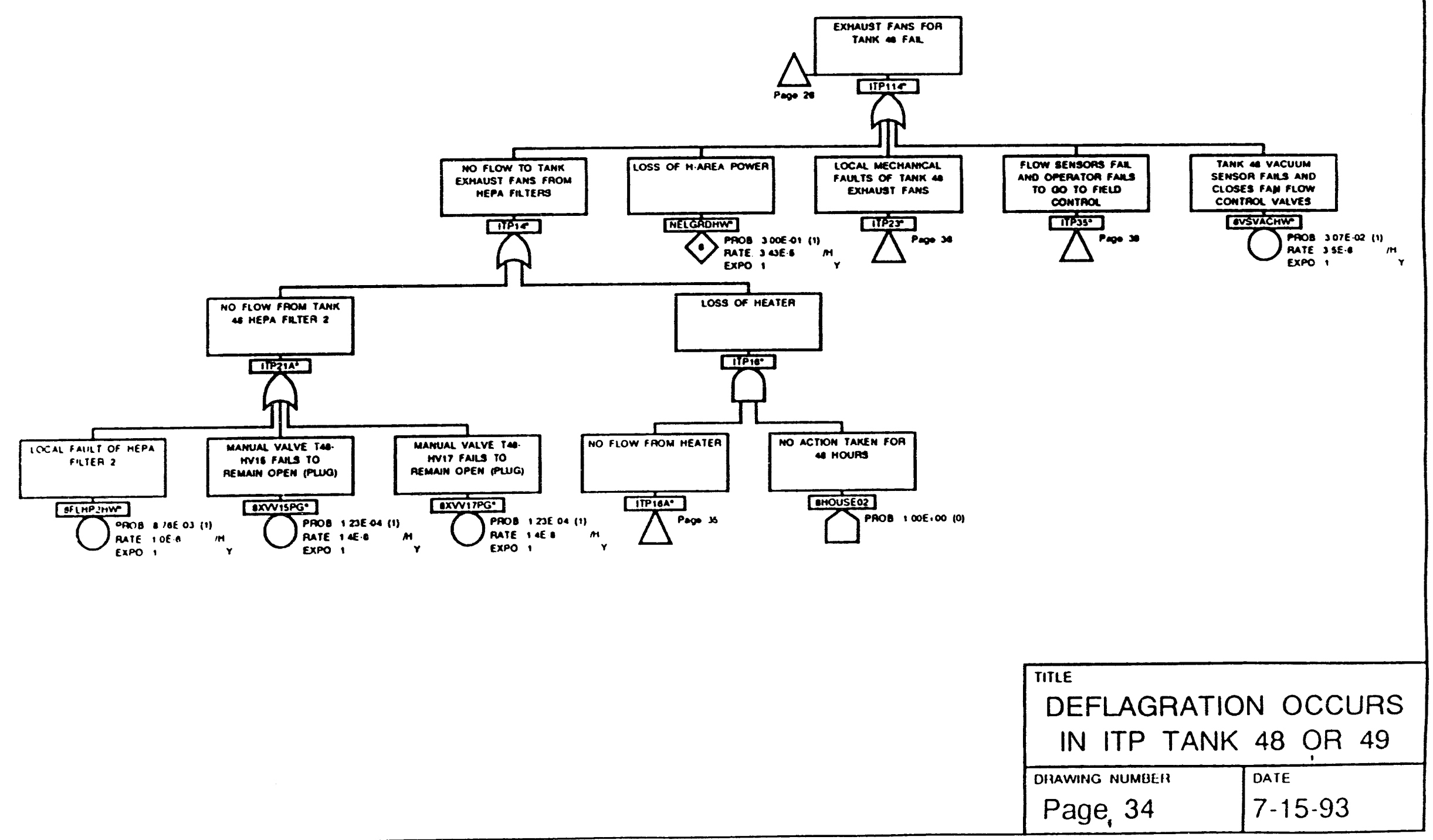









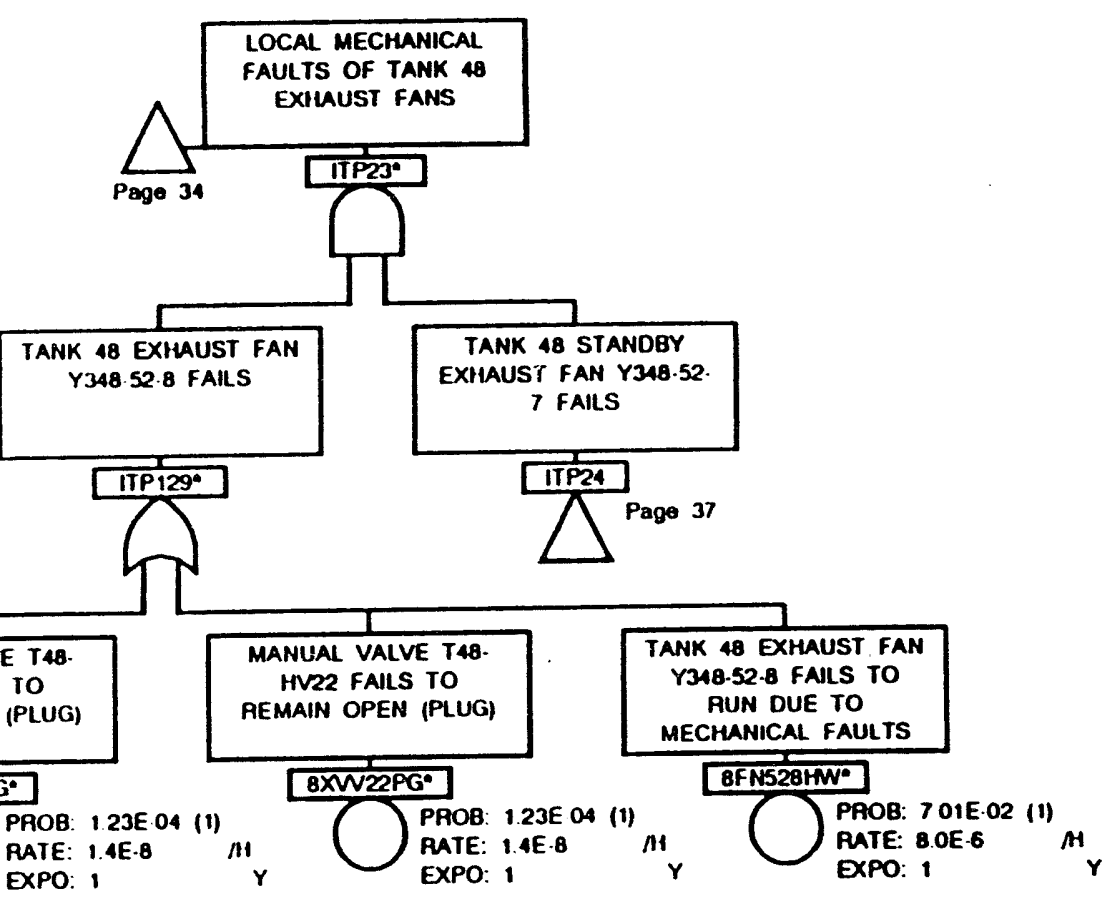

\begin{tabular}{|c|c|}
\hline \multicolumn{2}{|c|}{$\begin{array}{l}\text { DITE } \\
\text { DEFLAGRATION OCCURS } \\
\text { IN ITP TANK } 48 \text { OR } 49\end{array}$} \\
\hline $\begin{array}{l}\text { DRAWING NUMBER } \\
\text { Page } 36\end{array}$ & $\begin{array}{l}\text { DAIE } \\
7-15-93\end{array}$ \\
\hline
\end{tabular}




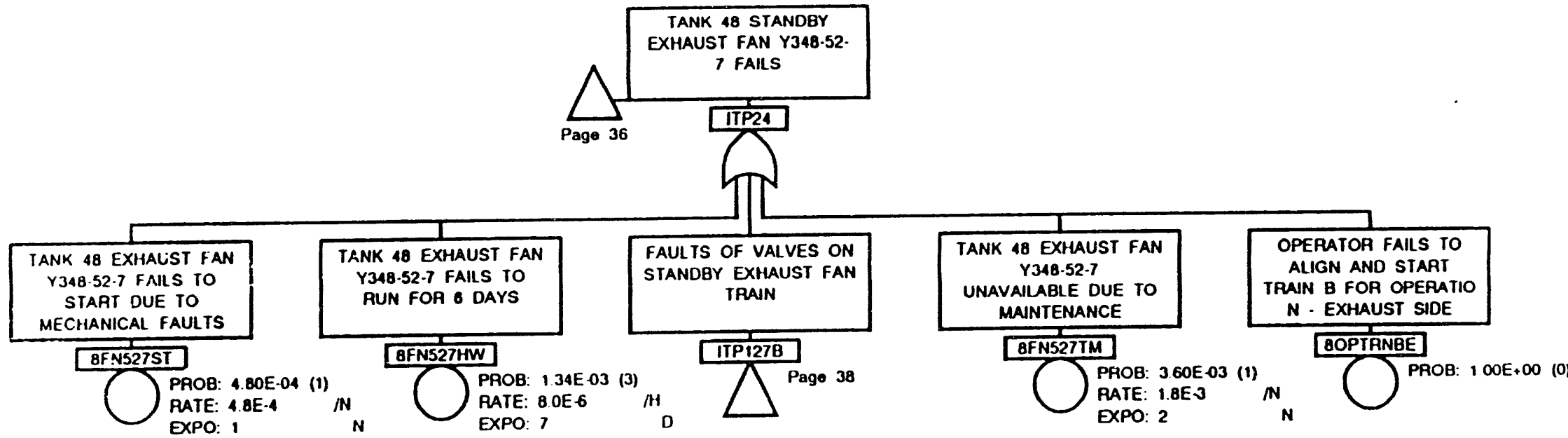

\begin{tabular}{|l|l|}
\hline \multicolumn{2}{|l|}{ ITILE } \\
DEFLAGRATION OCCURS \\
IN ITP TANK 48, OR 49 \\
\hline DRAWING NUMBER & DATE \\
Page 37 & $7-15-93$ \\
\hline
\end{tabular}




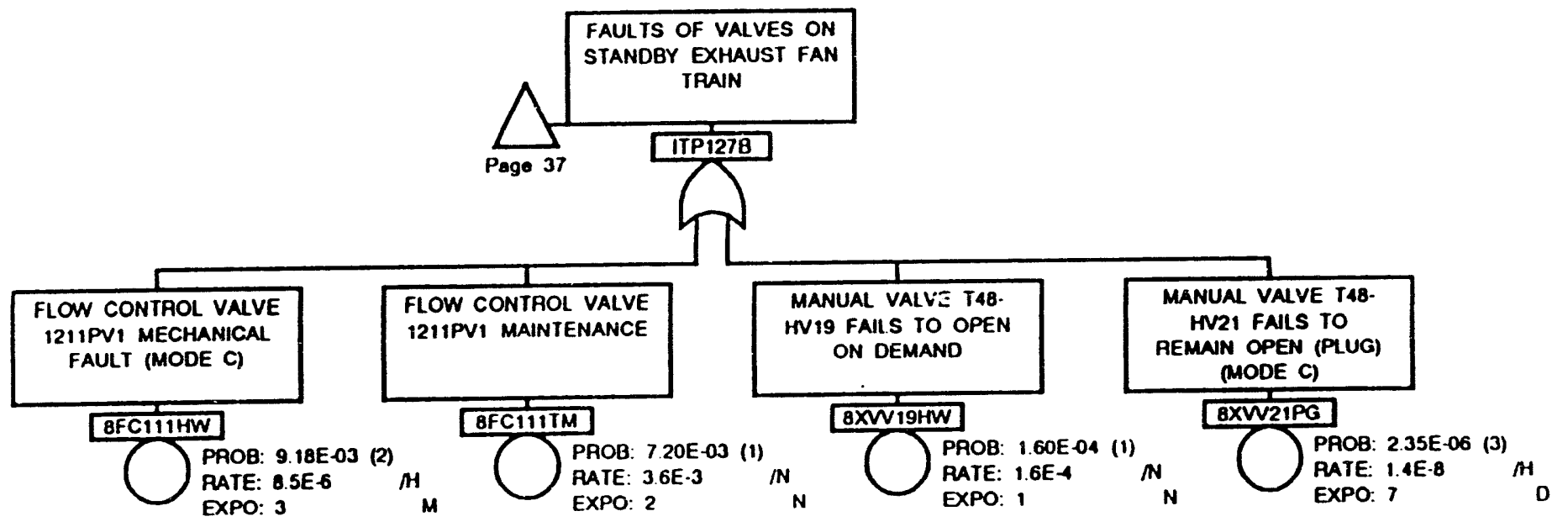

\begin{tabular}{l} 
TITLE \\
DEFLAGRATION OCCURS \\
IN ITP TANK 48, OR 49 \\
\hline \begin{tabular}{l|l|} 
DRAWING NUMnER & DATE \\
Page 38 & $7-15-93$ \\
\hline
\end{tabular}
\end{tabular}




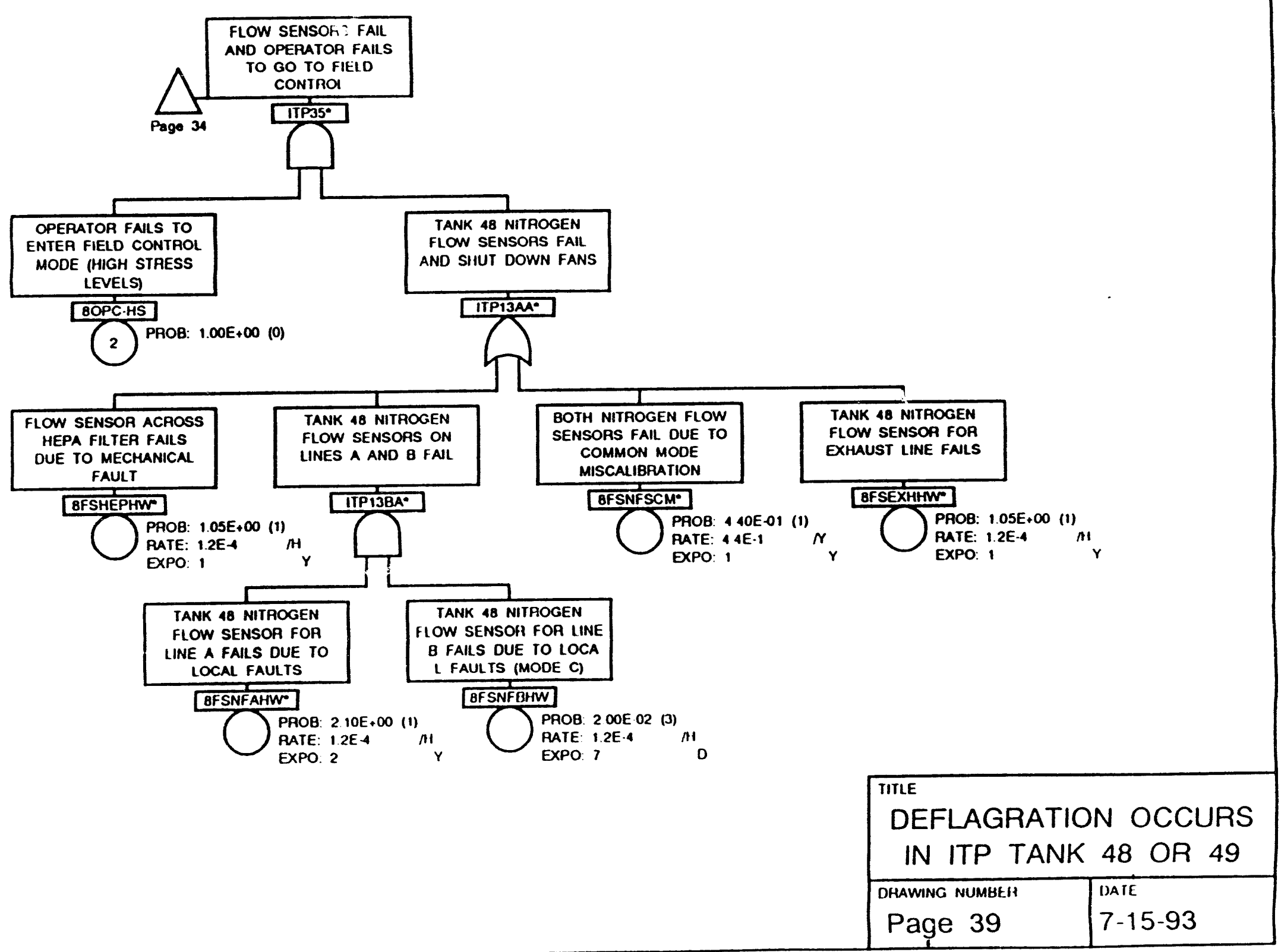




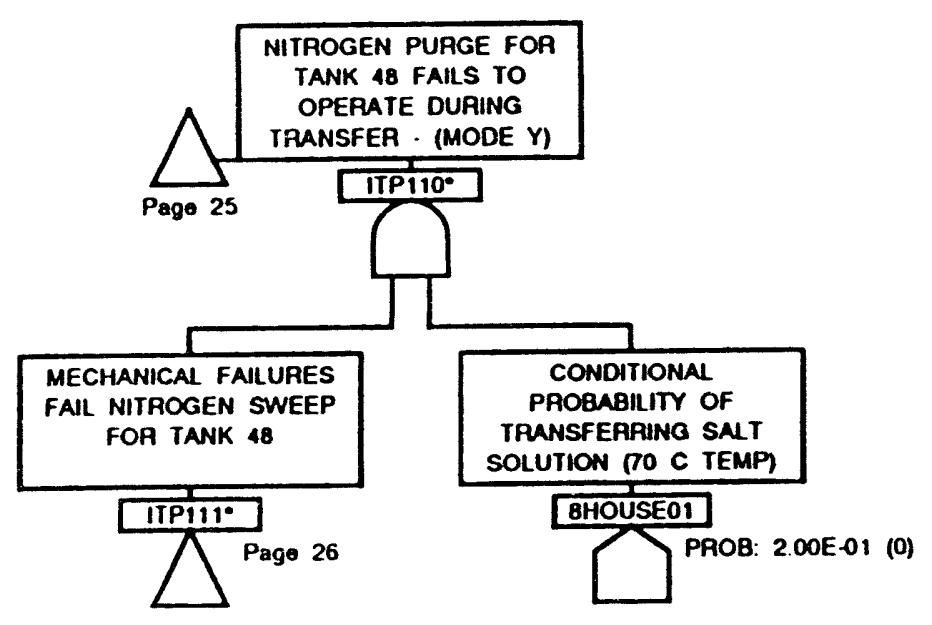

\begin{tabular}{|l|l|}
\hline TITLE \\
DEFLAGRATION OCCURS \\
IN ITP TANK 48, OR 49 \\
\hline $\begin{array}{l}\text { OHAWING NUMBEn } \\
\text { Page } 40\end{array}$ & DATE \\
\hline
\end{tabular}




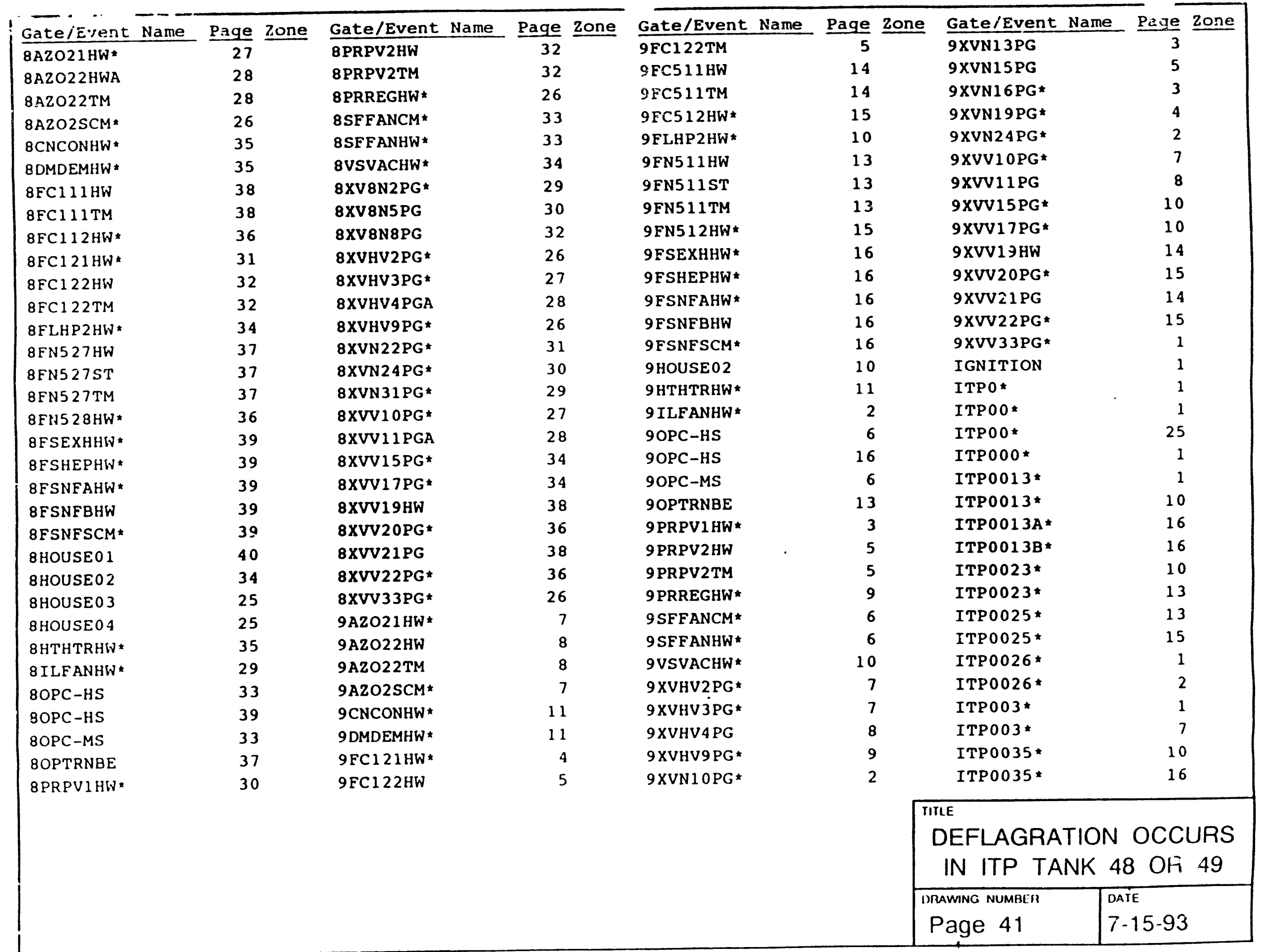




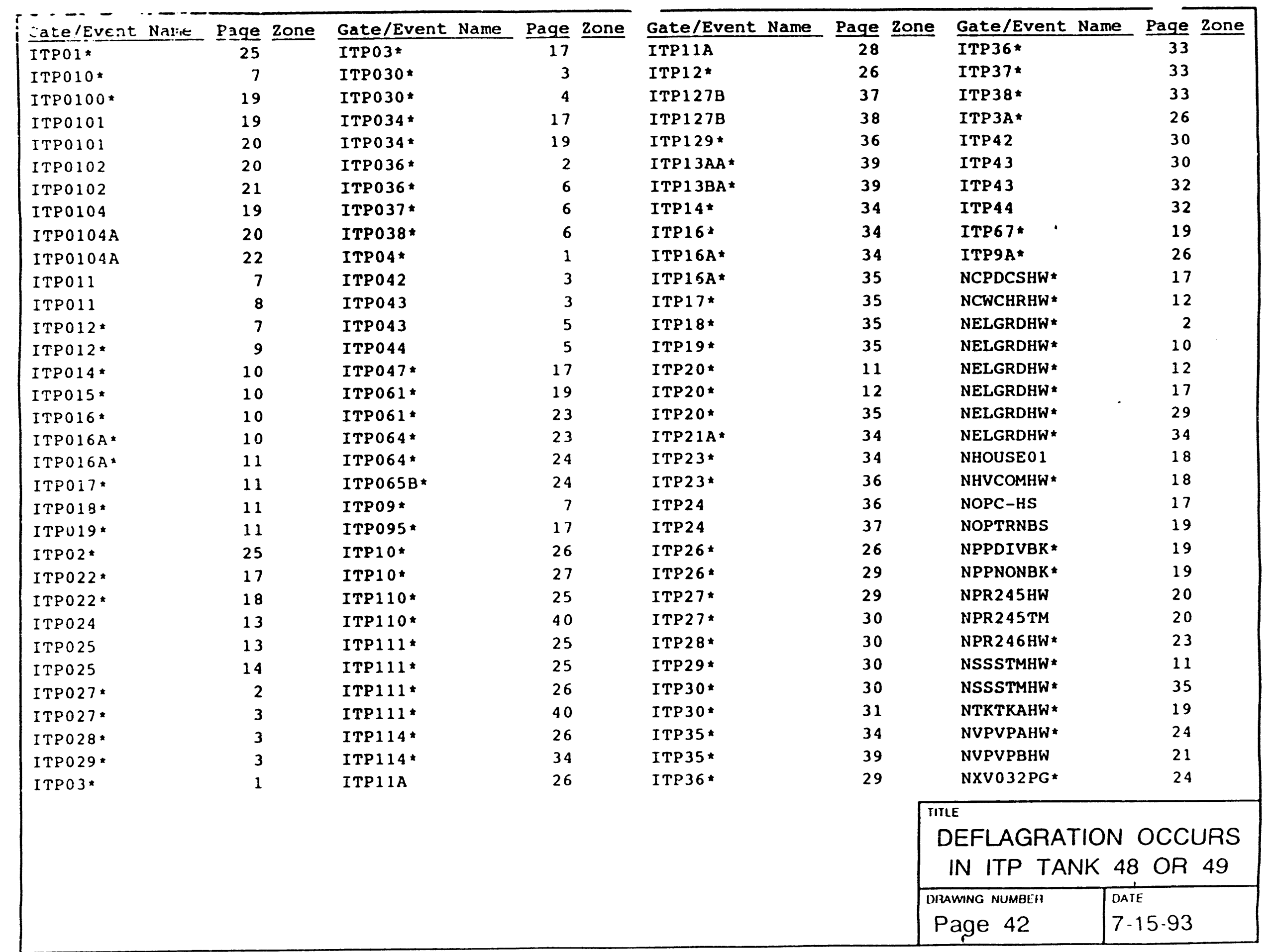



Gate/Event Name Page Zone NXVN1 2PG*

NXVN15 HW

NXVN $16 \mathrm{HW}$

NXVN1 8PG

NXVN2 OPG

20

NXVN 22 PG

23

20

NXVN24PG* 23

NXVN25PG 21

NXVN26PG * 24

NXVN33PG 21

NXVN46PG *

NXVN47HW 21

NXVN9 2PG * 19

\begin{tabular}{|c|c|}
\hline \multicolumn{2}{|c|}{ DEFLAGRATION OCCURS } \\
\hline IN ITP TANK & 48 OR 49 \\
\hline DHAWING NUMRER & \\
\hline Page 43 & $7-15-93$ \\
\hline
\end{tabular}




\section{APPENDICES B.1 AND B.2}

\section{CUTSETS FOR APPENDIX A FAULT TREE}

\section{APPENDIX B.1}

o Cutsets for Quantified Fault Tree (see Appendix A) without Recovery Actions or Repair Activities.

These cutsets represent the most probable failure combinations that would lead to a deflagration due to loss of the nitrogen purge system to either or both tanks coincident with the pressures of an ignition source if no operator recovery actions or repair activities are taken.

\section{APPENDIX B.2}

- Cutsets for Quantified Fault Tree (see Appendix A) with Recovery Actions and Repair Activities Included.

These cutsets are the same as those above but with recovery actions and repair activities included. After applying the recovery actions and/or repair activities, the cutsets are re-ordered based on probability in order to help identify the most critical system components. 


\section{APPENDIX B.1}

\section{CUTSETS FOR QUANTIFIED FAULT TREE}

\section{WITHOUT RECOVERY ACTIONS OR REPAIR ACTIVITIES}


1) ITPOOO*

1) SHOUSE02 IGNITION NSSSTMHW

2) 8HOUSE02 8HOUSEO4 IGNITION

3) 9FSEXHHW* 9OPC-HS IGNITION

4) 9FSHEPHW* 9OPC-HS IGNITION

5) IGNITION NCPDCSHW NOPC-HS

6) BESEXHHWBHOUSE 4 BOPC-HS

IGNITION

7) BESHEPHW 8 HOUSEO4 8OPC-HS IGNITION

8) 8HOUSEO 8 HOUSE03 IGNITION NSSSTMHW *

9) 8HOUSEOI 8 HOUSEO2 I GNITION NSSSTMHW*

101 9OPC-HS 9SEFANCM* IGNITION

11) 9ESNESCM 9OPC-HS

2) IGNITION IGNITION

3) 8ESNESCM 8 HOUSEO4 BOPC-HS IGNITION

14) BHOUSEO4
NO ACTION TAKEN FOR 48 HRS

CONDITIONAL PROBABILITY OF HAVING AN IGNITION SOURCE PRESENT LOSS OE STEAM SUPPLY TO HEATE

NO ACTION TAKEN FOR 48 HOURS

CONDITIONAL PROBABILITY OE BEING IN NORMAL PROCESSING MODE $140 \mathrm{C}$ CONDITIONAL PROBABILITY OF HAVING AN IGNITION SOURCE PRESENT LOSS OF STEAM SUPPLY TO HEATER

TANK 49 NITROGEN FLOW SENSOR FOR EXHAUST LINE FAILS

OPERATOR EAILS TO ENTER MODE C - FIELD CONTROL IHIGH STRESS LEVELS CONDITIONAL PROBABILITY OF HAVING AN IGNITION SOURCE PRESENT

ELOW SENSOR ACROSS HEPA FILTER FAILS DUE TO MECHANICAL FAUIT OPERATOR FAILS TO ENTER MODE C - FIELD CONTROL (HIGH STRESS LEVELS CONDITIONAL PROBABILITY OF HAVING AN IGNITION SOURCE PRESENT CONDITIONAL PROBABILITY OF HAVING AN IGNI

OPERATOR FAILS TO ENTER FIELD CONTROL MODE (HIGH STRESS LEVELS) TANK 48 NITROGEN ELOW SENSOR FOR EXHAUST IINE FAILS

TANK 48 NITROGEN FLOW SENSOR FOR EXHAST LINE EAILS MO MODE 140 CONDITIONAL PROBABILITY OF BEING IN NORTAL PROCESSING MODE $140 \mathrm{C}$ OPERATOR FAILS TO ENTER EIELD CONTNOL MODE (HGH STRESS LEVELSI CONDITIONAL PROBABILITY OF HAVING AN IGNITION SOURCE PRESENT

FLOW SENSOR ACROSS HEPA EILTER EAILS DUE TO MECHANICAL MADE $140 \mathrm{C}$ CONDITIONAL PROBABILITY OE BEING IN NORMAL PROCESSING MODE OPERATOR EAILS TO ENTER FIELD CONTROL MODE (HIGH STRESS LEVELS) CONDITIONAL PROBABILITY OF HAVING AN IGNITION SOURCE PRESENT NO ACTION TAKEN FOR 48 HOURS

CONDITIONAL PROBABILITY OE BEING IN WASH CYCLE

CONDITIONAL PROBABILITY OF HAVING AN IGNITION SOURCE PRESENT LOSS OF STEAM SUPPLY TO HEATER

CONDITIONAL PROBABILITY OF TRANSFERRING SALT SOLUTION $170 \mathrm{C}$ TEMP

NO ACTION TAKEN FOR 48 HOURS

CONDITIONAL PROBABILITY OF HAVING AN IGNITION SOURCE PRESENT LOSS OF STEAM SUPPLY TO HEATER

OPERATOR FAILS TO ENTER MODE C - FIELD CONTROL IHIGH STRESS LEVELS

COMMON MODE MISCALIBRATION FAILURE OE SENSORS DETECTING FAN OPERAT CONDITIONAL PROBABILITY OF HAVING AN IGNITION SOURCE PRESENT

CONDI TITROGEN BOTH NITROGEN FLOW SENSORS EAIL DUE TO COMON MODE MISCALIBRATION OPERATOR EAILS TO ENTER MODE C - FIELD CONTROL IHIGH STRESS LEVELS CONDITIONAL PROBABILITY OF HAVING AN IGNITION SOURCE PRESENT

INTERLOCK EAILURE IEAN EXHAUST ELOW METERI CLOSES FLOW CONTROL VA CONDITIONAL PROBABILITY OF HAVING AN IGNITION SOURCE PRESENT

BOTH NITROGEN FLOW SENSORS FAIL DUE TO COMMON MODE MISCALIBRATION CONDITIONAL PROBABILITY OE BEING IN NORMAL PROCESSING MODE $140 \mathrm{C}$ OPERATOR FAILS TO ENTER FIELD CONTROL MODE (HIGH STRESS LEVELS)

CONDITIONAL PROBABILITY OF HAVING AN IGNITION SOURCE PRESENT

CONDITIONAL PROBABILITY OF BEING IN NORMAL PROCESSING MODE $140 \mathrm{C}$

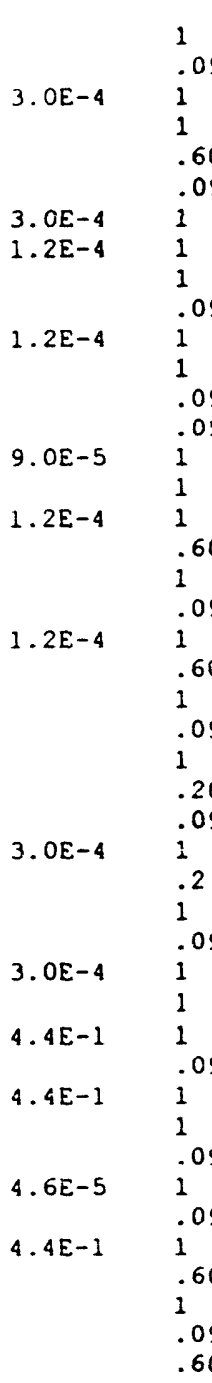
2.37E-01 $9.00 E-02$

$1.00 E+00 \quad 1.42 E-01$ $1.00 E+00$ $6.00 \mathrm{E}-01$

$9.00 E-02$

2. $63 E+00$

$1.05 E+00$

$1.00 E+00$

$9.00 \mathrm{E}-02$

$1.05 \mathrm{E}+00 \quad 9.46 \mathrm{E}-02$

$1.00 \mathrm{E}+00$

$9.00 \mathrm{E}-02$

9.00E-02 7.10E-02

$7.88 E-01$

$1.00 \mathrm{E}+00$

$1.05 \mathrm{E}+00 \quad 5.68 \mathrm{E}-02$

6. $00 \mathrm{E}-01$

1. $00 E+00$

$9.00 E-02$

$1.05 E+00 \quad 5.68 E-02$

$6.00 E-01$

$1.00 \mathrm{E}+00$

$1.00 E+00$

1. $00 E+00 \quad 4.73 E-02$

1. $00 \mathrm{E}+00$

2. $00 \mathrm{E}-01$

$9.00 \mathrm{E}-02$

$2.63 E+00$

2.00E-01

$1.00 E+00$

$9.00 \mathrm{E}-02$

$2.63 E+00$

$1.00 \mathrm{E}+00 \quad 3.96 \mathrm{E}-02$

4. $40 E-01$

$9.00 E-02$

4. $40 E-01 \quad 3.96 E-02$

$1.00 E+00$

$9.00 E-02$

$4.03 E-01 \quad 3.63 E-02$

$9.03 E-01$

$9.00 E-02$ 2. $38 \mathrm{E}-02$

$4.40 E-01$

$6.00 E-01$

$1.00 E+00$

6.00E-01 2.38E-02 
OPERATOR FAILS TO ENTER EIELD CONTROL MODE (HIGH STRESS LEVELS) COMMON MODE MISCALIBRATION EAILURE OF SENSORS DETECTING FAN TANK 49 O2 ANALYZER 1 HARDWARE EAULTS

$4.4 E-1$

3. $0 \mathrm{E}-4$

3. $0 \mathrm{E}-4$ YZRR 2 HARDWARE EAULTS

CONDITIONAI PROBABIIITY OF HAVING AN IGNITION SOURCE PRESENT CONDITIONAL PROBABILTY OF BEING IN NORMAL PROCESSING MODE $140 \mathrm{C} \mathrm{T}$ CONDITIONAL PROBABILITY OF BEING IN NORT ITL

6) 8HOUSE04 BILEANHW* IGNITION

7) $9 \mathrm{AZO2SCM}$

8) 9HOUSE02 IGNITION

BESEXHHW BESEXHHW
BHOUSE03 8OPC-HS IGNC-HS

20) BESHEPHW* 8HOUSE03 8OPC-HS IGNITION

2i) BFSHEPHW BHOUSEO1 8OPC-HS IGNITION

2) BESEXHHW 8HOUSE01 IGNITION

23) 9OPC-MS 9SFEANHW* IGNIT ION

24) $8 \mathrm{AZO} 21 \mathrm{HW}$ $8 \mathrm{AZO} 2 \mathrm{HWA}$ 8HOUSE04 IGNITION

25) $8 \mathrm{AZO} 2 \mathrm{SCM}$ BHOUSE 04 IGNITION NELGRDHW

27) BHOUSEC2 EHOUSE04 IGNITION
NCWCHRHW
CONDITIONAL PROBABILITY OF HAVING AN IGNITION SOURCE PRESENT COMMON MODE SENSOR MISCALIBRATION FAILURE FOR O2 ANALYZERS CONDITIONAL PKOBABILITY OF HAVING AN IGNITION SOI NO ACTION TAKEN FOR 48 HRS

CONDITIONAL PROBABILITY OE HAVING AN IGNITION SOURCE PRESENT MECHANICAL FAULTS IN CHROMATED COOLING WATER SYSTEM

TANK 48 NITROGEN FLOW SENSOR FOR EXHAUST LINE EAILS

CONDITIONAL PROBABILITY OF BEING IN WASH CYCLE

OPERATOR FAILS TO ENTER FIELD CONTROL MODE (HIGH STRESS LEVELS)

CONDITIONAL PROBABILITY OF HAVING AN IGNITION SOURCE PRESENT

CON SENSOR ACROSS HEPA FILTER FAILS DUE TO MECHANICAL FAULT

CONDITIONAI PROBABILITY OF BEING IN WASH CYCLE

CONDITIOR FAIUS TO ENTER FIEID CONTROL MODE (HIGH STRESS LEVELS)

OPERATOR EAJ LS TO ENTER F

FLOW SENSOR ACROSS HEPA FILTER EAILS

CONDITIONAL TROBABILITY OE TRANSAERRING SALT SOLUTION I TO C TEMPI

OPERATOR FAILS TO ENTER FIELD CONTROL MODE IHIGH STRESS LEVELSI

CONDITIONAL PROBABILITY OE HAVING AN IGNITION SOURCE PRESENT

TANK 48 NITROGEN FLOW SENSOR FOR EXHAUST LINE FAILS

(7) C TEMP)

OPERATOR FAILS TO ENTER FIELD CONTROL MODE (HIGH STRESS LEVELS

CONDITIONAL PROBABILITY OF HAVING AN IGNITION SOURCE PRESENT

OPERATOR FAILS TO ENTER MODE C - FIELD CONTROL (MODERATE STRESS LE SENSOR DETECTING FAN OPERATION FOR NORMALLY RUNNING FAN EAIL CONDITIONAL PROBABILITY OF HAVING AN IGNITION SOURCE PRESENT

TANK 48 O2 ANALYZER 1 HARDWARE FAULTS

TANK 4802 ANALYZER 2 HARDWARE FAULTS

CONDITIONAL PROBABILITY OF BEING IN NORMAL PROCESSING MODE $140 \mathrm{C}$

CONDITIONAL PROBABILITY OF HAVING AN IGNITION SOURCE PRESENT

COMMO MODE SENSOR MISCALIBRATION FAILURE FOR O2 ANALYZERS

COMMN MODE SENSOR MICCALIBRAING IN NORMAL PROCESSING MODE $140 \mathrm{C}$

CONDITIONAL PROBABILITY OE HAVING AN IGNITION SOURCE PRESENT

CONDITIONAL PROBABILIT

LOSS OF H-AREA POWER

CONDITIONAI PROBABILITY OF BEING IN NORMAL PROCESSING MODE $140 \mathrm{C} \mathrm{T}$

CONDITIONAL PROBABILITY OE BEING IN NORMAL PROCESSING MODE

CONDITIONAL PROBABILITY OF HAVING AN IGNITION SOURCE
MECHANICAL EAULTS IN CHROMATED COOLING WATER SYSTEM
CONDITIONAL PROBABILITY OF HAVING AN IGNITION SOURCE PRESENT

CONDITIONAL PROBABILITY OE HAVING AN IGNITION SOURCE PRESENT
4. $6 \mathrm{E}-5$

(1)

2. 38E-1

C.

2. $5 \mathrm{E}-5$

1. $2 E-4$

$\dot{1}$

$1.2 E-4$

1

$1.2 E-4$

i

1. $2 \mathrm{E}-4$

(1)

$2.1 E-5$

3. $0 E-4$

3. $O E-4$

.09

2. $38 \mathrm{E}-1 \quad 1$

.09

$3.43 E-5$

1

$2.5 E-5 \quad 1$
$1.00 E+00$

$4.40 E-01$

$9.00 \mathrm{E}-02$

. $26 E+00 \quad 2.33 E-02$

4. $92 \mathrm{E}-02$

$9.00 \mathrm{E}-02$

$6.00 \mathrm{E}-01 \quad 2.18 \mathrm{E}-02$

4. $03 \mathrm{E}-01$

$9.00 \mathrm{E}-02$

2.38E-01 2.14E-02

9. $00 \mathrm{E}-02$

$1.00 E+00 \quad 1.97 E-02$

9. $00 \varepsilon-02$

2.19E-01

$1.05 E+00 \quad 1.89 \mathrm{E}-02$

$2.00 E-01$

$1.00 E+00$

9. $00 \mathrm{E}-02$

$1.05 E+00 \quad 1.89 \mathrm{E}-02$

$2.00 E-01$

$1.00 E+00$

9.00E-02

$1.05 E+00 \quad 1.89 E-02$

$2.00 E-01$

$1.00 E+00$

$9.00 \mathrm{E}-02$

$1.05 \mathrm{E}+00$

$2.00 E-01$
$1.00 E+00$

$9.00 \mathrm{E}-02$

$1.005+00$

$1.00 E+00$

1.84E-01

$9.00 \mathrm{E}-02$

$5.26 E+00$
$4.92 E-02$

$6.00 E-01$

$9.00 \mathrm{E}-02$

$2.38 \mathrm{E}-01 \quad 1.29 \mathrm{E}-02$

$6.00 \mathrm{E}-01$

$9.00 \mathrm{E}-02$

$9.00 \mathrm{E}-02 \quad 2.70 \mathrm{E}-02$

3. $00 \mathrm{E}-01$

1. $00 \mathrm{E}+00$

$9.00 \mathrm{E}-02$

2.19E-01 

DESCRI PTION

28) 8HOUSE04 8OPC-MS BSEFANHW* IGNITION

29) 8HOUSEOI 8OPC-HS BSEFANCM+ IGNITION

30) 8HOUSE03 BOPC-HS 8SFEANCM* 8SFEANCM*

31) BFSNFSCM* BHOUSE 03 8OPC-HS

IGNITION
BESNESCM* 8 HOUSEO1 8OPC-HS IGNITION

33) 8HOUSE03 8ILEANHW* IGNITION

34) BHOUSEO1 8ILFANHW* IGNITION

35) $9 \mathrm{FC} 512 \mathrm{HW}^{*}$ 9OPTRNBE

36) 9ENS12HW* 9OPTRNBE IGNITION

37) $8 \mathrm{AZO21HW*}$ $8 \mathrm{AZO22HWA}$ BHOUSE03 IGNITION
8AZO21 HW*

38) $8 \mathrm{AZO21 \textrm {HW } *}$ 8AZO22HWA
8HOUSE01 IGNITION

39) $8 \mathrm{AZO2SCM}$ 8HOUSEO1 IGNITION

40) $8 \mathrm{AZO2SCM}$ * IGNITION
CONDITIONAL PROBABILITY OE BEING IN NORMAL PROCESSING MODE $140 \mathrm{CT}$ OPERATOR FAILS TO ENTER FIELD CONTROL MODE (MODERATE STRESS LEVEL
SENSOR DETECTING FAN OPERATION FOR NORMALLY RUNNING EAN EAILS SENSOR DETECTING EAN OPERATION FOR NORMALLY RUNNING EAN FAILS CONDITIONAL PROBABILITY OF HAVING AN IGNITION SOURCE PRESENT OPERATOR FAILS TO ENTER FIEID CONTROI MODE (HIGH STRESS LEVELS) COMMON MODE MISCALIBRATION FAILURE OE SENSORS DETECTING FAN OPERAT 4.4E CONDITIONAL PROBABILITY OF HAVING AN IGNITION SOURCE PRESENT CONDITIONAL PROBABILITY OE BEING IN WASH CYCLE

OPERATOR FAILS TO ENTER FIELD CONTROL MODE (HIGH STRESS LEVELS) COMMON MODE MISCALIBRATION FAILURE OF SENSORS DETECTING FAN OPERA CONDITIONAL PROBABILITY OF HAVING AN IGNITION SOURCE PRESENT

BOTH NITROGEN FLOW SENSORS FAIL DUE TO COMMON MODE MISCALIBRATION CONDITIONAL PROBABILITY OF BEING IN WASH CYCLE

OPERATOR FAILS TO ENTER EIELD CONTROL MODE (HIGH STRESS LEVELS) CONDITIONAI PROBABILITY OF HAVING AN IGNITION SOURCE PRESENT

CONDITIONAL PROBABILITY OE HAVING AN IGNITION SOURCE PRESENT BOTH NITROGEN FLOW SENSORS FAIL DUE TON COM SOLUTION $(70 \mathrm{C}$ TEMP) CONDITIONAL PROBABILITY OF TRANSFERRING SALT SOLUTION OPERATOR FAILS TO ENTER FIELD CONTROL MODE (HIGH STRESS LEVELSI

CONDITIONAL PROBABILITY OE HAVING AN IGNITION

CONDITIONAL PROBABILITY OE BEING IN WASH CYCLE CONDITIONAL PROBABILITY OF HAVING AN IGNITION SOURCE PRESENT

CONDITIONAL PROBABILITY OE TRANSFERRING SALT SOLUTION (70 C TEMP) INTERLOCK FAILURE (FAN EXHAUST FLOW METER) CLOSES FLOW CONTROL FLOW CONTROL VALVE 1251 PV2 MECHANICAL FAULT

OPERATOR FAILS TO ALIGN AND START TRAIN B FOR OPERATION - EXHAUST CONDITIONAL PROBABILITY OF HAVING AN IGNITION SOURCE PRESENT

TANK 49 EXHAUST FAN Y349-52-12 FAILS TO RUN DUE TO MECHANICAL EAUL OPERATOR FAILS TO ALIGN AND START TRAIN B FOR OPERATION - EXHAUST CONDITIONAL PROBABILITY OF HAVING AN IGNITION SOURCE PRESENT TANK 48 O2 ANALYZER I HARDWARE FAULTS TANK 48 O2 ANALYZER 1 HARDWARE EAULTS

TANK 4802 ANALYZER 2 HARDWARE EAULTS

CONDITIONAL PROBABILITY OF BEING IN WASH CYCLE TANK 48 O2 ANALYZER I HARDWARE FAULTS

TANK 4802 ANALYZER 1 HARDWARE FAULTS

CONDITIONAL PROBABILITY OF TRANSFERRING SALT SOLUTION (70 C TEMP)

CONDITIONAL PROBABILITY OF HAVING AN IGNITION SOURCE PRESENT

COMMON MODE SENSOR MISCALIBRATION EAILURE FOR O2 ANALYZERS

CONDITIONAL PROBABILITY OE TRANSFERRING SALT SOLUTION 170 C TEMP)

CONDITIONAL PROBABILITY OF HAVING AN IGNITION SOURCE PRESENT

COMMON MODE SENSOR MISCALIBRATION FAILURE FOR O2 ANALYZERS

CONDITIONAL PROBABILITY OF BEING IN WASH CYCLE

CONDITIONAL PROBABILITY OF HAVING AN IGNITION SOURCE PRESENT
B.E.

\begin{tabular}{|c|c|c|c|}
\hline \multirow{4}{*}{ RATE } & EXPOSURE & $\begin{array}{l}\text { B.E. } \\
\text { PROB. }\end{array}$ & $\begin{array}{l}\text { MOD. /CS. } \\
\text { PROB. }\end{array}$ \\
\hline & $-\cdots$ & --- & $\cdots$ \\
\hline & .60 & $6.00 E-01$ & $9.93 E-03$ \\
\hline & 1 & $1.00 E+00$ & \\
\hline \multirow[t]{4}{*}{$2.1 \mathrm{E}-5$} & 1 & $1.84 \mathrm{E}-01$ & \\
\hline & .09 & $9.00 \mathrm{E}-02$ & \\
\hline & .2 & $2.00 E-01$ & $7.92 E-03$ \\
\hline & 1 & $1.00 E+00$ & \\
\hline \multirow[t]{4}{*}{$4.4 E-1$} & 1 & $4.40 E-01$ & \\
\hline & .09 & $9.00 \mathrm{E}-02$ & \\
\hline & .20 & $2.00 E-01$ & $7.92 E-03$ \\
\hline & 1 & $1.00 E+00$ & \\
\hline \multirow{2}{*}{ 4. $4 E-1$} & 1 & $4.40 E-01$ & \\
\hline & .09 & $9.00 E-02$ & \\
\hline \multirow{4}{*}{ 4. $4 E-1$} & 1 & $4.40 E-01$ & $7.92 E-03$ \\
\hline & .20 & $2.00 E-01$ & \\
\hline & 1 & $1.00 E+00$ & \\
\hline & .09 & $9.00 \mathrm{E}-02$ & \\
\hline \multirow[t]{5}{*}{$4.4 E-1$} & 1 & $4.40 E-01$ & $7.92 \mathrm{E}-03$ \\
\hline & .2 & $2.00 \mathrm{E}-01$ & \\
\hline & 1 & $1.00 E+00$ & \\
\hline & .09 & $9.00 E-02$ & \\
\hline & .20 & $2.00 E-01$ & $7.25 \mathrm{E}-03$ \\
\hline \multirow[t]{3}{*}{$4.6 E-5$} & 1 & $4.03 E-01$ & \\
\hline & .09 & $9.00 E-02$ & \\
\hline & .2 & $2.00 E-01$ & $7.25 \mathrm{E}-03$ \\
\hline \multirow[t]{2}{*}{$4.6 E-5$} & 1 & $4.03 E-01$ & \\
\hline & .09 & $9.00 \mathrm{E}-02$ & \\
\hline \multirow[t]{3}{*}{$8.5 E-6$} & 1 & $7.45 \mathrm{E}-02$ & $6.70 \mathrm{E}-03$ \\
\hline & 1 & $1.00 E+00$ & \\
\hline & .09 & $9.00 \mathrm{E}-02$ & \\
\hline \multirow{3}{*}{$8.0 E-6$} & 1 & $7.01 \mathrm{E}-02$ & $6.31 E-03$ \\
\hline & 1 & $1.00 E+00$ & \\
\hline & .09 & $9.00 \mathrm{E}-02$ & \\
\hline $3.0 E-4$ & 2 & $5.26 E+00$ & $4.65 E-03$ \\
\hline \multirow[t]{3}{*}{$3.0 E-4$} & 7 & $4.92 \mathrm{E}-02$ & \\
\hline & .20 & $2.00 \mathrm{E}-01$ & \\
\hline & .09 & $9.00 \mathrm{E}-02$ & \\
\hline & 2 & $5.26 E+00$ & $4.65 E-03$ \\
\hline \multirow[t]{3}{*}{$3.0 \mathrm{E}-4$} & 7 & $4.92 E-02$ & \\
\hline & .2 & $2.00 E-01$ & \\
\hline & .09 & $9.00 \mathrm{E}-02$ & \\
\hline \multirow[t]{3}{*}{$2.38 E-1$} & 1 & $2.38 \mathrm{E}-01$ & $4.28 E-03$ \\
\hline & .2 & $2.00 E-01$ & \\
\hline & .09 & $9.00 \mathrm{E}-02$ & \\
\hline \multirow[t]{3}{*}{$2.38 E-1$} & 1 & $2.38 E-01$ & $4.28 E-03$ \\
\hline & .20 & $2.00 E-01$ & \\
\hline & .09 & $9.00 \mathrm{E}-02$ & \\
\hline
\end{tabular}



DESCRIPTION

41) $8 \mathrm{FCl12HW}$ 8HOUSE04 BOPTRNBE IGNITION

42) BHOUSE01 8HOUSE02 IGNITION

43) BHOUSE02 8 HOUSEO3 BHOUSE03 IGNITION

4) 8 FN528HW* BHOUSEO4 BOPTRNBE IGNITION

45) 8HOUSEOI 8OPC-MS 8SEFANHW IGNITION

46) 8HOUSEO3 8OPC-MS BSFEANHW* IGNITION

47) 9DMDEMHW 9HOUSEO2 IGNITION

8) 9VSVACHW* IGNITION

9) 9CNCONHW 9HOUSE02

9FSNEAHW 9ESNFBHW 9OPC-HS IGNITION

51) 9PRREGHW IGNITION

52) IGNITION NOPTRNBS NPR2 $46 \mathrm{HW}^{*}$

53) 8 DMDEMHW BHOUSE02 8HOUSEO4

54) $9 \mathrm{AZO} 1 \mathrm{HW}$
FLOW CONTROL VALVE 1211 PV2 MECHANICAL EAULT

CONDITIONAL PROBABILITY OF BEING IN NORMAL PROCESSING MODE $140 \mathrm{C}$ OPERATOR FAILS TO ALIGN AND START TRAIN B FOR OPERATION - EXHAUST CONDITIONAL PROBABILITY OF HAVING AN IGNITION SOURCE PRESENT CONDITIONAL PROBABILITY OE TRANSFERRING SALT SOLUTION $(70 \mathrm{C}$ TEMP) NO ACTION TAKEN EOR 48 HOURS

CONDITIONAL PROBABILITY OF HAVING AN IGNITION SOURCE PRESENT MECHANICAL FAULTS IN CHROMATED COOLING WATER SYSTEM

NO ACTION TAKEN FOR 48 HOURS

CONDITIONAL PROBABILITY OF BEING IN WASH CYCLE

CONDITIONAL PROBABILITY OF HAVING AN IGNITION SOURCE PRESENT

MECHANICAL FAULTS IN CHROMATED COOLING WATER SYSTEM

TANK 48 EXHAUST EAN Y348-52-8 FAILS TO RUN DUE TO MECHANICAL FAUL CONDITIONAL PROBABILITY OF BEING IN NORMAL PROCESSING MODE $140 \mathrm{C}$ OPERATOR FAILS TO ALIGN AND START TRAIN B FOR OPERATION - EXHAUST CONDITIONAL PROBABILITY OF HAVING AN IGNITION SOURCE PRESENT CONDITIONAL PROBABILITY OF TRANSFERRING SALT SOLUTION $(70 \mathrm{C}$ TEMP) OPERATOR FAILS TO ENTER FIELD CONTROL MODE (MODERATE STRESS LEVELS SENSOR DETECTING FAN OPERATION FOR NORMALLY RUNNING FAN FAILS SONSOR DETECTING FAN OPERAT HAVING AN IGNITION SOURCE PRESENT CONDITIONAL PROBABIIITY OF BEING IN WASH CYCLE

OPERATOR FAIIS TOBILITY OF BEING IN WASH CYCLE SENSOR DETECT TNG FAN OPERATION FOR NORMALLY RUNNING FAN FAILS CONDITIONAL PROBABILITY OE HAVING AN IGNITION SOURCE PRESENT LOCAL FAULTS OF TANK 49 DEMISTER

NO ACTION TAKEN FOR 48 HRS

CONDITIONAL PROBABILITY OF HAVING AN IGNITION SOURCE PRESENT TANK 49 VACUUM SENSOR EAILS AND CLOSES EAN FLOW CONTROL VALVES CONDITIONAL PROBABILITY OF HAVING AN IGNITION SOURCE PRESENT LOCAL EAULTS OF TANK 49 CONDENSER

NO ACTION TAKEN FOR 48 HRS

CONDITIONAL PROBABILITY OF HAVING AN IGNITION SOURCE PRESENT CONK 4 NITROGEN FLOW SENSOR FOR LINE A FAILS DUE TO LOCAL EAULTS TANK 49 NITROGEN ELOW SENSOR FOR LINE A FAILS DUE TO LOCAL EAULTS TANK 49 NITROGEN FLOW SENSOR FOR LINE A EAILS DUE TO LOCAL EAULTS ORERATOR FATLS TO ENTER MODE C - EIELD CONTROL YHIGH STRESS LEV

TANK 49 FAILURE OE PRESSURE REGULATING VALVE 1257 PV

作 OPERATOR FAILS TO ALIGN TRAIN B FOR OPERATION - SUPPLY SIDE PRESSURE REGULATING VAI,VE 2046PV FAILS

LOCAL FAULTS OF TANK 48 DEMISTER

NO ACTION TAKEN EOR 48 HOURS

CONDITIONAL PROBABILITY OF BEING IN NORMAL PROCESSING MODE $140 \mathrm{C}$

CONDITIONAL PROBABILITY OF HAVING AN IGNITION SOURCE PRESENT

TANK 49 O2 ANALYZER I HARDWARE FAULTS $\begin{array}{lll} & \text { B.E. } & \text { MOD./CS. } \\ \text { RATE } & \text { EXPOSURE } & \text { PROB. } \\ \text { PROB. }\end{array}$

8. $5 E-6$

60

1

$i^{2}$

$2.5 E-5 \quad \frac{1}{1}$

$i^{09}$
1
.20

.09

2.5E-5 1

1

$7.45 \mathrm{E}-02$ $6.00 \mathrm{E}-01$ 1. $00 \mathrm{E}+00$ $9.00 \mathrm{E}-02$ 2. $00 \mathrm{E}-01$ 1. $00 \mathrm{E}+00$ 9. $00 \mathrm{E}-02$ 2. $19 E-01$ 1. $00 \mathrm{E}+00$ 2.00E-01 9.00E-02 $2.19 \mathrm{E}-01$ 7. $01 E-02$ $6.00 E-01$ 1. $00 E+00$ 9. $00 \mathrm{E}-02$ 2. $00 \mathrm{E}-01$

1. $00 E+00$

$1.00 E+00$

$1.84 \mathrm{E}-01$ $9.00 E-02$ 2. $00 \mathrm{E}-01$ 1. $00 \mathrm{E}+00$ 1. $84 \mathrm{E}-01$ $9.00 \varepsilon-02$

3. $15 E-02$

1. $00 \mathrm{E}+00$

9. $00 \mathrm{E}-02$

3. $07 \mathrm{E}-02$

9. $00 \mathrm{E}-02$

2. $63 E-02$

1. $00 \mathrm{E}+00$

9. $00 \mathrm{E}-02$

$2.10 E+00 \quad 3.78 E-03$

1. $00 \mathrm{E}+00$

9. $00 \mathrm{E}-02$

$1.93 E-02$

9. $00 \mathrm{E}-02$

$9.00 E-02$

$1.00 E+00$

$1.93 \mathrm{E}-02$

$3.15 E-02 \quad 1.70 E-03$

$1.00 E+00$

$6.00 E-01$

$9.00 \mathrm{E}-02$

$5.26 E+00 \quad 1.70 E-03$
$.02 E-03$

$.94 E-03$

3. $94 E-03$

3. $78 E-03$

$31 E-03$

3. $31 E-03$

$2.84 E-03$

$2.76 \mathrm{E}-03$

2. $37 E-03$

$1.73 E-03$

$1.73 E-03$ 
58) $8 \mathrm{FCl} 12 \mathrm{HW}^{*}$ BHOUSE 03 BOPTRNBE IGNITION

59) $8 \mathrm{FC} 112 \mathrm{HW} *$ 8HOUSE01 BOPTRNBE IGNITION

60) 8EN528HW* BHOUSE01 BOPTRNBE IGNITION

61) 8 EN528HW* BHOUSEO3 BOPTRNBE IGNITION

62) BFSNEAHW* BESNEBHW BHOUSEO4 BOPC-HS 8OPC-HS

63) BHOUSE04 BPRREGHW* IGNITION

64) $\mathrm{BAZO21HW}$ 8AZO22TM 8HOUSE 04 IGNITION
9 FLHP2HW

65) 9FLHP2HW *
IGNITION

66) 8 DMDEMHW BHOUSE 01 BHOUSE02

TANK 49 O2 ANALY2ER 2 UNAVAILABLE DUE TO MATNTEN

$1.8 E-3$

CONDITIONAL PROBABILITY OF BEING IN NORMAL PROCESSING MODE $140 \mathrm{C}$ TANK 48 VACUUM SENSOR FAILS AND CLOSES FAN FLOW CONTROL VALVES CONDITIONAL PROBABILITY OF HAVING AN IGNITION SOURCE PRESENT CONDITNAI PROBABILITY OF HAVING AN IGNITION SOURCE PRESEN CONDITIONAL PROBABILITY OE HAVING AN IGNITUNR BEING $>80 \mathrm{~F}$ CONDITIONAL PROBABILITY OE OUTSIDE TEMPERATURE OPERATOR FAILS TO ENTER FIELD CONTROL MODE (HIGH STRESS LEVELS) LOCAL EAULTS OF TANK 48 CONDENSER

NO ACTION TAKEN FOR 48 HOURS

CONDITIONAL PROBABILITY OF BEING IN NORMAL PROCESSING MODE $140 \mathrm{C}$ T CONDITIONAL PROBABILITY OF HAVING AN IGNITION SOURCE PRESENT

FLOW CONTROL VALVE 1211 PV2 MECHANICAL FAULT

CONDITIONAL PROBABILITY OE BEING IN WPSH CYCLE OPERATOR FAILS TO ALIGN AND START TRAIN B EOR ORERATION - EXHAU CONDITIONAL PROBABILITY OF HAVING ANA IGNTTON

CONDITIONAL PROBABILITY OF TRANSFERRING SALT SOLUTION $170 \mathrm{C}$ TEMP CONDITIONAL PROBABILITY OE TERNSERRING SALT SOLUTION (70 C TEMPI OPERATOR FAILS TO ALIGN AND START TRAIN B FOR ORERATION - EXHAUS

CONDITIONAL PROBABILITY OE HAVING AN IGNITION SOURCE PRESENT TANK 48 EXHAUST FAN Y348-52-8 FAILS TO RUN DUE TO MECHANICAL EAULT CONDITIONAI PROBABILITY OF TRANSFERRING SALT SOLUTION 70 C TEMPI OPERATOR FAILS TO ALIGN AND START TRAIN B FOR OPERATION - EXHAUST

CONDITIONAL PROBABILITY OF HAVING AN IGNITION SOURCE PRESENT TANK 48 EXHAUST FAN Y348-52-8 FAILS TO RUN DUE

CONDITIONAL PROBABILITY OE BEING IN WASH CYCLE OPERATOR FAILS TO ALIGN AND START TRAIN B FOR OPERATION - EXHAUST CONDITIONAL PROBABILITY OF HAVING AN IGNITION SOURCE PRESENT TANK 48 NITROGEN FLOW SENSOR FOR LINE A FAILS DUE TO LOCAL FAULTS TANK 48 NITROGEN FLOW SENSOR FOR LINE B FAILS DUE TO LOCAL EAULTS OPERATOR FAILS TO ENTER FIELD CONTROL MODE (HIGH STRESS LEVELS) CONDITIONAI PROBABILITY OF HAVING AN IGNITION SOURCE PRESENT

CONDITIONAI PROBABILITY OF BEING IN NORMAL PROCESSING MODE $140 \mathrm{C} \mathrm{T}$ TANK 48 FAILURE OF PRESSURE REGULATING VALVE 1217PV

CONK 8 FAIT PROBABIIITY OF HAVING AN IGNITION SOURCE PRESENT TANK 48 O2 ANAIYZER I HARDWARE EAULTS

TANK 48 O2 ANALYZER 2 UNAVAILABLE DUE TO MAINTENANCE

TANK 48 O2 ANALYER 2 UNAVATLABLE DUE TOMAINENANCE MODE $140 \mathrm{c}$ CONDITIONAL PROBABILITY OE BEING IN NORMALT PROCESTRE PRESENT CONDITIONAL PROBABILITY OE HAVING AN I

LOCAL EAULT OF TANK 4 TE HEA HAVING AN IGNITION SOURCE PRESENT LOA FAULTS OF TANK 48 DEMISTER

LOCAL FAULTS OE TANK 48 DEMTSTER NO ACTION TAKEN FOR 48 HOURS

\begin{tabular}{|c|c|c|c|}
\hline & & & \\
\hline & .60 & $6.00 \mathrm{E}-01$ & $1.66 \mathrm{E}-03$ \\
\hline $3.5 E-6$ & 1 & $3.07 E-02$ & \\
\hline & .09 & $9.00 E-02$ & \\
\hline & .09 & $9.00 \mathrm{E}-02$ & $1.58 \mathrm{E}-03$ \\
\hline & 0.125 & $1.25 E-01$ & \\
\hline $1.6 E-5$ & 1 & $1.40 E-01$ & \\
\hline & 1 & $1.00 E+00$ & \\
\hline $3.0 E-6$ & 1 & $2.63 E-02$ & $1.42 \mathrm{E}-03$ \\
\hline & 1 & $1.00 E+00$ & \\
\hline & .60 & $6.00 E-01$ & \\
\hline & .09 & $9.00 E-02$ & \\
\hline 8. $5 E-6$ & 1 & $7.45 E-02$ & $1.34 \mathrm{E}-03$ \\
\hline & .20 & $2.00 E-01$ & \\
\hline & 1 & $1.00 E+00$ & \\
\hline & .09 & $9.00 E-02$ & \\
\hline $8.5 E-6$ & 1 & $7.45 E-02$ & $1.34 E-03$ \\
\hline & .2 & $2.00 \mathrm{E}-01$ & \\
\hline & 1 & $1.00 \mathrm{E}+00$ & \\
\hline & .09 & $9.00 \mathrm{E}-02$ & \\
\hline $8.0 E-6$ & 1 & $7.01 E-02$ & $1.26 \mathrm{E}-03$ \\
\hline & .2 & $2.00 E-01$ & \\
\hline & 1 & $1.00 E+00$ & \\
\hline & .09 & $9.00 E-02$ & \\
\hline $8.0 E-6$ & 1 & $7.01 \mathrm{E}-02$ & $1.26 \mathrm{E}-03$ \\
\hline & .20 & $2.00 E-01$ & \\
\hline & 1 & $1.00 E+00$ & \\
\hline & .09 & $9.00 E-02$ & \\
\hline 1. $2 E-4$ & 2 & $2.10 E+00$ & $2.27 E-03$ \\
\hline $1.2 E-4$ & 7 & $2.00 \Sigma-02$ & \\
\hline & .60 & $6.00 E-01$ & \\
\hline & 1 & $1.00 E+00$ & \\
\hline & .09 & $9.00 E-02$ & \\
\hline & .60 & $6.00 E-01$ & $1.04 E-03$ \\
\hline $2.2 E-6$ & 1 & 1. $93 E-02$ & \\
\hline & .09 & $9.00 E-02$ & \\
\hline 3. $0 E-4$ & 2 & $5.26 E+00$ & $1.02 E-03$ \\
\hline $1.8 E-3$ & 2 & $3.60 E-03$ & \\
\hline & .60 & $6.00 E-01$ & \\
\hline & .09 & $9.00 E-02$ & \\
\hline $1.0 E-6$ & 1 & $8.76 E-03$ & $7.88 \mathrm{E}-24$ \\
\hline & .09 & $9.00 E-02$ & \\
\hline $6 E-6$ & 1 & $3.15 E-02$ & $5.68 E-04$ \\
\hline & .2 & $2.00 E-01$ & \\
\hline & & $1.00 E+00$ & \\
\hline
\end{tabular}

$7.45 \mathrm{E}-02$

. $00 \mathrm{E}-02$

$7.45 \mathrm{E}-02$

9. $00 \mathrm{E}-02$

$2.005-01$

$1.00 E+00$

.00E-02

2.01E-02

$1.00 E+00$

2. $00 \mathrm{E}-02$

$6.00 E-01$

$6.00 \mathrm{E}-01$

$26 E+00 \quad 1.02 E-03$

$6.00 E-01$

8.76E-03

3. $15 \mathrm{E}-02$

$1.00 E+00$

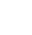


MODULE/EVENT NAME

IGNITION

67) 8DMDEMHW BHOUSE02 BHOUSEO3

IGNITION

68) BHOUSEOI BVSVACHW* IGNITION

69) BHOUSEO3 8VSVACHW*

IGNITION 8HOUSE02 8HOUSE0

1) BCNCONHW* BHOUSE01 8HOUSEO IGNITION

72) 8FLHP2HW* 8 HOUSE04 IGNITION

73) BFSNFAHW QESNEBHW QHOUSEO 8OPC-HS IGNITION

74) BESNFAHW* BESNFBHW BHOUSE03 8OPC-HS IGNITION

75) BHOUSEO3 BPRREGHW* IGNITION

76) BHOUSE01 OPRREGHW* IGNITION

77) BAZO21 HW* BAZO22TM 8HOUSEOI IGNITION

78) $8 \mathrm{AZO} 1 \mathrm{HW}$ BAZO22TM 8HOUSE0 3 IGNITION
Truncation Limit: $1.00 \mathrm{E}-08$

\section{DESCRIPTION}

CONDITIONAL PROBABILITY OE HAVING AN IGNITION SOURCE PRESENT LOCAL FAULTS OF TANK 48 DEMISTE

NO ACTION TAKEN FOR 48 HOURS

CONDITIONAL PROBABILITY OF BEING IN WASH CYCLE

CONDITIONAL PROBABILITY OF HAVING AN IGNITION SOURCE PRESENT CONDITIONAL PROBABILITY OF TRANSFERRING SALT SOLUTION $170 \mathrm{C}$ TEMP TANK 48 VACLUM SENSOR FAILS AND CLOSES FAN FLOW CONTROL VALVES CONDITIONAL PROBABILITY OF HAVING AN IGNITION SOURCE PRESENT CONDITIONAL PROBABILITY OF BEING IN WASH CYCLE

TANK 48 VACUUM SENSOR FAILS AND CLOSES FAN FLOW CONTROL VALVES CONDITIONAL PROBABILITY OF HAVING AN IGNITION SOURCE PRESENT LOCAL FAULTS OF TANK 48 CONDENSER

NO ACTION TAKEN FOR 48 HOURS

CONDITIONAL PROBABILITY OF BEING IN WASH CYCLE

CONDITIONAL PROBABILITY OF HAVING AN IGNITION SOURCE PRESENT LOCAI FAULTS OF TANK 48 CONDENSER

CONDITIONAL PROBABILITY OF TRANSFERRING SALT SOLUTION $(70 \mathrm{C}$ TEMP) NO ACTION TAKEN FOR 48 HOURS

CONDITIONAL PROBABILITY OF HAVING AN IGNITION SOURCE PRESENT LOCAI EAULT OF HEPA FILTER 2

CONDITIONAL PROBABILITY OF BEING IN NORMAL PROCESSING MODE $140 \mathrm{C} \mathrm{T}$

CONDITIONAL PROBABILITY OF HAVING AN IGNITION SOURCE PRESENT

TANK 48 NITROGEN FLOW SENSOR FOR LINE A FAILS DUE TO LOCAL FAULTS

TANK 48 NITROGEN ELOW SENSOR FOR LINE B FAILS DUE TO LOCAL FAULTS CONDITIONAL PROBABILITY OF TRANSFERRING SALT SOLUTION $170 \mathrm{C}$ TEMP) OPERATOR FAILS TO ENTER FIELD CONTROL MODE (HIGH STRESS LEVELSI

CONDITIONAL PROBABILITY OE HAVING AN IGNITION SOURCE PRESENT

TANK 48 NITROGEN FLOW SENSOR FOR LINE A EAILS DUE TO LOCAL FAULTS TANK 48 NITROGEN FLOW SENSOR FOR LINE B FAILS DUE TO LOCAL FAULTS CONDITIONAL PROBABILITY OE BEING IN WASH CYCLE

OPERATOR FAILS TO ENTER FIELD CONTROL MODE (HIGH STRESS LEVELS)

CONDITIONAL PROBABILITY OF HAVING AN IGNITION SOURCE PRESENT

CONDITIONAL PROBABILITY OF BEING IN WASH CYCLE

TANK 48 FAILURE OE PRESSURE REGULATING VALVE 1217 PV

CONDITIONAL PROBABILITY OF HAVING AN IGNITION SOURCE PRESENT

CONDITIONAL PROBABILITY OF TRANSFERRING SALT SOLUTION $170 \mathrm{C}$ TEMPI

TANK 48 FAILURE OF PRESSURE REGULATING VALVE 1217 PV

CONDITIONAI PROBABILITY OF HAVING AN IGNITION SOURCE PRESENT

TANK 48 O2 ANALYZER 1 HARDWARE FAULTS

TANK 48 O2 ANALYZER 2 UNAVAILABLE DUE TO MAINTENANCE

TANK 48 O2 ANALYZER 2 UNAVATLABLE DUE TO MATINTENANE

CONDITIONAL PROBABILITY OF TRANSFERRING SALT SOLUTION 170 C TEMP

CONDITIONAL PROBABILITY OF HAVING AN IGNITION SOURCE PRESENT

TANK 48 O2 ANALYZER 1 HARDWARE FAULTS

TANK $4 Q$ O2 ANALYZER 2 UNAVAILABLE DUE TO MU

CONDITIONAL PROBABILITY OF BEING IN WASH CYCLE

CONDITIONAL PROBABILITY OF HAVING AN IGNITION SOURCE PRESENT

\begin{tabular}{|c|c|c|c|}
\hline \multirow{2}{*}{ RATE } & EXPOSURE & $\begin{array}{l}\text { B.E. } \\
\text { PROB. }\end{array}$ & $\begin{array}{l}\text { MOD. /CS. } \\
\text { PROB. }\end{array}$ \\
\hline & $\ldots . . . .$. & $\ldots$ & $\ldots . . . .-$ \\
\hline \multirow{6}{*}{$3.6 E-6$} & .09 & $9.00 \mathrm{E}-02$ & \\
\hline & 1 & $3.15 E-02$ & $5.68 E-04$ \\
\hline & 1 & $1.00 E+00$ & \\
\hline & .20 & $2.00 \mathrm{E}-01$ & \\
\hline & .09 & $9.00 E-02$ & \\
\hline & .2 & $2.00 E-01$ & $5.52 \mathrm{E}-04$ \\
\hline \multirow[t]{3}{*}{$3.5 E-6$} & 1 & $3.07 E-02$ & \\
\hline & .09 & $9.00 E-02$ & \\
\hline & .20 & $2.00 \mathrm{E}-01$ & $5.52 E-04$ \\
\hline \multirow[t]{2}{*}{$3.5 E-6$} & 1 & $3.07 E-02$ & \\
\hline & .09 & $9.00 \mathrm{E}-02$ & \\
\hline \multirow[t]{4}{*}{$3.0 E-6$} & 1 & $2.63 E-02$ & $4.73 E-04$ \\
\hline & 1 & $1.00 E+00$ & \\
\hline & .20 & $2.00 E-01$ & \\
\hline & .09 & $9.00 \mathrm{E}-02$ & \\
\hline \multirow[t]{4}{*}{$3.0 E-6$} & 1 & $2.63 E-02$ & $4.73 E-04$ \\
\hline & .2 & $2.00 \mathrm{E}-01$ & \\
\hline & 1 & $1.00 E+00$ & \\
\hline & .09 & $9.00 \mathrm{E}-02$ & \\
\hline \multirow{2}{*}{$1.0 E-6$} & 1 & $8.76 E-03$ & $4.73 E-04$ \\
\hline & .60 & $6.00 E-01$ & \\
\hline & ;09 & $9.00 E-02$ & $7.55 E-04$ \\
\hline \multirow{4}{*}{$\begin{array}{l}1.2 E-4 \\
1.2 E-4\end{array}$} & 7 & $2.00 E-02$ & \\
\hline & .2 & $2.00 E-01$ & \\
\hline & 1 & $1.00 E+00$ & \\
\hline & .09 & $9.00 E-02$ & \\
\hline & 2 & $2.10 \mathrm{E}+00$ & $7.55 E-04$ \\
\hline \multirow[t]{5}{*}{$1.2 E-4$} & 7 & $2.00 \mathrm{E}-02$ & \\
\hline & .20 & $2.00 E-01$ & \\
\hline & 1 & $1.00 E+00$ & \\
\hline & .09 & $9.00 \mathrm{E}-02$ & \\
\hline & .20 & $2.00 E-01$ & $3.4 \% E-04$ \\
\hline \multirow[t]{3}{*}{$2.2 E-6$} & 1 & $1.93 E-02$ & \\
\hline & .09 & $9.00 E-02$ & \\
\hline & .2 & $2.00 E-01$ & $3.47 E-04$ \\
\hline \multirow{2}{*}{$2.2 E-6$} & 1 & $1.93 E-02$ & \\
\hline & .09 & $9.00 E-02$ & \\
\hline & 2 & $5.26 E+00$ & $3.41 E-04$ \\
\hline \multirow{3}{*}{$1.8 E-3$} & 2 & $3.60 E-03$ & \\
\hline & .2 & $2.00 E-01$ & \\
\hline & .09 & $9.00 E-02$ & \\
\hline \multirow{4}{*}{$\begin{array}{l}\text { 3. } 0 \mathrm{E}-4 \\
1.8 \mathrm{E}-3\end{array}$} & 2 & $5.26 E+00$ & $3.41 E-04$ \\
\hline & 2 & $3.60 E-03$ & \\
\hline & .20 & $2.00 E-01$ & \\
\hline & .09 & $9.00 \mathrm{E}-02$ & \\
\hline
\end{tabular}


79) IGNITION NOPTRNBS NVPVPAHW

80) 8FLHP2HW 8HOUSE0 3 IGNITION 8HOUSE01 IGNITION

82) 9 FC121 HW 9 PRPV 2TM

3FC121 HW 9 FC122TM IGNITION

84) 9FCSI1HW 9 FCS12HW

85) 8 FCI21 HW* 8 HOUSE 04 8PRPV2TM IGNITION

86) 8FC121 HW 8 FC122TM BHOUSEO4 IGNITION

87) $9 E C 511 \mathrm{HW}$ 9RN512HW* IGNITION

88) 9FC511TM 9FCSI2HW*

891 9 EC511TM 9EC511TM IGNITION

$90)$ BEC111HW $8 \mathrm{FCl1} 2 \mathrm{HW}$ 8HOUSEO4 IGNITION

91) $8 \mathrm{FC} 111 \mathrm{HW}$ BFN528HWBHOUSE04 IGNITION

92) 8 FC111TM 8 ECI1 $2 \mathrm{HW}$
3HOUSEO4
CONDITIONAI PROBABILITY OF HAVING AN IGNITION SOURCE PRESENT CNDTT OPERATOR EAILS TO ALIGN TRAIN B FOR ORERATION

LOCAL FAULT OF HEPA EILTER 2

CONDITIONAL PROBABILITY OF BEING IN WASH CYCLE

CONDITIONAL PROBABILITY OE HAVING AN IGNITION SOURCE PRESENT LOCAL GAULT PROBABILITY OE HAVI

CONDITIONAL PROBABILITY OF TRANSEERRING SALT SOLUTION $170 \mathrm{C}$ TEMP CONDITIONAL PROBABILITY OF HAVING AN IGNITION SOURCE PRESENT MECHANICAL EAULT OF TANK 49 FLON CONTROL VALVE $1251 \mathrm{FV}$

TANK 49 PRESSURE REGULATING VALVE. 1255PV2 UNAVAILABLE DUE TO MAINT $3.6 \mathrm{E}-3$ CONDITIONAL PROBABILITY OF HAVING AN IGNITION SOURCE PRESENT

MECHANICAL EAULT OF TANK 49 ELOW CONTROL VALVE $1251 \mathrm{FV}$

TANK 49 FLOW CONTROL VALVE $1252 \mathrm{FV}$ UNAVAILABLE DUE TO MAINTENANCE CONDITIONAI PROBABILITY OF HAVING AN IGNITION SOURCE PRESENT

FLOW CONTROL VALVE 1251 PVI MECHANICAL FAULT

FLOW CONTROL VALVE 1251 PV2 MECHANICAL FAULT

CONDITIONAL PROBABILITY OF HAVING AN IGNITION SOURCE PRESENT

MECHANICAL EAULT OF TANK 48 FLOW CONTROL VALVE $1201 F V$

MECHANICAL EAULT OE TANK 48 ELING IN NORMAL PROCESSING MODE $140 \mathrm{C} T$

CONDIT IAN

CONDITIONAL PROBABILITY OF HAVING AN IGN VION $1201 \mathrm{FV}$

MECHANICAL FAULT OF TANK 48 FLON CONTROL VALVE

TANK 48 FLOW CONTROL VALVE 1202 EN UNAVAILABLE DUE TO MAINTENANCE

CONDITIONAL PROBABILITY OF BEING IN NORMAL PROCESSING MODE $140 \mathrm{C}$

CONDITIONAL PROBABII

ELOW CONTROL VALVE 1251 PVI MECHANICAL EAULT CONDITIONAIAUST FAN Y349-52-12 EAILS TO RUN DUE TO MECHANICRI ELOW CONTROL VALVE 1251 PVI MAINTENANCE

FLOW CONTROL VALVE 1251 PV2 MECHANICAL FAULT

CONDITIONAL PROBABILITY OF HAVING AN IGNITION SOURCE PRESENT

FLOW CONTROL VALVE 1251 PVI MAINTENANCE

TANK 49 EXHAUST EAN Y349-52-12 EAILS TO RUN DUE TO MECHANICAL FAUL $\begin{aligned} & 3.6 E-3 \\ & 8.0 E-6\end{aligned}$ CONDITIONAL PROBABILITY OF HAVING AN IGNITION SOURCE PRESENT

FLOW CONTROL VALVE $1211 \mathrm{PVI}$ MECHANICAL FAULT (MODE C)

FLOW CONTROL VALVE 1211 PV2 MECHANICAL FAULT

CONDITIONAL PROBABILITY OF BEING IN NORMAL PROCESSING MODE $140 \mathrm{C} \mathrm{T}$

CONDITIONAL PROBABILITYY OE HAVING AN IGNITION SOURCE PRESENT

FLOW CONTROL VALVE 1211PVI MECHANICAL FAULT (MODE C)

TANK CONRL TO MECHANICAL FAULT 8.0E-6 CONDITIONAI PROBABILIT $\triangle$ OF BEING IN NORMAL PROCESSING MODE $140 \mathrm{C} \mathrm{T}$

CONDITIO PROBABIIITV OF HAVING AN IGNITION SOURCE PRESENT

CONDITINTL VALVE 1211 PVI MAINTENANCE

$3.6 \mathrm{E}-3$

$3.6 \mathrm{E}-3$
$8.5 \mathrm{E}-6$

CONTROL VALVE I2liPV2 MECHANICAL EAULT

CONDITIONAL PROBABILITY OF BEING IN NORMAL PROCESSING MODE $140 \mathrm{C} \mathrm{T}$
$9.00 E-02 \quad 3.23 E-04$

$1.00 E+00$

8. $76 E-03 \quad 1.58 E-04$

2. $00 \mathrm{E}-01$

$9.00 E-02$

8. $76 \mathrm{E}-03 \quad 1.58 \mathrm{E}-04$

$2.70 \mathrm{E}-01$

$2.00 E-01$

$1.49 E-01 \quad 9.65 E-05$

$1.49 E-01$

7. $20 \mathrm{E}-03$

$9.00 E-02$

$1.49 E-01$ 9.65E-05

. 20E-03

$9.00 E-02$

$9.18 E-03 \quad 6.15 E-05$

$7.45 \mathrm{E}-02$

$9.00 \mathrm{E}-02$

$1.49 E-01 \quad 5.79 E-05$

$6.00 E-01$

7. $20 \mathrm{E}-03$

9. $00 \mathrm{E}-02$

$1.49 E-01 \quad 5.79 E-05$

$7.20 E-03$

$6.00 E-01$

$9.00 \mathrm{E}-02$

9.18E-03 $5.79 E-05$

9.

9.01E-02

$9.00 E-02$

$4.83 \mathrm{E}-05$

$7.45 E-02$

$9.00 \mathrm{E}-02$

$7.20 E-03 \quad 4.54 E-05$

$9.00 \mathrm{E}-02$

$9.18 E-03 \quad 3.69 E-05$

7. $45 E-02$

$6.00 \mathrm{E}-01$

$9.00 E-02$

9.18E-03 $3.47 E-05$

7. $01 \mathrm{E}-02$

$6.00 E-01$

$9.00 E-02$

$7.20 E-03 \quad 2.90 E-05$

$7.45 E-02$

$6.00 E-01$ 
B.E.

RATE EXPOSURE PROB. DESCRI PTION

CONDITIONAL PROBABILITY OE HAVING AN IGNITION SOURCE PRESENT CONDITIONAL PROBABILITY OR HATITG AN IGNI

FANK 48 EXHAUST FAN Y 348-52-8 FAILS TO RUN DUE TO MECHANICAL EAULT TANK 48 EXHAUST FAN Y348-52-8 EAILS TO RUN DUE TO MECHANICAL EAULT CONDITIONAL PROBABILITY OF BEING IN NORMAL PROCESSING MODE CONDITIONAL PROBABILITY OF HAVING AN IGNITION SOURCE PRESENT TANK 49 FLOW CONTROL VALVE 1252EV UNAVAILABLE DUE TO MAINTENANCE MECHANICAL FAULTS OE TANK 49 PRESSURE REGULATING VALVE 1255 PV CONDITIONAL PROBABILITY OF HAVING AN IGNITION SOURCE PRESENT MECHANICAL FAULTS OF TANK 49 PRESSURE REGULATING VALVE 1255PVI TANK 49 PRESSURE REGULATING VALVE 1255 PV2 UNAVAILABLE DUE TO CONDITIONAL PROBABILITY OF HAVING AN IGNITION

FANK CONTROL VALVE 1251 PV2 MECHANICALILAULE DUE TO MAINTENANCE CONDITIONAI PROBABILITY OF HAVING AN IGNITION SOURCE PRESENT

TANK 49 EXHAUST EAN Y349-52-11 UNAVAILABLE DUE TO MAINTENANCE TANK 49 EXHAUST FAN Y349-52-12 FAIIS TO RUN DUE TO MECHANICAL FAUL CONDIGISAI PROBABILITY OF HAVING AN IGNITION SOURCE PRESENT MENITINAL PROBABILTTY OF CONDITIONAL PROBABILITY OE BEING IN WASH CYCLE

CONDITIONAL PROBABILITY OE BEING IN WOSPV CYCLE CONOIIONAI PROBABILITY OF HAVING AN IGNITION SOURCE PRESENT CONDITIONAL PROBABILITY OF HAVING AN TRN VALVE $1201 \mathrm{FV}$

MECHANICAL EAULT OE TANK 48 FLOW CONTROL VALVE $1201 F V$

CONDITIONAL PROBABILITY OF TRANSFERRING SALT SOLUTION 70 C TEMPI TANK 48 PRESSURE REGULATING VALVE 1205 PV 2 UNAVATLABLE DUE TO CONDITIONAL PROBABILITY OF HAVING AN IGNITION SOURCE MECHANICAL FAULT OF TANK 48 FLOW CONTROL VALVE $1201 \mathrm{FV}$
TANK 48 FLOW CONTROL VALVE $1202 \mathrm{FV}$ UNAVAILABLE DUE TO MAINTENANCE CONDITIONAL PROBABILITY OE BEING IN WASH CYCLE CONDITIONAL PROBABILITY OF HAVING AN IGNITION SOURCE MECHANICAL FAULT OF TANK 48 FLOW CONTROL VALVE $1201 F V$ TANK 48 FLOW CONTROL VALVE $1202 \mathrm{FV}$ UNAVAILABLE DUE TO MAINTENANCE CONDITIONAL PROBABILITY OF TRANSFERRING SALT SOLUTION $170 \mathrm{C}$ TEMP) CONDITIONAL PROBABILITY OF HAVING AN IGNITION SOUREE PRESENT MECHANICAL FAULT OF TANK 49 ELOW CONTROL VALVE 1251 FV MECHANICAI FAULT OE TANK 49 ELOW CONTROL VALVE 125?EV CONDITIONAI PROBABILITY OF HAVING AN IGNITION SOURCE PRESENT NO ACTION TAKEN FOR 48 HRS LOCAL MECHANICAI FAULTS OF TANK 49 HEATER CONDITI CONDITIONAI PROBABILITY OF BEING IN NORMAL PROCESSING MODE $140 \mathrm{C} \mathrm{T}$ CONDITIONAL PROBABILITY OF BE MECHANICAL EAULTS OE TANK 48 PRESSURE REGULATING VALVE 1205 PV2 UNAVAILABLE DUE TO MAINT TANK 48 PRESSURE REGULATING VALVE $1205 P V 2$ UNAVAILABLE DUE TO

CONDITIONAL PROBABILITY OF HAVING AN IGNITANE DUE TO MAINTENANCE TANK 48 FLOW CONTROL VALVE 1202 FV UNAVAILABLE DUE TO MAINTENANCE CONDITIONAL PROBABILITY OF BEING IN NORMAL PROCESSING MODE 140
MECHANICAL FAULTS OF TANK 48 PRESSURE REGULATING VALVE 1205 PVI

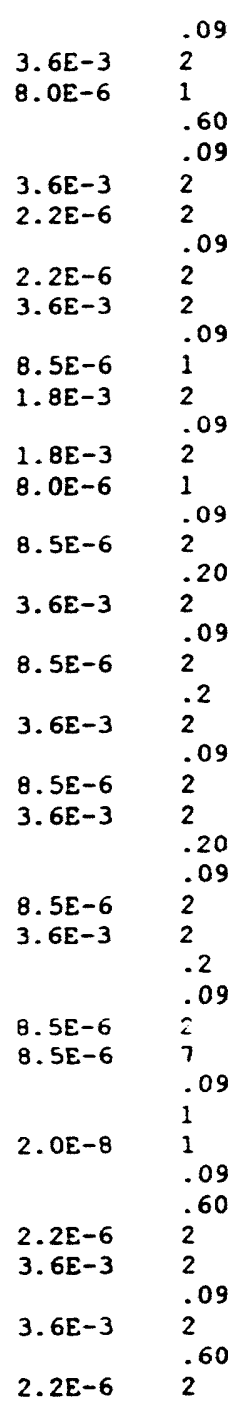

MOD./CS PROB.

$9.00 \mathrm{E}-02$ $7.20 \mathrm{E}-03$ $7.01 \mathrm{E}-02$ $6.00 \mathrm{E}-01$ $9.00 \mathrm{E}-02$

$7.20 E-03 \quad 2.50 E-05$ 3. $85 \mathrm{E}-02$ 3. $55 E-02 \quad 2.50 E-05$ $7.20 \mathrm{E}-03$ $9.00 \mathrm{E}-02$

$7.45 E-02 \quad 2.41 E-05$

3. $60 \mathrm{E}-03$

$9.00 E-02$

3. $60 \mathrm{E}-03 \quad 2.27 \mathrm{E}-05$

7.01E-02

9. $00 \mathrm{E}-02$

$1.49 E-01 \quad 1.93 E-05$

2. $00 \mathrm{E}-01$

7. $20 \mathrm{E}-03$

9. $00 \mathrm{E}-02$

$1.49 \mathrm{E}-01 \quad 1.93 \mathrm{E}-05$

2.00E-01

$7.20 E-03$
$9.00 E-02$

$1.49 E-01 \quad 1.93 E-05$

7. $20 \mathrm{E}-03$

2. $00 \mathrm{E}-01$

$1.49 \mathrm{E}-01 \quad 1.93 \mathrm{E}-05$

7.20E-03

2.00E-01

$9.00 E-02$

$1.49 E-01 \quad 1.91 E-05$

$1.43 E-03$

9. $00 \mathrm{E}-02$

$1.00 E+00 \quad 1.58 E-05$

$1.75 E-04$

$9.00 E-02$

6.00E-01 1.50E-05

3. $85 \mathrm{E}-02$

$7.20 \mathrm{E}-03$

$9.00 \mathrm{E}-02$

7. 20E-03 1. 50E-05

$6.00 E-01$

$6.00 E-01$

\author{
$2.72 E-05$
}

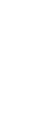

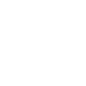


CONDITIONAL PROBABILITY OE HAVING AN IGNITION SOURCE PRESENT LUW CONTROL VALVE 1211 PV2 MECHANICAL EAULT

TANK 48 EXHAUST FAN Y348-52-7 UNAVAILABLE DUE TO MAINTENANCE CONDITIONAL PROBABILITY OF BEING IN NORMAL PROCESSING MODE $140 \mathrm{CI}$ CONDITIONAL PROBABILITY OF HAVING AN IGNITION SOURCE PRESENT TANK 48 EXHAUST FAN $Y 348-52-7$ UNAVAILABLE DUE TO MAINTENANCE TANK 48 EXHAUST EAN Y348-52-8 EAILS TO RUN DUE TO MECHANICAL EAULT CONDITIONAI PROBABILITY OF BEING IN NORMAL PROCESSING MODE $140 \mathrm{C}$ CONDITIONAL PROBABILITY OF HAVING AN IGNITION SOURCE PRESENT CONDITIONAL PROBABILITY OE HAVING AN IGNITION SOURCE PRESENT PRESSURE REGULATING VALVE 2045PV MAINTENANCE

PRESSJRE REGULATING VAIVE 2046PV FAILS

FLOW CONTROL VALVE 1211 PVI MECHANICAL EAULT (MODE C)

FLON CONTROL VALVE 1211 PV2 MECHANICAL FAULT

CONDITIONAI PROBABILITY OF BEING IN WASH CYCLE

CONDITIONAI PROBABILITY OF HAVING AN IGNITION SOURCE PRESENT

CON CONTROL VALVE 1211PVI MECHANICAI FAULT (MODE Cl

DOW CONTROL VALVE 1211 PV 2 MECHANICAI FAUIT

CONDITIONAL PROBAOILITY OE TRANSFERING SAIT SOLUTION $(70 \mathrm{C}$ TEMP) CONDITIONAL PROBAEILTY OF HAVTNG AN IGNITION SOURCE PRESENT

CLOW CONTROL VALVE 1211 PVI MECHANICAL FAULT (MODE $C$ )

TLW CONTROL VALVE 1211 OVI MECHANICAL FAULT IMODE CI TANK 48 EXHAUST FAN Y $30-52$ 0 FAILS TO RUN DUE TO MECHANICAL FAUL CONDITIONAL PROBABILITY OF TRANSFERRING SALT SOLUTION

HON CONTROL VALVE 1211 PVI MECHANICAL EAULT MUODE C) TANK 48 EXHAUST FAN Y348-52-8 FAILS TO RUN DUE TY

CONDITIONAL PROBABILITY OF HAVING AN IGNITION SOURCE PRESENT MECHANICAL EAULT OF TANK 48 FLOW CONTROL VALVE $1201 \mathrm{FV}$

MECHANICAL FAULT OF TANK 48 FLOW CONTROL VALVE $1202 \mathrm{EV}$ CONDITIONAL PROBABILITY OE BEING IN NORMAL PROCESSING MODE $140 \mathrm{C}$ T CONDITIONAL PROBABILITY OE HAVING AN IGNITION SOURCE PRESEN OPERATOR EAILS TO ALIGN AND START TRAIN B FOR OPERATION - EXHAUST MANUAL VALVE T49-HV22 FAILS TO REMAIN OPEN (PLUG)

CONDITIONAL PROBABILITY OE HAVING AN IGNITION SOURCE PRESENT CONDITIONAL PROBABI CONDITIONAL PROBABILITY OE HAVING VALVE NI 2 FROM THE NIRUON SUPRY FAILS TO REMAIN OREN (PLUG MANUAI VAIVE T49-HV2O FAILS TO REMAIN OPEN (PLUG)

MANUAL VAIVE T49-HV2O EAILS TO REMAIN OPEN TPLUG CONDITIONAL PROBABILITY OF HAVING AN IGNITION SOURCE PRESENT CONDITIONAL PROBABILITY OI HAVING AN IGNITION SOURCE PRESENT OPERATOR FAILS TO ALICN TRAIN B FOR OPERATION - SUPPLY SIDE PATH A OUTLET VALVE N2O EAILS TO REMATN OPEN (PLUG) CONDITIONAL PROBABILITY CE HAVING AN IGNITION SOURCE RRESENT OPERATOR EAILS TO ALIGN TRAIN B FOR OPERATION - SUPPLY SIDE PATH A INLET VALVE N24 FAILS TO REMAIN OPEN (PLUG)

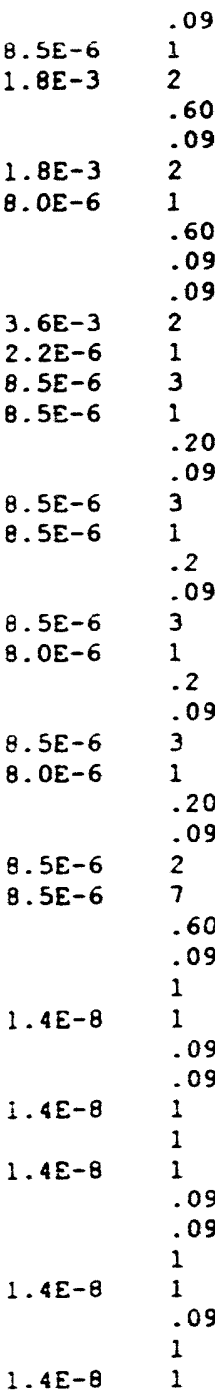

9.00E-02

$7.45 E-02 \quad 1.45 E-05$

$3.60 E-03$

$6.005-01$

$9.00 \mathrm{E}-02$

$3.60 \mathrm{E}-03 \quad 1.36 \mathrm{E}-05$

$7.01 \mathrm{E}-02$

$7.01 E-02$

$6.00 \mathrm{E}-01$

$9.00 E-02 \quad 1.25 \varepsilon-05$

$9.00 \mathrm{E}-02$

$7.20 \mathrm{E}-03$

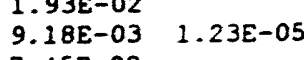

$7.45 E-02$

2. $00 \mathrm{E}-01$

$9.18 E-03 \quad 1.23 E-05$

$7.45 E-02$

2. $00 \mathrm{E}-01$

9. $00 \mathrm{E}-02$

9.18E-03 1.16E-05

7. $01 E-02$

2. $00 \mathrm{E}-01$

9. $00 \mathrm{E}-02$

9. $18 \mathrm{E}-03 \quad 1.16 \mathrm{E}-05$

$7.01 \varepsilon-02$

$2.01 E-02$

$2.00 \mathrm{E}-01$

1.49E-01 1.15E-05

$1.49 E-01$

$1.43 E-03$

6.00E-01

9. $00 \mathrm{E}-02$

$1.00 E+00 \quad 1.10 E-05$

1. $23 E-04$

$9.00 E-02$

9. 00 E-02 I. $10 E-05$

$1.23 E-04$

1. $00 E+00$ 1. $10 E-05$

1.23E-04

$9.00 E-02$

9.00E-02 1.10E-05

$1.00 E+00$

$3.23 E-04$

$9.00 E-02,1.10 E-05$

$1.4 E-8$

1. $00 \mathrm{E}+00$

1. 23E-04 
B.E.

RATE

EXPOSURE PROB.

DESCRIPTION

MANUAL VALVE T49-HV33 EAILS TO REMAIN OPEN (PLUG)

CONDITIONAL PROBABILITY OF HAVING AN IGNITION SOURCE PRESENT MANUAI VALVE T49-HVI7 FAILS TO REMAIN OPEN (PLUG)

MANUAL VALVE T49-HVITY EAILS TO REMATN OREN (PLUG) CONDITIONAL PROBABILITY OFS TO REMATN OREN (PLUGI TANK 49 TANK INLET VALVE T49-N24 FAILS TO REMAIN OPEN IPLUG CONDITIONAL PROBABILITY OF HAVING AN IGNITION SOURCE PRESENT CONDITIONAL PROBABILITY OE HAVING AN IGNITION - SUPPLY SIDE OPERATOR FAILS TO ALIGN TRAIN B FOR OPERATION

MANUAL VALVE N46 EAILS TO REMAIN OREN (PLUG) MANUAL VALVE N46 EAILS TO REMAIN OPEN (PLUG)
TANK 49 O2 ANALYZER DISCHARGE VALVE T49-HV9 FAILS TO REMAIN OPEN $1 \begin{aligned} & 1.4 E-8 \\ & \text { CONDITIONAL PROBABILITY OF HAVING AN IGNITION SOURCE PRESENT }\end{aligned}$ MANUAL VALVE T49-HV2 FAILS TO REMAIN OPEN (PLUG)

CONDITIONAL PROBABILITY OE HAVING AN IGNITION SOURCE PRESENT MANUAL VALVE T49-N1O FAILS TO REMAIN OPEN (PLUG)

CONDITIONAL PROBABILITY OE HAVING AN IGNITION SOURCE PRESENT MANUAL VALVE T49-HV15 FAILS TO REMAIN OPEN (PLUG)

CONDITIONAL PROBABILITY OF HAVING AN IGNITION SOURCE PRESENT CONDITIONAL PROBABILITY OF HAVING AN IGNITION SOURCE PRESENT CONDITIONAL PROBABILITY OF HAVING AN IGNITION OPERATOR FAILS TO ALIGN TRAIN B FOR OPERATION

CONDITIONAIE NROBABILIT OE HAVING AN IGNITION SOURCE PRESENT OPERATOR FAILS TO ALIGN TRAIN B FOR OPERATION - SUPPLY SIDE OPERATOR FAILS TO ALIGN TRAIN B FOR OPERATION

MANUAL VALVE NT2 FAILS OE HAVING AN IGNITION SOURCE PRESENT MANUAI VALVE N92 EAILS TO REMAIN OPEN (PLUG)

MANUAL VALVE N92 EAILS TO REMAIN OPEN

FLOW CONTROL VALVE 1211 PV1 MAINTENANCE

FLOW CONTROL VALVE 1211 PV2 MECHANICAL FAULT

CCNDITIONAL PROBABILITY OE BEING IN WASH CYCLE

CONDITIONAL PROBABILITY OF HAVING AN IGNITION SOURCE PRESEN

FLOW CONTROL VALVE 1211 PVI MAINTENANCE

FLOW CONTROL VALVE 1211PV2 MECHANICAL FAULT

CONDITIONAL PROBABILITY OF TRANSFERRING SALT SOLUTION $170 \mathrm{C}$ TEMP

CONDITIONAL PROBABILITY OF HAVING AN IGNITION SOURCE PRESENT

NO ACTION TAKEN FOR 48 HOURS

CONDITIONAL PROBABILITY OF BEING IN NORMAL PROCESSING MODE $140 \mathrm{C} \mathrm{T}$ LOCAL MECHANICAL FAULTS OF TANK 48 HEATER

CONDITIONAI PROBABILITY OF HAVING AN IGNITION SOURCE PRESENT

FLOW CONTROL VALVE 1211 PVI MAINTENANCE

$1.4 E-8$

$1.4 E-8 \quad i^{0}$

$1.4 E-8$

TANK 48 EXHAUST FAN Y348-52-8 EAILS TO RUN DUE

CONDITIONAL PROBABILITY OE BEING IN WASH CYCLE

CONDITIONAL PROBABILITY OF MAVNG AN IGNI

ELOW CONTROL VALVE 1211 OVI MAINTENANCE TANK 48 EXHAUST FAN Y348-52-8 FAILS TO RUN DUE TO MECHANICAL EAULT CONDITIONAL PROBABILITY OF HAVING AN IGNITION SOURCE PRESENT FLOW CONTROL VALVE 1251 PV2 MECHANICAL EAULT

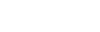

$4 E-8 \quad i^{-09}$

1
1
1

$1.4 E-8$

109

$1.4 E-8-1$

1. $4 E-8 \quad i$

.09
.09

$1.4 E-8$

1. $4 \mathrm{E}-8$

$1.4 \mathrm{E}-8$

$1.4 E-8$

3. $6 \mathrm{E}-3$

3. $6 E-3$
$8.5 E-6$

09
09
09
09
09
09
09
09
09

$i$

09

.

09

\begin{tabular}{|c|c|}
\hline $.23 E-04$ & $1.10 \mathrm{E}-0$ \\
\hline $9.00 E-02$ & \\
\hline $\begin{array}{l}1.23 E-04 \\
9.00 E-02\end{array}$ & $1.10 \mathrm{E}-05$ \\
\hline $\begin{array}{l}9.00 E-02 \\
1.23 E-04\end{array}$ & $1.10 \mathrm{E}-05$ \\
\hline $9.00 E-02$ & \\
\hline $9.00 E-02$ & $1.10 \mathrm{E}-05$ \\
\hline $1.00 E+00$ & \\
\hline $1.23 E-04$ & \\
\hline $\begin{array}{l}1.23 E-04 \\
9.00 E-02\end{array}$ & $1.10 E-05$ \\
\hline $1.23 E-04$ & $1.10 \mathrm{E}-05$ \\
\hline $9.00 \varepsilon-02$ & \\
\hline $1.23 E-04$ & $1.10 \mathrm{E}-05$ \\
\hline $9.00 E-02$ & \\
\hline $1.23 E-04$ & $1.10 E-05$ \\
\hline $9.00 \mathrm{E}-02$ & \\
\hline $9.00 \mathrm{E}$ & $1.10 \mathrm{E}-05$ \\
\hline 1.00 & \\
\hline 1.23 & \\
\hline $9.00 E-02$ & $1.10 \mathrm{E}-05$ \\
\hline $1.00 E+00$ & \\
\hline 1.23 & \\
\hline 9.00 & $1.10 \mathrm{E}-05$ \\
\hline $1.23 E-04$ & \\
\hline 7.201 & $9.65 E-06$ \\
\hline $7.45 E-02$ & \\
\hline $2.00 E-01$ & \\
\hline $9.00 \varepsilon-02$ & \\
\hline $7.20 E-03$ & $9.65 E-06$ \\
\hline $7.45 E-02$ & \\
\hline $2.00 E-01$ & \\
\hline $9.00 \mathrm{E}-02$ & \\
\hline $1.00 \varepsilon+00$ & $9.46 \Xi-06$ \\
\hline $6.00 E-01$ & \\
\hline $1.75 E-04$ & \\
\hline $9.00 \mathrm{E}-$ & \\
\hline $7.20 \mathrm{E}-03$ & $9.08 \mathrm{E}-06$ \\
\hline $7.01 E-02$ & \\
\hline $2.00 \mathrm{E}-\mathrm{C}$ & \\
\hline & \\
\hline $7.20 \mathrm{E}-03$ & $9.08 E-06$ \\
\hline $7.01 E-02$ & \\
\hline & \\
\hline & \\
\hline $745 E-02$ & $9.00 \mathrm{E}-$ \\
\hline
\end{tabular}

MOD./CS.

PROB. 


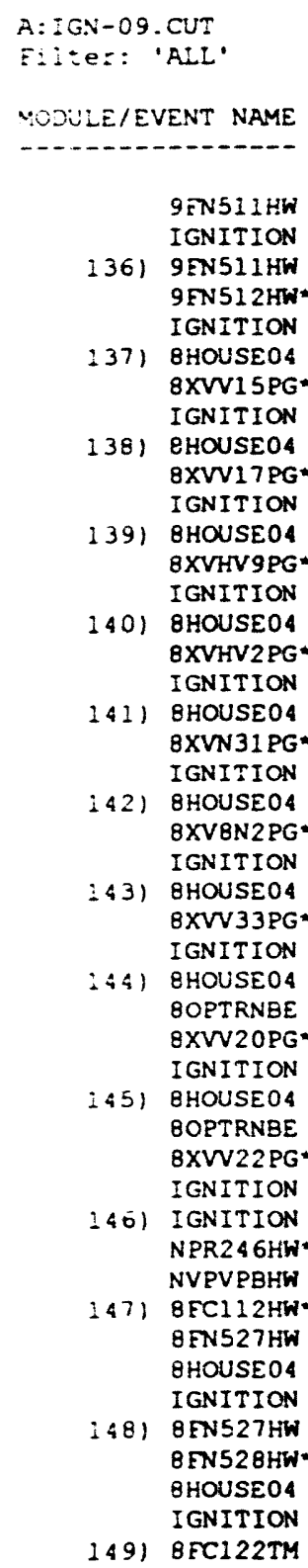

B.E. EXPOSURE PROB. PRCA.

TANK 49 EXHAUST FAN Y349-52-12 EAILS TO RUN DUE TO MECHANICAL EAUL $8.0 E-6$ CONDITIONAL PROBABILITY OF HAVING AN IGNITION SOURCE PRESENT

TANK 49 EXHAUST FAN Y349-52-11 EAILS TO RUN DUE TO MECHANICAL FAUL 8.OE-6 TANK 9 EXHAUST FAN Y349-52-12 FAILS TO RUN DUE TO MECHANICAL FAUL $8.0 E-6$ TANK 9 EXHAUST EAN Y349-52-12 EAILN TO RUN DN SOURCE PRESENT

CONDITIONAL PROBABILITY OE HAVING AN IGNITION SOURCE PRESENT CONDITIONAL PROBABILITY OE BEING IN NORMAL PROCESSI

CONDITIONAL PROBABILITY OF HAVING AN IGNITION SOURCE PRESEN CONDITIONAL PROBABILITY OF BEING IN NORMAL PROCESSING MODE $140 \mathrm{C} \mathrm{T}$ MANUAL VALVE T48-HVI 7 FAILS TO REMAIN OPEN (PLUG)

CONDITIONAL PROBABILITY OF HAVING AN IGNITION SOURCE PRESENT

CONDITIONAL PROBABILITY OF BEING IN NORMAL PROCESSING MODE $140 \mathrm{C} \mathrm{T}$

TANK 48 O2 ANALYZER DISCHARGE VALVE T48-HV9 FAILS TO REMAIN OPEN 1 CONDITIONAL PROBABILITY OF HAVING AN IGNITION SOURCE PRESENT

CONDITIONAL PROBABILITY OE BEING IN NORMAL PROCESSING MODE $140 \mathrm{C} \mathrm{T}$ MANUAL VALVE T48-HV2 EAILS TO REMAIN OPEN (PLUG)

CONDITIONAI PROBABILITY OF HAVING AN IGNITION SOURCE PRESENT

CONDITIONAI PROBABILITY OF BEING IN NORMAL PROCESSING MODE $140 \mathrm{C} \mathrm{T}$ TANK 48 TANK INLET VALVE T48-N31 FAILS TO REMAIN OPEN (PLUG) TANK 48 TANK INLET VALVE T48-N3I EAILS TOREMATN OREN (PLUG)

CONDITIONAL PROBABILITY OE HAVING AN IGNITION SOURCE PRESEN $140 \mathrm{C} \mathrm{I}$ TANK 48 VALVE T48-N2 FROM THE NITROGEN SUPPLY FAILS TO RESENT

CONDITIONAL PROBABILITY OF HAVING AN IGNITION SOURCE PRESENT CONDITIONAL PROBABILITY OE BEING IN NORMAL PROUES

MANUAL VALVE T48-HV33 FAILS TO REMAIN OPEN (PLUG)

CONDITIONAL PROBABILITY OF HAVING AN IGNITION SOURCE PRESENT

CONDITIONAL PROBABILITY OE BEING IN NORMAL PROCESSING MODE $140 \mathrm{CT}$
OPERATOR FAILS TO ALIGN AND START TRAIN B FOR OPERATION - EXHAUST MANUAL VALVE T48-HV20 EAILS TO REMAIN OPEN (PLUG)

CONDITIONAL PROBABILITY OE HAVING AN IGNITION SOURCE PRESEN

CONDITIONAL PROBABILITY OF BEING IN NORMAL PROCESSING MODE $140 \mathrm{C} \mathrm{T}$ OPERATOR FAILS TO ALIGN AND START TRAIN B FOR OPERATION - EXHAUST MANUAL VALVE T48-HV22 FAILS TO REMAIN OPEN (PLUG)

CONDITIONAL PROBABILITY OF HAVING AN IGNITION SOURCE PRESENT

CONDITIONAI PROBABIIITY OF HAVING AN IGNITION SOURCE PRESENT

PRESSURE REGULATING VAIVE 2046PV FAILS

EAILURE OE VAPORIZER B DUE TO HARDWARE EAULTS

EAILURE OF VAPORIZER B DUE TO HARDWARE EAULTS

FLNK CONROL VALVE 1211 BV2 MECTANICAL FAULT

CONDITIONAL FROBABILITY OF BEING IN NORMAL PROCESSING MODE $140 \mathrm{C} \mathrm{T}$ CONDITIONAL FROBABILITY OE BEING IN NORMAL PROCESSING MODE

CONDITIONAL PROBABILITY OF HAVING AN IGNITION SOURCE

TANK 48 EXHAUST FAN Y348-52-8 FAILS TO RUN DUE TO MECHANICAL FAULT

CONDITIONAI PROBABILITY OF BEING IN NORMAL PROCESSING MODE $140 \mathrm{C} \mathrm{T}$

CONDITIONAL PROBABILITY OF HAVING AN IGNITION SOURCE PRESENT

TANK 48 FLOW CONTROL VALVE 1202 FV UNAVAILABLE DUE TO MAINTENANCE

$1.4 E-8$

$1.4 E-8$

1. $4 E-8$

1. $4 E-8$

$1.4 E-8$

$1.4 \mathrm{E}-8$

.

$1.4 E-8$

$1.4 E-8$

$4 E-8$

2. $2 \mathrm{E}-6$

4. $2 E-7$

9.5E-6

8. OE-6

8. $0 E-6$

$8.0 E-6$

$3.6 E-3$
$1.34 E-03$

$9.00 \mathrm{E}-02$

1.34E-03 8. $47 E-06$

$7.01 E-02$
$9.00 E-02$

$9.00 E-02$ (6. $62 E-06$

1. $23 \mathrm{E}-04$

6.00E-01 6.62E-06

6.00E-01

1. $23 E-04$

$9.00 E-02$

6.00E-01 6.62E-06

1. $23 E-04$

$9.00 E-02$

6.00E-01 6.62E-06

1. $23 \mathrm{E}-04$

$9.00 E-02$

6.00E-01 6.62E-06

$1.23 E-04$

$9.00 E-02$

$6.00 E-01 \quad 6.62 E-06$

$1.23 E-04$

$1.23 E-04$
$9.00 E-02$

6.00E -02

6. $00 \mathrm{E}-01$

$1.23 E-04$

$9.00 E-02$

$6.00 E-01$

1. $00 E+00$

$1.23 E-04$
$9.00 E-02$

9.00E-02
$6.00 E-01 \quad 6.62 E-06$

$1.00 E+00$

1. $23 E-04$

$9.00 E-02$

9.00E-02 1.19E-07

$1.93 \mathrm{E}-02$

$6.89 E-05$

$7.45 E-02 \quad 5.40 E-06$

1. $34 \mathrm{E}-03$

$6.00 E-01$

$9.00 E-02$

1. $34 E-03 \quad 5.08 E-06$

1. $34 E-03$

$7.01 E-02$

$6.00 E-01$

$9.00 E-02$
$7.20 E-03 \quad 5.00 E-06$ 


\begin{tabular}{|c|c|c|c|c|c|c|}
\hline \multicolumn{2}{|c|}{ MODULE/EVENT NAME } & DESCRIPTION & RATE & EXPOSURE & PROB. & PROB. \\
\hline & 8HOUSEOI & CONDITIONAL PROBABILITY OE TRANSFERRING SALT SOLUTION (70 C TEMP) & & .2 & 2.00E-01 & \\
\hline & 8PRPVIHW* & MECHANICAL EAULTS OF TANK 48 PRESSURE REGULATING VALVE $1205 \mathrm{PV} 1$ & $2.2 E-6$ & 2 & $3.85 E-02$ & \\
\hline & IGNITION & CONDITIONAL PROBABILITY OE HAVING AN IGNITION SOURCE PRESENT & & .09 & $9.00 E-02$ & \\
\hline \multirow{2}{*}{1501} & $8 F C 122 T M$ & TANK 48 FLOW CONTROL VALVE $1202 E V$ UNAVAILABLE DUE TO MAINTENANCE & $3.6 E-3$ & 2 & & $5.00 E-06$ \\
\hline & BHOUSE 03 & CONDITIONAL PROBABILITY OF BEING IN WASH CYCLE & & .20 & $\begin{array}{l}2.00 E-01 \\
3.85 E-02\end{array}$ & \\
\hline \multirow[t]{2}{*}{$151)$} & 8HOUSE03 & $\begin{array}{l}\text { CONDITIONAL PROBABILITY OF HAVING AN IGNITION SOURCE PRESENT } \\
\text { CONDITIONAL PROBABILITY OF BEING IN WASH CYCLE }\end{array}$ & & $\begin{array}{l}.09 \\
.20\end{array}$ & $2.00 E-01$ & $5.00 E-06$ \\
\hline & 8PRPVI HW* & MECHANICAL FAULTS OE TANK 48 PRESSURE REGULATING VALVE 1205 PV 1 & $2.2 E-6$ & 2 & $3.85 E-02$ & \\
\hline \multirow[t]{2}{*}{2521} & BHOUSEOI & CONDITIONAL PROBABILITY OF TRANSFERRING SALT SOLUTION $170 \mathrm{C}$ TEMP) & & .09 & $2.00 E-01$ & $5.00 \varepsilon-06$ \\
\hline & BPRPVIHW* & MECHANICAL EAULTS OF TANK 48 PRESSURE REGULATING VALVE 1205 PVI & $2.2 E-6$ & 2 & $3.85 E-02$ & \\
\hline \multirow{2}{*}{1531} & $\begin{array}{l}\text { IGNITION } \\
\text { 9FC122HW }\end{array}$ & $\begin{array}{l}\text { CONDITIONAL PROBABILITY OF HAVING AN IGNITION SOURCE PRESENT } \\
\text { MECHANICAL FALLT OE TANK } 49 \text { FLOW CONTROL VALVE } 1252 \text { FV }\end{array}$ & $8.5 E-6$ & 7 & $1.43 E-03$ & $4.95 E-06$ \\
\hline & $\begin{array}{l}\text { 9PRPVIHW* } \\
\text { IGNITION }\end{array}$ & $\begin{array}{l}\text { MECHANICAL FAULTS OE TANK } 49 \text { PRESSURE REGULATING VALVE } 1255 \mathrm{PV} 1 \\
\text { CONDITIONAL PROBABILITY OF HAVING AN IGNITION SOURCE PRESENT }\end{array}$ & $2.2 E-6$ & 2.09 & $\begin{array}{l}3.85 E-02 \\
9.00 E-02\end{array}$ & \\
\hline 1541 & $9 \mathrm{EC} 121 \mathrm{HW} *$ & MECHANICAL FAULT OF TANK 49 ELOW CONTROL VALVE $1251 \mathrm{FV}$ & $8.5 E-6$ & 2 & $1.49 E-01$ & $4.95 E-06$ \\
\hline \multirow[t]{4}{*}{1551} & $\begin{array}{l}\text { IGNITION } \\
\text { 8FCIII HW* }\end{array}$ & $\begin{array}{l}\text { CONDITIONAL PROBABILITY OF HAVING AN IGNITION SOURCE PRESENT } \\
\text { FLOW CONTROL VALVE } 1211 \text { PV2 MECHANICAL EAULT }\end{array}$ & 8. $5 E-6$ & $i$ & $7.45 E-02$ & $4.83 E-06$ \\
\hline & 8EN527TM & TANK 48 EXHAUST FAN Y $348-52-7$ UNAVAILABLE DUE TO MAINTENANCE & $1.8 E-3$ & 2 & $3.60 E-03$ & \\
\hline & 8HOUSEOL & CONDITIONAL PROBABILITY OF TRANSFERRING SALT SOLUTION $(70 \mathrm{C}$ TEMP) & & .2 & $2.00 E-01$ & \\
\hline & IGNITION & CONDITIONAL PROBABILITY OF HAVING AN IGNITION SOURCE FRESENT & & .09 & $9.00 E-02$ & \\
\hline \multirow[t]{4}{*}{$156)$} & $8 \mathrm{FCl} 12 \mathrm{HW}^{*}$ & FLOW CONTROL VALVE 1211 PV2 MECHANICAL FAULT & 8. $5 E-6$ & 1 & $7.45 E-02$ & $4.83 E-00$ \\
\hline & $8 \mathrm{FN} 527 \mathrm{TM}$ & TANK 48 EXHAUST FAN Y 348-52-7 UNAVAILABLE DUE TO MAINTENANCE & $1.8 E-3$ & 2 & $3.60 E-03$ & \\
\hline & 8HOUSEO3 & CONDITIONAL PROBABILITY OF BEING IN WASH CYCLE & & .20 & $2.00 E-01$ & \\
\hline & IGNITION & CONDITIONAL PROBABILITY OF HAVING AN IGNITION SOURCE PRESENT & & .09 & $9.00 E-02$ & \\
\hline \multirow[t]{4}{*}{1571} & BEN527TM & TANK 48 EXHAUST EAN Y 348-52-7 UNAVAILABLE DUE TO MAINTENANCE & $1.8 E-3$ & 2 & $3.60 E-03$ & $4.54 E-06$ \\
\hline & $8 F N 528 \mathrm{HW} *$ & TANK 48 EXHAUST EAN Y348-52-8 FAILS TO RUN DUE TO MECHANICAL FAULT & 8. OE-6 & 1 & $7.01 E-02$ & \\
\hline & 8HOUSE01 & CONDITIONAL PROBABILITY OF TRANSFERRING SALT SOLUTION (70 C TEMP) & & .2 & $2.00 E-01$ & \\
\hline & IGNITION & CONDITIONAL PROBABILITY OF HAVING AN IGNITION SOURCE PRESENT & & .09 & $9.00 E-02$ & \\
\hline \multirow[t]{4}{*}{1581} & $8 F N 527 \mathrm{TM}$ & TANK 48 EXHAUST FAN Y $348-52-7$ UNAVAILABLE DUE TO MAINTENANCE & $1.8 E-3$ & 2 & $3.60 E-03$ & $4.54 \bar{E}-06$ \\
\hline & BENS28HW* & TANK 48 EXHAUST FAN Y348-52-8 FAILS TO RUN DUE TO MECHANICAL FAULT & B. OE-6 & 1 & $7.01 E-02$ & \\
\hline & BHOUSE03 & CONDITIONAL PROBABILITY OF BEING IN WASH CYCLE & & .20 & $2.00 E-01$ & \\
\hline & IGNITION & CONDITIONAL PROBABILITY OF HAVING AN IGNITION SOURCE PRESENT & & .09 & $9.00 E-02$ & \\
\hline \multirow[t]{3}{*}{1591} & IGNITION & CONDITIONAL PROBABILITY OF HAVING AN IGNITION SOURCE PRESENT & & .09 & $9.00 E-02$ & 4. $12 E-06$ \\
\hline & NPR245HW & PRESSURE REGULATING VALVE 2045 PV FAILS & $2.2 E-6$ & 3 & $2.38 E-03$ & \\
\hline & NPR2 $46 \mathrm{HW} *$ & PRESSURE REGULATING VALVE 2046 PV FAILS & $2.2 E-6$ & 1 & $1.93 \mathrm{E}-02$ & \\
\hline \multirow[t]{4}{*}{2601} & $8 F C 121 \mathrm{HW}^{*}$ & MECHANICAL FAULT OE TANK 48 FLOW CONTROL VALVE $1201 \mathrm{FV}$ & $8.5 E-6$ & 2 & $1.49 E-01$ & $3.83 E-06$ \\
\hline & $8 \mathrm{FCl} 22 \mathrm{HW}$ & MECHANICAL FAULT OF TANK 48 FLOW CONTROL VALVE $1202 \mathrm{FV}$ & 8. $5 E-6$ & 7 & $1.43 E-03$ & \\
\hline & BHOUSEO3 & CONDITIONAL PROBABILITY OE BEING IN WASH CYCLE & & .20 & $2.00 \mathrm{E}-01$ & \\
\hline & IGNITION & CONDITIONAL PROBABILITY OE HAVING AN IGNITION SOURCE PRESENT & & .09 & $9.00 E-02$ & \\
\hline \multirow{2}{*}{1611} & $8 F C 121 \mathrm{HW}$ & MECHANICAL FAULT OE TANK 48 ELOW CONTROL VALVE $1201 \mathrm{FV}$ & 8. $5 E-6$ & 2 & $1.49 E-01$ & $3.83 E-06$ \\
\hline & $8 F C 122 \mathrm{HW}$ & MECHANICAL FAULT OF TANK 48 ELON CONTROL VALVE $1202 E \mathrm{~V}$ & 8. $5 E-6$ & 7 & $1.43 E-03$ & \\
\hline
\end{tabular}


CONDITIONAL PROBABILITY OE TRANSFERRING SALT SOLUTION $170 \mathrm{C}$ TEMP। CONDITIONAI PROBABILITY OE HAVING AN IGNITION SOURCE PRESENT

CONDITIONAL PROBABILITY OE HAVING ANCLI TAULT

BHOUSEO2

TANK CONTROL VALVE 1251 OV2 MECHANICAL EAULT

TANK 4 EXHAUT EAN Y

NO ACTION TAKEN EOR 48 HOURS

CONDITIONAL PROBABILITY OE BEING IN WASH CYCLE

LOCAL MECHANICAL EAULTS OF TANK 48 HEATER

BHTHTRHW*

IGNITION

164) BHOUSE01

BHOUSE02

8HTHTRHW

IGNITION

165) 9EN511ST 9 FN512HW IGNITION

166) 8 FC122HW 8 HOUSE04 8PRPVIHW* IGNITION CONDITIONAL PROBABILITY OF HAVING AN IGNITION SOURCE PRESENT CONDITIONAL PROBABILITY OF TRANSEERRING SAIT SOLUTION $170 \mathrm{C}$ TEMP NO ACTION TAKEN FOR 48 HOURS

LOCAL MECHANICAL FAULTS OF TANK 48 HEATER

$8.5 E-6$
$4.8 E-4$

2

09

$2.00 E-01$

CONDITIONAL PROBABILITY OF HAVING AN IGNITION SOURCE PRESENT

$\begin{array}{ll} & 1 \\ 2.0 E-8 & 1 \\ & i \\ 2.0 E-8 & 1 \\ 4.8 E-4 & 1 \\ 8.0 E-6 & 1 \\ 8.5 E-6 & 1\end{array}$

TANK 49 EXHAUST FAN Y349-52-11 EAILS TO START DUE TO MECHANICAL EA $4.8 E-4$
TANK 49 EXHAUST FAN Y349-52-12 EAILS TO RUN DUE TO MECHANICAL FAUL $8.0 E-6$

CONDITIONAI PROBABILITY OF HAVING AN IGNITION SOURCE PRESENT

MENANICAL EAULT OF TANK 48 FLOW CONTROL VAIVE 1202 FV

$8.5 E-6$

CONDITIONAL PROBABILITY OF BEING IN NORMAL PROCESSING MODE $140 \mathrm{C} \mathrm{T}$ T

PROBABIILITY OE BEING IN NORYAL PROCESSING MODE

CONDITIONAL PROBABILITY OF HAVING AN IGNITION SCURCE PRESENT

B FC121HW-

BHOUSEO4

IGNITION

168) IGNITION NPR245TM NVPVPAHW*

169) 8HOUSEO1 8XVV33PG* IGNITION

170) BHOUSEOI 8XV8N2PG* IGNITION

i71) BHOUSEO3 QXVVI 5PG IGNITION

172) 8HOUSE01 8XVVI 5PG IGNITION

173) 8HOUSEOI $8 \times V V I 7 P G *$ IGNITION

174) BHOUSE03 $8 X V N 31$ PG* IGNITION

275) BHOUSEOI

CONDITIONAL PROBABILITY OF BEING IN NORMAL PROCESSING MODE 140

MECANICAL FAULTS OE TANK 8 HAVING AN IGNITION SOURCE PRESENT

CONDITIONAL PROBABILITY OE HAVING AN IGNITION SOURCE PRESENT

CONDITIONAL PROBABILITY OF HAVING AN IGNITION

PRESSURE REGULATING VALVE 2045 PV MAINTENANCE

CONDITIONAL PROBABILITY OF TRANSFERRING SALT SOLUTION $170 \mathrm{C}$ TEME

MANUAI VALVE T48-HV33 FAISS TO REMAIN OPEN (PLUG)

CONDITIONAL PROBABILITY OE HAVING AN IGNITION SOURCE PRESENT

CONDITIONAI PROBABILITY OF TRANSFERRING SALT SOLUTION (70 C TEMP)

TANK 48 VALVE T48-N2 EROM THE NITROGEN SUPPLY FAILS TO REMAIN OPEN

CONDITIONAL PROBABILITY OF HAVING AN IGNITION SOURCE PRESENT

CONDITIONAI PROBABILITY OF BEING IN WASH CYCLE

MANUAL VAIVE T4B-HV15 FAIIS TO REMATN OPEN IPIUG

CONUIT VALVE T48-HVIST EAILS TOVING AN IGNITION SOURCE PRESENT

CONDITIONAL TROBABILITY OE HAVING ANIGN SATT SOLUTION $170 \mathrm{C}$ TEMP

CONDITIONAL PROBABILITY OE TRANSERRTNG SAIT (PLUG)

MANUAL VALVE T48-HVIS FAILS TO REMAIN OPEN (PLUG

CONDITIONAL PROBABILITY OF HAVING AN IGNITION SOURCE PRESENT

CONDITIONAL PROBABILITY OE TRANSFERRING SALT SOLUT

MANUAL VALVE T48-HVI7 FAILS TO REMAIN OPEN (PLUG)

CONDITIONAL PROBABILITY OE HAVING AN IGNITION SOU

CONDITIONAL PROBABILITY OF BEING IN WASH CYCLE

TANK 48 TANK INLET VALVE T48-N31 FAILS TO REMAIN OPEN (PLUG)

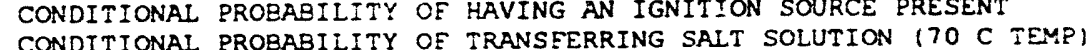

8. $5 E-6$

$2.2 E-6$

.09

$3.6 \Xi-3$

$4 \cdot 1 E-7$

1. $4 \mathrm{E}-8$

1. $4 E-8$

4. $80 \bar{E}-04$

$9.00 E-02$

$1.00 E+00 \quad 3.25 E-06$

2. $00 E-01$

1. $75 E-04$

$1.75 E-04$

2.00E-01 3.15E-06

$1.00 E+00$

$1.75 E-04$

9. $00 \mathrm{E}-02$

$4.80 E-04 \quad 3.03 E-06$

7. $01 \mathrm{E}-02$

$9.00 E-02$

1. $43 E-03 \quad 2.97 E-06$

6. $00 E-01$

3. $85 E-02$

$9.00 E-02$

$1.49 E-01 \quad 2.97 E-06$

$6.00 E-01$

$3.70 E-04$

9. $00 E-02$

9. $00 E-02 \quad 2.33 E-06$

$7.20 \mathrm{E}-03$

$3.59 E-03$

2. $00 E-01 \quad 2.21 E-06$

$2.00 \mathrm{E}-01$

1. $23 E-04$

9.
$2.00 E-02$
1.01

1. $23 \mathrm{E}-04$

9. $00 \mathrm{E}-02$

$2.00 E-01 \quad 2.21 E-06$

$1.23 E-04$

9. $00 E-02$

2. $00 E-01 \quad 2.21 E-06$

$1.23 E-04$

$9.00 E-02$

2.00E-01 2.2:E-06

$4 E-8 \quad i^{2}$

$2.00 \mathrm{E}-01$
$1.23 \mathrm{E}-04$

$1.23 \mathrm{E}-04$

. $005-01221=-06$

1. $23 E-04$

$1.23 E-04$

$9.00 E-02$

$2.00 E-01 \quad 2.22 E-06$ 
MODULE/EVENT NAME

8XVN31PG* IGNITION

176) 8HOUSE01 8XVHV2PG* IGNITION

177) 8HOUSEO 8XVHV 9PG* IGNITION

178) 8HOUSEO3 BOPTRNBE QXVV22PG* IGNITION

179) BHOUSEO 8XV8N2PG* IGNITION

0) BHOUSEO BXVHV2PG. BXVFIV2PG IGNITION

181) 8HOUSE03 8XVHV9PG* IGNITION

1821 BHOUSE03 XVV17PG IGNITION

183) BHOUSEOI BOPTRNBE 8XVV2OPG* IGNITION

184) BHOUSEO 8XVV33PG* IGNITION

185) 8HOUSEO BOPTRNBE IGNITION IGNITION OHOUSEOI 8OPTRNBE BXVV22PG IGNITION

197) 8EC112 HW 8EN527ST IGNITION

188) BEN527ST 8 EN528 $\mathrm{HW}^{*}$ 8 HOUSEO4
Truncation Limit: $1.00 E-08$

\section{DESCRIPTION}

TANK 48 TANK INLET VALVE T48-N31 FAILS TO REMAIN OPEN (PLUG) CONDITIONAL PROBABILITY OF HAVING AN IGNITION SOURCE PRESENT CONDITIONAL PROBABILIY OL TO REMAIN OPEN (PLUG)

MANUAL VALVE T $8-H V$ FAIL TH RING AN IGNITION SOURCE PRESENT

CONDITIONAL PROBABILITY OF HAVING AN IGNITION SOURCE PRESENT

CONDITIONAL PROBABILITY OF TRANSFERRING SALT SOLUTION (TOC TEMPI

TANK 48 O2 ANALYZER DISCHARGE VALVE T IGNITION SOURCE PRESENT

CONDITIONAL PROBABILITY OF HAVING AN WASH CYCLE

CONDITIONAL PROBABILITY OE BEING IN WASH CYCLE MANUAL VALVE T48-HV22 FAILS TO REMAIN OPEN (PLUG)

CONDITIONAL PROBABILITY OE HAVING AN IGNITION SOURCE PRESENT CONDITIONAL PROBABILITY OE BEING IN WASH CYCLE

TANK 48 VALVE T48-N2 FROM THE NITROGEN SUPPIY FAILS TO REMAIN OPEN CONDITIONAL PROBABILITY OE HAVING AN IGNITION SOURCE PRESENT

CONDITIONAL PROBABILITY OF BEING IN WASH CYCLE

MANUAL VALVE T48-HV2 FAILS TO REMAIN OPEN (PLUG)

CONDITIONAL PROBABILITY OF HAVING AN IGNITION SOURCE PRESENT

CONDITIONAL PROBABILITY OF BEING IN WASH CYCLE

TANK 40 O2 ANALYZER DISCHARGE VALVE T48-HV9 EAILS TO REMAIN OPE

CONDITIONAI PROBABILITY OF HAVING AN IGNITION SOURCE PRESENT

CONDITIONAL PROBABILITY OF BEING IN WASH CYCLE

CONDIT VALVE TA8-HVI7 FAILS TO REMAIN OPEN (PLUG)

CONDITIONAL PROBABILITY OF HAVING AN IGNITION SOURCE PRESENT

CONDITIONAL PROBABILITY OF TRANSFERRING SALT SOLUTION $170 \mathrm{C}$ TEMPI

OPERATOR FAILS TO AIIGN AND START TRAIN B FOR OPERATION - EXHAUST

MANUAI VALVE

MANUAL VALVE I48-HV20 FAILS TO REMAN ORNTTION SOURCE PRESENT

CONDITIONAI PROBABILITY OF BEING IN WASH CYCLE

CONDITIONAL PROBABILITY OF BEING IN WASH CYCLE

MANUAL VALVE T48-HV 33 FAILS TO REMAIN OPEN (PLUG)

CONDITIONAL PROBABILITY OF HAVING AN IGNITION SOU

OPERATOR FAILS TO ALIGN AND START TRAIN B FOR OPERATION - EXIIAUS MANUAL VALVE T4B-HV2O FAILS TO REMAIN OPEN (PLUG)

CONDITIONAL PROBABILITY OF HAVING AN IGNITION SOURCE PRESENT

CONDITIONAL PROBABILITY OF TRANSFERRING SALT SOLUTION $170 \mathrm{C}$ TEMP)

OPERATOR FAILS TO ALIGN AND START TRAIN B FOR OPERATION - EXHAUST MANUAL VALVE T48-HV22 FAIIS TO REMAIN OPEN (PLUG)

CONDITIONAI PROBABILITY OF HAVING AN IGNITION SOURCE PRESENT

TLOW CONTROL VALVE 1211 PV2 MECHANICAL FAULT

TANK 48 EXHAUST FAN Y348-52-7 FAILS TO START DUE TO MECHANICAL FAU TANK 48 EXHAUST FAN Y CONDITIONAL PROBABLITY OF BEING IN NORMATION SOURCE PRESENT

TANK 48 EXHAUST FAN Y $348-52-7$ FAILS TO START DUE TO MECHANICAL FAU

TANK 48 EXHAUST FAN Y348-52-7 FAILS TO START DUE TO MECHANICAL FAU

TANK 48 EXHAUST EAN Y348-52-8 FAILS TO RUN DROCESSING MODE $140 \mathrm{C} \mathrm{T}$

\section{B.E. MOD.lCS. \\ RATE EXPOSURE PROB.}

$1.4 E-8 \quad 1 \quad 1.23 E-04$

$.05-8 \quad 109$

$\begin{array}{lll}.2 & 2.00 E-01\end{array}$

1.23E-04

9. $00 E-02$

2. $00 E-01 \quad 2.21 E-06$

$1.23 E-04$

$9.00 \mathrm{E}-02$

$2.00 E-01 \quad 2.21 E-06$

1. $00 E+00$

$1.00 E+00$

$1.23 E-04$
$9.00 E-02$

2.00E-01 2.21E-06

1. 23E-04

9. $00 \mathrm{E}-02$

2.00E-01 2.21E-06

$1.23 E-04$

$9.00 E-02$

2.00E-01 2.21E-06

1. $23 \mathrm{E}-04$

$9.00 \mathrm{E}-02$

2. $00 E-01 \quad 2.21 E-00$

1. $23 E-04$

$9.00 E-02$

$2.00 E-01 \quad 2.21 E-06$

1. $00 E+00$

1. $23 E-04$

$9.00 E-02$

$2.00 E-01 \quad 2.21 E-06$

1. 23E-04

$2.00 E-01 \quad 2.21 E-06$

$1.00 E+00$

$1.23 E-04$

9. $00 \mathrm{E}-02$

2.00E-01 2.21E-06

$1.00 E+00$

1. $23 \mathrm{E}-04$

9. $00 \mathrm{E}-02$

7. $45 E-02 \quad 1.93 E-06$

4. $80 \mathrm{E}-04$

6.00E-01

9. $00 \mathrm{E}-02$

4. $80 \mathrm{E}-04 \quad 1.82 \mathrm{E}-06$

7. $01 \mathrm{E}-02$

$6.00 E-01$ 
-.--

CONDITIONAL PROBABILITY OF HAVING AN IGNITION SOURCE PRESENT CONDITIONAL PROBABILITY OE HAVING AN IGNITION SOURCE PRESENT CONDITIONAL PROBABILITY OF HA
NITROGEN STORAGE TANK 1 LEAKS

190) 8 EC112HW 8EN527HW IGNITION

191) 8FC112HW* BEN527HW IGNITION

192) 8EN527HW 8 EN528HW* OHOUSE01 IGNITION

193) 8EN527HW $8 \mathrm{EN} 528 \mathrm{HW}$ 8HOUSE03 IGNITION

94) 9PRPVIHW*
9PRPV2HW IGNITION

FLOW CONTROL VALVE 1211 PV2 MECHANICAL FAULT

TANK 48 EXHAUST EAN Y 348-52-7 FAILS TO RUN FOR 6 DAYS

CONDITIONAL PROBABILITY OF TRANSFERRING SALT SOLUTION (70 C TEMP) CONDITIONAL PROBABILITY OF HAVING AN IGNITION SOURCE PRESENT FLOW CONTROL VALVE 1211 PV2 MECHANICAL EAULT

TANK 48 EXHAUST EAN Y348-52-7 FAILS TO RUN FOR 6 DAYS CONDITIONAL PROBABILITY OF BEING IN WASH CYCLE CONDITIONAL PROBABILITY OF HAVING AN IGNITION SOURCE PRESENT TANK 48 EXHAUST EAN Y 348-52-7 EAILS TO RUN FOR 6 DAYS

$\begin{array}{rr}.09 & 9.00 \mathrm{E}-02 \\ .09 & 9.00 \mathrm{E}-02\end{array}$

2. $3 \mathrm{E}-9 \quad 1 \quad 2.01 \mathrm{E}-05$

$12.01 E-05$

TANK 48 EXHAUST EAN Y348-52-8 FAILS TO RUN DUE TO MECHANICAL FAUL CONDITIONAL PROBABILITY OF TRANSEERRING SALT SOLUTION $170 \mathrm{C}$ TEMP

CONDITIONAL PROBABILITY OF HAVING AN IGNITION SOURCE PRESENT

TANK 48 EXHAUST FAN Y 348-52-8 FAILS TO FUN DUE TO CONDITIONAL PROBABILITY OF BEING IN WASH CYCLE

CONDITIONAL PROBABILITY OF HAVING AN IGNITION SOURCE PRESENT MENANICAI FAULTS OF TANK 49 PRESSURE REGULATING VALVE 1255 PVI MECHANICAL EAULTS OF TANK 49 PRESSURE REGULATING VALVE 1255 PV2 MENAN IOAL CONDITIONAL PROBABILITY OE HAVING AN IGNITION SOURCE PRESENT FAILURE OF VAPBRIILR A DUE TO HARDWARE FAULTS FAILURE OF VAPORIZER A DUE TO HARDWARE FAULTS EAILURE OF VAPORIZER B DUE TO HARDWARE NVPVPAHW NVPVPBHW

196) $9 A 2021 \mathrm{HW}$ $9 X V V 11 P G$ IGNITION

197) 9 AZO21 HW $9 X V H V 4$ PG

198) $9 \mathrm{AZO22 \textrm {HW }}$ $9 \times V V 10 \mathrm{PG}^{*}$ IGNITION

$19919 \mathrm{RZO22HW}$ $9 X V H V 3 P G$ IGNITION

$20019 \mathrm{FCS} 12 \mathrm{HW}$ 9XVV1 $9 \mathrm{HW}$ IGNITION

20119 FN512HW 9XVV1 $9 \mathrm{HW}$

2021 BEC122HW BHOUSE01 BPRPVI HW.
MANUAL VALVE T49-HVII FAILS TO REMAIN OPEN (PLUG)

CONDITIONAL PROBABILITY OE HAVING AN IGNITION SOURCE PRESENT TANK 49 O2 ANALYZER 1 HARDWARE FAULTS

MANUAL VALVE T49-HV4 FAILS TO REMAIN OPEN (PLUG)

CONDITIONAL PROBABILITY OF HAVING AN IGNITION SOURCE PRESENT TANK 49 O2 ANALYZER 2 HARDWARE FAULTS

CONDITIONAI PROBABILITY OF HAVING AN IGNITION SOURCE PRESENT CONDITIONAL PROBABILITY OF HAVING ANTS

TANK 49 O2 ANALYZER 2 FARD TO REMAIN OPEN (PLUG)

MANUAL VALVE T49-HV3 FAILS TO REMAIN OPEN (PLUG)

FLOW CONTROL VALVE 1251 PV2 MECHANICAL FAULT

ELOW CONTROL VALVE 1251 PV2 MECHANICAL FAULT

MANUAL VALVE T49-HV19 FAILS TO OPEN ON DEMAND

CONDITIONAL PROBABILITY OF HAVING AN IGNITION SOURCE PRESENT

Y 349-52-12 EAILS TO RUN DUE TO MECHANICAL EAUL

MANUAL VALVE T49-HV19 FAILS TO OPEN ON DEMAND

CONDITIONAL PROBABILITY OF HAVING AN IGNITION SOURCE PRESENT

MECHANICAL FAULT OF TANK 48 ELOW CONTROL VALVE 1202FV

CONDITICNAL PROBABILITY OF TRANSFERRING SALT SOLUTION $(70 \mathrm{C}$ TEMP)

MECHANICAL FAULTS OF TANK 48 PRESSURE REGULATING VALVE 1205 PVI
MANUAL VAIVE T49-HVIO FAILS TO REMAIN OPEN (PLUG)
8. $0 E-6$

8. $5 E-6$
$8.0 E-6$

8. $0 E-6$

8. $0 \mathrm{E}-6$

B. OE-

$8.0 \mathrm{E}-6$

$2.2 \mathrm{E}-6$

$2.2 \mathrm{E}-6$

4.1E-7

4.1E-7

3. $0 E-4$

1. $4 E-8$

$3.0 \mathrm{E}-4$

$1.4 E-8$

3. $0 E-4$

1. $4 E-8$

3. $0 E-4$
1. $4 E-8$

8. $5 \mathrm{E}-6$

1. $6 \mathrm{E}-4$

8. $0 E-6$

1. $6 E-4$

8. $5 E-6$

2. $2 \mathrm{E}-6$
7. $45 \mathrm{E}-02$

1. $34 \mathrm{E}-03$

$2.00 \mathrm{E}-01$
$9.00 \mathrm{E}-02$

$9.00 E-02$

7. $45 \mathrm{E}-02$

$1.34 E-03$

$2.00 \mathrm{E}-01$

$1.34 \mathrm{E}-03 \quad 1.69 \mathrm{E}-06$

1.81E-06

$1.80 E-06$

. $80 \mathrm{E}-06$

$7.01 \mathrm{E}-02$

2.00E-01

$9.00 \mathrm{E}-02$

$1.34 \mathrm{E}-03 \quad 1.69 \mathrm{E}-06$

$7.01 \mathrm{E}-02$

2. $00 E-01$

$9.00 E-02$

3.85E-02 $1.28 \mathrm{E}-06$

3. $70 \mathrm{E}-04$

$9.00 \mathrm{E}-02$

9. $00 E-02 \quad 2.23 E-08$

3. $59 \mathrm{E}-03$

$6.89 E-05$

5. $26 \mathrm{E}+00$

2. $35 E-06$

9. $00 E-02$

$5.26 \mathrm{E}+00$

2. $35 E-06$

$9.00 E-02$

$4.92 \mathrm{E}-02$
$2.45 \mathrm{E}-04$

$9.00 \mathrm{E}-02$

4. $92 \mathrm{E}-02 \quad 1.09 \mathrm{E}-06$

2. 45E-04

$9.00 E-02$

$7.45 \mathrm{E}-02 \quad 1.07 \mathrm{E}-06$

$1.60 \mathrm{E}-04$

$9.00 \mathrm{E}-02$

7. $01 E-02 \quad 1.01 E-06$

$1.60 E-04$

$1.60 E-04$

$1.43 E-03$ 9. $90 E-07$

$1.43 \mathrm{E}-03$

$2.00 E-01$ 


\section{MODULE/EVENT NAME}

IGNITION

203) $8 \mathrm{ECl} 22 \mathrm{HW}$ 8HOUSE03 BPRPVIHW* IGNITION

204) 8EC121 HW 8 HOUSE 03 BPRPV2HW IGNITION

205) $8 F C 121 \mathrm{HW}$ BHOUSE01 8PRPV2HW IGNITION

206) IGNITION NPPNONBK

207) IGNITION NPPDIVBK*

8) 8HOUSEO4 8PRPV1 HW IGNITION

209) IGNITION NPR245HW NVPVPAHW*

210) $8 A 2021 \mathrm{HW}$ 8 HOUSE04 BHOUSE04 8XVVI1PGA IGNITION

211) $8 \mathrm{AZO21HW}$ BHOUSEO4 8XVHV4 PG IGNITION

212) $8 \mathrm{AZO22HWA}$ 8HOUSEO4 8XVVIOPG* IGNITION

213) BAZO22HWA BHOUSE 04 $8 X V H V 3 P G$ IGNITION

214) $8 \mathrm{FCI} 12 \mathrm{HW}$ BHOUSEO4 BXVV19HW IGNITION

215) $8 \mathrm{FCl} 12 \mathrm{HW}$ BFN527ST
Truncation Limit: $1.00 \mathrm{E}-08$

DESCRI PTION

CONDITIONAL PROBABILITY OE HAVING AN IGNITION SOURCE PRESENT MECHANICAL FAULT OF TANK 48 FLOW CONTROL VALVE 1202F

CONDITIONAL PROBABILITY OE BEING IN WASH CYCLE

MECHANICAL FAULTS OF TANK 48 PRESSURE REGULATING VALVE 1205 PVI

CONDITIONAL PROBABILITY OF HAVING AN IGNITION SOURCE PRESENT

MECHANICAL FAULT OF TANK 48 FLOW CONTROL VALVE 1201FV

CONDITIONAL PROBABILITY OF BEING IN WASH CYCLE

MECHANICAL FAULTS OF TANK 48 PRESSURE REGULATING VALVE 1205 PV2

CONDITIONAL PROBABILITY OF HAVING AN IGNITION SOURCE PRESENT

MECHANICAL FAULT OF TANK 48 FLOW CONTROL VALVE $1201 \mathrm{FV}$

CONDITICNA PROBABI TTY OF TRANSFERRING SAIT SOLUTION 170 C TEMP

MECHANICAL FAULTS OF TANK 48 PRESSURE REGULATING VALVE 1205 PV2

CONDITIONAI PROBABIIITY OF HAVING AN IGNITION SOURCE PRESENT

CONDITIONAL PROBABILITY OE HAVING AN IGNITION SOURCE PRESENT

NON-ISOIABLE GUILLOTINE PIPE BREAK

CONDITIONAL PROBABILITY OF HAVING AN IGNITION SOURCE PRESENT

ISOLABLE GUILLOTINE PIPE BREAK

CONDITIONAL PROBABILITY OE BEING IN NORMAL PROCESSING MODE $140 \mathrm{C} \mathrm{T}$

MECHANICAL FAULTS OF TANK 48 PRESSURE REGULATING VALVE 1205PVI

MECHANICAL FAULTS OF TANK 48 PRESSURE REGULATING VALVE 1205PV

CONDITIONAL PROBABILITY OF HAVING AN IGNITION SOURCE PRESEN

CONDITIONAL PROBABILITY OF HAVING AN IGNITION SOURCE PRESEN

PRESSURE REGULATING VALVE 2045PV FAILS

EAILURE OF VAPORIZER A DUE TO HARDWARE FAULTS

TANK 48 O2 ANALYZER 1 HARDWARE EAULTS

CONDITIONAL PROBABILITY OF BEING IN NORMAL PROCESSING MODE $140 \mathrm{C} T$

MANUAL VALVE T48-HV11 FAILS TO REMAIN OPEN (PLUG)

CONDITIONAL PROBABILITY OF HAVING AN IGNITION SOURCE PRESEN

TANK 48 O2 ANAIYZER I HARDWARE FAULTS

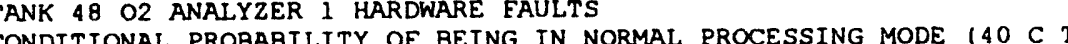

MANUAL VALVE T4B-HV4 EAILS TO REMAIN OPEN (PLUGI

AN IGNITION SOURCE PRESENT

TAUK 48 O2 ANALYZER 2 HARDWARE EAULTS

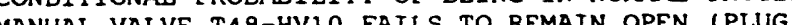

CONDITIONAL PROBRBILITY OF HAVING AN IGNITION SOURCE PRESENT

TANK 48 O2 ANALYZER 2 HARDWARE FAULTS

IN NORMAL PROCESSING MODE $140 \mathrm{C} \mathrm{T}$

TAILS TO REMAIN OPEN (PLUG)

CONDITIONAL PROBABILITY OE HAVING AN IGNITION SOURCE PRESENT

LOW CONTROL VALVE 1211 PV2 MECHANICAL FAULT

CONDITIONAL PROBABILITY OF BEING IN NORMAL PROCESSING MODE $140 \mathrm{C} \mathrm{T}$ MANUAL VALVE T48-HV19 FAILS TO OPEN ON DEMAND

CONDITIONAL PROBABILITY OF HAVING AN IGNITION SOURCE PRESEN

FLOW CONTROL VALVE 1211 PV2 MECHANICAL FAULT

TANK 48 EXHAUST FAN Y348-52-7 FAILS TO START DUE TO MECHANICAL FAU $4.8 \mathrm{EE}-4$
B.E.

EXPOSURE PROB

$9.00 \mathrm{E}-02$

9. 90E-07

$2.00 \varepsilon-01$

3.85E-02

9. $00 \mathrm{E}-02$

$1.49 E-01 \quad 9.91 E-07$

$2.00 \mathrm{E}-01$

3. $70 \mathrm{E}-04$

9. $00 \mathrm{E}-02$

$1.49 \mathrm{E}-01 \quad 9.91 \mathrm{E}-07$

2. $00 \mathrm{E}-01$

3. $70 \mathrm{E}-04$

9. $00 \mathrm{E}-02$

9.00E-02 7.88E-07

$8.76 \mathrm{E}-06$

$9.005-027.88 E-07$

8. $76 \mathrm{E}-06$

$6.00 E-01>7.69 E-07$

3. $85 \mathrm{E}-02$

3.70E-04

9. $005-02$

9. $00 \mathrm{E}-02 \quad 7.68 \mathrm{E}-07$

$2.38 E-03$

$3.59 E-03$

$5.26 E+00 \quad 6.68 E-07$

$6.00 \mathrm{E}-01$

2. 35E-06

9. $00 \mathrm{E}-02$

$5.26 E+00 \quad 6.68 E-07$

$6.00 \mathrm{E}-01$

2. 35E-06

9. $00 \mathrm{E}-02$

4. $92 \mathrm{E}-02 \quad 6.51 \mathrm{E}-07$

$2.45 \mathrm{E}-04$

4.92E-02 6.51E-07

$6.00 E-01$

$6.00 \mathrm{E}-01$

$2.45 E-04$

$7.45 E-02 \quad 6.43 E-07$

6. $00 \mathrm{E}-01$

$6.00 \mathrm{E}-01$

$1.60 E-04$

$9.00 \mathrm{E}-02$

$7.45 E-02 \quad 6.43 E-07$

$4.80 E-04$
MROB.

9. $91 E-07$

$6.51 E-07$ 
MODULE/EVENT NAME

BHOUSEOI

IGNITION

$21618 \mathrm{BC} 112 \mathrm{HW}$

8EN527ST

8HOUSE03

IGNITION

217) 8 EN527ST HOUSE01 IGNITION

218) 8FN527ST $8 \mathrm{EN} 528 \mathrm{HW}^{*}$ BHOUSEO

IGNITION

219) BEN528HW 8HOUSEO4 BXVV1 9HW IGNITION

220) IGNITION NPR2 24 $6 \mathrm{HW}$ NXVN1 6HW

221) IGNITION NPR246HW NXVN47HW

222) IGNITION NPR246HW* NXVN15HW

2231 8HOUSE03 8PRPVIHW* BPRPV2HW I GNITION

224) BHOUSEOI BPRPV1 HW BPRPVIHWOPRPV2HW IGNITION

225) 8AZO21HW BHOUSE01 8XVVIIPGA IGNITION

226) $8 \mathrm{AZO21HW}$ 8HOUSE01 $8 X V H V 4$ PGA IGNITION

227) $8 \mathrm{AZO21 \textrm {HW }}$ BHOUSEO3 $8 \times V V 11 P G A$
Truncation Limit: $1.00 E-08$

DESCRIPTION

CONDITIONAI PROBABILITY OF TRANSFERRING SALT SOLUTION 170 C TEMP) CONDITIONAL RROBABILITY OF HAVING AN IGNITION SOURCE PRESENT

CONDI IONAL PALE 1211 PV2 MECHANICAL FAULT

TLN CONTROL VALVE CONDITIONAL PROBABILITY OF BEING IN WASH CYCLE

CONDITIONAL PROBABILITY OE BEING IN WASHITION SOURCE PRESENT

CONDITIONAL PROBABILITY OF HAVING AN IGNITION SOURCE PRESENT

TANK 48 EXHAUST FAN Y348-52-7 FAILS TO START DUE TO MECHANICAL FAU

TANK 48 EXHAUST EAN Y348-52-8 FAILS TO RUN DUE TO MECHANICAL EAULT

CONDITIONAL PROBABILITY OF TRANSFERRING SALT SOLUTION $170 \mathrm{C}$ TEMP

CONDITIONAL PROBABILITY OF HAVING AN IGNITION SOURCE PRESEN

TANK 48 EXHAUST FAN Y348-52-7 FAILS TO START DUE TO MECHANI

TANK 48 EXHAUST FAN Y348-52-8 EAILS TO RUN DUE

CONDITIONAI PROBABILITY OE HAVING AN IGNITION SOURCE PRESENT

TANK 48 EXHAUST EAN Y348-52-8 FAILS TO RUN DUE TO MECHANICAL EAULT

CONK TIONAL PROBABILITY OE BEING IN NORMAL PROCESSING MODE $190 \mathrm{C}$

MANUAL VALVE T48-HVI9 FAILS TO OPEN ON DEMAND

CONDITIONAI PROBABILITY OF HAVING AN IGNITION SOURCE PRESENT CONDITIONAI PROBABILITY OF HAVING AN IGNITION SOURCE PRESENT PRESSURE REGULATING VALVE 2046 PV FAILS

MANUAL VALVE NIG EAILS TO OPEN ON DEMAND

CONDIONAI PROBABILITY OF HAVING AN IGNITION SOURCE PRESENT

CONDITIONAL BROBABILITY OE HAVING ANIS

MANUAL VALVE N47 FAILS TO OPEN ON DEMAND

MANUAL VALVE NA7 BAILS TO OPEN ONG DEM IGNITION SOURCE PRESENT

PRESSURE REGULATING VALVE 2046 PV FAILS

PRESSURE REGULATING VALVE 2046 N

CONDITI NALVE NIS FAILS TO OPEN

CONDITIONAL PROBABILITY OE BEING IN WASH CYCLE

MECHANICAL EAULTS OF TANK 48 PRESSURE REGULATING VALVE 1205 PV 1

MECHANICAL FAULTS OF TANK 48 PRESSURE REGULATING VALVE 1205P

CONDITIONAL PROBABILITY OF HAVING AN IGNITION PROBABIIITY OF TRANSFERRING SALT SOLUTION $170 \mathrm{C}$ TEMP

MECHANICAL FAULTS OF TANK 48 PRESSURE REGULATING VALVE 1205I'V]

MECHANICAL EAULTS OF TANK 48 PRESSURE REGULATING VALVE 1205 PV 2

CONDITIONAI PROBABILITY OF HAVING AN IGNITION SOURCE PRESENT

TANK 48 O2 ANALYZER 1 HARDWARE FAULTS

TANK 4O O2 ARLYER

MANUAL VALVE T48-HV1) SAILS TO REMAIN OPEN (PLUG)

CONDI UALE PROBABIT

TANK 40 O2 ANALYZER I HARDWARE EAULTS

TANK 48 O2 ANALYZER I HARDWARE FAULTS SALT SOLUTION (70 C TEMP)

CONDITIONAL PROBABILITY OF TRANSEAN OPEN (PLUG)

CONDIL

CONDITIONAL PROBABILITY OF HAVING ANTS

COND

MANUAL VALVE T48-HVII EAILS TO REMAIN OPEN (PLUG)
RATE

EXPOSUR

B. E.

$8.5 E-6$

- PROB

MOD. /CS

$.09 \quad 2.00 \mathrm{E}-01$

1

$.8 \mathrm{E}-4$

8. $0 E-6$

$4.8 E-4$

8. $0 \mathrm{E}-6$

$.0 E-6$

$1.6 E-4$

$2.2 E-6$
$1.6 E-4$

$2.2 E-6$

$1.6 \mathrm{E}-4$

$2.2 \mathrm{E}-6$

$1.6 \Sigma-4$

$2.2 \mathrm{E}-6$

$2 \cdot 2 \mathrm{E}-6$

$2.2 E-6$
$2.2 E-6$

3. $0 E-4$

$1.4 E-8$

$3.0 E-4$

1. $4 E-8$

3. $0 E-4$

1. $4 \mathrm{E}-8$
9. $00 \mathrm{E}-02$

7. 45E-02 6.43E-07

4. $80 \mathrm{E}-04$

2. $00 \mathrm{E}-01$

9. $00 \mathrm{E}-02$

4. 80E-04 6.05E-07

7. $01 \mathrm{E}-02$

2.00E-01

9. $00 \mathrm{E}-02$

$4.80 E-04 \quad 6.05 E-07$

$7.01 \mathrm{E}-02$

$2.00 \mathrm{E}-02$

$2.00 \mathrm{E}-01$

$9.00 \mathrm{E}-02$

$7.01 E-02 \quad 6.05 E-07$

6. $00 \mathrm{E}-01$

1. $60 \mathrm{E}-04$

9. $00 \Sigma-02$

$9.00 \mathrm{E}-02$

$1.93 \mathrm{E}-02$

1. $60 \mathrm{E}-0$

$9.00 \mathrm{E}-02$

1. $93 E-02$

1. $60 \mathrm{E}-04$

9. $00 \mathrm{E}-02 \quad 2.78 \mathrm{E}-07$

1. $93 \mathrm{E}-02$

1. $60 \mathrm{E}-04$

2. $00 \mathrm{E}-01 \quad 2.56 \mathrm{E}-07$

3. $85 \mathrm{E}-02$

$3.85 E-02$

3.70E-04

$2.00 \mathrm{E}-02$

3. $85 \mathrm{E}-02$

3. $85 \mathrm{E}-02$

3. $70 \mathrm{E}-04$

9. $00 \mathrm{E}-02$

5. $26 \mathrm{E}+00$

2. $00 \mathrm{E}-01$

9. $00 \mathrm{E}-02$

$5.26 E+00 \quad 2.23 E-07$

2. $00 \mathrm{E}-01$

2. $35 E-06$

9. $00 \mathrm{E}-02$

5. $26 E+00 \quad 2.23 E-07$

2. $00 \mathrm{E}-01$

2. 35E-06 
MODULE/EVENT NAME

MODULE/EVENT NAME

IGNITION

228) $8 \mathrm{AZO21HW}$ 8HOUSE03 8XVHV4 PGA IGNITION

229) 8AZO22HWA 8 HOUSEO1 8XVVIOPG* IGNITION

230) 8 AZO22 BHOUSE01 8XVHV3PG* IGNITION

231) 8AZO22HWA 8 HOUSE 03 8XVVIOPG*

32) 8AZO22HWA 8HOUSE 03 8XVHV3PG* IGNITION

233) $8 \mathrm{FC} 112 \mathrm{HW}$ * 8HOUSEO1 $8 \times \mathrm{OV} 19 \mathrm{HW}$ IGNITION

234) 8FC112 $\mathrm{HW}^{*}$ 8HOUSE 03 $8 X V 19 \mathrm{HW}$

235) BEN528HW* 8HOUSE01 8XVV1 9HW IGNITION

236) 8FN528HW* $8 \mathrm{HOUSEO} 3$ $8 \times V V 19 H W$ IGNITION

237) 9FC122TM 9XVN16PG* IGNITION

238) 9PRPV2TM 9XVN19PG* IGNITION

239) 9FC122TM IGNITION
Truncation Limit: $1.00 \mathrm{E}-08$

\section{DESCRIPTION}

CONDITIONAL PROBABILITY OF HAVING AN IGNITION SOURCE PRESENT TANK 48 O2 ANALYZER 1 HARDWARE FAULTS

CONDITIONAL PROBABILITY OF BEING IN WASH CYCLE

MANUAL VALVE T48-HV4 FAILS TO REMAIN OPEN (PLUG)

CONDITIONAL PROBABILITY OF HAVING AN IGNITION SOURCE PRESENT TANK 4802 ANALYZER 2 HARDWARE FAULTS

CONDITIONAL PROBABILITY OF TRANSEERRING SALT SOLUTION $170 \mathrm{C}$ TEMP MANUAL VALVE T48-HV10 FAILS TO REMAIN OPEN (PLUG)

CONDITIONAL PROBABILITY OF HAVING AN IGNITION SOURCE PRESENT

TANK 4802 ANALYZER 2 HARDWARE FAULTS

CONDITIONAL PROBABILITY OF TRANSFER" NG SALT SOLUTION $170 \mathrm{C}$ TEMP)

MANUAL VALVE T48-HV3 FAILS TO REF $\cong$ OPEN (PLUG)

CONDITIONAL PROBABILITY OF HAVING AN IGNITION SOURCE PRESENT

TANK 4802 ANALYZER 2 HARDWARE EAULTS

CONDITIONAL PROBABILITY OF BEING IN WASH CYCLE

MANUAI VAL TOBABILITY OF BEING IN WASH CYCLE

CONDITIONAL PROBABILITY OF HAVING AN IGNITION SOURCE PRESENT

TANK 4802 ANALYZER 2 HARDWARE FAULTS

CONDITIONAL PROBABILITY OF BEING IN WASH CYCLE

MANUAL VALVE T48-HV3 EAILS TO REMAIN OPEN (PLUG)

CONDITIONAL PROBABILITY OE HAVING AN IGNITION SOURCE PRESEN

FLOW CONTROL VALVE 1211 PV2 MECHANICAL FAULT

CONDITIONAL PROBABILITY OE TRANSFERRING SALT SOLUTION $170 \mathrm{C}$ TEMP

MANUAL VALVE T48-HV19 FAILS TO OPEN ON DEMAND

CONDITIONAL PROBABILITY OF HAVING AN IGNITION SOURCE PRESENT

FLOW CONTROL VALVE $1211 \mathrm{PV} 2$ MECHANICAL FAULT

CONDITIONAL PROBABILITY OF BEING IN WASH CYCLE

MANUAI VALVE T48-HVI9 FAILS TO OPEN ON DEMAND

CONDITIONAL PROBABILITY OF HAVING AN IGNITION SOURCE PRESENT

TANK 48 EXHAUST EAN Y 348-52-8 EAILS TO RUN DUE TO MECHANICAL FAULT

CONDIT

CONDITIONAL PROBABILITY OF TRANSERR ING SALT

CONDITIONAL PROBABI

TANK 48 EXHAUST FAN Y348-52-8 FAILS TO RUN DUE TO MECHANICAL FAULT TANK 48 EXHAUST FAN Y348-52-8 EAILS WO RUN DYL

CONDITIONAL PROBABILITY OF BEING IN WASH CYALE

MANUAL VALVE TA-ABILITY OF HAVING AN IGNITION SOURCE PRESENT

CONDITIONAL PROBABILITY OF HAVING AN IGNITION SOURCE MRENTENANCE

TANK 49 PATH A DISCHARGE VALVE T49-N16 FAILS TO REMAIN OPEN (PLUG)

CONDITIONAL PROBABILITY OF HAVING AN IGNITION SOURCE PRESENT

TANK 49 PRESSURE REGULATING VALVE 1255PV2 UNAVAILABLE DUE TO MAINT

TANK 49 PATH A INLET VALVE T49-N19 EAILS TO REMAIN OPEN (PLUG)

CONDITIONAL PROBABILITY OF HAVING AN IGNITION SOURCE PRESENT

TANK 49 FLOW CONTROL VALVE $1252 \mathrm{FV}$ UNAVAILABLE DUE TO MAINTENANCE

TANK 49 PATH A INLET VALVE T49-N19 FAILS TO REMAIN OPEN (PLUG)

CONDITIONAL PROBABILITY OF HAVING AN IGNITION SOURCE PRESENT
RATE

EXPOSURE B.E.

9.00E-02

$5.26 \mathrm{E}+00$

2. $00 \mathrm{E}-01$

$2.35 \mathrm{E}-06$

$9.00 \mathrm{E}-02$

4. $92 \mathrm{E}-02$
$2.00 \mathrm{E}-01$

$2.00 E-01$

$2.45 E-04$
$9.00 E-02$

$2.00 \mathrm{E}-01$

$2.45 E-04$

9. $00 \mathrm{E}-02$

4. 92E-02 2.17E-07

2. $00 \mathrm{E}-01$

$2.45 \mathrm{E}-04$

4. 92E-02 2.17E-07

2. $00 \mathrm{E}-01$

$2.45 E-04$

$9.00 E-02$

$7.45 \mathrm{E}-02$
$2.00 \mathrm{E}-01$

2. $00 \mathrm{E}-01$

$1.60 \mathrm{E}-04$

9. $00 \mathrm{E}-02$

7. $45 E-02$
$2.00 E-01$

$1.60 \mathrm{E}-04$

9. $00 \mathrm{E}-02$

$7.01 E-02 \quad 2.02 E-07$

2. $00 E-01$

1. $60 \mathrm{E}-04$

9. $00 \mathrm{E}-02$

$7.01 E-02 \quad 2.02 E-07$

2. $00 \mathrm{E}-01$
$1.60 \mathrm{E}-04$

$1.60 E-04$

$9.00 E-02$

20E-03 1.59E-07

$2.45 E-04$

$9.00 \mathrm{E}-02$

$7.20 E-03 \quad 1.59 E-07$

$2.45 \mathrm{E}-04$

$9.00 \mathrm{E}-02$

$\begin{array}{ll}7.20 E-03 & 1.59 E-07\end{array}$

$2.45 \mathrm{E}-04$

9. $00 \mathrm{E}-02$
PROB.

$2.23 E-07$

$.17 E-07$

$2.17 E-07$

$2.14 E-07$ 


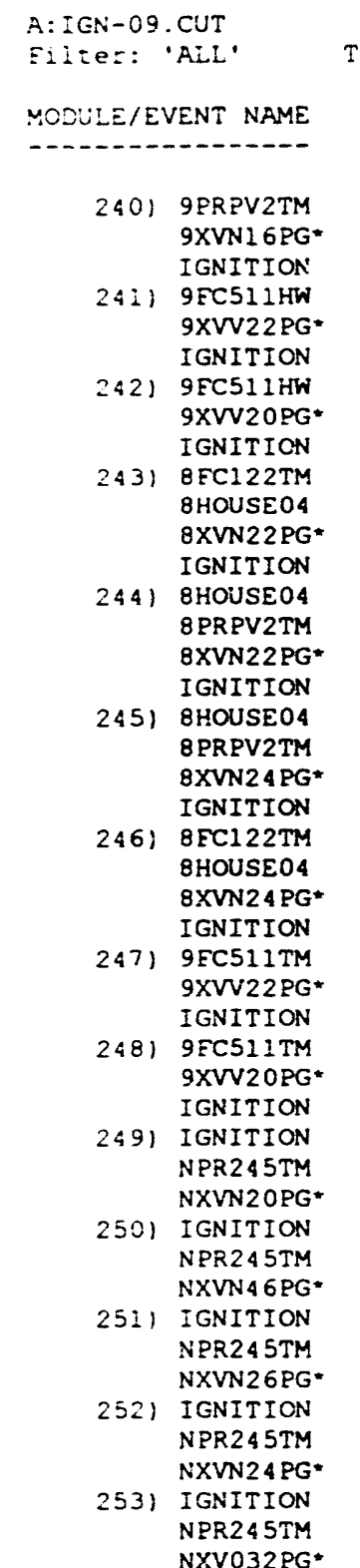

Truncation Limit: $1.00 \mathrm{E}-08$

CUTSET REPORT

DESCRIPTION

TANK 49 PRESSURE REGULATING VALVE 1255 PV2 UNAVAILABLE DUE TO MAINT 3.6 -3 TANK 49 PATH A DISCHARGE VALVE T49-N16 FAILS TO REMAIN OPEN (PLUG) 1.4E-8 CONDITIONAL PROBABILITY OF HAVING AN IGNITION SOURCE PRESENT ELOW CONTROL VALVE 1251 PVI MECHANICAL EAULT

MANUAL VALVE T49-HIV22 EAILS TO REMAIN OPEN (PLUG)

CONDITIONAL PROBABILITY OF HAVING AN IGNITION SOURCE PRESENT FLOW CONTROL VALVE 1251 PVI MECHANICAL FAULT

MANUAL VALVE T49-HV20 FAILS TO REMAIN OPEN (PLUG)

CONDITIONAL PROBABILITY OF HAVING AN IGNITION SOURCE PRESENT

TANK 48 FLOW CONTROL VALVE 1202 EV UNAVAILABLE DUE TO MAINTENANCE

CONDITIONAL PROBABILITY OF BEING IN NORMAL PROCESSING MODE $140 \mathrm{C} \mathrm{T}$

TANK 48 PATH A INLET MANUAL VALVE T48-N22 FAILS TO REMAIN OPEN 1

CONDITIONAL PROBABILITY OF HAVING AN IGNITION SOURCE PRESENT

CONDITIONAL PROBABIITY OF OEING IN NORMAI PROCESSING MODE $140 \mathrm{C}$

CONDITIONL

TANK 48 PRESSURE REGULATING VALVE 1205PV UNATL TO REMAIN OPEN $11.4 E-8$ TANK 48 PATH A INLET MANUAL VALVE TA IGITITION SOURCE PRESENT

CONDITIONAL PROBABILITY OF HAVING AN IGNITION SOURCE PRESENT

CONDITIONAL PROBABILITY OF BEING IN NORMAL PROCESSING MODE $140 \mathrm{C}$

TANK 48 PRESSURE REGULATING VALVE 120SPV2 UNAVAILABLE DUE TO MAINT $3.6 E-3$

CONDITIONAL PROBABIIITY OF HAVING AN IGNITION SOURCE PRESENT

PROBABILITY OF HAVING AN IGNTTION SOURCE BRESENT

CONDITIONAI CONTROL VALVE 1202EV UNAVAILABLE DUE TO MAINTENANCE

DEING IN NORHAL PROCESSING MODE (40 C T

CONDITIONAL PROBABILITY OF HAVING AN IGNITION SOURCE PRESENT

FLOW CONTROL VALVE 1251 PVI MAINTENANCE

MANUAL VALVE T49-HV22 EAILS TO REMAIN OPEN (PLUG)

CONDITIONAL PROBABILITY OE HAVING AN IGNITION SOURCE PRESENT

FLOW CONTROL VALVE 1251 PVI MAINTENANCE

MANUAI VALVE T49-HV20 FAILS TO REMAIN OPEN (PLUG)

CONDITIONAL PROBABILITY OF HAVING AN IGNITION SOURCE PRESENT

CONDITIONAL PROBABILITY OF HAVING AN IGNITION SOURCE PRESENT PRESSURE REGULATING VALVE $2045 P V$ MAINTENANCE

PATH A OUTLET VAIVE Y2O FAIIS TO REMAIN OPEN (PLUG)

PATH A OUTLET VAIVE N2O FAILS TO REMAIN OPEN (PLUG) PRESSURE REGULATING VALVE 2045 PV MAINTENANCE

PRESSURE REGULATING VALVE $2045 P V$ MAINTENANCE

MANUAL VALVE N46 FAILS TO REMAIN OPEN (PLUG) SOURCE PRESENT CONDITIONAL PROBABILITY OF HAVING AN IGNITION

PRESSURE REGULATING VALVE 2045 PV MAINTENANCE

CONDITIONAL PROBABILITY OE HAVING AN IGNITION SOURCE PRESENT PRESSURE REGULATING VALVE 2045PV MAINTENANCE

PATH A INLET VALVE N24 FAILS TO REMAIN OPEN (PLUG)

CONDITIONAL PROBABILITY OE HAVING AN IGNITION SOURCE PRESENT PRESSURE REGULATING VALVE 2045 PV MAINTENANCE

MANUAL VALVE N32 FAILS TO REMAIN OPEN (PLUG)
1-10-94 12:41 Page 19

B.E. MOD. ICS

EXPOSURE PROB. PROB.

$20 E-03 \quad 1.59 E-07$

$2.45 E-04$

$9.00 E-02$

$9.18 E-03$

$1.23 E-04$

$9.00 \mathrm{E}-02$

$9.18 E-03 \quad 1.01 E-07$

$1.23 E-04$

$9.00 \mathrm{E}-02$

7. 20E-03 9.54E-08

$6.00 E-01$

$2.45 E-04$

$9.00 \mathrm{E}-02$

$6.00 E-01 \quad 9.54 \Sigma-08$

7. 20E-03

$2.45 E-04$

$9.00 E-02$

6.00E-01 $9.54 E-08$

$7.20 \mathrm{E}-03$

$2.45 \mathrm{E}-04$

$2.45 E-04$
$9.00 E-02$

$7.20 E-03 \quad 9.54 E-08$

$7.20 E-03$

$6.00 E-01$

$2.45 E-04$

$9.00 E-02$
$7.20 E-03 \quad 7.95 E-08$

$1.23 E-04$

$9.00 E-02$

7. 20E-03 7.95E-08

$1.23 E-04$

$9.00 \mathrm{E}-02$

9. $00 E-02 \quad 7.95 E-08$

$7.20 E-03$

1. $23 E-04$

9.00E-02 7.95E-08

$1.23 E-C 4$

$9.00 E-02 \quad 7.95 E-08$

7. $20 E-03$

i. $23 E-04$

$9.00 E-02 \quad 7.95 E-08$

$1.23 E-04$

$9.00 E-02 \quad 7.95 E-08$

7. $20 \mathrm{E}-03$

1. $23 E-04$ 
254) 9AZO22TM $9 \times V V 10$ PG* $^{*}$ IGNITION

255) 9AZO22TM 9XVHV3PG*
IGNITION

256) $8 \mathrm{FCI} 11 \mathrm{HW}$ 8 HOUSE 04 XVV20PG* IGNITION

257) 8FC111HW BHOUSE04 $8 X V V 22 P G$ IGNITION

258) IGNITION NVPVPAHW* NXVN15HW

259) IGNITION NVPVPAHW* NXVN16 HW

260) IGNITION NVPVPAHW* NXVN47HW

261) 8FC111TM 8HOUSE 04 $8 X V V 20 P G$ IGNITION

262) 8FCIIITM BHOUSE 04 BXVV22PG IGNITION

263) $8 A 2022 T M$ 8HOUSE04 8XVV10PG* IGNITION

264) 8AZO22TM 8HOUSE 04 8XVHV3PG* IGNITION

265) 9FN511TM 9XVV22PG* IGNITION

266) 9FN511TM 9XVV2OPG*
IGNITION

267) ignition
TANK 49 O2 ANALYZER 2 UNAVAILABLE DUE TO MAINTENANCE MANUAL VALVE T49-HV10 EAILS TO REMAIN OPEN (PLUG)

CONDITIONAL PROBABILITY OF HAVING AN IGNITION SOURCE PRESENT TANK 49 O2 ANALYZER 2 UNAVAILABLE DUE TO MAINTENANCE

MANUAL VALVE T49-HV3 FAILS TO REMAIN OPEN (PLUG)

CONDITIONAL PROBABILITY OF HAVING AN IGNITION SOURCE PRESENT

FLOW CONTROL VALVE 1211 PVI MECHANICAL FAULT (MODE C)

CONDITIONAL PROBABILITY OF BEING IN NORMAL PROCESSING MODE $140 \mathrm{C} \mathrm{T}$ MANUAL VALVE T4B-HV2O EAILS TO REMAIN OPEN (PLUG)

CONDITIONAL PROBABILITY OF HAVING AN IGNITION SOURE

CONDITIONAL PROBABILITY OE HAVING AN IGNTTY SOURCE PRESENT

CONDITIONAL VROBAB 1211PVI MECHANICAN IGNITION SOURCE PRESENT

MANUAI VALVE T48- IVI2 FAILS TO REMAIN OPEN (PLUGI

MANUAL VALVE T48-HV22 FAILS TO REMAIN OPEN (PLUG)

CONDITIONAL PROBABILITY OF HAVING AN IGNITION SOURCE PRESENT

CONDITIONAL PROBABILITY OE HAV TAR AN IGNIAUE FAULTS

MANUAL VALVE N15 FAILS TO OPEN

CONDITIONAL PROBABILITY OF HAVING AN IGNITION SOURCE PRESENT

FAILURE OE VAPORIZER A DUE TO HARDWARE FAULTS

MANUAL VALVE N16 FAILS TO OPEN ON DEMAND

CONDITIONAL PROBABILITY OF HAVING AN IGNITION SOURCE PRESENT FAILURE OF VAPORIZER A DUE TO HARDWARE FAULTS

MANUAL VALVE N47 EAILS TO OPEN ON DEMAND

FLOW CONTROL VALVE 1211 PVI MAINTENANCE

CONDITIONAL PROBABILITY OF BEING IN NORMAL PROCESSING MODE $140 \mathrm{C} \mathrm{T}$

MANUAL VALVE T48-HV20 FAILS TO REMAIN OPEN (PLUG)

CONDITIONAL PROBABILITY OF HAVING AN IGNITION SOURCE PRESEN

FLOW CONTROL VAIVE 1211 PVI MAINTENANCE

CONDITIONAL PROBABILITY OF BEING IN NORMAL PROCESSING MODE $140 \mathrm{C}$

MANUAI VALVE TAB-HV22 FAILS TO REMAIN OPEN (PLUG)

CONDITIONAL PROBABILITY OF HAVING AN IGNITION SOURCE PRESENT

TANK

CONDIG O2 ANALYZER 2 UNAVAILABLE DUE TO MATNTENANCE MODE $140 \mathrm{C}$

MANUAL VALVE T48-HVIO FAILS TO REMAIN OPEN (PLUG)

CONDITIONAL PROBABILITY OF HAVING AN IGNITION SOURCE PRESEN

TANK 48 O2 RROBABILITY OF 2 INAVAILABLE DUE TO MAINTENANCE

TANK 48 O2 ANALYZER 2 UNAVAILABLE DUE TO MAINTENANCE

CONDITIONAL PROBABILITY OE BEING IN NORMAL PROCESS

CONDITIONAIE T48-HV3 FAILS TO REMAIN OPEN (PLUG)

TANK 49 EXHAUST FAN Y 349-52-11 UNAVAILABLE DUE TO MAINTENANCE

MANUAL VALVE T49-HV22 FAILS TO REMAIN OPEN (PLUG)

CONDITIONAL PROBABILITY OF HAVING AN IGNITION SOURCE PRESENT

TANK 49 EXHAUST FAN Y349-52-11 UNAVAILABLE DUE TO MAINTENANCE

MANUAL VALVE T49-HV20 EAILS TO REMAIN OPEN (PLUG)

CONDITIONAL PROBABILITY OF HAVING AN IGNITION SOURCE PRESENT

CONDITIONAI PROBABILITY OF HAVING AN IGNITION SOURCE PRESENT
RATE

RATE

$1.8 E-3$
$1.4 E-8$

1. $8 E-3$

$1.8 E-3$
$1.4 E-8$

$8.5 E-6$

$4 E-8$

$.4 E-8$

$5 E-6$

$1.4 \mathrm{E}-8$

4. $1 E-7$
$1.6 E-4$

$4.1 E-7$

$1.6 E-4$

4.1E-7

$1.6 \mathrm{E}-4$

3. $6 \mathrm{E}-3$

$1.4 E-8$

$3.6 E-3$

$1.4 E-8$

$1.8 \mathrm{E}-3$

1. $4 \mathrm{E}-8$

$1.8 E-3$

$1.4 E-8$

$1.8 E-3$

$1.4 E-8$

$1.8 \mathrm{E}-3$

1. $4 E-8$

EXPOSURE PROB.

2

.09

2

.09

3

.60

109

3

.60

1

.09

1

.09

1

.0

1

2

i

.09

60

1

.09

2.60

2

2

.60

2.09

2

.09

2

.09

.09

$3.60 E-03 \quad 7.95 E-08$

$2.45 E-04$

$9.00 \mathrm{E}-02$

3. $60 E-03 \quad 7.95 E-08$

$2.45 E-04$

$9.00 E-02$

9. $18 \mathrm{E}-03 \quad 6.08 \mathrm{E}-08$

$6.00 \mathrm{E}-01$

$1.23 E-04$

9.00E-02

9.18E-03 $6.08 E-08$

$6.00 \mathrm{E}-01$

$1.23 E-04$

9.00E-02

9.00E-02 5.17E-08

$3.59 \mathrm{E}-03$

$3.59 \mathrm{E}-03$
$1.60 \mathrm{E}-04$

9.00E-02 5.17E-08

$9.00 \mathrm{E}-02$

$3.59 E-03$
$1.50 E-04$

9.00E-02 5.17E-08

3.59E-03

$1.60 E-04$

$7.20 E-03 \quad 4.77 E-08$

6. $00 E-01$

1. $23 E-04$

$9.00 E-02$

7.20E-03 4.77E-08

$6.00 \mathrm{E}-01$

$1.23 E-04$

$9.00 E-02$

3. $60 \mathrm{E}-03$

$6.00 E-01$

6.00E-01

$2.45 E-04$

9. $00 \mathrm{E}-02$

$3.60 \mathrm{E}-03$

6. $00 \mathrm{E}-01$

$2.45 E-04$

$9.00 E-02$

$3.60 E-03 \quad 3.97 E-08$

$1.23 E-04$

$9.00 E-02$

3.60E-03 3.97E-08

$1.23 E-04$

$9.00 \mathrm{E}-02$

9.00E-02 7.60E-10 


\begin{tabular}{|c|c|}
\hline$A: I G N-09$. & \\
\hline Fitez: & ALL' \\
\hline MODULE/EV & VENT NAME \\
\hline & nvpvpbhw \\
\hline 2681 & nxvn20pg* \\
\hline 2001 & $\begin{array}{l}\text { nvpvpbhw } \\
\text { nxvn24pg* }\end{array}$ \\
\hline 2691 & $\begin{array}{l}\text { 1gnition } \\
\text { nvpvpbhw } \\
\text { nxvn46pg. }\end{array}$ \\
\hline 2701 & $\begin{array}{l}\text { ignition } \\
\text { nvpvpbhw } \\
\text { nxvn26pg* }\end{array}$ \\
\hline 2711 & $\begin{array}{l}\text { ignition } \\
\text { nvpvpbhw } \\
\text { nxv032pg* }\end{array}$ \\
\hline 2721 & $\begin{array}{l}8 F C 122 \mathrm{TM} \\
\text { 8HOUSEO3 }\end{array}$ \\
\hline & $8 X V N 24 P G^{*}$ \\
\hline & IGNITION \\
\hline 2731 & BHOUSE03 \\
\hline & 8PRPV2TM \\
\hline & $8 X V N 22 P G$ \\
\hline & I GN ITION \\
\hline 2741 & 8HOUSEO3 \\
\hline & BPRPV2TM \\
\hline & $8 \times V N 24 P G$ \\
\hline & IGNITION \\
\hline 2751 & $8 F C 122 T M$ \\
\hline & 8HOUSE 03 \\
\hline & $8 X V N 22 P G$ \\
\hline & IGNITION \\
\hline 2761 & BHOUSE01 \\
\hline & 8PRPVZTM \\
\hline & $8 \times V N 22 P G$ \\
\hline & IGNITION \\
\hline 2771 & $8 \mathrm{EC} 122 \mathrm{TM}$ \\
\hline & BHOUSEOI \\
\hline & $8 X V N 228 G^{\circ}$ \\
\hline & IGNITION \\
\hline 2781 & BHOUSEOI \\
\hline & BPRPV2TM \\
\hline & $8 X V N 24 P G$ \\
\hline & IGNITION \\
\hline 2791 & $8 \mathrm{FC122TM}$ \\
\hline & 8HOUSEO 1 \\
\hline & $8 X V N 24 P G$ \\
\hline & IGNITION \\
\hline
\end{tabular}
DESCRIPTION

FAILURE OF VAPORIZER B DUE TO HARDWARE FAULTS

PATH A OUTLET VALVE N2O FAILS TO REMAIN OPEN (PLUG)

CONDITIONAI PROBABILITY OF HAVING AN IGNITION SOURCE PRESENT

FATLURE OF VAPORIZER B DUE TO HARDWARE FAULTS

PATH A INLET VALVE N24 FAILS TO REMAIN OPEN (PLUG)

PATH A INLET VALVE N24 FA HAVING AN IGNITION SOURCE PRESENT

FAILURE OF VAPORIZER B DUE TO HARDWARE FAULTS

MANUAL VALVE N46 FAILS TO REMAIN OPEN (PLUG)

CONDITIONAL PROBABILITY OF HAVING AN IGNITION

EAILURE OF VAPORIZER B DUE TO HARDWARE FAULTS

MANUAL VALVE N26 FAILS TO REMAIN OPEN (PLUG)

CONDITIONAL PROBABILITY OE HAVING AN IGNITION SOURCE PRESENT

EAILURE OF VAPORIZER B DUE TO HARDWARE EAULTS

MANUAL VALVE N32 EAILS TO REMAIN OPEN (PLUG)

TANK 48 FLOW CONTROL VALVE $1202 \mathrm{FV}$ UNAVAILABLE DUE TO MAINTENANCE

CONDITIONAL PROBABILITY OF BEING IN WASH CYCLE

TANK 48 PATH A DISCHARGE VALVE T4B-N24 FAILS TO REMAIN OPEN (PLUG)

CONDITIONAL PROBABILITY OF HAVING AN IGNITION SOURCE PRESENT

CONDITIONAI PROBABIIITY OF BEING IN KASH CYCLE

TANK 40 PRESSURE REGULATING VALVE 1205PV2 UNAVAILABLE DUE TO MAINT 3.6E-3

TANK 9 PATH A INLET MANUAL VAIVE T48-N22 FAILS TO REMAIN OPEN $11.4 E-8$

TANK

CONDITIONAL PROBABLITY OF HAVING AN WASH CYCLE

CONK

TANK 48 PRESSURE REGULATING VALVE 1205PV2 UNAVAILABLE DUE TO MATNT 3 GE-3

TANK 48 PATH A DISCHARG OE HAVING AN IGNITION SOURCE PRESENT

TANK 4 GLON CONTROL VALVE 1202 V UN IGNITION SOURCE BRESENT

$\quad 3.6 \mathrm{E}-3$

CONDITIONAL PROBABILITY OF BEING IN WASH CYCLE

APEN $1.4 E-8$

CONDITIONAL PROBABILITY OF HAVING AN IGNITION SOURCE PRESENT

CONDITIONAL PROBABILITY OF TRANSFERRING SALT SOLUTION $170 \mathrm{C}$ TEMP)

TANK 48 PRESSURE REGULATING VALVE 1205 PV2 LNAVAILABLE DUE TO MAINT $3.6 E-3$

TANK 48 PATH A INLET MANUAL VALVE T48-N22 FAILS TO REMAIN OPEN $11.4 E-8$

CONDITIONAL PROBABILITY OF HAVING AN IGNITION SOURCE PRESENT

TANK 48 FLOW CONTROL VALVE $1202 \mathrm{FV}$ UNAVAILABLE DUE TO MAINTENANCE

CONDITIONAL PROBABILITY OF TRANSFERRING SALT SOLUTION (70 C TEMP)

CONDITIONAL PROBABILITY OF HAVING AN IGNITION SOURCE PRESENT

CNDITIONAL PROBABILTY OF TRANSFERRING SALT SOLUTION 170 C TEMPI

TANK 4B PRESSURE REGULATING VALVE 1205 PV2 UNAVAILABLE DUE TO MAINT

TANK 4Q PRESH ARE REGLATING TALE T48-N24 FAILS TO REMAIN OPEN (PIUG) $1.6 E-3$

TANK

TONK

TANK 48 FLOW CONTROL VALVE 1 202EV UNAVAILALE DUE TO MATNTENANCE

CONDITIONAL PROBABILITY OE TRANSEERRING SALT SOLUTYNIN OPEN (PLUG)

CONDITIONAL PROBABILITY OF HAVING AN IGNITION SOURCE PRESENT

\section{EXPOSURE PROB.}

MOD. $/ \mathrm{CS}$

PROB.

$.23 E-04$

$.00 E-02 \quad 7.60 E-10$

$6.89 E-05$

$1.23 E-04$

$9.00 E-02 \quad 7.60 E-10$

$6.89 E-05$

1. $23 E-04$

$9.00 E-02 \quad 7.60 E-10$

6. $89 \mathrm{E}-05$

9.00E-02 7.60E-10

$6.89 E-05$

6. $89 E-05$

$1.23 E-04$

$7.20 \mathrm{E}-03 \quad 3.18 \mathrm{E}-08$

2. $00 \mathrm{E}-01$

$2.45 E-04$

$9.00 \mathrm{E}-02$

2.00E-01 3.18E-08

$7.20 E-03$

2. 45E-04

9. $00 E-02$

2.00E-01 3.18E-08

$7.20 E-03$

$2.45 E-04$

9.00E-02

$7.20 E-03 \quad 3.18 E-08$

$2.00 E-01$

$2.45 E-04$

2.00E-01 3.18E-08

$2.00 E-01$
$7.20 E-03$

$2.45 E-04$

9. $00 E-02$

$7.20 \varepsilon-03 \quad 3.18 E-08$

2. $00 E-01$

2. $45 E-0.4$

9. $00 \mathrm{E}-02$

2. $00 E-01 \quad 3.18 E-08$

$7.20 E-03$

$2.45 \mathrm{E}-04$

9. $00 \mathrm{E}-02$

7.20E-03 3.18E-0E

$2.00 E-01$

$2.45 E-04$

9. $00 \mathrm{E}-02$

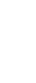


280) $9 \mathrm{FCl} 22 \mathrm{HW}$ 9XVN19PG* IGNITION

281) 9FC122HW 9XVN16PG* IGNITION

$282195 \mathrm{Cl} 121 \mathrm{HW}$ 9XVN15PG

IGNITION 9XVN13PG 9XVN13PG

284) IGNITION NPR2 45HW NPR245HW

285) IGNITION NPR2 45HW $N X V N 26 P G *$

286) IGNITION NPR24 SHW NXVN2OPG*

287) IGNITION NPR245HW

288) IGNITION NPR245HW NXVN46PG*

289) 8EN527TM 8 HOUSE04 $8 X V V 20 P G *$ IGNITION

290) 8FN527TY 8 HOUSEO4 $8 \times W 22 P G$ IGNITION

29i) BFCIIIHW OHOUSE 03 8XVV20PG IGNITION

292) BFC111HW 8HOUSE03 8XVV22PG. IGNITION

293) BFC111 HW BHOUSE01 BXVV2OPG.

MECHANICAL EAULT OF TANK 49 FLOW CONTROL VALVE $1252 \mathrm{FV}$ TANK 49 PATH A INLET VALVE T49-N19 FAILS TO REMAIN OPEN (PLUG) TANK 49 PATH A INLET VALVE T49-NI9 FAILS TO REMAIN OPEN IPLUG, CONDITIONAL PROBABILITY 49 FLOW CONTROL VALVE 1252 EV

MECHANICAL FAULT OE TANK 49 ELON CONTROL VALVE 1252 IN TANK 49 PATH A DISCHARGE VALVE T49-N16 FAILS TO REMAIN OPEN CONDITIONAL PROBABILITY OF HAVING AN IGNITION SOURCE

MECHANICAL EAULT OF TANK 49 ELOW CONTROL VALVE 1251FV TANK 49 PATH B DISCHARGE VALVE T49-N15 FAILS TO REMAIN OPEN (PLUG) CONDITIONAL PROBABILITY OF HAVING AN IGNITION SOURCE PRESENT MECHANICAL FAULT OF TANK 49 FLON CONTROL VALVE 1251FV MANUAL VALVE T49-N13 FAILS TO REMAIN OPEN (PLUG)

CONDITIONAL PROBABILITY OF HAVING AN IGNITION SOURCE PRESENT CONDITIONAL PROBABILITY OF HAVING AN IGNITION SOURCE PRESENT PRESSURE REGULATING VA:VE 2045PV FAILS

MANUAL VALVE N32 FAILS TO REMAIN OPEN (PLUG)

CONDITIONAI PROBABILITY OF HAVING AN IGNITION SOURCE PRESENT PRESSUPS REGULATING VALVE 2045PV FAIIS

RANUA VAIVE N26 FAIIS TO REMAIN OPEN (PLUG)

CONDITINAI PROBABILITY OF HAVING AN IGNITION SOURCE PRESENT CONDTT

(PLUG)

PATH A OUTLET VALVE N2O FAI HAVING AN IGNITION SOURCE PRESENT PRESSURE REGULATING VAIVE. 2045 PV FAILS

PRESSURE REGULATING VAIVE 2045 PV FAILS

PATH A IINLET VALVE N24 FAILS TO REMAN IGNITION SOURCE PRESENT PRESSURE REGULATING VALVE 2045 PV FAILS

MANUAL VALVE N46 FAIIS TO REMAIN OPEN (PLUG)

TANK 48 EXHAUST EAN Y340-52-7 UNAVAILABLE DUE TO MAINTENANCE

CONDITIONAL PROBABILITY OF BEING IN NORMAL PROCESSING MODE $140 \mathrm{C}$ MANUAL VAIVE T48-HV2O FAILS TO REMAIN OPEN (PLUG)

CONDITIONALL PROBABILITY OF HAVING AN IGNITION SOURCE PRESEN TANK 48 EXHAUST FAN Y348-52-7 UNAVAILABLE DUE TO MAINTENANCE CONDITIONAL PP $2: B B_{1}$ ITY OF BEING IN NORMRL PROCESSING MODE $140 \mathrm{C}$ MANUAL VALVE TGL-HY?2 FAILS TO REMAIN OPEN (PLUG)

CONDITIONAL PROBABILITY OF HAVING AN TGNITION SOURCE PRESENT

FLOW CONTROL VALVE 1211 PVI MECHANICAL FAULT (MODE C)

CONDITIONAL PROBABILITY OF BEING IN WASH CYCLE

MANUAL VALVE T48-HV20 EAILS TO REMAIN OPEN IPLUGI

MANUAL VALVE T48

FLOW CONTROL VALVE 1211 PVI MECHANICAL FAULT (MODE C)

CONDITIONAL PROBABILITY OF BEING IN WASH CYCLE

CONDITIONAL PROBABILITY OF BEING IN WAS OPEN (PLUG)

MANUAL VALVE T48-HV22 EAILS TAVING AN IGNITION SOURCE PRESENT

CONDITIONAL PROBABILITY PVI MECHANICAL FAULT (MODE C)

CON CONTROL VALVE 1211PVI MECHANICAL EAULT IMOLUTION $170 \mathrm{C}$ TEMPI

MANUAL VALVE T48-HV2O FAILS TO REMAIN OPEN (PLUG)
RATE

EXPOSURE PROB.

PROB.

$5 E-6$

7

1. $4 E-8 \quad 2$

$1.4 E-8 \quad 2$

$5 E-6$

. $4 E-8$

$8.5 E-6$

$1.4 E-8$

$1.43 E-03$

3. $15 E-08$

. $.45 E-04$

$1.43 E-03 \quad 3.15 E-08$

$2.45 E-04$

$2.45 E-04$

$1.49 E-01 \quad 3.15 E-08$

2. $95 E-06$

1.49E-01 3.15E-08

$1.49 E-01$

$2.35 E-06$

$9.00 E-02$
$9.00 E-02$
$2.62 E-08$

2. 38E-03

$1.23 E-04$

$9.00 E-02 \quad 2.62 E-08$

$2.2 E-6$
$1.4 E-8$

2.38E-03

1. $23 E-04$

9.00E-02 2.62E-08

2. $38 \mathrm{E}-03$

1. 23E-04

9.00E-02 2.62E-08

$2.38 \varepsilon-03$

1.23E-04

$9.00 E-02 \quad 2.62 E-08$

$2.38 E-03$

3. $60 E-03 \quad 2.38 E-08$

$6.005-01$

1. $23 \mathrm{E}-04$

$1.23 E-04$

3. $60 E-03 \quad 2.38 E-08$

6. $00 \mathrm{E}-01$

1. $23 \mathrm{E}-04$

9.00E-02

9.18E-0, 2.03E-08

2.00E-01

1. 23E-04

9. $00 \mathrm{E}-02$

9.18E-03 2.03E-0B

2. $00 E-01$

1. $23 E-04$

9.00E-02

$9.18 E-03 \quad 2.03 E-08$

$2.00 E-01$

$2.00 E-01$ 
CONDITIONAL PROBABILITY OF HAVING AN IGNITION SOURCE PRESENT

FLN CONTROL VALVE 1211 PVI MECHANICAL FAULT (MODE C)

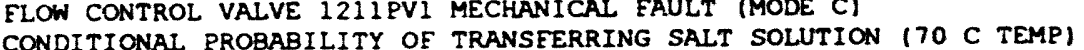

CONDITIONAL PROBABILITY OF TRANSEERRING SALI SOLUTI

MANURL VALVE T48-HV22 FAILS TO REMAIN OPEN (PLUG)
CONDITIONAL PROBABILITY OF HAVING AN IGNITION SOURCE PRESENT

MECHANICAL FAULT OE TANK 48 FLOW CONTROL VALVE $1202 \mathrm{FV}$

CONDITIONAL PROBABILITY OE BEING IN NORMAL PROCESSING MODE $140 \mathrm{C}$ TANK 48 PATH A INLET MANUAL VALVE T4B-NE. ILS TO REMAIN OPEN 1 CONDITIONAL PROBABILITY OF HAVING AN IGNITI UN SOURCE PRESENT MECHANICAL EAULT OF TANK 48 FLOW CONTROL VALVE $1202 \mathrm{FV}$ CONDITIONAL PROBABILITY OF BEING IN NORMAL PROCESSING MODE $140 \mathrm{C}$ TANK 48 PATH A DISCHARGE VALVE T48-N24 FAILS TO REMAIN OPEN (PLUG) CONDITIONAL PROBABILITY OE HAVING AN IGNITION SOURCE PRESENT

MECHANICAL FAULT OF TANK 48 FLON CONTROL VALVE $1201 \mathrm{FV}$ CONDITIONAL PROBABILITY OF BEING IN NORMAL PROCESSING MODE $140 \mathrm{C} \mathrm{T}$ MANUAL VALVE T48-NB FAIIS TO REMAIN OPEN (PLUG) CONDITIONAL PROBABILITY OF HAVING AN IGNITION SOURCE PRESENT BHOUSE04 BXV8N8PG IGNITION

298) BEC121 HW BHOUSE04 8XVEN5PG IGNITION

299) BECIIITM QHOUSE03 BXVV20PG IGNITION

300) BECIIITM BHOUSE0 3 EXVV22PG" IGNITION

301) 8FCIIITM BHOUSEOI BXVV2OPG BXVV2OPG IGNITION

3021 EFC11:TM BHOUSEOI 8XVV22PG IGNITION

3031 8AZO22TM BHOUSEOI $8 X V 1 O P G$ IGNITION MECHANTCAL FAUTT OF TANK 48 FLON CONTROL VALVE 1201 TV CONDITIONAL PROBABILITY OF BEING IN NORMAL PROCESSING MODE $140 \mathrm{C}$ CONUAI VAIVE T48-N5 FAILS TO REMAIN OPEN (PLUG)

CONDITIONAL PROABILITY OF HAVING AN IGNITION SOURCE PRESENT FLOW CONTROL VALVE 1211 PVI MAINTENANCE

CONDITIONAL PROBABILIY OE BEING IN WASH CYCLE

MANUAL VAIVE T4B-HV20 FAILS TO REMAIN OPEN (PLUG)

CONDITIONAL PROBABILITY OF HAVING AN IGNITION SOURCE PRESENT FLOW CONTROL VALVE 1211 PVI MAINTENANCE

CONDITIONAL PROBABILITY OE BEING IN WASH CYCLE

MANUAL VALVE T48-HV22 EAILS TO REMAIN OREN (PLUG)

CONDITIONAL PROBABILITY OF HAVING AN IGNITION SOURCE PRESENT

FLOW CONTROL VALVE 1211 PVI MAINTENANCE

CONDITIONAL PROBABILITY OE TRANSFERRING SALT SOLUTION $170 \mathrm{C}$ TEMP

MANUAL VALVE T48-HV2O EAILS TO REMAIN OPEN (PLUG)

CONDITIONAL PRCBABILITY OF HAVING AN IGNITION SOURCE PRESENT

FLOW CONTROL VALVE 1211 PVI MAINTENANCE

CONDITIONAI PROABILITY OF TRANSFERRING SALT SOLUTION $(70 \mathrm{C}$ TEMP) MANUAI VALVE T48-HV22 FAILS TO REMAIN OPEN (PLUG)

CNDITIONAI PROEARISTY OF HAVING AN IGNITION SOURCE PRESENT CONDITIONAL PROBABILITY OE HAVING AN IGNITION SOURCE

TANK 48 O2 ANALYZER 2 UNAVAILABLE DUE TO MAIN CONDITIONAL PROBABILITY OF TRANSERRTNG SALT SOLUTI

MANUAL VALVE T48-HVI0 FAILS TO REMAIN OPEN (PLUG)

CONDITIONAL PROBABILITY OF HAVING AN IGNITION SOURCE

TANK 48 O2 ANALYZER 2 UNAVAILABLE DUE TO MAINTENANCE

BHOUSE01

BXVUSEO

IGNITION

作 MANUAL VALVE T48-HV3 FAILS TO REMAIN OPEN (PLUG)

CONDITIONAL PRCBABILITY OE HAVING AN IGNITION SOURCE PRESENT

TANK 48 O2 ANALYZER 2 UNAVAILABLE DUE TO MAINTENANCE

$0.5 E-6 \quad .09$

1. $4 E-8 \quad i^{2}$

.09

1. $4 E-8 \quad 2$

$.5 E-6$

$1.4 E-8$

8.5E-6

$1.4 E-8$

8. 5E-6

8. $5 E-6$

1. $4 E-8$

$3.6 \mathrm{E}-3$

1. $4 E-8$

$3.6 E-3$

$1.4 E-8$

3. $6 E-3$

1. $4 E-8$

$3.6 E-3$

1. $4 E-8$

1. $8 E-3$

1. $4 E-8$

1. $8 E-3$

1. $4 E-8$

1. $8 E-3$

9. $00 \mathrm{E}-02$

$9.18 E-03$

$2.00 \mathrm{E}-01$

2. $23 E-004$

$1.23 E-04$
$9.00 E-02$

$9.00 E-02$

1.89E-0

$6.00 E-01$

$2.45 E-04$

$9.00 E-02$

$1.43 E-03 \quad 1.89 E-08$

$6.00 E-01$

2. 45E-04

$9.00 E-02$

$1.49 E-01 \quad 1.89 E-08$

6.00E-01

2.35E-06

9. $00 \mathrm{E}-02$

$1.49 E-01 \quad 1.89 E-08$

6. $00 E-02$

2. 35E-06

$9.00 E-02$

$7.20 E-03 \quad 1.59 E-08$

1. $23 E-04$

1. $23 E-04$

$9.00 E-02$
$7.20 E-03$

$2.00 E-01$

$2.00 E-01$

1. $23 E-04$

$9.00 E-02$
$7.20 E-03$

2. $00 E-01$

1. 23E-04

9. $00 \mathrm{E}-02$

$7.20 E-03 \quad 1.59 E-08$

2. $00 E-01$

1. $23 E-04$

9. $00 \mathrm{E}-02$

3. $60 E-03 \quad 1.59 E-08$

305) BAZO22TM

2. $00 E-01$

$2.45 E-04$

$9.00 E-02$

3. $60 E-03 \quad 1.59 E-08$

$3.60 E-03$

$2.00 E-01$

$2.45 E-04$
$9.00 E-02$

$3.60 E-03 \quad 3.59 E-00$ 
CONDITIONAL PROBABILITY OE BEING IN WASH CYCLE

BXV10PG*

MANUAI VAL TRBABILITY OE BEING IN WASH CYCLE

BAZO22TM

CONDITIONAL PROABILT OR HAVING AN IGNITION SOURCE PRESENT

TANK 48 O2 ANALYZER 2 UNAVAILABLE DUE TO MAINTENANCE

CONDITIONAI PROBABILITY OF BEING IN WASH CYCLE

BHOUSEO3.

MANUAL VALVE T48-HV3 FAILS TO REMAIN OPEN (PLUG)

TGNITION

CONDITIONAL PROBABILITY OF HAVING AN IGNITION SOURCE PRESENT

IGNITION

FLOW CONTROL VAIVE 125IPV2 MECHANICAL EAULT

$9 \times V V 21 P G$

MANUAL VALVE T49-HV21 EAILS TO REMAIN OPEN (PLUG)

RATE

EXPOSURE

BRos.

PROB.

308) 9EN511 HW 9XVV22PG*

CONDITIONAL PROBABILITY OF HAVING AN IGNITION SOURCE PRESENT

TANK 99 EXHAUST FAN Y 349-52-11 FAILS TO RUN DUE TO MECHANICAL FAUL

MANUAI VALVE T49-HV22 ERILS TO REMAIN OPEN (PLUG)

$20 \quad 2.00 E-01$

MANUAL VALVE T

$1.4 E-8$

$\begin{array}{ll}1.4 E-8 & 2 \\ 1.09 & .09\end{array}$

1. $8 \mathrm{E}-3 \quad 2$

$1.4 E-8$

.20

B. $5 E-6$

$1.4 E-8$

$i$

.09

8. $0 E-6$
$1.4 E-8$

CONDITIONAL PROBABILITY OF HAVING NN IGNITION SOURCE PRESENT

1

TANK 49 EXHAUST FAN Y349-52-11 EAILS TO RUN DUE TO

$2 E-8$ 9XVV20PG*

IGNITION

MANUAL VALVE T49-HV20 EAILS TO REMAIN OPEN (PLUG)

$1.4 E-8$

$8.0 E-6$

9ENS12HW*

TANK 49 EXHAUST FAN Y 349-52-12 FAILS TO RUN DUE

IGNITION

MANUAL VALVE TA-HV 1 FAILS TO REMAN ORENTION SOURCE PRESENT

$2.00 E-01$

$2.45 E-04$
$9.00 E-02$

3. $60 \mathrm{E}-03 \quad 1.59 \bar{E}-08$

$2.00 E-01$

$2.45 E-04$

$9.00 E-02$

7. 15E-02 i. $58 E-08$

2. 35E-06

$9.00 E-02$

$1.34 E-03 \quad 1.48 E-08$

$1.23 E-04$

$9.00 E-02$

$1.34 E-03 \quad 1.48 E-08$

$1.23 \mathrm{E}-04$

$09 \quad 9.00 E-02$

$7.01 E-02 \quad 1.48 E-06$

2. 35E-06

$09 \quad 9.00 E-02$ 
APPENDIX B.2

CUTSETS FOR QUANTIFIED FAULT TREE

WITH RECOVERY ACTIONS AND REPAIR ACTIVITIES INCLUDED 
Truncation Limit: $1.00 E-15$

DESCRIPTION

CONDITIONAL PROBABILITY OF HAVING AN IGNITION SOURCE PRESENT LOCAL MECHANICAL FAULTS OF DCS COMPUTER

OPERATOR FAILS TO ENTER FIELD CONTROL MODE (HIGH STRESS LEVELS) PROBABILITY OF NOT PERFORMING A MODERATE REPAIR PROCEDURE

OPERATOR FAILS TO ALIGN OR START EMERGENCY PURGE VENT EQUIP OR HAR

TANK 49 O2 ANALYZER 1 HARDWARE EAULTS
TANK 49 O2 ANALYZER 2 HARDWARE EAULTS

CONDITIONAL PROBABILITY OF HAVING AN IGNITION SOURCE PRESENT

FROBABILITY OF NOT FERFORMING A MODERATE REPAIR PROCEDURE

OPERATOR FAILS TO ALIGN OR START EMERGENCY PURGE VENT EQUIP OR HAR NO ACTION TAKEN FOR 48 HRS

CONDITIONAL PROBABILITY OE HAVING AN IGNITION SOURCE PRESENT

LOSS OF STEAM SUPPLY TO HEATER

PROBAIITY OF NOT REPIACING/REPAIRING HEPA FILTER IS NEGLIGIBLE

OPERATOR FAILS TO ALIGN OR START EMERGENCY PURGE VENT EQUIP OR HAR COMMON MODE SENSOR MISCALIBRATION FAILURE FOR O2 ANALYZERS COMMON MODE SENSOR MISCALIBRATING AN IGNITION SOURCE PRESENT CONDITIONAL PROBABILITY OE HAVING ANERATE REPAIR PROCEDURE

OPERATOR EAILS TO AIIGN OR START EMERGENCY PURGE VENT EQUIP OR HAR OPERATOR FAILS TO ALIGN OR STA

NO ACTION TAKEN FOR 48 HOURS CONDITIONAL PRORABILITY OE BEING IN NORMAL PROCESSING MODE 140

CONDITIONAI PROBABILITY OF HAVING AN IGNITION SOURCE PRESEN

LOSS OE STEAM SUPPLY TO HEATER

PROBABILITY OF NOT PEREORMING A SIMPLE REPAIR PROCEDURE

OPERATOR FAILS TO ALIGN OR START EMERGENCY PURGE VENT EQUIP OR HAR TANK 19 NITROGEN FLOW SENSOR FOR EXHAUST LINE FAILS

OPERATOR FAILS TO ENTER MODE C - FIELD CONTROL (HIGH STRESS LEVELS CONDITIONAL PROBABILITY OF HAVING AN IGNITION SOURCE PRESENT

PROBABILITY OE NOT PERFORMING A SIMPLE REPAIR PROCEDURE

OPERATOR FAILS TO ALIGN OR START EMERGENCY PURGE VENT EQUIP OR HAK FLOW SENSOR ACROSS HEPA FILTER FAILS DUE TO MECHANICAL FAULT

OPERATOR FAILS TO ENTER MODE C - FIELD CONTROL IHIGH STRESS LEVELS CONDITIONAI PROBABILITY OF HAVING AN IGNITION SOURCE PRESENT PROPABILITY OF NOT PERFORMING A SIMPLE REPAIR PROCEDURE

ORERATOR FAIIS TO AIIN OR START EMERGENCY PURGE VENT EOUIP OR HAR OPERATOR EAILS TO ALIGN OR START EMERGENCY PUT

ELOW CONTROL VALVE 1251 PV2 MECHANICAL EAULT OPERATOR FAILS TO ALIGN AND START TRAIN B TOR OPERATION - EXHAU CCNDITIONAL PROBABILITY OF HAVING AN IONITION SOURCE PRESENT

PROBABILITY OE NOT PERF OR START EMERGENCY PURGE VENT EQUIP OR HAR OPERATOR EAILS TO ALIGN OR START EMERGENCY PURGE VENT EQUIP OR HAR TANK 49 EXHAUST FAN Y349-52-12 FAILS TO RUN DUE TO MECHANICAL FAUL OPERATOR EAILS TO ALIGN AND START TRAIN B FOR OPERATION - EXHAUS

CONDITIONAL PROBABILITY OE HAVING AN IGNITION SOURCE PRESENT

PROBABILITY OF NOT PEREORMING A MODERATE REPAIR PROCEDURE
OPERATOR EAILS TO ALIGN OR START EMERGENCY PURGE VENT EQUIP OR HAR
B.E.

RATE EXPOSURE PROB.

MOD./CS.

PRO3.

$-7.21 E-08$

$\begin{array}{llll} & .09 & 9.00 E-02 & 1.83 E-08 \\ 9.0 E-5 & i & 7.88 E-01 & \end{array}$

$1 \quad 7.88 \varepsilon-01$

011 1.10E-02

2. 35E-5 $2.10 E-02$

$2.35 E-5 \quad 2.35 E-05 \quad 6.01 E-09$

$3.08-4$

$7 \quad 1.92 \mathrm{E}-02$

$.09 \quad 9.00 E-02$

$.011 \quad 1.10 E-02$

2.35E-5 2.35E-05

$\begin{array}{ll}1 & 1.00 E+00 \\ .09 & 9.00 E-02\end{array}$

$9.00 E-02$
$2.63 E+00$

$1.03 E-3 \quad 1.03 E-03$

2. $35 E-5 \quad 2.35 E-05$

$102.38 E-01$

$.09 \quad 9.00 E-02$

2. $35 E-5 \quad 2.35 E-05$

$2.35 E-5 \quad 2.35 E-05$

$160 \quad 6.00 E+00$

$60 \quad 6.00 E-01$

$.09 \quad 9.00 E-02$

$1.03 E-3 \quad 2.63 E+00$

$1.03 E-3 \quad 1.03 E-03$

$2.35 E-5 \quad 2.35 E-05$

$1 \quad 1.00 E+00$

$.09 \quad 9.00 E-02$

$1.03 E-3 \quad 1.03 E-03$

2.35E-5 2.35E-05

1 1.05E +00

$11.00 E+00$

$.09 \quad 9.00 \mathrm{E}-02$

1.03E-3 1.03E-03

2. $35 E-5 \quad 2.35 E-05$

$1.35 E-5 \quad 2.35 E-05$

$1 \quad 1.00 E+00$

$.09 \quad 9.00 E-02$

.011 1.10E-02

$2.35 E-5 \quad 2.35 E-05$

$112.01 E-02$

$.099 .00 E-02$

$\begin{array}{ll}.011 & 1.10 E-02 \\ 2.35 E-5 & 2.35 E-05\end{array}$ 


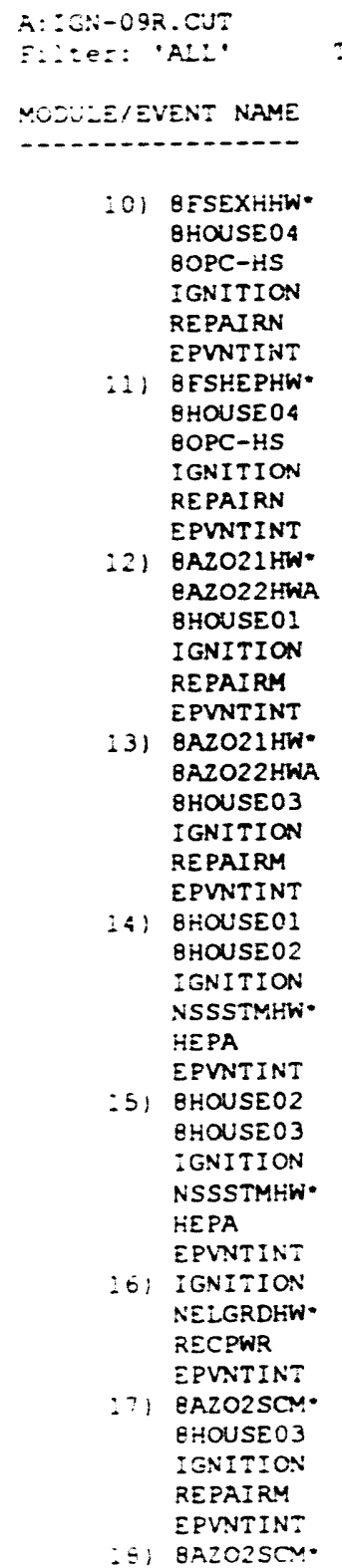

DESCRIETION

DESCRT CONDITIONAL PROSABILITY OE BEING IN NORMAL PROCESSING MODE $140 \mathrm{C}=$ CONDITION FAILS TO ENTER FIELD CONTROL MODE (HIGH STRESS LEVELS) OPERATOR EAILS COENIER FO HAVING AN IGNITION SOURCE PRESENT CONDITIONAL PROBABITITY PROBABILITY OF NOT PERFORM NG A SIMPLE REPAIR PROCEDURE OPERATOR EAILS TO ALIGN OR SIART EMERGENCY PURGE VENT EQUIP OR FLOW SENSOR ACROSS HEPA FILTER FAILS DUE TO MECHANICAL EAUL: CONDITIONAL PROBABILITY OF BEING IN NORMAL PROCESSING MODE OPERATOR EAILS TO ENTER FIELD CONTROL MODE IHIGH STRESS LEVELSI CONDITIONAL PROBABILITY OF HAVING AN IGNITION SOURCE PRESE PROBABILITY OF NOT PERFURMING A SIMPLE REPAIR PROCEDURE
OPERATOR EAILS TO ALIGN OR START EMERGENCY PURGE VENT EQUIP OR HAR TANK 48 O2 ANALYZER 1 HARDWARE FAULTS

TANK 4802 ANALYZER 2 FARDWARE FAULTS

CONDITIONAI PROBABILITY OE TRANSFERRING SALT SOLUTION $170 \mathrm{C}$ TEMP) CONDITIONAL PROBABILITY OF HAVING AN IGNITION SOURCE PRESENT

PROBABILITY OF NOT PERFORMING A MODERATE REPAIR PROCEDURE

OPERATOR FAILS TO ALIGN OR START EMERGENCY PURGE VENT EQUIP CR HAR TANK 48 O2 ANALYZER I HARDWARE FAULTS

TANK 48 O2 ANAYYER 2 HARDWARE FAULTS

IANK 48 O2 ANALY

CONDITIONAL PROBABILITY OE BEING IN WASH CYCLE SOURCE PRESENT

CONDITIONAL PROBABILITY OFM HU MODERATE REPAIR PROCEDURE

PROBABILITY OF NOT PEREN OR START EMERGENCY PURGE VENT EOUIP OF HAR OPERATOR FAILS TO ALIGN OR START EMERGENCY PURGE VENT EQUTP OR HAR CONDITIONAL PROBABILITY OF TRA

NO ACTION TAKEN FOR 48 HOURS

CONDITIONAL PROBABILITY OF HAVIN

LOSS OE STEAM SUPPLY TO HEATER

PROBABILITY OF NOT REPLACING/REPAIRING HEPA EILTER IS NEGLIGIELE

OPERATOR FAILS TO ALIGN OR START EMERGENCY PURGE VENT EQUIP OR HAR NO ACTION TAKEN FOR 48 HOURS

CONDITIONAL PROBABILITY OE BEING IN WASH CYCLE

CONDITIONAL PROBABIIITY OF HAVING AN IGNITION SOURCE PRESENT

LOSS OE STEAM SUPPLY TO HEATER

PRCBABILITY OF NOT REPLACING/REPAIRING HEPA EILTER IS NEGLIGIEEE

OPERATOR EAILS TO AIIGN OR START EMERGENCY PURGE VENT EQUIP OR HAT

CONDITIONAI PROBABIIITY OF HAVING AN IGNITION SOURCE PRESENT

CONDITIONAL PROBABILIT

LOSS OE H-AREA POWER

PROBABILITY OE NOT RECOVERING OEESITE POWER PURGE VENT EOUIP OR HAR

EQUIP OR HAR

CORON MODE

CONON MODE SENSOR MISCP. OF BEING IN WASH CYCLE

CONDITIONAI PROBABILITY OE HAVING AN IGNITION SOURCE PRESENT

PROBIONA

OPERATOR FAILS TO ALIG: OR START EMERGENCY PURGE VENT EQUIP OR HAR

COMMON MODE SENISOR MISIALIERATION FAILURE FOR O2 ANALYZERS 
E:Iter: 'ALL'

MODULE/EVENT NAME

8HOUSEO1

IGNITION

REPAIRM

19) 9ESNFSCM*

9OPC-HS

IGNITION

REPAIRN

EPVNTINT

201 9OPC-HS

9SFFANCM*

IGNITION

REPAIRN

EPVNTINT

IGNITION

REPAIRN

EPVNTINT

22) 8FSNFSCM *

BOPC-HS

IGNITION

REPAIRN

EPVNTINT

23) BHOUSEO4

8OPC-HS

BSEEANCM *

IGNITION

REPAIRN

EPVNTINT
BHOUSEO4

BILEANHW*

IGNITION

REPAIRN

EPVNTINT

25) 9HOUSEO2

IGNITION

HEPA

EPVNTINT

26) BFSEXHHW-

BOPC-HS

IGPC-HS

IGNITION

EPVNTINT
Truncation Limit: 1.00E-15

DESCRIPTION

CONDITIONAL PROBABILITY OF TRANSFERRING SALT SOLUTION (70 C TEMP) CONDITIONAL PROBABILITY OF HAVING AN IGNITION SOURCE PRESENT

PROBABILITY OF NOT PERFORMING A MODERATE REPAIR PROCEDURE

OPERATOR FAILS TO ALIGN OR START EMERGENCY PURGE VENT EQUIP OR HAR BOTH NITROGEN FLOW SENSORS FAIL DUE TO COMMON MODE MISCALIBRATION

OPERATOR FAILS TO ENTER MODE C - FIELD CONTROL (HIGH STRESS LEVELS

CONDITIONAL PROBABILITY OF HAVING AN IGNITION SOURCE PRESENT

PROBABIITY OF NOT PEREORMING A SIMPLE REPAIR PROCEDURE

OPERATOR FAILS TO ALIGN OR START EMERGENCY PURGE VENT EOUIP OR HAR

OPERATOR EAILS TO ALIGN OR START EMERGENCY POR IHIGH STRESS LEVEIS

OPERATOR EAILS TO ENTER MODE C CONDITIONAL PROBABILITY OF HAVING AN IGNITION SOURCE PRESENT

CONDITIONAL PROBABILITY OE HAVING AN IGNITPAN PROCEDURE

PROBABILITY OF NOT PEREORM NG A SIMPLE REPA PURGE VENT EOUIP OR HAR

OPERATOR EATLS TO ALIGN OR START EMERGENCY PURGE VENT EQUIP OR HAR INTERLOCK FAILURE (EAN EXHAUST FLO MN IGNITION SOURCE PRESENT

CONDITIONAL PROBABILITY OF HAVING AN IGNITION SOURCE PRES

PPERATOR FAIIS TO ALIGN OR START EMERGENCY PURGE VENT EQUIP OR HAR BOTH NITROGEN FLOW SENSORS FAIL DUE TO COMMON MODE MISCALIBRATION CONDITIONAI OPERATOR FAILS TO ENTER FIEID CONTROL MODE (HIGH STRESS LEVELS)

CONDITIONAL PROBABILITY OE HAVING AN IGNITION SOURCE PRESENT

PROBABILITY OF NOT PERFORMING A SIMPLE REPAIR PROCEDURE

OPERATOR FAILS TO ALIGN OR START EMERGENCY PURGE VENT EQUIP OR HAR CONDITIONAL PROBABILITY OF BEING IN NORMAL PROCESSING MODE $140 \mathrm{C} \mathrm{T}$ OPERATOR FAILS TO ENTER FIELD CONTROL MODE (HIGH STRESS LEVELS)

MORE MISCALIBRATION FAILURE OF SENSORS DETECTING EAN OPERAT CONDITIONAI PROBABILITY OF HAVING AN IGNITION SOURCE PRESENT

PROBABILITY OF NOT PERFORMING A SIMPLE REPAIR PROCEDURE

OPERATOR FAIIS TO ALIGN OR START EMERGENCY PURGE VENT EQUIP OR HAR OPERATOR FAILS TO ALIGN OR START EMEREENCY PURGE VENT EQUIP OR HAR INTERLOCK FAILURE (EAN EXHAUST FLOW METER) CLOSES ELOW CONTROL

CONDITIONAL PROBABILITY OF HAVING AN IGNITION SOURCE PRE

PROBABILITY OF NOT PERFORMING A SIMPLE REPAIR PROCEDURE OPERATOR FAILS TO ALIGN OR

NO ACTION TAKEN EOR 48 HRS

CONDITIONAL PROBABILITY OF HAVING AN IGNITION SOURCE

MECHANICAL FAULTS IN CHROMATED COOLING WATER SYSTEM

PROBABILITY OF NOT REPLACING/REPAIRING HEPA FILTER IS NEGLIGIBLE

OPERATOR FAILS TO ALIGN OR START EMERGENCY PURGE VENT EQUIP UR HAR

TANK 48 NITROGEN FLOW SENSOR FOR EXHAUST LINE EAILS

CONDITIONAL PROBABILITY OF BEING IN WASH CYCLE

OPERATOR FAILS TO ENTER FIELD CONTROL MODE (HIGH STRESS LEVELS)

CONDITIONAL PROBABILITY OE HAVING AN IGNITION SOURCE PRESENT

PROBABILITY OF NOT PERFORMING A SIMPLE REPAIR PROCEDURE

OPERATOR FAILS TO ALIGN OR START EMERGENCY PURGE VENT EOUIP OR HAR

\begin{tabular}{|c|c|c|c|}
\hline & EXPOSURE & $\begin{array}{l}\text { B.E. } \\
\text { PROB. }\end{array}$ & $\begin{array}{l}\text { MOD. /CS. } \\
\text { PROB. }\end{array}$ \\
\hline \multirow{5}{*}{$\begin{array}{l}\text { RATE } \\
-\end{array}$} & $\ldots \ldots$ & $\cdots$ & 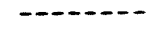 \\
\hline & .2 & $2.00 \mathrm{E}-01$ & \\
\hline & .09 & $9.00 E-02$ & \\
\hline & .011 & $1.10 E-02$ & \\
\hline & $2.35 E-5$ & $2.35 E-05$ & \\
\hline \multirow[t]{6}{*}{$4.4 E-1$} & 1 & $4.40 E-01$ & $9.59 E-10$ \\
\hline & 1 & $1.00 E+00$ & \\
\hline & .09 & $9.00 E-02$ & \\
\hline & $1.03 E-3$ & $1.03 E-03$ & \\
\hline & $2.35 E-5$ & 2. $35 E-05$ & \\
\hline & 1 & $1.00 E+00$ & $9.59 E-10$ \\
\hline \multirow{4}{*}{$4.4 E-1$} & 1 & $4.40 E-01$ & \\
\hline & .09 & $9.00 E-02$ & \\
\hline & $1.03 \mathrm{E}-3$ & $1.03 \varepsilon-03$ & \\
\hline & $2.35 E-5$ & $2.35 E-05$ & \\
\hline \multirow[t]{4}{*}{ 4. $6 E-5$} & 1 & $4.03 E-01$ & $8.78 E-1 C$ \\
\hline & .09 & $9.00 E-02$ & \\
\hline & $1.03 E-3$ & $1.03 E-03$ & \\
\hline & $2.35 E-5$ & $2.35 E-05$ & \\
\hline \multirow[t]{8}{*}{ 4. $4 E-1$} & 1 & $4.40 E-01$ & $5.75 E-10$ \\
\hline & .60 & $6.00 E-01$ & \\
\hline & 1 & $1.00 E+00$ & \\
\hline & .09 & $9.00 E-02$ & \\
\hline & $1.03 E-3$ & $1.03 E-03$ & \\
\hline & $2.35 E-5$ & $2.35 E-05$ & \\
\hline & .60 & $6.00 E-01$ & $5.75 E-10$ \\
\hline & 1 & $1.00 \varepsilon+00$ & \\
\hline \multirow[t]{5}{*}{$4.4 E-1$} & 1 & $4.40 E-01$ & \\
\hline & .09 & $9.00 \mathrm{E}-02$ & \\
\hline & $1.03 E-3$ & $1.03 E-03$ & \\
\hline & $2.35 E-5$ & $2.35 E-05$ & \\
\hline & .60 & $6.00 E-01$ & $5.27 E-10$ \\
\hline \multirow[t]{6}{*}{$4.6 \mathrm{E}-5$} & 1 & $4.03 E-01$ & \\
\hline & .09 & $9.00 E-02$ & \\
\hline & $1.03 E-3$ & $1.03 E-03$ & \\
\hline & $2.35 E-5$ & $2.35 E-05$ & \\
\hline & 1 & $1.00 E+00$ & $4.77 E-10$ \\
\hline & .09 & $9.00 E-02$ & \\
\hline \multirow[t]{3}{*}{$2.5 E-5$} & 1 & $2.19 E-01$ & \\
\hline & $1.03 E$ & $1.03 E-03$ & \\
\hline & $2.35 E-5$ & $2.35 E-05$ & \\
\hline \multirow[t]{6}{*}{ 1. $2 E-4$} & 1 & $1.05 E+00$ & $4.58 E-10$ \\
\hline & .20 & $2.00 E-01$ & \\
\hline & 1 & $1.00 \varepsilon+00$ & \\
\hline & .09 & $9.00 E-02$ & \\
\hline & $1.03 E-3$ & $1.03 E-03$ & \\
\hline & $2.35 E-5$ & $2.35 E-05$ & \\
\hline
\end{tabular}

(1)


27) QESEXHHW BHOUSE 01 SOPC-HS IGNITION REPAIRN EPVNTINT

28) BFSHEPHW BHOUSE01 8OPC-KS IGNITION REPAIRN EPVNTINT

29) BFSHEPHW 8HOUSEO3 BOPC-HS IGNITION REPAIRN EPVNTINT

30) 9PRREGHW IGNITION REPAIRM EPVNTINT

31) IGNITION NOPTRNBS RPR246HW REPAIRM

32) EARTINT SAZO22TM IGNITION REPAIRM EPVNTINT

33) IGNITION NHOUSE 01 NHVCOMHW NOPC-HS REPAIRM EPVNTINT

34) 9OPC-MS ISFEANHW* IGNITION REPAIRN EPVNTINT

35) $8 \mathrm{FC1} 12 \mathrm{HW}$ BHOUSEOI BOPTRNBE
TANK 48 NITROGEN FLOW SENSOR EOR EXHAUST LINE FAILS CONDITIONAL PROBABILITY OF TRANSFERRING SALT SOLUTION (70 C TEMP) OPERATOR FAILS TO ENTER FIELD CONTROL MODE (HIGH STRESS LEVELS) CONDITIONAL PROBABILITY OE HAVING AN IGNITION SOURCE PRESENT PROBABILITY OF NOT PERFORMING A SIMPLE REPAIR PROCEDURE OPERATOR FAILS TO ALIGN OR START EMERGENCY PURGE VENT EQUIP OR HAR FLOW SENSOR ACROSS HEPA FILTER FAILS DUE TO MECHANICAL FAULT CONDITIONAL PROBABILITY OE TRANSFERRING SALT SOLUTION $170 \mathrm{C}$ TEMP) OPERATOR FAILS TO ENTER FIELD CONTROL MODE (HIGH STRESS LEVELS) CONDITIONAL PROBABILITY OE HAVING AN IGNITION SOURCE PRESENT PROBABIITTY OF NOT PERFORMING A SIMPLE REPAIR PROCEDURE PREATER FAIL TO ALIGN OR START EMERGENCY PURGE VENT EOUIP OR HAR OPERATOR FAILS TO ALIGN OR START EMERGENCY PURGE VENT EQUIP OR ELOW SENSOR ACROSS HEPA EILTER EAILS DUE TO MECHA

CONDITIONAL PROBABILITY CE BEING IN WASH CYCLE OFERATOR FAILS TO ENTER FIELD CONTROL MODE (HIGH STRESS LEVELSI CONDITIONAL PROBABILITY OF HAVING AN IGNITION SOURCE PRESEN PROBABILITY OE NOT PERFORMING A SIMPLE REPAIR PROCEDURE OPERATOR FAILS TO ALIGN OR START EMERGENCY PURGE VENT EQUIP OR HAR TANK 49 FAILURE OF PRESSURE REGULATING VALVE 1257 PV CONDITIONAL PROBABILITY OF HAVING AN IGNITION SOURCE PRESENT PROBABILITY OF NOT PERFORMING A MODERATE REPAIR PROCEDURE OPERATOR FAILS TO ALIGN OR START EMERGENCY PURGE VENT EQUIP OR HAR CONDITIONAL PROBABILITY OF HAVING AN IGNITION SOURCE PRESENT OPERATOR FAILS TO ALIGN TRAIN B FOR OPERATION - SURPLY SIDE PRESSURE REGULATING VALVE 2046PV FAILS

PROBABILITY OF NOT PERFORMING A MODERATE REPAIR PROCEDURE OPERATOR FAILS TO ALIGN OR START EMERGENCY PURGE VENT EQUIP OR HAR TANK 49 O2 ANALYZER 1 HARDWARE FAULTS

TANK 49 O2 ANALYZER 2 UNAVAILABIE DUE TO MAINTENANCE CONDITIONAI PROBABI PRDITINAL PROBABTLITY OE HAVING ANETE RTONA PROCEDURE PROBABILITY OF NOT SERFORMI GTART EMERGENCY PURGE VENT EOUIP OR HAR CONDITIONAL PROBABILITY OF HAVING AN IGNITION SOURCE PRESENT CONDITIONAL PROBABILITY OF OUTSIDE TEMPERATURE BEING $>80 \mathrm{E}$ CONDITIONAL PROBABILITY OF OUTSIDE TEMPERATURE

LOSS OF HVAC TO ROOM CONTAINING DCS COMPUTER OPERATOR EAILS TO ENTER FIELD CONTROL MODE (HIGH STRESS LEV PROBABILITY OE NOT PERFORMING A MODERATE REPAIR PROCEDURE OPERATOR FAILS TO ALIGN OR START EMERGENCY PURGE VENT EQUIP OR HAR OPERATOR FAILS TO ENTER MODE C - FIELD CONTROL (MODERATE STRESS LE SENSOR DETECTING FAN OPERATION FOR NORMALLY RUNNING EAN EAILS CONDITIONAL PROBABILITY OF HAVING AN IGNITION SOURCE PRESENT PROBABILITY OF NOT PEREORMING A SIMPLE REPAIR PROCEDURE OPERATOR FAILS TO ALIGN OR START EMERGENCY PURGE VENT EQUIP OR HAR FLOW CONTROL VALVE 1211 PV2 MECHANICAL FAULT

CONDITIONAL PROBABILITY OF TRANSFERRING SALT SOLUTION (70 C TEMP) OPERATOR FAILS TO A:IGN AND START TRAIN B FOR OPERATION - EXHAUST

\begin{tabular}{|c|c|c|c|}
\hline 1. $2 E-4$ & $\begin{array}{l}1 \\
i^{2} \\
.09 \\
1.03 E-3 \\
2.35 \mathrm{E}-5\end{array}$ & $\begin{array}{l}1.05 E+00 \\
2.00 E-01 \\
1.00 E+00 \\
9.00 E-02 \\
1.03 E-03 \\
2.35 E-05\end{array}$ & $4.58 E-10$ \\
\hline $1.2 E-4$ & $\begin{array}{l}1 \\
i^{2} \\
.09 \\
1.03 \mathrm{E}-3 \\
2.35 \mathrm{E}-5\end{array}$ & $\begin{array}{l}1.05 E+00 \\
2.00 E-01 \\
1.00 E+00 \\
9.00 E-02 \\
1.03 E-03 \\
2.35 E-05\end{array}$ & 4. $58 \mathrm{E}-10$ \\
\hline $1.2 E-4$ & $\begin{array}{l}1 \\
.20 \\
1 \\
.09 \\
1.03 E-3 \\
2.35 E-5\end{array}$ & $\begin{array}{l}1.05 \mathrm{E}+00 \\
2.00 \mathrm{E}-01 \\
1.00 \mathrm{E}+00 \\
9.00 \mathrm{E}-02 \\
1.03 \mathrm{E}-03 \\
2.35 \mathrm{E}-05\end{array}$ & $4.58 \mathrm{E}-10$ \\
\hline $2.2 E-6$ & $\begin{array}{l}1 \\
.09 \\
.011 \\
2.35 \mathrm{E}-5\end{array}$ & $\begin{array}{l}1.93 \mathrm{E}-02 \\
9.00 \mathrm{E}-02 \\
1.10 \mathrm{E}-02 \\
2.35 \mathrm{E}-05\end{array}$ & $4.48 E-10$ \\
\hline & & $\begin{array}{l}9.00 E-02 \\
1.00 E+00\end{array}$ & $4.48 E-10$ \\
\hline $2.2 E-6$ & $\begin{array}{l}1 \\
.011 \\
2.35 \mathrm{E}-5\end{array}$ & $\begin{array}{l}1.93 E-02 \\
1.10 E-02 \\
2.35 E-05\end{array}$ & \\
\hline $\begin{array}{l}\text { 3. } 0 E-4 \\
1.8 E-3\end{array}$ & $\begin{array}{l}2 \\
2 \\
.09 \\
.011 \\
2.35 E-5\end{array}$ & $\begin{array}{l}5.26 E+00 \\
3.60 E-03 \\
9.00 E-02 \\
1.10 E-02 \\
2.35 E-05\end{array}$ & $4.40 E-10$ \\
\hline & $\begin{array}{l}.09 \\
0.125\end{array}$ & $\begin{array}{l}9.00 E-02 \\
1.25 E-01\end{array}$ & $4.08 E-10$ \\
\hline 1. $6 E-5$ & $\begin{array}{l}1 \\
1 \\
.011 \\
2.35 E-5 \\
1\end{array}$ & $\begin{array}{l}1.40 E-01 \\
1.00 E+00 \\
1.10 E-02 \\
2.35 E-05 \\
1.00 E+00\end{array}$ & $4.01 E-10$ \\
\hline $2.1 E-5$ & $\begin{array}{l}1 \\
.09 \\
1.03 E-3 \\
2.35 E-5\end{array}$ & $\begin{array}{l}1.84 E-01 \\
9.00 E-02 \\
1.03 E-03 \\
2.35 E-05\end{array}$ & \\
\hline $8.5 E-6$ & $i^{2}$ & $\begin{array}{l}7.45 \mathrm{E}-02 \\
2.00 \mathrm{E}-01 \\
1.00 \mathrm{E}+00\end{array}$ & $3.46 E-10$ \\
\hline
\end{tabular}




\section{DESCRI PTION}

IGNITION REPAIRM EPVNTINT

36) $8 \mathrm{FC} 112 \mathrm{HW}$ * 8HOUSEO3 BOPTRNBE IGNITION REPAIRM

EPVNTINT
BAZO21HW* BAZO22HWA 8 HOUSE 04 IGNITION REPAIRN EPVNTINT

38) 8EN528HW* BHOUSE03 IOPTRNBE IGNITION EPVNTINT

39) 8EN528HW* BHOUSE01 BOPTRNBE IGNITION REPAIRM

EPVNTINT

40) $8 \mathrm{AZO2SCM}$ * BHOUSEO4 IGNITION REPAIRN EPVNTINT

41) BHOUSE02 8HOUSE 04 IGNITION NCWCHRHW* REPAIRN EPUNTINT

2) BOPC-MS BSEFANHW* IGNITION REPAIRN EPVNTINT

43) 8FSNESCM
8HOUSE03
CONDITIONAL PROBABILITY OF HAVING AN IGNITION SOURCE PRESENT PROBABILITY OF NOT PEREORMING A MODERATE REPAIR PROCEDURE OPERATOR FAILS TO ALIGN OR START EMERGENCY PURGE VENT EQUIP OR HAR FLOW CONTROL VALVE 1211 PV2 MECHANICAL FAULT

CONDITIONAL PROBABILITY OF BEING IN WASH CYCLE

OPERATOR FAILS TO ALIGN AND START TRAIN B FOR OPERATION - EXHAUST CONDITIONAL PROBABILITY OE HAVING AN IGNITION SOURCE PRESENT PROBABILITY OF NOT PERFORMING A MODERATE REPAIR PROCEDURE OPERATOR FAILS TO ALIGN OR START EMERGENCY PURGE VENT EQUIP OR HAR TANK 48 O2 ANALYZER I HARDWARE ERULTS

TANK 48 O2 ANALYZER 2 HARDWARE GAULTS

CONDITIONAL PROBABILITY OF BEING IN NORMAL PROCESSING MODE $140 \mathrm{C} \mathrm{T}$ CONDITIONAL PROBABILITY OF HAVING AN IGNITION SOURCE PRESEN PROBABILITY OF NOT PERFORMING A SIMPLE REPAIR PROCEDURE OPERATOR FAILS TO ALIGN OR START EMERGENCY PURGE VENT EQUIP OR HAR TANK 48 EXHAUST FAN Y348-52-8 FAILS TO RUN DUE TO MECHANICAL FAULT CONDITIONAL PROBABILITY OF BEING IN WASH CYCLE

OPERATOR FAILS TO ALIGN AND START TRAIN B FOR OPERATION - EXHAUST CONDITIONAL PROBABILITY OF HAVING AN IGNITION SOURCE PRESENT

PROBABILITY OF NOT PERFORMING A MODERATE REPAIR PROCEDURE

OPERATOR FAILS TO ALIGN OR START EMERGENCY PURGE VENT EQUIP OR HAR TANK 48 EXHAUST FAN Y348-52-8 FAILS TO RUN DUE TO MECHANICAL EAULT CONDITIONAL PROBABILITY OF TRANSFERRING SALT SOLUTION $(70 \mathrm{C}$ TEMP) OPERATOR FAILS TO ALIGN AND START TRATN B FOR OPERATION - EXHAUST CONDITIONAL PROBABILITY OE HAVING AN TENITION SOURCE PRESENT

PROBABILITY OF NOT PEREORMING A MODERATE REPAIR PROCEDURE

OPERATOR EAILS TO ALIGN OR START EMERGENCY PURGE VENT EQUIP OR HAR COMMON MODE SENSOR MISCALIBRATION EAILURE FOR O2 ANALYZERS

CONDITIONAL PROBABILITY OF BEING IN NORMAL PROCESSING MODE $140 \mathrm{C} \mathrm{T}$

CONDITIONAL PROBABILITY OF HAVING AN IGNITION SOURCE PRESEN

PROBABILITY OF NOT PERFORMING A SIMPLE REPAIR PROCEDURE

OPERATOR FAILS TO ALIGN OR START EMERGENCY PURGE VENT EQUIP OR HAR NO ACTION TAKEN FOR 48 HOURS

CONDITIONAL PROBABILITY OF BEING IN NORMAL PROCESSING MODE $140 \mathrm{C} \mathrm{T}$ CONDITIONAL PROBABILITY OE HAVING AN IGNITION SOURCE PRESENT

MECHANICAL FAULTS IN CHROMATED COOLING WATER SYSTEM

PROBABILITY OE NOT PERFORMING A SIMPLE REPAIR PROCEDURE

OPERATOR FAILS TO ALIGN OR START EMERGENCY PURGE VENT EQUIP OR HAR CONDITIONAL PROBABILITY OF BEING IN NORMAL PROCESSING MODE $140 \mathrm{C} T$ OPERATOR EAILS TO ENTER FIELD C SENSOR DETECTING FAN OPERATION EOR NORMALLY RUNING EAN EAILS SENSOR DETECTING EAN OPERATION FOR NORMALLY RUNNING BAN FATLS CONDITIONAL PROBABILITY OF HAVING AN IGNITION SOURCE PRE

PROBABILITY OE NOT PER ON OPERATOR FAILS TO ALIGN OR START EMERGENCY PURGE VENT EQUIP OR HAR CONDITIONAL PROBABILITY OF BEING IN WASH CYCLE CONDITTONAI PROBABILITY OF HAVING AN IGNITION SOURCE PRESENT
B.E.

\begin{tabular}{|c|c|c|c|}
\hline \multirow[t]{4}{*}{ RATE } & EXPOSURE & $\begin{array}{l}\text { B.E. } \\
\text { PROB. }\end{array}$ & $\begin{array}{l}\text { MOD./CS. } \\
\text { PROB. }\end{array}$ \\
\hline & .09 & $9.00 \mathrm{E}-02$ & \\
\hline & .011 & $1.10 E-02$ & \\
\hline & $2.35 E-5$ & $2.35 E-05$ & \\
\hline \multirow[t]{6}{*}{$8.5 E-6$} & 1 & $7.45 E-02$ & 3. $46 E-10$ \\
\hline & .20 & $2.00 E-01$ & \\
\hline & & $1.00 E+00$ & \\
\hline & .09 & $9.00 E-02$ & \\
\hline & .011 & $1.10 E-02$ & \\
\hline & $2.35 E-5$ & $2.35 E-05$ & \\
\hline $3.0 E-4$ & 2 & $5.26 E+00$ & 3. $38 \mathrm{E}-10$ \\
\hline \multirow[t]{5}{*}{ 3. $0 E-4$} & 7 & $4.92 E-02$ & \\
\hline & .60 & $6.00 E-01$ & \\
\hline & .09 & $9.00 \mathrm{E}-02$ & \\
\hline & $1.03 \mathrm{E}-3$ & $1.03 \mathrm{E}-03$ & \\
\hline & $2.35 E-5$ & $2.35 E-05$ & \\
\hline \multirow[t]{6}{*}{$8.0 E-6$} & 1 & $7.01 E-02$ & $3.26 \mathrm{E}-10$ \\
\hline & .20 & $2.00 \mathrm{E}-01$ & \\
\hline & 1 & $1.00 E+00$ & \\
\hline & .09 & $9.00 E-02$ & \\
\hline & .011 & $1.10 \mathrm{E}-02$ & \\
\hline & $2.35 E-5$ & $2.35 E-05$ & \\
\hline \multirow[t]{6}{*}{$8.0 \mathrm{E}-6$} & 1 & $7.01 E-02$ & $3.26 \mathrm{E}-10$ \\
\hline & .2 & $2.00 E-01$ & \\
\hline & 1 & $1.00 \mathrm{E}+00$ & \\
\hline & .09 & $9.00 \mathrm{E}-02$ & \\
\hline & .011 & $1.10 \mathrm{E}-02$ & \\
\hline & $2.35 E-5$ & $2.35 E-05$ & \\
\hline \multirow[t]{8}{*}{$2.38 \mathrm{E}-1$} & 1 & $2.38 \mathrm{E}-01$ & $3.11 E-10$ \\
\hline & .60 & $6.00 E-01$ & \\
\hline & .09 & $9.00 E-02$ & \\
\hline & $1.03 E-3$ & $1.03 E-03$ & \\
\hline & $2.35 E-5$ & $2.35 E-05$ & \\
\hline & 1 & $1.00 E+00$ & $2.86 E-10$ \\
\hline & .60 & $6.00 E-01$ & \\
\hline & .09 & $9.00 E-02$ & \\
\hline \multirow[t]{5}{*}{$2.5 E-5$} & 1 & $2.19 E-01$ & \\
\hline & $1.03 E-3$ & $1.03 E-03$ & \\
\hline & $2.35 E-5$ & $2.35 E-05$ & \\
\hline & .60 & $6.00 \mathrm{E}-01$ & $2.40 E-10$ \\
\hline & 1 & $1.00 E+00$ & \\
\hline \multirow[t]{4}{*}{$2.1 E-5$} & 1 & $1.84 \mathrm{E}-01$ & \\
\hline & .09 & $9.00 E-02$ & \\
\hline & $1.03 E-3$ & $1.03 \mathrm{E}-03$ & \\
\hline & $2.35 E-5$ & $2.35 \mathrm{E}-05$ & $1.92 E-10$ \\
\hline $4.4 E-1$ & 1.20 & $\begin{array}{l}4.40 E-01 \\
2.00 E-01\end{array}$ & $1.3<2-10$ \\
\hline
\end{tabular}


DESCRIPTION

8OPC-HS

IGNITION

REPAIRN

4) BESNESCM*

BHOUSEOI

BOPC-HS

IGNITION

REPAIRN

EPVNTINT

45) BHOUSEO

BOPC-HS

OSFFANCM.

IGNITION

EPVNTINT

46) 8HOUSEO3

BOPC-HS

BSFEANCM*

IGNITION

REPAIRN

EEVNTINT

47) BHOUSEOI

BILEANHW*

IGNITION

REPAIRN

EPVNTINT

BILEANHW*

IGNITION

REPAIRN

EPVNTINT

49) 8 EC112HW*

BHOUSEO4

BOPTRNBE

IGNITION

REPARN

50) BHOUSEOI

8HOUSE02

IGNITION

NCWCHRHW

HEPA.

EPVNTINT

51) 8HOUSEO

8HOUSEO
OPERATOR FAILS TO ENTER FIELD CONTROL MODE (HIGH STRESS LEVELS)

CONDITIONAL PROERBILITY OF HAVING AN IGNTTION SOURCE PRESENT

PROBABILITY OF NOT FERFORMING A SIMPLE REPAIR PROCEDURE

OPERATOR FAILS TO ALIGN OR START EMERGENCY PURGE VENT EQUIP OR HAR BOTH NITROGEN FLOW SENSORS FAIL DUE TO COMMON MODE MISCALIBRATION CONDITIONAL PROBABILITY OF TRANSFERRING SALT SOLUTION $170 \mathrm{C}$ TEMP) OPERATOR FAILS TO ENTER FIELD CONTROL MODE (HIGH STRESS LEVELS) CONDITIONAI PROBABILITY OF HAVING AN IGNITION SOURCE PRESENT

CONDITIONAL PROBABILITY OE HAVING AN IGNIEION PROCEDURE

OPERATOR FAILS TO ALIGN OR START EMERGENCY PURGE VENT EQUIP OR HAR CONDITIONAL PROBABILITY OE TRANSTERRING SALT SOLUTION $170 \mathrm{C}$ TEMP)

OPERATOR FAILS TO ENTER FIELD CONTROL MODE (HIGH STRESS LEVELS)

COMMON MODE MISCAIIBRATION EAILURE OF SENSORS DETECTING FAN OPERAT 4.4E-1

CONDITIONAL PROBABILITY OE HAVING AN IGNITION SOURCE PRESENT

PROBABILITY OF NOT PERFORMING A SIMPLE REPAIR PROCEDURE

OPERATOR FAILS TO ALIGN OR START EMERGENCY PURGE VENT EQUIP OR HAR CONDITIONAL PROBABILITY OF BEING IN WASH CYCLE

OPERATOR FAILS TO ENTER FIELD CONTROL MODE (HIGH STRESS LEVELS)

COMMON MODE MISCALIBRATION FAILURE OF SENSORS DETECTING FAN OPERAT 4.4E-1

CONDITIONAL PROBABILITY OF HAVING AN IGNITION SOURCE PRESENT

PROBABILITY OE NOT PERFORMING A SIMPLE REPAIR PROCEDURE

OPERATOR FAILS TO ALIGN OR START EMERGENCY PURGE VENT EQUIP OR HAR

CONDITIONAL PROBABILITY OF TRANSFERRING SALT SOLUTION $170 \mathrm{C}$ TEMP)

INTERLOCK FAILURE (FAN EXHAUST FLOW METER) CLOSES FLOW CONTROL VAL 4.6E-5

CONDITIONAL PROBABILITY OF HAVING AN IGNITION SOURCE PRESENT

CONDITIONAL PROBABILITY OE HAVING AN IENIPION SOURCE PRES

OPERATOR FAILS TO ALIGN OR START EMERGENCY PURGE VENT EQUIP OR HAR CONDITIONAL PROBABILITY OE BEING IN WASH CYCLE

INTERLOCK FAILURE (FAN EXHAUST FLOW METER) CLOSES FLOW CONTROL VAL 4.6E-5

CONDITIONAL PRCBABILITY OF HAVING AN IGNITION SOURCE PRESENT

PROBABILITY OF NOT PERFORMING A SIMELE REPAIR PROCEDURE

OPERATOR EAILS TO ALIGN OR START EMERGENCY PURGE VENT EQUIP OR HAR ELOW CONTROL VALVE $1211 \mathrm{PV} 2$ MECHANICAL EAULT

CONDITIONAL PROBABILITY OF BEING IN NORMAL PROCESSING MODE $140 \mathrm{C} \mathrm{T}$ OPERATOR FAILS TO ALIGN AND START TRAIN B FOR OPERATION - EXHAUST

CONDITIONAI PROBABILITY OF HAVING AN IGNITION SOURCE PRESENT

PROBABILITY OF NOT PERFORMING A SIMPLE REPAIR PROCEDURE

OPERATOR FAILS TO AIIGN OR START EMERGENCY PURGE VENT EOUIP OR HAR CONDITIONAI PROBABILITY OE TRANSEERRING SALT SOLUTION $170 \mathrm{C}$ TEMP) NO ACTION TAKEN FOR 48 HOURS

CONDITIONAI PROSABILITY OF HAVING AN IGNITION SOURCE PRESENT

MECHANICAL FAULTS IN CHROMATED COOLING WATER SYSTEM

PROABI

PRCBABILITY OE NOT REPLACING/REPAIRING HEPA EIRTER VENT EQUIP OR HAR

NO ACTION TAKEN EOR 48 HOURS

CONDITIONAL PROBABILITY OE BEING IN WASH CYCLE
B.E.

\begin{tabular}{|c|c|c|c|}
\hline RATE & EXPOSURE & $\begin{array}{l}\text { B.E. } \\
\text { PROB. }\end{array}$ & $\begin{array}{l}\text { MOD. / CS. } \\
\text { PROB. }\end{array}$ \\
\hline \multirow[t]{5}{*}{$\cdots$} & $\ldots$ & $\cdots$ & $\cdots$ \\
\hline & 1 & $1.00 E+00$ & \\
\hline & .09 & $9.00 E-02$ & \\
\hline & $1.03 E-3$ & $1.03 E-03$ & \\
\hline & 2. $35 E-5$ & $2.35 E-05$ & \\
\hline \multirow[t]{8}{*}{$4.4 E-1$} & 1 & $4.40 E-01$ & $1.92 E-10$ \\
\hline & .2 & $2.00 E-01$ & \\
\hline & 1 & $1.00 E+00$ & \\
\hline & .09 & $9.00 \mathrm{E}-02$ & \\
\hline & $1.03 E-3$ & $1.03 E-03$ & \\
\hline & $2.35 E-5$ & $2.35 E-05$ & \\
\hline & .2 & $2.00 \mathrm{E}-01$ & 1. $92 E-10$ \\
\hline & 1 & $1.00 E+00$ & \\
\hline \multirow{6}{*}{$4.4 E-1$} & 1 & $4.40 E-01$ & \\
\hline & .09 & $9.00 \mathrm{E}-02$ & \\
\hline & $1.03 E-3$ & $1.03 E-03$ & \\
\hline & $2.35 \varepsilon-5$ & $2.35 E-05$ & \\
\hline & .20 & $2.00 E-01$ & $1.92 \mathrm{E}-10$ \\
\hline & 1 & $1.00 E+00$ & \\
\hline \multirow[t]{5}{*}{$4.4 E-1$} & 1 & $4.40 E-01$ & \\
\hline & .09 & $9.00 \mathrm{E}-02$ & \\
\hline & $1.03 E-3$ & $1.03 E-03$ & \\
\hline & $2.35 E-5$ & $2.35 E-05$ & \\
\hline & .2 & $2.00 E-01$ & $1.76 \mathrm{E}-10$ \\
\hline \multirow[t]{5}{*}{$4.6 E-5$} & 1 & $4.03 E-01$ & \\
\hline & .09 & $9.00 E-02$ & \\
\hline & $1.03 E-3$ & $1.03 E-03$ & \\
\hline & $2.35 E-5$ & $2.35 E-05$ & \\
\hline & .20 & $2.00 E-01$ & $1.76 E-10$ \\
\hline \multirow[t]{4}{*}{ 4. $6 E-5$} & 1 & $4.03 E-01$ & \\
\hline & .09 & $9.00 E-02$ & \\
\hline & $1.03 E-3$ & $1.03 E-03$ & \\
\hline & $2.35 E-5$ & $2.35 E-05$ & \\
\hline \multirow[t]{9}{*}{$8.5 E-6$} & 1 & $7.45 E-02$ & $9.73 \mathrm{E}-11$ \\
\hline & .60 & $6.00 E-01$ & \\
\hline & 1 & $1.00 E+00$ & \\
\hline & .09 & $9.00 \mathrm{E}-02$ & \\
\hline & $1.03 E-3$ & $1.03 E-03$ & \\
\hline & $2.35 \mathrm{E}-5$ & $2.35 E-05$ & \\
\hline & .2 & $2.00 E-01$ & $9.54 E-11$ \\
\hline & 1 & $1.00 E+00$ & \\
\hline & .09 & $9.00 E-02$ & \\
\hline \multirow[t]{5}{*}{$2.5 E-5$} & 1 & $2.19 E-01$ & \\
\hline & $1.03 E-3$ & $1.03 E-03$ & \\
\hline & 2. $35 \Sigma-5$ & $2.35 \varepsilon-05$ & \\
\hline & 1 & $1.00 E+00$ & $9.54 E-1 i$ \\
\hline & .20 & $2.00 \varepsilon-01$ & \\
\hline
\end{tabular}


A: IGN-09R. CUT

MODULE/EVENT NAME

IGNITION NCWCHRHW HEPA

EPVNTINT

52) 8EN528HW BHOUSE04 BOPTRNBE IGNITION REPAIRN EPVNTINT

53) BHOUSE01 BPRREGHW* IGNITION REPAIRM EPVNTINT

54) BHOUSEO3 BPRREGHW* BPRREGHW IGNITION REPAIRM

EPVNTINT

BAZO21 HW 8A2022TM BHOUSEO3 IGNITION REPAIRM

EPVNTINT

56) BAZO21 HW 8AZO22TM 8 HOUSE01 IGNITION REPAIRM EPVNTINT

57) BHOUSEOI BOPC-MS BSFFANHW* IGNITION REPAIRN EPVNTINT

8) BHOUSE0 BOPC-MS BOPC-MS BSFEANHW IGNITION REPAIRN EPVNTINT

59) 9DMDEMHW
9HOUSEO2
Truncation Limit: $1.00 E-15$

DESCRI PTION

CONDITIONAL PROBABILITY OF HAVING AN IGNITION SOURCE PRESENT MECHANICAL FAULTS IN CHROMATED COOLING WATER SYSTEM PROBABILITY OF NOT RE.PLACING/REPAIRING HEPA FILTER IS NEGLIGIBLE OPERATOR EAILS TO ALIGN OR START EMERGENCY PURGE VENT EOUIP OR HAR TANK 48 EXHAUST FAN Y 348-52-8 FAILS TO RUN DUE TO MECHANICAL FAULT CONDITIONAL PROBABILITY OF BEING IN NORMAL PROCESSING MODE $140 \mathrm{CT}$ CONDATOR FAIIS TO ALIGN AND START TRAIN B FOR OPERATION - EXHAUST CONDITIONAI PROBABIL CONDITIONAL PROBABILITY OF HAVING AN IGNITION SOURCE PRESE OPERATOR FAI CONDITIONAL PROBABILITY OE TRANSFERRING SALT SOLUTION $(70 \mathrm{C}$ TEMP) TANK 48 FAILURE OF PRESSURE REGULATING VALVE 1217PV

CONDITIONAL PROBABILITY OE HAVING AN IGNITION SOURCE PRESENT PROBABILITY OF NOT PERFORMING A MODERATE REPAIR PROCEDURE OPERATOR FAILS TO ALIGN OR START EMERGENCY PURGE VENT EQUIP OR HAR CONDITIONAL PROBABILITY OF BEING IN WASH CYCLE

TANK 48 FAILURE OF PRESSURE REGULATING VALVE 1217 PV

CONDITIONAL PROBABILITY OF HAVING AN IGNITION SOURCE PRESENT

PROBABILITY OE NOT PEREORMING A MODERATE REPAIR PROCEDURE

OPERATOR FAILS TO ALIGN OR START EMERGENCY PURGE VENT EQUIP OR HAR TANK 48 O2 ANALYZER 1 HARDNARE FAULTS

TANK 48 O2 ANALYZER 2 UNAVAILABLE DUE TO MAINTENANCE

CONDTTIONAL PROBABIITTY OF BEING IN WASH CYCLE

CONDITIONAL PROBABILITY OF HAVING AN IGNITION SOURCE PRESENT

PROPABINTY OF NOT PEREORMING A MODERATE REPAIR PROCEDURE

OPERATOR FAILS TO ALIGN OR START EMERGENCY PURGE VENT EQUIP OR HAR

TANK 48 O2 ANALYZER 1 HARDWARE EAULTS

TANK 48 O2 ANALYZER 2 UNAVAILABLE DUE TO MAINTENANCE

CONDITIONAI PROBABILITY OF TRANSFERRING SALT SOLUTION $170 \mathrm{C}$ TEMP)

CONDIONAL PROBABILITY OE TRANSEERR UG SALT SOLUTION SOURCE PRESENT

CONDITIONAL PROBABILITY OF HAVING AN IGNITION SOURCE PRESENT

OPERATOR FAILS TO ALIGN OR START EMERGENCY PURGE VENT EQUIP OR HAR

CONDITIONAI PROBABILITY OF TRANSFERRING SALT SOLUTION (70 C TEMP)

OPERATOR FAILS TO ENTER FIELD CONTROL MODE (MODERATE STRESS LEVELS SENSOR DETECTING EAN OPERATION FOR NORMALLY RUNNING FAN FAILS

CONDITIONAL PROBABILITY OF HAVING AN IGNITION SOURCE PRESEN

PROBABILITY OF NOT PEREORMING A SIMPLE REPAIR PROCEDURE

OPERATOR FAILS TO ALIGN OR START EMERGENCY PURGE VENT EQUIP OR HAR CONDITIONAL PROBABILITY OF BEING IN WASH CYCLE

OPERATOR FAILS TO ENTER FIELD CONTROL MODE (MODERATE STRESS LEVELS SENSOR DETECTING FAN OPERATION FOR NORMALLY RUNNING FAN EAILS CONDITIONAL PROBABIIITY OF HAVING AN IGNITION SOURCE PRESENT PROBABILITY OF NOT PERFORMING A SIMPLE REPAIR PROCEDURE

OPERATOR FAILS TO ALIGN OR START EMERGENCY PURGE VENT EQUIP OR HAR DPERTOR EAILS TO ALIGN OR START

NO ACTION TAKEN FOR 48 HRS
1-10-94 12:46 Page

B.E. MOD./CS.

$\begin{array}{llll} & \text { B.E. } & \text { MOD./CS. } \\ \text { RATE } & \text { EXPOSURE } & \text { PROB. } & \text { PROB. }\end{array}$

\begin{tabular}{|c|c|c|c|}
\hline \multirow{4}{*}{$2.5 E-5$} & .09 & $9.00 \mathrm{E}-02$ & \\
\hline & 1 & $2.19 E-01$ & \\
\hline & $1.03 \mathrm{E}-3$ & $1.03 \mathrm{E}-03$ & \\
\hline & $2.35 E-5$ & $2.35 E-05$ & \\
\hline \multirow{7}{*}{$8.0 \mathrm{E}-6$} & 1 & $7.01 E-02$ & $9.16 \mathrm{E}-11$ \\
\hline & .60 & $6.00 E-01$ & \\
\hline & 1 & $1.00 E+00$ & \\
\hline & .09 & $9.00 \mathrm{E}-02$ & \\
\hline & $1.03 E-3$ & $1.03 \mathrm{E}-03$ & \\
\hline & $2.35 E-5$ & $2.35 \mathrm{E}-05$ & \\
\hline & .2 & $2.00 E-01$ & $8.97 E-11$ \\
\hline \multirow[t]{5}{*}{$2.2 E-6$} & 1 & $1.93 \mathrm{E}-02$ & \\
\hline & .09 & $9.00 \varepsilon-02$ & \\
\hline & .011 & 1. $10 \mathrm{E}-02$ & \\
\hline & $2.35 \mathrm{E}-5$ & 2. $35 E-05$ & \\
\hline & .20 & $2.00 E-01$ & $8.97 E-11$ \\
\hline \multirow[t]{4}{*}{$2.2 E-6$} & $i$ & 1. $93 \mathrm{E}-02$ & \\
\hline & .09 & $9.00 \mathrm{E}-02$ & \\
\hline & .011 & $1.10 \mathrm{E}-02$ & \\
\hline & $2.35 E-5$ & $2.35 \mathrm{E}-05$ & \\
\hline $3.0 E-4$ & 2 & $5.26 E+00$ & $8.80 E-11$ \\
\hline \multirow{5}{*}{$1.8 \mathrm{E}-3$} & 2 & $3.60 \mathrm{E}-03$ & \\
\hline & .20 & $2.00 E-01$ & \\
\hline & .09 & $9.00 E-02$ & \\
\hline & .011 & $1.10 E-02$ & \\
\hline & $2.35 E-5$ & $2.35 E-05$ & \\
\hline $3.0 E-4$ & 2 & $5.26 E+00$ & $8.80 E-11$ \\
\hline \multirow{7}{*}{$1.8 \mathrm{E}-3$} & 2 & $3.60 \varepsilon-03$ & \\
\hline & .2 & $2.00 E-01$ & \\
\hline & .09 & $9.00 E-02$ & \\
\hline & .011 & $1.10 \varepsilon-02$ & \\
\hline & $2.35 E-5$ & $2.35 E-05$ & \\
\hline & .2 & $2.00 E-01$ & $8.01 E-11$ \\
\hline & 1 & $1.00 E+00$ & \\
\hline \multirow{6}{*}{$2.1 E-5$} & 1 & $1.84 \mathrm{E}-01$ & \\
\hline & .09 & $9.00 E-02$ & \\
\hline & $1.03 \mathrm{E}-3$ & $1.03 E-03$ & \\
\hline & $2.35 \mathrm{E}-5$ & $2.35 E-05$ & \\
\hline & .20 & $2.00 E-01$ & $8.01 E-11$ \\
\hline & 1 & 1. $00 E+00$ & \\
\hline \multirow[t]{4}{*}{$2.1 E-5$} & 1 & $1.84 E-01$ & \\
\hline & .09 & $9.00 \mathrm{E}-02$ & \\
\hline & $1.03 E-3$ & $1.03 E-03$ & \\
\hline & 2. $35 E-5$ & $2.35 E-05$ & \\
\hline \multirow[t]{2}{*}{$3.6 \mathrm{E}-6$} & 1 & $3.15 E-02$ & $6.87 \mathrm{E}-11$ \\
\hline & 1 & $1.00 E+00$ & \\
\hline
\end{tabular}


CONDITIONAL PROBABILITY OF HAVING AN IGNITION SOURCE PRESENT

OPERATOR FAILS TO ALIGN OR START EMERGENCY PURGE VENT EQUIP OR TANK 49 VACUUM SENSOR FAILS AND CLOSES TIONAL PROBABILITY OF HAVING AN IGNITION SOURCE PRESENT PROBABILITY OF NOT PERFORMING A SIMPLE REPAIR PROCEDURE

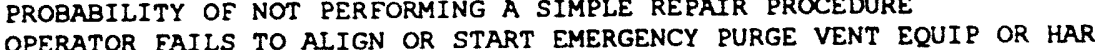
OPERATOR FAILS TO ALIGN OR START

1CNCONHW

9HOUSE02

IGNITION

HEPA

LOCAL FAULTS OF TANK 49 COND
NO ACTION TAKEN FOR 48 HRS

NO ACTION TAKEN FOR 48 HRS HAVING AN IGNITION SOURCE PRESENT

CONDITIONAL PROBABILITY OF HAVING AN IGNITION SOURCE PRESENT
PROBABILITY OF NOT REPLACING/REPAIRING HEPA FILTER IS NEGLIGIBLE

EPVNTINT

62) 9FSNEAHW 9ESNFBHW 9OPC-HS IGNITION IGNITION REPAIRN

63) 8DMDEMTH

8DMDEMHW

8HOUSE 02

8HOUSE04

IGNITION REPAIRN

EPVNTINT

64) BHOUSE04

BVSVACHW*

IGNITION

REPAIRN

EPVNTINT

65) 8CNCONHW

8 HOUSE02

8HOUSE04

IGNITION

REPAIRN

66) 8FSNEAHW

BESNEAHW

8HOUSEO 4

8OPC-HS

IGNITION

REPAIRN

2) BHOUSEO4

BPRREGHW

IGNITION

OPERATOR FAILS TO ALIGN OR START EMERGENCY PURGE VENT EQUIP OR HAR

TANK 49 NITROGEN FLOW SENSOR FOR LINE A FAILS DUE TO LOCAL FAULTS

TANK 49 NITROGEN FLOW SENSOR FOR LINE B FAILS DUE TO LOCAL FAULTS CONDITIONAL PROBABILITY OF HAVING AN IGNITION SOURCE PRESENT

PROBABILITY OF NOT PERFORMING A SIMPLE REPAIR PROCEDURE

OPERATOR FAILS TO ALIGN OR START EMERGENCY PURGE VENT EQUIP OR HAR LOCAL EAULTS OE TANK 48 DEMISTER

NO ACTION TAKEN FOR 48 HOURS

CONDITIONAL PROBABILITY OE BEING IN NORMAL PROCESSING MODE $140 \mathrm{C} \mathrm{T}$ CONDITIONAL PROBABILITY OF HAVING AN IGNITION SOURCE PRESENT

PROBARIIITY OF NOT PERFORMING A SIMPLE REPAIR PROCEDURE

OROBATLR FIIS TO ALIGN OR START EMERGENCY PURGE VENT EOUIP OR HAR OPERATOR FAILS TO ALIGN OR START EMERGENCY PURGE VENT EQUIP OR HAR CONDITIONAL PROBABILITY SAILS AND CLOSES FAN FLOW CONTROL VALVES TANK 48 VACUUM SENSOR EAILS ANING AN IGNITION SOURCE PRESENT CONDITIONAL PROBABILITY OF HAVING AN IGNITION SOURCE PRES PROBABILITY OF NOT PERFORMING A SIMPLE REPAIR PROCEDURE
OPERATOR FAILS TO ALIGN OR START EMERGENCY PURGE VENT EQUIP OR HAR LOCAL FAULTS OF TANK 48 CONDENSER NO ACTION TAKEN FOR 48 HOURS

CONDITIONAL PROBABILITY OE BEING IN NORMAL PROCESSING MODE $140 \mathrm{C}$ CONDITIONAL PROBABILITY OF HAVING AN IGNITION SOURCE PRESENT

PROBABILITY OF NOT PERFORMING A SIMPLE REPAIR PROCEDURE

OPERATOR EAILS TO ALIGN OR START EMERGENCY PURGE VENT EQUIP OR HAR TANK $4 B$ NITROGEN ELOW SENSOR FOR LINE A FAILS DUE TO LOCAL EAULTS TANK $O$ NITROGEN FLOW SENSOR FOR LINE B FAILS DUE TO LOCAL EAULTS CONDITIONAL PROBABILITY OF BEING IN NORMAL PROCESSING MODE $140 \mathrm{C} T$ OPERATOR FAILS TO ENTER FIELD CONTROL MODE (HIGH STRESS LEVELS)

CONDITIONAL PROBABITTY OF HAVING AN IGNITION SOURCE PRESENT

CONDITIONAL PROBABILITY OE HAVING AN IGNIEPAR PROCEDRE

PROBABILITY OF NOT PER OPERATOR EAILS TO ALIGN OR START EMERGENCY PURGE NSNT MUDE $140 \mathrm{C}$ CONDITIONAL PROBABI IT

TANK 48 FAILURE OF PRESSURE REGULATING VALVE 1217PV

REPAIRN

PROBABILITY OF NOT PERFORMING A SIMPLE REPAIR PROCEDURE

$3.5 E-6$

$3.0 \mathrm{E}-6$

$1.2 E-4$
$1.2 E-4$

$3.6 E-6$

EXPOSURE

PROB.

PROB.

$1.03 E-3 \quad 1.03 E-03$

$2.35 E-5 \quad 2.35 E-05$

$09 \quad 3.07 \mathrm{E}-02$

$1.03 E-3 \quad 1.03 E-03$

2.35E-5 2.35E-05

.09

1. $.03 E-3$

$2.35 E-5$

2

1

.09

i. $03 \mathrm{E}-3$

2. $35 E-5$

1

.60

.09

$1.03 E-3$

$2.35 E-5$

.60

3. $5 \mathrm{E}-6$

109

.09

2.35E-5

3. $0 E-6$

1

.60

$1.03 E-3$

2. $35 E-5$

$1.2 E-4$
$1.2 E-4$

60

1

.09

$2.63 \mathrm{E}-02$

1. $00 \mathrm{E}+00$

$9.00 E-02$

$1.03 E-03$

2. $35 E-05$

$2.35 E-05$

2.10E+CO

$2.00 \mathrm{E}-02$

$1.00 \mathrm{E}+00$

$9.00 E-02$

$1.03 E-03$

$2.35 \mathrm{E}-05$
$3.15 \mathrm{E}-02$

$1.00 E+00$

$6.00 E-01$

$9.00 E-02$

$1.03 E-03$

$2.35 E-05$

6.00E-01 4.01E-1

$3.07 \mathrm{E}-02$

9. $00 \mathrm{E}-02$

$1.03 \mathrm{E}-03$

2. 35E-05

2. $63 \mathrm{E}-02$

$1.00 E+00$

$6.00 \mathrm{E}-01$

$9.00 \mathrm{E}-02$

$1.03 E-03$
$2.35 E-05$

$2.35 E-05$

$2.10 E+00$

$2.00 \mathrm{E}-02$

$6.00 E-01$

$1.00 E+00$

$9.00 \mathrm{E}-02$

$1.03 E-3 \quad 1.03 E-03$

$2.35 E-5 \quad 2.35 E-05$

$.60 \quad 6.00 E-01$

1. $93 \mathrm{E}-02$

1. $03 E-3 \quad 1.03 E-03$
$6.68 E-11$

$5.72 E-11$

$9.14 E-11$

4.12E-11

3. $43 E-11$

$.48 E-11$

$2.52 E-11$ 
B.E.

\section{DESCRI PTION}

OPERATOR FAILS TO ALIGN OR START EMERGENCY PURGE VENT EQUIP OR HAR

68) $9 \mathrm{FC} 121 \mathrm{HW}$

9 FC122TM

IGNITION

REPAIRM

69) 9FC121 HW*

9PRPV2TM

IGNITION

REPAIRM

EPVNTINT

70) 8AZO21 HW*

8A2022TM

BHOUSEO4

IGNITION

REPAIRN

EPVNTINT
9ELHP2HW*

IGNITION

HEPA.

EPVNTINT

72) 9EC511HW 9 EC512HW* IGNITION REPAIRM EPVNTINT

73) 9FC511HW 9EN512HW* IGNITION REPAIRM

74) BDMDEMHW* BHOUSE02 BHOUSEO2 IGNITION HEPA EPVA

75) 8 DMDEMHW * 8HOUSEO1 8HOUSE02 IGNITION HEPA

EPVNTINT

76) BHOUSEOI BVSVACHW* IGNITION
MECHANICAL FAULT OF TANK 49 FLOW CONTROL VALVE 1251 FV TANK 49 FLOW CONTROL VALVE 1252 EV UNAVAILABLE DUE TO MAINTENANCE CONDITIONAL PROBABILITY OF HAVING AN IGNITION SOURCE PRESENT PROBABILITY OF NOT PEREORMING A MODERATE REPAIR PROCEDURE OPERATOR EAILS TO ALIGN OR START EMERGENCY PURGE VENT EQUIP OR HAR MECHANICAL FAULT OF TANK 49 FLOW CONTROL VALVE 1251 FV

TANK 49 PRESSURE REGULATING VALVE 1255 PV2 UNAVAILABLE DUE TO MAINT CONDITIONAL PROBABILITY OF HAVING AN IGNITION SOURCE PRESENT

PROBABILITY OE NOT PEREORMING A MODERATE REPAIR PROCEDURE

OPERATOR FAILS TO ALIGN OR START EMERGENCY PURGE VENT EQUIP OR HAR TANK 48 O2 ANALYZER 1 HARDWARE FAULTS

TANK 48 O2 ANALYZER 2 UNAVAILABLE DUE TO MAINTENANCE

CONDITIONAL PROBABILITY OF BEING IN NORMAL PROCESSING MODE $140 \mathrm{C} \mathrm{T}$

CONDITIONAI PROBABILITY OE HAVING AN IGNITION SOURCE PRESENT

PROBAAILITY OF NOT PERFORMING A SIMPLE REPAIR PROCEDURE

OPERATOR FAILS TO ALIGN OR START EMERGENCY PURGE VENT EQUIP OR HAR OPERATOR FATLS TO ALIGN OR START BMERGE

LOCAL FAULT OE TANK 49 HEPA FILTER 2 IGNITION SOURCE PRESENT

CONDITIONAL PROBABILITY OE HAVING AN IGNITION SITR IS NEGLIGIBLE

PROBABILR OF NOT AIIGN OR START EMERGENCY PURGE VENT EOUIP OR HAR

FLOW CONTROL VALVE 1251 PVI MECHANICAL FAULT

FLOW CONTROL VALVE 1251 PV2 MECHANICAL EAULT

CONDITIONAL PROBABILITY OF HAVING AN IGNITION SOURCE PRESENT

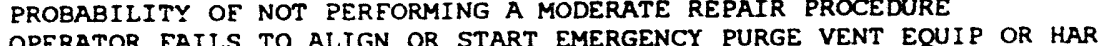
OPERATOR FAILS TO ALIGN OR START EMERGENCY PURGE VENT EQUIP OR HAR

FLOW CONTROL VALVE 1251 PVI MECHANICAL FAULT CONDITIONAL PROBABILITY OE HAVING AN IGNITION SOURCE PRESEN

PROBABILITY OF NOT PERFORMING A MODERATE REPAIR PROCEDURE

OPERATOR FAILS TO ALIGN OR START EMERGENCY PURGE VENT EQUIP OR HAR LOCAL FAULTS OF TANK 48 DEMISTER

NO ACTION TAKEN FOR 48 HOURS

CONDITIONAI PROBABILITY OF BEING IN WASH CYCLE

CONITTIONAI PROBABIIITY OF HAVING AN IGNITION SOURCE PRESENT

PROABILTY OF NOT REPLACING/REPAIRING HEPA FILTER IS NEGLIGIBLE

PROBABILITY OF NOT REPLACING OPERATOR FAILS TO TANK $4:$ DEMISTER

LOCAL FAULTS OF TANK 4L DEMITAR NO ACTION TAKEN FOR 48 HOURS

NO ACTION TAKEN FOR 48 HOURS

CONDITIONAI PROBABILITY OF HAVING AN IGNITION SOURCE PRESENT

PROBABILITY OF NOT REPLACING/REPAIRING HEPA FILTER IS NEGUIP OR HAR

OPERATOR FAILSTO ALIGN OR START EMRING SALT SOLUTION $170 \mathrm{C}$ TEMP)

TANK 4 VAC PROBABILITY OF TRANSFERRING SALT SOLUTION

CONDITIONAL PROBABILITY OF HAVING AN IGNITION SOURCE PRESENT
RATE

8. $5 E-6$

3. $6 \mathrm{E}-3$

$8.5 E-6$

3. $6 \mathrm{E}-3$

2

$3.0 E-4$
$1.8 E-3$

(

$1.0 E-6 \quad 1$

$2.35 E-5$

8. $5 E-6$

3. $5-6$

$8.0 E-6$

$3.6 E-6$

1.0

$3.6 E-6$

.

.09

1. $03 \mathrm{E}-3$

2. $35 E-5$

.2

$3.5 E-6$

\begin{tabular}{|c|c|c|}
\hline $\begin{array}{l}2.35 E-5 \\
2\end{array}$ & $\begin{array}{l}2.35 E-05 \\
1.49 E-01\end{array}$ & $2.49 \mathrm{E}-11$ \\
\hline 2 & $7.20 E-03$ & \\
\hline .09 & $9.00 \mathrm{E}-02$ & \\
\hline .011 & $1.10 \varepsilon-02$ & \\
\hline $2.35 E-5$ & $2.35 E-05$ & \\
\hline 2 & $1.49 E-01$ & $2.49 \mathrm{E}-11$ \\
\hline 2 & $7.20 \mathrm{E}-03$ & \\
\hline .09 & $9.00 \mathrm{E}-02$ & \\
\hline .011 & $1.10 \mathrm{E}-02$ & \\
\hline $2.35 E-5$ & $2.35 E-05$ & \\
\hline 2 & $5.26 E+00$ & $2.47 \mathrm{E}-11$ \\
\hline 2 & $3.60 E-03$ & \\
\hline .60 & $6.00 \mathrm{E}-01$ & \\
\hline .09 & $9.00 E-02$ & \\
\hline $1.03 E-3$ & $1.03 \mathrm{E}-03$ & \\
\hline $2.35 E-5$ & $2.35 E-05$ & \\
\hline 1 & $8.76 E-03$ & $1.91 E-11$ \\
\hline .09 & $9.00 E-02$ & \\
\hline $1.03 \mathrm{E}-3$ & $1.03 E-03$ & \\
\hline $2.35 E-5$ & 2. $35 E-05$ & \\
\hline 3 & $9.18 \mathrm{E}-03$ & $1.59 \mathrm{E}-11$ \\
\hline 1 & $7.45 E-02$ & \\
\hline .09 & $9.00 E-02$ & \\
\hline .011 & 1.10E-02 & \\
\hline $2.35 E-5$ & $2.35 E-05$ & \\
\hline 3 & $9.18 E-03$ & $1.50 \mathrm{E}-11$ \\
\hline 1 & $7.01 E-02$ & \\
\hline .09 & $9.00 E-02$ & \\
\hline .011 & $1.10 E-02$ & \\
\hline $2.35 E-5$ & $2.35 E-05$ & \\
\hline 1 & $3.15 E-02$ & $1.37 \mathrm{E}-11$ \\
\hline$i$ & 1. $.00 E+00$ & \\
\hline .20 & $2.00 E-01$ & \\
\hline .09 & $9.00 \mathrm{E}-02$ & \\
\hline $1.03 E-3$ & $1.03 E-03$ & \\
\hline $2.35 E-5$ & 2. $35 \varepsilon-05$ & \\
\hline 1 & $3.15 E-02$ & $1.37 E-11$ \\
\hline .2 & $2.00 E-01$ & \\
\hline 1 & $1.00 E+00$ & \\
\hline .09 & $9.00 E-02$ & \\
\hline $1.03 \mathrm{E}-3$ & $1.03 E-03$ & \\
\hline $2.35 E-5$ & $2.35 E-05$ & \\
\hline .2 & $2.00 \mathrm{E}-01$ & $1.34 E-11$ \\
\hline 1 & $3.07 E-02$ & \\
\hline .09 & $9.00 \mathrm{E}-02$ & \\
\hline
\end{tabular}

MOD./CS.

PROB.

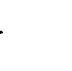

.


PROBABILITY OE NOT PEREORMING A SIMPLE REPAIR PROCEDURE
OPERATOR FAILS TO ALIGN OR START EMERGENCY PURGE VENT EQUIP OR HAR

77) 8HOUSEO3

BVSVACHW*

IGNITION

REPAIRN

EPVNTINT

78) 9 FC511TM

IGNITION

REPAIRM

EPVNTINT

79) 9FC511TM

9FNSI2HW-

REPAIRM

EPVNTINT

80) 8 CNCONHW* BHOUSEO1 BHOUSE02 IGNITION HEPA OPERATOR FAILS TO ALIGN OR START EMERGENCY PURGE

TANK 48 VACUUM SENSOR FAILS AND CLOSES EAN FLOW CONTROL VALVES TANK 40 VACUUM SENSOR FAILS AND CLOSES FAN FIOW CONTROL VALVS CONDITIONAL PROBABILITY OF HAT A SIMPLE REPAIR PROCEDURE

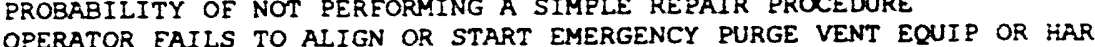
OPERATOR FAILS TO ALIGN OR START EMERGENC

FLOW CONTROL VALVE 1251 PVI MAINTENANCE

FLOW CONTROL VALVE 1251 PV2 MECHANICAI FAULT CONDITIONAL PROBABILITY OF HAVING AN IGNITION SOURCE PRESENT PROBABILITY OF NOT PERFORMING A MODERATE REPAIR PROCEDURE OPERATOR EAILS TO ALIGN OR START EMERGENCY PURGE VENT EQUIP OR HAR FLOW CONTROL VALVE 125IPVI MAINTENANCE TANK 49 EXHAUST FAN Y 349-52-12 FAILS TO RUN DUE TO MECHANICAL EAUL $8.0 E-6$ CONDITIONAL PROBABILITY OF HAVING AN IGNITION SOURCE PRESENT

PROBABILITY OF NOT PEREORMING A MODERATE REPAIR PROCEDURE

OPERATOR FAILS TO ALIGN OR START EMERGENCY PURGE VENT EQUIP OR HAR LOCAL FAUITS OF TANK 48 CONDENSER

CONDITIONAL PROBABILITY OF TRANSFERRING SALT SOLUTION (70 C TEMP) NO ACTION TAKEN FOR 48 HOURS

CONDITIONAI PROBABIITTY OF HAVING AN IGNITION SOURCE PRESENT

CONDITIONAL PROBABILITY OE HAVING AN IGNITION SOURE PRESENT PROBABILITY OF NOT REPLACING/REPAIRING HERA EILTER IS NEGLIGIBLE OPERATOR EAILS TO ALIGN OR START EM LOCAL FAULTS OE TANK 48 CONDENS

i) $8 \mathrm{CNCONHW}$ BHOUSE02 BHOUSE03 IGNITION HEPA EPVNTINT

82) BELHP2HW BHOUSEO4 IGNITION REPAIRN EPVNTINT

831 BESNEAHWGESNFBHW QHOUSE03 $8 O P C-H S$ IGNITION REPAIRN EPVNTINT

84) 8ESNEAHW BFSNFBHW BHOUSEOI BnEc-his IGNITION

CONDITIONAI PROBABILITY OF BEING IN WASH CYCLE

CONDITIONAL PROBABILITY OE BEING IN WN IGNITION SOURCE PRESENT

CONDITIONAL PROBABILITY OE HAVING AN IGNITION SOURCE PRESENI

PROBABILITY OF NOT REPLACING/REPAIRING HEPA EILTER IS NEGLIGIBLE OCAL FAULT OF HEPA FILTER

CONDITIONAL PROBABI IITY OF BEING IN NORMAL PROCESSING MODE $140 \mathrm{C}$ CONDITIONAL PROBABILITY OF HAVING AN IGNITION SOURCE PRESENT PROBABILITY OF NOT PERFORMING A SIMPLE REPAIR PROCEDURE OPERATOR FAILS TO ALIGN OR START EMERGENCY PURGE VENT EQUIF OR HAR TANK 48 NITROGEN FLOW SENSOR FOR LINE A EAILS DUE TO LOCAL FAULTS TANK 48 NITROGEN FLOW SENSOR FOR LINE B EAILS DUE TO LOCAL EAULIS CONDITIONAL PROBABILITY OF BEING IN WASH CYCLE

OPERATOR EAILS TO ENTER EIELD CONTROL MODE (HIGH STRESS LEVELS) CONDITIONAI PRCBABILITY OF HAVING AN IGNITION SOURCE PRESENT PROBABILITY OF NOT PEREORMING A SIMPLE REPAIR PROCEDURE OPERATOR EAIIS TO ALIGN OR START EMERGENCY PURGE VENT EQUIP OR HAR OPERATOR EAILS TO ALIGN OR START EMTNE A FAILS DUE TO LOCAL FAULTS TANK 48 NITROGEN FLOW SENSOR FOR LINE A FAILS DUE TO LOCAL EAULTS TANK 48 NITROGEN FLOW SENSOR FOR LINE B FAILS DUE TO LOCAL FAULTS CONDITIONAL PROBABILITY OE TRANSFERRING SALT SOLUTION (TO C TEMPI OPERATOR FAILS TO ENTER FIELD CONTROL MODE (HIGH STRESS LEVELSI

$3.5 E-6$
$3.6 E-3$
$9.5 E-6$

$3.6 E-3$
$8.0 E-6$

3. $0 E-6$

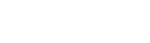

$3.0 E-6$

$1.03 E-3 \quad 1.03 E-03$

2.35E-05

109

$1.03 E-3$

$2.35 E-5$

2

.09

2. $35 \Sigma-5$

2

.09

$2.35 \mathrm{E}-5$

12

$i^{2}$

.09

2. $35 E-5$

1

20

.20

i. $.03 E-3$

$2.35 E-5$

$1.0 E-6$

.60

1. $.03 \mathrm{E}-3$

2. $35 \mathrm{E}-5$

1. $2 E-4$

1. $2 E-4$

2

$i^{70}$

.09

1.03E-3

1. $2 E-4$

1. $2 E-4$

9. $00 \mathrm{E}-02$

$9.00 E-02$
$1.03 E-03$

$1.03 E-03$
$2.35 E-05$

$7.45 E-02$
$9.00 E-02$

1. $105-02$

1.10E-02

$7.01 E-02$

9. $00 \mathrm{E}-02$

1. $10 E-02$

2. 35E-05

2. $00 \mathrm{E}-01$

1. $00 \mathrm{E}+00$

$9.00 E-02$

1. $03 \mathrm{E}-03$

$2.35 E-05$

$1.00 \mathrm{E}+00$

2. $00 \mathrm{E}-01$

$9.00 E-02$

$1.03 E-03$
$2.35 E-05$

$6.00 E-01$

9.00E-02

1. $03 E-03$

$2.00 E-01$

$1.00 E+00$

9. $\mathrm{COE}-02$

1. $03 E-03$

2. $35 E-05$

2.00E-02
$2.00 E-01$

3. $07 E-02$

7.20E-03 :.25E-:?

$2.35 E-05$

.20E-03 1.17E-i

2.63E-02 1.14E-11

$2.63 \mathrm{E}-02$

2.35E-05

6. 14 E-11

2. $35 \mathrm{E}-05$

$2.10 E+00$
$2.00 E-02$

$2.10 \varepsilon+00$-. $83 \equiv-1$

$.22 .00 E-01$

$.09 \quad 9.00 E-02$ 

OPERATOR FAIIS TO ALIGN OR START EMERGENCY PURGE VENT EQUIP OR HAR CONDITIONAI PROBABILITY OF HAVING AN IGNITION SOURCE PRESENT

OPERATOR SAILS TO ALIGN TRAIN B FOR OPERATION - SUPPLY SIDE

$2.35 E-5 \quad 2.35 E-05$

87) 9PRPV1HW 9PRPV2TM IGNITION REPAIRM EPVNTINT

88) 9 EC512HW 9 FN511TM IGNITION REPAIRM EPVNTINT

89) 9EN511TM 9ENS12HW* IGNITION REPAIRM EPVNTINT

90) BFC121 HW 8 HOUSE01 BPRPV 2TM BPRPV 2TM IGNITION EPVNTINT

91) $8 F C 121 \mathrm{HW}$ * BFC122TM BHOUSEO 3 IGNITION REPAIRM EPVNTINT

92) BEC121 HW BFC122TM BHOUSEOI IGNITION REPAIRM EPVNTINT

93) 8FCl21 tiw FAILURE OF VAPORIZER A DUE TO HARDWARE FAULTS

PROBABIT

OPERATOR FAILS TO ALIGN OR START EMERGENCY PURGE VENT EQUIP OR HAR TANK 49 FLOW CONTROL VALVE 1252 FV UNAVAILABLE DUE TO MAINTENANCE MECHANICAL FAULTS OF TANK 49 PRESSURE REGULATING VALVE 1255PV CONDITIONAL PROBABILITY OF HAVING AN IGNITION SOURCE PRESENT PROBABILITY OF NOT PERFORMING A MODERATE REPAIR PROCEDURE OPERATOR EAILS TO ALIGN OR START EMERGENCY PURGE VENT EQUIP OR

$4.1 E-7$ MECHANICAL FAULTS OF TANK 49 PRESSURE REGULATING VALVE 1255 PVI TANK 49 PRESSURE REGULATING VALVE 1255 PV2 UNAVAILABLE DUE TO PROBABILITY OF NOT PERFORMING A MODERATE REPAIR PROCEDURE OPERATOR FAILS TO ALIGN OR START EMERGENCY PURGE VENT EQUIP OR HAR FLOW CONTROI VALVE 125IPV2 MECHANICAL FAULT

TANK CO EXHAUST FAN Y 349-52-11 UNAVAILABLE DUE TO MAINTENANCE TANK 49 EXHAUST FAN Y CONDITIONAL PROBABILITY OE HAVING AN TGNITIONR PROCEDRE OPERATOR FAILS TO ALIGN OR START EMERGENCY PURGE VENT EQUIP OR HAR OPERATOR FAILS TO ALIGN OR START EMERGENCY PURGE VENT EQUIP OR HAR TANK 49 EXHAUST IAN Y349-52-11 UNAVAILABLE DUE TO MAINTENANCE TANK 49 EXHAUST FAN Y349-52-12 FAILS TO RUN DUE TO MECHANICAL CONDITIONAL PROBABILITY OF HAVING AN IGNITION SOURCE PRESENI PROBABILITY OE NOT PERFORMING A MODERATE REPAIR PROCEDURE OPERATOR FAILS TO ALIGN OR START EMERGENCY PURGE VENT EQUIP OR HAR MECHANICAL EALLT OF TANK 48 FLON CONTROL VALVE $1201 \mathrm{FV}$

CONDITIONAL PROBABILITY OE TRANSFERRING SALT SOLUTION $170 \mathrm{C}$ TEMP TANK 48 PRESSURE REGULATING VALVE 1205 PV2 UNAVAILABLE DUE TO MAIN CONDITIONAL PROBABILITY OE HAVING AN IGNITION SOURCE PRESENT PROBABILITY OF NOT PERFORMING A MODERATE REPAIR PROCEDURE OPERATOR FAILS TO ALIGV CR START EMERGENCY PURGE VENT EQUIP OR HAR MECHANICAL FALLT OF TANK 48 FLOW CONTROL VALVE $1201 \mathrm{FV}$

TANK CONDITIONAI PROBABILITY OF BEING IN WASH CYCLE

CONDITIONAL PROBABILITY OF BEING IN WUSH CYCLE SOURCE PRESENT CONDITIONAL PR PRERATOR FAIIS TO AITN OR START EMERGENCY PURGE VENT EOUIP OR HAR MPERATR FAILS TO ALION OR START EMERTENCY VALVE 1201 TV MECHANICAL EAULT OF TANK 48 FLON CONTROL VALVE 1201 CONDITIONAL PROBABILITY UF TRANSFERRING SALT SOLUTION $170 \mathrm{C}$ TEMP) CONDITIONAL PROBABILITY OF TRANSERR IGNTITION SOURCE PRESENT CONDITIONAL PROBABILITY OF HAVING AN IGNITION SOURCE PRESENT PROBABILITY OF NOT PERFORMING A MODERATE REPAIR PROCEDURE OPERATOR FAILS TO ALIGN OR START EMERGENCY PURGE VENT
MECHANICAL FAULT OF TANK 48 FLOW CONTROL VALVE $1201 \mathrm{~V}$
$.09 \quad 9.00 E-02$

$3.6 \varepsilon-3$

$2.2 E-6$

3.59E-03

$1.03 E-3 \quad 1.03 E-03$ $2.35 E-5 \quad 2.35 E-05$ 011 (.00E-02 $\begin{array}{ll}.011 & 1.10 E-02 \\ 2.35 E-5 & 2.35 E-05\end{array}$ $\begin{array}{lll}2.2 E-6 & 2 & 3.85 E-02 \\ 6 E-3 & 2 & 7.20 E-03\end{array}$ $.09 \quad 9.00 E-02$ $011 \quad 1.10 \mathrm{E}-02$ $2.35 E-5 \quad 2.35 E-05$ $1 \quad 7.45 \mathrm{E}-02$ $09 \quad 3.60 E-03$ $.011 \quad 1.10 E-02$ 2.35E-5 2.35E-05 2 . $35 E-5$. 1 3.60E-03 $09 \quad 7.01 E-02$ $09 \quad 9.00 \mathrm{E}-02$ . $35 E-5 \quad 2.35 E-05$ $2.35 \mathrm{E}-5 \quad 2.35 \mathrm{E}-05$ $1.49 E-01$ $2.00 E-01$ $\begin{array}{ll}2 & 7.20 E-03 \\ .09 & 9.00 E-02 \\ .011 & 1.10 E-02\end{array}$ $\begin{array}{ll}2 & 7.20 E-03 \\ .09 & 9.00 E-02 \\ .011 & 1.10 E-02\end{array}$ $.011 \quad 1.10 E-02$ 2.35E-5 2.35E-05 $\begin{array}{ll}2 & 1.19 E-01 \\ 2 & 7.20 E-03\end{array}$ $20 \quad 2.00 E-0$ $.09 \quad 9.00 \mathrm{E}-02$ $.011 \quad 1.10 \mathrm{E}-02$ 2.35E-5 2.35E-05 2 . $1.35 E-5-01$ . $5 E-6$ 2 7.20E-03 $2.00 \mathrm{E}-0$

$9.00 \mathrm{E}-02$ $0.35 \mathrm{E}-5 \quad 2.35 \mathrm{E}-0 \mathrm{~S}$ $2.35 \mathrm{E}-5 \quad 2.35 \mathrm{E}-0 \mathrm{~S}$

1. $49 E-01$ 4. $95-12$

$7.82 E-12$

$6.46 E-12$ 
B.E.

MOD./CS.

CONDITIONAL PROBABILITY OF BEING IN WASH CYCLE

$20 \quad 2.00 E-01$ TANK 48 PRESSURE REGULATING VALVE 1205 PV2 UNAVAILABLE DUE TO MAINT $3.6 E-3$ CONDITIONAL PROBABILITY OF HAVING AN IGNITION SOURCE PRESENT

PROBABILITY OF NOT PERFORMING A MODERATE REPAIR PROCEDURE

OPERATOR FAILS TO ALIGN OR START EMERGENCY PURGE VENT EQUIP OR HAR MECHANICAL FAULT OF TANK 49 FLON CONTROL VALVE 1251 FV

94) $9 F C 121 \mathrm{HW}^{*}$ 9FC122HW IGNITION REPAIRM EPVNTINT

95) BFLHP2HW" 8HOUSE01 IGNITION HEPA EPVNTINT

96) BFLHP2HW* 8HOUSE03 IGNITION HEPA

EPVNTINT

97) IGNITION NPR2 $45 T M$ NPR246HM REPAIRM EPVNTINT 98) 8FC111HW BHOUSEO1 IGNITION REPAIRM EPVNTINT

99) BFC111HW 8ECI12HW* EHOUSE 03 IGNITION REPAIRM EPVNTINT

1001 BECIIIHW 8 EN52BHA* 3HOUSE03 IGNITION REPAIRM PVNTINT 8FNS28HW* CALT TALT OE TANK 49 FLON CONTROL VALVE 1252EV MECHNICAL EAULT OE TANK 9 FLUNG AN IGNITION SOURCE PRESENT CONDITIONAL PROBABILITY OE HAVING AN IGN PROBABILITY OF NOT PEREORMING A MODERATE REPAIR PROCEDURE OPERATOR FAILS TO ALIGN OR START EMERGENCY PURGE VENT EQUIP OR HAR
LOCAL FAULT OF HEPA FILTER 2

CONDITIONAL PROBABILITY OF TRANSEERRING SALT SOLUTION $170 \mathrm{C}$ TEMP) CONDITIONAL PROBABILITY OF HAVING AN IGNITION SOURCE PRESENT PROBABILITY OE NOT REPLACING/REPAIRING HEPA FILTER IS NEGLIGIBLE OPERATOR FAILS TO ALIGN OR START EMERGENCY PURGE VENT EQUIP OR HAR LOCAL FAULT OF HEPA EILTER 2

CONDITIONAL PROBABILITY OF BEING IN WASH CYCLE

CONDITIONAL PROBABILITY OF HAVING AN IGNITION SOURCE PRESENT

PROBABILITY OE NOT REPLACING/REPAIRING HEPA FILTER IS NEGLIGIBLE

OPERATOR FAILS TO ALIGN OR START EMERGENCY PURGE VENT EQUIP OR HAR CONDITIONAL PROBABILITY OF HAVING AN IGNITION SOURCE PRESENT

PRESSURE REGULATING VALVE 2045PV MAINTENANCE

PRESSURE REGULATING VALVE 2046PV FAILS

$\cos 2$

$.09 \quad 9.00 E-02$

$2.35 E-5 \quad 2.35 E-05$

$2.35 E-05$
$1.49 E-01$

$\begin{array}{lll}8.5 E-6 & 2 & 1.49 E-01 \\ 8.5 E-6 & 7 & 1.43 E-03 \\ & .09 & 9.00 E-02\end{array}$

$.09 \quad 9.00 E-02$

$2.35 E-5 \quad 2.35 E-05$

$2.35 E-5 \quad 2.35 E-05$

$2 \quad 8.76 E-03$

$.22 .00 E-01$

O.

$1.03 E-3 \quad 1.03 E-03$

2.35E-5 2.35E-05

$20 \quad 2.00 E-01$

$09 \quad 9.00 \mathrm{E}-02$

$1.03 E-3 \quad 1.03 E-03$

2.35E-5 2.35E-05

$.09 \quad 9.00 E-02$

$9.00 E-02$
$7.20 E-03$

$\begin{array}{ll}1.011 & 1.93 E-02 \\ 2 & 1.10 E-02\end{array}$

2.35E-5 2.35E-05

PROBABILITY OF NOT PERFORMING A MODERATE REPAIR PROCEDURE

FLOW CONTROL VALVE 1211 PVI MECHANICAL FAULT (MODE C)

ILW CONTROL VALVE 1211PVI MECHANICAL EAULT IO

CON CONAL VALVE 1211Y 2 MECHANICARTING SAIT SOLUTION $170 \mathrm{C}$ TEMP CONDITIONAL PROBABILITY OE TRANING AN IGNITION SOURCE PRESENT

CONDITIONAL PROBABILITY OE HAVING AN IGNITION SOURCE PRESENT

OPERATOR EAILS TO ALIGN OR START EMERGENCY PURGE VENT EQUIP OR HAR

FLOW CONTROL VALVE 1211 PVI MECHANICAL EAULT IMOD

FLOW CONTROL VALVE 1211 PV2 MECHANICAL FAULT

CONDITIONAL PROBABILITY OF BEING IN WASH CYCLE

CONDITIONAL PROBAEILITY OF HAVING AN IGNITION SOURCE PRESENT
PROBABIIITY OE NOT PERFORMING A MODERATE REPAIR PROCEDURE

OPERATOR FAILS TO ALIGN OR START EMERGENCY PURGE VENT EQUIP OR HAR

FLOW CONTROL VALVE 1211 PVI MECHANICAL FAULT (MODE C)

$3.6 E-3$
$2.2 E-6$

$2.35 E-5$

$9.18 E-03$

$7.45 E-02$

$.2 \quad 2.00 \mathrm{E}-01$

$09119.00 E-02$

$2.35 E-5 \quad 2.35 E-05$

$2.35 E-5 \quad 2.35 E-05$

$9.18 E-03$

8. 5E-6

1

$7.45 E-02$
$2.00 E-01$

$\begin{array}{ll}.20 & 2.00 E-01 \\ 09 & 9.00 E-02\end{array}$

$\begin{array}{ll}.09 & 9.00 E-02 \\ .011 & 1.10 E-02\end{array}$

2.35E-5 2.35E-05

$\begin{array}{ll}2.35 E-5 & 2.35 E-05 \\ 3 & 9.13 E-03\end{array}$

9. $1 \mathrm{SE}-03$
$7.01 \mathrm{E}-02$

$20 \quad 2.00 E-01$

$.09 \quad 9.00 E-02$

$.0111 .10 E-02$

$2.35 E-5 \quad 2.35 E-05$

CONDITIONAL PROBABILITY OF HAVING AN IGNITION SOURCE PRESENT

PROBABILITY OE NOT PERFORMING A MODERATE REPAIR PROCEDURE

OPERATOR FAILS TO ALIGN OR START EMERGENCY PURGE VENT EQUIP OR HAR

FLOW CONTROL VALVE 1211 PVI MECHANICAL FAULT (MODE C)

8. $5 E-6$

TANK CONTROL

CONDITIONAL PROBABILITY OF TRANSFERRING SALT SOLUTION $170 \mathrm{C}$ TEMP)

$9.18 \varepsilon-03$

$2 \quad 2.00 E-01$

4. $94 E-12$

$3.82 E-12$

3. $82 E-12$

$3.23 E-12$

3.18E-12

$3.18 \varepsilon-12$

$2.99 E-12$

$2.99 E-12$ 

PROBABILITY OF NOT PEREORMING A MODERATE REPAIR PROCEDURE OPERATOR FAILS TO ALIGN OR START EMERGEN

REPAIRM

EPVNTINT

1021 8FC111TM
8EC112HW*

BHOUSE01

IGNITION

REPAIRM

103) 8FC111TM

8HOUSEO3

BHOUSE 03

REPAIRM

EPPAIRM

104) 8EC111TM

8 RN528HW*

8HOUSE01

IGNITION

REPAIRM
EPVNTINT

105) 8FC111TM

8 FN528HW*

8 HOUSEO3

IGNITION

REPAIRM

EPVNTINT
9FC512 $\mathrm{HW}$ -

9FNSIIHW

IGNITION

REPAIRM

EPVNTINT

1011 9FN511HW

9 ENS12 HW*

IGNITION

EPVNTINT

1081 BECi21 HW* BEC122TM 8 HOUSEO4 IENITION REPAIRN EPVNTINT
BFC121 HW* QHOUSE04 BPRPV2TM
FLOW CONTROL VALVE 1211 PV2 MECHANICAL FAULT

CONDITIONAL PROBABILITY OF TRANSFERRING SALT SOLUTION (70 C TEMP)

CONDITIONAL PROBABIIITY OF HAVING AN IGNITION SOURCE PRESENT

PROBABILITY OF NOT PERFORMING A MODERATE REPAIR PROCEDUR

OPERATOR EAILS TO AIIGN OR START EMERGENCY PURGE VENT EQUIP OR HAR FLOW CONTROL VALVE 1211 PVI MAINTENANCE

FLON CONTROL VALVE 1211 PV2 MECHANICAL FAULT

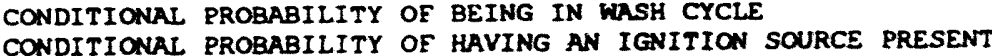

OPERATOR FAILS TO ALIGN OR START EMERGENCY PURGE VENT EQUIP OR HAR

FLON CONTROL VALVE 1211 PV1 MAINTENANCE

TANK 48 EXHAUST FAN Y348-52-8 FAILS TO RUN DUE TO MECHANICAL FAULT

CONDITIONAL PROBABILIIY OF TRANSFERRING SALT SOLUTION $(70 \mathrm{C}$ TEMP)

CONDITIONAL PROBABILITY OF HAVING AN IGNITION SOURCE PRESENT

CONDITIONAL PROBABILTTY OF HAVTNG ANETTE REPAIR PROCEDURE

PROBABILR TI TOT PER OR START EMERGENCY PURGE VENT EOUIP OR HAR OPERATOR FAILS TO ALIGN OR START EMERGE CONDITIONAL PROBABILITY OF BEING IN WASH CYCLE

CONDITIONAL PROBABILITY OF BEING IN WASH CYCLE

CONDITIONAL PROBABILITY OF HAVING AN TGNITION SOURCE PRESEN

PROBABILITY OF NOT PERF OR START EMERGENCY PURGE VENT EOUIP OR HAR

OPERATOR FAILS TO ALIGN OR START EMERGENCY PURGE VENT EQUIP OR HAR

FLOW CONTROL VALVE 1251 PV2 MECHANICAL FAULT

TANK 49 EXHAUST FAN Y349-52-11 FAILS TO RUN DUE TO MECHANICAL EAUL 8.0E-6 CONDITIONAL PROBABILITY OF HAVING AN IGNITION SOURCE PRESENT

PROBABILITY OF NOT PERFORMING A MODERATE REPAIR PROCEDURE

OPERATOR FAILS TO ALIGN OR START EMERGENCY PURGE VENT EQUIP OR HAR TANK 49 EXHAUST FAN Y $149-5:-11$ FAILS TO RUN DUE TO MECHANICAI. $\triangle A U L$ Y.OE-O TANK 49 EXHAUST FAN Y349-52-12 FAILS TO RUN DUE TO MECHANICAL EAUL $8.0 E-6$ CONDITIONAL PROBABILITY OF HAVING AN IGNITION SOURCE PRESENT

PROBABILITY OF NOT PERFURMING A MUDERATE REPAIR PROCEDURE

OPERATOR FAILS TO ALIGN OR START EMERGENCY PURGE VENT EQUIP OH HAR MECHANICAI EAULT OF TANK 48 FLOW CONTROL VALVE 1201EV

TANK 48 FLOW CONTROL VALVE 1202 FV UNAVAILABLE DUE TO MAINTENANCE

CONDITIONAL PROBABILITY OF BEING IN NORMAL PROCESSING MODE $140 \mathrm{C}$

CONDITIONAI PROBABILITY OF HAVING AN IGNITION SOURCE PRESENT

PROBABILITY OF NOT PERFORMING A SIMPLE REPAIR PROCEDURE

OPERATOR FAILS TO ALIGN OR START EMERGENCY PURGE VENT EQUIP OR HAR MECHANICAL FAULT OF TANK 48 FLOW CONTROL VALVE 1201 FV

CONDITIONAI PROBABILITY OF BEING IN NORMAL PROCESSING MODE $140 \mathrm{C} \mathrm{T}$

CONDITIONAL PROBABILITY OF BEING IN NORMAL PROCESSING MODE
PROBABILITY OF NOT PERFORMING A MODERATE REPAIR PROCEDURE

FLW CONTROL VALVE 1211 PV $\begin{array}{ll}.09 & 9.00 E-02 \\ .011 & 1.10 E-02\end{array}$

3. $6 E-3$

8. $5 E-6$

$3.6 E-3$

8. $5 E-6$

3. $6 E-3$

$.0 \mathrm{E}-6$

3. $65-3$

8. $08-6$

$5 E-6$

$2.35 E-5 \quad 1.10 E-02$

$2.35 E-5 \quad 2.35 E-05$

$1 \quad 7.45 E-02$

$.22 .00 E-01$

09 9.00E-02

$.011 \quad 1.10 E-02$

2.35E-5 2.35E-05

1

7. $20 \mathrm{E}-03$

7. $45 E-02$

.20 2.00E-01

$\begin{array}{ll}9.00 E-02 \\ .011 & 1.10 E-02\end{array}$

2.35E-5 2.35E-05

$27.20 E-03$

$17.01 E-02$

.2 2.00E-01

$.09 \quad 9.00 \mathrm{E}-02$

$.011 \quad 1.10 E-02$

$2.35 E-5 \quad 2.35 E-05$

$2.35 \varepsilon-5$

$7.20 E-03$

$7.01 E-02$

$.20 \quad 2.00 E-01$

$.09 \quad 9.00 E-02$

2. $35 E-5 \quad 2.35 E-05$

$2.35 E-5 \quad 2.35 E-05$

$7 \quad 1.34 \mathrm{E}-03$

$.09 \quad 9.008-02$

$1.10 E-02$

$2.35 E-5 \quad 2.35 E-05$

7

1.09

011

$2.35 \varepsilon-5$

8. $5 E-6$

3. $6 E-3$

2

$1.34 E-03$
$7.01 E-02$

$7.01 E-02$

$9.00 E-02$

1. $10 E-02$

2.35E-05

1. $49 E-01$ 1. $40 E-12$

$60 \quad 7.20 E-03$

$60 \quad 6.00 E-01$

.09 9.00E-02

2.35E-5 $2.35 E-05$

$2.35 E-5 \quad 2.35 E-05$

$.60 \quad 6.00 E-01$

$1.40 E-12$

$7.20 \varepsilon-03$ 


\begin{tabular}{|c|c|}
\hline $\begin{array}{l}\text { A:IGN-09i } \\
\text { D:Lez: }\end{array}$ & $\begin{array}{l}\text { CUT } \\
\text { ILL: }\end{array}$ \\
\hline$\because C 2 U: E / E$ & IENT NAME \\
\hline & IGNITION \\
\hline & REPAIRN \\
\hline & EPVNTINT \\
\hline$\therefore 201$ & $8 \mathrm{FC122TM}$ \\
\hline & 8HOUSE03 \\
\hline & BPRPVIHW" \\
\hline & IGNITION \\
\hline & REPAIRM \\
\hline & EPVNTINT \\
\hline i111 & $8 F C 122 \mathrm{TM}$ \\
\hline & BHCUSEO1 \\
\hline & BPRPVI HW* \\
\hline & IGNITION \\
\hline & REPAIRM \\
\hline & EPVNTINT \\
\hline$\therefore: 21$ & 8HOUSE 01 \\
\hline & EPRPVI HW: \\
\hline & 8PRPV2TM \\
\hline & IGNITION \\
\hline & REPAIRM \\
\hline & EPVNTINT \\
\hline i131 & BHOUSEO3 \\
\hline & SPRPVI HW \\
\hline & IENITION \\
\hline & REPAIRM \\
\hline & EPVNTINT \\
\hline$:: 4 !$ & 9EC121 HW. \\
\hline & 9PRPV2HW \\
\hline & IGNITION \\
\hline & REPAIRM \\
\hline & EPUNTINT \\
\hline $2: 31$ & $9 F C 122 \mathrm{HW}$ \\
\hline & 9PRPVI HW- \\
\hline & IGNITION \\
\hline & FEPAIRM \\
\hline & EFVNTINT \\
\hline $2: 6 ;$ & $9 F C 112 \mathrm{HW}$ \\
\hline & 8DN527TM \\
\hline & EHOUSEO3 \\
\hline & IGNITION \\
\hline & REFAIRM \\
\hline & EPVNTINT \\
\hline$:: 71$ & SEC112:Th \\
\hline & EลN527TM \\
\hline & EHOUSEOI \\
\hline
\end{tabular}

CONDITIONAL PROBABILITY OF HAVING AN IGNITION SOURCE PRESENT PROBABILITY OF NOT PERFORMING A SIMPLE REPAIR PROCEDURE OPERATOR FAILS TO ALIGN OR START EMERGENCY PURGE VENT EQUIP OR HAF OPERATOR FAILS TO ALIGN OR START EMENGENCY TANK 8 TION PROBABILITY OF BEING IN WASH CYCLE

CONDITIONAL PROBABILITY OF BEING IN WASH CYCLE VALVE 1205 PV MECHANICAL FAULTS OF TANK 4B PRESSURE REGULATING VALVE 2205 V CONDITIONAL PROBABILITY OF HAVING AN IGNITION SOURCE PRESENT PROBABILITY OF NOT PERFORMING A MODERATE REPAIR PROCEDURE
OPERATOR FAILS TO ALIGN OR START EMERGENCY PURGE VENT EQUIP OR HAR TANK 48 ELOW CONTROL VALVE 2202 EV UNAVAILABLE DUE TO MATNTENANCE CONDITIONAL PROBABILITY OF TRANSEERRING SALT SOLUIION 70 C TEMP MECHANICAL FAULTS OF TANK 48 PRESSURE REGULATING VALVE 1205 PV CONDITIONAL PROBABILITY OE HAVING AN IGNITION SOURCE PRESENT PROBABILITY OE NOT PEREORMING A MODERATE REPAIR PROCEDURE OPERATOR FAILS TO ALIGN OR START EMERGENCY PURGE VENT EQUIP OR HAT CONDITIONAL PROBAGILITY OF TRANSEERRING SALT SOLUTION $170 \mathrm{C}$ TEMP MECHANICAL FAULTS OF TANK 48 PRESSURE REGULATING VALVE 2205 VVI TANK 48 PRESSURE REGULATING VALVE 1205 PV2 UNAVAILABLE DUE TO MAINT 3.6E-3 CONDITIONAL PROBABILITY OE HAVING AN IGNITION SOURCE PRESEN PROGABILITY OF NOT RERFORMING A MODERATE REPAIR PROCEDURE OPERATOR FAILS TO AITGN OR START EMERGENCY PURGE VENT EQUIP CR HAA CONDITIONAI PROBABILITY OF BEING IN WASH CYCLE

CONDITIONAL PROBAS OE TAVK 8 PRESSURE REGULATING VAIVE 1205PV: MECHANTCAL FAUTS OE TANK 4B PRESSURE REGU UATNG TANK 48 PRESSURE REGULATING VALVE 1205 PVI UNAVAILABLE DUE TO CONDITIONAL PROBABIIIT: OF HAVING AN IENT TON SOURCE PRESENT PROBABILITY OE NOT PER ORAT START EMERGENCY PURGE VENT EQUIP OR HAT OPERATOR FAILS TO ALIGN OR START EMERGENCY PURGE VENT MECHANICAL EAUIT OF TANK 49 FLOW CONTROL VALVE 25 IF MECHANICAL FAULTS OF TANK 49 PRESSURE REGULATING VALVE 1255 PV CONDITIONAL PROBABILIT: OF HAVING AN IGNITION SOURCE FRESENT PROBABILITY OF NOT FER FORMING A HODERATE REPAIR PROCEDURE OPERATOR FAILS TO ALIGN OR START EMERGENCY PURGE VENT EQUIP OA HAT MECHANICAL FAU:T OF TANK 49 FLON CONTROL VALYE $1252 \mathrm{FV}$ MECHANICAL FAULTS OE TANK 49 PRESSURE REGULATING VALVE 1255PV. CONDITIONAL PROBABILITY OE HAVING AN IGNIIION SOURCE PRESEN PROBABILITY OE NOT PER OOAMING A MODERATE REPAIR PROCEDURE OPERATOR FAILS TO ALIGIN OR START EMERGENCY PURGE VENT EQUIP OF HAR FIOW CONTROL VALVE 1211 PV2 MECHANICAL FAULT

TANK 48 EXHAUST EAN Y348-52-7 UNAVAILABLE DUE TO MAINTENANCE CONDITIONAL PROBABILITY OF GEING IN WASH CYCLE

CONDITIONAL FROBABILITY OF HAVING AN IGNITION SCURCE PRESENT FROBAAITIT OF NOT PERFORMING A MODERATE REPAIR PROCEDURE OPERATOR FAIIS TO FIIGN OR START EMERGENCY PURGE VENT EQUIP OR HAF FLOW CONTROL VALVE II:IPVZ MECHANICAL FAULT

FLOW CONTROL VALVE I2:1PV2 MECHANTCAL FAULI COND:TYONAL PROEABILITY OE TRANSFERRING SALT SOLUTION $170 \mathrm{C}$ TEMPI

RATE EXPOSURE PROB.

.09

$.09 \quad 9.00 E-02$

$1.03 E-3 \quad 1.03 E-03$

2. $35 E-5 \quad 2.35 E-05$

$207.20 E-03$

$20 \quad 2.00 E-01$

$.099 .00 E-02$

$.011 \quad 1.20 E-02$

$2.35 E-5 \quad 2.35 E-05$

$27.208-03$

$.22 .005-01$

2 3. $25 \mathrm{E}-02$

.09 $9.00 \mathrm{E}-02$

$.011 \quad 1.10 E-02$

$2.35 E-5 \quad 2.35 E-05$

$2 \quad 2.00 E-0$ ?

3. $35 E-02$

$7.205-03$

$039.00 E-02$

$.011 \quad 1.10 E-02$

$2.35 E-5 \quad 2.35 E-05$

$.20 \quad 2.00 E-0$

2.00E-01 :.29E-:2

$3.05 E-02$
$7.20 E-03$

$.09 \quad 9.00 E-02$

$.011 \quad 1.10 E-02$

$2.35 E-5 \quad 2.35 E-05$

$2.35 E-5 \quad 2.35 E-05$

$2 \quad 1.49 E-0$

$09 \quad 9.00 E-02$

$0: 1 \quad 1.10 E-02$

$2.35 E-5 \quad 2.35 E-05$

. $3 E-03 \quad 2.2 E E-: 2$

2

09

.011

2. $35 E-5$

3. $85 E-02$

$9.00 E-02$

$1.105-02$

$5 E-6$
$8 E-3$

2

$7.45 E-02 \quad 2.25 E-12$

$.09 \quad 9.00 E-02$

$\begin{array}{ll}.011 & 2.10 E-02 \\ 2.35 E-5 & 2.35 E-05\end{array}$

e. $5 E-6$ 2. $35 E-5$

7. $15 E-02$

$=\quad 3.60 E-0$ proe.

$.29 \Xi-12$

:.29E-12

$1.29 E-: 2$

$\therefore .28 E-: 2$

$.25 \Sigma-12$

$.2 \leq E-22$ 
PROBABILITY OF NOT PERFORMING A MODERATE REPAIR PROCEDURE

OPERATOR FAILS TO ALIGN OR START EMERGENCY PURGE VENT EQUIP OR HAR

TANK 48 EXHAUST FAN Y348-52-7 UNAVAILABLE DUE TO MAINTENANCE
TANK 48 EXHAUST FAN $Y 348-52-8$ FAILS TO RUN DUE TO MECHANICAL EAULT $9.08-6$ CONDITIONAL PROBABILITY OE BEING IN WASH CYCLE

CONDITIONAL PROBABILITY OF HAVING AN IGNITION SOURCE PRESENT

PROBABILITY OF NOT PERFORMING A MODERATE REPAIR PROCEDURE

OPERATOR FAILS TO ALIGN OR START EMERGENCY PURGE VENT EQUIP OR HAR

TANK 48 EXHAUST FAN Y348-52-7 UNAVAILABLE DUE TO MAINTENANCE 1 1.8E-3

CONDITIONAL PROBABILITY OF TRANSFERRING SALT SOLUTION $170 \mathrm{C}$ TEMPI

CONDITIONAI PROBABILITY OF HAVING AN IGNITION SOURCE PRESENT

CONDITIONAL PROBABILITY OE HAVING AN IENIT REAIR PROCEDURE

PROBABILITY OF NOT PER FORING A MODERTTE RE PURGE VENT EOUIP OR HAR OPERATOR FAILS TO ALIGN OR START ENTERGENCY PUN SOURCE PRESENT

PRESSURE REGULATING VALVE 2045PV FAILS

PRESSURE REGULATING VALVE 204SPV PAILS

PROBSABILITY OF NOT PERFORMING A MODERATE REPAIR PROCEDURE

PROBABILITY OF NOT PERFORMING A MODERATE REPAIR PROCEDURE

OPERATOR FAILS TO ALIGN OR START EMERGENCY PURGE VENT EQU

MECHANICAL FAULT OF TANK 48 FLOW CONTROL VALVE $1201 \mathrm{FV}$

MECHANICAL FAULT OF TANK 48 FLON CONTROL VALVE 1202FV

CONDITIONAL PROBABILITY OE TRANSFERRING SALT SOLUTION $170 \mathrm{C}$ TEMP)

CONDITIONAL PROBABILITY OF HAVING AN IGNITION SOURCE PRESENT

PROBABILITY OF NOI PERFORMING A MODERATE REPAIR PROCEDURE

OPERATOR FAILS TO ALIGN OR START EMERGENCY PURGE VENT EQUIP OR HAR

MECHANICAL FAULT OF TANK 48 FLOW CONTROL VALVE 1201F

MECHANICAI EAULT OF TANK 48 FLOW CONTROL VALVE 1202 FV

CONDITIONAL PROBABILITY OF BEING IN WASH CYCLE

CONDITIONAL PROBABILITY OF HAVING AN IGNITION SOURCE PRESENT

PROBABILITY OF NOT PEREORMING A MODERATE REPAIR PROCEDURE

OPERATOR FAILS TO ALIGN OR START EMERGENCY PURGE VENT EOUIP OR HAR

FLOW CONTROL VALVE 1211 PVI MECHANICAL EAULT (MODE C)

FLON CONTROL VALVE 1211PVI MECHANICAL EAULT IM

CLOW CONTROL VALVE 12

CONDITIONAL PROBABILITY OF HAVING AN IGNITION SOURCE PRESENT

CONDITIONAL PROBABILITY OF HAVING AN IGNITION SOURCE PRES

PROBABILITY OF NOT PERFORMING A SIMPLE REPAIR PROCEDURE

FLOW CONTROL VALVE 1211 PVI MECHANICAL FAULT (MODE C)

TANK 48 EXHAUST EAN Y 348-52-8 FAILS TO RUN DUE TO MECHANICAL EAULT

CONDITIONAL PROBABILITY OF BEING IN NORMAL PROCESSING MODE 140

CONDITIONAL PROBABILITY OF HAVING AN IGNITION SOURCE PRESE

PROBABILITY OF NOT PERFORMING A SIMPLE REPAIR PROCEDURE

OPERATOR FAILS TO ALIGH OR START EMERGENCY

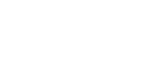

.09

$09 \quad 9.00 E-02$

$1.10 E-02$

$2.35 E-5 \quad 2.35 E-05$

$2 \quad \begin{array}{ll}3.60 E-03 \\ 1\end{array} \quad 7.01 E-02$

$.20 \quad 2.00 E-01$

$.099 .00 E-02$

.011 1.10E-02

2.35E-5 2.35E-05

$2 \quad 3.60 E-03$

$1.01 \varepsilon-02$

$2 \quad 2.00 E-01$

$.099 .00 E-02$

$011 \quad 1.10 E-02$

$2.35 E-5 \quad 2.35 E-05$

$\begin{array}{ll}.09 & 9.00 E-02 \\ 3 & 2.38 E-03\end{array}$

$2.2 E-6$

2. $2 E-6$

$011 \quad 1.93 E-02$

.011 1.10E-02

$\begin{array}{lll}9.5 E-6 & 2.35 E-5 & 2.35 E-05 \\ 0 & 1.49 E-01\end{array}$

$1.43 E-03$

2 2.00E-01

$09 \quad 9.00 E-02$

.011 1.10E-02

2.35E-5 2.35E-05

$\begin{array}{lll}8.5 E-6 & 2 & 1.49 E-01 \\ 8.5 E-6 & 7 & 1.43 E-03\end{array}$

$.20 \quad 2.00 E-01$

$.09 \quad 9.00 E-02$

$.011 \quad 1.10 E-02$

$2.35 E-5 \quad 2.35 E-05$

3

$9.18 E-03$ 8.93E-13

$60 \quad 6.00 E-01$

$.099 .00 E-02$

$1.03 E-3 \quad 1.03 E-03$

$2.35 E-5 \quad 2.35 E-05$

8. $5 E-6$

3

2. $35 E-05$

9.18E-03

$7.01 E-02$

$099.00 E-02$

$1.03 E-3 \quad 1.03 E-03$

TANK 49 EXHAUST FAN Y349-52-11 FAILS TO START DUE TO MECHANICAL FA $4.8 E-4$ 


\begin{tabular}{|c|c|}
\hline \multirow{2}{*}{\multicolumn{2}{|c|}{ A: IGN-09R.CUT }} \\
\hline & \\
\hline \multicolumn{2}{|c|}{ MONUI.E/EVENT NAME } \\
\hline & IGNITION \\
\hline & REPAIRM \\
\hline & EPVNTINT \\
\hline \multirow[t]{5}{*}{1261} & 9RN511ST \\
\hline & 9FN512HW \\
\hline & IGNITION \\
\hline & REPAIRM \\
\hline & EPVNTINT \\
\hline \multirow[t]{5}{*}{ 127) } & $\begin{array}{l}8 \mathrm{FC} 111 \mathrm{TM} \\
8 \mathrm{CC} 112 \mathrm{HW}\end{array}$ \\
\hline & 8HOUSEO4 \\
\hline & IGNITION \\
\hline & RERAIRN \\
\hline & EPUNTINT \\
\hline \multirow[t]{5}{*}{1281} & $\begin{array}{l}8 \mathrm{FCl} 11 \mathrm{TM} \\
\text { 8FN528HW }\end{array}$ \\
\hline & 8HOUSEO4 \\
\hline & IGNITION \\
\hline & REPAIRN \\
\hline & EPVNTINT \\
\hline \multirow[t]{4}{*}{1291} & IGNITION \\
\hline & NTKTKAHW \\
\hline & REPAIRM \\
\hline & EPVNTINT \\
\hline \multirow[t]{6}{*}{1301} & $8 \mathrm{FCl} 12 \mathrm{HW}$ \\
\hline & $8 \mathrm{EN} 527 \mathrm{HW}$ \\
\hline & 8HOUSEO1 \\
\hline & IGNITION \\
\hline & REPAIRM \\
\hline & EPVNT INT \\
\hline \multirow[t]{6}{*}{1311} & $8 F C 112 \mathrm{HW}$ \\
\hline & 8 EN527 HW \\
\hline & BHOUSEO3 \\
\hline & IGNITION \\
\hline & REPAIRM \\
\hline & EPVNTINT \\
\hline \multirow[t]{6}{*}{1321} & 85N527HW \\
\hline & $8 \mathrm{EN} 528 \mathrm{HW}$ \\
\hline & BHOUSE03 \\
\hline & IGNITION \\
\hline & REPAIRM \\
\hline & EPVNTINT \\
\hline \multirow[t]{4}{*}{1331} & $8 \mathrm{FN} 527 \mathrm{HW}$ \\
\hline & BFN528HW \\
\hline & 8HOUSE01 \\
\hline & IGNITION \\
\hline
\end{tabular}

Truncation Lim1t: $1.00 E-15$

CUTSET REPORT

DESCRI PTION

CONDITIONAL PROBABILITY OF HAVING AN IGNITION SOURCE PRESENT

PROBAPILITY OF NOT PEREORMING A MODERATE REPAIR PROCEDURE

OPERATOR FAILS TO ALIGN OR START EMERGENCY PURGE VENT EQUIP OR HAR

TANK 9 EXUAUST

TANK 9 EXHAUST FAN Y349-52-12 EAILS TO RUN DUE TO MECHANICAL FAUL B.OE-6

CONDITIONAI PROBABILITY OF HAVING AN IGNITION SOURCE PRESENT

PROBABILITY OF NOT PERFORMING A MODERATE REPAIR PROCEDURE

TOBABILITY OE NOT PEREORMING A MODERATE RY PUR TE VENT EOUIP OR HAR

OPERATOR EAILS TO ALIGN OR START EMERGEN

DLON CONTROL VALVE 1211 PVI MAINTENANCE

CONDITIONAL PROBABILITY OE BEING IN NORMAL PROCESSING MODE $140 \mathrm{C}$

CONDITIONAL PROBABILITY OF HAVING AN IGNITION SOURCE PRESENT

PROBABILITY OF NOT PEREORMING A SIMPLE REPAIR PROCEDURE

OPERATOR FAILS TO ALIGN OR START EMERGENCY PURGE VENT EQUIP OR HAR

FLOW CONTROL VALVE 1211 PVI MAINTENANCE

TANK 48 EXHAUST FAN Y348-52-8 FAILS TO RUN DUE TO MECHANICAL FAULT

CONDITIONAI PROBABILITY OF BEING IN NORMAL PROCESSING MODE $140 \mathrm{C}$

CONDITIONAI PROBABILITY OF HAVING AN IGNITION SOURCE PRESENT

PROBABILITY OF NOT PERFORMING A SIMPLE REPAIR PROCEDURE

OPERATOR CONDITIONAI PROBABIIITY OF HAVING AN IGNITION SOURCE PRESENT NITROGEN STORAGE TANK 1 LEAKS

PRROGN STY OF NOT PERFORMING A MODERATE REPAIR PROCEDURE

PROBABILITY OF NOT PER OR START EMERGENCY PURGE VENT EQUIP OR HAR OPERATOR FAILS TO ALIGN OR START EMERGENCY

FLOW CONTROL VALVE 1211 PV2 MECHANICAL EAULT

TANK 18 EXHAUST EAN Y348-52-7 FAILS TO RUN FOR 6 DAYS $170 \mathrm{C}$ TEMP)

CONDITIONAL PROBABILITY OF TRANSFERRING SALT SOLUTION $170 \mathrm{C}$ TEM

CONDITIONAL PROBABILITY OF HAVING AN IGNITION SOURCE PRESENT

PRORABILITY OF NOT PERFORMING A MODERATE REPAIR PROCEDURE

OPERATOR FAILS TO ALIGN OR START EMERGENCY PURGE VENT EQUIP OR HAR FLOW CONTROL VALVE 1211 PV2 MECHANICAL FAULT

TANK 48 EXHAUST EAN Y348-52-7 FAILS TO RUN FOR 6 DAYS

CONDITIONAL PROBABILITY OF BEING IN WASH CYCLE

CONDITIONAL PROBABILITY OF HAVING AN IGNITION SOURCE PRESENT

PROBARIIITY OF NOT PERFORMING A MODERATE REPAIR PROCEDURE

OPERATOR FAILS TO ALIGN OR START EMERGENCY PURGE VENT EQUIP OR HAR

TANK 48 EXHAUST FAN Y 348-52-7 FAILS TO RUN FOR 6 DAYS TANK 48 EXHAUST EAN Y $348-52-8$ FAILS TO RUN DUE

CONDITIONAI PROBABILITY OE HAVING AN IGNITION SOURCE PRESENT

PROBABIIATY OF NOT PERFORMING A MODERATE REPAIR PROCEDURE

OPERATOR FAILS TO ALIGN OR START EMERGENCY PURGE VENT EQUIP OR HAR OPERATOR FAILS TO ALIGN OR START EMERGENCY PURGE VAYS

TANK 48 EXHAUST FAN Y348-52-7 EAILS TO RUN FOR 6 DAYS

TANK 48 EXHAUST EAN Y

CONDITIONAL PROBABILITY OF TRANSFERRING SALT SOLUTION
1-10-94 12:46 Page 16

$\begin{array}{lll} & \text { B.E. } & \text { MOD./CS. } \\ \text { RATE EXPOSURE PROB. } & \text { PROB. }\end{array}$

0

$\begin{array}{ll}.011 & 1.10 E-02 \\ 2.35 E-5 & 2.35 E-05\end{array}$

$2.35 E-5 \quad 2.35 E-05$

$.09 \quad 9.00 E-02$

$2.35 E-5 \quad 1.102-02$

$2.35 E-5 \quad 2.35 E-05$

$7.20 E-03 \quad 7.01 E-13$

$3.6 E-3$

.60

$6.00 E-01$

$9.00 E-02$

$1.03 E-3 \quad 1.03 E-03$

2.35E-5 2.35E-05

$7.20 E-03$
$7.01 E-02$

$60 \quad 6.00 \varepsilon-0$

$.099 .00 E-02$

$1.03 E-3 \quad 1.03 E-03$

2.35E-5 2.35E-05

.005-02 4.69E-13

$122.01 E-05$

2.35E-5 2.35E-05

$2.35 E-5 \quad 2.35 E-05$

$7.45 \mathrm{E}-02$
$1.34 \mathrm{E}-03$

$1.34 \mathrm{E}-03$

$2.00 E-01$

9.00E-02

$\begin{array}{ll}.011 & 1.10 E-02 \\ 2.35 E-5 & 2.35 E-05\end{array}$

$\begin{array}{ll}2.35 E-5 & 2.35 E-05 \\ 1 & 7.45 E-02\end{array}$

$1.34 \mathrm{E}-03$

$\begin{array}{ll}.20 & 2.00 E-01 \\ .09 & 9.00 E-02\end{array}$

$011 \quad 1.10 E-02$

$\begin{array}{ll}2.35 E-5 & 2.35 E-05 \\ 7 & 1.34 E-03\end{array}$

$7.01 E-02$

2. $00 E-01$

$\begin{array}{ll}.09 & 9.00 E-02 \\ .011 & 1.10 E-02\end{array}$

$\begin{array}{ll}.09 & 9.00 E-02 \\ .011 & 1.10 E-02\end{array}$

2.35E-5 2.35E-05

1.34E-03

$.2 \quad 2.00 E-01$

4. $38 E-13$

$9.00 E-02$ 
DESCRIPTION

PROBABILITY OF NOT PEREORMING A MODERATE REPAIR PROCEDURE OPERATOR FAILS TO ALIGN OR START EMERGENCY PURGE VENT EQUIP OR HAR NO ACTION TAKEN FOR 48 HRS

LOCAL MECHANICAL FAULTS OF TANK 49 HEATER

CONDITIONAL PROBABILITY OF HAVING AN IGNITION SOURCE PRESENT

PROBABILITY OF NOT REPIACING/REPAIRING HEPA FILTER IS NEGLIGIB I

OPERATOR FAIL TO REI OR START EMERGENCY PURGE VENT EOUIP OR HAR

TANK 48 ELOH CONTROL VALVE 2202 FV UNAVAILABLE DUE TO MAINTENANCE

TANK 48 FLOH CONTRL CONDITIONAL PROBABILITY OE BEING IN NORMAL PRING VALVE 1205 PVI

MECHANICAL EAULTS OF TANK 48 PRESSURE REGUIATING VALVE 1205 PV

CONDITIONAL PROBABILITY OF HAVING AN IGNITION SOURCE PRE

PROBABILITY OF NOT PERFORMING A SIMPLE REPAIR PROCEDURE

OPERATOR EAILS TO ALIGN OR START EMERGENCY PURGE VENT EQUIP OR HAR

CONDITIONAL PROBABILITY OF BEING IN NORMAL PROCESSING MODE $140 \mathrm{C}$

MECHANICAL FAULTS OF TANK 48 PRESSURE REGULATING VALVE 1205PVI

TANK 48 PRESSURE REGULATING VALVE 1205 PV2 UNAVAILABLE DUE TO MAI

CONDITIONAL PROBABILITY OF HAVING AN IGNITION SOURCE PRES

OPERATOR FAILS TO ALIGN OR START EMERGENCY PURGE VENT EQUIP OR HAR FLOW CONTROL VALVE 1211 PV2 MECHANICAL EAULT

TANK 48 EXHAUST FAN Y348-52-7 UNAVAILABLE DUE TO MAINTENANCE

CONDITIONAL PROBABILITY OF BEING IN NORMAL PROCESSING MODE $140 \mathrm{C} \mathrm{T}$

CONDITIONAI PROBABILITY OF HAVING AN IGNITION SOURCE PRESENT

PROBABILTY OF NOT PERFORMING A SIMPLE REPAIR PROCEDURE

OPERATOR EAILS TO AIIGN OR START EMERGENCY PURGE VENT EOUIP OR HAR MERAN MECHANICAL EAULTS OE TANK 49 PRESSURE REGULATING VAVE 1255 PVI MECHANICAL FAULTS OE TANK 49 PRESSURE REGUATN SOURCE PRESENT CONDITIONAL PROBABILITY OE HAVING AN IGNIT

OPERATOR FAILS TO ALIGN OR START EMERGENCY PURGE VENT EQUIP OR HAR OPERATOR FAILS TO ALIGN OR START EMERGENCY PURGE VENT EQUIP

TANK 48 EXHAUST FAN Y348-52-7 UNAVAILABLE DUE TO MAINTENANCE

TANK 48 EXHAUST FAN Y348-52-8 FAILS TO RUN DUE TO MECHANICAL FAULT CONDITIONAL PROBABILITY OF BEING IN NORMAL PROCESSING MODE

CONDITIONAL PROBABILITY OF HAVING AN IGNITION SOURCE PRESEN

PROBABILITY OF NOT PERFORMING A SIMPLE REPAIR PROCEDURE OPERATOR FAILS TO ALIGN OR START EMERGENCY PURGE VENT EQUIP OR HAR MECHANICAL FAULT OF TANK 48 FLOW CONTROL VALVE $1201 \mathrm{FV}$ MECHANICAI FAUIT OF TANK 48 FLON CONTROL VALVE I $\angle U 2 E V$ CONDITIONAL PROBABILITY OF BEING IN NORMAL PROCESSING MODE $140 \mathrm{C} \mathrm{T}$ CONDITIONAL PROBABILITY OF HAVING AN IGNITION SOURCE PRESENT

PROBABILITY OF NOT PERFORMING A SIMPLE REPAIR PROCEJURE

OPERATOR EAILS TO ALIGN OR START EMERGENCY PURIJE VENT EQUIP OR HAR OPERATOR FAILS TO ALIGN AND START TRAIN B FOR CPERATION - EXHAUST MANUAL VALVE T49-HV22 EAILS TO REMAIN OFEN (PLUC)

CONDITIONAL PROBABILITY OF HAVING AN IGNITION SOL'RCE PRESENT

PROBABILITY OF NOT PEREORMING A SIMPLE REPAIR PROCEDURE
RATE

\section{EXPOSURE $\begin{aligned} & \text { B.E. } \\ & \text { PROB. }\end{aligned}$}

MOD. /CS PROB.

$2.35 E-5 \quad 2.35 E-05$

$1 \quad 1.00 E+00$

.09

$9.00 E-02$

1.03E-3 1.03E-03

2. $35 E-5 \quad 2.35 E-05$

$27.20 E-03$

$.606 .00 E-01$

$23.85 E-02$

$09 \quad 9.00 E-02$

$1.03 E-3 \quad 1.03 E-03$

2. $35 E-5$ 2.

60

2

$2.2 E-6$

$3.6 E-3$

2

9.00E-02

$1.03 E-3 \quad 1.03 E-03$

2.35E-5 2.35E-05

$\begin{array}{lll}8.5 E-6 & 1 & 7.45 E-02 \\ 8 E-3 & 2 & 3.60 E-03\end{array}$

$.606 .00 \mathrm{E}-01$

$.099 .00 E-C 2$

1. $03 E-3 \quad 1.03 E-03$

2.35E-5 2.35E-05

2. $2 E-6$

2. $2 \mathrm{E}-6$

7

3. $70 E-04$

$.099 .00 E-02$

$.011 \quad 1.10 E-02$

2. $35 E-5 \quad 2.35 E-05$

$\begin{array}{lll}.8 E-3 & 2 & 3.60 E-03\end{array}$

$6.01 E-02$

$60 \quad 6.00 E-01$

$.09 \quad 9.00 E-02$

$1.03 E-3 \quad 1.03 E-03$

2. 35E-5 2.35E-OS

8. $5 E-6$

8. $5 E-6$

$60 \quad 1.43 E-03$

$.60 \quad 6.00 E-01$

1.03E-3 $1.00 \mathrm{E}-02$

$1.035 E-5 \quad 2.03 E-03$

1

$\begin{array}{ll}.09 & 9.00 E-02 \\ 1.03 E-3 & 1.03 E-03\end{array}$
$2.35 E-05$

6.00E-01 3.63E-13

$1.00 E+00 \quad 2.67 E-13$

$3.82 E-13$

$3.63 E-13$

$3.50 E-13$

3. $31 E-13$

3. $30 E-13$

$2.78 E-13$ 
B.E.

EXPOSURE PROB.

EPVNTINT

142) 9OPTRNBE $9 X V V 20 P^{*}$ IGNITION REPAIRN EPVNTINT

143) 9XVHV2PG* IGNITION REPAIRN EPVNTINT

144) 9XVHV9PG IGNITION REPAIRN EPVNTINT

145) $9 \times 1$ IGNITION REPAIRN EPVNTINT

146) 9XVN24PG* IGNITION REPAIRN EPVNTINT

147) 9XVV15PG* IGNITION EPVNTINT

148) 9XVV17PG* IGNITION EPVNTINT

149) 9XVV33PG* IGNITION REPAIRN EPVNTINT

i50) IGNITION NOPTRNBS NXVN2 4 PG* REPAIRN EPVNTINT

151) IGNITION NOPTRNBS NXVN20PG* REPAIRN EPVNTINT

152) IGNITION NOPTRNBS
DESCRI PTION

OPERATOR FAILS TO ALIGN OR START EMERGENCY PURGE VENT EQUIP OR HAR MANUAT VAIVE TO 9 -HVIGN AND START TRAIN B FOR OPERA

CONDITIONAL PROBABILITY OF HAVING AN IGNITION SOURCE PRESENT PROBABILITY OF NOT PERFJRMING A SIMPLE REPAIR PROCEDURE OPERATOR FAILS TO ALIGN OR START EMERGENCY PURGE VENT EQUIP OR HAR MANUAL VALVE T49-HV2 FAILS TO REMAIN OPEN (PLUG)

CONDITIONAL PROBABILITY OF HAVING AN IGNITION SOURCE PRESENT PROBABILITY OE NOT PERECRMING A SIMPLE REPAIR PROCEDURE

OPERATOR FAILS TO ALIGN OR START EMERGENCY PURGE VENT EQUIP OR HAR TANK 49 O2 ANALYZER DISCHARGE VALVE T49-HV9 FAILS TO REMAIN OPEN 1 CONDITIONAL PROBABILITY OF HAVING AN IGNITION SOURCE PRESENT

PROBABILITY OF NOT PEREORMING A SIMPLE REPAIR PROCEDURE

OPERATOR FAILS TO ALIGN OR START EMERGENCY PURGE VENT EQUIP OR HAR MANUAL VALVE T49-N10 FAILS TO REMAIN OPEN (PLUG)

CONDITIONAL PROBABILITY OF HAVING AN IGNITION SOURCE PRESENT

PROBABILITY OF NOT PERFORMING A SIMPLE REPAIR PROCEDURE

OPERATOR FAILS TO ALIGN OR START EMERGENCY PURGE VENT EQUIP OR HAR

TANK 49 TANK INLET VALVE T49-N24 FAILS TO REMAIN OPEN (PLUG)

CONDITIONAL PROBABILITY OF HAVING AN IGNITION SOURCE PRESENT

PROBABILITY OF NOT PERFORMING A SIMRLE REPATR PROCEDURE

VENT EQUIP OR HAR MANUAL VALVE T49-HV15 FAILS TO REMAIN OPEN (PLUG)

CONDITIONAL PROBABILITY OE HAVING AN IGNITION SOURCE PRESENT

PROBABILITY OF NOT PERFORMING A SIMPLE REPAIR PROCEDURE

OPERATOR FAILS TO ALIGN OR START EMERGENCY PURGE VENT EQUIP OR HAR MANUAL VALVE T49-HV17 FAILS TO REMAIN OPEN (PLUG)

RATE

Exposure

$2.35 E-5$

$2.35 E-5$

PROBABILITY OF NOT PERFORMING A SIMPLE REPAIR PROCEDURE

OPERATOR FAILS TO ALIGN OR START EMERGENCY PURGE VENT EQUIP OR HAR MANUAL VALVE T49-HV33 FAILS TO REMAIN OPEN (PLUG)

CONDITIONAL PROBABILITY OF HAVING AN IGNITION SOURCE PRESENT

PROBABILITY OF NOT PERFORMING A SIMPLE REPAIR PROCEDURE

OPERATOR FAILS TO ALIGN OR START EMERGENCY PURGE VENT EQUIP OR HAR CONDITIONAL PROBABILITY OF HAVING AN IGNITION SOURCE PRESENT

OPERATOR FAILS TO ALIGN TRAIN B FOR OPERATION - SUPPLY SIDE

PATH A INLET VALVE N24 FAILS TO REMAIN OPEN (PLUG)

PROBAPINLY VINE N2

OPERATOR FAIS

CONDITI FAIS TO ALIGN OR START EMER IGNITION SOURCE PRESEN

OPERATOR EAILS TO ALIGN TRAIN B EOR OPERATION - SUPPLY SIDE

PATH A OUTLET VALVE N2O EAILS TO REMAIN OPEN (PLUG)

PROBABILITY OE NOT PERFORMING A SIMPLE REPAIR PROCEDURE

OPERATOR FAILS TO ALIGN OR START EMERGENCY PURGE VENT EQUIP OR HAR

CONDITIONAL PROBABILITY OF HAVING AN IGNITION SOURCE PRESEN

OPERATOR FAILS TO ALIGN TRAIN B FOR OPERATION - SUPPLY SIDE
2. 35E-5

$.03 \mathrm{E}-3$

$2.35 \mathrm{E}-5$

09

$1.03 E-3$

2. $35 E-5$

.09

$1.03 E-3$
$2.35 E-5$

.09

$1.03 E-3$

109

i. $03 E-3$

1. $03 E-3$

2. 35E-5

.09

$.03 E-3$

$2.35 \varepsilon-5$

2. 35E-05

1. $00 \mathrm{E}+00 \quad 2.67 \mathrm{E}-13$

$1.23 E-04$

1. $035-03$

1. $23 \mathrm{E}-04$

1. $23 \mathrm{E}-04$

$9.00 E-02$

$1.03 E-03$

$2.35 \mathrm{E}-05$

$1.23 \mathrm{E}-04 \quad 2.67 \mathrm{E}-13$

. 0 OE-O2

$1.03 E-03$

$9.00 \mathrm{E}-02$

$1.03 E-03$

$2.35 \mathrm{E}-0.5$

$1.23 E-04 \quad 2.67 E-13$

9. $00 \mathrm{E}-02$

$1.03 E-03$

2. $35 \mathrm{E}-05$

$1.23 E-04 \quad 2.67 E-13$

$9.00 \mathrm{E}-02$

$1.03 E-03$

$2.35 \mathrm{E}-05$

$1.23 \mathrm{E}-04$

9.00E-02

1. $03 \mathrm{E}-03$

$2.35 E-05$

$1.23 E-04 \quad 2.67 E-13$

10

$1.03 E-3 \quad 1.03 E-03$

$2.35 \mathrm{E}-5 \quad 2.35 \mathrm{E}-05$

9.00E-02 2.67E-13

$1.00 E+00$

$1.23 E-04$

1. $1.03 E-03$

$1.03 \mathrm{E}-3 \quad 1.03 \mathrm{E}-03$

$2.35 \mathrm{E}-05$

$109 \quad 1.00 \mathrm{E}+00$

$1.00 E+00$

$1.23 E-04$

$1.03 E-3 \quad 1.03 E-03$

2. $35 \mathrm{E}-5 \quad 2.35 \mathrm{E}-05$

$\begin{array}{ll}.09 & 9.00 E-02 \\ 1 & 1.00 E+00\end{array}$ 
MODULE/EVENT NAME

-..-.

NXVN 4 6PG* REPAIRN EPVNTINT

153) IGNITION NOPTRNBS NXVN26PG* REPAIRN EPVNTINT

154) IGNITION $\mathrm{NXVN12PG*}$ REPAIRN EPVNTINT

155) IGNITION NXVN 92 PG* $^{*}$ REPAIRN EPVNTINT

156) IGNITION NOPTRNBS NXV032PG REPAIRN

157) 8EC121 HW* BHOUSE01 8PRPV2HW IGNITION REPAIRM EPVNTINT

158) 8EC121 $\mathrm{HW}^{*}$ 8HOLSE03 8PRPV2HW IGNITION REPAIRM EPVNTINT

159) $8 \mathrm{FCl} 22 \mathrm{HW}$ 8HOUSE03 8PRPV1 HW* IGNITION REPAIRM EPVNTINT

160) 8 FC122HW 8HOUSE01 BPRPVIHW* IGNITION REPAIRM EPVNTINT
Truncation Limit: $1.00 \mathrm{E}-15$

DESCRIPTION

MANUAL VALVE N46 FAILS TO REMAIN OPEN (PLUG)

PROBABILITY OF NOT PEREORMING A SIMPLE REPAIR PROCEDURE

OPERATOR FAILS TO ALIEN OR START EMERGENCY PURGE VENT EQUIP OR HAR

CONDITIONAL PROBABILITY OE HAVING AN IGNITION SOURCE PRESEN

OPERATOR FAILS TO ALIEN TRAIN B FOR OPERATION - SUPPLY SIDE

MANUAL VALVE N26 FAILS TO REMAIN OPEN (PLUG)

PROBABILITY OF NOT PERFORMING A SIMPLE REPAIR PROCEDURE

OPERATOR FAILS TO ALIGN OR START EMERGENCY PURGE VENT EQUIP OR HAR

CONDITIONAL PROBABILITY OF HAVING AN IGNITION SOURCE PRESENT

VALVE N12 FROM THE NITROGEN SUPPLY FAILS TO REMAIN OPEN (PLUG)

PROBABILITY OF NOT PEREORMING A SIMPLE REPAIR PROCEDURE

OPERATOR FAILS TO ALIGN OR START EMERGENCY PURGE VENT EQUIP OR HAR

CONDITIONAL PROBABILITY OF HAVING AN IGNITION SOURCE PRESENT

MANUAL VALVE N92 EATLS TO REMAIN OPEN (PLUG)

PROBABILITY OF NOT PERFORMING A SIMPLE REPAIR PROCEDURE

PROBATOR FAIIS TO ALIGN OR START EMERGENCY PURGE VENT EOUIP OR HAR

CONDITIONAI PROBABILITY OF HAVING AN IGNITION SOURCE PRESENT

CONDITIONAL PROBABILITY OF HAVING AN IGNITION SOURE PRESENT

MANAT VALVE NT2 FAILS TO REMAIN OPEN (PLUGI

MROA TALE N 2 FAILS TO REMAIN OPENE REPAIR PROCEDURE

OPBRATOR FAIIS TO ALIGN OR START EMERGENCY PURGE VENT EQUIP OR HAR OPERATOR FAILS TO ALIGN OR START EMERGENCY PURGE VENT

MECHANICAL FAULT OE TANK 48 FLOW CONTROL VALVE $1201 F V$

CONDITIONAL PROBABILITY OE TRANSEERRING SALT SOLUTION 170 C TEMPI

MECHANICAL FAULTS OF TANK 48 PRESSURE REGULATING VALVE 1205 PV2

CONDITIONAL PROBABILITY OF HAVING AN IGNITION SOURCE PRESEN

PROBABILITY OF NOT PERFORMING A MODERATE REPAIR PROCEDURE MECHANICAL FAULT OF TANK 48 FLOW CONTROL VALVE $1201 \mathrm{FV}$

CONDITIONAL PROBABILITY OF BEING IN WASH CYCLE

MECHANICAL FAULTS OF TANK 48 PRESSURE REGULATING VALVE $1205 \mathrm{PV} 2$

CONDITIONAI PROBABILITY OF HAVING AN IGNITION SOURCE PRESENT

PROBABIIITY OF NOT PEREORMING A MODERATE REPAIR PROCEDURE

OPERATOR FAILS TO ALIGN OR START EMERGENCY PURGE VENT EQUIP OR HAR MERATOR EAILS TO ALIGNK CONDITIONAL PROBABILITY OF BEING IN WASH CYCLE

CONDITIONAL PROBABILITY OF BEING IN WASH CYCLE

MECHANICAL EAULTS OF TANK 48 RRESSURE REGULATING VALVE $1205 P V$

CONDITIONAL PROBABILITY OE HAVING AN IGNIT RON SOURCE PRESENI

PROBABILITY OE NOT PEREOMING A MODERATE RE PURGE VENT EOUIP OR HAR MERATOR FAILS TO ALIGN OR START EMERGEN VALVE $1202 \mathrm{FV}$

MECHANICAL FAULT OE TANK 48 FLOW CONTROL VALVE 1202FV $170 \mathrm{C}$ TEMP)

CONDITIONAL PROBABILITY OE TRANSFERRING SALT SOLUTION $(70 \mathrm{C}$ TEMP

MECHANICAL FAULTS OE TANK 48 PRESSURE REGULATING VALVE 1205PVI

CONDITIONAL PROBABILITY OE HAVING AN IGNITION SOURCE PRESENT

PROBABILITY OF NOT PERFORMING A MODERATE REPAIR PRO

OPERATOR FAILS TO ALIGN OR START EMERGENCY PURGE VENT EQUIP OR HAR NO ACTION TAKEN FOR 48 HOURS
B.E.

EXPOSURE PROB

RATE

$-\cdots$

PROB.

$1.4 \mathrm{E}-8 \quad 1$

$1.03 E-3 \quad 1.03 E-03$

$2.35 E-5$

$.09 \quad 9.00 \mathrm{E}-02$

$1 \quad 1.00 \mathrm{E}+00$

1 1.23E-04

$1.03 E-3 \quad 1.03 E-03$

2. $35 \mathrm{E}-5 \quad 2.35 \mathrm{E}-05$

$.09 \quad 9.00 \mathrm{E}-02$

$1 \quad 1.23 E-04$

$1.03 E-3 \quad 1.03 E-03$

$2.35 \mathrm{E}-5 \quad 2.35 \mathrm{E}-05$

$.09 \quad 9.00 \mathrm{E}-02$

1 1.23E-04

$2.35 E-5 \quad 2.35 E-05$

$09 \quad 9.00 E-02$

$1 \quad 1.00 E+00$

$1.23 E-04$

$1.03 E-3 \quad 1.03 E-03$

$2.35 \mathrm{E}-5 \quad 2.35 \mathrm{E}-05$

$21.49 E-01$

$i^{2} \quad 2.00 E-01$

$7 \quad 3.70 \mathrm{E}-04$

$.09 \quad 9.00 E-02$

.011 1.10E-02

2.35E-5 2.35E-05

$\begin{array}{ll}2 & 1.49 E-01 \\ 20 & 2.00 E-01\end{array}$

2. $00 \mathrm{E}-01$

$9.00 \mathrm{E}-02$

$\begin{array}{ll}.09 & 9.00 \mathrm{E}-02 \\ .011 & 1.10 \mathrm{E}-02\end{array}$

2.35E-5 2.35E-05

$7 \quad 1.43 E-03$

$.20 \quad 2.00 \mathrm{E}-01$

$2 \quad 3.85 \mathrm{E}-02$

$.0919 .00 E-02$

2. $35 E-5 \quad 2.35 E-05$

$2.35 \mathrm{E}-5 \quad 2.35 \mathrm{E}-05$

$7 \quad 1.43 E-03$

$.^{2} \quad 2.00 E-01$

$2 \quad 3.85 E-02$

$.09 \quad 9.00 E-02$

$.011 \quad 1.10 \mathrm{E}-02$

$2.35 E-5 \quad 2.35 E-05$

$1.00 \mathrm{E}+00 \quad 2.29 \mathrm{E}-13$ 


\section{RATE}

EXPOSURE

PROB.

BHOUSEO4

BHTHTRHW

REPAIRN

REPAIRN

EPVNTINT

$162)$ IGNITION
NPPNONBK* NPPNONBK REPAIRM
EPVNTINT

163) IGNITION NPPDIVBK REPAIRM EPVNTINT

164) BFC112HW* 8 FN527ST 8HOUSE03 IGNITION REPAIRM EPVNTINT

165) 8 FCI12HW* BFN527ST IGNST IGNITION REPAIRM EPVNTINT

166) 8HOUSE04 $8 X V V 17 P G *$ IGNITION REPAIRN EPVNTINT

167) 8HOUSEO4 8XVHV9PG IGNITION REPAIRN EPVNTINT

168) 8HOUSEO4 BXVHV2PG IGNITION REPAIRN

1691 BHOUSE04 BXVN31PG IGNITION REPAIRN EPVNTINT
8HOUSE0 4
CONDITIONAL PROBABILITY OF BEING IN NORMAL PROCESSING MODE $140 \mathrm{C} \mathrm{T}$ LOCAL MECHANICAL FAULTS OF TANK 48 HEATER

CONDITIONAL PROBABILITY OF HAVING AN IGNITION SOURCE PRESENT PROBABILITY OF NOT PERFORMING A SIMPLE REPAIR PROCEDURE

OPERATOR EAIIS TO ALIGN OR START EMERGENCY PURGE VENT EQUIP OR HAR CONDITIONAL PROBABILITY OF HAVING AN IGNITION SOURCE PRESENT NON-ISOLABLE GUILLOTINE PIPE BREAK

NON-ISOLABLE GUILLOTINE PIPE BREAK

PROBABILITY OF NOT PERF OPERATOR FAILS TO ALIGN OR START EMERGENCY PURGE VENT EQUIP OR CONDITIONAL PROBABILITY OF HAVING

ISOLABLE GUILLOTINE PIPE BREAK

PROBABILITY OF NOT PERFORMING A MODERATE REPAIR PROCEDURE OPERATOR FAILS TO ALIGN OR START EMERGENCY PURGE VENT EQUIP OR HAR

TANK 48 EXHAUST FAN 348-52-7 FAILS TO START DUE TO MECHANICAL FAU $4.8 E-4$ CONDITIONAL PROBABILITY OF BEING IN WASH CYCLE

CONDITIONAL PROBABILITY OF HAVING AN IGNITION SOURCE PRESENT

PROBABILITY OF NOT PERFORMING A MODERATE REPAIR PROCEDURE

OPERATOR FAILS TO ALIGN OR START EMERGENCY PURGE VENT EQUIP OR HAR

FLOW CONTROL VALVE 1211 PV2 MECHANICAL FAULT

TANK 48 EXHAUST FAN Y348-52-7 FAILS TO START DUE TO MECHANICAL FAU CONDITIONAL PROBABILITY OF TRANSFERRING SALT SOLUTION $170 \mathrm{C}$ TEMP)

CONDITIONAL PROBABILITY OF HAVING AN IGNITION SOURCE PRESENT

PROBABITTY OF NOT PERFORMING A MODERATE REPAIR PROCEDURE

OPERATOR FAILS TO ALIGN OR START EMERGENCY PURGE VENT EQUIP OR HAR CORATOR EAILS TO ALIGN OR START EMERGECY PROCESSING MODE $140 \mathrm{C}$ MANUAI VALVE T48-HV17 FAILS TO REMAIN OPEN (PLUG)

MANUAL VALVE T48-HVI

CONDITIONAL PROBABILITY OF HAV A SIMPLE REPAIR PROCEDURE

PROBABILITY OE NOT PERFORMING A SIMPLE REPAIR PROCEDURE OPERATOR FAILS TO ALIGN OR START EMERGENCY PURGE VENT EQUIP OR HAR CONDITIONAL PROBABILITY OF BEING IN NORMAL PROCESSING MODE $140 \mathrm{C}$ TANK 48 O2 ANALYZER DISCHARGE VALVE T48-HV9 FAILS TO REMAIN OPEN CONDITIONAL PROBABILITY OF HAVING AN IGNITION SOURCE PRE 'ENT

PROBABILITY OF NOT PERFORMING A SIMPLE REPAIR PROCEDURE

OPERATOR EAILS TO ALIGN OR START EMERGENCY PURGE VENT EQUIP OR HAR CONDITIONAL PROBABILITY OF BEING IN NORMAL PROCESSING MODE $140 \mathrm{C}$ MANUAL VALVE T48-HV2 FAILS TO REMAIN OPEN (PLUG)

CONDITIONAL PROBABILITY OF HAVING AN IGNITION SOURCE PRESENT

PROBABILITY OF NOT PERFORMING A SIMPLE REPAIR PROCEDURE

OPERATOR FATLS TO ALIGN OR START EMERGENCY PURGE VENT EQUIP OR HAR CONDITIONAL PROBABILITY OF BEING IN NORMAL PROCESSING MODE $140 \mathrm{C} \mathrm{T}$ TANK 48 TANK INLET VALVE T48-N31 FAILS TO REMAIN OPEN (PLUG)

CONDITIONAL PROBABILITY OF HAVING AN IGNITION SOURCE PRESENT

PROBABIITY OF NOT PERFORMING A SIMPLE REPAIR PROCEDURE

OPERATOR FAILS TO AITGN OR START EMERGENCY PURGE VENT EOUIP OR HAR CONDITIONAL PROBABILITY OF BEING IN NORMAL PROCESSING MODE $140 \mathrm{C} \mathrm{T}$

\begin{tabular}{|c|c|c|c|}
\hline & .60 & $6.00 \mathrm{E}-01$ & \\
\hline \multirow{5}{*}{$2.0 \mathrm{E}-8$} & 1 & $1.75 E-04$ & \\
\hline & .09 & $9.00 \mathrm{E}-02$ & \\
\hline & $1.03 E-3$ & $1.03 E-03$ & \\
\hline & $2.35 E-5$ & $2.35 E-05$ & \\
\hline & .09 & $9.00 E-02$ & $2.04 E-13$ \\
\hline \multirow[t]{4}{*}{$1.0 \mathrm{E}-9$} & 1 & $8.76 E-06$ & \\
\hline & .011 & $1.10 \mathrm{E}-02$ & \\
\hline & $2.35 E-5$ & $2.35 E-05$ & \\
\hline & .09 & $9.00 \mathrm{E}-02$ & $2.04 E-13$ \\
\hline \multirow[t]{3}{*}{$1.0 E-9$} & 1 & $8.76 E-06$ & \\
\hline & .011 & $1.10 \mathrm{E}-02$ & \\
\hline & $2.35 E-5$ & 2. 35E-05 & \\
\hline $8.5 E-6$ & 1 & $7.45 E-02$ & $1.66 \mathrm{E}-13$ \\
\hline \multirow[t]{5}{*}{$4.8 E-4$} & 1 & $4.80 \mathrm{E}-04$ & \\
\hline & .20 & $2.00 E-01$ & \\
\hline & .09 & $9.00 \mathrm{E}-02$ & \\
\hline & .011 & $1.10 \mathrm{E}-02$ & \\
\hline & $2.35 E-5$ & $2.35 E-05$ & \\
\hline 8. $5 E-6$ & 1 & $7.45 E-02$ & $1.66 \varepsilon-13$ \\
\hline \multirow[t]{6}{*}{$4.8 E-4$} & 1 & $4.80 E-04$ & \\
\hline & .2 & $2.00 E-01$ & \\
\hline & .09 & $9.00 E-02$ & \\
\hline & .011 & $1.10 \mathrm{E}-02$ & \\
\hline & $2.35 E-5$ & $2.35 E-05$ & \\
\hline & .60 & $6.00 \mathrm{E}-01$ & $1.60 E-13$ \\
\hline \multirow[t]{5}{*}{$1.4 E-8$} & 1 & $1.23 E-04$ & \\
\hline & .09 & $9.00 \mathrm{E}-02$ & \\
\hline & $1.03 \mathrm{E}-3$ & $1.03 \mathrm{E}-03$ & \\
\hline & $2.35 E-5$ & 2. $35 E-05$ & \\
\hline & .60 & $6.00 \mathrm{E}-01$ & $1.60 E-13$ \\
\hline \multirow[t]{5}{*}{$1.4 E-8$} & 1 & $1.23 E-04$ & \\
\hline & .09 & $9.00 E-02$ & \\
\hline & $1.03 \mathrm{E}-3$ & $1.03 E-03$ & \\
\hline & $2.35 E-5$ & 2. $35 E-05$ & \\
\hline & .60 & $6.00 \mathrm{E}-01$ & $1.60 E-13$ \\
\hline \multirow[t]{5}{*}{$1.4 E-8$} & 1 & $1.23 E-04$ & \\
\hline & .09 & $9.00 \mathrm{E}-02$ & \\
\hline & $1.03 E-3$ & $1.03 E-03$ & \\
\hline & $2.35 E-5$ & $2.35 E-05$ & \\
\hline & .60 & $6.00 E-01$ & $1.60 \mathrm{E}-13$ \\
\hline \multirow[t]{5}{*}{$1.4 E-8$} & 1 & $1.23 E-04$ & \\
\hline & .09 & $9.00 E-02$ & \\
\hline & $1.03 E-3$ & $1.03 E-03$ & \\
\hline & $2.35 E-5$ & $2.35 E-05$ & \\
\hline & .60 & $6.00 E-01$ & $1.6 p E-13$ \\
\hline
\end{tabular}

MOD. / CS.

PROB 
173) 8HOUSE04 BOPTRNBE $8 X V 22 P^{*}$ IGNITION REPAIRN EPVNTINT

174) BHOUSE04 $8 X V V 15 P G *$ IGNITION REPAIRN

75) 8EN527ST 8EN528HW* BHOUSE03 IGNITION REPAIRM EPVNTINT

170) 8EN527ST 8 EN528HW* 8HOUSEO1 IGNITION REPAIRM EPVNTINT

177) IGNITION NPR246HW* NVPVPBHW REPAIRN EPVNTINT

178) 8 FC112 $\mathrm{HW}^{*}$ BEN527HW BHOUSE 4

TANK 48 VALVE T48-N2 EROM THE NITROGEN SUPPLY EAILS TO REMAIN OPEN $1.4 \mathrm{E}-8$ CONDITIONAL PROBABILITY OF HAVING AN IGNITION SOURCE PRESENT PROBAOT

OPERATOR EATLS TO ALIGN OR START EMERGENCY PURGE VENT EQUIP OR HAR CORDITIONAL PROBABILITY OF BEING IN NORMAL PROCESSING MODE $140 \mathrm{C} \mathrm{T}$ CONDITIONAL PROBABILITY OE BEING IN NORMAL PROCESSIN

CONDITIONAL PROBABILITY OF HAVING AN IGNITION SOURCE PRESENT

PROBABILITY OF NOT PEREORMING A SIMPLE REPAIR PROCEDURE

OPERATOR EAILS TO ALIGN OR START EMERGENCY PURGE VENT EQUIP OR HAR CONDITIONAL PROBABILITY OF BEING IN NORMAL PROCESSING MODE $140 \mathrm{C}$ OPERATOR FAILS TO ALIGN AND START TRAIN B FOR OPERATION - EXHAUST MANUAL VALVE T48-HV20 FAILS TO REMAIN OPEN (PLUG)

CONDITIONAL PROBABILITY OF HAVING AN IGNITION SOURCE PRESENT

PROBABILITY OF NOT PERFORMING A SIMPLE REPAIR PROCEDURE

OPERATOR FAILS TO ALIGN OR START EMERGENCY PURGE VENT EQUIP OR HAR CONDITIONAL PROBABILITY OF BEING IN NORMAL PROCESSING MODE $140 \mathrm{C}$ OPERATOR FAILS TO ALIGN AND START TRAIN B FOR OPERATION - EXHAUST MANUAL VALVE T48-HV22 FAILS TO REMAIN OPEN (PLUG)

CONDITIONAL PROBABILITY OF HAVING AN IGNITION SOURCE PRESENT CONDITIONAL PROBABILITY OE HAVING AN IGNITION SOURCE PRES PROBABILITY OF NOT PERF OR START EMERGENCY PURGE VENT EOUIP OR HAR OPERATOR EAILS TO ALER CONDITIONAL PROBABILITY OF BEING IN NORMAL PROCESSING PRESENT COABILITY OF NOT PEREORMING A SIMPLE REPAIR PROCEDURE

OPERATOR FAIIS TO ALIGN OR START EMERGENCY PURGE VENT EQUIP OR HAR

OPERATOR FAILS TO ALIGN OR START EMERGENCY TO

TANK 48 EXHAUST FAN Y348-52-7 EAILS TO START DUE TO MECHANICAL FAU COND 8 EXHAUST EAN Y348-52-8 EAILS TO RUN DYCL

CONDITIONAL PROBABILITY OF HAVING AN IGNITION SOURCE PRESENT PROBABILITY OF NOT PERFORMING A MODERATE REPAIR PROCEDURE

OPERATOR FAILS TO ALIGN OR START EMERGENCY PURGE VENT EQUIP OR HAR TANK 48 EXHAUST FAN $Y 3.18-52-7$ FAILS TO START DUE TO MECHANICAL FAU TANK 48 EXHAUST FAN Y348-52-8 EAILS TO RUN DUE TO MECHANICAL EAULT CONDITIONAL PROBABILITY OF TRANSEERRING SALT SOLUTION 170 C TEMP) CONDITIONAL PROBABILITY OF HAVING AN IGNITION SOURCE PRESENT PROBABI TTY OF NOT PEREORMING A MODERATE REPATR PROCEDURE OPERATOR FAILS TO ALIGN OR START EMERGENCY PURGE VENT EQUIP OR HAR OPERATOR FAILS TO ALIGN OR START EMERGENCY PURGE VENT ERUENT CONDITIONAL PROBABILITY OF HAVING AN IGNI FAILURE OF VAPORIZER B DUE TO HARDWARE FAULTS

$1.4 \mathrm{E}-8$

$.09 \quad 1.23 E-04$

$1.03 E-3 \quad 1.03 E-03$

$2.35 \mathrm{E}-5 \quad 2.03 \mathrm{E}-03$

$2.35 \mathrm{E}-5$ 2. $25 \mathrm{E}-05$

$6.00 E-01$

$09 \quad 9.00 E-02$

$1.03 E-3 \quad 1.03 E-03$

$2.35 E-5 \quad 2.35 E-05$

$6.00 \mathrm{E}-01$

$1.00 \mathrm{E}+00$

9.00E-02

$1.03 \mathrm{E}-3 \quad 1.03 \mathrm{E}-03$

$2.35 \mathrm{E}-5 \quad 2.35 \mathrm{E}-05$

6. $00 \mathrm{E}-01$

1. $4 \mathrm{E}-8$

.09

1.23E-04

$9.00 \mathrm{E}-02$

1.03E-3 1.03E-03

$2.35 E-5 \quad 2.35 E-05$

60 6.00E-01

$\begin{array}{lll}1.4 \mathrm{E}-8 \quad i .60 & 1.00 \mathrm{E}-01 \\ & 1 & 1.23 \mathrm{E}-04\end{array}$

$.09 \quad 9.00 E-02$

$\begin{array}{ll}1.03 E-3 & 1.03 E-03 \\ 2.35 E-5 & 2.35 E-05\end{array}$

$2.35 \mathrm{E}-5 \quad 2.35 \mathrm{E}-05$

$1 \quad 7.01 \mathrm{E}-02$

$20 \quad 2.00 E-01$

$.099 .00 \mathrm{E}-02$

$011 \quad 1.10 \mathrm{E}-02$

$2.35 \mathrm{E}-5 \quad 2.35 \mathrm{E}-05$

$\begin{array}{lll}4.8 E-4 & 1 & 4.80 E-04 \\ 8.0 E-6 & 1 & 7.01 E-02\end{array}$

$.2 \quad 2.00 \mathrm{E}-01$

$.09 \quad 9.00 E-02$

$011 \quad 1.10 E-02$

2.35E-5 2.35E-05

$2.09 \mathrm{~g}-5$ 9.00E-02

PROBABILITY OF NOT PERFORMING A SIMPLE REPAIR PROCEDURE

$4 \cdot 15-7$

OPERATOR FAIS TO PER OR START EMERGENCY PURGE VENT EOUIP OR HAR FLOW CONTROL VAIVE 1211 PV 2 MECHANICAL FAULT

TANK 48 EXHALST FAN Y348-52-7 FAILS TO RUN FOR 6 DAYS

CONDITIONAL PROBABILITY OE BEING IN NORMAL PROCESSING MODE $140 \mathrm{cl}$

$8.5 E-6$
$8.0 E-6$ 
CONDITIONAL PROBABILITY OF HAVING AN IGNITION SOURCE PRESENT PROBABILITY OF NOT PEREORMING A SIMPLE REPAIR PROCEDURE OPERATOR FAILS TO ALIGN OR START EMERGENCY PURGE VENT EQUIP OR HAR TANK 48 EXHAUST FAN Y348-52-7 FAILS TO RUN FOR 6 DAYS

$-\cdot-$ 8. $0 E-6$ TANK 48 EXHAUST TAN Y340-52-7 EAILS TO RUN FUR TANK 48 EXHAUST EAN $348-52-8$ EAILS TO RUN DUE TO MECHANICAL FAULT CONDITIONAL PROBABILITY OF BEING IN NORMAL PROCESSING MODE $140 \mathrm{C}$ CONDITIONAL PROBABILITY OF HAVING AN IGNITION SOURCE PRESEN PROBABILITY OF NOT PEREORMING A SIMPLE REPAIR PROCEDURE REY PURGE VENT EQUIP OR HAR CONDITIONAL PROBABILITY NO ACTION TAKEN FOR 48 HOURS

LOCAL MECHANICAL EAULTS OF TANK 48 HEATER

CONDITIONAL PROBABILITY OE HAVING AN IGNITION SOURCE PRESENT

PROBABILITY OF NOT REPLACING/REPAIRING HEPA FILTER IS NEGLIGIBLE

CPERATOR FAILS TO ALIGN OR START EMERGENCY PURGE VENT EQUIP OR HAR NO ACTION TAKEN FOR 48 HOURS

CONDITIONAL PROBABILITY OF BEING IN WASH CYCLE

LOCAL MECHANICAL FAULTS OF TANK 48 HEATER

CONDITIONAL PROBABIIITY OF HAVING AN IGNITION SOURCE PRESENT

PROBABI TTY OF NOT REPLACING/REPAIRING HEPA FILTER IS NEGLIGIBLE

PROBABILITY OF NOT RERLACIN START EMERGENCY PURGE VENT EOUIP OR HAR MECHANICAL EAULT OF TANK 48 FLOW CONTROL VALVE $1201 \mathrm{FV}$. CONDITIONAL PROBABILITY OF BEING IN NORMAL PROCESSING MODE $140 \mathrm{C} \mathrm{T}$ MECHANICAL FAULTS OF TANK 48 PRESSURE REGULATING VALVE 1205 PV2 MECHANICAL FAULTS OF TANK 48 PRESSURE REGULATING VALVE $1205 P$ CONDITIONAL PROBABILITY OF HAVING AN IGNITION SOURCE PRESE PROBABILITY OE NOT PERFORMING A SIMPLE REPAIR PROCEDURE
OPERATOR FAILS TO ALIGN OR START EMERGENCY PURGE VENT EQUIP OR HAR MECHANICAL EAULT OE TANK 48 ELIN CONTROL VALVE 12O2EV

CONDITIONAL PROBABILITY OE BEING IN NORMAL PROCESSING MODE $140 \mathrm{C}$ MECHANICAL FAULTS OF TANK 48 PRESSURE REGULATING VALVE 1205PVI CONDITIONAL PROBABILITY OF HAVING AN IGNITION SOURCE PRESENT PROBABILITY OF NOT PERFORMING A SIMPLE REPAIR PROCEDURE OPERATOR EAILS TO ALIGN OR START EMERGENCY PURGE VENT EQUIP OR HAR CONDITIONAL PROBABILITY OF TRANSFERRING SALT SOLUTION $170 \mathrm{C}$ TEMP) MECHANICAL FAULTS OF TANK 48 PRESSURE REGULATING VALVE 1205 PVI MECHANICAL EAULTS OF TANK 48 PRESSURE REGULATING VALVE 1205PV2 CONDITIONAL PROBABIIITY OE HAVING AN IGNITION SOURCE PRESENT PROBABILITY OF NOT PEREORMING A MODERATE REPAIR PROCEDURE OPERATOR FAIIS TO ALIGN OR START EMERGENCY PURGE VENT EQUIP OR HAR CONDITIONAL PROBABILITY OE BEING IN WA

CONDITIONAL PROBABILITY OF BEING IN WASH CYCLE MECHANICAL FAULTS OE TANK 4 B PRESSURE REGULATING VALVE 1205 PVI MECHANICAL FAULTS OE TANK 40 PRESSURE REGULATING VALVE 1205 PV CONDITIONAL PROBABILITY OF HAVING AN IGNITION SOURCE PRESENT

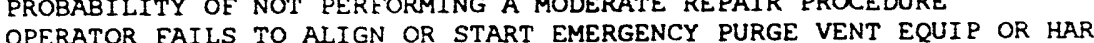
OPERATOR FAILS TO ALIGN OR START EMERGENCY PURGE VENT EQUIP OR

$8.5 E-6$

B. $5 E-6$
9. $00 \mathrm{E}-02$

$1.03 E-3 \quad 1.03 E-03$ 2.35E-5 2.35E-05

60

09

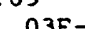

$1.03 E-3$
$2.35 E-5$

1

1

.09

$1.03 E-3$
$2.35 E-5$

1

.20

109

i. $03 \mathrm{E}-3$

2. 35E-5 2

$i^{60}$

09

.09

$1.03 E-3$
$2.35 E-5$ 
188) BHOUSEO1 8XVN31PG* IGNITION REPAIRN EPVNTINT

189) 8HOUSE01 8XVV33PG* IGNITION REPAIRN EPVNTINT

190) BHOUSE01
BXVHV2PG. 8XVHV2PG* IGNITION REPAIRN EPVNTINT

191) BHOUSE01 8OPTRNBE 8XVV2OPG* IGNITION REPAIRN EPVNTINT

192) 8HOUSE01 8XV8N2PG* IGNITION REPAIRN EPVNTINT

193) BHOUSEOI BXVV15PG* IGNITION REPAIRN EPVNTINT

194) BHOUSEO1 BXVHV9PG* IGNITION REPAIRN PRESSURE REGULATING VALVE 2045PV MAINTENANCE PROBABILITY OF NOT PERFORMING A SIMPLE REPAIR PROCEDURE OPERATOR FAILS TO ALIGN OR START EMERGENCY PURGE VENT EQUIP OR HAR OPERATOR FAILS TO ALIGN OR START EMERGENCY PURGE VENT EQUIP OR HAR CONDITIONAL PROBABILITY OE TRANSFERRING SALT SOLUTION I - CXHAUST OPERATOR FAILS TO ALIGN AND START TRAIN B EOR OPERA

CONDITIONAI PROBABILITY OF HAVING AN IGNITION SOURCE PRESENT PROBABILITY OF NOT PERFORMING A SIMPLE REPAIR PROCEDURE OPERATOR FAILS TO ALIGN OR START EMERGENCY PURGE VENT EQUIP OR HAR CONDITIONAL PROBABILITY OF TRANSFERRING SALT SOLUTION $(70 \mathrm{C}$ TEMP) TANK 48 TANK INLET VALVE T48-N31 FAILS TO REMAIN OPEN (PLUG) CONDITIONAL PROBABILITY OE HAVING AN IGNITION SOURCE PRESENT PROBABILITY OE NOT PERFORMING $A$ SIMPLE REPAIR PROCEDURE OPERATOR FAILS TO ALIGN OR START EMERGENCY PURGE VENT EQUIP OR HAR CONDITIONAL PROBABILITY OF TRANSFERRING SALT SOLUTION (70 C TEMP) MANUAL VALVE T48-HV33 FAILS TO REMAIN OPEN (PLUG)

CONDITIONAL PROBABILITY OF HAVING AN IGNITION SOURCE PRESENT PROBABILITY OE NOT PEREORMING A SIMPLE REPAIR PROCEDURE

OPERATOR FAILS TO ALIGN OR START EMERGENCY PURGE VENT EQUIP OR HAR CONDITIONAL PROBABILITY OF TRANSFERRING SALT SOLUTION $170 \mathrm{C}$ TEMPI MANUAI VALVE T48-HV2 FAILS TO REMAIN OPEN (PLUG) CONDITIONAL PROBABILITY OF HAVING AN IGNITION SOURCE PRESENT PROBABILITY OF NOT PERFORMING A SIMPLE REPAIR PROCEDURE PROBABILITY OE NOT PER ORMING A SIMER REPY PURGE VENT EOUIP OR HAR OPERATOR FAILS TO ALIGN OR START EMERGENCY PURGE VENT EQUIP OR HAR CONDITIONAL PROBABILITY OE TRANSEERRING SALT SOLUTION (TO C TEMP OPERATOR EAILS TO ALIGN AND SIART TRAIN B MOR ORERAT: MANUAL VALVE T48-HV2O FAILS TO REMAIN OPEN (PLUG!

CONDITIONAL PROBABILITY OE HAVING AN IGNITION SOURCE PRESENT PROBABILITY OF NOT PERFORMING A SIMPLE REPAIR PROCEDURE OPERATOR EAILS TO ALIGN OR START EMERGENCY PURGE VENT EQUIP OR HAR CONDITIONAL PROBABILITY OF TRANSFERRING SALT SOLUTION (70 C TEMP) TANK 48 VALVE T48-N2 FROM THE NITROGEN SUPPLY FAILS TO REMAIN OPEN 1.4E-8 CONDITIONAL PROBABILITY OF HAVING AN IGNITION SOURCE PRESENT EKOBABILITY OF NOT PERFORMING A SIMPLE REPAIR PROCEDURE OPERATOR FAILS TO ALIGN OR START EMERGENCY PURGE VENT EQUIP OR HAR CONDITIONAL PROBABILITY OF TRANSFERRING SALT SOLUTION $170 \mathrm{C}$ TEMP) MANUAL VALVE T48-HV15 FAILS TO REMAIN OPEN (PLUG)

CONDITIONAI PROBABILITY OF HAVING AN IGNITION SOURCE PRESENT PROBABILITY OF NOT PERFORMING A SIMPLE REPAIR PROCEDURE OPERATOR EAILS TO ALIGN OR START EMERGENCY PURGE VENT EQUIP OR HAR CONDITIONAL PROBABILITY OF TRANSFERRING SALT SOIUTION $170 \mathrm{C}$ TEMP ORE ORI HAVING AN IGNITION SOURCE PRESENT CONDITIONAL PROBABILITY OE HAVING AN IGNITION SOURCE

OPERATOR FAIL TO ALIGN OR START EMERGENCY PURGE VENT EQUIP OR HAR

\begin{tabular}{|c|c|c|c|}
\hline RATE & EXPOSURE & $\begin{array}{l}\text { B.E. } \\
\text { PROB. }\end{array}$ & $\begin{array}{l}\text { MOD. / CS } \\
\text { PROB. }\end{array}$ \\
\hline $3.6 E-3$ & 2 & $7.20 \mathrm{E}-03$ & \\
\hline \multirow[t]{5}{*}{$4.1 E-7$} & 1 & $3.59 E-03$ & \\
\hline & $1.03 E-3$ & $1.03 E-03$ & \\
\hline & $2.35 E-5$ & $2.35 E-05$ & \\
\hline & .2 & $2.00 E-01$ & $5.34 E-14$ \\
\hline & 1 & $1.00 \varepsilon+00$ & \\
\hline \multirow[t]{5}{*}{ 1. $4 E-8$} & 1 & $1.23 E-04$ & \\
\hline & .09 & $9.00 E-02$ & \\
\hline & $1.03 E-3$ & $1.03 E-03$ & \\
\hline & $2.35 E-5$ & $2.35 E-05$ & \\
\hline & .2 & $2.00 \mathrm{E}-01$ & $5.34 \mathrm{E}-14$ \\
\hline \multirow[t]{5}{*}{$1.4 E-8$} & 1 & $1.23 E-04$ & \\
\hline & .09 & $9.00 E-02$ & \\
\hline & $1.03 E-3$ & $1.03 E-03$ & \\
\hline & $2.35 E-5$ & $2.35 E-05$ & \\
\hline & .2 & $2.00 E-01$ & $5.34 E-14$ \\
\hline \multirow[t]{5}{*}{ 1. $4 E-8$} & 1 & $1.23 E-04$ & \\
\hline & .09 & $9.00 E-02$ & \\
\hline & $1.03 E-3$ & $1.03 E-03$ & \\
\hline & $2.35 \mathrm{E}-5$ & 2. $35 E-05$ & \\
\hline & .2 & $2.00 E-01$ & $5.34 E-14$ \\
\hline \multirow[t]{6}{*}{$1.4 E-8$} & 1 & $1.23 E-04$ & \\
\hline & .09 & $9.00 E-02$ & \\
\hline & $1.03 E-3$ & $1.03 \varepsilon-03$ & \\
\hline & $2.35 E-5$ & $2.35 E-05$ & \\
\hline & .2 & $2.00 E-01$ & $5.34 \mathrm{E}-14$ \\
\hline & 1 & $1.00 E+00$ & \\
\hline \multirow[t]{5}{*}{ 1. $4 \mathrm{E}-8$} & 1 & $1.23 E-04$ & \\
\hline & .09 & $9.00 E-02$ & \\
\hline & $1.03 \mathrm{E}-3$ & $1.03 E-03$ & \\
\hline & $2.35 E-5$ & $2.35 E-05$ & \\
\hline & .2 & $2.00 E-01$ & $5.34 E-14$ \\
\hline \multirow[t]{5}{*}{ 1. $4 E-8$} & 1 & $1.23 E-04$ & \\
\hline & .09 & $9.00 \varepsilon-02$ & \\
\hline & $1.03 E-3$ & $1.03 E-03$ & \\
\hline & $2.35 E-5$ & $2.35 E-05$ & \\
\hline & .2 & $2.00 \mathrm{E}-01$ & $5.34 E-14$ \\
\hline \multirow{5}{*}{$1.4 E-8$} & 1 & $1.23 E-04$ & \\
\hline & .09 & $9.00 \mathrm{E}-02$ & \\
\hline & $1.03 E-3$ & $1.03 E-03$ & \\
\hline & $2.35 E-5$ & $2.35 E-05$ & \\
\hline & .2 & $2.00 E-01$ & $5.34 E-14$ \\
\hline \multirow[t]{4}{*}{$1.4 E-8$} & 1 & $1.23 E-04$ & \\
\hline & .09 & $9.00 E-02$ & \\
\hline & $1.03 E-3$ & $1.03 E-03$ & \\
\hline & 2. $35 E-5$ & $2.35 E-05$ & \\
\hline
\end{tabular}




\begin{tabular}{|c|c|}
\hline \multicolumn{2}{|c|}{ A:IGN-09R.CUT } \\
\hline & \\
\hline \multicolumn{2}{|c|}{ MODULE/EVENT NAME } \\
\hline \multirow{5}{*}{1951} & 8HOUSEOI \\
\hline & $8 \times V V 1>P G$ \\
\hline & IGNITION \\
\hline & REPAIRN \\
\hline & EPVNTINT \\
\hline \multirow{5}{*}{1961} & 8HOUSE 03 \\
\hline & $8 X V V 33 P G *$ \\
\hline & IGNITION \\
\hline & REPAIRN \\
\hline & EPVNTINT \\
\hline \multirow[t]{5}{*}{1971} & 8HOUSE 03 \\
\hline & $8 \times V V 17 P G *$ \\
\hline & IGNITION \\
\hline & REPAIRN \\
\hline & EPVNTINT \\
\hline \multirow[t]{5}{*}{1981} & 8HOUSE03 \\
\hline & 8XVHV9PG* \\
\hline & IGNITION \\
\hline & REPAIRN \\
\hline & EPVNTINT \\
\hline \multirow[t]{5}{*}{1991} & 8 HOUSE 03 \\
\hline & $8 X V N 31 P G$ \\
\hline & IGNITION \\
\hline & REPAIRN \\
\hline & EPVNTINT \\
\hline \multirow[t]{6}{*}{2001} & 8HOUSE 03 \\
\hline & 8OPTRNBE \\
\hline & $8 \times V V 20 P G$ \\
\hline & IGNITION \\
\hline & REPAIRN \\
\hline & EPVNTINT \\
\hline \multirow[t]{5}{*}{2011} & 8 HOUSE 03 \\
\hline & $8 X V H V 2 P G^{*}$ \\
\hline & IGNITION \\
\hline & REPAIRN \\
\hline & EPVNTINT \\
\hline \multirow[t]{6}{*}{2021} & BHOUSE 03 \\
\hline & 8OPTRNBE \\
\hline & $8 X V V 22 P G$ \\
\hline & IGNITION \\
\hline & REPAIRN \\
\hline & EPVNTINT \\
\hline \multirow[t]{4}{*}{2031} & 8 HOUSEO3 \\
\hline & $8 X V 8 N 2 P^{*}$ \\
\hline & IGNITION \\
\hline & REPAIRN \\
\hline
\end{tabular}

CONDITIONAL PROBABILITY OF TRANSFERRING SALT SOLUTION $170 \mathrm{C}$ TEMP) MANUAL VALVE T48-HV17 FAILS TO REMAIN OPEN (PLUG)

CONDITIONAI PROBABILITY OF HAVING AN IGNITION SOURCE PRESENT

PROBABILITY OF NOT PERFORMING A SIMPLE REPAIR PROCEDURE

PROBABTOR FAIIS TO ALIGN OR START EMERGENCY PURGE VENT EOUIP OR HAR CONDITIONAL PROBABILITY OF BEING IN WASH CYCLE

CONDITIONAL PROBABILITY OF BEING IN WASH CN (PLUG)

CONDIIIONAL PROBABIITTY OF HAVING AN IGNITION SOURCE PRESENT

PROBABILITY OF NOT PERFORMING A SIMPLE REPAIR PROCEDURE

PROBABILITY OF NOT PERF OR START EMERGENCY PURGE VENT EQUIP OR HAR

CONDITIONAL PROBABILITY OF BEING IN WASH CYCLE

MANUA

CONDITIONAL PROBABILITY OF HAVING AN IGNITION SOURCE PRESENT

PROBABILITY OF NOT PERFORMING A SIMPLE REPAIR PROCEDURE

OPERATOR FAILS TO ALIGN OR START EMERGENCY PURGE VENT EQUIP OR HAR

CONDITIONAL PROBABILITY OF BEING IN WASH CYCLE

TANK 48 O2 ANALYZER DISCHARGE VALVE T48-HV9 FAILS TO REMAIN OPEN $11.4 \mathrm{E}-8$

CONDITIONAL PROBABILITY OF HAVING AN IGNITION SOURCE PRESENT

PROBABILITY OF NOT PERFORMING A SIMPLE REPAIR PROCEDURE

OPERATOR FAILS TO ALIGN OR START EMERGENCY PURGE VENT EQUIP OR HAR

CONDITIONAL PROBABILITY OF BEING IN WASH CYCLE

CONK 48 TANK INLET VALVE T48-N31 FAILS TO REMAIN OPEN (PLUG)

TAN

PROBABILITY OF NOT PERFORMING A SIMPLE REPAIR PROCEDURE

PROBABILITY OE NOT PERN OR START EMERGENCY PURGE VENT EQUIP OR HAR

OPERATOR EAILS TO ALIGN OR START EMERGENCY PURGE

CONDITIONAL PROBABILITY OF BEING IN WASH CYCLE

OPERATOR FAILS TO ALIGN AND START TRATN B FOR OPERA

MANUAL VALVE T48-HV2O FAILS TO REMAIN OPEN (PLUG)

CONDITIONAL PROBABILITY OF HAVING AN IGNITION SOURCE PRESEN
PROBABILITY OF NOT PEREORMING A SIMPLE REPAIR PROCEDURE

PROBABILITY OE NOT PERFORMING A SIMPLE REPAIR PROCEDURE
OPERATOR FAILS TO ALIGN OR START EMERGENCY PURGE VENT EQUIP OR HAR

CONDITIONAL PROBABILITY OE BEING IN WASH CYCLE

1.4

$.4 E-8$

.2

- - - -

$5.34 \mathrm{E}-14$

$.099 .00 \mathrm{E}-02$

$1.03 E-3 \quad 1.03 E-03$

$2.35 \mathrm{E}-5 \quad 2.35 \mathrm{E}-05$

$\begin{array}{llll} & .20 & 2.00 E-01 & 5.34 E-14 \\ .4 E-8 & 1 & 1.23 E-04 & \end{array}$

$.09 \quad 9.00 \mathrm{E}-02$

$1.03 E-3 \quad 1.03 E-03$

$2.35 \mathrm{E}-5 \quad 2.35 \mathrm{E}-05$

$1 \quad 1.23 \mathrm{E}-04$

$09 \quad 9.00 \mathrm{E}-02$

$1.03 E-3 \quad 1.03 E-03$

$\begin{array}{lll}2.35 E-5 & 2.35 E-05 & \\ 20 & 2.00 E-01 & 5.34 E-14\end{array}$

3

1.09

$.09 \quad 1.23 \mathrm{E}-04$

$1.03 \mathrm{E}-3 \quad 1.00 \mathrm{E}-02$

$2.35 \mathrm{E}-5$

20 2.35E-5 $2.35 E-05$

2.00E-01 5.34E-14

.09

$1.23 E-04$

$9.00 \mathrm{E}-02$

$1.03 \mathrm{E}-3 \quad 1.03 \mathrm{E}-03$

$2.35 E-5 \quad 2.35 E-05$

$20 \quad 2.00 E-01$

$1.00 E+00$

$1.23 E-04$

$9.00 E-02$

$1.03 E-3 \quad 1.03 E-03$

$1.03 E-3 \quad 2.35 E-05$

$20 \quad 2.00 E-01 \quad 5.34 E-14$

CONDITIONAL PROBABILITY OE HAVING AN IGNITION SOURCE PRESENT

PROBABILITY OF NOT PERFORMING A SIMPLE REPAIR PROCEDURE

OPERATOR FAILS TO ALIGN OR START EMERGENCY PURGE VENT EQUIP OR HAR

CONDITIONAL PROBABILITY OF BEING IN WASH CYCLE

OPERATOR FAILS TO ALIGN AND START TRAIN B FOR OPERATION - EXHAUST

MANUAL VAIVE T48-HV22 FAILS TO REMAIN OPEN (PLUG)

CONDITIONAI PROBABIIITY OF HAVING AN IGNITION SOURCE PRESENT

CONDITIONAL PROBA UITY OFM A SIMPLE REPAIR PROCEDURE

PROBABILITY OF NO IIRN OR START EMERGENCY PURGE VENT EOUIP OR HAR

OPERATOR FAILS TO ALIGN OR START EMERGENCY PURGE

$2.00 E-01$
$1.23 E-04$
$9.00 E-02$

$09 \quad 9.00 E-02$

$1.03 E-3 \quad 1.03 E-03$

2.35E-5 2.35E-05

$.20 \quad 2.00 E-01$

$1.00 E+00$
$1.23 E-04$

$109 \quad 9.23 E-04$

$1.03 E-3 \quad 1.03 E-03$

$2.35 E-5 \quad 2.35 E-05$

$20 \quad 2.00 E-01$

2.00E-01 $5.34 E-14$

TANK 48 VALVE T48-N2 FROM THE NITROGEN SUPPLY FAILS TO REMAIN OPEN $1.4 E-8 \quad 1 \quad 1.23 E-04$

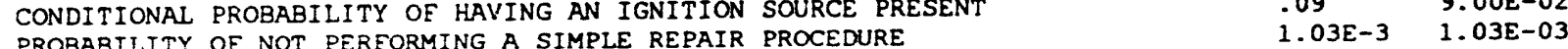


B.E.

\section{DESCRIPTION}

EPVNTINT

204) 8HOUSE03 $8 X V 15$ PG* IGNITION REPAIRN EPVNTINT

205) 8FC112HW* 8FN527ST BHOUSE04 IGNITION REPAIRN EPVNTINT

206) 8EN5275T BEN528HW* BHOUSEO4 IGNITION REPAIRN EPVNTINT

207) Ignition nvpvpahw* nvpvpbhw repairn efvntint

208) 9A2O21 9XVHV 4 PG IGNITION REPAIRN EPVNTINT

209) 9RZO21HW 9XVV11PG IGNITION REPAIRN EPVNTINT

210) 9AZO22HW 9XVV1OPG* IGNITION REPAIRN EPVNTINT

211) 9A2O22HW 9XVHV3PG* IGNITION EPVNTINT

212) 9FC512HW 9XVV19HW IGNITION
OPERATOR FAILS TO ALIGN OR START EMERGENCY PURGE VENT EQUIP OR HAR CONDITIONAL PROBABILITY OF BEING IN WASH CYCLE

MANUAL VALVE TA8-HVI5 EAILS TO REMAIN OPEN (PLUG)

CONDITIONAL PROBABILITY OF HAVING AN IGNITION SOURCE PRESENT

PROBABILITY OF NOT PERFORMING A SIMPLE REPAIR PROCEDURE

OPERATOR FAILS TO ALIGN OR START EMERGENCY PURGE VENT EQUIP OR HAR FLOW CONTROL VALVE 1211 PV2 MECHANICAL FAULT

FLON CONTOL VALVE 1211 V 2 MECHANICAL TO START DUE TO MECHANICAL FAU TANK 48 EXAA PROBABILITY OF BEING IN NORMAL PROCESSING MODE $140 \mathrm{C} \mathrm{T}$ CONDITIONAL PROBABILIY OF HAVING AN IGNITION SOURCE PRESENT

CONDITIONAL PROBABILITY OE HAVING AN IGNITION PROCEDURE

PROBABILITY OF NOT PERFORM START EMERGENCY PURGE VENT EQUIP OR HAR

OPERATOR FAILS TO ALIGN OR START EMERGENCY PURGE VENT EQUIP OR HAR

TANK 48 EXHAUST FAN Y348-52-7 FAILS TO START DUE TO MECHANICAL EAU

TANK 48 EXHAUST FAN Y348-52-8 FAILS TO RUN DUE TO MECHANICAL FAULT CONDITIONAL PROBABILITY OF BEING IN NORMAL PROCESSING MODE

CONDITIONAL PROBABILITY OF HAVING AN IGNITION SOURCE PRESEN

PROBABILITY OF NOT PERFORMING A SIMPLE REPAIR PROCEDURE OPERATOR FAILS TO ALIGN OR START EMERGENCY PURGE VENT EQUIP OR

CONDITIONAL PROBABILITY OF HAVING AN IGNITIST

FAILURE OF VAPORIZER B DUE TO HARDWARE FAULTS

PROBABILITY OF NOT PERFORMING A SIMPLE REPAIR PROCEDURE

OPERATOR FAILS TO ALIGN OF START EMERGENCY PURGE VENT EOUIP OR HAR TANK 49 O2 ANALYZER 1 HARDWARE FAULTS

MANUAI VAIVE T49-HV4 FAIS TO REMAIN OPEN (PLUG)

CONAL VALVE T4PAVA SAT OE HAVING AN IGNITION SOURCE PRESENT

PROBABILITY OF NOT PERFORMING A SIMPLE REPAIR PROCEDURE

PROBABILITY OF NOT

TANK 49 O2 ANALYZER 1 HARDWARE FAULTS

MANUAL VALVE T49-HVII FAILS TO REMAIN OPEN (PLUG)

CONDITIONAL PROBABILIY

PROBABILITY OF NOI PERFORMING A SIMPLE REPAIR PROCEDURE

VENT EQUIP OR HAR TANK 49 O2 ANALYZER 2 HARDWARE FAULTS

MANUAL VALVE T49-HV10 FAILS TO REMAIN OPEN (PLUG)

CONDITIONAL PROBABILITY OE HAVING AN IGNITION SOURCE PRESENT

PROBABILITY OF NOT PERFORMING A SIMPLE REPAIR PROCEDURE

OPERATOR FAILS TO ALIGN OR START EMERGENCY PURGE VENT EQUIP OR HAR

TANK 49 O2 ANALYZER 2 HARDWARE FAULTS

MANUAL VALVE T49-HV3 FAILS TO REMAIN OPEN (PLUG)

CONDITIONAL PROBABILITY OF HAVING AN IGNITION SOURCE PRESENT

PROBABILITY OF NOT PERFORMING A SIMPLE REPAIR PROCEDURE

OPERATOR FAILS TO ALIGN OR START EMERGENCY PURGE VENT EQUIP OR HAR

FLOW CONTROL VALVE 1251 PV2 MECHANICAL EAULT

MANUAI VALVE T49-HVI9 FAILS TO OPEN ON DEMAND

CONDITIONAL PROBABILITY OE HAVING AN IGNITION SOURCE PRESENI
RATE

$-\cdots$

EXPOSURE

$2.35 E-5$

20

$i$

.09

$1.03 E-3$

2. $35 \mathrm{E}-5$

1

$1.03 E-3$

$2.35 \mathrm{E}-5$

1

1

.60

1. $03 \mathrm{E}-3$

2. 35E-5

.09

4.1E-7

4.1E-7

7

1. 03E-3

2. $35 E-5$

3. $0 E-4$

1. $4 \mathrm{E}-8$

.09

i. $03 \mathrm{E}-3$

2. $35 E-5$

3. $0 \mathrm{E}-4$

1. $4 E-8$

2

1.09

2. $35 E-5$

$.0 E-4$
$.4 E-8$

.09

1. $09 \mathrm{E}-3$

2. $35 E-5$

$3.0 E-4$

1. $4 E-8$

2

09

1. $.03 E-3$

2. 35E-5

8. $5 E-6$

1. $6 \mathrm{E}-4$
$09 \quad 9.00 E-02$

MOD./CS

PROB.

$2.35 E-05$

$2.00 \mathrm{E}-01$

$1.23 E-04$

$9.00 E-02$

$1.03 E-03$

$2.35 E-05$

$7.45 E-02$

6. $00 \mathrm{E}-01$

9.00E-02

$1.03 E-03$

2. 35E-05

4. $80 \mathrm{E}-04$

$7.01 E-02$

$6.00 E-01$

$9.00 E-02$

$1.03 E-03$

2. $35 E-05$

9.00E-02 5.39E-16

$3.59 \mathrm{E}-03$

$6.89 \mathrm{E}-05$

$1.03 E-03$

2. 35E-05

5. $26 E+00 \quad 2.69 E-14$

9.00E-02

$1.03 \mathrm{E}-03$

$2.35 \mathrm{E}-05$

5. $26 E+00$

$2.35 E-06$
$9.00 E-02$

$9.00 E-02$

2. 35E-05

4. $92 \mathrm{E}-02$

$2.45 E-04$

$9.00 E-02$

1. $03 \mathrm{E}-03$

2. 35E-05

4.92E-02 2.63E-14

$2.45 E-04$

$9.00 E-02$

$1.03 E-03$

$2.35 E-05$

$7.45 \mathrm{E}-02 \quad 2.60 \mathrm{E}-14$ 
REPAIRN EPVNTINT

213) 9 EN512HW 9XVVI $9 \mathrm{HW}$ IGNITION REPAIRN EDVNTINT

214) BHOUSE04 BPRPVIHW* BPRPV2HW IGNITION REPAIRN EPVATINT

2151 IGNITION NPR245HW NVPVPAHW REPAIRN EPVNTINT

216) BAZO21HWBHOUSE O4 BXVVIIPGA
IGNITION IGNITION REPAIRN EPVNTINT

2171 BA2O21 HW BHOUSEO4 8XVHV4PGA IGNITION REPAIRN EPVNTINT

2iB) 8 AZO22HWA 8 HOUSEO4 BXVV1 OPG. IGNITION EPVNTINT

9) EAZO22HWA 8HCUSEO4 8XVHV 3PG IGNITION REPAIRN EPVNTINT

220) 8FC112HW 8 HOUSEO 4 8XVV1 9HW IGNITION
PROBABIITY OF NOT FERFORMING A SIMPLE REPAIR PROCEDURE

OPERATOR FAIIS TO AIIGN OR START EMERGENCY PURGE VENT EQUIP OR HAF TANK 9 EXHAUST FAN Y 349-52-12 FAILS TO RUN DUE TO MECHANICAL EAUI MANUAI VALVE T49-HVI 9 FAILS TO OPEN ON DEMAND

CONDITIONAL PROBABILITY OF HAVING AN IGNITION SOURCE PRESENT PROBABILITY OF NOT PEREORMING A SIMPLE REPAIR PROCEDURE

OPERATOR FAILS TO ALIGN OR START EMERGENCY PURGE VENT EQUIP OR HAR CONDITIONAL PROBABILITY OE BEING IN NORMAL PROCESSING MODE $140 \mathrm{C}$ MECHANICAL FAULTS OE TANK 48 PRESSURE REGULATING VALVE 1205PV1 MECHANICAL FAULTS OF TANK 48 PRESSURE REGULATING VALVE 1205 PV 2 CONDITIONAL PROBABILITY OF HAVING AN IGNITION SOURCE PRESENT PROBABILITY OF NOT PERFORMING A SIMPLE REPAIR PROCEDURE OEERATOR FAILS TO ALIGN OR START EMERGENCY PURGE VENT EQUIP OR HAR CONDITIONAL PROBABILITY OF HAVING AN IGNITION SOURCE PRESENT PRESSURE REGULATING VALVE 2045 PV EAILS

FAILURE OF VAPORIZER A DUE TO HARDWARE FAULTS

PROCEDURE

PROBABILITY OE NOT PEREORMING A SIMPLE REPAIR PROCEDURE

OPERATOR FAILS TO ALIGN OR START EMERGENCY PURGE VENT EQUIP OR HAR TANK 48 O2 ANALYZER I HARDWRE FAULTS

CONDITIONAL PROBABILITY OF BEING IN NORMAI PROCESSING MODE $140 \mathrm{C}$ CONDI IONAL PROBABILITY OF BEING IN NORMAL PROCESSI

CONDITIONAI PROBABIIITY OF HAVING AN IGNITION SOURCE PRESENT PROBABINTY NOT PERFORMING A SIMPLE REPAIR PROCEDURE

OPERATOR FAIIS TO ALIGN OR START EMERGENCY PURGE VENT EQUIP OR HAR MANK 48 O2 ANALYZER I HARDWARE EAULTS

CONDITIONAL PROBABILITY OF BEING IN NORMAL PROCESSING MODE $140 \mathrm{C} \mathrm{I}$ MANUAI VAI PROBABILITY OF BEING IN NORMAL PROCESS

CONDITIONAI PROBABILITY OF HAVING AN IGNITION SOURCE PRESENT

PROBABILITY OE NOT PERFORMING A SIMPLE REPAIR PROCEDURE

OPERATOR FAILS TO AIIGN OR START EMERGENCY PURGE VENT EQUIP OR HAR TANK 48 O2 ANALYZER 2 HARDWARE FAULTS

CONDITIONAL PROBABILITY OF BEING IN NORMAL PROCESSING MODE $140 \mathrm{C}$ ? MANUAL VALVE T48-HVIO FAILS TO REMAIN OPEN (PLUG)

CONDITIONAL PROBABILITY OF HAVING AN IGNITION SOURCE PRESENT

PROBABILITY OF NOT PERFORMING A STMPLE REPAIR PROCEDURE

OPERATOR FAILS TO AIION OR START EMERGENCY PURGE VENT EQUIP OR HAR

TANK 48 O2 ANALYZER 2 HARDWARE FAULTS

CONDIO ONAL PROBABILITY OF GEING IN NORMAL PROCESSI

MANUAL VALVE T48-HVJ FAILS TO REMAN OPEN (PLUG)

CONDITIONAL PROBABILITY OF HAVING AN IGNITION SOURCE PRES

PROBABILITY OE NOT PEREORMING A SIMPLE REPAIR PROCEDURE

OPERATCR EAILS TO ALIGN OR SIART EMERGENCY PURGE

FLOW CONTROL VALVE 1211 PV2 MECHANICAL FAULT

CONDITIONAL PROBABILITY CF BEING IN NORMAL PROCESSING MODE $140 \mathrm{C}$ ?

MINUAL VALVE T48-HVI 9 FAILS OO OPEN ON DEMAND
CONDITICNAL PGCBABILITY OF HAVING AN IGNITION SOURCE PRESENT
8. $0 E-6$

1. $6 E-4$$$
1.03 E-3
$$$$
2.35 \Xi-5
$$

1

.09

$1.03 E-3$

$2.35 E-5$

$2.2 E-6$

2. $2 E-6$

2

.09

$1.09 \mathrm{E}-3$

2. $35 E-5$

.09

2.2E-6

$4.1 E-7$

1. $03 E-3$

2. 35E-5

$3.0 E-4$

$i^{60}$

1. $4 E-8$

09

1. $03 \mathrm{E}-3$

2. $35 E-5$

3. $O E-4$

2

$i^{60}$

09

i. $03 E-3$

$2.35 E-5$

$3.0 E-4$

.60

2

.09

1. $03 E-3$

2. $35 E-5$

$3.0 E-4$

.60

209

.09

$2.35 E-5$

.60

1.09
1. $03 E-03$

2. 35E-05

$.01 E-02 \quad 2.44 E-14$

1. $60 \mathrm{E}-04$

. $005-02$

$1.03 E-03$

2. $35 \mathrm{E}-05$

$6.00 E-01 \quad 1.86 E-14$

3. $85 E-02$

$3.70 E-04$

$9.00 \mathrm{E}-02$

$1.03 E-03$

9.00E-02 1.86E-14

$2.38 \mathrm{E}-03$

$3.59 \mathrm{E}-03$

1. $33 E-03$

$2.35 E-05$

$5.26 E+00$

2. 35E-06

$9.00 E-02$

9. $00 E-02$

$2.03 E-03$
$2.35 E-05$

5. $26 E+00,62 E-14$

$6.00 E-01$

2. $35 E-06$

$2.35 E-06$

1. $03 E-03$

2. $35 E-65$

4. $928-02$

$6.00 E-01$

$2.45 E-04$

$9.00 E-02$

$1.03 E-03$

2. $35 E-05$

4. $92 E-02 \quad 1.58 E-14$

$2.45 E-04$

$1.03 E-03$

$2.35 E-05$

$1.60 \mathrm{E}-04$

$9.00 E-02$ 
PROBABILITY OF NOT PERFORMING A SIMPLE REPAIR PROCEDURE

$1.03 E-3 \quad 1.03 E-03$ OPERATOR FAILS TO ALIGN OR START EMERGENCY PURGE VENT EQUIP OR HAR OPANA OR EAILUST TAN Y TANK 48 EXHAUST FAN Y348-52-8 FAILS TO RUN DUE TO MECHANICAL FAULT CONDITIONAL PROBABILITY OE BEING IN NORMAL PROCE

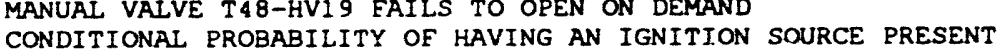
CONDITIONAL PROBABILITY OF HAVING AN IGNITION SOURCE PRESE

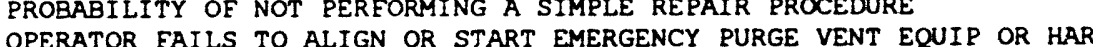
OPERATOR FAILS TO ALIGN OR START EMERGENCY PURGE VENT EQUIP

PRESSURE REGULATING VALVE $2046 \mathrm{PV}$ FAILS

MANUAL VALVE N47 FAILS TO OPEN ON DEMAND

PROBABIIITY OF NOT PEREORMING A SIMPLE REPAIR PROCEDURE

OPERATOR FAILS TO ALIGN OR START EMERGENCY PURGE VENT EQUIP OR HAR CONDITIONAL PROBABILITY OF HAVING AN IGNITION SOURCE PRESENT PRESSURE REGULATING VALVE 2046 PV FAILS

MANUAL VALVE N16 EAILS TO OPEN ON DEMAND

2. $35 E-5$

$1.03 E-03$

8.0E-6

PROBABILITY OF NOT PERFORMING A SIMPLE REPAIR PROCEDURE

$1.6 E-4$

109

$1.03 E-3 \quad 1.03 E-03$

$7.01 E-02$
$6.00 E-01$

$6.00 \mathrm{E}-01$

$1.60 \mathrm{E}-04$

$2.35=-5$ 2.35E-05

$2.35 \mathrm{E}-05$

6.72E-15

2. $2 \mathrm{E}-6$

1

$1.93 \mathrm{E}-02$

$1.60 \mathrm{E}-04$

$1.03 E-3 \quad 1.03 E-03$

2.35E-5 2.35E-05

$.09 \quad 9.00 \mathrm{E}-02$

$9.00 E-02$
$1.93 E-02$

$\begin{array}{lll}2.2 E-6 & 1 & 1.93 E-02 \\ 1.6 E-4 & 1 & 1.60 E-04 \\ & 1.03 E-3 & 1.03 E-03\end{array}$

$\begin{array}{ll}1.03 E-3 & 1.03 E-03 \\ 2.35 E-5 & 2.35 E-05\end{array}$

$\begin{array}{ll}.09 & 9.00 E-02 \\ 1 & 1.93 E-02\end{array}$

OPERATOR FAILS TO ALIGN OR START EMERGENCY PURGE VENT EQUIP OR HAR

PRESSURE REGULATING VALVE $2046 \mathrm{PV}$ FAILS

$\begin{array}{lll}2.2 E-6 & 1 & 1.93 E-02 \\ 1.6 E-4 & 1 & 1.60 E-04\end{array}$

$1.03 E-3 \quad 1.03 E-03$

$2.35 E-5 \quad 2.35 E-05$

PROBABILITY OF NOT PERFORMING A SIMPLE REPAIR PROCEDURE

OPERATOR EAILS TO ALIGN OR START EMERGENCY PURGE VENT EQUIP OR HAR

TANK 48 O2 ANALYZER 1 HARDWARE EAULTS

(70 C TEMP)

MANUAL VALVE T48-HVII EAILS TO REMAIN OPEN (PLUG)

$i^{2}$

$5.26 E+00$

$2.00 E-01$

$2.35 E-06$

2.

$\begin{array}{lll}\text { CONDITIONAL PROBABILITY OF HAVING AN IGNITION SOURCE PRESENT } & .09 & 9.00 E-02 \\ \text { PROBABILITY OE NOT PERFORMING A SIMPLE REPAIR PROCEDURE } & 1.03 E-3 & 1.03 E-03\end{array}$

OPERATOR FAILS TO ALIGN OR START EMERGENCY PURGE VENT EQUIP OR HAR TANK 48 O2 ANALYZER I HARDWARE EAULTS

3. $0 E-4$

CONDITIONAL PROBABILITY OF TRANSFERRING SALT SOLUTION $(70 \mathrm{C}$ TEMP)

MANUAL VALVE T48-HV4 FAILS TO REMAIN OPEN (PLUG)

$2.35 \Sigma-05$

$5.26 E+00 \quad 5.39 E-15$

$.2 \quad 2.00 E-01$

$7 \quad 2.35 E-06$

$.099 .00 E-02$

$1.03 E-3 \quad 1.03 E-03$

$2.35 E-5 \quad 2.35 E-05$

PROBABI?.ITY OF NOT PEREORMING A SIMPLE REPAIR PROCEDURE

TANK 48 O2 ANALYZER 1 HARDWARE FAULTS

CONDITIONAL PROBABILITY OF BEING IN WASH CYCLE

$5.26 E+00 \quad 5.39 E-15$

MANUAL VALVE T48-HV4 FAILS TO REMAIN OPEN (PLUG)

CONDITIONAL PROBABILITY OF HAVING AN IGNITION SOURCE PRESENT

PROBABITTY OE NOT PEREORMING A SIMPLE REPAIR PROCEDURE

OPERATOR FAILS TO ALIGN OR START EMERGENCY PURGE VENT EQUIP OR HAR

OPERATOR FAILS TO ALIGN OR START EMERGE

TANK 48 O2 ANALYZER 1 HARDWARE EAULTS

CONDITIONAL PROBABILITY OF BEING IN WASH CYCLE

MANUAL VALVE T48-HVI1 FAILS TO REMAIN OPEN (PLUG)

CONDITIONAL PROBABILITY OF HAVING AN IGNITION SOURCE PRESENT
PROBABILITY OF NOT PERFORMING A SIMPLE REPAIR PROCEDURE

2.35E-06

$9.00 E-02$

$1.03 E-03$

$1.03 E-3 \quad 1.03 E-03$

$\begin{array}{ll}2.35 E-5 & 2.35 E-05 \\ 2 & 5.26 E+00 \\ 20 & 2.00 E-01\end{array}$

$\begin{array}{lll}1.4 \mathrm{E}-8 & i^{20} & 2.00 \mathrm{E}-01 \\ & .09 & 2.35 \mathrm{E}-06 \\ & 1.03 \mathrm{E}-3 & 9.00 \mathrm{E}-02 \\ & 1.03 \mathrm{E}-03\end{array}$

$\begin{array}{lll}1.4 \mathrm{E}-8 & 7 & 2.00 \mathrm{E}-01 \\ & .09 & 2.35 \mathrm{E}-06 \\ & 1.03 \mathrm{E}-3 & 9.00 \mathrm{E}-02 \\ & 1.03 \mathrm{E}-03\end{array}$

$\begin{array}{lll}1.4 \mathrm{E}-8 & 7 & 2.00 \mathrm{E}-01 \\ & .09 & 2.35 \mathrm{E}-06 \\ & 1.03 \mathrm{E}-3 & 9.00 \mathrm{E}-02 \\ & 1.03 \mathrm{E}-03\end{array}$ 


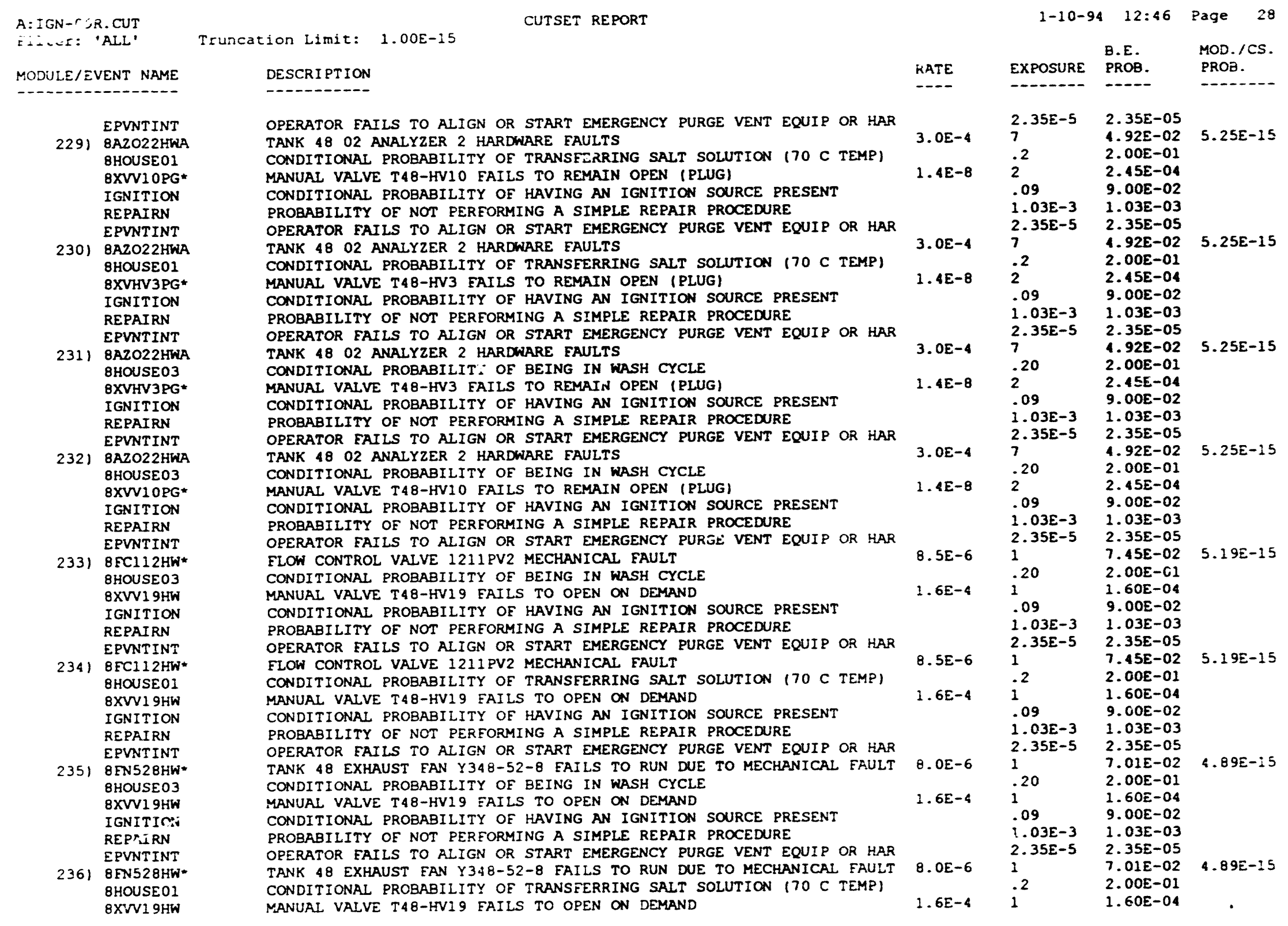


CONDITIONAL PROBABILITY OF HAVING AN IGNITION SOURCE PRESENT PROBABILITY OF NOT PERFORMING A SIMPLE REPAIR PROCEDURE OPERATOR FAILS TO ALIGN OR START EMERGENCY PURGE VENT EQUIP OR HAR OPERATOR FAILS TOL TANK 9 PLTH A INLET VALVE T49-N19 FAILS TO REMAIN OPEN (PLUG) CONK 49 PATH A INLET VAV OE TAVING AN IGNITION SOURCE PRESENT PROBABILITY OF NOT PERFORMING A SIMPLE REPAIR PROCEDURE OPERATOR FAIIS TO ALIGN OR START EMERGENCY PURGE VENT EQUIP OR HAR OPERATOR EAILS TO ALIGN OR START EMERGENCY PURGE VENT EQUTP OR HAR TANK 49 FLOW CONTROL VALVE 1252FV UNAVAILABLE DUE TO MAINTENANCE TANK 49 PATH A DISCHARGE VALVE TA

CONDITIONAL PROBABILITY OE HAVING AN IGNITION SOURCE PRESE

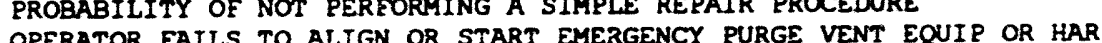
OPERATOR FAILS TO ALIGN OR START EMERGENCY PURGE VENT EQUIP OR HAR TANK 49 PRESSURE REGULATING VALVE 1255PV2 UNAVAILABLE DUE TO MAIN TANK 49 PATH A INLET VALVE T49-N19 FAILS TO REMAIN OPEN (PLUG) CONDITIONAL PROBABILITY OF HAVING AN IGNITION SOURCE PRESENT PROBABILITY OE NOT PERFORMING A SIMPLE REPAIR PROCEDURE OPERATOR FAILS TO ALIGN OR START EMERGENCY PURGE VENT EQUIP OR HAR TANK 49 PRESSURE REGULATING VALVE 1255PV2 UNAVAILABLE DUE TO MAINT TANK 49 PATH A DISCHARGE VALVE T49-N16 FAILS TO REMAIN OPEN (PLUG) CONDITIONAI PROBABILITY OF HAVING AN IGNITION SOURCE PRESENT

PROBABILITY OF NOT PERFORMING A SIMPLE REPAIR PROCEDURE

OPERATOR FAILS TO ALIGN OR START EMERGENCY PURGE VENT EQUIP OR HAR FLOW CONTROL VALVE 1251 PVI MECHANICAL FAULT

MANUAL VALVE T49-HV20 FAILS TO REMAIN OPEN (PLUG)

CONDITIONAI PROBABILITY OF HAVING AN IGNITION SOURCE PRESENT

CONDITIONAL PROBAB PITY OEMTA A SIMPLE REPAIR PROCEOURE

PROBATLITY OF NOT PER OPERATOR. FAILS TO 1251 PVI MECHANICAL FAULT

MANUAL VALVE T49-HV22 FAILS TO REMAIN OPEN (PLUG)

$099.00 E-C 2$

$1.03 E-3 \quad 1.03 E-0.3$

$2.35 E-5 \quad 2.35 E-05$

$3.6 \varepsilon-3$

$7.20 E-03$ 3.8SE-15

$1.03 E-3 \quad 1.03 E-03$

2. 35E-5 2.35E-05

$2.35 E-5$

3. $6 E-3$

2

09

1. $03 E-3$

2. $35 E-5$

$6 E-3$

$1.4 E-8$

2

$.0999 .00 E-02$

$7.20 E-03$

$2.45 E-04$

9. $00 E-02$

$1.03 E-03$

$2.35 E-05$
$7.20 E-03$

$7.20 E-03$

$1.03 E-3 \quad 1.03 E-03$

$2.35 E-5 \quad 2.35 E-05$

$1.4 E-8$

REPAIRN

41) 9FC511HW

IGNITION

REPAIRN

EPVNTINT

242) 9FC511HW

9XVV22PG*

REPAIRN

EPVNTINT

243) 8FC122TM

8HOUSE04

EXVN22PG.

IGNITION

REPAIRN

EPVNTINT

244) 8FC122TM

BHOUSEO4

$8 X V N 24 P G$ *

IGNITION

REPAIRN

CONDIL

CONDITIONAL PROBABILITY OF HAVING AN IGN REAR PROCEDURE

OPERATOR FAII.S TO ALIGN OR STAR'T EMERGENCY PUKGE VENT EYUII' UW HAT

TANK 48 FLOW CONTROL VALVE 1202 FV UNAVAILABLE DUE TO MAINTENANCE

CONDITIONAI PROBABILITY OF BEING IN NORMAL PROCESSING MODE $140 \mathrm{C}$ I

TANK 48 PATH A INLET MANUAL VALVE T48-N22 FAILS TO REMAIN OEEN 1 1.4E-

CONDITIONAL PROBABILITY OF HAVING AN IGNITION SOURCE PRESENT

PROBABILITY OE NOT PERFORMING A SIMPLE REPAIR PROCEDURE

OPERATOR FAILS TO ALIGN OR START EMERGENCY PURGE VENT EQUIP OR HAR

TANK 48 ELOW CONTROL VALVE $1202 \mathrm{FV}$ UNAVAILABLE DUE TO MAINTENANCE

CONDITIONAL PROBABILITY OF BEING IN NORMAL PROCESSING MODE $140 \mathrm{CT}$

TANK 48 PATH A DISCHARGE VALVE T48-N24 FAILS TO REMAIN OPEN (PLUG)

CONDITIONAI PROBABILITY OF HAVING AN IGNITION SOURCE PRESENT

PROBABILITY OF NOT PERFORMING A SIMPLE REPAIR PROCEDURE

OPERATOR FAIIS TO ALIGN OR START EMERGENCY PURGE VENT EQUIP OR HAR

CONDITIONAL PROBABILITY OF BEING IN NORMAL PROCESSING MODE $140 \mathrm{C} \mathrm{T}$

$1.23 E-04$

$9.00 \mathrm{E}-02$

$1.03 E-3 \quad 1.03 E-03$

$2.35 E-5 \quad 2.35 E-05$

$8.5 E-6 \quad 3 \quad 9.18 E-03$

$109 \quad 1.23 E-04$

$1.03 E-3 \quad 3.03 E-03$

$1.03 E-3$ 1.03E-OS

$2.35 E-5$

2. $1 \mathrm{SE}-0 \mathrm{~S}$

$.20 E-03 \quad 2.31:=-15$

$2.45 E-04$

$1.03 E-3 \quad 1.03 E-03$

$2.35 E-5 \quad 2.35 E-05$

$27.20 \mathrm{E}-03$

.60 6.00E-01

$09 \quad 2.45 E-04$

$1.03 E-3 \quad 1.03 E-03$

2. 35E-5 2. $35 E-05$

$.60 \quad 6.00 E-01 \quad 2.31 E-15$ 


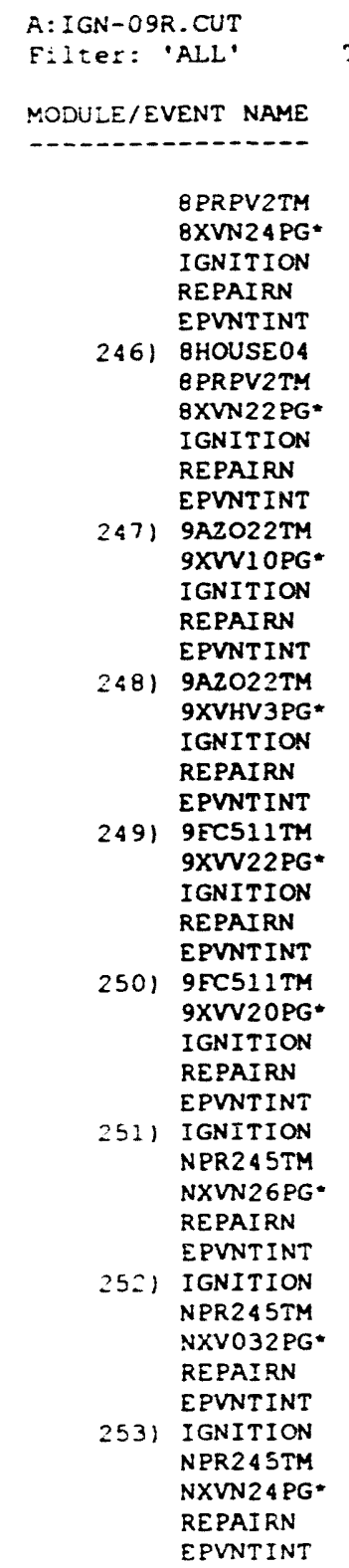

Truncation Limit: $1.00 \mathrm{E}-15$

TANK 48 PRESSURE REGULATING VALVE 1205 PV2 UNAVAILABLE DUE TO MAINT $3.6 E-3$ TANK 48 PATH A DISCHARGE VALVE T48-N24 EAILS TO REMAIN OPEN (PLUG) 1.4E-8 CONDITIONAL PROBABILITY OF HAVING AN IGNITION SOURCE PRESENT PRDIIONAL PROBABILITY OE HAV A SIMPIE REPAIR PROCEIIRE

OPEPATOR I OF NO! PERF OR START EMERGENCY PURGE VENT EOUIP OR HAR CONDITR FAILS TO ALIGN OR START EMERGENCY PROCESSING MODE $140 \mathrm{C} \mathrm{T}$ CONDITIONAL PROBABILITY OF BEING IN NORYAL PROCESSING MODE $140 \mathrm{C} T$ TANK 48 PRESSURE REGULATING VALVE $1205 P V 2$ UNAVAILABLE DUE TO MAINT $3.6 E-3$ TANK 48 PATH A INLET MANUAL VALVE TA8-N22 EAILS TO REMAIN CONDITIONAI PROBABILITY OF HAVING AN IGNITION SOURCE PRESEN PROBABILITY OF NOT PERFORMING A SIMPLE REPAIR PROCEDURE OPERATOR FAILS TO ALIGN OR START EMERGENCY PURGE VENT EQUIP OR HAR TANK 49 O2 ANALYZER 2 UNAVAILABLE DUE TO MAINTENANCE MANUAL VALVE T49-HVIO FAILS TO REMAIN OPEN (PLUG) CONDITIONAL PROBABILITY OE HAVING AN IGNITION SOURCE PRESENT PROBABILITY OF NOT PERFORMING A SIMPLE REPAIR PROCEDURE OPERATOR FAILS TO ALIGN OR START EMERGENCY PURGE VENT EQUIP OR HAR TANK 49 O2 ANALYZER 2 UNAVAILABLE DUE TO MAINTENANCE

MANUAL VALVE T49-HV3 EAILS TO REMAIN OPEN (PLUG)

CONDITIONAL PROBABILITY OF HAVING AN IGNITION SOURCE PRESENT PROBADIITY OE NOT PERFORMING A SIMPLE REPAIR PROCEDURE OREATOR FAILS TO ALIGN OR START EMERGENCY PURGE VENT EQUIP OR HAR OPERATOR FAILS TO ALIGN OR START EMERGEN

FLOW CONTROL VALVE 1251 PVI MAINTENANCE

2 2

$7.20 E-03$ $2.45 E-04$ $09 \quad 9.00 E-02$

1. $03 E-3$ 1.03E-03

2. $35 E-5 \quad 2.35 E-05$

$.60 \quad 6.00 E-01$

$27.20 E-03$

$209 \quad 2.45 E-04$

$.0938-3.002-02$

$1.03 E-3 \quad 1.03 E-03$

$2.35 E-5 \quad 2.35 E-05$

$1.8 E-3$ 2

$09 \quad 9.00 \mathrm{E}-02$

.60E-03 $1.92 E-15$

$1.03 E-3 \quad 1.03 E-03$

$2.35 E-5 \quad 2.35 E-05$

$3.60 E-03 \quad 1.92 E-15$

$1.8 E-3 \quad 2$

09

$2.45 E-04$

$9.00 E-02$

$1.03 E-3 \quad 1.03 E-03$

$2.35 E-5 \quad 2.35 E-05$

$7.20 \mathrm{E}-03 \quad 1.92 \mathrm{E}-15$

MANUAL VALVE T49-HV22 EAILS TO REMAIN OPEN (PLUG)

CONDITIONAL PROBABILITY OF HAVING AN IGNITION SOURCE PRES

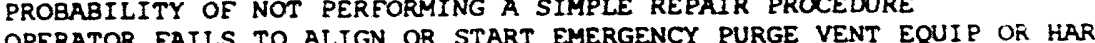

ELOW CONTROL VALVE 1251 PV1 MAINTENANCE

MANUAL VALVE T49-HV20 FAILS TO REMAIN OPEN (PLUG)

$.6 E-3$

$1.6 E-3$

109

$09 \quad 9.00 E-02$

$1.03 E-3 \quad 1.03 E-03$

2.35E-5 $2.35 E-05$

$3.6 E-3$

CONDITIONAL PROBABILITY OE HAVING AN IGNITION SOURCE PRESENT

PROBRBILITY OF NOT PERFORMING A SIMPLE REPAIR PROCEDURE

OPERATOR FAILS TO AI.IGN OR START EMERGENCY PURGE VENT EQUIP OR HAR CONDITIONAL PROBABILITY OF HAVING AN IGNITION SOURCE PRESENT

PRESSURE REGULATING VALVE 2045PV MAINTENANCE

MANUAL VALVE N26 FAILS TO REMAIN OPEN (PLUG)

PROBABILITY OF NOT PERFORMING A SIMPLE REPAIR PROCEDURE

$1.4 E-8$

$7.20 E-03$
$1.23 E-04$

$9.00 \mathrm{E}-02$

$1.03 E-3 \quad 1.03 E-03$

$2.35 E-5 \quad 2.35 E-05$

$09 \quad 9.00 E-02$

$7.20 E-03$

$1.23 E-04$

$1.03 E-3 \quad 1.03 E-03$

$2.35 E-5 \quad 2.35 E-05$

$\begin{array}{llll}\text { CONDITIONAL PROBABILITY OF HAVING AN IGNITION SOURCE PRESENT } & .09 & 9.00 E-02 \\ \text { PRESSURE REGULATING VALVE 2045PV MAINTENANCE } & 3.6 E-3 & 2 & 7.20 E-03 \\ \end{array}$

$\begin{array}{llll}\text { CONDITIONAL PROBABILITY OF HAVING AN IGNITION SOURCE PRESENT } & .09 & 9.00 E-02 \\ \text { PRESSURE REGULATING VALVE 2045PV MAINTENANCE } & 3.6 E-3 & 2 & 7.20 E-03 \\ \end{array}$

PRESSURE REGULATING VALVE 2045PV MAINTENANCE

$1.4 E-8$

PRUA VALV NO2 FAIS TORMING A SIMPLE REPAIR PROCEDURE

$1.03 E-03$

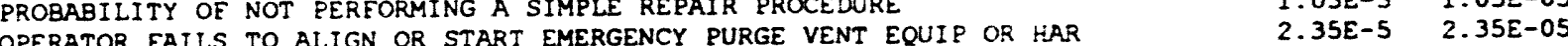

CONDITIONAI PROBABILITY OF HAVING AN IONITION SOURCE PRESENT

PRESSURE REGULATING VALVE 2045 PV MAINTENANCE

$9.00 E-02$
$7.20 E-03$

$3.6 E-3$

PATH A INLET VALVE N24 FAILS TO REMAIN OPEN (PLUG)

1. $4 E-8$

.09

$1.03 E-3 \quad 1.23 E-04$

..03E- $1.03 E-03$ 


\section{MODULE/EVENT NAME}

254) IGNITION NPR2 245TM NXVN46PG* REPAIRN EPVNTINT

255) IGNITION NPR2 45TM NXVN2OPG RERAIRN

256) 8 EC111HW 8 HOUSE04 8XVV22PG* IGNITION REPAIRN

57) BEC111HW 8HOUSE04 8XVV20PG* IGNITION REPAIRN EPVNTINT

258) IGNITION NVPVPAHW* NXVN15HW REPAIRN EPVNTINT

259) IGNITION NVPVPAHW* NXVN16HW NXVN16HW EPVNTINT

60) IGNITION NVPVPAHW* NXVN47HW REPAIRN EPVNTINT

261) 8A2022TM 8 HOUSE 04 8XVHV3PG* IGNITION REPAIRN EPVNTINT

262) 8A2O22TM BHOUSE 04 8XVV1OPG*
Truncation Limit: $1.00 \mathrm{E}-\mathrm{is}$

\section{DESCRI PTION}

CONDITIONAL PROBABILITY OF HAVING AN IGNITION SOURCE PRESENT PRESSURE REGULATING VALVE 2045PV MAINTENANCE

MANUAL VALVE N46 EAILS TO REMAIN OPEN (PLUG)

PROBABILITY OE NOT PERFORMING A SIMPLE REPAIR PROCEDURE

OPERATOR FAILS TO ALIGN OR START EMERGENCY PURGE VENT EQUIP OR HAR CONDITIONAL PROBABILITY OF HAVING AN IGNITION SOURCE PRESENT

PRESSURE REGULATING VALVE 2045PV MAINTENANCE

PATH A OUTLET VALVE N2O FAILS TO REMAIN OPEN (PLUG)

PROBABILITY OF NOT PERFORMING A SIMPLE REPAIR PROCEDURE

OPERATOR FAILS TO ALIGN OR START EMERGENCY PURGE VENT EQUIP OR HAR

FLON CONTROL VALVE 1211 PVI MECHANICAL FAULT (MODE $C$ I

MANUAL VALUE T48-HV22 EAILS TO REMAIN OPEN (PLUG)

MANUAL VALE T4BOHL

CONDITIONAL TROBABILITY OF HAVING AN IGNITION SOURCE PRES

PROBABILITY OF NOT PEREORMING A SIMPLE REPA PURGE VENT EOUIP OR HAR

OPERATOR EAILS TO ALIGN OR START EMERGENEY PURGE VENT EQUIP OR HAR

FLON CONTROL VALVE 1211PVI MECHANICAL ERMLT PROCESSING MODE $140 \mathrm{C} \mathrm{T}$

CONDITIONAL PROBABILITY OF BEING IN NORIRL PROCESSI

MANUAL VALVE T48-HV2O EAILS TO REMAIN OPEN (PLUG)

CONDITIONAL PROBABILITY OF HAVING AN IGNITION SOURCE PRESEN

PROBABILITY OF NOT PERFORMING A SIMPLE REPAIR PROCEDURE

AN IENTY PURGE VENT EQUIP OR HAR

CONDITIONAL PROBABILITY OF HAVING AN IGNITION SOURCE PRESENT

FAILURE OF VAPORIZER A DUE TO HARDWARE FAULTS

MANUAL VALVE N15 FAILS TO OPEN

PROBABILITY OF NOT PERFORMING A SIMPLE REPAIR PROCEDURE

OPERATOR FAILS TO ALIGN OR START EMERGENCY PURGE VENT EG 'JIP OR HAR CONDITIONAL PROBABILITY OF HAVING AN IGNITION SOURCE PRESENT

FAILURE OF VAPORIZER A DUE TO HARDWARE FAULTS

MANUAL VALVE N1 6 EAILS TO OPEN ON DEMAND

PROBABILITY OF NOT PERFORMING A SIMPLE REPAIR PROCEDURE

OPERATO FAIIS TO AIIGN OR START EMERGENCY PURGE VENT EOUIP OR HAR CPERATOK EAILS TO ALIGN OR HAVING AN IGNITION SOURCE PRESENT

CONDITIONAL PROBABILITY OF HAVING AN IENITION S

EAILURE OE VAPORIZER A DUE TO HARDWARE FAUL

PROPAOITY

PRERATIT TANK 48 O2 ANALYZER 2 UNAVAILABLE DUE TO MAINTENANCE

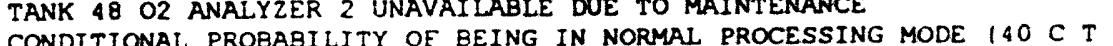

CONDITIONAL PROBABILITY OE BEING IN NORMAL PROCESSI

MANUAL VALVE T48-HV 3 FAILS TO REMAIN OPEN (PLUG)

CONDITIONAL PROBABILITY OE HAVING AN IGNITION SOURCE PRESE

OPERATOR FAILS TO ALICY OR START EMERGENCY PURGE VENT EQUIP OR HAR TANK 48 O2 ANALYZER 2 UNAVAILABLE DUE TO MAINTENANCE

CONDITIONAL PROBABILITY OF BEING IN NORMAL PROCESSING MODE $140 \mathrm{C} \mathrm{T}$ MANUAL VALVE T48-HVIO FAILS TO REMAIN OPEN (PLUG)
RATE

RATE

3. $6 E-3$
$1.4 E-8$

$\sqrt{3}$

$3.6 \mathrm{E}-3$

$1.4 E-8$

8. $5 E-$

1. $4 \mathrm{E}-8$

อ. 5E-6

1. $4 E-8$

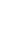

. $1 E-7$

1. $6 E-4$

$4.1 E-7$
$1.6 E-4$

4. $1 E-7$

4. $1 E-7$

(1)

$1.4 E-8$ . $8 E-3$

1. $4 E-8$
B.E.

EXPOSURE PROB.

09

2

$1.03 \mathrm{E}-3$

2. $35 \mathrm{E}-5$

.09

1. $03 E-3$

3

.60

1

1. $.09 \mathrm{E}-3$

2. $35 E-5$

3

$i^{.60}$

.09

$1.03 \mathrm{E}-3$

$2.35 E-5$

1

1

$1.03 E-3$

$2.35 E-5$

.09

1

$1.03 E-3$

2.35

1

1

$1.03 E-3$
$2.35 E-5$

60

2

.09

$1.03 E-3$
$2.35 E-5$

2

.60
$9.00 E-02$

$7.20 \mathrm{E}-03$

1. $23 E-04$

.

2. $35 E-05$

$9.00 E-02$
$7.20 E-03$

$1.23 E-04$

$1.03 E-03$

$2.35 E-05$

9.18E-03 1.47E-15

$6.00 \mathrm{E}-01$

$1.23 E-04$

$9.00 \mathrm{E}-02$

. $03 E-03$

2. 35E-05

$9.18 E-03$

6.00E-01

$1.23 E-04$

$9.00 E-02$

$1.03 E-03$

2. 35E-05

1.25E-15

.

$1.60 E-04$

$1.03 E-03$

$2.35 E-05$

$9.00 E-02$
$3.59 E-03$

$1.60 E-04$

$1.03 E-03$

2.35E-05

9.00E-02 $1.25 \mathrm{E}-15$

$3.59 E-03$

1. $60 \mathrm{E}-04$

$1.03 E-03$

$2.35 E-05$

3. $60 \mathrm{E}-03$
$6.00 \mathrm{E}-01$

6. $00 E-01$

$2.45 E-04$

$9.00 E-02$

1. $03 E-03$

2. $35 E-05$

3.60E-03 1.15E-15

$6.00 E-01$

$2.45 E-04$
D. /CS

. $92 E-15$

$.92 E-15$

$1.47 E-15$

$1.25 E-15$

$1.15 E-15$ 
$1-10-94$ 12:46 Page 32
B.E. MOD./CS.

MODULE./EVENT NAME DESCRI PTION

IGNITION REPAIRN EPVNTINT

263) 8EC111TM BHOUSE04 $8 X V V 22 P G$ * IGNITION REPAIRN EPVNTINT

264) 8FC111TM 8 HOUSEO4 $8 X V V 20 \mathrm{PG}^{\star}$ IGNITION REPAIRN

265) 9fn511tm 9xvv22pg* ignition repairn

266) 9 fn511tm $9 \times v v 20 p^{\star}$ * ignition repairn epvntint

267) 1gnition nvpvpbhw nxvn26pg repairn

268) ignition nvpvpbhw nxv032pg* repairn epvintint

2691 ignition nvpvpbhw
nxvn24pg* repairn

270) 1gnition nvpvpbhw nxvn20pg* repairn

$271)$ 1gnition
CONDITIONAL PROBABILITY OF HAVING AN IGNITION SOURCE PRESENT PROBABILITY OF NOT PERFORMING A SIMPLE REPAIR PROCEDURE PROBABILITY OE NOT PERT OR START EMERGENCY PURGE VENT EQUIP OR HAR OPERATOR EAILS TO ALIGN OR START EMERGENCY PURGE VENT EQUIP OR HAR ELOW CONTROL VALVE 1211 PVI MATNTENANCE

NORAL PROCESSING MODE $140 \mathrm{C} \mathrm{T}$ MANUAL VALVE T48-HV22 FAILS TO REMAIN OPEN (PLUG)

CONDITIONAL PROBABILITY OE HAVING AN IGNITION SOURCE PRESENT PROBABILITY OF NOT PERFORMING A SIMPLE REPAIR PROCEDURE OPERATOR FAILS TO ALIGN OR START EMERGENCY PURGE VENT EQUIP OR HAR FLOW CONTROL VALVE 1211 PVI MAINTENANCE

CONDITIONAL PROBABILITY OE BEING IN NORMAL PROCESSING MODE $140 \mathrm{C} \mathrm{T}$ MANUAL VALVE T48-HV20 FAILS TO REMAIN OPEN (PLUG)

CONDITIONAL PROBABILITY OF HAVING AN IGNITION SOURCE PRESENT

PROBABILITY OF NOT PERFORMING A SIMPLE REPAIR PROCEDURE.

OPERATOR FAILS TO ALIGN OR START EMERGENCY PURGE VENT EQUIR OR HAR TANK 49 EXHAUST FAN Y349-52-11 UNAVAILABLE DUE TO MAINTENANCE

MANUAL VALVE T49-HV22 FAILS TO REMAIN OPEN (PLUG)

CONDITIONAI PROBABILITY OE HAVING AN IGNITION SOURCE PRESENT

PROBABIITY OF NOT PERFORMING A SIMPLE REPAIR PROCEDURE

OPERATOR OPERATOR FAILS TO AL TON ORT START EMERGECY DUR TO MAINTENANCE MANUAL VALVE T49-HV20 FAILS TO REMAIN OPEN (ZLUG)

MANUAL VALVE T4 -HV

CONDITIONAL PROBABILIT ORMING A SIMPLE REPAIR PROCEDURE

PROBABILITY OE NOT PERFORMING A SIMPLE REPAIR PROCEDURE

OPERATOR FAILS TO ALIGN OR START EMERGENCY PURGE VENT EQUIP OR

FAILURE OF VAPORIZER B DUE TO HARDWARE FAULTS

MANUAL VALVE N26 FAILS TO REMAIN OPEN (PLUG)

PROBABILITY OF NOT PERFORMING A SIMPLE REPAIR PROCEDURE

OPERATOR FAILS TO ALIGN OR START EMERGENCY PURGE VENT EQUIP OR HAR CONDITIONAL PROBABILITY OF HAVING AN IGNITION SOURCE PRESENT

FAILURE OF VAPORIZEK B DUE TO HARDWARE FAULTS

MANUAL VALVE N32 FAILS TO REMAIN OPEN (PLUG)

PROBABILITY OE NOT PERFORMING A SIMPLE REPAIR PROCEDURE

EAILURE OF VAPORIZER B DUE TO HARDWARE EAULTS

PATH A INLET VALVE N24 FAILS TO REMAIN OPEN (PLUG)

PATOBABIIITY OF NOT PERFORMING A SIMPLE REPAIR PROCEDURE

PROBABILITY OF NOT PERFORMING A SIMPLE REPAIR PROCEDURE

OPERATOR FAILS TO ALIGN OR START EMERGENCY PURGE VENT EQUIP OR HAR

EAILURE OF VAPORIZER B DUE TO HARDWARE FAULTS

PATH A OUTLET VALVE N20 FAILS TO REMAIN OPEN (PLUG)

PROBABILITY OF NOT PERFORMING A SIMPLE REPAIR PROCEDURE

OPERATOR FAILS TO ALIGN OR START EMERGENCY PURGE VENT EQUIP OR HAR CONDITIONAL PROBABILITY OF HAVING AN IGNITION SOURCE PRESENT
OPERATOR FAILS TO ALIGN OR START EMERGENCY PURGE VENT EOUIP OR HAR OPERATR FAT
KAT

EXTOSURE PROB.

PRo.....

$1.03 E-3 \quad 1.00 E-02$

$2.35 E-5 \quad 2.35 E-05$

$.6 \mathrm{E}-3 \quad 2 \quad 7.20 \mathrm{E}-03$

$60 \quad 6.00 \mathrm{E}-01$

$160 \quad 6.00 \mathrm{E}-01$

$.09 \quad 9.00 \mathrm{E}-02$

$1.03 \mathrm{E}-3 \quad 1.03 \mathrm{E}-03$

$3.6 \mathrm{E}-3 \quad 2 \quad 7.20 \mathrm{E}-03$

$.60 \quad 6.00 \mathrm{E}-01$

$1 \quad 1.23 E-04$

$.09 \quad 9.00 \mathrm{E}-02$

$1.03 E-3 \quad 1.03 E-03$

$2.35 \mathrm{E}-5 \quad 2.35 \mathrm{E}-05$

$2 \quad 3.60 \mathrm{E}-03$

$.09 \quad 9.00 \mathrm{E}-02$

1.03E-3 1.03E-03

2. $35 \mathrm{E}-5 \quad 2.35 \mathrm{E}-05$

$1.8 \mathrm{E}-3$

$1.4 E-8$

1

.09

$09 \quad 9.00 E-02$

$2.35 \mathrm{E}-5 \quad 2.35 \mathrm{E}-05$

$4.1 E-7$

1

1. $03 \mathrm{E}-3$

$1.03 E-3 \quad 1.03 E-03$

$2.35 E-5 \quad 2.35 E-05$

$.09 \quad 9.00 \mathrm{E}-02$

$1.03 E-3 \quad 1.23 E-04$

$i^{\circ} \quad 6.89 \mathrm{E}-05$

$1.03 E-3 \quad 1.23 E-04$

$1.03 E-3 \quad 1.03 E-03$

$\begin{array}{lll}2.35 \mathrm{E}-5 & 2.35 \mathrm{E}-05 & \\ .09 & 9.00 \mathrm{E}-02 & 1.84 \mathrm{E}-17\end{array}$
2.35E-5 2.35E-05

$1.03 \mathrm{E}-3 \quad 1.03 \mathrm{E}-03$

$9.00 \mathrm{E}-02$

$.09 \quad 9.00 \mathrm{E}-02$

. $1.03 E-3 \quad 1.03 E-03$

$2.35 E-5 \quad 2.35 E-05$
3. $60 \mathrm{E}-03$
$1.23 \mathrm{E}-04$

3. $60 \mathrm{E}-03 \quad 9.62 \mathrm{E}-16$

1. 23E-04

$6.89 E-05$

6. $89 \mathrm{E}-05$

1. $23 \mathrm{E}-04$

$6.89 \mathrm{E}-05$

$1.23 E-04$

$1.15 E-15$

$1.15 E-15$

$9.62 E-16$

$1.84 \mathrm{E}-17$

$1.84 E-17$

$1.84 E-17$

$1.84 E-17$ 
273) $8 \mathrm{fcl} 22 \mathrm{tm}$

8house01

8house01

$8 x v n 22 p g *$

Ignition

epvitint

274) $8 \mathrm{fcl} 22 \mathrm{tm}$ 8 house 03 $8 \times v n 24 \mathrm{pg} *$ Ignition repairn

275) $8 \mathrm{fc1} 22 \mathrm{tm}$ 8house01 $8 \times v n 24 \mathrm{pg}^{\star}$ ignition repairn epvntint

276) Bhouse01 8prpv2tm $8 \times \sin 24 \mathrm{pg}^{*}$ ignition repalin

277) Bhouse01 Bprpv2tm $8 \times v r 22 p^{*}$ ignition repairn epvitint

278) 8house03 8 prpv2tm $8 \times v n 24 p g *$ ignition repairn epvntint

FAILURE OF VAPORIZER B DUE TO HARDWARE FAULTS FAILURE OF VAPORT2ER B DUE TO HARDWARE EAULT PROBABILITY OF NOT PERFORMING A SIMPLE REPAIR PROCEDURE OPERATOR FAIIS TO ALIGN OR START EMERGENCY PURGE VENT EQUIP OR HAR OPANK 4 B ELILS TO ALIEN OR START EMERGENCY BURGE VENT EQUIP OR HAR TANK 48 FLOW CONTROL VALVE 1202FV UNAVAILABLE

CONDITIONAL PROBABILITY OF BEING IN WASH CYCLE CONDITIONAL PROBABILITY OF HAVING AN IGNITION SOURCE PRESENT PROBABILITY OF NOT PERFORMING A SIMPLE REPAIR PROCEDURE OPERATOR FAILS TO ALIGN OR START EMERGENCY PURGE VENT EQUIP OR HAR TANK 48 FLOW CONTROL VALVE 1202 EV UNAVAILABLE DUE TO MAINTENANCE CONDITIONAL PROBABILITY OF TRANSFERRING SALT SOLUTION $170 \mathrm{C}$ TEMP) TANK 48 PATH A INLET MANUAL VALVE T48-N22 FAILS TO REMAIN OPEN 1 CONDITIONAL PROBABILITY OE HAVING AN IGNITION SOURCE PRESENT

PROBABILITY OF NOT PERFORMING A SIMPLE REPAIR PROCEDURE

OPERATOR FAILS TO ALIGN OR START EMERGENCY PURGE VENT EQUIP OR HAR TANK 48 FLOW CONTROL VALVE $1202 F V$ UNAVAILABLE DUE TO MAINTENANCE

CONDITIONAI PROBABILITY OF BEING IN WASH CYCLE

TANK 48 PATH A DISCHARGE VALVE T48-N24 FAILS TO REMAIN OPEN (PLUG) CONDITIONAL PROBABILITY OF HAVING AN IGNITION SOURCE PRESENT

PROBABILITY OF NOT PEREORMING A SIMPLE REPAIR PROCEDURE

OPERATOR FAILS TO ALIGN OR START EMERGENCY PURGE VENT EQUIP OR HAR TANK 48 FLOW CONTROL VALVE $1202 \mathrm{FV}$ UNAVAILABLE DUE TO MAINTENANCE

TANK 48 FLOW CONTROL VAL

CONDITIONAL PROBABILITY OF TRANSERR CONDIT PATH A DISCHARGE VALVE T4

PROBABILITY OF NOT PER ORMING A SIMPLE REPAIR PROCEDURE

OPERATOR FAILS TO ALIGN OR START EMERGENCY PURGE VENT EQUIP OR HAR CONDITIONAL PROBABILITY OE TRANSFERRING SALT SOLUTION 170 C TEMP TANK 48 PRESSURE REGULATING VALVE 1205PV2 UNAVAILABLE DUE TO MAINT TANK 48 PATH A DISCHARGE VALVE T48-N24 FAILS TO REMAIN OPEN (PLUG) CONDITIONAL PROBABILITY OF HAVING AN IGNITION SOURCE PRESENT

PROBABILITY OE NOT PEREORMING A SIMPLE REPAIR PROCEDURE

OPERATOR FAIIS TO ALIGN OR START EMERGENCY PURGE VENT EQUIP OR HAR CONDITIONAL PROBABILITY OF TRANSEERRING SALT SOLUTION $170 \mathrm{C}$ TEMP)

TANK 48 PRESSURE REGULATING VALVE 1205 PV2 UNAVAILABLE DUE TO MAINT TANK 48 PATH A INLET MANUAL VALVE T48-N22 FAILS TO REMAIN OPEN CONDITIONAI PROBABILITY OE HAVING AN IGNITION SOURCE PRESENT CROIT OPERATOR EATLS TO ALIGN OR START EMERGENCY PURGE VENT EQUIP OR HAR OPERATOR EAILS TO ALIGN OR START EMERGENCY PURGE

CONDITIONAL PROBABILITY OF BEING IN WASH CYCLE

TANK 48 PRESSURE REGULATING VALVE 1205PV2 UNAVAILABLE DUE TO MAINT TANK 48 PATH A DISCHARGE VALVE T48-N24 FAILS TO REMAIN OPEN (PLUG CONDITIONAL PROBABILITY OF HAVING AN IGNITION SOURCE PRE

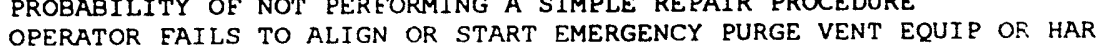

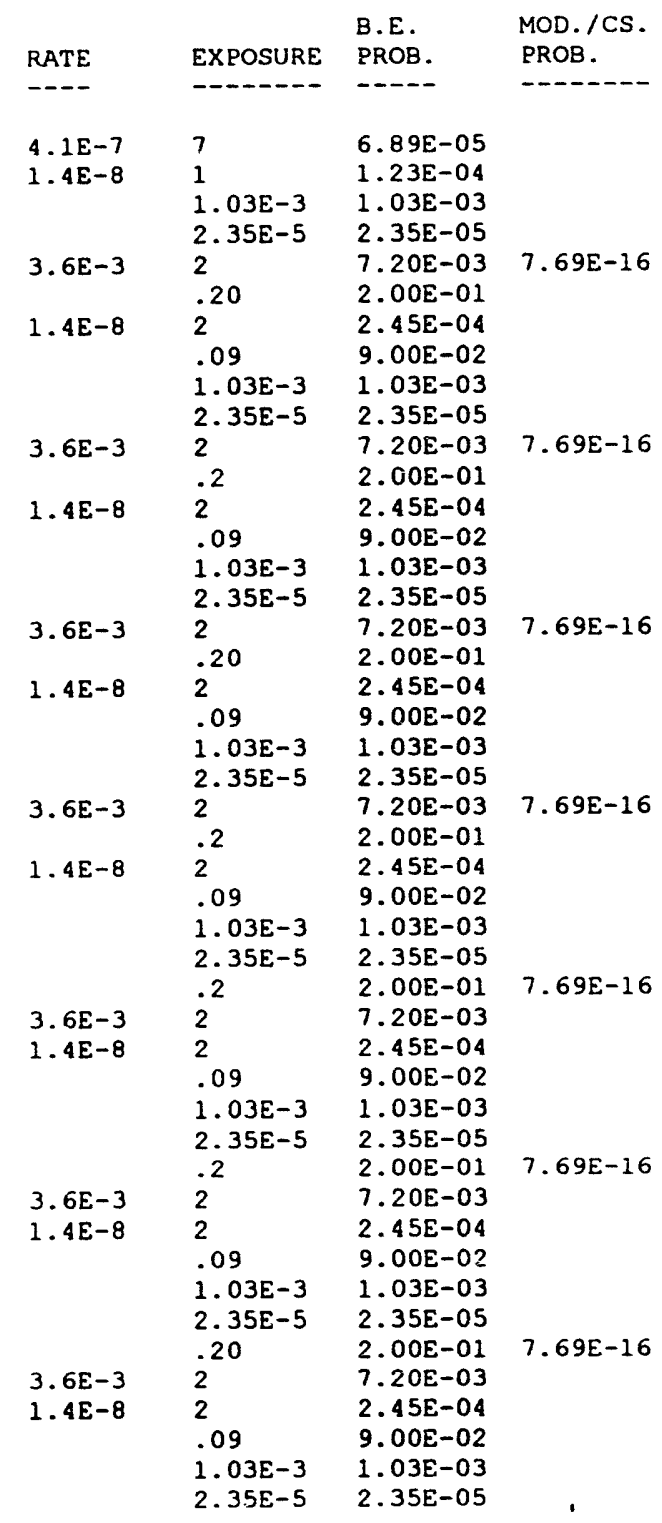









\section{MODULE/EVENT NAME}

288) ignition npr245hw nxvn4 6pg * repairn

289) $8 \mathrm{fn} 527 \mathrm{tm}$ 8 house 04 $8 \times v v 22 p{ }^{*}$ $8 \times \log 22 \mathrm{pg}^{*}$ ignition repairn

290) 8 fns27tm 8 house 04 Bxvv20pg* ignition repairn epvntint

291) 8fcllihw 8house 01 $8 x v v 22 p g *$ ignition repalirn epvitint

292) 8fclilhw 8house 01 $8 x v v 20 p{ }^{*}$ $8 x v 20 \mathrm{pg}$ ignition repairn

293) 8fclilhw 8house 03 $8 x v v 22 \mathrm{pg}$ * ignition repairn epvntint

294) 8fclllhw 8house 03 $8 \times v 20$ p * ignition repairn epvitint

295) $8 \mathrm{fc} 21 \mathrm{hw}^{*}$ 8 house 04 8house04 8xv8n5pg ignition
Truncation Limit: $1.00 \mathrm{E}-15$

\section{DESCRIPTION}

CONDITIONAL PROBABILITY OF HAVING AN IGNITION SOURCE PRESENT PRESSURE REGULATING VALVE 2045PV EAILS

MANUAL VALVE N46 EAILS TO REMAIN OPEN (PLUG)

PROBABILITY OF NOT PERFORMING A SIMPLE REPAIR PROCEDURE

OPERATOR FAILS TO ALIGN OR START EMERGENCY PURGE VENT EQUIP OR HAR

TANK 48 EXHAUST FAN Y348-52-7 UNAVAILABLE DUE TO MAINTENANCE

CONDITIONAL PROBABILITY OF BEING IN NORMAL PROCESSING MODE $140 \mathrm{C}$ ?

MANUAL VALVE T48-HV22 FAILS TO REMAIN OPEN (PLUG)

CONDITIONAL PROBABILITY OF HAVING AN IGNITION SOURCE PRESENT

PROBABILITY OF NOT PEREORMING A SIMPLE REPAIR PROCEDURE

OPERATOR EAILS TO ALIGN OR START EMERGENCY PURGE VENT EQUIP OR HAR

TANK 48 EXHAUST EAN Y348-52-7 UNAVAILABLE DUE TO MAINTENANCE

CONDITIONAL PROBABI ITY OF BEING IN NORMAL PROCESSING MODE $140 \mathrm{C} \mathrm{T}$

CANUAI VALVE T48-HV2O EAILS TO REMAIN OPEN (PLUG)

CONDITIONAL PROBABILITY OF HAVING AN IGNITION SOURCE PRESENT

PROBABILITY OF NOT PERFORMING A SIMPLE REPAIR PROCEDURE

OPERATOR FAILS TO ALIGN OR START EMERGENCY PURGE VENT EQUIP OR HAR

FLOW CONTROL VALVE 1211 PVI MECHANICAL FAULT (MODE C)

CON

CONDITIONAL PROBABILITY OE TRANSEERRING SALT (PIULU)

CONDITIONAL PROBABILITY OF HAVING AN IGNITION SOURCE PRESENT

PROBABILITY OF NOT PERFORMING A SIMPLE REPAIR PROCEDURE

OPERATOR FAILS TO ALIGN OR START EMERGENCY PURGE VENT EQUIP OR HAR

FLOW CONTROL VALVE 121IPVI MECHANICAL FAULT (MODE C)

CONDITIONAL PROBABILITY OF TRANSFERRING SALT SOLUTION $(70 \mathrm{C}$ TEMP)

MANUAL VALVE T48-HV20 EAILS TO REMAIN OPEN (PLUG)

CONDITIONAL PROBABILITY OF HAVING AN IGNITION SOURCE PRESENT

PROBABILITY OF NOT PERFORMING A SIMPLE REPAIR PROCEDURE

OPERATOR FAIIS TO ALIGN OR START EMERGENCY PURGE VENT EQUIP OR HAR

FLON CONTROL VALVE 1211 PVI MECHANICAL FAULT (MODE C)

CONDITIONAL PROBABILITY OF BEING IN WASH CYCLE

MANUAI VALVE T48-HV22 FAILS TO REMAIN OPEN (PLUG)

CONDITIONAL PROBABILITY OF HAVING AN IGNITION SOURCE PRESENT

CONDITIONAL PROBABILITY OE HAVING AN IGNITION SOURCE PRESE

ROBABILITY OE NOT PERFORMING A SIMPLE REPAIR PROCEDURE

PERATOR EAILS TO ALIGN OR START EMERGENCY PURGE VENT

LOW CONTROL VALVE 1211 PVI MECHANICAL EAULT IMODE

CONDITIONAL PROBABILITY OF BEING IN WASH CYCLE

MANUAL VALVE T48-HV2O FAILS TO REMAIN OPEN (PLUG)

CONDITIONAL PROBABILITY OF HAVING AN IGNITION SOURCE PRESENT

PROBABILITY OF NOT PERFORMING A SIMPLE REPAIR PROCEDURE

OPERATOR FAILS TO ALIGN OR START EMERGENCY PURGE VENT EQUIP OR HAR MECHANICAL FAULT OF TANK 48 FLOW CONTROL VALVE $1201 \mathrm{FV}$

CONDITIONAL PROBABILITY OE BEING IN NORMAL PROCESSING MODE $140 \mathrm{C}$

MANUAL VALVE T48-N5 EAILS TO REMAIN OPEN (PLUG)

CONDITIONAL PROBABILITY OF HAVING AN IGNITION SOURCE PRESENT

PROBABILITY OF NOT PERFORMING A SIMPLE REPAIR PROCEDURE
RATE

$2.2 E-6$
$1.4 E-8$

$1.8 \mathrm{E}-3$

1. $4 E-8$

$1.8 \mathrm{E}-3$

1. $4 \mathrm{E}-8$

20

8. $5 E-6$

1. $4 E-8$

8. $5 E-6$

$1.4 E-8$

8. $5 E-6$

$1.4 \mathrm{E}-8$

(2)

8. $5 E-6$

1. $4 \mathrm{E}-8$

8. $5 \mathrm{E}-6$

$1.4 E-8$
B.E.

EXPOSURE PROB MOD./CS.

$9.00 \mathrm{E}-02$

$2.38 \mathrm{E}-03$

$1.23 \mathrm{E}-04$

.03E-3 1.03E-03

2.35E-5 2.35E-05

$60 \quad 6.00 \mathrm{E}-01$

6. $00 \mathrm{E}-01$

$1.23 E-04$
$9.00 E-02$

$\begin{array}{ll}1.03 E-3 & 1.03 E-03 \\ 2.35 E-5 & 2.35 E-05\end{array}$

$35 E-5$

3. $60 \mathrm{E}-03$

6. $00 \mathrm{E}-01$

$1.23 E-04$

1.03E-3 $1.03 \mathrm{E}-03$

$2.35 E-5 \quad 2.35 E-05$

$2 \quad 9.18 \mathrm{E}-03$

$2.00 E-01$

$1.238-04$

$\begin{array}{ll}.09 & 9.00 \mathrm{E}-02 \\ 1.03 \mathrm{E}-3 & 1.03 \mathrm{E}-03\end{array}$

$2.35 E-5 \quad 2.35 E-05$

$9.18 E-03$
$2.00 E-01$

$2.00 E-01$
$1.23 E-04$

9.00E-02

$.03 E-3 \quad 1.03 E-03$

$2.35 \mathrm{E}-5 \quad 2.35 \mathrm{E}-05$

9.18E-03 4.91E-16

2. $00 \mathrm{E}-01$

1. $23 \mathrm{E}-04$

9.00E-02

$1.03 E-03$

$1.03 E-03$
$2.35 E-05$

9.18E-03 $4.91 E-16$

2. $00 \mathrm{E}-01$

2.00E-01

$1.23 E-04$

$\begin{array}{ll}.09 & 9.00 E-02 \\ 1.03 E-3 & 1.03 E-03\end{array}$

$2.35 E-5 \quad 2.35 E-05$

.60

7
.09

$1.49 \mathrm{E}-01$
$6.00 \mathrm{E}-01$

$6.00 E-01$
$2.35 E-06$

9.00E-02

$1.03 E-3 \quad 1.03 E-03$
$35 E-16$

5. $77 \mathrm{E}-16$

$5.77 E-16$

4. $91 E-16$

4. $91 E-16$

4. $58 E-16$

. 
$8 \times 18 n 8 p$

ignition

repairn

repairn

297) 8fc122hw

8house 04

8xvn22pg*

ignition

repairn

298) 8fcl22hw

8 house 04

$8 \times v n 24 p g *$

ignition

repairn

epvatint

299) 8azo22tm

8 house 03

ignition repairn

epvitint

300) 8azo22tm

Bhouse 01

8xvvlopg

ignition

repairn

$301) 8$ azo22tm

8 house 01

8xvhv3pg*

ignition repairn

epvntint

$302) 8 \mathrm{azo} 2 \mathrm{tm}$

8house 03

$8 \times$ vhv3pg*

Ignition

repairn

epvntint

303) $8 \mathrm{fcll1tm}$

8xvv20pg*

OPERATOR FAILS TO ALIGN OR START EMERGENCY PURGE VENT EQUIP OR HAR

MECRANI EAILS TO ALIGN OR START EMERGENCY PURGE VENT EQUIP OR HAR

MECHANICAL EAULT OF TANK 48 ELOW CONTROL VALVE 1201FV MODE $140 \mathrm{C} \mathrm{T}$

MANUAL VALVE T48-N8 FAILS TO REMAIN OPEN (PLUG)

PROBABILITY OF NOT PERFORMING A SIMPLE REPAIR PROCEDURE

OPERATOR FAILS TO ALIGN OR START EMERGENCY PURGE VENT EQUIP OR HAR MECHANICAL FAULT OF TANK 48 FLOW CONTROL VALVE 1202FV

CONDITIONAL PROBABILITY OF BEING IN NORMAL PROCESSING MODE $140 \mathrm{C} \mathrm{T}$

TANK 48 PATH A INIET MANUAL VALVE T48-N22 FAILS TO REMAIN OPEN

CONDITIONAI PROBABILITY OF HAVING AN IGNITION SOURCE PRESENT

PROBABILITY OF NOT PERFORMING A SIMPLE REPAIR PROCEDURE

OPERATOR EAILS TO ALIGN OR START EMERGENCY PURGE VENT EQUIP OR HAR MERANTCAL FAULT OF TANK 48 FLOW CONTROL VALVE 1202 FV

TANK 4 PATH A DISCHARGE VALVE T48-N24 EATLS TO REMATN OPEN (RLUG) TANK 48 PATH A DISCHARG VA HAVING AN IGNITION SOURCE PRESENT

CONDITIONAL PROBABILITY OF HAVING AN IGNITION SOURCE PRE

CROBABILITY OE NOT PERTORMING A SIMPLE REPAIR PROCEDTE

OPERATOR FAILS TO ALIGN OR START EMERGENCY PURGE VENT

TANK 48 O2 ANALYZER 2 UNAVAILABLE DUE TO MAINTEN

CONDITIONAL PROBABILITY OF BEING IN WASH CYCLE

MANUAL VALVE T48-HVIO FAILS TO REMAIN OPEN (PLUG)

CONDITIONAL PROBABILITY OF HAVING AN IGNITION SOURCE PRESE

OPERATOR FAILS TO ALIGN OR START EMERGENCY PURGE VENT EQUIP OR HAR TANK 48 O2 ANALYZER 2 UNAVAILABLE DUE TO MAINTENANCE

CONDITIONAL PROBABILITY OF TRANSFERRING SALT SOLUTION $170 \mathrm{C}$ TEMP MANUAI VALVE T48-HV10 FAILS TO REMAIN OPEN (PLUG)

CONDITIONAL PROBABILITY OF HAVING AN IGNITION SOURCE PRESENT

PROBABILITY OF NOT PERFORMING A SIMPLE REPAIR PROCEDURE

OPERATOR FAILS TO ALIGN OR START EMERGENCY PURGE VENT EQUIP OR HAR TANK 48 O2 ANALYZER 2 UNAVAILABLE DUE TO MAINTENANCE

CONDITIONAL PROBABILITY OF TRANSFERRING SALT SOLUTION $170 \mathrm{C}$ TEMP

MANUAI VALVE T48 HV3 FAILS TO REMAIN OPEN (PLUG)

MANUAL VALVE TAB-HV3 EAILS TOREMATN OPENTTON SOURCE PRESENT

CONDITIONAL PROBABILITY OE HAVING AN IGNITION SROCEDURE

PROBABILITY OF NOT PEREORMING A SIMPLE REPAIR PRECEDURE DUE TO MAINTENANCE

CONDI TONAI PROBABILITY OF BEING IN WASH CYCLE

CONDITIONAL PROBABILITY OF BEING IN WASH CYCLE

MANUAL VALVE T48-HV 3 EAILS TO REMAIN OPEN (PLUG)

CROBTIONAL PROBABILITY OF HAVING AN IGNITION SOURCE PRESE

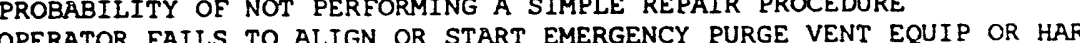
FLOW CONTROL VALVE 1211 PVI MAINTENANCE

CONCITIONAL PROBABILITY OF TRANSFERRING SALT SOLUTION $170 \mathrm{C}$ TEMP)

MANUAL VALVE T48-HV2O EAILS TO REMAIN OPEN (PLUG)

$8.5 E-6$

$2.35 \mathrm{E}-5 \quad 2.35 \mathrm{E}-05$

$1.49 \mathrm{E}-01$

$60 \quad 6.00 \mathrm{E}-01$

$090.35 \mathrm{E}-06$

.

$1.03 E-3 \quad 1.03 E-03$

$2.35 E-5 \quad 2.35 E-05$

2

09

$1.43 \mathrm{E}-03$

6.00E-01

2. $45 \mathrm{E}-0$

9.00E-02

$2.35 E-5 \quad 2.35 E-05$

$8.5 \mathrm{E}-6 \quad 7 \quad 1.43 \mathrm{E}-03$

6. $00 \mathrm{E}-01$

$2.45 \mathrm{E}-04$
$9.00 \mathrm{E}-02$

$.09 \quad 9.00 E-02$

2. $35 E-5$ - $2.35 E-05$

$2.35 E-5 \quad 2.35 E-05$

$20 \quad 3.60 \mathrm{E}-03$

$20 \quad 2.00 E-01$

$09 \quad 9.00 \mathrm{E}-02$

$1.03 \mathrm{E}-3 \quad 1.03 \mathrm{E}-03$

2.35E-5 2.35E-05

$\begin{array}{ll}2 & 3.60 \mathrm{E}-03 \\ 2 & 2.00 \mathrm{E}-01\end{array}$

$2 \quad 2.45 \mathrm{E}-04$

$.09 \quad 9.00 \mathrm{E}-02$

$1.03 E-3 \quad 1.03 E-03$

2. $35 \mathrm{E}-5 \quad 2.35 \mathrm{E}-05$

3. $60 \mathrm{E}-03$

2. $00 \mathrm{E}-01$

2 2.45E-04

$1.03 E-3 \quad 1.03 E-03$

2.35E-5 2.35E-05

$2.35 E-5 \quad 2.35 E-05$

$.20 \quad 2.00 \mathrm{E}-01$

$2 \quad 2.45 \mathrm{E}-04$

9.00E-02

$1.03 \mathrm{E}-3 \quad 1.03 \mathrm{E}-03$

$2.35 \mathrm{E}-5 \quad 2.35 \mathrm{E}-05$

$2 \quad 2.00 \mathrm{E}-01$

3. $85 E-16$

1.23E-04 
Truncation Limit: $1.00 \mathrm{E}-15$

\section{DESCRI PTION}

CONDITIONAL PROBABILITY OE HAVING AN IGNITION SOURCE PRESENT PROBABILITY OF NOT PERFORMING A SIMPLE REPAIR PROCEDURE

OPERATOR FAILS TO ALIGN OR START EMERGENCY PURGE VENT EQUIP OR HAR FLOW CONTROL VALVE 1211 PVI MAINTENANCE

CONDITIONAL PROBABILITY OF BEING IN WASH CYCLE

MANUAL VALVE T48-HV22 FAILS TO REMAIN OPEN (PLUG)

CONDITIONAL PROBABILITY OE HAVING AN IGNITION SOURCE PRESENT

PROBABILITY OF NOT PERFORMING A SIMPLE REPAIR PROCEDURE

OPERATOR FAILS TO ALIGN OR START EMERGENCY PURGE VENT EQUIP OR HAR FLOW CONTROL VALVE 1211PVI MAINTENANCE

CONDITIONAL PROBABILITY OF TRANSFERRING SALT SOLUTION (70 C TEMP)

MANUAL VALVE T48-HV22 FAILS TO REMAIN OPEN (PLUG)

CONDITIONAI PROBABILITY OF HAVING AN IGNITION SOURCE PRESENT

PROBABILITY OF NOT PEREORMING A SIMPLE REPAIR PROCEDURE

PRERATOR EAILS TO ALIGN OR START EMERGENCY PURGE VENT EOUIP OR HAR FLOW CONTROL VALVE 1211 PVI MAINTENANCE

CONDITIONAL PROBABILITY OF BEING IN WASH CYCLE

CONDITIONAL PROBABILITY OF BEING IN WASH CYCLE

CONDI

CROBABIIITY OF NOT PEREORMING A SIMPLE REPAIR PROCEDURE

PROBABILITY OE NOT PERFORMING A SIMPLE REPAIR PROCEDURE

FLOW CONTROL VALVE 1251 PV2 MECHANICAL FAULT

MANUAL VAIVE T49-HV21 FAILS TO REMAIN OPEN (PLUG)

CONDITIONAI

PROBABILITY OF NOT PERFORMING A SIMPLE REPAIR PROCEDURE

OPERATOR FAILS TO ALIGN OR START EMERGENCY PURGE VENT EQUIP OR HAR

TANK 49 EXHAUST FAN Y349-52-12 FAILS TO RUN DUE TO MECHANICAL FAUL

MANUAL VALVE T49-HV21 FAILS TO REMAIN OPEN (PLUG)

CONDITIONAL PROBABILITY OF HAVING AN IGNITION SOURCE PRESENT

PROBABILITY OF NOT PERFORMING A SIMPLE REPAIR PROCEDURE

OPERATOR FAILS TO ALIGN OR START EMERGENCY PURGE VENT EQUIP OR HAR

TANK 49 EXHAUST EAN Y349-52-11 FAILS TO RUN DUE TO MECHANICAL FAUI

MANUAL VALVE TT 9-HV22 FAILS TO REMAIN OL'EN (PLUG)

CONDITIONAI PROBABILITY OF HAVING AN IGNITION SOURCE PRESENT

PROBABILITY OF NOT PEREORMING A SIMPLE REPAIR PROCEDURE

OPERATOR FAILS TO ALIGN OR START EMERGENCY PURGE VENT EQUIP OR HAR

TANK 49 EXHAUST FAN Y349-52-11 FAILS TO RUN DUE TO MECHANICAL FAUL

MANUAL VALVE T49-HV2O FAILS TO REMAIN OPEN (PLUG)

CONDITIONAL PROBABILITY OE HAVING AN IGNITION SOURCE PRESENT

PROBABILITY OF NOT PEREORMING A SIMPLE REPAIR PROCEDURE

OPERATOR FAILS TO ALIGN OR START EMERGENCY PURGE VENT EQUIP OR HAR
B.E.

EXPOSJRE PROB.

.09

$2.35 \mathrm{E}-5$ 2.03E-0

$2.35 \mathrm{E}-5 \quad 2.35 \mathrm{E}-05$

$1.4 \mathrm{E}-8 \quad i^{20}$

$7.20 \mathrm{E}-03$
$2.00 \mathrm{E}-01$

$1.23 E-04$

$1.23 E-04$
$9.00 E-02$

$\begin{array}{ll}.09 & 9.00 E-02 \\ 1.03 E-3 & 1.03 E-03\end{array}$

$2.35 \mathrm{E}-5 \quad 2.35 \mathrm{E}-05$

$7.20 \mathrm{E}-03$

2. $00 \mathrm{E}-01$

$i^{2} \quad 1.23 \mathrm{E}-04$

$.09 \quad 9.00 \mathrm{E}-02$

1. $03 \mathrm{E}-3 \quad 1.03 \mathrm{E}-03$

2. 35E-5 2.35E-05

$2.35 \mathrm{E}-5$

3. $6 \mathrm{E}-3$

1. $4 \mathrm{E}-8$

109

$7.20 \mathrm{E}-03$

2.00E-01

$1.23 E-04$
$9.00 E-02$

$9.00 E-02$

$1.03 E-03$

2. $35 \mathrm{E}-5 \quad 2.35 \mathrm{E}-05$

$17.45 \mathrm{E}-02$

$09 \quad 0.00 \mathrm{E}-02$

$.03 E-3 \quad 1.03 E-03$

2.35E-5 2.35E-05

$17.01 \mathrm{E}-02$

2.35E-06

$.09 \quad Y .00 \mathrm{E}-02$

1.03E-3 1.03E-03

2. $35 E-5 \quad 2.35 E-05$

1. $34 \mathrm{E}-03$

1. $23 \mathrm{E}-04$

$09 \quad 9.00 E-02$

$\begin{array}{ll}1.03 E-3 & 1.03 E-03 \\ 2.35 E-5 & 2.35 E-05\end{array}$

$1.03 E-3 \quad 1.003 E-03$

$\begin{array}{ll}1.03 E-3 & 1.03 E-03 \\ 2.35 E-5 & 2.35 E-05\end{array}$
D. /CS.

PROB.

3. $85 E-16$

$3.85 E-16$

$3.85 E-16$

$3.82 E-16$

$3.59 E-16$

$3.59 E-16$

$3.59 E-16$ 


\section{APPENDIX C}

\section{FAULT TREES AND CUTSETS FOR EXTERNAL AND RECOVERY EVENTS -}

- (EXT100) Failure of Emergency Purge Ventilation Equipment (EPVE) to Start or Run (Page 1)

This fault tree models the failure to start or run of the EPVE. It is used in the event trees for: 1) severe winter storm, 2) seismic, high winds, 3) other (miscellaneous) external events and 4) recovery with internal events.

o BE File for External Events Fault Trees

This section contains an alphabetical listing of the basic events used in the external event fault trees.

o TC File for External Events Fault Trees

This section contains an alphabetical listing of the type code identifiers used in the external events fault trees.

o Cutsets for External Events Fault Tree (EXT100) - No Recoveries Applied

The external events fault tree was quantified and its cutsets are included in this Appendix. Recoveries have not been app'ied to these cutsets except those recoveries included in the calculation for the common cause events. 







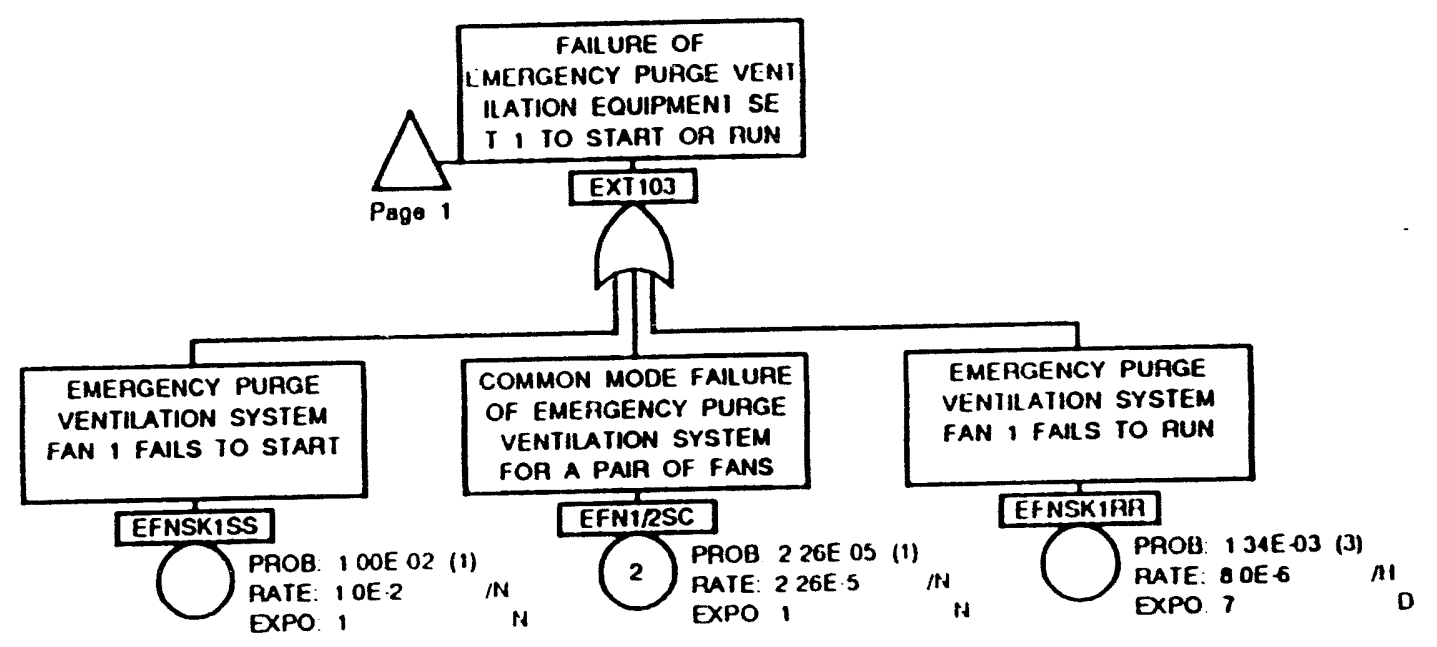

\begin{tabular}{|l|l|}
\hline IitLE \\
EXTERNAL EVENTS \\
RELATED FAULT. TREES \\
\hline oramng NuMBER \\
Page 2 & $7-15-93$ \\
\hline
\end{tabular}




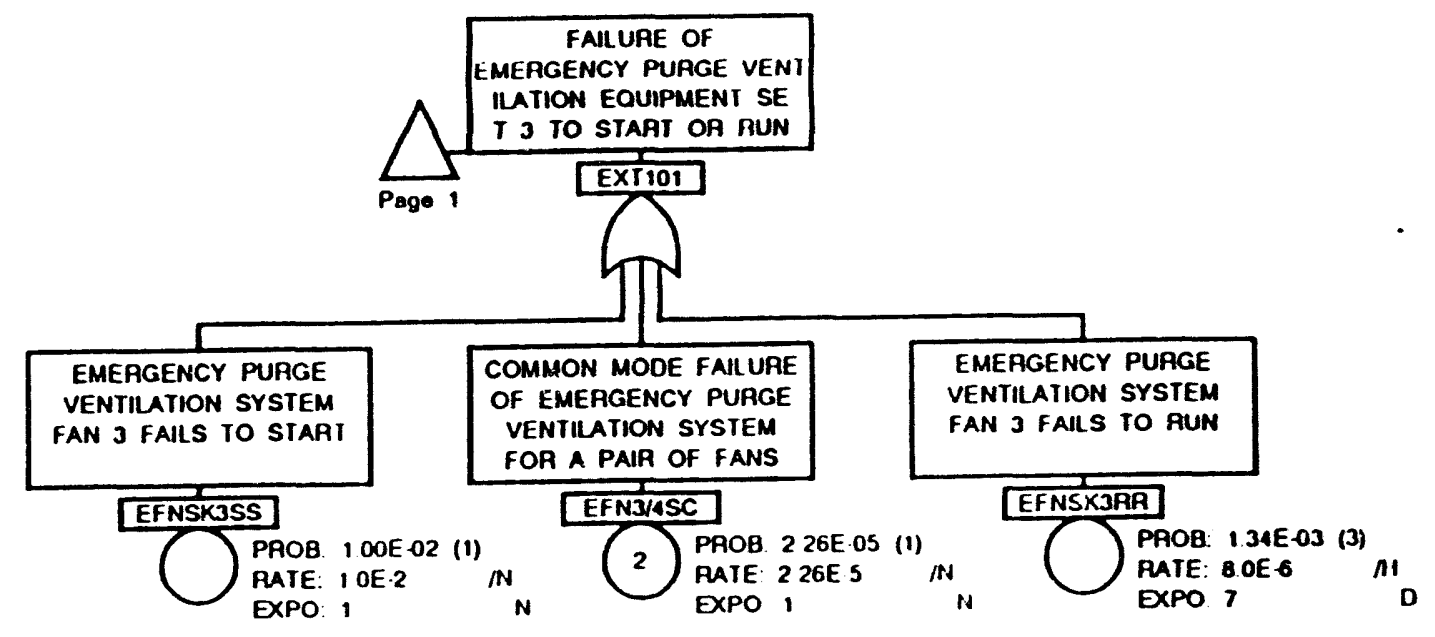

\begin{tabular}{|c|c|}
\hline \multicolumn{2}{|c|}{$\begin{array}{l}\text { IIILE } \\
\text { EXTERNAL EVENTS } \\
\text { RELATED FAULT TREES }\end{array}$} \\
\hline DPAWNG NUMGEA & \\
\hline Page 3 & $7-15-93$ \\
\hline
\end{tabular}




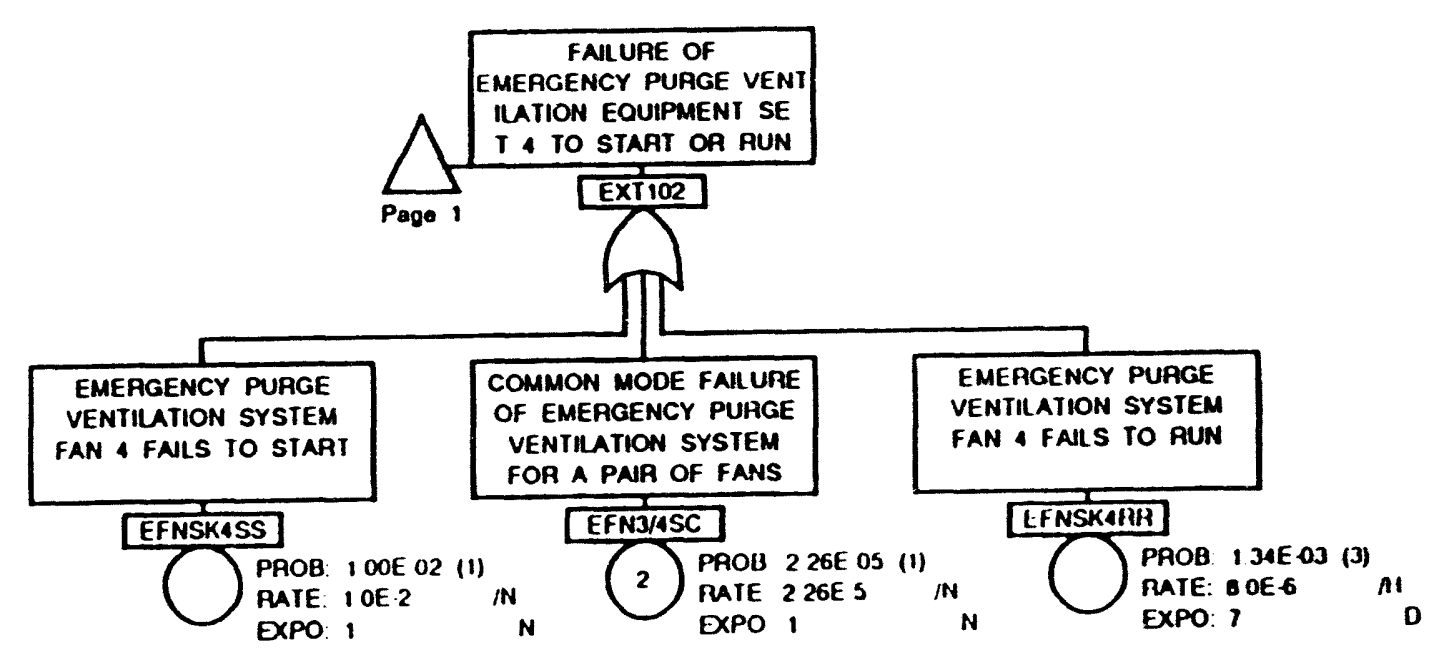

\begin{tabular}{|l|l|}
\hline "iine \\
EXTERNAL EVENTS \\
RELATED FAULT TREES \\
\hline mathing nUmulr"1 \\
Pąge 4 & $7-15-93$ \\
\hline
\end{tabular}




\section{BE FILE FOR EXTERNAL EVENT FAULT TREES}




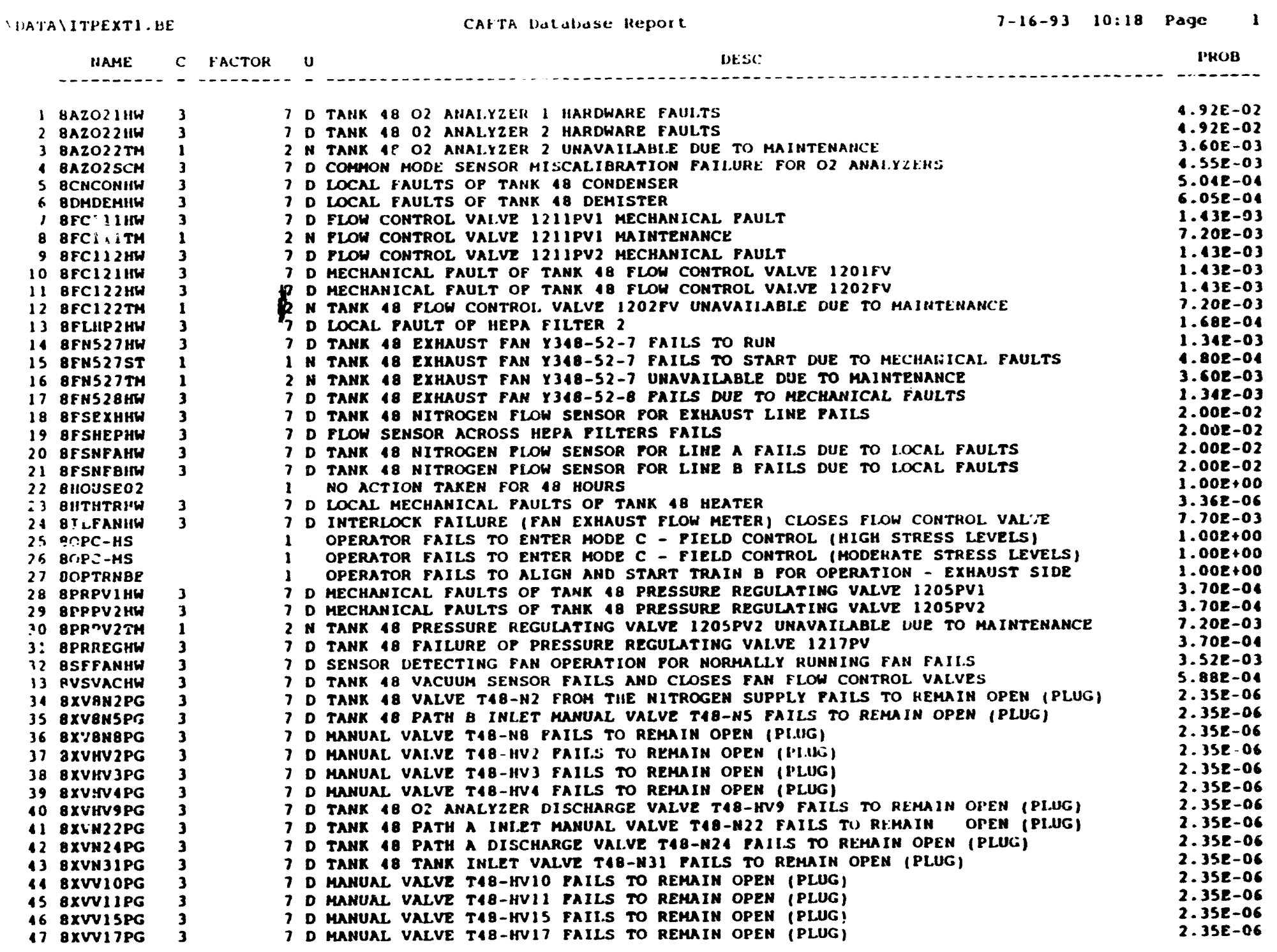


98 8XVV19HW 19 BYVV2OPC so $8 \times V V 21 P C$ $518 \times V 22 P G$ $528 \times 20214$ $549 A 2022 \mathrm{HL}$ SS $9 \times 2022 \mathrm{TM}$ 56 9A2O2SCM S7 9CNCONHH $5 Q$ 9 DMDEMHW 39 FC121 HW $609 \mathrm{FC} 122 \mathrm{HW}$ $619 F C 122 \pi$ 62 9FCS11 HW 63 98C511T4 64 9FCS12H 65 9FLHP2HW 66 9FNSIIHW 67 gFHSIIST 68 9ENS11TH 69 9FNS12 HW 70 9FSEXHНH i) 9 F EHEPHW

72 SESNFAHH 73 9FSNFBIIHB 74 HOUSEO2 75 YHTHTR:H 77 9OPC-HS 78 9DPC-MS 19 gOT TRN3E OO TPRPVIHA [.1 3PRPV2 HW 82 9PRIVITM 63 9PRREGHW 84 9SPFANHW 85 9VSVACHW 06 9XVHV2P 8: 9xเIN $3 P G$ 8 9XVIVPG 8 9xVIVPG 90 9xv1MPG 21 9xU1 92 93 9XVN16PG
N MANUAL VALVE T48-HVI9 FAILS TO OPEN ON DEMAND

D MANUAL VALVE T48-HV20 FAILS TO REMAIM OPEN (PLUG,

7 D MANUAL VALVE TAB-HV21 FAILS TO REMAM OPEM (PLUG)

D manual VALVe T18-hV22 FAILS TO REMAIN OPEN (PLLG)

D manual valve T48-HV33 patls to REMAin OPEN (PLUG)

7 D TANX 49 O2 ANALYZER 1 MARDWARE PAULTS

2 N TANK 49 O2 ANALYZER 2 UMAVAILABLE DUE TO MAINTEMANCE

7 D COMMON MODE SENSOR MISCALIBRATION FAILURE FOR OŹ ANAI.YZEKS

D LOCAL FAULTS OP TANK 19 CONDENSE

D LOCAL Faults OP TANK

7 D MEChan TCAL PAULT OF TANK 49 FLOW CONTROL VALVE 1251 FV

7 D mechancal FAuLt OF TAMK 49 FLOW CONTROL VALVE $1252 \mathrm{FV}$

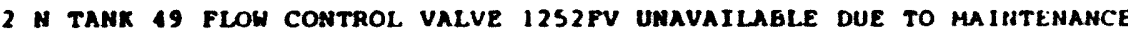

7 D Flow CONTROL VAlve 1251PV1 mechanical pault

MAINTEMANCE

7 D FLOH CONTROL Valve 1251PV2 mechantcal pault

7 D LOCAL FAULT OP TAMK 19 HEPA PILTER 2

7 D TANK 19 EXHAUST FAN Y349-52-11 PAILS TO RUH

1 N TANX 49 EXHAUST FAN Y349-52-11 PAILS TO START DUE tO MECHAHICAL PAULTS

2 M TANK 4 EXHAUST FAN $7349-52-11$ UNAVA

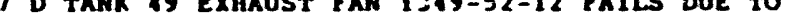

7 D TANK 19 NITROGEN PLOW SENSOR FOR EXHAUST LIME FAILS

7 D FLON SENSOR ACROSS HEPA FILTERS PAILS

7 D TANK 49 NITROGEN PIOW SENSOR FOR LIME a FAILS DUE TO LOCAL FAULTS

7 D TANK 49 NITROGEN PLOW SENSOR FOR GIME B FAILS DUE TO LOCAL FAULTS NO ACTION TAKEN FOR 30 HRS

7 D LOCAL mechanical. PAULts op tank 99 heater

7 D IRTERLOCK FAILURE (FAN EXHAUST PLOW METER) CLOSES FLOW CONTROL VALVE OPPRATOR FAILS TO ENTER HODE C - PIELD CONTROL (HIGH STRESS LEVRLS) OPERATOR FAILS TO ENTER MODE C - FIRLD CONTROL (HODERATR STRESS LEVELS) D MECHAMICAL FAULTS OF TANK 19 PRESSURE REGULATING VALVE 1255 SVI

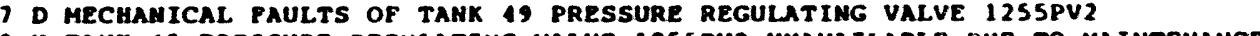
TAMK 99 PRESSURE REGuLATING VALve 1255 VV 7 D TANK 49 FAILURE OP PRESSURE REGULATING VALVE $1257 P V$

7 D SEMSOR DETECTING PAN OPERATION POR NONUALLY RUNNING FAN FAILS

7 D MAMUAL VALVE T49-HV2 PAILS TO REMAIN OPEM (PLUG)

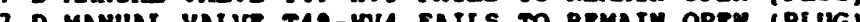

7 D TAMK 92 OHACYeR DISCHARGE VALVE TA9-HVil PAILS TO REMAIN OPEA (PLUG)

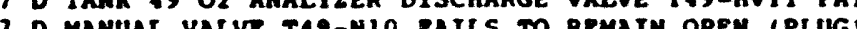

7 D MANUAL VALVE T49-N10 FAILS TO RERAIN OPEN (PLUG)

7 D TAHK 49 PATH D DISCHARGE VALVE T49-MIS PAILS TO REMAIN OPEN (PI.UG)

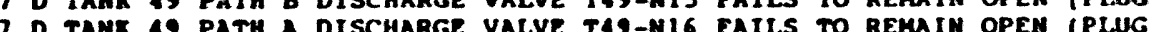

7 D TAMK 9 PATH A IMLET VALUE T49-N19 PAILS TO REMAIN OPEN (PLUG)
$1.60 E-04$

$2.33 E-06$
$2.35 E-06$

2.35E-06

2.35E-06

$1.92 E-02$

$1.922-02$

3. $60 \mathrm{E}-03$

1. SSE-03

5.04E-0

6. OSE-04

$1.43 E-03$

$1.43 E-03$

$7.208-03$

$1.43 E-03$

$7.20 E-03$

$1.438-03$

1. $682-0$

1.34E-03

$4.80 \mathrm{E}-04$

3. $60 \mathrm{E}-03$

1.34E-03

2.00E-02

2.00E-02

$2.00 E-02$

2.00E-02

$1.00 E+00$

3. 36E-06

$1.702-03$

$1.00 E+00$

$1.00 E+00$

$1.00 E+00$

3. TOE-O4

$3.70 E-01$

$3.208-03$

3. $708-04$

3.52E-03

5.

2. $35 E-06$

$2.352-06$

2. $25 E-06$

$2.35 E-06$

$2.35 E-06$
$2.35 E-06$

$2.35 E-06$

$2.35 E-06$
$2.35 E-06$

2.35E-06 


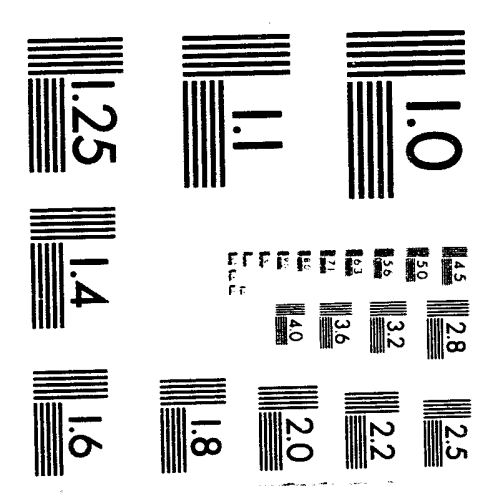



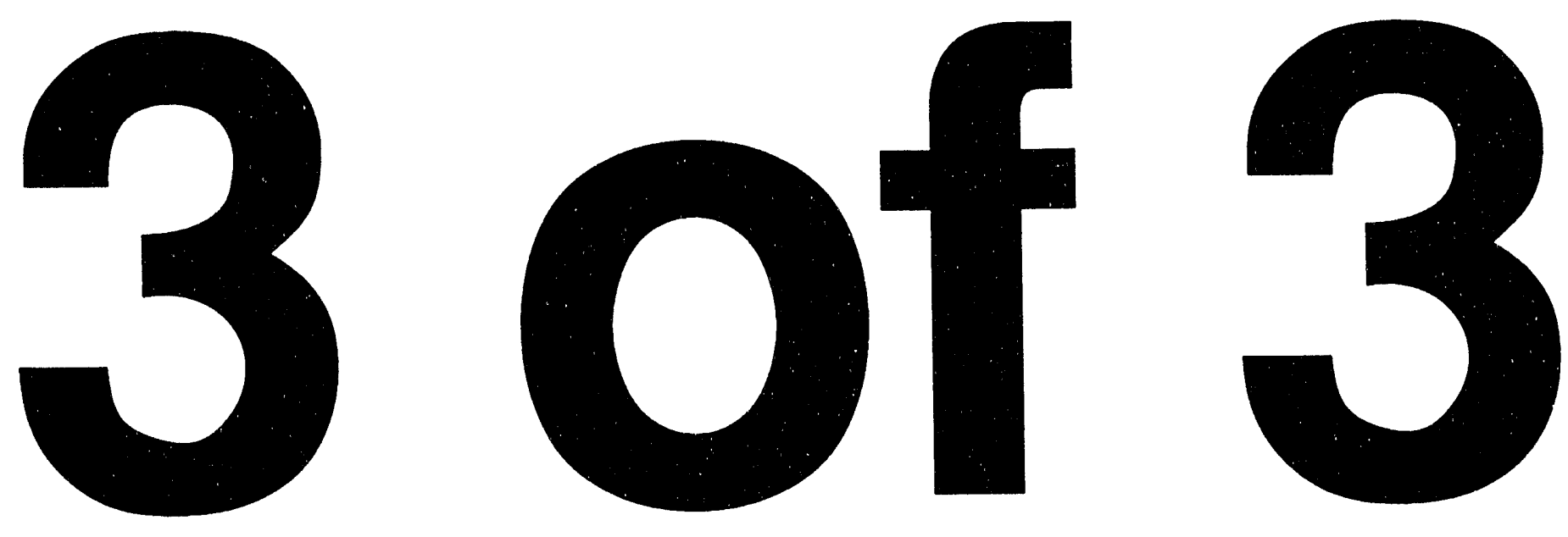
HAME C FACTOR I

DESC PROBis

is $9 X V N 24 P G$ 96 9XVVIOPG $979 \times V V 11 P G$ 88 $9 \times V V 15 P G$ 99 9XVV17PG $1009 \times V V 19 H W$ $1019 \times V V 20 P G$ $1029 \times V V 21 P G$ $1039 \times V \cdot 228 G$ $10: 9 \times V V 33 P G$ 105 E.FN1/2SC 106 EFHJ/4SC 107 EFNCCN>2 108 EFNSKIRR 109 EFNSK1SS 110 EFNSK 2RR 11 EFTSK2SS 11) EFNSK 3 RS 1) EFNSK 14 EFNSK iis NCPDCSHW 17 NCWCHRIIW II NCWCHRIH 19 NFSNFSCM 120 NHOUSEO 121 NHVCOMHW 122 NOPC-HS 123 NOPTRNBS 124 NRPDIVAK 125 NPPNONAK $125 \mathrm{NrR245 \textrm {HW }}$ :27 NPR245TM 129 NEFFANCM 31 NTKTKAIW 133 NUPUPAIWW $134 \mathrm{NXV032PG}$ 135 NXVN12PG $36 \mathrm{NXVN} 15 \mathrm{HW}$ $137 \mathrm{NXVN16 \textrm {HW }}$ 38 NXVNIAPG 139 NXVN208G 141 NXVN24PG
7 D TANK 49 TANK INLET VAI.VE T49-H24 FAILS TO REMAIN OPEH (PLUG)

7 D MAHUAL VALVE T49-HVIO FAILS TO REMAIN OPEN (PLUG

D MANUAL VALVE T49-HVII FAILS TO REMAIN OPEN (PI.UG)

7 D manual VALVE T49-HVIS FaILS TO REMaIN OPEN (PI.UG)

7 D MANUAL VALVE T49-HVI7 FAILS TO REMAIN OPEN (PI.UG)

1 N MANUAL VALVE T49-IVI9 FAILS TO OPEN ON DEHAND

D MANUAL VALVE T49-IVZ20 PAIL.S TO REMAIN OPEN (PI.UG)

? D manUAL VALVE T49-HV21 FaILS TO REMAIN OPEN (PLUG)

7 D manUal VALVE T49-IIV22 FaILS TO REMain OPEN (PLUG)

D manUal VALVE T49-HV33 FaILS TO REmaIN OPEN (PLUG)

N COMMON MODE FAILURE OF EMERGENCY PURGE VENTILATION SYSTEM FOR A PAIR OP FAIS

VENTILATION SYSTEM FOR A PAIR OP FANS

1.13 E-5 COMMON CAUSE FAILURE OF EMERGENCY PURGE VENTILATION SYSTEM FOR $>2$ FANS

D EMERGENCY PURGE VENTILATION SYSTEM PAN 1 FAILS TO RUN

1 N EMERGENCY PURGE VENTILATION SYSTEM PAN 1 FAILS TO START

D EMERGENCY PURGE VENTILATION SYSTEM PAN 2 PAILS TO RUN

D

D EMERGENCY PURGe VENTILATION SYSTEM BAK 3 PAILS TO RUN

D EMERGENCY PURGE VENTILATION SYSTEM PAM

D EMERGEMCY PURGe VENTILATtOn SYSTEM PAM

D LOCal mechanical FautTs op dos computra

D mechanical paults in CHRomated cooling water system

7 D LOSS OF H-AREA POWER

7 D BOTH NITROGEN FLOW SENSORS FATL DUE TO COMMON MODE MISCALIBRATIOH

0.125 CONDITIONAL PROBABILITY OP OUTSIDE TEMPERATURE BEING > $80 \mathrm{~F}$

7 D LOSS OP HVAC TO ROOM CONTAINING DCS COMPUTER

1 OPERATOR FAILS TO ENTER MODE C - PIELD CONTROI. (HIGII STRESS I.EVELS) OPERATOR PAILS TO ALIGN TRAIN B FOR OPERATION - SUPPLY SIDE

D ISOLABLE GUILLOTINE PIPE BREAK

D NON-ISOLABLE GUILLOTINE PIPE BREAX

7 D PRESSURE REgULATOR 2045PV FAILS

N PRESSURe REgULATOR 2045PV MAINTENANCE

D PRESSURR REgULATOR 2046PV FAILS

D MISCALIBRATION FAIIURE OF SENSORS DETECTING FAN OPERATIOH

D LOSS OF STEAM SUPPI.Y TO HEATER

D NITROGEN STORAGE TANK I LEAKS

D PAILURE OP VAPORIZER A UUE TO HARDWARE FAULTS

D FAI LURE OP VAPORIZER B DUE TO HARDWARE FAULTS

D 'ALVE N12 FROH THE NITROGEN SUPPLY PAILS TO REMAIN OPEN (PLUG

I N MANUAL VALVE NIS PaILS TO OPEN

N MANUA: VALVE N16 FAILS TO OPEN OR

7 D PATH B OUTLET VALVE N18 FAILS TO REMAIN OPEN (PLUG

7 D PATH A OUTLET VALVE N20 FAILS TO REMAIN OPEN (PLUG)

7 D PATH A INI.ET VALVE N24 FAILS TO REMAIN OPEN (PLUG)
. 35E-06

2. 35E-06

$2.35 E-06$

2. $35 E-06$

$1.60 E-01$

2.35E-06

$2.35 E-06$

$2.35 E-06$

$2.35 E-06$

$2.26 E-05$

$2.26 E-05$

1. 1 E 05

$1.00 \mathrm{E}-02$

1. $34 E-03$

1. $00 \mathrm{R}-02$

$1.348-03$

1. $00 \mathrm{E}-02$

$1.34 E-03$

1. $00 \mathrm{E}-02$

$1.00 E-02$

1. $19 \mathrm{E}-03$

5.75E-03

8. $40 E-03$

8. $25 E-01$

$1.68 \mathrm{~B}-03$
2.03

$1.00 E+00$

1. $00 E+00$

$1.68 \mathrm{E}-07$

1. $68 \mathrm{BE}-07$

3. $70 \mathrm{E}-04$

$7.20 E-03$

$3.708-04$

8. 40E-03

1. $92 \mathrm{E}-02$

3.86E-07

$6.89 E-05$

$6.89 E-05$

2.35E-06

2.35E-06

$1.60 \mathrm{E}-04$

1. $60 \mathrm{E}-04$

2. $35 E-06$

$2.35 E-06$

2. $35 \mathrm{E}-06$ 


\section{MAME}

C FACTOR u

DESC

PROB

142 HXVN25PG $3 \quad 7$ D MANUAL VALVE N25 FAII.S TO REMAIN OPEN (PLUG

143 NXVN26PG 37 D MANUAL VALVE N26 FAILS TO REMAIN OPEN (PLUG)

$\begin{array}{lll}145 \text { HXVN33PG } & 3 & 7 \text { D MANUAL VALVE N33 FAIIS TO REMAIN OPEN (PLUG) } \\ 145 \text { NXUN } 6 \text { FPG } & 3 & 7 \text { D MANUAL VAIVE N45 FAIIS TO REMAIN OPEN (PI.UG) }\end{array}$

1 N manual VALVE NA7 FaIIS TO OPEN OH DEmand

7 D MANUAL VALVE 92 FAILS TO REMAIN OPEN (PI.UG)

$2.35 E-06$

$2.35 E-05$

$2.35 E-06$
$2.35 E-06$

$2.35 E-06$
$1.60 E-04$

$2.35 E-06$

1 
TC FILE FOR EXTERNAL EVENT FAULT TREES 
$2,38 E-1$ Y O2 ANALYZER COMMON MODE MISCALIDILATION 3.0E-4 H O2 ANALYZER CP MRCHANICAL FAULT 1. $8 E-3$ N O2 ANALYZER CPQ MAINTENANCE

3. $0 E-6$ H CONDENSER PeE MECHANICAL FAULT

$9.0 E-5$ H DIGITAL CONTROL SYSTEM Q $Q$ M MECHAHICAL FAULT

$2.5 E-5$ H COOLING WATER MECHANICAL FAULT

3.6E-6 HI DEMISTER CIE FAILS DUR TO PLUGGING

$3.4 J E-5$ H LOSS OP H-AREA POWER

1.OE-4 N COMMON CAUSE FAILURE OF FLOW CONTROL VALVES TO OPEN

9.5E-6 H PLOW CONTROL VALVE

1.0E-3 N F.OW CONTROL VALVE fel FAILS TO OPEM

3.6E-3 N F FOH CONTROL VALVE CE PAINTENANCE

$1.02-6$ H HEPA FILTER TEQ MECHANICAL FAULT

$1.8 E-3$ N HEPA PILTER CTE MATNTENANCE

1. . BE-5 N COMHON CAUSE FAJLURE OF PANS TO START

8.08-6 H EXHAUST TAN RE FAILS TO RUN

9.0E-6 H EMERGENCY PURGE VENTILATION SYSTEM QEQ FAIL.S TO RUN

2.26E-5 N COMHON MODE PAILURE OF EMERGENCY PURGE VENTILATION SYSTEH

STA TO STAR

1.8E-1 N EXHAUST PAN Le fAILS TO START

1.8E-3 N EXHAUST PAN Cle MAINTENANCE

$4.18-1$ Y FLOW SENSOR MISCALIBRATION

1.2R-1 H PLOH SENSOR CE MECHANICAL FAU

$2.08-8$ H HEATER CE MECHANICAL
$1.68-5$ H HUAC MECHANICAL. PAULT

1.6E-5 H HVAC MECHANICAL PAULT

1.6E-5 H INTERLOCK MECHANICAL PAU

1.0E-9 H GUILLOTINE PIPE BREAK

8.1E-4 N COMESURE REGULATING VALVE

2.2E-6 H PRESSURE REGULATING VALVE Ele MECHANICAL PAULT

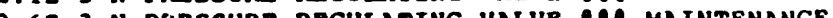

A. $Y$ PAN SENSOR MISCALIBKATION

2.1E-5 H FAN SENSOR CPE MECHANICAL FAULT

1.

2. 3E-9 H HITROGEN STORAGE TANK Cle LEAKS

1.

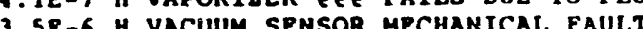

1. GE- 4 MAMUAL YALVE PeE PAILS TO OPEN ON DEMAND

1. EE-4 N MANUAL VALVE Pe? PAILS TO REMAIN OPEN (PLUG)
Table $1-1,78$, Pg 10

Calculation

Table $1-1,13$

Table 4-1, 5

Table 1-1, 6

Table 1-1, 10

Table 1-1,

Section 1.1.

Table 1-1, 1, Pg 35

Table 1-1, 2, Pg 38

Calculation

Table 1-1, 1, Pg 16

CALCULATION

Section 1.1.2
Table 1-1, Pg 16

Tablo 1-1,

Table 1-1,

Table 1-1, 10

Calculation

Calculation

Table 1-1, 1, Pg 16

Table 1-1, H.

Table 1 , th

Cp 8

Table i-1.

Tecte 1,09

Table 4-1, 11, Pg 22

Table -1, 10

Cable lation

Table -1 ,

Table 1-1, 1 pg 25

Table 1-1, 6

Table 1-1,

Table 1-1,

Table 1-1, 1, Pg 25

Table 1-1, M, cp 57

Table $1-1,4$, Cp 5 
CUTSETS FOR EXTERNAL EVENTS FAULT TREE (EXT100) NO RECOVERIES APPLIED 
COMMON CAUSE FAILURE OF EMERGENCY PURGE VENTILATION SYSTEM FOR $>2$ EMERGENCY PURGE VENTILATION SYSTEM FAN 1 FAILS TO START EMERGENCY PURGE VENTILATION SYSTEM FAN 2 FAILS TO START EMERGENCY PURGE VENTILATION SYSTEM FAN 3 FAILS TO START EMERGENCY PURGE VENTILATION SYSTEM FAN 1 FAILS TO START EMERGENCY PURGE VENTILTTION SYSTEM FAN 2 FAILS TO START EMERGENCY PURGE VENTILATION SYSTEM FAN 1 FAILS TO START EMERGENCY PURGE VENTILATION SYSTEM FAN 2 FAILS TO START EMGENCY PURGE VENTILATION SYSTEM FAN 3 FAILS TO START EMERGENCY PURGE VENTILATION SYSTEM FAN 1 FAILS TO START EMERGENCY PURGE VENTIIATION SYSTEM FAN 3 FAILS TO START EMERGENCY PURGE VENTILATION SYSTEM FAN 4 FAIIS TO START EMERGENCY PURGE VENTILATION SYSTEM FAN 2 FAILS TO START EMERGENCY PURGE VENTILATION SYSTEM FAN 3 PAILS TO START EMTRGEHCY PURGE VENTIATION SYSTEM FAN VETILATION SYSTEM FOR A PA 2.26R-5 COMMON MODE FAILURE OF EMERGENCY PURGE VENTILATION SYSTEM FOR A PA $2.26 E-5$ EMFRGENCY PURGE VENTILATION SYSTEM FAN A FAILS TO START EMERGENCY PURGE VENTILATION SYSTEM FAN 3 FAILS TO RUN EMERGENCY PURGE VENTILATION SYSTEM FAN 4 FAILS TO START EMERGENCY PURGE VENTILATION SYSTEM FAN 1 FAILS TO RUN EMERGENCY PURGE VENTILATION SYSTEH FAN 2 FAILS TO START EMERGENCY PURGE VENTILATION SYSTEM PAN 3 FAILS TO START EMERGENCY PURGE VENTILATION SYSTEH PAN I FAILS TO START EMERGENCY PURGE VENTILATION SYSTEH PAN 2 PAILS TO START EMERGENCY PURE VENTLATION SYSTEM FAN 2 PATLS TO RUM EMERGENCY PURGE VENTLLTION SYSTEM FAN 2 PAILS TO START EMERGENCY PURGE VENTILATTON SYYTEM FAN O FAILS TO RUA EMERG EMERGENCY PURGE VENTILATION SYSTEM FAM 4 PAILS TO RUM EMERGENCY PURGE VENTILATION SYSTEM FAN 3 FAILS TO START EMERGENCY PURGE VENTILATTON SYSTEM FAN FERTENCY PURGE VENTILATION SYSTEM EAN 2 FAILS TO START EMERGENCY PURGE VENTILATION SYSTEM FAN 3 FAILS TO RUN BMERGENCY PURGE VPNTILATION SYSTEM FAN \& FAILS TO START EMERGENCY PURGE VENTILATION SYSTEM FAN 1 FAILS TO START EMERGENCY PURGE VENTILATION SYSTEM FAN 2 FAILS TO START EMERGENCY PURGE VENTILATION SYSTEM FAN 4 FAILS TO RUN

\begin{tabular}{|c|c|c|c|}
\hline & $1.13 E-5$ & 1. $13 E-05$ & $1.13 E-05$ \\
\hline $.0 E-2$ & 1 & & \\
\hline $1.0 \mathrm{E}-2$ & 1 & $1.00 E-02$ & \\
\hline $1.0 \mathrm{E}-2$ & 1 & $1.00 E-02$ & \\
\hline $1.0 \mathrm{E}-2$ & 1 & $1.00 E-02$ & $1.00 E-06$ \\
\hline $1.0 \mathrm{E}-2$ & 1 & $1.00 E-02$ & \\
\hline $1.0 \mathrm{E}-2$ & 1 & $1.00 \mathrm{E}-02$ & \\
\hline $1.0 \mathrm{E}-2$ & 1 & $1.00 E-02$ & $1.00 E-06$ \\
\hline $1.0 \mathrm{E}-2$ & $i$ & $1.00 \mathrm{e}-02$ & \\
\hline 1. $0 E-2$ & 1 & $1.00 E-02$ & \\
\hline $1.0 \mathrm{E}-2$ & 1 & $1.00 E-02$ & $1.00 E-06$ \\
\hline $1.0 \mathrm{E}-2$ & 1 & $1.00 \mathrm{E}-02$ & \\
\hline $1.0 E-2$ & 1 & $1.00 \mathrm{E}-02$ & \\
\hline $2.26 E-5$ & 1 & $2.26 E-05$ & $2.26 E-07$ \\
\hline $1.0 z-2$ & 1 & $1.00 E-02$ & \\
\hline $2.26 \mathrm{E}-\mathrm{S}$ & $i$ & $2.26 E-0 S$ & $2.26 E-07$ \\
\hline $1.0 \mathbb{E}-2$ & $i$ & $1.00 \mathrm{E}-02$ & \\
\hline $2.26 \mathrm{E}-5$ & 1 & $2.26 \mathrm{E}-05$ & $2.26 E-07$ \\
\hline $1.0 \mathrm{E}-2$ & 1 & $1.00 E-02$ & \\
\hline $2.26 E-5$ & 1 & $2.26 \mathrm{E}-05$ & $2.26 E-07$ \\
\hline $1.0 E-2$ & $i$ & $1.00 E-02$ & \\
\hline $1.08-2$ & 1 & $1.00 E-02$ & $1.34 E-07$ \\
\hline $8.0 \mathrm{E}-6$ & 7 & 1. $34 E-03$ & \\
\hline $1.0 E-2$ & $i$ & $1.00 \mathrm{E}-02$ & \\
\hline $8.0 E-6$ & 7 & $1.34 E-03$ & $1.34 E-07$ \\
\hline $1.0 E-2$ & 1 & $1.00 \mathrm{E}-02$ & \\
\hline $1.0 z-2$ & i & $1.00 E-02$ & \\
\hline $1.0 \mathrm{E}-2$ & 1 & $1.00 \mathrm{E}-02$ & $1.34 E-07$ \\
\hline $1.0 \mathrm{E}-2$ & 1 & $1.00 \mathrm{E}-02$ & \\
\hline $8.0 z-6$ & 7 & $1.34 E-03$ & \\
\hline $1.0 \mathrm{E}-2$ & 1 & $1.00 E-02$ & $1.34 E-07$ \\
\hline $1.0 \mathrm{E}-2$ & 1 & $1.00 \mathrm{E}-02$ & \\
\hline 8. $0 \mathrm{OE}-6$ & 7 & $1.34 E-03$ & \\
\hline $1.0 z-2$ & $i$ & $1.00 \mathrm{E}-02$ & $1.34 E-07$ \\
\hline $1.0 \mathrm{E}-2$ & 1 & $1.00 \mathrm{E}-02$ & \\
\hline $8.0 \mathrm{E}-6$ & 7 & $1.34 R-03$ & \\
\hline $8.0 z-6$ & 7 & $1.34 \mathrm{E}-03$ & 1. $34 E-07$ \\
\hline 1. $O E-2$ & 1 & $1.00 E-02$ & \\
\hline $1.0 \mathrm{E}-2$ & i & $1.00 \mathrm{E}-02$ & \\
\hline $1.0 \mathrm{E}-2$ & 1 & $1.00 \mathrm{E}-02$ & $1.34 E-07$ \\
\hline $8.0 \mathrm{E}-6$ & 7 & $1.34 E-03$ & \\
\hline $1.0 \mathrm{E}-2$ & 1 & $1.00 E-02$ & \\
\hline $1.0 \mathrm{E}-2$ & $i$ & $1.00 E-02$ & $1.34 E-07$ \\
\hline $1.0 \mathrm{E}-2$ & 1 & $1.00 E-02$ & \\
\hline $8.0 E-6$ & 7 & $1.34 E-03$ & \\
\hline
\end{tabular}




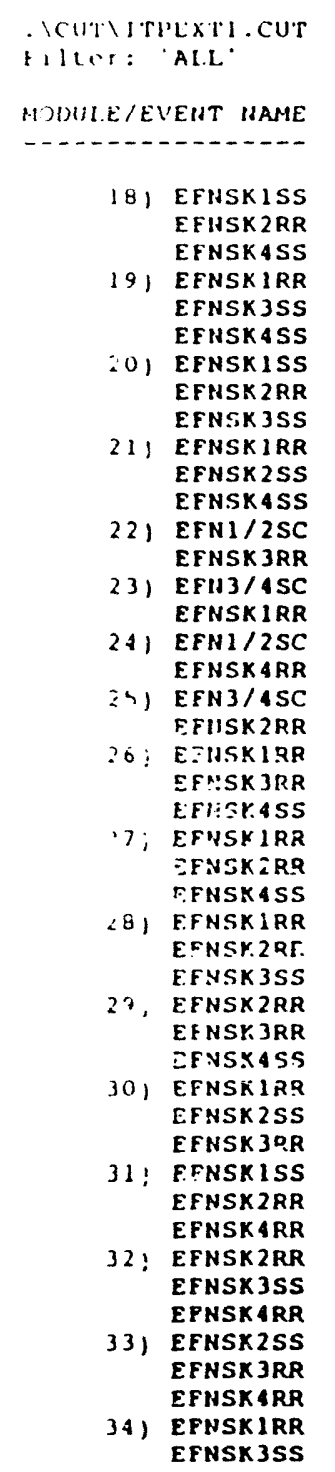

EMERGENCY PURGE VENTILATION SYSTEM FAN 1 FAILS TO START EMERGENCY PURGE VENTILATION SYSTEM FAN 2 FAILS TO RUN EMERGPNCY PURG VENTILATION SYSTEM FAN I FAILS TO RUN EMRRGENCY PURGE VENTILATION SYSTEM FAN 3 FAILS TO START EHERGPNCY PURGE VENTILATION SYSTEM FAN EMERGENCY PURGE VENTILATION SYSTEM FAN 1 PAILS TO START EMERGENCY PURGE VENTILATION SYSTEM FAN 2 FAILS TO RUN EALRGENCY PURGE VENTILATION SYSTEM FAN 3 FAILS TO START EGERGENCY DURGE VENTILATION SYSTEM FAN 1 FAILS TO RUN EMERGENCY YURGE VENTILATION SYSTEM PAN 2 FAILS TO START EMERGENCY PURGE VENTILATION SYSTEM FAN 4 FAILS TO START COMMON MODE PAILURE OP EMERGENCY PURGE VENTILATION SYSTEM FOR A PA EMERGENCY PURGE VENTILATION SYSTEM PAN 3 FAILS TO RUN COMMON MODE FAILURE OF RMERGENCY PURGE VENTILATION SYSTEM FOR A PA EMERGENCY PURGE VENTILATION SYSTEM PAN 1 FAILS TO RUN COMMON MODE FAILURE OF EMERGENCY PURGE VENTILATION SYSTEM FOR A PA EMERGENCY PURGE VENTILATION SYSTEM FAN I FAILS TO RUN COMMON MODE FAILURE OF EMERGENCY PURGE VENTILATION SYSTEM FOR A PA EMERGFICY PURGE VENTILATION SYSTEM PAN 2 FAILS TO RUN ER!ERGENCY PURGE VENTILATION SYSTEM FAN 1 FAILS TO RUN EN.ERGENCY PURGE VENTILATION SYSTEM PAN 3 FAILS TO RUN EMERGENCY PURGE VENTILATION SYSTEM FAN 1 FAILS TO START E!-RGENCY PURGE VENTILATION SYSTEM PAN 1 FAILS TO RUN EMFRGENCY PURGE VENTILATION SYSTEM FAN 4 FAILS TO START EMRECENCY PURE VENTILATION SYSTEM TAN PAILS TO START EMERGENCY PURGE VENTILATION SYSTEM FAM 2 FAILS TO RUN EHERGENCY PURGE VENTIIATION SYSTEM PAN 3 FAILS TO START EMERGENCY PURGE VENTILATION SYSTEM PAN 2 FAILS TO RUN EMERGENCY PURGE VENTILATION SYSTEM PAN 3 FAILS TO RUN EMERGENCY PURGE VENTILATION SYSTEM PAN I PAILS TO START EMERGENCY PURGE UENTILATION SYSTEM FAN 1 FAILS TO RUN EMERGENCY PURGE VENTILATION SYSTEM FAN 2 PAILS TO START EMERGENCY PURGE VENTILATION SYSTEM FAN 3 FAILS TO RUN EMERGENCY PURGE VENTILATION SYSTEM FAN 1 PAILS TO START EMRRGENCY PURGE VENTILATION SYSTEM FAN 2 FAILS TO RUN EMERGENCY PURGE VENTILATION SYSTEM FAN \& FAILS TO RUN EHERGENCY PURGE VENTILATION SYSTEM PAN 2 PAILS TO RUN EMERGENCY PURGE VENTILATION SYSTEM PAN 3 FAILS TO START EMERGENCY PURGE VENTILATION SYSTEH PAN 4 PAILS TO RUN EMERGENCY PURGE VENTYLATION SYSTEM PAN 2 PAILS TO START EMERGENCY PURGE VENTILATION SYSTEM PAN 3 FAILS TO RUN EMERGENCY PURGE VENTILATION SYSTEM PAN 4 PAILS TO RUN EMRRGENCY PURGE VENTILATION SYSTEM PAN 1 FAILS TO RUN
EMERGENCY PURGE VENTILATION SYSTEM FAN 3 FAILS TO START
$1.0 \mathrm{E}-2$

8. $0 \mathrm{E}-6$
$1.0 \mathrm{~B}-2$

$1.08-2$

$1.0 \mathrm{~B}-2$

$1.0 \mathrm{E}-2$
$1.0 \mathrm{E}-2$

$1.0 \mathrm{E}-2$

B. $0 \mathrm{E}-6$

$1.0 \mathrm{E}-2$

B. $0 \mathrm{E}-6$

1. $\mathrm{OE}-2$ $8.0 \mathrm{E}-6$

$2.268-5$ $8.0 \mathrm{E}-6$ $2.26 E-5$ $8.0 \mathrm{E}-6$ 2. $26 \mathrm{E}-5$ $8.0 \mathrm{R}-6$ $8.0 E-6$

$1.08-6$

$1.08-2$

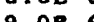

$1.08-6$

9.08-2

B. $08-6$

$1.0 \mathrm{E}-2$

8. $0 \mathrm{R}-6$

8.08-6

$1.0 \mathrm{E}-2$

8.0R-6

$1.0 \mathrm{E}-2$

$8.0 \mathrm{E}-6$

$1.0 \mathrm{E}-2$

8.0R-6

8.0P. -6

1.UE-2

$8.08-6$

$1.0 E-2$

$8.0 \mathrm{E}-6$

$8.0 \mathrm{E}-6$

8. $0 \mathrm{E}-6$
$1.0 \mathrm{E}-2$
DOE $-02 \quad 1.34 E-07$ $1.34 E-03$
$1.00 E-02$

$.348-03,34 E-07$

$1.34 E-03$
$1.00 \mathrm{E}-02$

$1.00 \mathrm{E}-02$

$1.00 \mathrm{E}-02 \quad 1.34 \mathrm{E}-07$

$1.34 \mathrm{E}-03$

$1.34 \mathrm{E}-03$
$1.00 \mathrm{E}-02$

$1.34 E-03 \quad 1.34 E-07$

$1.008-02$

$1.00 E-02$

2.26E-05 3.04E-08

$1.34 E-03$

$2.26 E-05$

1.34E-03

$2.26 \mathrm{E}-05$

$1.34 E-03$

2. $26 \mathrm{E}-05$

$1.34 \mathrm{E}-03$

$1.34 \mathrm{E}-03 \quad 1.80 \mathrm{E}-0$

$1.34 E-03$

1. $348-03 \quad 1.80 E-08$

$1.342-03$

$1.00 \mathrm{E}-02$

1.34E-03 1.80E-08

1.34R-03

$1.008-02$

$1.34 \mathrm{E}-03 \quad 1.80 \mathrm{E}-08$

$1.34 \mathrm{E}-03$

$1.34 \mathrm{E}-03$
$1.00 \mathrm{E}-02$

1.34E-03 $1.80 \mathrm{E}-08$

$1.00 \mathrm{E}-02$

$1.34 E-03$

$1.00 E-02 \quad 1.80 E-08$

$1.34 E-03$

$1.34 E-03$

$1.348-03 \quad 1.80 \mathrm{E}-08$

$1.00 \mathrm{E}-02$

$1.34 E-03$

1.008-02 1.808-08

1. $34 \mathrm{E}-03$

$1.34 E-03$

$1.34 E-03 \quad 1.80 E-08$

$1.00 E-02$

EFNSKIRR
EFNSK 3SS 
EFNSK 4RR EFNSK JRR EFNSK

36) EFNSK1RR EPNSK2SS

37) EFNSKISS EFNSK 2RR EFNSK JRR

38) EFNSKIRR EFISSK 2RR EFNSK 3RR

39) EFHSKIRR EFNSK2RR EFNSKARR

4O) EFHSK2RR EFHSK 3RR EFHSKARR

I EENSK ?RR

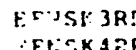

42: VFHI/2SC EFis $314 \mathrm{SC}$
EMERGENCY PURGE VENTILATION SYSTEM FAN 4 FAILS TO RUN EMERGENCY PURGE VENTILATION SYSTEM FAN 1 FAILS TO START EMERGENCY PURGE VENTILATION SYSTEM FAN 3 FAILS TO RUN EMERGENCY PURGE VENTILATION SYSTEM FAN TAILS TO RUN EMERGENCY PURGE VENTILATION SYSTEM FAN 1 PAILS TO RUN EMERGENCY PURGE VENTILATION SYSTEM FAN 2 FAILS TO START EMERGENCY PURGE VENTILATION SYSTEM PAN 4 FAILS TO RUN EMERGENCY PURGE VENTILATION SYSTEM FAN 1 FAILS TO START EMERENCY PURGE VENTILATION SYSTEM FAN 2 FAILS TO RUN EMEGENCY PURGE VENTILATION SYSTEM FAN 3 FAILS TO RUN EMERGENCY PURGE VENTILATION SYSTEM FAN I FAILS TO RUN EMERGENCY PURGE VENTIIATION SYSTEM FAN 2 FAILS TO RUN EMERGENCY PURGE VENTILATION SYSTEM FAN 3 FAILS TO RUN EMERGENCY PURGE VENTILATION SYSTEM FAN I FAILS TO RUN EMERGENCY PURGE VENTILATION SYSTEM FAN 2 FAILS TO RUN EMERGENCY PURGE VENTILATION SYSTEH FAN 4 PAILS TO RUN EMERGENCY PURGE VENTILATION SYSTEM FAN 2 FATIS TO RUN EMERGENCY PURGE VENTILATION SYSTEM FAN J FAILS TO RUN EMERGENCY PURGE VENTILATION SYSTEM FAM 4 FAILS TO RUM EMERGENCY PURGE VENTILATION SYSTEM FAN I FATLS TO RUN EMERGENCY PURGE VENTILATION SYSTEM FAN I FAILS TO RUN COMMON MODE FAILURE OP EMERGENCY PURGE VEMTILATION SYSTEM FOR A PA COMMON MODE FAILURE OP EMERGENCY PURGE VENTILATION SYSTEM FOR A PA $2.26 E-5$

RATE-

EXPOSURE PROB. PROB.

$1.0 E-2$
$8.0 E-6$

$8.0 \mathrm{E}-6$
$8.0 \mathrm{E}-6$

8. OE -6

1. $0 \mathrm{E}-2$

1. $0 \mathrm{E}-2$

$8.0 E-6$

8. $0 \mathrm{E}-6$

$8.0 \mathrm{E}-6$

$8.0 E-6$

B. $0 E-6$

$8.0 E-6$

8. 0 E -6

$8.0 \mathrm{E}-6$

8. $08-6$

.

$8.0 E-6$

8. $0 E-6$

$8.0 \mathrm{E}-6$
$1.34 E-03$

$1.00 \mathrm{E}-02 \quad 1.80 \mathrm{E}-08$

$1.34 \mathrm{E}-03$

$1.34 \mathrm{E}-03$

1.34E-03 1.80E-08

1. $00 E-02$

$1.34 \mathrm{E}-03$

$1.00 \mathrm{E}-02 \quad 1.80 \mathrm{E}-08$

1. $34 \mathrm{E}-03$

1. $34 \mathrm{E}-03$

1.34E-03 2.42E-09

1. $34 E-03$

$\begin{array}{ll}1.34 E-03 & 2.42 E-09\end{array}$

1. $34 \mathrm{E}-03$

1. $34 \mathrm{E}-03$

1. $34 \mathrm{E}-03 \quad 2.42 \mathrm{E}-09$

$1.348-03$

1. $34 \mathrm{E}-03$

1. $348-032.42 E-09$

$1.348-03$

1. $34 E-03$

2.26E-0S 5.11E-10

2.26E-05 
TC FILE FOR EXTERNAL EVENT FAULT TREES

$\infty$ 


$$
\text { ryer: }
$$

RA':E U

DE:S:

sounce

Table 1-1,

I IM

$2 A 2$ II

3 AZ TM

5 IP 11 N

6 CW

7 CW IIW

7
$B$

3 EL IIW

3 FC CH
10 FC $\mathrm{HW}^{2}$

$11 \mathrm{FC} \mathrm{NM}$

12 FC TH

$13 \mathrm{FL} \mathrm{HH}$

$14 \mathrm{FL}$ TH

15 FN CM

16 FN I:W

17 FN RR

18 FN SC

$19 \mathrm{FN} \mathrm{SS}$

20 FN ST

$21 \mathrm{FN} \mathrm{TM}$

22 FS CH

23 IS HH

$24 \mathrm{HT}$ HW

25 IiV H:

26 II. $\mathrm{HW}$

$27 \mathrm{PP}$ BK

$\because 2$ PR CM

29 PR IIH

JC PR IIN

3: PR $T$ TH

$\begin{array}{lll}32 & \text { SF } & \text { CM } \\ 33 & \text { SE } & \text { IIS }\end{array}$

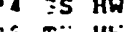

3 .

$3=$ VP !I

3? $\because 5$ HW

$\begin{array}{lll}30 & X V & P G\end{array}$
OE-4 H O2 AMALYZER EQ MECHANICAL FAULT

1. BE-3 N 02 ANALYZER Cl MAINTENANCE

2.5E-5 H COOLING WATER MRCHANICAL FAULT

3.6E-6 II DEMISTER CE FAILS DUE TO PLUGGING

$3.43 E-5$ H LOSS OP H-AREA POWER

L. OR-4 COMMON CAUSE PAILURE OF FLOH CONTROL VALVES TO OPEN

8.5E-6 H PLOW CONTROL VALVE cle MECIHANICAL FAULT

$1.0 E-3$ N POH CONTROL VALVE TEe FAILS TO OPEN

3.6E-3 N K OW CONTROL VALVE CE MAINTENANCE

$1.8 E-3$ N HEPA PILTER Cl MAINTENANCE

1.8E-5 N COMHON CAUSE FAILURE OF PANS to START

OE-6 H EXHAUST PAN TCE FAILS TO RUN

SYTEM QEQ FAII.S TO HUM

COERE

$2.26 E-5$ N COHAON MODE PAILURE OF EMERGENCY PURGE VENTS TO START

1.0E-2 A ERERGENCY PURGE VENTILAT TO START

1.8E-4 N EXHAUST FAN EE FAILS TO STAR

$1.8 E-3$ M EXHAUST TAN OCE HATNTENANCE

1. YE-1 Y FLOW SENSOR MISCALTBRATYON FAULT

1. OR-B H HEATER PCE MECHANICAL FAULT

1. 6E-5 H HVAC MECHANICAL PAULT

6E-5 H INTERLOCK MECHANICAL FAULT

1. OE-9 H GUILOTINE PIPE BREAK

14 COTLOOT

28-6 H PRESSURE REGULATIMG VALVE ele MECHANICAL FAULT

.

G.

4.

2. IE-5 H FAN SENSOR Tle MECHANICAL FAULT

J.

4. IE ? I VAPORIZER IEE PAILS DUE TO PLUGGING

SE-6 H VACUUM SENSOR meCHANICAL FAULT

.

1. GE-4 N MANUAL VALVE Re PAILS TO REMAIN OPEN (PLUG)
2.38E-1 Y O2 ANALYZER COMMON MODE MISCALIBRATION

.0E-6 H CONDENSER CeQ MECHANICAL FAULT CHANICAL FAULT
Table 1-1, *1, Pg 10

Calculation

Table 1-1,

Table $1-1$, is

Table $1-1,0$

Table 1-1, 10

Table $4-1,1$

Table $1-1,1, P g 35$

Table 1-1, 1, Pg 35

Table -1,

Table 1-1, 11, Pg 16

Table 4 -

Section 1.1 .2

Table 1-1, 1, Pg 16

Table -1,

Table -1 ,

Table $1,1,9$

Table $-1,10$

calculation

Table -1,

Table $1-1,1$, Pg 16

Table 1-1,

Table 1-1, 4, cp 8

rable 4-1.

Table 1-1, 1, Pg 2

section 1.1.2

rable 1-1, 11, Pg 22

Table $-1,10$

Calculation

rable -1 ,

rable 1-1, 1, Pg 25

Table 1-1,

Table 1-1,

Table -1 ,

rable 1-1, 1, Pg 25

Table 1-1, 14, CP 57

rable 1-1, M, cp 57 
CUTSETS FOR EXTERNAL EVENTS FAULT TREE (EXT100) -

NO RECOVERIES APPLIED 


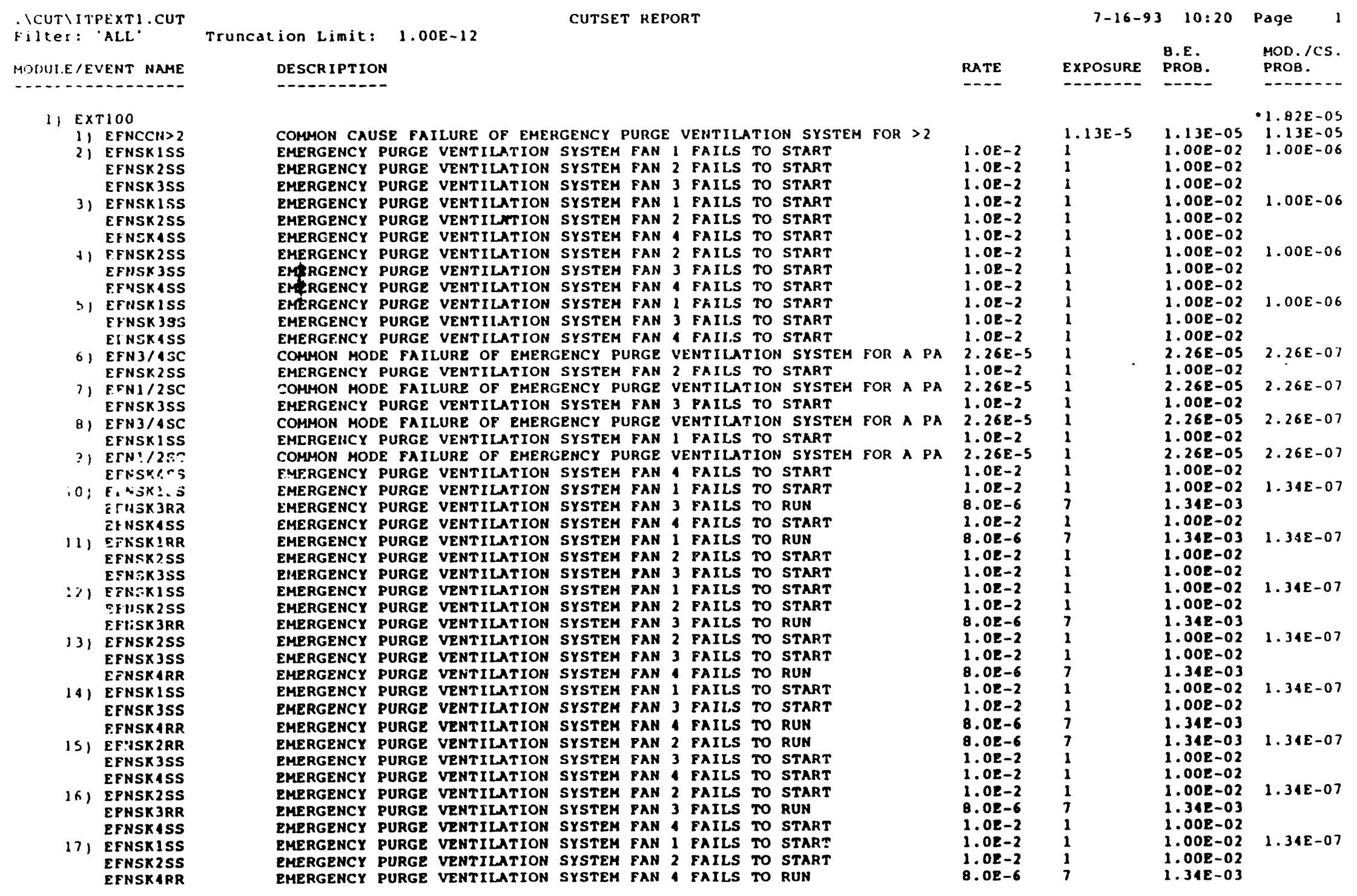




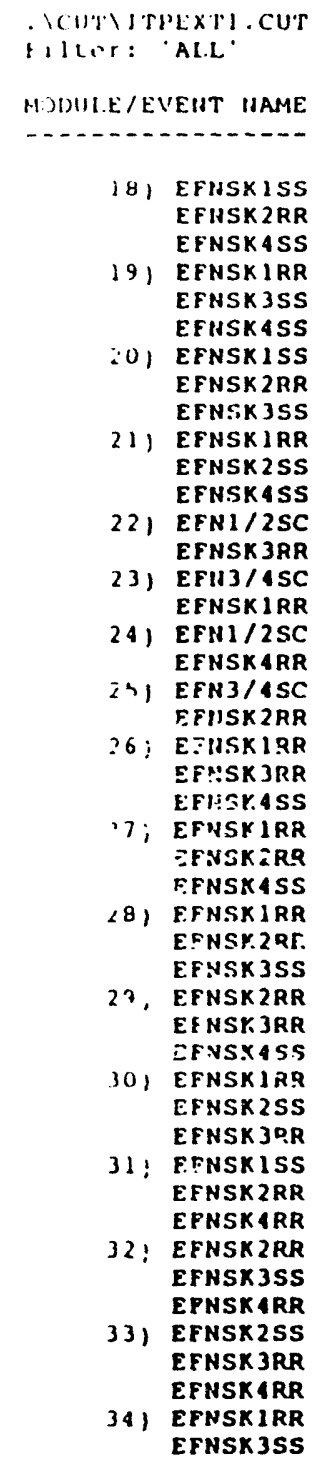

Truncation Limit: $1.00 E-12$

DESCRIPTION

EMERGENCY PURGE VENTILATION SYSTEM FAN I FAILS TO START EMERGENCY PURGE VENTILATION SYSTEM FAN 2 FAILS TO RUN EMERGENCY PURGE VENTILATION SYSTEM FAN 4 FAILS TO START EMERGENCY PURGE VENTILATION SYSTEM FAN I FAILS TO RUN EMRRGENCY PURGE VENTILATION SYSTEM FAN 3 FAILS TO START RHERGENCY PURGE VENTILATION SYSTEH FAN 1 FAILS TO START EMERGENCY PURGE VENTILATION SYSTEM FAN 1 PAILS TO START EHERGENCY PURGE VENTILATION SYSTEM FAN 2 FAILS TO RUN ELRGENCY PURGE VENTILATION SYSTEM FAN 3 FAILS TO START EIERGENCY PURGE VENTILATYON SYSTEM FAN I FAILS TO RUN EMERGENCY PURGE VENTILATION SYSTEM PAN 2 FAILS TO START EMERGENCY PURGE VENTILATION SYSTEH PAN 4 FAILS TO START PA PAN I PAILS TO RUN EMERGENCY PURGe VENTILATION SYSTEM PAN 1 PAILS TO RUN COMMON MODE FAILURE OF EMERGENCY PURGE VENTILATION SYSTEM FOR A PA EMERGFICY PURGE VENTILATION SYSTEM PAN 2 FAILS TO RUN EMERGENCY PURGE VENTILATION SYSTEM PAN 1 PAILS TO RUN EYERGENCY PURGE VENTILATION SYSTEM FAN 3 FAILS TO RUN EMERGENCY PURGE VENTILATION SYSTEM FAN I FAILS TO START E!ERGENCY PURGE VENTILATION SYSTEM PAN 1 FAILS TO RUN EMERGENCY PURGE VENTILATION SYSTEM FAN 2 PAILS TO RUN EMFRGENCY PURGE VENTILATION SYSTEM FAN 4 FAILS TO START EMEF.TENCY PURGE VENTILATION SYSTEM PAN 1 FAILS TO RUN EMERGENCY PURGE VENTILATION SYSTEM PAN 2 FAILS TO RUN EMERGENCY PURGE VENTILATION SYSTEM PAN 3 FAILS TO START EMERGENCY PURGE VENTILATION SYSTEM PAN 2 PAILS TO RUM EMERGENCY PURGE VENTILATION SYSTEM FAN 3 FAILS TO RUN EMERGENCY PURGE VENTILATION SYSTEM PAN TAILS TO START EMERGENCY PURGE VENTILATION SYSTEM FAN I FAILS TO RUN EMERGENCY PURGE VENTILATION SYSTEM PAN 2 PAILS TO START EMERGENCY PURGE VENTILATION SYSTEM PAN J PAILS TO RUN EMERGENCY PURGE VENTILATION SYSTEH PAN 1 PAILS TO START EMERGENCY PURGE VENTILATION SYSTEH PAN 2 PAILS TO RUM EMERGENCY PURGE VENTILATION SYSTEH PAN 2 FAILS TO TON EMERGENCY PURGE VENTILATION SYSTEM PAN 3 FAILS TO START EMRRGENCY PURGE VENTIIATION SYSTEM PAN PAILS TO RUN EMPRGEHCY PURGE VENTILATION SYSTRM PAN 2 PAILS TO START EMERGENCY PURGE VENTILATION SYSTEM FAN 3 FAILS TO RUN EMERGENCY PURGE VENTILATION SYSTEM FAN 1 FAILS TO RUU EMERGENCY PURGE VENTILATION SYSTEM PAN 1 FAILS TO RUN EMERGENCY PURGE VENTILATION SYSTEM PAN 2 FAILS TO RUN
EMERGENCY PURGE VENTILATION SYSTEM FAN 3 FAILS TO START
7-16-93 10:20 Paye 2

EXPOSURE PROB. PROB.

$1.0 E-2$
8.

$1.0 \mathrm{E}-2$

8. $0 \mathrm{E}-6$

$1.0 \mathrm{E}-2$

$1.0 \mathrm{E}-2$

$1.0 \mathrm{E}-2$

8.0E-6

$1.0 \mathrm{E}-2$

a.Oe-6

$1.0 \mathrm{E}-2$

$.26 E-5$

8.0E-6

.

$26 \mathrm{E}-5$

3. $0 R-6$

3. $26-6$

. $0 \mathrm{E}-6$

$8.0 \mathrm{E}-6$
$8.0 \mathrm{E}-6$

8.0E-6

1. $0 \mathrm{E}-2$

.0E-6

.08-6

.0R-2

3.0E-6

8.0E-6

$1.0 \mathrm{E}-2$

$8.08-6$

B. 0E-6

$1.0 \mathrm{E}-2$

$8.0 \mathrm{E}-6$

$1.0 \mathrm{E}-2$

$1.0 \mathrm{E}-6$

$1.0 \mathrm{E}-2$

.OE-6

OE-6

10

(1)

1.08-2

8. $0 \mathrm{P}-6$

8.08-6

8. $08-6$

$8.08-6$
$1.08-2$
$1.00 E-02 \quad 1.34 E-07$ $1.34 E-03$
$1.008-02$

$1.34 E-03 \quad 1.34 E-07$

$1.00 \mathrm{E}-02$

$1.00 R-02$

$1.008-02 \quad 1.34 E-07$

$1.34 \mathrm{E}-03$

$1.008-02$

$1.342-03 \quad 1.34 E-07$

$1.008-02$

$2.26 \mathrm{E}-05 \quad 3.04 \mathrm{E}-08$

$2.26 z-05$

2.26E-05 3:04E-08

$2.268-05$

$2.26 \mathrm{E}-05 \quad 3.04 \mathrm{E}-08$

$1.34 \mathrm{E}-03$

$1.34 E-03$
$2.26 E-05$
$1.01 E-08$

$1.34 \mathrm{E}-03$

$1.34 E-03 \quad 1.80 E-08$

$1.34 \mathrm{E}-03$

1. $00 \mathrm{E}-02$

1.34E-03 1.80E-08

1.34E-03

$1.00 E-02$

1.34E-03 1.80E-08

$1.34 E-03$

$1.00 \mathrm{E}-02$

$1.34 E-03 \quad 1.80 E-08$

1. $34 E-03$

1. $00 \mathrm{E}-02$

$1.34 E-03 \quad 1.80 E-0 B$

$1.00 \mathrm{E}-02$

1.00E-02 1.80E-08

$1.00 E-02$

$1.34 E-03$

$1.34 \mathrm{E}-03 \quad 1.80 \mathrm{E}-08$

$1.34 \mathrm{E}-03$

$1.34 E-03$

$1.00 E-02$
$1.34 E-03$

$1.34 E-03$
$1.31 E-03$

$1.34 E-03 \quad 1.80 E-08$

$1.00 \mathrm{E}-02$
RATE EXPOSURE PROB. $\begin{array}{ll}\text { MOD./CS } \\ \text { PROB. }\end{array}$

$1.008-02 \quad 1.808-08$ 
MUTYITPEXT.CUT

Truncation Limit: $1.00 \mathrm{E}-12$

CUTGET REPORT

MOEULE/EVENT HAME

EFNSK 4RR
EFNSKISS EFNSK 3RR EFNSK 4RR

36) EFNSKIRR EPNSK2SS EFNSKARR

37) EFNSKISS EFNSK 3RR

38) EFHSK IRR EFIISK 2RR EFNSK 3RR

39) EFNSK IRR EFNSK 2RR EFNSK ARR

(C) EFNSK 2RR EFHSK 3RR EFHSK 4 RR

$\supset$, EFHSK ! RR E.TSK $3 R R$

42: I:FHI/2SC EFI3 $4 \mathrm{SC}$

\section{DESCR IPTION}

EMERGENCY PURGE VENTILATION SYSTEM FAN 4 FAILS TO RUN EMERGENCY PURGE VENTILATION SYSTEM FAN 1 FAILS TO START EMERGENCY PURGE VENTILATION SYSTEM FAN 3 FAILS TO RUN EMERGENCY PURGE VENTILATION SYSTEM FAN 4 FAILS TO RUN EMERGENCY PURGE VENTILATION SYSTEM FAN I PAILS TO RUN RHERGENCY PURGE VENTIIATION SYSTEM FAN 2 PAILS TO START EMERGENCY PURGE VENTILATION SYSTEM PAN \& FAILS TO RUN EMERGENCY PURGE VENTILATION SYSTEM FAN 1 FAILS TO START EM RGENCY PURGE VENTILATION SYSTEM FAN 2 FAILS TO RUN EMLRGENCY PURGE VENTILATION SYSTEM FAN 3 FAILS TO RUN EMERGENCY PURGE VENTILATION SYSTEM FAN 1 FAILS TO RUN EMERGENCY PURGE VENTILATION SYSTEM FAN 2 FAILS TO RUN EMERGENCY PURGE VENTILATION SYSTEM FAN 3 FAILS TO RUN EMERGENCY PURGE VENTILATION SYSTEM FAN 1 FAILS TO RUN EMERGENCY PURGE VENTILATION SYSTEM FAN 2 FAILS TO RUN EMERGENCY PURGE VENTILATION SYSTEH FAN 4 FAILS TO RUN EMERGENCY PURGE VENTILATION SYSTEM PAN 2 PAILS TO RUN EMERGENCY PURGE VENTILATION SYSTEM PAN J FAILS TO RUN EMERGENCY PURGE VENTILATION SYSTEM FAN G FAILS TO RUN EMERGENCY PURGE VENTILATION SYSTEM FAN 1 FAILS TO RUN EMERGE SYSTEM FOH A PA COMMN HODE PAILURE OF EMERGENCY PURGE VENTILATION SYSTEM FOR A PA
7-16-93 10:20 Page 3 B.E. MOD./CS. RATE EXPOSURE PROB. PROB.

8.0E-6 $7 \quad 1.34 \mathrm{E}-03$

$\begin{array}{llll}8.0 E-6 & 7 & 1.34 E-03 & \\ 1.0 E-2 & 1 & 1.00 E-02 & 1.80 E-0 B \\ 8.0 E-6 & 7 & 1.34 E-03 & \\ 8.0 E-6 & 7 & 1.34 E-03 & \\ 8.0 E-6 & 7 & 1.34 E-03 & 1.80 E-08 \\ 1.0 E-2 & 1 & 1.00 E-02 & \\ 8.0 E-6 & 7 & 1.34 E-03 & \\ 1.0 E-2 & 1 & 1.00 E-02 & 1.80 E-08 \\ 8.0 E-6 & 7 & 1.34 E-03 & \\ 8.0 E-6 & 7 & 1.34 E-03 & \\ 8.0 E-6 & 7 & 1.34 E-03 & 2.42 E-09 \\ 8.0 E-6 & 7 & 1.34 E-03 & \\ 8.0 E-6 & 7 & 1.34 E-03 & \\ 8.0 E-6 & 7 & 1.34 E-03 & 2.42 E-09 \\ 8.0 E-6 & 7 & 1.34 E-03 & \\ 8.0 E-6 & 7 & 1.34 E-03 & \\ 8.0 E-6 & 7 & 1.34 E-03 & 2.42 E-09 \\ 8.0 E-6 & 7 & 1.34 E-03 & \\ 8.0 E-6 & 7 & 1.34 E-03 & \\ 8.0 E-6 & 7 & 1.34 E-03 & 2.42 E-09 \\ 8.0 E-6 & 7 & 1.34 E-03 & \\ 8.0 E-6 & 7 & 1.34 E-03 & \\ 2.26 E-5 & 1 & 2.26 E-05 & 5.11 E-10 \\ 2.26 E-5 & 1 & 2.26 E-05 & \\ & & & \end{array}$



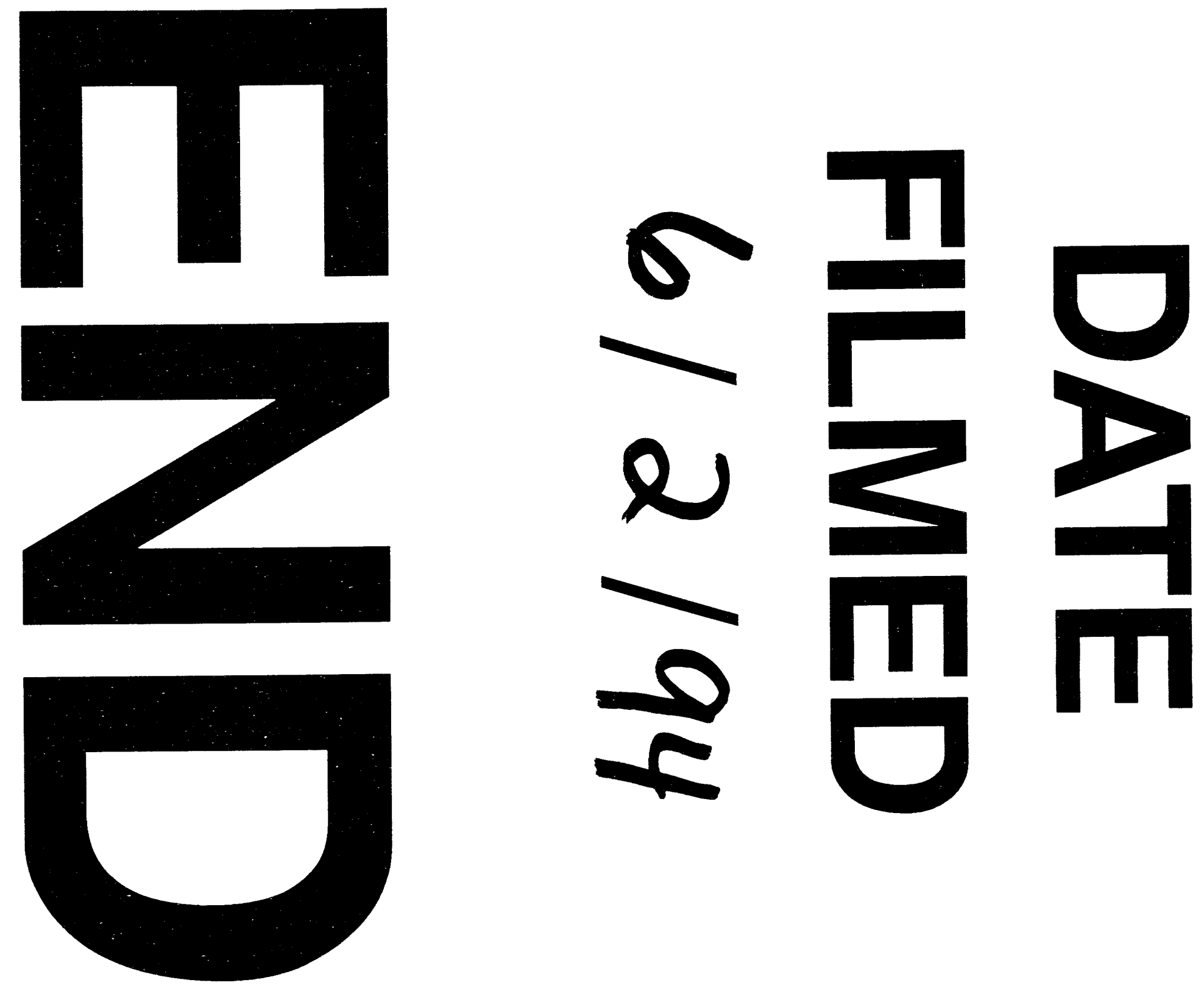


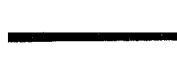

$$
-
$$

